\title{
Households, automobility and emissions : the Dutch case, 1985-2015
}

Citation for published version (APA):

Schenk, E. A. M. (1998). Households, automobility and emissions : the Dutch case, 1985-2015. [Doctoral Thesis, Maastricht University]. Universiteit Maastricht. https://doi.org/10.26481/dis.19981002es

Document status and date:

Published: 01/01/1998

DOI:

10.26481/dis.19981002es

Document Version:

Publisher's PDF, also known as Version of record

\section{Please check the document version of this publication:}

- A submitted manuscript is the version of the article upon submission and before peer-review. There can be important differences between the submitted version and the official published version of record.

People interested in the research are advised to contact the author for the final version of the publication, or visit the DOI to the publisher's website.

- The final author version and the galley proof are versions of the publication after peer review.

- The final published version features the final layout of the paper including the volume, issue and page numbers.

Link to publication

\footnotetext{
General rights rights.

- You may freely distribute the URL identifying the publication in the public portal. please follow below link for the End User Agreement:

www.umlib.nl/taverne-license

Take down policy

If you believe that this document breaches copyright please contact us at:

repository@maastrichtuniversity.nl

providing details and we will investigate your claim.
}

Copyright and moral rights for the publications made accessible in the public portal are retained by the authors and/or other copyright owners and it is a condition of accessing publications that users recognise and abide by the legal requirements associated with these

- Users may download and print one copy of any publication from the public portal for the purpose of private study or research.

- You may not further distribute the material or use it for any profit-making activity or commercial gain

If the publication is distributed under the terms of Article $25 \mathrm{fa}$ of the Dutch Copyright Act, indicated by the "Taverne" license above, 
Households, Automobility and Emissions the Dutch case

$$
1985-2015
$$

Proefschrift

Ter verkrijging van de graad van doctor aan de Universiteit Maastricht op gezag van de Rector Magnificus, Prof.dr. A.C.Nieuwenhuijzen Kruseman, volgens het besluit van het College van Decanen,

in het openbaar te verdedigen op vrijdag 2 october 1998 om 16.00 uur

door

Eugène A. M. Schenk 
Promotores: Prof.dr. H.J.M. Peters

Prof.dr. F.C. Palm

Beoordelingscommissie:

Prof.dr. L. Soete (voorzitter)

Prof.dr. Bernard Paulré (Université de Paris I, Panthéon - Sorbonne)

Prof.dr. ir. drs. O. J. Vrieze

Prof.dr. J. Rotmans 


\section{Acknowledgements}

In 1993 the idea of this research starts as an EC proposal for the DG XII. Not awaiting the outcome I designed the model structure and after consulting the statistical offices I redesigned many times the model structure in order to match the available data as close as possible. The available data sources were unexpectedly abundant and covered a broad area of the themes in question. From time budget surveys (TBO) to displacement surveys (OVG) and detailed new car sales data from the RAI, not to forget the population -, household forecasts and the motorist panel data (PAP) of the CBS. The collaboration of the CBS staff members was exceedingly, many unpublished and unique data sets were put at my disposal, many thanks.

Thanks also to Hans Peters and Franz Palm for the many hours of reading and puzzling in text and content and who guarded me for profound mistakes and chaotic reasoning. 
In memory of

Ingrid Philips $1951-1998$

Paulus van Hees 1948 - 1997

who left us prematurely 


\section{Content}

Preface

Chapter 1 General overview 1

Chapter 2 The population model 50

Chapter 3 Households, mobility and consumer lifestyles 85

$\begin{array}{lll}\text { Chapter } 4 \quad \text { New car sales and the car stock } & 120\end{array}$

$\begin{array}{lll}\text { Chapter } 5 \quad \text { Vintage car stock models } & 151\end{array}$

Chapter 6 Car ownership, car use and kilometrage 193

$\begin{array}{lll}\text { Chapter } 7 & \text { The emission model } & 218\end{array}$

Chapter 8 Automobility and emissions, some scenarios 240

Closing remarks $\quad 262$

Appendix A State space models, definitions 266

$\begin{array}{lll}\text { Appendix B } & \text { Filter equations } & 267\end{array}$

$\begin{array}{lll}\text { Appendix C Search techniques } & 268\end{array}$

$\begin{array}{ll}\text { References } & 273\end{array}$

Summary in Dutch (Samenvatting) $\quad 276$ 


\section{Preface}

\section{Some hilistorical notes}

During the last centuries the work and life conditions of Western Europeans have been altered dramatically. Under the influence of the unprecedented technological progress of the means of transport, of rail, automobile and aeroplane, the traditional mobility patterns have seen dramatic changes. The relationship between technological changes of the means of transport and the genera: mobility pattern in the modem world is strong, because the means of transport have accomplished an important degree of mobility freedom.

However, the changes referenced above are in fact a part of a continual and steady evolution of the mobility of Westem Europeans. Already before 1850 and even before 1500 great variations can be discovered in voluntary or forced migrations in a technical environment which in our modern view is "less developed" or equipped. "The history of human mobility is far from a simple variant of the history of technological development in general. For example, there is an interesting parallel between the rate of urbanisation and the level of traffic intensity, expressed by the average speed of the transport and the greater distance done in a shorter period of time. The relationship between urbanisation and traffic intensity was already visible in the $12^{\text {th }}$ century and even during the Roman Empire. With the conquest of the larger part of Westem Europe, from the Hadrian wall to RhineDonau frontier, the first cities developed. The linkage between these cities, the famous Roman roadsystem of about 100,000 kilometres, was especially built for military and political usage. The roads were used for quick displacement of armies (in their wake followed by craftsmen, artisans, and merchants), for mail horses, for the traffic of public servants, and in the last place for private traffic. The llong distance carriage traffic was hardly done by carts, but by horses and mules. The development of cities and metropolises during the twelfth century in Italy, Southern Germany and the Low Lands was involved with technical improvements in the carts transport system and horse harness equipment. These improvements resulted in an increased speed and capacity of the road traffic, followed by road improvements in southern Europe (Italy) into the north-west direction during the thirteenth and fourteenth century. For the water-carriage and especially the sea-carriage the capacity increase of the cog, the outstanding mediaeval marine ship, was the result of steady improvements. Till that time freight transport accounts for the bulk of the disposable transport capacity, leaving the remainder to person transport, artisans, scholars, monks and politicians. This slowly changed during the centuries to come. A technical-organisational innovation of uttermost importance was the booming during the $17^{\text {th }}$ century of the building of canals in the coastal area of Northern Germany, Holland and Belgium. In the Dutch case, for example, there was a direct relation between urbanisation and traffic needs. In the urban concentrations the traffic flow rose and the public authorities searched for cheap mass transport. In this case the Low Lands' 'beurtvaarten' are illustrative in this way, regular service of sail wessels between the cities of Flanders, Brabant, Sealand and Holland. During the $18^{\text {th }}$ century a slow but steady improvement of roads and canals and even some lengthening of the road system occurred especially in Austrian-Netherlands, leading to increased traffic capacity. However, transport of goods and persons remained a bottleneck and hampered a continual increase of urbanisation. During the first part of the $19^{\text {th }}$ century the private transport played a dominant role, especially the distances done by walking and horses (coaches). The train played a minor role in the public transportation and the bicycle was not yet present in the private transportation. It is to be estimated for the period 1850 (Blockmans, 1993) that the yearly outdoors distance done per head of the population was less than 1500 kilometres. For the second part of the $19^{\text {th }}$ century this picture underwent dramatic changes. The public transport by means of train and passenger steamers allowed to transport goods and persons over long distances at steadily decreasing prices per kilometres, while the steam- or electric tramway met the increasing demand of short distance trips. The unfolding industrialisation, urbanisation and traffic intensity entered now the exponential phase of its development process. The average number of kilometres done per rail per person rose from about 0 to 250 during this period. In the first part of the $20^{\text {th }}$ century these tendencies continued at increasing rates, for example the average number of kilometres done per rail per person. 
doubled from about 250 to 500 . In most countries this increase was already realised before World

War II. In Germany, France and Belgium the 750 kilometres per person per year was even reached in 1925. All in all the average Western European travelled outdoors about 2000 kilometres per year at the turn of the century. Moreover, passenger traffic by air and private car was still a neglectable quantity.

\section{The present time}

Now at the end of the millennium the average per capita Western European covers outdoors about 12000 kilometres per year, of which nearly $70 \%$ by car, about $20 \%$ by public transport (of which the half part by air); the remainder will be done by walking or biking. What strikes most is the all importance of the automobile. One of every three Westem Europeans owes a car, and the car use accounts for many motives. About $30-40 \%$ can be accounted for commuting between home and workplace, $10 \%$ shopping and the remainder for home tasks and recreation or entertainment. This remainder is expected to increase substantially during the next decades. Note, however, that professional traffic does not merely consist of commuting activities: the truck is of all importance for the goods or carrying traffic.

The actual size of geographical mobility, however, is a relatively recent phenomenon. Around 1950 the situation was quite different. The number of kilometres done per capita by public traffic, be it busses, tramway, metro and train was for most countries substantially higher than today. Aviation on the contrary was of minor importance: per head of the population only some ten kilometres. The tremendous difference has been accounted for by the car. Around 1950 one out of hundred Western Europeans owed a car! Albeit more kilometres per car were done, the number of kilometres per head was about 400 . But there were alternatives like motor-cycle and moped, which were of equal importance in those days. Around 1960 the private traffic by car surpassed the public traffic, probably an everlasting fact. Concerning public traffic the long distance transport by sea was still a good altemative to the traffic by air. In sum, one can assume that the average Western European in the midst of the century covered about 4000 kilometres per year outdoors.

\section{Policy objectives}

The first attention of drawbacks of unlimited growth of car use, causing congestion and air pollution, was in the 50 s and 60 s in the United States. The first legislation on air pollution caused by car use appeared end 60s and early 70s. Europe followed the US in the 70s and the first directive on air pollution introduced by the Commission of the European Community in 1970 was followed by many new directives sharpening input/output characteristics of the new cars. The input characteristics refer to the fuel quality and the output characteristics to the emission of exhaust gasses. In order to base the directives with consistent and scientifically justified data the Commission of the European Community installed a working group on emission factors, CORINAIR, for calculating 1985 emissions from road traffic (Eggleston, et al, 1989). A few years later this was redone for the year 1990. In the early 90s the Dutch ministry of "Verkeer en Waterstaat" decided to enlarge and refine the methodology in order to track the effects of diffusion of new car engine technology on the emissions. Especially the "Instituut voor Wegtransportmiddelen TNO" was accounted for this task (Rijkeboer, et al, 1990). Own research (Rijkeboer, et al, 1992) and research done by the UBA/TUV-Rheinland (UBA/TUV, 1987) resulted in a complex methodology which will be applied in this thesis.

Beside the emission model referred to above the other critical issues to be dealt with are the development or growth potential of the

- mobility, and especially automobility

- car ownership, and

- qualitative composition of the car stock (or car fleet).

The qualitative composition of the car stock depends on the rate of diffusion of the new wehicle technology. In the recent past several researchers have approached these topics from different viewpoints and therefore with different models. In general one can distinguish

- economic approaches, in which financial parametric variables are applied as explanatory variables for car ownership forecasts and the technology substitution process (Jorgensen, 1990); 
- system dynamics approaches, without financial explanatory variables, the growth processes are approached as logistic (population) processes (Romanowicz, et al, 1988). These studies can be characterised as being "not data driven';

- engineering approaches, which are primarily based on empirical analysis, account only implicitly (if at all) for the influence of financial variables (Zachariadis, et al, 1995). The critical determinants, for example total traffic volume is decomposed into two factors, total car stock and distance driven by each car.

The most elaborated research up to this time was the Zachariadis-study. The Zachariadismethodology combines two processes:

1. the replacement of old cars with new ones due to the internal process of ageing and scrap in the car market irrespective of competition between technologies, and

2. technology substitution, which in their case is stimulated or enforced through more stringent emission legislation rather than consumer choice behaviour.

Several approaches have been used to assess the evolution of cat fleets, as has been proposed in an European setting by the group of Jost, Hassel and Brosthaus (Jost et al, 1983). Their proposal is to express normalised car ownership or car density as a sigmoid function of time only. We will take up this approach but augment the car ownership function by financial variables (f.e. permanent income) and variable saturation levels. Car density will generally be described in terms of cars per (adult) person. The Zachariadis-study used predictions of car density per total population, which is less reliable in case of future shifts in age distribution of the population. In contrast to the total or adult population approach we take the households by size as primary determinant of car ownership. In this case the determination of one-or-more car ownership per household by size is possible. The Zachariadis-study used a subset of the CORNNAIR methodology, as developed by the EC CORINAIR Working Group on Emission Factors from road traffic (Samaras, ef al, 1989), in our study we apply an extended dynamic VERSIT-emission model developed by IW-TNO (CBS, 1993 C). In the CORINALR methodology the emission behaviour of cars depends, among other things, on the size of the car engine, its technology level, and the operating conditions, measured by different road types (inner city, highways, etc.). Cars are usually classified into three classes according to the fuel type usage, gasoline, diesel oil, or liquefied petroleum gas (LPG), and each is further subdivided according to the engine size. The engine size is measured by engine's cylinder content, where three subclasses are discerned: less than $1400 \mathrm{cc}$ ( 1.4 litre), between 1400 and $2000 \mathrm{cc}$, and over $2000 \mathrm{cc}$. Zachariadis, et al, use a common function to forecast the total car density and applied factors expressing the fraction of the total car fleet belonging to a specific fuel, size, and technology category. In contrast we apply estimation and forecast of new cars sales differentiated by the different fuel types, and apply engine size and technology distribution parameters in order to compute the needed new car sales by fuel type, by size, by technology

For car use the Zachariadis-study applies the COPERT methodology (Samaras, ef $a l, 1989$ ). In the framework of COPERT national experts from the EU countries have submitted car use data for 1985 and 1990 only. The estimated vehicle kilometres, combined with average measured specific fuel consumption for each car type and technology leads to an estimation of total fuel consumption which should be in agreement with the actual fuel salles figures given in national statistics. In contrast to Zachariadis-study we take a quite different route by analysing past household by size (car) displacement behaviour differentiated to displacement motives. In this way we arrive at total yearly veluicle kilometres needed as inpur for the calculation of the yearly emissions of the car fleet. Looking back over the past decades the difference with the 80 s and 90 s lies in the

- leisure traffic,

- home task (a subset of home production), and to a lesser extent in

- commuting.

These topics and their evolution, the relationship between mobility and population, especially the household formation, are further investigated in this thesis. Moreover, as the resulting emissions are also a subject of investigation, the developments of the car park, both quantitative and qualitative, are also integrated into the subject-matter of this thesis. 


\section{Chapter 1 \\ A General Overview}

\subsection{Introduction}

Since World War II wealth in the Netherlands, like in the rest of the western world, has increased substantially. Car ownership and car use have reflected a similar pattern. In 1996 the car use is thirty times as great as in 1950, while the use of public transportation only doubled. Both phenomena reflect the umprecedented increase of mobility, which after a retardation in the early $80^{\prime} \mathrm{s}$ regained since. Figure 1.1 shows the development of the travellers kilometres of car use and public transport in the Netherlands.

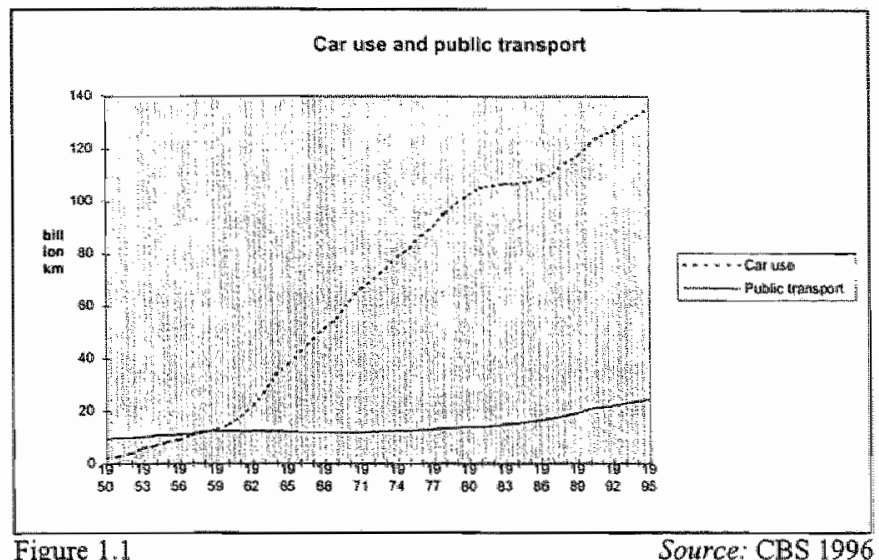

Figure 1.1

Source: CBS 1996

As we are, also, interested in the emissions of the car use a different measure of car use is needed, namely the total of the car kilometres driven in a year, the yearly vehicle kilometres (in short veh $\mathrm{km}^{\mathrm{k}}$ ). The relation between travellers and wehicle kilometres is explained by the equation:

and

$\begin{gathered}\text { average } \\ \text { avar stock }\end{gathered} \quad \mathrm{km}=\begin{gathered}\text { vehicle } \\ \mathrm{km}\end{gathered}$

$$
\begin{gathered}
\text { wehicle } \\
\mathrm{km}
\end{gathered} \text { accupation }=\begin{gathered}
\text { travellers } \\
\mathrm{km}
\end{gathered}
$$

Conventional wisdom explains the development of mobility as related to economic growth, population growth, sub-urbanisation and scalle increases. However, these factors explain only part of the mobility development. Additional factors are a number of characteristic features of modem lifestyles, such as emancipation, decrease of household size, task combination of partners in the home production, and diversification of leisure behaviour (SCP 1993).

The objectives of this thesis will be:

1. An analysis of structural changes of consumer lifestyles and the resulting mobility for the Netherlands, especially its impact on car use or "automobilism", which causes, besides the satisfaction of ultimate human needs, harmful emissions and congestion. The time scale or period. under investigation is 1980-2015, the data sources cover the period 1980-1995 and the scenario analysis applies to the period 1995-2015

2. An application of:

- hill climbing search techniques to perform optimisation and estimation in state space modelling, 
- parameter sensitivity techniques in order to examine local-to-global stability properties of unknown but estimated parameter values, and

- model parameter sensitivity or Monte-Carlo simulation in order to examine model sensitivity to changing parameter input values, sequentially or simultaneously.

Moreover, besides estimation, one can perform, by formulating an adequate objective or payoff function, policy optimisation by assigning optimal values to selected search parameters which maximise a stated objective function.

Plan of research. A modular model structure has been chosen with each separate module modelling a distinct subject-matter. By choosing a modular structure one reduces the complexity of the madel to manageable proportions with the modules acting as independent processes driven by the outputs of the preceeding modules. As shown below each module receives inputs from the preceding module(s) and sends outputs to the next module(s), from left to right, as a representation of the one-way causallity.

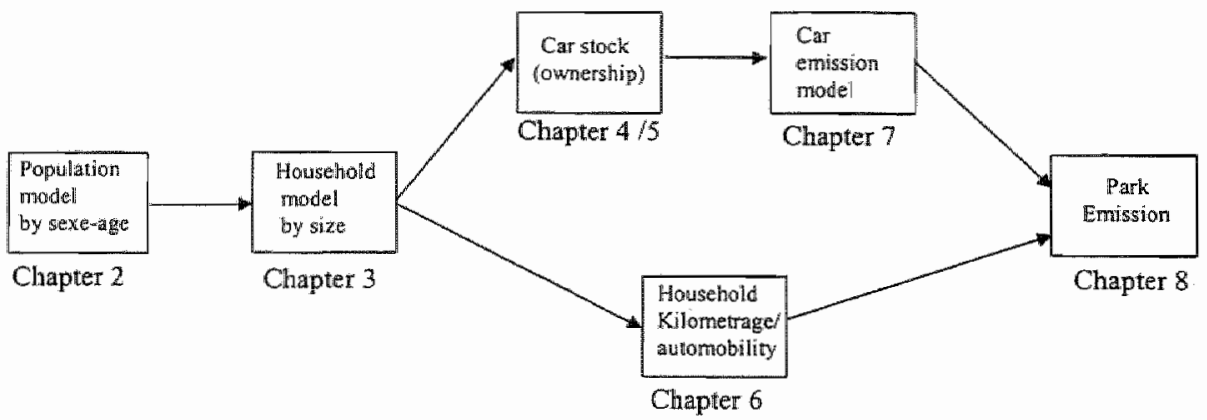

The causation runs from the population (inhabitants) development to the household formation behaviour to:

- the car ownership development of the households by size to the emission exhausit model which calculates for each year of construction for different fuel types, $\mathrm{cc}^{1}$-classes, and imput/output technologies, the carbon monoxide $(C O)$, nitrogen oxides $\left(N O_{x}\right)$, volatile organic compounds $(\mathrm{VOC})$, carbon dioxide $\left(\mathrm{CO}_{2}\right)$, and sulphur dioxide $\left(\mathrm{SO}_{2}\right)$ per vehicle $\mathrm{km}$ (veh- $\left.\mathrm{km}\right)$;

- household mobility development expressed in yearly vehicle kilometres (veh-km) by motive; both determine the yearly park emission.

The park emission model computes the yearly $\mathrm{CO}, \mathrm{NO}_{x}, \mathrm{FOC}_{2} \mathrm{CO}_{2}$ and $\mathrm{SO}_{2}$ caused by the automobility of the Dutch households. The car emission model needs, beside specific chemical reaction - and physical technical equations, as input the yearly composition of the new car sales by fuel type (gasoline, diesel, LPG), by cylinder content or cc $(<1.4 \mathrm{~L}, 1.5-2.0,>2.0 \mathrm{~L})$, and by input-, output technology in order to compute the required vintage ${ }^{2}$ emission factors which multiplied by vintage car stock and the average year kilometrage per vintage (traffic performance) result in the yearly park emission wolumes. Technology applies to engine's input-output systems and combustion techniques. Input systems refer to the fuel injection techniques (direct or indirect) and output systems to the abatement or clean-up processes (oxidation or reduction) of the exhaust gasses performed. among others, by catalytic converters. The technical progress of both input/output systems and the combustion processes are tied or coupled to the year of construction of the automobiles, called vintage. The car stock by year of construction will be approximated by the observed data series "new car sales' mimus the scrap by year of construction. It is in this way that the quantitative development of the vintage car stock reflects and acts as a proxy of the technological or qualitative development of the car stock in question.

\footnotetext{
1 'ce' denotes cylinder content.

2 "vintage' refers to 'year of construction"
} 
In sum, the park emission model requires as imput:

- the car stock by fuel type and by vintages, and

- the total vehicle kilometres by fuel type and by vintages.

The total kilometrage of the Dutch car stock by fuel type and by vintage will be approached from and based upon two independent CBS statistical sources (1980-1995, yearly observed):

- the person car panel $(P A P)$, and

- the mobility survey of the Dutch population (OGW).

As we take the household characterised by size, one- to six-or-more person households $(1-6 \mathrm{pHSH})$, as basic unit of analysis we estimate the past (1980-1995) households developments. The household model is driven by a six-age class population model and makes forecasts up to the year 2015 . The same procedure will be applied for the estimation and forecast of the total yearly kilometrage of the Dutch households. The data sources are from yearly surveys of the consumer time budget, especially displacement (trip), mobility and car use (automobilism) behaviour of the $l-6 p H S H$ by eight motives for the period 1980-1994. The estimated 1-6pHSH model supplies the numbers of the one to six-ormore person households for the period 1985-2015. By multiplication and summation we arrive at the total yearly vehicle kilometres (veh-km). Equivalent vehicle kilometres figures will be derived from $P A P$ data sources, based also on yearly surveys, and will be compared with the $O G V$ results, before estimation will take place. In this way we arrive at the kilometrage or traffic performance of the Dutch society for the period 1980-1995 and the future development up to 2015 of the 1-to 6-or-more person households. The simulated total kilometrage for the period 1980-1995 is in agreement (within $1 \%$ ) with the observed total kilometrage from the PAP. As we need vintage car stock data by fuel type and by input-output technology as input data of the car emission model, we developed four models to describe and explain the development of the Dutch car stock from 1980-1995.

From

- the total yearly vehicle kilometres

- the average vehicle kilometres by fuel type and by vintage, and

- the car stock by fuel type and vintage

one arrives at the total yearly vehicle kilometres by vintage, by fuel type and by input-output technology used as input driver of the car emission model. By properly describing and estimating past behaviour (1980-1995), especially the structural changes, we arrive at exploring the future by scenario runs. The structural changes will be approximated by the observed developmerit of the 1 . and 2-person households. As we start from the displacement behaviour by car use (automobilism) for the period 1980-1995 we describe and analyse the structural changes and by exploring the future we can simulate the trajectories by taking the expected changes of the 8 mobility motives in sceriario strategies. These observed data series and the estimated models will be described and analysed for the period 1980-1995 where possible. With these models, scenarios can be implemented in order to scan the future (1995-2015) traffic performance and related emissions.

The remainder of this chapter will be devoted to an extensive description of the seven chapters, each treating a distinct subject and translated in a simulation module, all integrated in chapter 8 to scan the cause-and-effect of future automobilism. 


\section{Chapter 2. The population model}

\section{2.. 1. Iritrodaction}

In international conparisons the population density per sq. $\mathrm{km}$ land is often used as one of the many indicators for environmental stress. Howewer, environmental stress depends to a great extent on the number of households', because many of the space consuming activities are more related to the number of households than to the size of population. The most appealing example for this is the housing demand and private transport with its related harmful ecological effects. Since the 60 s the relative increase in households has pointed to what could be called a household explosion (CBS 1993). In only thirty years the number of households doubled, whereas the size of population only increased by one third. The increase in households therefore became relatively more important than before for the envirommental stress in a country. However, in developing a dynamic household model a dynamic population madel is needed as a driving input. The development of the population model is the aim of chapter 2. A parsimonious population model will be estimated with the official CBS population model acting as a benchmark, which is far too complex for our purpose at hand. The CBS population matrices of the period $1980-89^{4}$ are used as estimation benchmarks. On the other hand the CBS population forecasts 1995-2015 are applied as a benchmark for the estimation of the levels of age classes and therefore indirectly of the possible (unobservable) changing transition rates or cohort shifts with regard to the base period 1980-1989. Given the inherent uncertainty the high -, mid - and low scenarios of birth rates and migration flows of the same CBS population forecasts are used in a Monte Carlo simulation to test the sensitivities of the population parameter dynamics.

\subsection{Demographic evolution and environmental stress}

When the relative growth of the population and the number of households are reviewed over a period of 100 years (Figure 2.1) a turning point becomes visible. During the first half and a part of the second half of this century the relative development of the population ( $\cdots . . . P O P$ ) and those of the households (- HSH) follow a similar pattern. In the early 60 s a turning point in the trend direction of the household development became manifest. The graph (Figure 2.1) shows the household

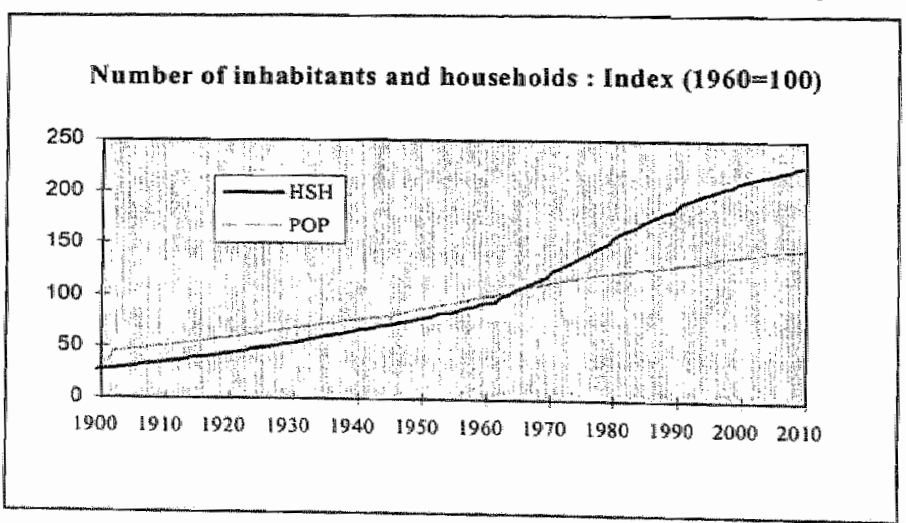

development exceeding more and more the population development. The relative increase in households could be called a household explosion. In only thirty years the number of households doubled (from 3.2 to $6 \mathrm{mln}$ ), whereas the size of the population only grew by one third (from 11.4 to $14.9 \mathrm{~m} / \mathrm{n}$ ). It is to be expected that the relative increase of the number of households will. diminish or dampen during

the next decades. However, the relative growth of the number of households will outrun the relative growth of the population. The effects for the environmental stress in the Netherlands can be illustrated by the development of the housing stock or the development of the road traffic. In agreement with the growth of the number of households the housing stock doubled. The car ownership increased tenfold and the length of the highways nearly sixty fold. However, the growth of the number of households is not the only determmant factor for the soaring growth of road traffic, but

\footnotetext{
"In fact private households. Private households are defined as a number of natural persons sharing common living places, excluding people living in old people's homes, nursing-homes, etc, called institutional households, this research.s
} 
surely it will be an important one. The automobility of nodem societies is the product of lifestyles and the level of the car stock; lifestyle being determined, among others, by individualising and increasing stock of wealth. The ewolving lifestyles, approximated by changing household size, do increase the automobility and, among others, car use causing car stock to increase, increased car ownership causes again the automobility and car use to increase, etc. A 5-person household, for example a family with 2 parents and 3 children, will show less trips, measured in traveller-km, than five 1-person households. Trips, and in our case, car driving behaviour can be divided into the following main activities : commuting, shopping and recreation. It will be shown that there exists a (direct) relationship between households development and the evolving travel behaviour. This development causes concern because of external effects in terms of congestion and harmful emissions. For the same reason there exists a relationship between household by size $(n-p H S H)$ development and other activities for which households are important consuming- or housekeeping unit in economic analysis or basic emitting unit in ecological analysis. Households as basic emitting unit refers to the fact that households, as basic unit of analysis, give more information about the emissions development than do per capita indicators. Think of energy-using durables, land- and water-use or waste disposal and their external effects.

\subsection{Demographic evolution and the number of households}

A divergent population and household development may have many different causes (CBS 1993).

- High birth rates in the first instance do increase the size of population, without influencing however the number of households. New born children are added to existing households and therefore not creating new households for the next 15 year or so. They are, for the moment, not entering the house- or car market as a demand factor per se, although they might lead to an increase of demand for larger housing or bigger cars.

- Is the growth of population caused by a negative migration balance, then the new households enter the house- and the car market immediately, except in cases of family reunion.

- Another cause may be the ageing of the population. Ageing does change the life cycle of the average inhabitant: more people stay in the adult phase. This effects the increase of the number of households, especially the 1- and 2-person households. Theoretically, the last effect can potentially increase the number of households without changing the size of population.

- Finally, the number of households will be influenced by changing behaviour (lifestyle). Young people do create more and earlier in time 1-person households than those of earlier generations, thereby influencing the number of households. Also the changing divorce behaviour, the partners remaining alone for the time being or when elder population remain longer independent persons, (as nursing-homes are accounted for institutional households) all influencing the number of households.

Divergence in the relative development of population and of households, as shown in Figure 2.1, is caused simultaneously by the factors mentioned above.

Without posing the question to what extent the factors mentioned above have influenced the development of the households, some societal and demographic developments will be touched upon which have had in general an influence on the increasing number of households. Societal changes during the sixties influenced the changing household positions. The strong increase of the number of households was accompanied by:

- An increase of the diworce rate causing many households to separate into two households (at least temporarily, because some partners joining after some time an existing household).

- An increased popularity of living apart for youngsters.

- Emancipatory developments causing more young women to live apart.

- Ageing population living (often necessarily) longer independent caused by capacity of intramural aid staying behind the potential demand and caused by the public policy to provide facilities to elder people with the aim to allow them to stay independently as long as possible.

Besides, demographic changes have played a role in the unequal increase of population and households. There are: 
- The changing age structure of the population. After World War II a birth explosion caused voluminous after-war generations. From the 60 s on these generations entered the housing-and car market.

- The increasing life expectancy by which relatively small households (1- and 2 person) of elder people stay longer "alive".

- The successful introduction of new forms of effective anti-conception by which the average family size decreased and the ratio between the size of population and households changed.

- The transformation of Westem Europe into an immigration area by which the increase of the size of population partly coincided with a dinect increase of the number of households, causing also a changing tatio between the increase of the population and of the households. This phenomenon took place in the 80 s and will continue in the near future.

\subsection{Population model by age classes and by sex}

The population of an area is the total number of inhabitants alive at a particular point in time. The population can be classified by sex, which provides information about the sex distribution of the population. The population can further be divided into age classes, in our case (0-3), (4-14), (15-24), $(25-44),(45-64)$ and $65+$, and, if each group is expressed as a fraction of the total, information is provided about the relative age composition of the population. Figure 2.2 gives an example of the age structure of total population of the Netherlands during the period 1980-1988.

Note the age class $65+$ is measured on the vertical right axis.

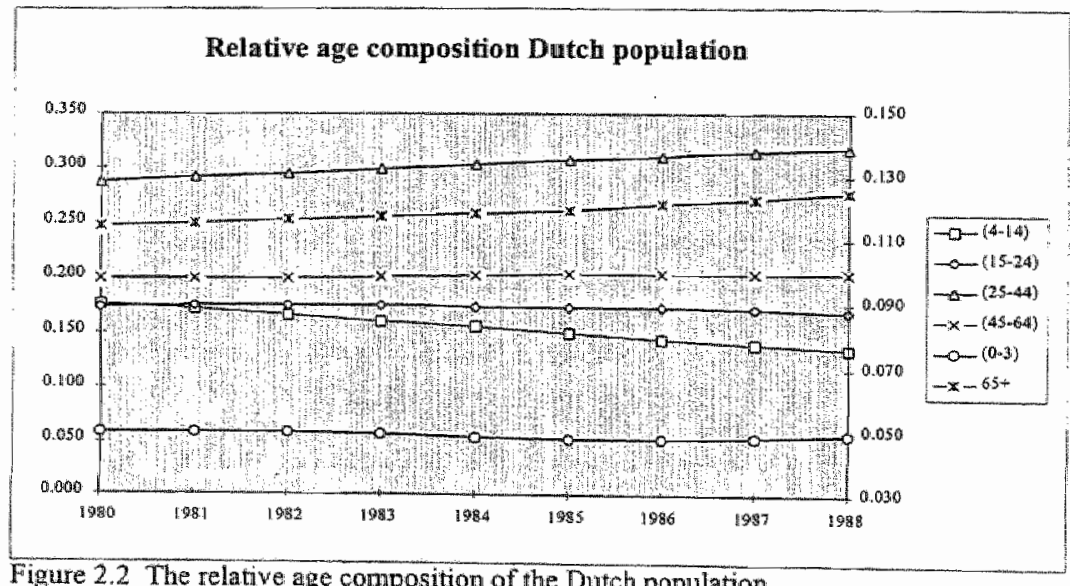

Figure 2.2 The relative age composition of the Dutch population

Of cotirse an 8 year overview does not easily allow to detect trends, but two changes can be distinguished:

- the decrease of (4-14) age class, indicating a "degreening" of the population (however, reversed in the 90 s!), and

- the slight but steady increase of the age classes (25-44) and 65+, indicating a 'greying' of the population.

Crude birth rates, defined as live births per 1000 inhabitants, are at a certain point in time the result of an interaction of at least three factors (Lutz 1994):

- the level of fertility;

- the age structure of the population (especially of its female component); and

- the age distribution of fertility.

The developed population module consists of 6 age-sex classes. The dynamic model is based on stock-flow analysis, where each age class is treated as a stock- or level variable, integrating the inflow minus outflow per unit of time. The inflow in the first age class (0-3) year equals the birth rate plus immigration. By ageing, for example, people becoming 4 year old, flow into the (4-15) age class, 
staying there till the age of 16 and moves than into the (16-24) age class, etc. These transitions or cohort shifts can be captured in a transition matrix, showing the in-and outflows for each age class. In fact these population matrices are the database (only avalable for the period 1980-1988), they act as a benchmark for the $P_{1}^{6}$-population model to be estmated. The estimation results (bold line) for the period 1980-88 are shown in Figure 2.3, summed for the total Dutch population The simulated 6 age-sex class population model, based on the estimated transition rates, is used as an input driver of the household model, to be dealt with in chapter 3.

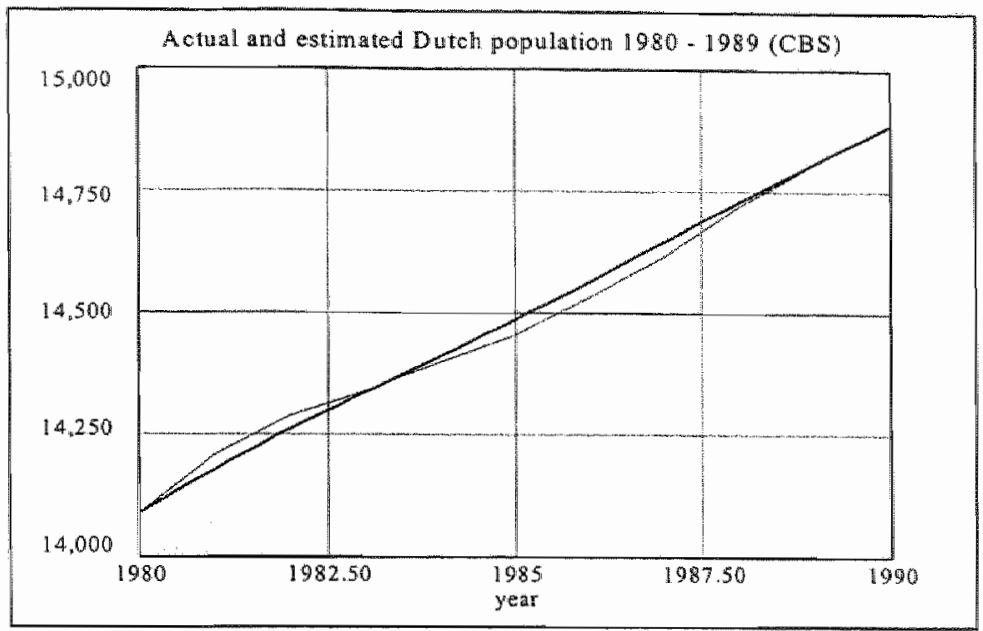

Figure 2.3 The observed and simulated (bold line) total Dutch population

Based on the estimated transition rates and the CBS projections of
1. birth rates
2. migration rates

we arrive at the simulation of the Dutch population by 6 age-sex classes up to 2015 . Note the birth and migration rates are the exogenous- or driving imput variables. The development of the male- and female population are shown in Figure 2.4, those of the total population in Figure 2.5. As noted above the simulation of the 6 age-sex classes are the input drivers of the household model.

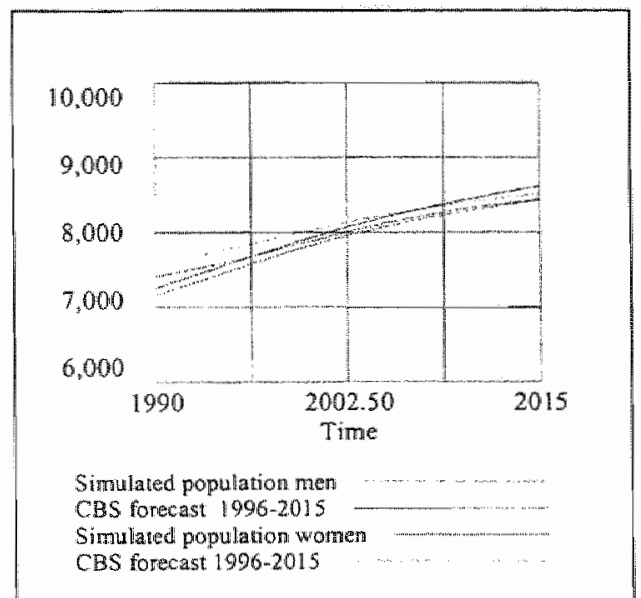

Figure 2.4 Sirmulation versus CBS forecast

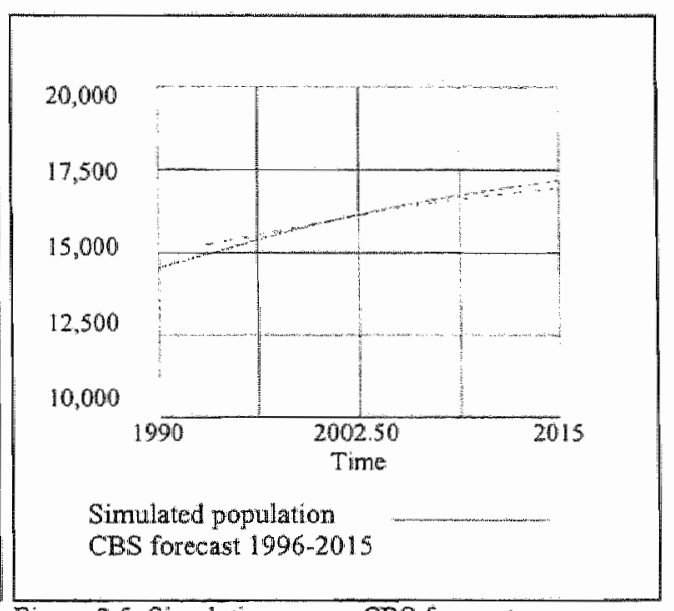

Figure 2.5 Simulation versus CBS forecast 


\subsection{The Monte-Carlo simulation}

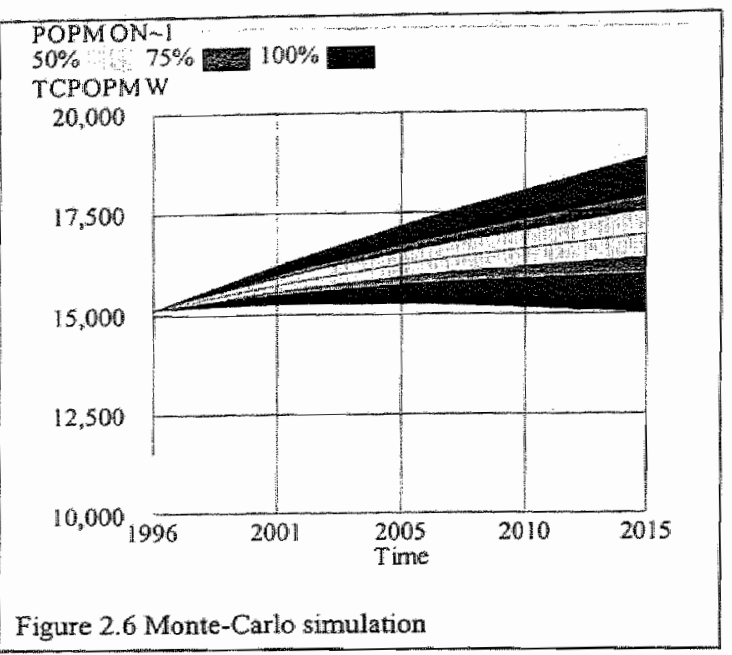

Monte-Carlo simulation is a technique to test the sensitivity of the variables in the model with respect to changes in the selected parameters. In our case the selected variables are the birth rates of males and females and the immigrationand emigration rates. The birth rates changes randomly $\pm 17 \%$, the random selection criteria is based on the triangular distribution. The migration rates changes randomly is $\pm 50 \%$, the random selection criteria is based on the uniform distribution. Note the birth - and migration rates are the CBS mid-variant. After 1500 simulation-rums the graph (Figure 2.6) show's the uncertainty in the total Dutch population (TCPOPMW) as it may changes over time. At any time, half of the simulations have generated a value within the $50 \%$ region, three quarters within the $75 \%$ region and so on. If one compares the Monte-Carlo simulation results with the simulation of the 3-CBS based variants (Figure 2.33 in chapter 2) it seems clear that the 3 -variant simulation falls with the $75 \%$ range of Monte-Carlo simulation and that the additional $25 \%$ range (the black band) is mainly due to the uncertainty assumptions of the net external rrigration explained before. In fact $\pm 20 \%$ of the simulation runs shows a negative net external migration, which means that the emigration is greater in numbers than the immigration with the net effect of zero population growth. In $\pm 50 \%$ of the simulation runs the net external migration is above its mean value of 35.000 a year (CBS midvariant), resulting in more high growth simulation runs.

\subsection{Conclusion}

The Dutch population keeps on growing. CBS expects that in 2030 the maximum number of 18 million will be reached. In 1990 the 15 million level was reached, the step from 14 to 15 million took nearly 11 years. The step towards the next million will go faster. In 1995 the 15.5 million level has been reached and during the year 2000 the 16 million limit will be surpassed. From the population model the conclusion can be drawn that in the 90 s the average population growth will be higher than during the 80 s. This results from the combined effect of birth rates and the net migration which are substantially higher than in the 80s. In the short run the major part of the population growth will be caused by the birth-surplus (the difference between birth and death). During the remainder of the century the birth-surplus will be on average 70 thousand per year. That will be $\pm 65 \%$ of the total population growth of 110 thousand. The remaining $35 \%$ of the growth comes from the net migration (the balance of immigration and emigration). After 2000 it is to be expected that the speed of the population growth will retard. But the most important cause of the retardation of the population growth is the fact that the number of deaths will increase more and more. The cohorts of the babyboom generations after World War II are entering the age class of $65+$. Around the year 2020 it is to be expected that the number of deaths equals the number of births. After that point the number of deaths will increase. The birth-surplus will become negative. The population remains growing during some years due to a positive net migration. 


\section{Chapter 3. The household model}

\subsection{Introduction}

The objective of chapter 3 is the development of a household by size model. The n-person household ranges from one-to six-person household and is driven by the output of the population model, developed in chapter 2. The output of the household by size model drives the car ownership (chapter 4), car use (chapter 5) and the travel behaviour of the Dutch households (chapter 6).

The Amnual Household Statistics (JHS) are based on the Labour Force Survey (EBB) (CBS 1994 B). The data are yearly averages and refer only to private households, excluding institutional households. The data we use hereafter are presented on the person level as well as on the household level. On the person level the position held in relation to a reference person is indicated. Single persons live alone in a 1-person household. In multiple-person households the distinguished positions are cohabiting, living at parental home, lone parent and other. Any person not being a partner or child of the reference person nor a child of the partner, occupies the position "other". On the household level the household is characterised by the positions the household members occupy with respect to each other. The position of the reference person plays an important role; households in which "others" reside are not separately indicated.

In this section the changes in households during the period 1960-1990 will be analysed. The number of households increased from \pm 3.1 million to \pm 6.0 million. This growth was partly caused by the population increase, but this was not the only reason. Also the size of the households became smaller. In 1990 the average Dutch household consists of 2.5 persons. In 1960 this Figure was 3.6 person on average. This development is not unique for the period 1960-1990. The reduction of the household size started already in the end of the 19 th century. However the prime factors differ from period to period. Looking at the changes in household size since the end of the 19th century three periods can be distinguisied (SCP 1994):

- the period from the end of the 19 th century till the end of the $60 \mathrm{~s}$;

- the period from the end of the 60 s till 1980 ;

- the period of or since the $80 \mathrm{~s}$.

The most remarkable development for the first period is that marriage and family play an increasing role in the process of household formation. At the end of the 60 s the situation was that marriage and getting children were common place in society. Other lifestyles than marriage and family were not appreciated or even not accepted. Staying or living alone was in that period not an acceptable way of living. Living together unmarried was hardly tolerated by the society. The increased role of marriage and family as model for the individual life went hand in hand with the change in the expectations about marriage and farnily. Marriage and family were judged of their sense for the personal development. The logical counterpart of this evolution was a more tolerant consent about divorce. This greater tolerance became visible in the increasing number of divorces during the $60 \mathrm{~s}$.

The second period starts at the end of the 60 s and continued till 1980. This period was marked by opposition and critical attitude against, among others, marriage and family and the discussions about alternative ways of life: as are living in community, living apart together and living alone. This discussion influenced the process of household formation. In general young people left at a younger age the parental home and a marriage was delayed. Instead they lived alone (temporarily) or were cohabiting unmarried. A stagnation of the decreasing age of marriage took place. Postponement and abandonment of getting children became increasingly popular. The increase of the number of divorces, starting in the $60 \mathrm{~s}_{\text {, }}$ continued and even accelerated in the 70 s.

The third period starts about 1980 . The discussions of the 60 s and 70 s settled down and the unmarried cohabitation was accepted by society as a new lifestyle. The new ideas about postponement and abandonment of getting children became more and more popular and penetrated through all strata of society. The strong decrease of age at which to leave parental home stopped end 80 s and a small increase was observable. However the trend of increasing interest in leaving home under the youngsters and liwe alone or cohabiting unmarried continued. Initially this process went together with the continuing decreasing interest for marriage. At the end of the 80 s an increase of the number of marriages was discemible, but this increase was more a catch up of the postponement of 
marriage. The number of birth increased from 1983 till 1995, probably also a catch up of earlier postponement. However the trend in postponement and abandonment of parentalship continued. The strong increase in divorce rates halted in this period.

\subsection{Composition of the households}

Changes in the composition of households are dominant in the period 1960-1990. The composition of household can be classified as:

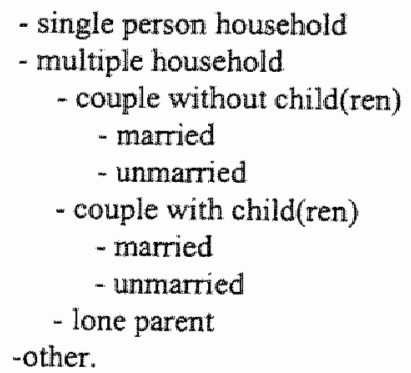

The data on households have been assembled by size and by composition (CBS 1993 A). Only from 1988 on consistent data are available (Tables 3.1 and 3.2)

\begin{tabular}{|c|c|c|c|c|c|c|c|}
\hline \multicolumn{3}{|c|}{ House holds by size and comphosition (CBS) } & \multicolumn{2}{|c|}{ yoar average } & \multirow[b]{2}{*}{ PS-pHSH } & \multirow[b]{2}{*}{ Total } & \multirow[b]{2}{*}{$\%$} \\
\hline 1988 & I-PHSH & $2-D$ HSH & $3-\mathrm{pHSH}$ & 4-pHSH & & & \\
\hline Sugle-person household & 1677 & & & & & 1677 & 29 \\
\hline Multiple-pers on bousebold & 8 & & & & & & \\
\hline Couple whoul chidd(ren) & & & & & & & \\
\hline manied & 7 & 1255 & 61 & & & 127 & 22 \\
\hline Jon-manied & & 321 & & & & 321 & 6 \\
\hline Couple whth chidd(ren) & & & & & & & \\
\hline mantied & & & 706 & 989 & $436 !$ & 2131 & 37 \\
\hline nom-maried & & & 28 & 14 & 6 & 48 & I \\
\hline Lome parrent & & 172 & 100 & 29 & 12 & 313 & 5 \\
\hline Onther & & 56 & 12 & 7 & 3 & 75 & I \\
\hline Tomal & 1677 & 1804 & 862 & 1036 & 457 & 5836 & 100 \\
\hline
\end{tabular}

Table 3.1 Households by size by composition 1988

\begin{tabular}{|c|c|c|c|c|c|c|c|}
\hline \multicolumn{3}{|c|}{ Hous eholds by size and composidon (CBS) } & \multirow[b]{2}{*}{ 3-pHSA } & \multirow[b]{2}{*}{ 4-DHSH } & \multirow[b]{2}{*}{ 5 pHSH } & \multirow[b]{2}{*}{ Total } & \multirow[b]{2}{*}{$\%$} \\
\hline 1993 & T-pHSLI & $2-\mathrm{pHASH}$ & & & & & \\
\hline Singleperson hous ehold & 1968 & & & & & 1908 & 31 \\
\hline Mulluple-pers on hous ehold & & & & & & 0 & \\
\hline Couple without ohide(ren) & & & & & & 0 & \\
\hline Thertied & & 1442 & 13 & & & 445 & 23 \\
\hline non-mamed & & 433 & & & & 433 & 7 \\
\hline Couple mill chudren) & & & & & & 0 & \\
\hline mimed & & & 724 & 902 & 42 & 2038 & 32 \\
\hline mon-mamed & & & $45^{3}$ & 27 & $9:$ & 81 & 1 \\
\hline Lone parent & & 184 & 95 & 29 & 10 & 318 & 5 \\
\hline Other & & $61^{1}$ & 8 & 5 & 11 & 75 & $\mathrm{~T}$ \\
\hline rotal & 1668 & 2120 & 885 & $963:$ & 432 & 16368 & 100 \\
\hline
\end{tabular}

The number of people living alone or better 1 -person households ( 1 -pHSH) increased during the period $1960-1990$ from 373.000 to 1.813 million, to increase further to 1.970 million in 1993 . Their

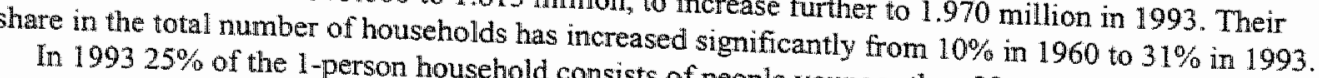
and older than 65 years, most of them women. Because young younger than 30 years, $26 \%$ is widowed 
person household and by the increase of the divorces, the mean age decreased during the period 1960 1990.

In $196025 \%$ was younger than 45 years, in 1990 nearly $50 \%$ was younger than 45 years. This trend will reverse after 2000 . The number of households consisting of married - and unmarried couples without children (2-pHSH) was in 19881.6 million $(27 \%)$ and increased to 1.85 million $(30 \%)$ in 1993 . Most of these households consists of married people. The non-married couples are in the minority. Within the class of couples without children living at home (2-person household) the elder people are relatively strong represented. Unmarried couples without children are much younger aged. The share of couples without children living at home in the total number of households increased from $18 \%$ in 1960 to $30 \%$ in 1993 .

Within the class of households with children the following distinction can be made:

$$
\begin{aligned}
& \text { - couples with child(ren) } \\
& \text { - married } \\
& \text { - non-married } \\
& \text { - lone parent }
\end{aligned}
$$

These three household types together counts in 1960 for more than $50 \%$ and decreased to $43 \%$ in 1988 to $38 \%$ in 1993 . These married couples take the largest share for their account. The lone parent group is and remains modest, despite the doubling share since 1960.

\subsection{Households by size}

The household by size ( 1 to 6-and-more persons) will be the unit of analysis for our research, because most relevant statistics do allow a division of households by size. For example, car ownership by households by size, displacement by household by size, etc. Figure 3.1 shows the dynamics of household by size for the period 1960-1990. Figure 3.1 confirms the continuing growth of the past decades of the number of two classes of households:

- I-person households, and

-2-person households

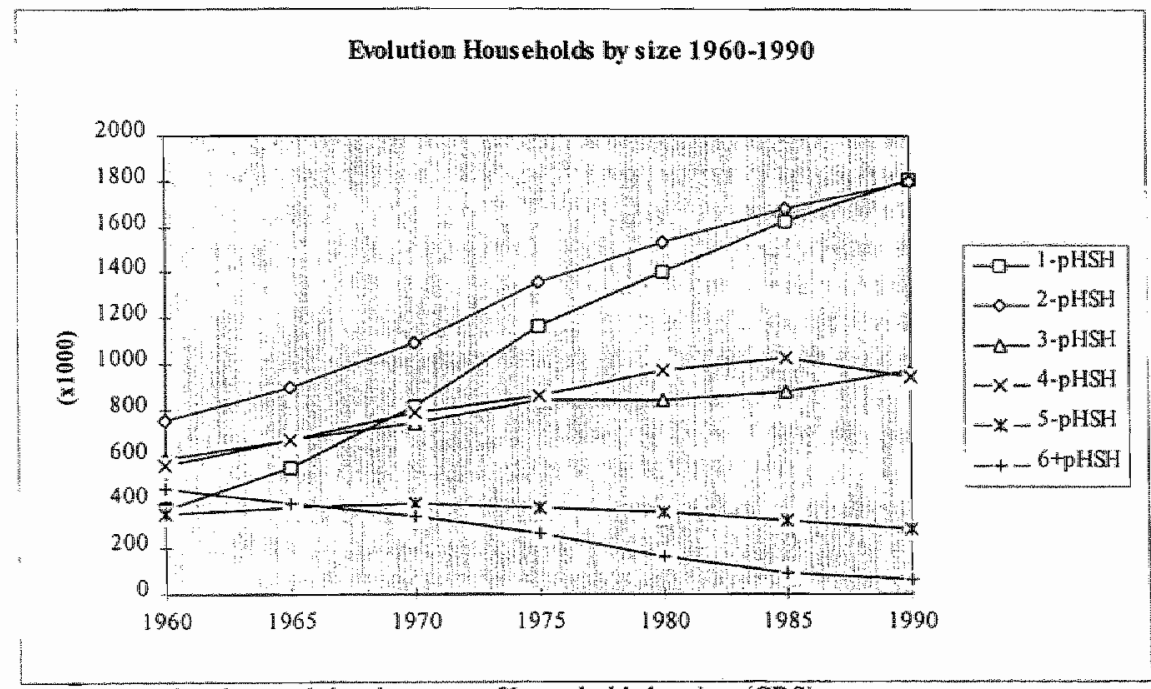

Figure 3.1 The observed development of households by size (CBS)

The sharp growth or stated otherwise the positive feedback phase of both series lies in the 60 s and 70 s, with the 1-person household exhibiting a prolonged (stretched) asymptotic growth path. The dominant loop shift, that is the shift from positive loop to negative loop or mathematically speaking the point of inflection in the sigmoid curve, is situated in the early 70s for the 2-person households and in the mid of the 70 s for the 1 -person households. From our simulation cxperiments the number 
of 2-person households growth rate saturates or comes to maximum in the early 2000 , the number of 1 -person households saturates approximately two decades later, mainly due to the "greying". The number of 3-and 4-person households stabilise in the 80 s after a modest growth in the $60 \mathrm{~s}$ and $70 \mathrm{~s}$. The number of 5-and 6-person households stabilise also during end 80 s and early 90 s, but after a decrease during the 60 s and 70 s.

\subsection{The future}

The following social cultural aspects dominate the behavioural changes in the near future:

- Leaving home

Living apart for youngsters was very popular during the $60 \mathrm{~s}$ and $70 \mathrm{~s}$, but reversed somewhat during the 80 s probably due to lengthening of the education and the increasing starting cost of 1 -person households in a stagnant economic environment. During the early 90 s the age of leaving parental home did not change and stabilised at $50 \%$ for 21 year old women and 23 year old men. In the CBS forecasts it is assumed that the median age at which youngsters leave parental home does not change. Nonetheless, by the growth of the number of youngsters, the number of living-at-home will increase from \pm 4.5 million in 1995 to \pm 4.7 million in 2015 .

\section{- Living apart}

More youngsters, while leaving parental home, become single, for the time being, before becoming a couple. In the CBS forecasts it is assumed that the percentage singles of youngsters will increase. So it is assumed that the percentage male singles less than thirty years will increase from $20 \%$ in 1995 to $25 \%$ in $2015^{\circ}$. For women of the same age category an increase from $13 \%$ to $16 \%$ will be expected. The difference between men and women lies in the fact that young women become earlier a couple than men and their number is smaller than that of men in the same age category. This last fact induced that the percentage men living-together is smaller than that of women living-together. In 1995 the inhabitants aged $20-30$ years accounts for \pm 800 thousand singles. It is projected that this figure does not change in 2015 , nonetheless the increase of the percentage singles. This is caused by a decrease of the inhabitants aged $20-30$ years.

- Living-together married and non-married

During the 80 s the number of non-married couples has increased very strongly. More than half of the youngsters lives, for some time, together. At least three quarter will choose for the married status. According to the CBS forecasts the percentage unmarried couples of men aged 30 years will increase from $22 \%$ to $28 \%$ in 2015 . For women the increase will be $17 \%$ to $25 \%$. In $1995 \pm 900$ thousand people aged 20-30 years lives as unmarried couples. In 2015 it is to be expected to increase slightly to \pm 950 thousand. The slight increase is caused by the fact that the number of people aged 20 -30 years decreases. Table 3.3 summarises the parameter values.

\begin{tabular}{|c|c|c|c|c|c|c|}
\hline \multirow[t]{2}{*}{ Year } & \multicolumn{2}{|l|}{ Single } & \multicolumn{2}{|c|}{ Couples unmarried } & \multicolumn{2}{|c|}{ Couples married } \\
\hline & Men & Women & Men & Women & Men & Women \\
\hline 1995 & 20 & 13 & 22 & 17 & 49 & 63 \\
\hline 2015 & 25 & 16 & 28 & 25 & 39 & 53 \\
\hline
\end{tabular}

- Children

Many men and women follow longer education, go later at work, live later together, marry later and get children later. The average number of children per woman has decreased strongly during the last younger genera women born before World War II $50 \%$ bore 3 or more children, against $25 \%$ with younger generations. Moreover, more women are childless (12\% against $20 \%$ ). The increasing the expected increase of childtant cause of the decrease of the average number of children. Despite

she reason for this assumption is unclear, probably it is an extrapolation of past and recent trend 
$1995 \pm 2.1$ million families with two parents and child(ren), in $2015 \pm 2.25$ million are to be expected. The increase is due to the increase of the number of people of 40 years (from \pm 2.3 million in 1995 to \pm 2.75 million in 2015 ).

\section{- Divorce}

After a strong increase during the 70 s the number of divorces has stabilised since the mid $80 \mathrm{~s}$. Slightly more than $25 \%$ of the marriages ends in divorce. In the forecasts it is assumed that the divorce rate will hardly change in the future. Partly this assumption is based on the increase of the number of non-married couples. Less stable relations end sooner, before becoming a matrimony. Couples with children divorce less quickly than childless couples. Nonetheless in 1995 there were \pm 300 thousand one-parent families, $12 \%$ of the total families. It is to be expected that this remains unchanged in the near future.

\section{- Life expectancy}

The life expectancy increases still further. The lengthening of the life expectancy is not caused in the first place by the elder people getting older, but especially by the fact that more people becoming elder. The most important reason is the decreasing death chance at middle age. It is to be expected. that in the near future the life expectancy will further increase, but at a decreasing rate compared with the recent past. Of the 80 year old women more than $50 \%$ is single, against $20 \%$ of the 80 year old men. According to the CBS forecasts the 1-person households of age 65 twill increase from \pm 700 thousand in 1995 to \pm 1.5 million in 2015.

\section{Other scenarios}

The figures shown above are from the mid-variant of the CBS forecasts. In this variant it is assumed that the growth of the percentage singles will increase less the next 15 years than the past 15 years. (CBS 1996 A). Reason for this is the assumption of the mid-variant that singles for the most of the youngsters will be temporary. A further growth of singles will therefore be limited. For elder people living alone has often a pernanent character.

However, other scenarios are imaginable. For example the changes of the past 15 years will continue for the next 15 years or even at an increasing rate. In the age group 20-50 the percentage singles has been doubled the past 15 years. If an extreme individualisation scenario will be assumed that the next 15 years the percentage will double again than the number of 1-person households will increase from \pm 2.6 million to \pm 3.3 million in 2010 . The number of couples will than decrease slightly from 4.3 to 4.1 million, due to the change of the age profile of the Dutch population.

On the other side one can imagine a family scenario, by which it is assumed that the percentage of singles decreases and that an increasing percentage of the inhabitants will live together (married or unmarried). This would mean a trend reversal with respect to the developments of the last decade. If the percentage singles between the age of 20 and 50 decreases from $14 \%$ in 1995 to $9 \%$ in 2010 , than the total number of singles in 2010 will be equal to the number in 1995 . This means that if the percentage singles decreases by more than $5 \%$ than the number of singles also decreases. In this scenario the number of couples increase from 4.1 million in 1995 to 4.6 million in 2010 . In sum, a strong trend reversal is needed in order to stabilise the number of singles the next 15 year.

The conclusion drawn from the alternative scenarios is that even under extreme future assumptions about living alone or together a fundamental different wiew of the future development of singles and couples does not arise. This is so because the strong influence of change in the future age profile on the household development are frozen (long gestation period) or fixed in the actual age profile. Uncertainty about the future rumber of births has, for the period 1995-2015, no influence on the number of households.

\subsection{The household model ( $H_{1}^{6+}$-model)}

The $H_{1}^{6+}$-model uses the projected age classes of the $P_{1}^{6}$-population model as input driver and the computed transition ratios to compute the household formation by size. The observed and forecast data of households are used as benchmarks in order to map the (causal) structure into a parsimonious 
set of relationships. The information available are the allocation of 16 age classes (from 15-19 to $90 \div$ ) to the 1 - to 6 -and-more person households. After converting the 16 age classes into 6 age classes, the number of inhabitants in each separate age class of the 1 - to 6-person household is computed.

After simulation the household model has been compared with the CBS forecast. The total number of households is compared in Figure 3.2 starting in 1995 . The difference between both series is small and acceptable.

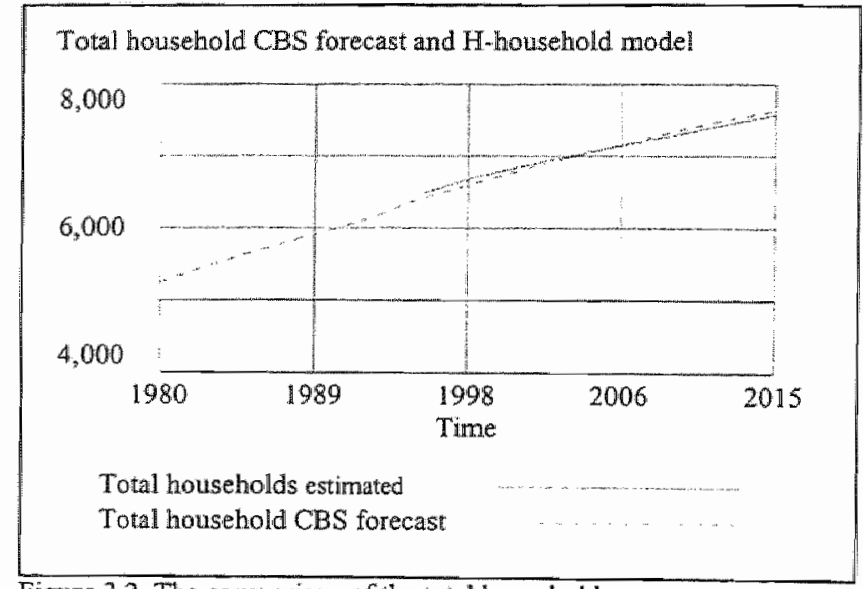

Figure 3.2 The comparison of the total households

Figure 3.3 shows the decomposition of the total household series estimated and the CBS forecast. From Figure 3.3 one sees immediately that the 1 -person households $(1-p H S H)$ are not be expected to stabilise in 2015. CBS foresees this to be happen between 2020 and 2030. The other 2- to 6-and-more person households stabilise during next decade from above, for example, the 2-pHSH or from below, for example, the 5-and 6-and-more person households. The 1-person and 2-person households are growing particularly' by the 'greying' of the population which causes the widows (age 75t) and the elder couples (age 65-80) to increase. For the 4-and 5-person households the increase is very small with regard to the $80 \mathrm{~s}$, while the 6-and-more person household declines somewhat from the $80 \mathrm{~s}$ on.

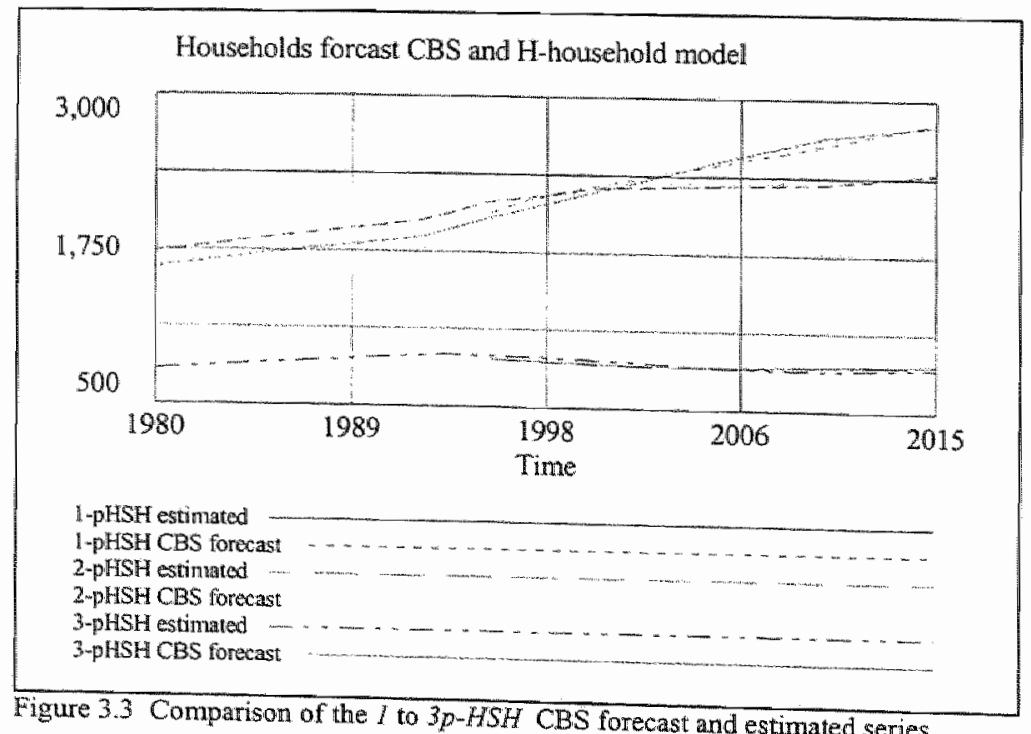

Figure 3.3 Comparison of the 1 to $3 p-H S H$ CBS forecast and estimated series 
Demographic scenarios are the same as applied in chapter 2 and the household formation is shown in Figure 3.4. No future lifestyle changes are assumed, so only demographic changes are effective. The demographic variants have of course the expected simulation results for the household formation, the stabilisation occurs earlier in time in the low variant and vice versa. The 1-person households grows the strongest in both senses, from $31 \%$ in 1990 to $37 \%$ in 2015 , stabilising after 2020 , whereas the 2 person households grows a little in absolute terms but hardly in relative terms, from $33 \%$ in 1990 to $32 \%$ in 2015 .

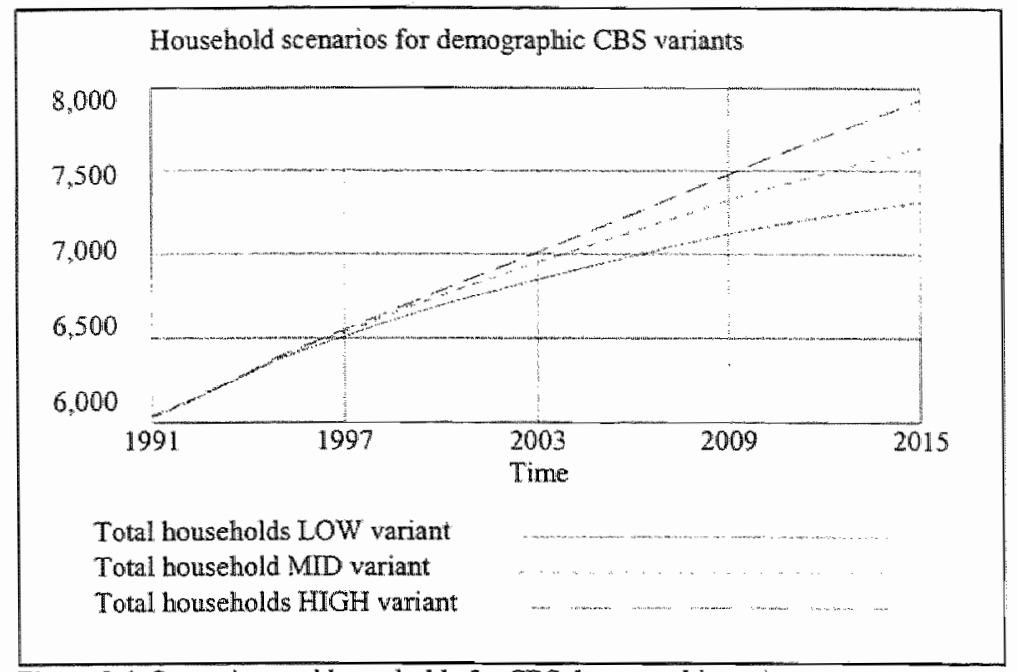

Figure 3.4 Scenarios total households for CBS demographic variants

\subsection{Households time budget, time allocation and lifestyle}

Explaining the mobility development of the households in the modem westem societies it seems essential to state that the demand of mobility is more or less deduced from the spatial distribution of supply and demand of goods and services, labour supply and demand and finally of the production process itself. "The first cluster determines the demand of displacements by the motives: shopping, education, recreation and entertainment, the second cluster the demand of commuting and the third cluster the demand of business traffic or visits. For each cluster not only the extent of the activities is of importance, but especially the spatial distribution between living place and the places where activities take place (shopping, recreation/entertainment centres, schools $s_{s}$ offices and enterprise). The historical growth of the mobility by these motives is empirically linked with the increase of the number of households. On the other hand the growth of the commuting kilometres is mainly determined by the increase of the traversed distance per household - which in turn is determined by

- the kind of employment,

- social characteristics of the employees (for example mamied labour participating women with children have a quite distinct or unique mobility pattern), and

- spatial planning,

and less by the development of the number of employed persons per se.

In sum, the spatial distribution of the organisation of the consumption and production process turns out to be the dominant factor, but the spatial distribution is in turn dependent of the available transpont system.

\subsection{Time allocation, time budget and transport systems}

In general the availability of faster modes of transport has further increased the spatial distribution and the demand of mobility (Klaassen 1972). For example the introduction of the automobile has allowed a very fine and extreme sub-urbanisation, this in tum is supported by an active and 
anticipating public policy, for example the supply of infrastructure, a favourable tax/pricing system for car ownership and usage, increasing in stead of correcting for externalities. All these processes caused a strong increase in the need of transport. These kind of processes are an example of positive feedback(s) causing initially exponertial growth followed by negative feedback(s) as system. boundaries become visible lleading to a damping or retardation of the growth process. These processes can be described by sigmoid functions. The more efficient (in terms of $\mathrm{km}$ per time unit), the cartransport system did not lead to a shortening of the total travel tirnes. On the contrary, the increase of mobility seems more desirable and attractive. In sum the technological development has changed the time restrictions : the avalability of faster transport systems does increase the travel potentials within a fixed delimited time period (24 hours). Essential is the increase of the range or radius of action and the coupled increasing possibilities per additional travelled kilometre.

With this process another essential aspect of the demand of mobility comes into view, the displacement causes time costs. Fixed delimited time budgets (up to 24 hours) are available to the consumers and members of the households and are therefore scarce. Persons don't only allocate their income over different goods and services, but also over the available time. As the referenced activities and the displacements to these activities cost time, not only the number of displacements but also the potential (but valued at a higher utility) locations for these activities are restricted. It is therefore quite possible that given the spatial distribution of the activities the introduction of a faster transport system causes longer travel distances by equal time costs to visit these locations giving a higher utility (Oort 1969). Besides, seen in a dynamic perspective, the economic growth is attended by a process of specialisation and economies of scale which also has a spatial dimension. The developments in spatial distribution may be different per activity by which the demand of mobility has been stimulated. Simultaneously the government did and still does support actively the spatial distribution by official space planning. However, the continuing spatial distribution is only possible by the increased transport potentials in water, rail, road and air.

The aggregate demand of mobility is a reflection of the spatial organisation of the society and economy which themselves again are determined by the actual structure of transport systems. Increased spatial distribution was stimulated by endogenous processes - specialisation and economies of scale - and exogenous processes - government policy - and realised by the rapid diffusion of faster (efficient) transport systems. After World War II the automobile (car and lorries) transport system showed a large scale diffusion (especially in the 60s) and was responsible for the strong increase of the mobility during and after that period, besides it made possible the increased spatial distribution which is one of the main determinants of economic growth. Mobility is a necessary but not sufficient condition of economic growth measured in conventional economic terms.

\subsection{The demand and supply of mobility}

The conventional theory of consumer behaviour indicates the way how a rational consumer spends his money income to different goods and services. Conventional economic wisdom states that: grven the income and prices it can be shown that under the assumption of decreasing marginal utility the total satisfaction reaches a maximum subject to the budget constraints, if for each good or service the tharginal utility equals the utility of the money offered for the purchase of that marginal quantity. Stated in this form the marginal utility theory is subject to a number of restrictions (Klaassen 1972)

1. the theory is static, however dynamic versions including habit formation, changing tastes, and durability have been formulated.

2. the spending of income is timeless, e.g. no time costs.

This means that only money is the restricting factor in the consumption process, but the consumption process has to be done within 24 hours a day and 365 days a year. So there exists a physical limit, within which the consumption process has to take place. As will be shown later $r_{3}$ the money budget restriction will be complemented explicitly by the time budger restriction in the advanced westem 
societies ${ }^{6}$ (Becker, 1965). This implies a diminishing dominant role for the price mechanism in controlling the consumption (or care use) process.

3. In addition to restriction 2 the mere act of consuming (to enjoy the utility of a good or service) does not only cost money but also time, called consumption time, as a third time element

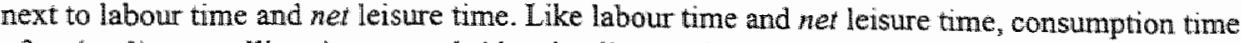
often implies travelling time, as to bridge the distance berween living place and the consumption location. In principle the consumer and member of a household has some alternatives at his disposal in order to bridge the distances depending of income, cost and speed of the travel time. A dynamic theory includes the time dimension, a spatial theory includes the distance, e.g. a spatial elament. 4. The last restriction concerns the infinite divisibility in physical sense of the consumption goods and services. This restriction is important in the spatial sense of the consumption process. In bridging distances the consumer is not able to choose in an infinite divisible way an optimal mix of transport systems to match his wanted displacements, for example, private or public transport system. As the private transport system is an investment in a consumer durable good, one has to separate ownership and usage each with its own, different, decision criteria. Decisions related to the choice of a transport system have a discrete character, dominated by its fixed cost, its efficiency and related time cost structure while usage and especially the intensity or frequencies of usage of consumer durable are among other factors partly determined by the ownership itself and partly by its variable cost structure. One can imagine that the household first chooses its transport systems, given the existing or expected infrastructure, for the different activities and than the living location (domicile) will be determined. Most of the time the number of alternative transport systems are very restricted to one or two. The concept of marginal utility becomes therefore an empty concept. The choice of the household takes place based on a comparison of his total utility in, for example, two situations, that is, assuming alternative $\mathbb{1}$ has been chosen and the remaining income and net leisure time will be spent in an optimal way, or alternative 2 has been chosen and the remaining income and time will be spent in an optimal way. Note that the formulation stated above holds for the time activities in a time budget framework with a disjoint character, work versus non-work, consuming versus non-consuming. In this way the absolute physical time limit adds up to 24 hours a day. But going deeper in detail, it will be possible to do different activities within the same time unit, for example dish washing while cooking with or without a magnetron during a musical intermezzo on radio or CD player. This simultaneity of activities introduces the relative or flexible time limit, and the total available activity time could be larger than (added to) 24 hours. So, if the relative time limit exceeds the absolute one, then the consumpilon intensity per unit of time increases (or equivalent the time intensity decreases as a function of the capital intensity) and the greater this gap the greater the time productivity of the consumption process. From time budget surveys it can be concluded that the free variable net leisure time comes increasingly under pressure, in effect it declines, depending among others on the wageearner position(s) and this development has far reaching consequences for the consumer/household behaviour and therefore consumer lifestyle, especially for the mobility, the chosen transport systems and in our case car ownership and car use on the one hand and the price mechanism on the other hand. The price mechanism as regulatory mechanism of car use becomes less and less effective in controlling the mobility demand. This has indeed far reaching consequences for the effectiveness of the traditional public policy in the area of (public) transportation

\subsection{Summary}

Starting from a given living location and labour market participation(s) the $n$-person household has to take into account, in order to maximise its satisfaction or utility, four cost components:
a. the supply price of the good or service,
b. the consumption time of the good or service,
c. the transport cost to and from the supply side of the good or service,

\footnotetext{
However implicit the time restriction appears in the money budget constraint through libour income or the allocation of labour time versus net leisure time with leisure giving positive utility.

"An additional argument in this aspect is the comtimuing increasing fuel efficiency of the new engines
} 
d. the transport time needed to and from the demand side (home side).

The physical consumption time, travel time being a subset, becomes the additional variable to be minimised, besides the traditional household expenditures per se. Pressure on net leisure time results, next to scale effects of the more-person households, in choosing the most efficient or optimal transport system. A transport system consists of all types of means of transport available, broadly divided into collective means of transport, like train, busses, etc ${ }_{t}$, and private means of transport, like bicycle, automobile, etc. The private means of transport are the most flexible in the time-distance space and can satisfy more or less all the displacement motives of the n-person households. The collective means of transport are fixed in the same time-distance space and can therefore satisfy some displacement motives only. The $n$-person household chooses its optimal transport systems given the assumptions and conditions stated above, and it is evident that there exists a range of optimal transport systems for the 1-person and 4-person household or in general for the $n$-person households. The more efficient the transport system the more kilometres can be travelled per unit of time or more displacements within the given available travel time. If the free time, or net leisure time comes under pressure the choice of more displacements within the available travel time is more likely than the same displacements within less travel time. Travel time will not be minimised, the number of displacements will be maximised. These propositions are theoretically based on the general model of household's time-allocation and will be (indirectly) scrutinised in chapter 3.

\subsection{Mobility and time budget surveys}

Analysis of traffic and transport often links the development of mobility to factors such as economic growth, population growth, sub-urbanisation and scale increase. There are indications that, in conjunction with these factors, changes in lifestyle too affect mobility. Surveys have made frequent reference to the number of married or cohabiting women entering the labour market and to the number of 1-and 2-person households. An analysis of time budget data also shows that arrangements made within households regarding the division of home-production (task combinations) and the use of net leisure time affect the need for displacements (trips). Much of this information is derived from research in which individual differences in the extent of mobility were measured at one particular point in time or part of a year. A recent Dutch research (SCP 1993) investigated the question whether mobility has also increased over time (1975-1990) because lifestyle changes are now diffused in society. The statistical sources are the time budget surveys (TBO) for the period 1975-1990. The findings support the thesis that the characteristic 'household by size' is an important element in the explanation of mobility and car use. Four aspects of a modern life style proved to be important in explaining mobility and the growth of mobility,

- reduction in the size of households,

- women emancipation;

- the combination of various tasks;

- the diversity of leisure behaviour.

These factors refer to different aspects but are not completely disjoint and therefore overlap only partially. It was also first established that the effect of these factors on the number of individual trips is partly due, if at all, to the effects of differences in age, income, education or car ownership. The main problem examined may be stated as follows:

- What influence does the reduction in the size of households, increasing emancipation and task combination, and decreasing net leisure time have on the transport system chosen and the usage of the means of transport (in our case car use) 


\subsection{Changes in activities and displacement (trips)}

The shifs in the use of time observed during the period 1975-1990 have mainly led to greater contrasts between younger and older age classes and, accordingly, to greater changes too between employed people and nom-employed (unemployed plus those in retirement or early retirement). Since 1975 people in the (20-50) age class have for various reasons spent an increasing amount of time on all their activities together and therefore had less net leisure time in 1990 than in the 70 s (Figures 3.9 and 3.10 ).

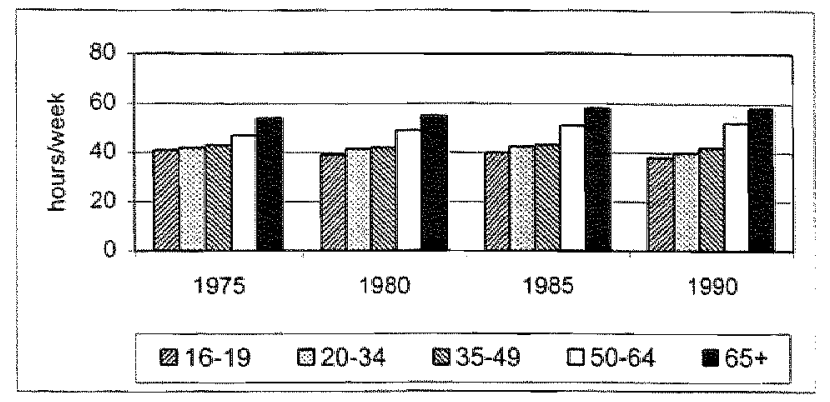

Figure 3.9 Average time spert on leisure activities by age class

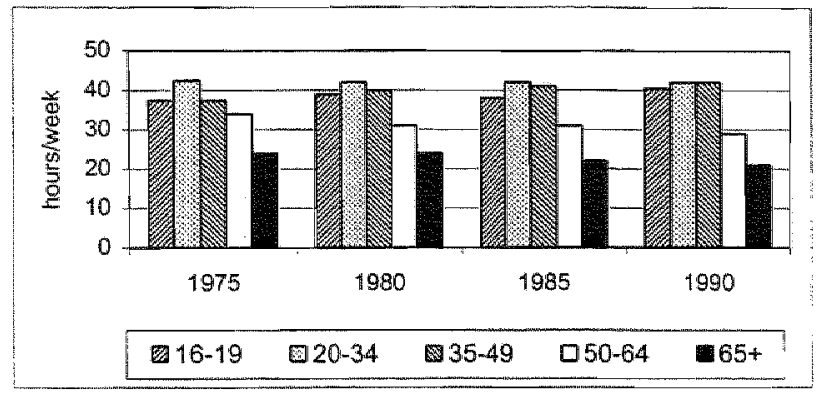

By contrast, the $50^{+}$, particularly the men, now have much less labour work than in 1975 and considerably more net leisure time. The extra net leisure time for middle-aged and old people means that the differences in net leisure time from age class to age class have broaden further since 1975. Besides the contrast between young and old, the division of work and net leisure time among the various educational categories has also become more unequal: the lower the educational level, the less busy the person is. Note that the percentage difference increases with higher educational levels. The same conclusion holds for the kilometrage per person per day by car. The idea that everyone is getting more and more nei leisure time is based on a misunderstanding, in any event, if one takes a normal working week.

Figure 3.10 Average tme spent on obligatory activities by age class Although the number of days during which a person need not work has increased for some employees when calculated on a year scale (due to more days' leave and shorter working hours), data recorded during a week in which all activities take place as normal (a normal working week) provide the best information about the possible causes of the increased mobility.

\subsubsection{General view of changes in displacement reasons and mode of transport}

People whose obligation(s) are largely outside the home (i.e. people following courses, working men and women) make more trips in a week than those who have no daily duties outside the home

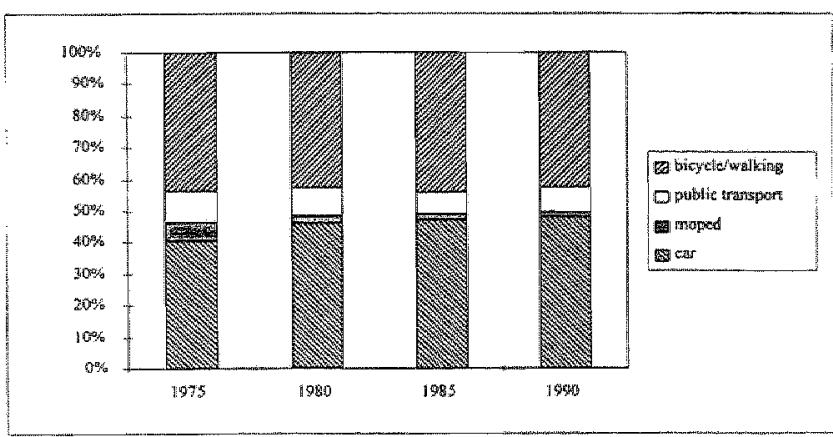

Figure 3.13 Average number of trips per week by means of transport (housewives, mon-employed people). Young people make more trips than elder people, and people with a higher educational level make more trips than people with a lower educational level. The increase in the number of trips between 1975 and 1990 is most apparent among the group who were initially least mobile: women (particularly housewives), non-employed and elder people aged over 65 . These shifts (behavioural changes) point to 
a levelling off of the differences in the extent of mobility: groups whose activities consisis mainly of home tosts and leisure pursuits have become more mobile.

The car was the mode of transport whose use increased the most between 1975 and 1990 (Figure 3.10) The increase between 1975 and 1990 was $30 \%$ (from 6.7 to 8.8 trips per week) which was almost thee times the average rise in overall mobility (from 16.5 to 18.3 trips per week). In addition, walking and cycling increased, albeit to a much lesser extent $(+8 \%)$. The use of public transport decreased between 1975 and 1990 , as did the use of mopeds. The share of public transport in the total number of trips declined from $10 \%$ in 1975 to $8 \%$ in 1990 , while the share of the car increased from $41 \%$ to $48 \%$. The time spend on car use (hours per week) rose from 3.3 in 1975 to 4.2 in 1990, an increase of $27 \%$. Although people on the whole made less frequent use of the train, bus, tram and metro, they did spend more time in them on average.

\section{5}

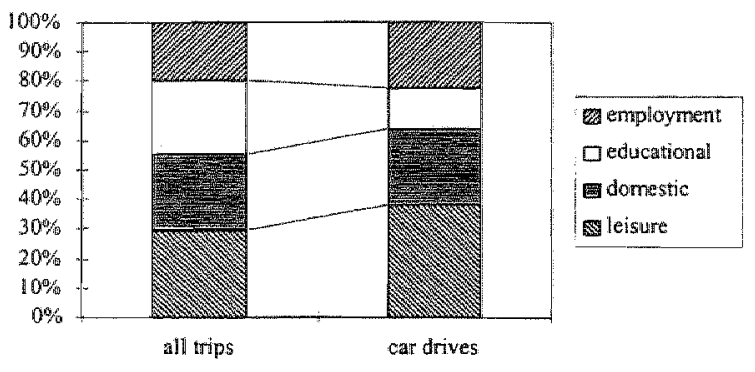

Figure 3.14 Total trips by car drive 1975

\section{0}

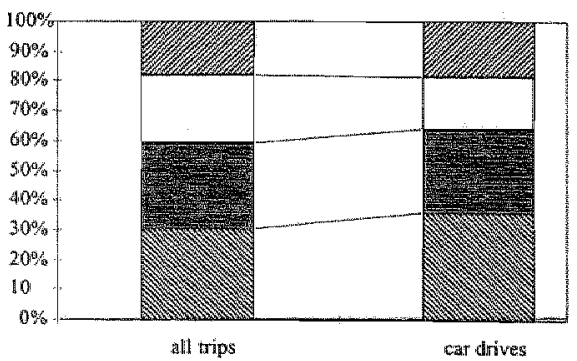

The use of net leisure time (recreation and entertainment) is the most frequently quoted reason for trips and the category on which the most time is spent. People leave home \pm 6 times a week to wisit friends and relatives, play sport, attend a club, do voluntary activities and/or take part in an activity involving politics, religion, etc. Home-production (in particular shopping) also accounts for trips by a larger number of people, although the number of trips is still smaller

than due to leisure activities. Nonetheless, the number of trips made in connection with homeproduction in 1990 (Figure 3.12) already exceeded the number made in connection with employment. This was not the case in 1975 (Figure 3.11). Figures 3.11 and 3.12 show the number of trips and car drives per week by motive (in \%) for 1975 and 1990

The figures from the TBO surveys on the modes of transport used and the reasons given for the trips agree closely with those obtained from the

Figure 3.15 Total trips by car drive 1990

special OVG transport surveys. As regards the absolute extent of the number of recorded trips and the trend since 1975, the similarities between the two surveys are less great. It remains unclear, however, to what extent this can be attributed to differences in the method of measurement or different weights, therefore from 1995 on the weights are modified in order to match both surveys and to correct for differences in population, different minimum time needed for the definition of a trip, etc. 


\section{Summary}

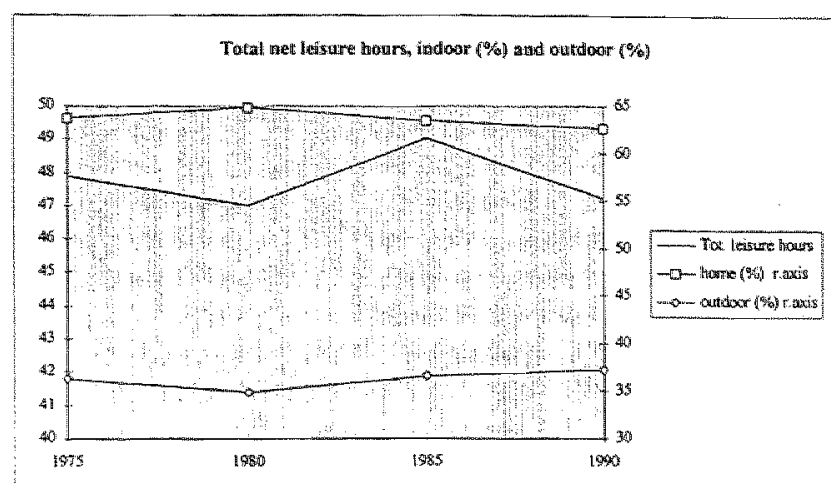

Figure 3.20 Total absolute leisure time in and outdoor (\%)
It is often said that the more net leisure time people have the more likely they are performing outdoors activities. This comimon sense statement is not supported by the facts. Indeed, the converse is true since in general the less net leiswre time people have the greater percentage of such time is spent in outdoors activities (Figure 3.13). Employed people under 35 and also people at educational institutions have fewer net leisure hours, but spend a higher than average propartion of them $( \pm 40 \%)$ in

outdoors activities. There is also a connection between social status and the extent to which people invest in outdoors activities: the higher the educational level the more time is allocated to outdoors activities. Net leisure time spent outdoors (sports, entertainment, visits to friends etc.) belongs to the category of activity which generates a relatively large number of trips: in 1990 on average every 2.3 hours (4.3 trips per 10 hours spent outdoor). As many more people are actively engaged in leisure activities than in employment or education, net leisure time has generated more trips than employment and education together since 1985. Employed, middle and high educated between 20 and 50 , people make the most trips in their net leisure time. The changes between 1975 and 1990 indicate that there has been some levelling off of the initial differences regarding age and the nature of the activities: older people and/or non-employed and housewives became more mobile in their net leisure time. Especially future young elder are likely to be more mobile than the actual one. However, the differences in terms of social status remained considerable: employed people are more mobile (went out more frequently) in their net leisure time than people economically non-active, and people with a medium or high level of education are more mobile (went out more often) than people with a lower level of education.

The car is the most used mode of transport for net leisure time activities: cycling and walking come second. In net leisure time means of transport also serve mainly as recreational aids. This explains the modest position of public transport now and in the future. The relationship between the various modes of transport did not alter greatly between 1975 and 1990 .

The (20-50) age class makes the most frequent use of the car for leisure activities. Once again, this especially true of employed people and the more highly educated in this age class. But here too, groups such as housewives and retired people who in 1975 could still make little use of a car in their net leisure time are catching up.

Car ownership is once again accompanied not only by the more frequent use of the car but also and more generally by higher frequency of trips. Public transpiort has not lost ground on awerage, but it has done so among those groups who still made little use of the car in 1975 (housewives and retired persons). It is striking that the use made of public transport has even declined among the inflabitants of the three major Dutch cities, who have a comprehensive public transport network at their disposal.

\section{Chapter 4. An aggregate long term car stock model}

\subsection{Introduction}

In the past many relationships explaining car sales include both demand (often total sales in monetary terms) and supply elements without distinguishing which variables serve to explain short-run fluctuations and which to explain long-run developments. Moreover, most of the research is focused on total automobile demand without taking into account differences in quality characteristics of different model types, fuel type and cylinder content class. In these studies, the depreciation level of 
the currently held car stock is usually related to the demand for new stock. This approach leads to a very general stock of adjustment or generalised acceleration framework. The estimates of price elasticities from these studies range from -1 to -1.5 , and the estimates of income elasticities range from 1.5 to 4 .

The second approach is based on viewing automobiles as bundles of individual attributes for which no explicit markets exist. The difficulty with this approach is that the prices of individual

characteristics are not observed but must be imputed from differences in prices of otherwise identical bundles (but with different characteristics). The implicit prices of automobile characteristics are obtained from the hedonic regression, and than used, free of quality-differences, in the second-stage estimation of demand parameters. The residuals from hedonic price regressions are used as the price adjusted for quality differences. The main advantage of this approach over the aggregate demand is its treatment of the automobille as a differentiated good. This allows the investigation of the influence that model characteristics will have on automobile demand. However seen our goal we need a differentiation of new versus used automobiles, by year of construction (vintage), by fuel type, cylinder content, and by input-output technology. Differentiation by fuel type leads to two main bramches: gasoline versus non-gasoline (diesel o11) or LPG (liquefied petrol gas)), the cylinder content in three 3 classes ( $c c<1400,1400 \leq c c<2000, c c \geq 2000$ ), and technology, input technique (direct- versus indirect fuel injection) and output technique (open-versus closed loop catalytic converter). Ideally one needs a five-stage discrete choice model in stead of the two-stage procedure

I. the first choice will be between new or used automobiles,

11. the second choice will be gasoline versus non-gasoline engine system based mainly on the break-ewen point of total yearly user cost versus yearly average kilometrage, for example in 1995 (1991) the break-even point for a LPG automobile (1400-cc) was 27000 (20000) $\mathrm{km} /$ year, for diesel $25000(24000) \mathrm{km}$, so consumers with a yearly kilometrage $<20000 \mathrm{~km}$ will likely chose for the gasoline automobile system,

III. the third choice of the cc-classes,

IV. the fourth choice the input-output technology and

$V$. the fifth choice the remaining difference in attributes.

Due to lack of avallable data we are obliged to take a different route. We will relate directly the longrun dynamics of demand to the stock of cars and permanent income, rather than account for in proxy fashion by the rate of change of income. The supply of new cars at retail can be modelled as depending on sale price, the wholesale price of the car and on dealer"s cast of operations, however seen the scope of our study we take the simple assumption that the supply of new cars will be derived from the sale of new cars, this is justified in a buyers market (or replacement market) environment.

\subsection{Developing and estimating long-run new car sales functions}

A framework for analysing consumer behaviour is the stock adjustment model, viewing the houselnolds as attempting to adjust actual to desired (or planned) stocks of assets. Within this framework, survey measures of consumer purchase expectations (chapter 4, section 1.1) can be interpreted as a subjective estimate of the difference between actual and desired stock, with reported purchase expectation reflecting the speed of the adjustment process as well as the underlying determinants of desired stock. And survey measures of consumer attitudes (optimism, pessimism) might be interpreted as one of the arguments in the desired stock function. It should be pointed out that by their nature, durables goods are not purchased to be used up themselves but for the flow of services received from these goods until the product is fully depreciated or scrapped. The analysis of demand for consumer durables focuses on the demand for durable goods stock, and only indirectly examines purchases. In the next section a model will be developed that relates several aspects of purchase behaviour to stock demand. The model has to take provision for the lagged adjustment of the stock of automobiles to changes in the equilibrium level of stocks, for the expectational basis of stock demand, and for the distinction between transitory and permanent influences on demand. In general terms, the model views consumers as having a 'target' or 'desired' value of durables stocks to which they adjust gradually. Adjustments are not made instantaneously partly because of decision and 
purchasing lags, partly because the level of desired stock represents a target demand about which there exists some uncertainty, and partly because of transaction costs. Household investment decisions are sensitive to uncertainty because resale markets are imperfect; a decision to invest represents a commiment to consume a certain level of serwices well into the future. Net investment is viewed as having a "permanent" or "planned' component and also "unforeseen" or "transitory" components. In general the distinction between permanent and transitory investment may come from an unexpected but permanent income change which alters the rate of consumption and therefore the level of durable stock held. However, the permanent component depends on long-run expectations and average adjustment lags, while the transitory component represents the immediate reaction to unexpected income flows. The transitory component accounts for the volatile behaviour of (automobile) investment because of unforeseen economic phenomena (expected unemployment, and related consumer sentiment) alter the time pattern of stock adjustment.

\subsection{Estimation of the car stock models}

In order to track the future development of car use the future car ownership is one of prime determinants. Four models will be developed and estimated namely:

- an aggregate stock-flow adjustment model, a general car stock-sale model, which relates the permanent income development and the car stock and past new car sales to be developed in chapter 4;

- a general logistic model, relating the permanent income development and the relative discrepancy between maximum (saturation) car ownership level and the actual car stock. a desaggregated car stock model by fuel type, to be developed in chapter 5 ;

- a logistic symmetric function model, a desaggregated car stock model by fuel type, to be developed in chapter 5 ; and

- the logistic asymmetric function model, a desaggregated car stock model by fuel type, to be developed in chapter 5 .

The logistic model describes a limiting process, the interrelationship between a positive feedback (permanent income related) and a negative, stabilising, feedback becoming more and more dominant when the actual car ownership approaches the maximum car ownership, leading to an asymptotic growth path. Both logistic (a)symmetric function models are in fact hybrid curve fitting models with no explicit causal relationship between maximum and the actual car ownership.

The data of new car siales and active car stock are compiled from CBS statistics (CBS 1994 A) Figure 4.1 illustrates the time series from 1960 to 1994. Note: the new car sales (x 1000) and real disposable income $(\mathrm{x}$ mln) are measured on the right axis, the car stock $(\mathrm{x} 1000)$ on the left axis. Of interest are the sales figures of the period $60 \mathrm{~s}-70 \mathrm{~s}$.

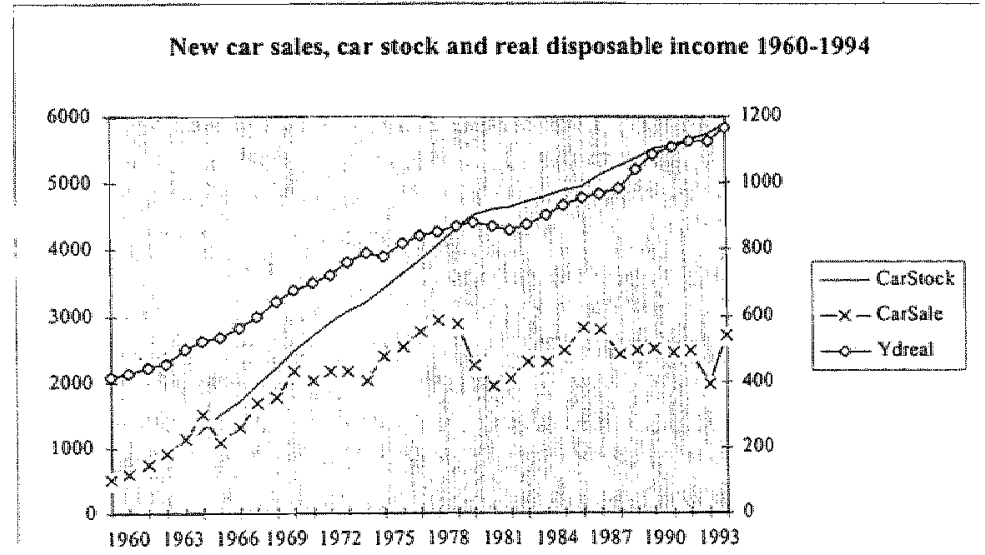

Figure 4.1 CarStock ( 1000$)$ left axis; Ydreal (x mln), Carsale ( 1000$)$ right axis.
Unprecedented car :alles resulting in an exponential growth of the car stock, closing the gap between the relation of the real disposable income and the desired car stock (not shown). The same development is depicted very clearly in Figure 4.2 This development is based on strong income growth effects (with accelerating desired car stock levels) and a starting diffusion effect, both signalling the 
area of automobilism, supporting the exponential increase of mobility of the Dutch society. During the period 1972 en 1979 the number of cars increases with 1 million to 4.3 million, an increase of $41 \%$. Round 1978 a point of inflection occurred introducing the begining of a new growth area or regime, the accelerated growth rate of the car stock changes into more moderate growth rates. The rate of growth of the car stock in 1990 was $29 \%$ for the period $1979-1990$ (from 4.3 to 5.5 million). This increase of the number of cars did not involve a corresponding increase of the diffusion rate of the car ownership in the private households (an analysis of the diffusion rate of the car stock and car ownership will be presented in chapter 6 ).

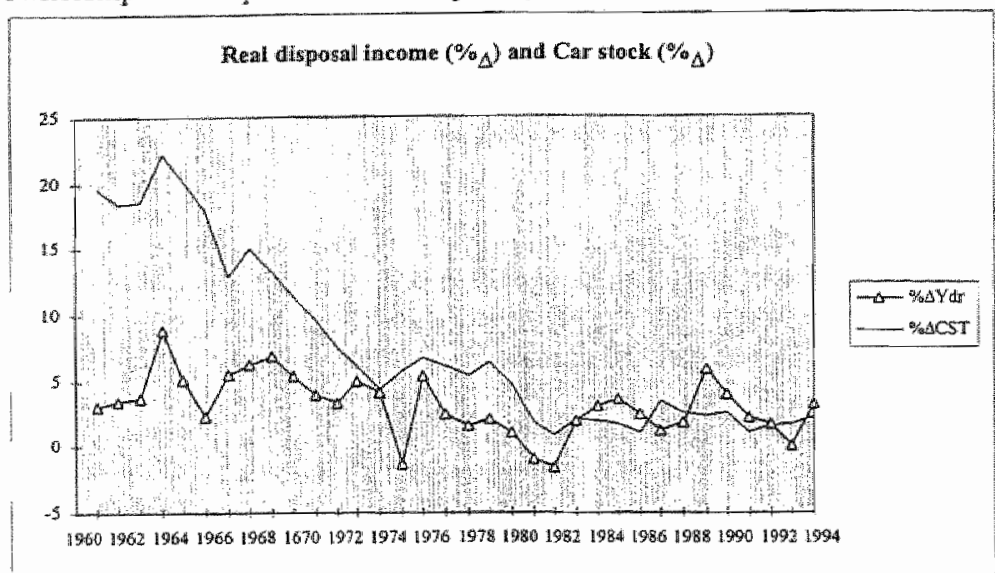

Since the 80 s the growth rate follows those of the real disposable income and of the number of households. Probably giving more weight to the household development in the recent and next decade( $(s)$, than to the development of real disposable income. After 1980 the new car sales undergo eratic up and downs, following

Figure 4.2 Real disposable income $(\% \Delta)$ and car stock (\% or preceding the recession of the early $80 \mathrm{~s}$ and $90 \mathrm{~s}$. The steep drop of car sales in the early $80 \mathrm{~s}$ was followed by a remarkable recovery in the mid 80 s. These instabilities characterise the car market's change into a replacement (buyers) market. At the moment experts in the car market do not expect the same pattem (resurgence) will happen in the mid $90 \mathrm{~s}$ after the steep decline of the early $90 \mathrm{~s}$.

\subsection{Estimation results}

The estimation (search) process is embedded in the simulation procedure (explained in detail in chapter 4). Figures 4.3 and 4.4. show the graphical display of the observed time series and the estimated siock-flow model. The turning point here lies around the year 1978, however the applied model does not allows more explanation about this phenomenon, because the addition of the lagged dependent variable to the independent variables loses critical explanatory information. We have to rely on a logistic model or logistic functions to model the causal relationship of this phenomenon.

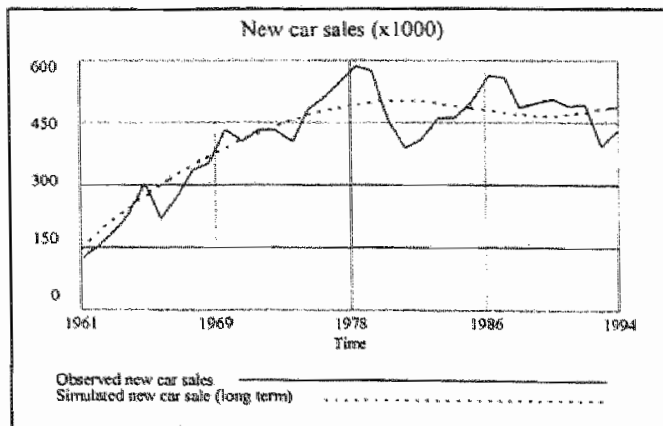

Figure 4.3 Observed and simulated new car sales

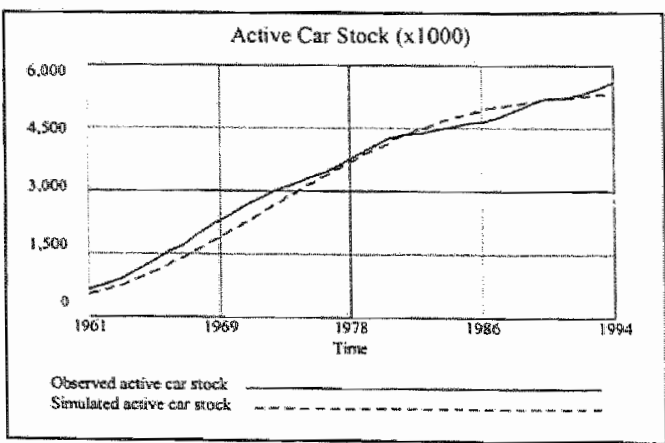

Figure 4.4 Observed and simulated car stock 


\section{Chapter 5. Estimation vintage structures car stock by fuel type}

\subsection{Introduction}

As the emission module needs, among others, cars by fuel type as input, we have to divide up the total active car stock into gasoline, diesel, and LPG driven cars and investigate the new car sales and the scrap by fuel type. Inspecting Figure 5.1 it is remarkable that the number of LPG cars is declining since 1990. The reason is the introduction of more expensive emission control devices for LPG type cars, which increase the user cost and the break-even point from $20000 \mathrm{~km} / \mathrm{year}$ in 1990 to 27000 $\mathrm{km} / \mathrm{year}$ since 1991 for a mid-class automobile $(1400 \leq \mathrm{cc}<2000)$. So there was and still is a switch from LPG to diesel or gasoline, depending among others on the yearly kilometrage. The gasoline shows a moderate recovery in the mid 80 s, and diesel exhibited a stretched sigmoidal growth curve. Note: The the total car stock (x1000) is measured on the left axis, whereas the gasoline -, diesel - and LPG car stock ( $x 1000)$ is measured on the right axis,

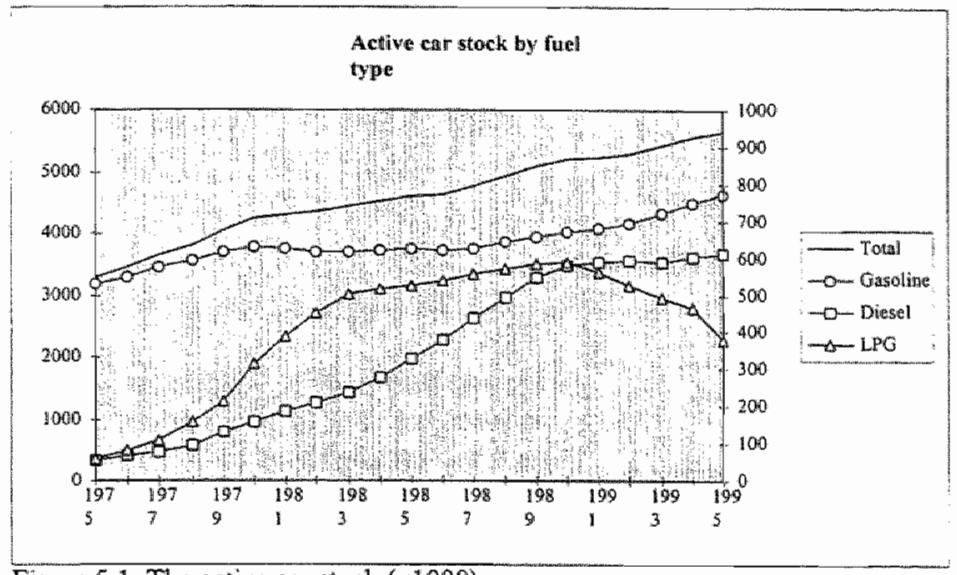

Figure 5.1 The active car stock (x1000)

\subsection{The logistic (function) models}

Referring to the exponential growth of the Dutch car fleet in the 60 s and the diesel cars in the 80 s, the number of cars in a car stock at a point in time did follow an exponential law of growth. This law assumes that at a point in time the rate of growth of the car stock is proportional to the number of cars in that car stock. However, under exponential growth, a car stock would get infinitely large as time goes on. In reality, however, when the car stock gets large enough there are environmental factors that slow down the rate of growth, like biological growth processes. For example, besides money constraints, lack of space, congestion, emission, etc. These factors cause the rate of growth eventualliy to decrease. The car market becomes a replace market, the diffusion or penetration has been completed, and the growth comes only from the growth in the absolute level of households. It is reasonable to assume that the level of the car stock is limited to some maximum number. In sum, we want to develop and estimate three models consisting of the

1. general logistic model

2. symmetric logistic function, and

3. asymmetric logistic function model

which exhibit exponential growth initially but which also includes the effects of saturation and environmental resistance to too large car stock growth. The analytical derivation of the three models and the estimation/validation information are treated in chapter 5 . In the next section the three estimated (function) models are shown. The general logistic model is a process estimation of the interplay between positive and negative feedback, whereas the estimation of the (a)symmetric logistic function can be described as curve fitting approach. Only a subset of the estimation results are shown in the next sections. 


\section{2a. The gasoline cars symmetric logistic function: base period 1986-1994}

The symmetric logistic function has been estimated for the gasoline and diesel case. The asymmetric function has been estimated for the diesel case only, as there was no improvement for the gasoline case.

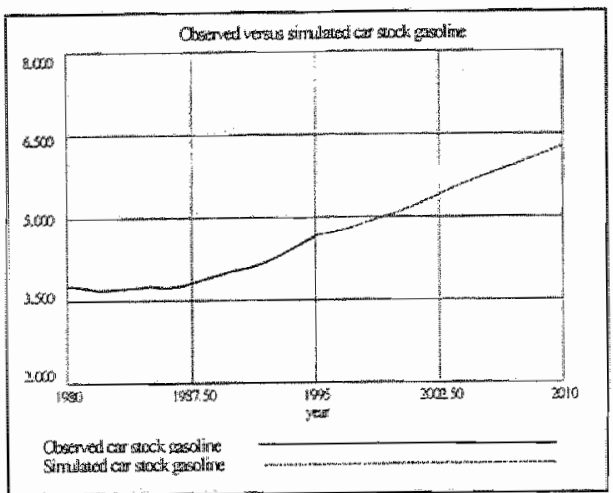

Figure 5.2 The symmetric logistic function
As can be seen from Figure 5.2 the fit is quite close and the forecast is based on a $2.5 \%$ growth rate of net disposable income and constant future relative fuel prices and tax rates. This means that the fuel price and tax ratios conditions of gasoline, diesel oil and IPG remains constant. For reasons explained in chapter 5 the simulated (estimated) gasoline car stock starts in 1986. The main reason is the introduction in 1985 of the periodic car inspection, the "APK', which caused an at once scrap of old vintages, disturbing the composition of the car stock.

\section{2b. The diesel car stock symmetric logistic function: base period 1986-1994}

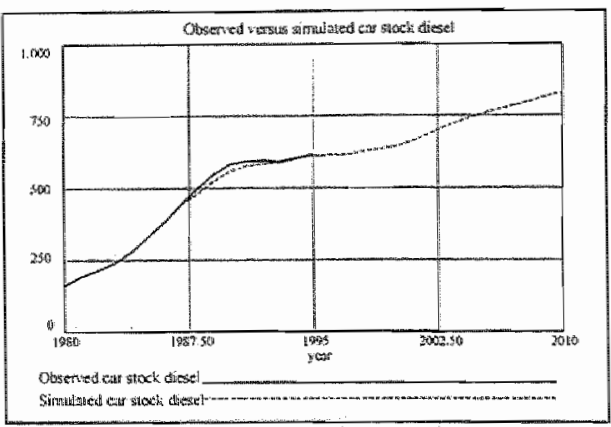

Figure 5.3 The symmetric logistic function
The symmetric logistic function (5.3) performed a reasonable fit as can be shown and Figure 5.3. After a sharp increase during the 80 s the share of the diesel cars stabilises in the mid $90^{\circ} \mathrm{s}$, for reasons to be explained in chapter 5 . Here we can state that mainly fiscal reasons, the fixed cost part, favoured the substitution of LPG and diesel cars. Together with changes of the fuel price ratios, the variable cost part, the government can exert a substantial influence upon the composition of the car stock.

\section{2c. The diesel car stock asymmetric logistic function: base period 1986-1994}

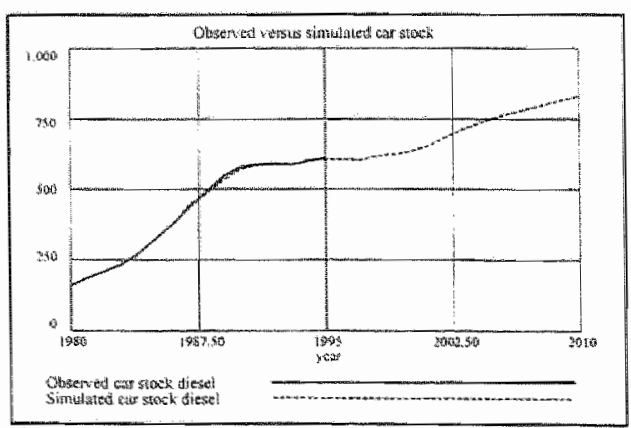

Format 5.4 Asymmetric Verhulst-Pearl function
The asymmetric logistic function performs somewhat better than the symmetric one. This follows from the fact that the point of inflection is located near the top side of the curve to the right, around 1987, however this has no significant influence on the forecast results. 
The next Figure 5.5 shows three test nus with alternative growth figures of the real disposable income, $0,1,2,3 \%$, from 1995 on. With a zero growth of disposable income the saturation level will be reached around the year 2000 , (of course the higher the growth rate the later the saturation level).

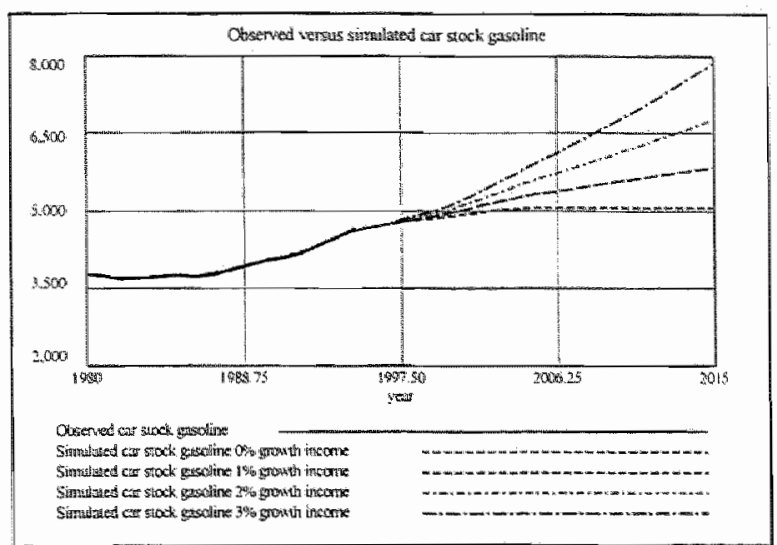

Figure 5.5 Growth rate scenario's and gasoline car stock 1980-2015 


\section{Chapter 6. Car ownership, car use and kilometrage}

\subsection{Penetration rate of cars over Dutch households}

During the two decades 1960-1980 the strong increase of the number of cars was not matched by a corresponding strong increase in the number of households. In $196016 \%$ of the households owned a car, in 1972 this was increased to $62 \%$, and to $69 \%$ in 1979 . As detalled survey data are available from 1979 on, the car ownership over more person households are known. First we show the car ownership over the total household followed by car ownership over more-person households. Figure 6.1 shows the car ownership over total households, the '0-car' and ' 1 -car' measured on the left axis, the '2-cars' and '3-cars' series on the right axis. The car ownership is still slightly increasing, in 1979 '0-car households", or "O-carHSH', accounted for $30 \%$, in 1994 it decreased to $23 \%$. The " 1 -car households', stabilise at $61 \%$ from 1985 on, the "2-car households" on the contrary increases from $10 \%$ in 1985 to $14.5 \%$ in 1994 . The '>2-car households" shows no definitive trend and oscillates between $11 \%$ and $17 \%$

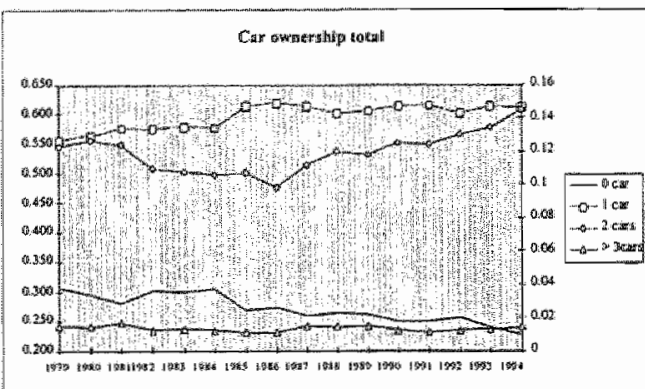

Figure 6.1 The car ownership by total households

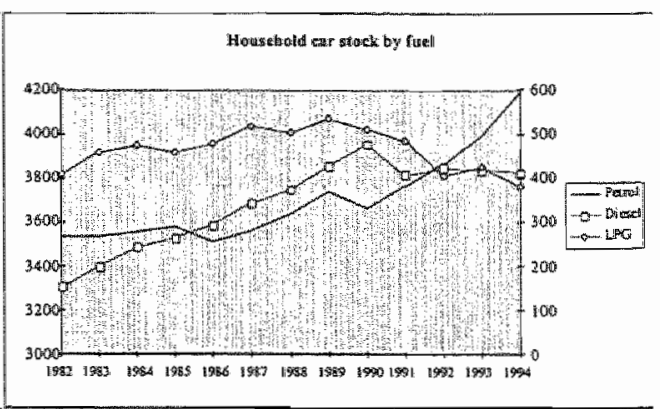

Figure 6.2 Households car stock by fuel type

Figure 6.2 shows some interesting developments,

- the rising share of the gasoline cars, from $3.530 \mathrm{~min}$ in 1979 to $4.200 \mathrm{mln}$ in 1994 ,

- an exponential increase of the number of diesel cars in the 80 s but from 1990 on with 0.477 min a decrease which holds on to 1994 to $0.410 \mathrm{~min}$ diesel cars (in 1995 the diesel car sales and therefore also the diesel stock resume the growth process), and

- the LPG cars (which exhibited exponential growth in the 70s) shows in the 80 s a moderate increase till 1990, with $0.591 \mathrm{mln}$ LPG cars, from 1990 on the LPG car stock decreased continuously to $0.380 \mathrm{~min}$ in 1995 .

The above elaborated dynamics hide some important background developments within the household sector, especially household characterised by size, e.g. 1- to 6-or-more person households.

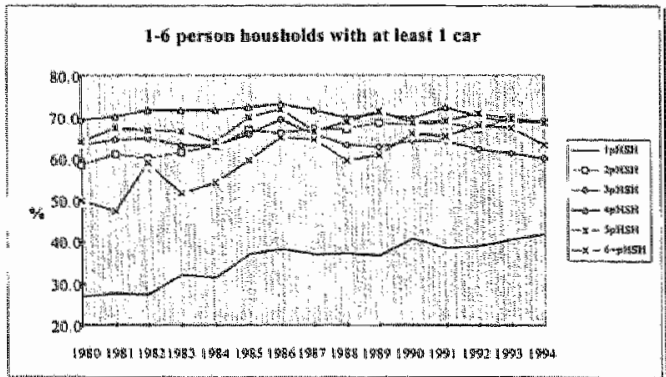

Figure 6.31 - to 6 -person households with 1 car.

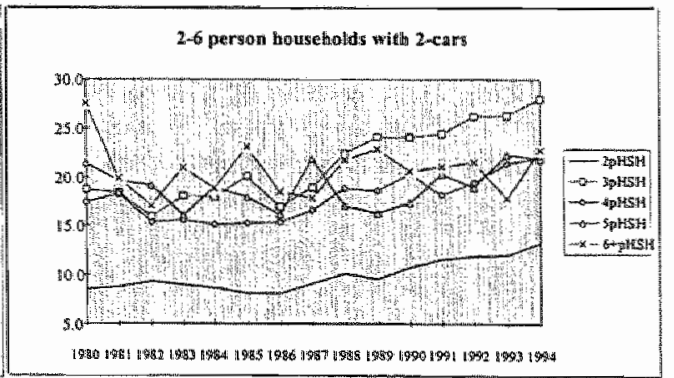

Figure 6.4 1- to 6-person households with 2 cars

The most important development during the 80 s is the strong increase of the 1-and 2-person households, as explained in chapter 3. The 1-car ownership of 1-person households rose from $24.8 \%$ in 1979 (the first observed year) to $44.9 \%$ in 1995 (Figure 6.3) a $68 \%$ relative increase in 15 year. The 
1-car ownership of 2-person households increased from $57 \%$ in 1979 to $69 \%$ in 1995 , a moderate $21 \%$ relative increase in 15 year.

The 2-car ownership of 2-person households rose from $7.4 \%$ in 1979 to $13.3 \%$ in 1994 (Figure 6.4 ), a $80 \%$ relative increase over 15 year, for the 3 -person households the following figures applies: from $17.5 \%$ in 1979 to $28 \%$ in 1994 , a $60 \%$ relative increase; for the 4 -person households from $18.4 \%$ in 1979 to $22 \%$ in 1994 , a $20 \%$ relative increase. The other household types remain nearly constant around $20-22 \%$.

The car ownership of households has been approximated from two different statistical sources:

1. the private car panel (PAP) for the total households, and

2. the displacement behaviour survey (OVG) for the $\mathbb{l}$-6person households

The objective of the private car panel research $(\mathbb{P A P})$ is the investigation of ownership and use of private cars and the determination of the relationship existing between ownership and use features. Tables 6.1 and 6.2 show the penetration of the car ownership over the households by size during the 80 s and early $90 \mathrm{~s}$. Onlly the penetration of the car ownership for the year 1980 and 1994 will be illustrated in Tables 6.1 and 6.2 .

\begin{tabular}{|c|c|c|c|}
\hline Fouseholds by size and car ownership & \\
\hline 1980 & 1 car & 2 cars & $>2$ cars \\
\hline $1 \mathrm{pHSH}$ & 26.8 & & \\
\hline $2 \mathrm{pHSH}$ & 58.6 & 8.6 & \\
\hline 3pHSH & 63.3 & 18.7 & 1.0 \\
\hline $4 \mathrm{pHSH}$ & 69.4 & 17.4 & 2.0 \\
\hline 5pHSH & 65.1 & 21.4 & 4.3 \\
\hline 6+pHSH & 50.0 & 27.6 & 8.6 \\
\hline Total & 56.4 & 12.7 & 1.4 \\
\hline
\end{tabular}

\begin{tabular}{|c|c|c|c|}
\hline Households by size and car ownership & \\
\hline 1994 & $11 \mathrm{car}$ & $2 \mathrm{cars}$ & $>2 \mathrm{car}$ \\
\hline IpHSH & 41.7 & & \\
\hline $2 \mathrm{pHSH}$ & 68.8 & 13.3 & \\
\hline $3 \mathrm{pHSH}$ & 60.1 & 28.0 & 2.4 \\
\hline 4 pHSH & 68.8 & 220 & 3.6 \\
\hline 5 pHSH & 68.6 & 21.8 & 4.5 \\
\hline $6+$ pHSH & 63.2 & 22.7 & 7.0 \\
\hline Total & 61.2 & 14.5 & 1.4 \\
\hline
\end{tabular}

Table 6.1 Penetration of cars $1980(\%)$ over the households by size

The evolution of the car ownership during the period 1980-1994 is most impressive for the 1- and 2person households. It is to be expected that the car ownership of the 1-person households will continue to increase, as the class of young elder (65-75 year old) will substantially increase during the next. decades. To a lesser extent this holds also true for the 2-person households: this theme will return in the scenario analysis of chapter 8 . 


\subsection{Comparing the car stock derived from the logistic models (chapter 5) with the car ownership of the m-person households.}

The period of observation in both cases is 1986-1995, while the forecast period is 1996-2015. As can be seen from Figure 6.5 the total car stock arriwes at $\pm 7.75 \mathrm{mln}$ in 2010 and $\pm 8.3 \mathrm{~min}$ in 2015 for the

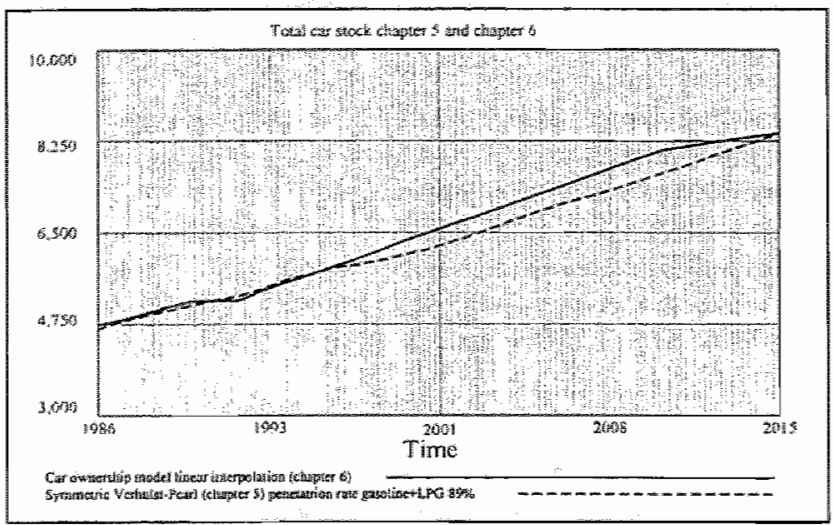

Figure 6.5 Total car stock chapter 5 and chapter 6

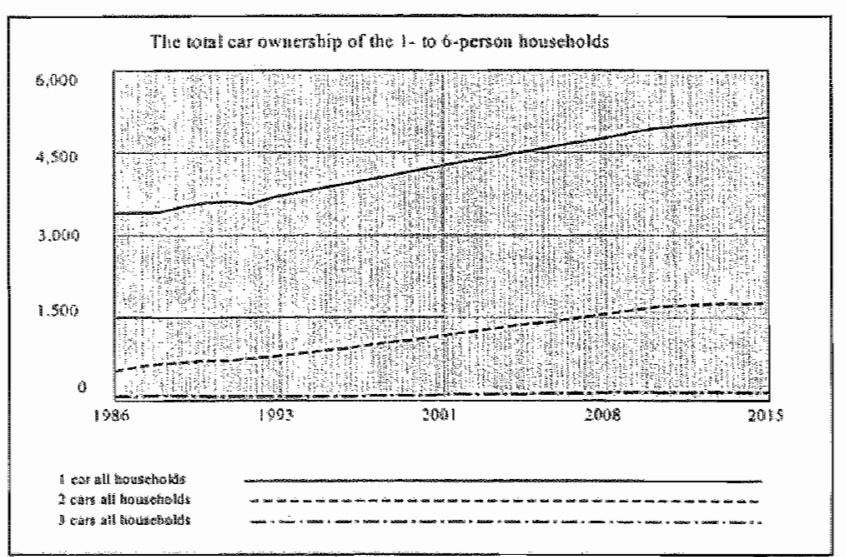

Figure 6.6 The 1-, 2-, and 3-or-more car ownership by all households car ownership model of section 6.1. The models of chapter 5 arrive at $\pm 8.25 \mathrm{~mm}$ in 2015 . In view of the different underlying dynamic processes of the logistic models and the population-household model their trajectories are different, albeit approximating the upper limit of 8.5 min cars in 2015. The dymamics of the population-households model has been dealt with in chapter 2 and 3 , the dynamics of the logistic model in chapter 5. However it is interesting to notice the difference between the trajectories of the total household-model car ownership and the 1- to 6-person household by 1 to 3-or-more car ownership. This is due to the aggregation in the total household model which has a smoothing effect on its dyniamic interaction, as in the $n$-person household model the development of the 1-and 2-person households and their assumed saturation levels of car ownership are decisive (see Table 6.1 and 6.2 ). The growing influence comes from the 1 - and 2 person households and the 1 - and 2. car ownership

\subsection{Households and car use}

From the consumer time budget surveys referenced in chapter 3 the social cultural causes of the mobility changes during the 80 s were explained. Now we start from the $n$-person household and look after their car use by motive. The statistical source supplying these figures is the survey of the mobility behaviour of the Dutch population (OGV) available from 1979-1995. Figure 6.7 shows the development during the 80 s and early 90 s of the distance travelled by car driver by" motive (a subset only). The distance is measured as average $\mathrm{km}$ per person per day. Note that the Total distance travelled is measured on the left vertical axis. All motives (except visiting family/friends) show an 
increase. The small decrease in 1994 can be due to random error, within the confidence bounds). By multiplying the figures with total Dutch population and 365 days one arrives at the yearly total vehicle$\mathrm{km}$. The vehicle- $\mathrm{km}$ times the average occupation rate per vehicle equals the traveller-km. As we are using the $n$-person household as unit of analysis we will look after figures which distributes the distance travelled by car driver by motive.

The motive for car use are classified as : 1. Commuting; 2. Business visit; 3. Family visit; 4. Shopping; 5. Education; 6. Trip; 7. Recreation/sport; 8. Rest

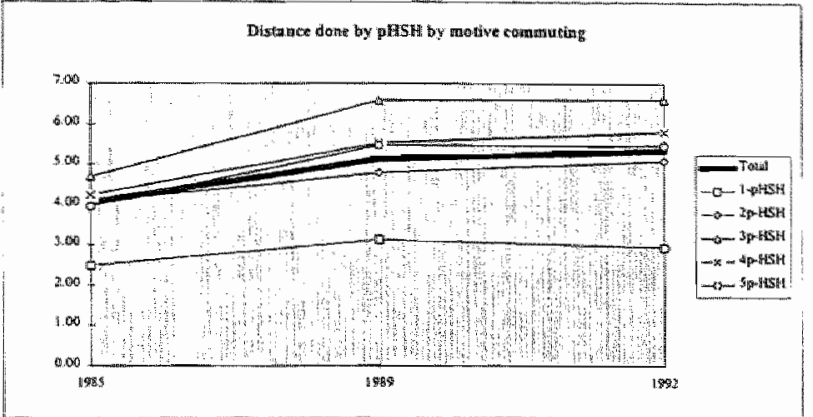

Figure 6.8 Veh-km per person-day by commuting mative

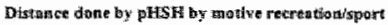

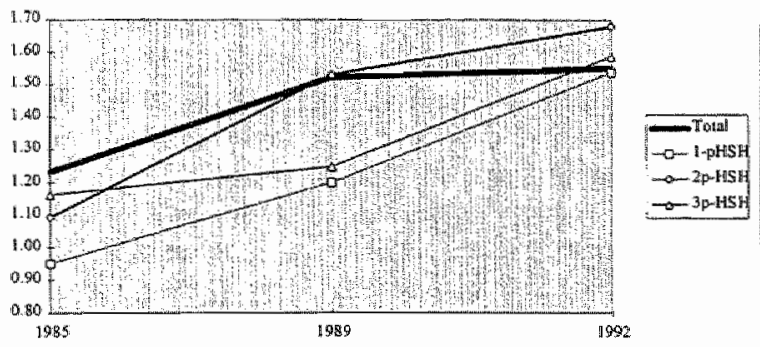

Figure 6.9 Veh-km per person-day recreation/sport motive
A pictorial representation of some motives are shown in Figures 6.8 through 6.10. These data form the basis to link the $n$-person household(s) to the total vehicle kilometrage using the formalism developed in chapter 6.3.1. As can be seen in Figure 6.10 the (average) total kilometrage per personday increased in the midst of the 80 s to change again during the period $1989 / 90$ to al lower growth pattem. By decomposing the total figure into the underlying motive commuting and to a lesser extent shopping and recreation/ sport are the dominant factors influencing the growth of mobility in the 80 s. Looking at the $n$-person household level as reproduced in the Figures 6.8 through 6.10 the commuting motive of car use increases for all person households, with the 1person household, as an exception (Figure 6.8). The reason will be: 1. the introduction of free public. transport permits for the students in

1989, as the student population forms an important subset of the 1-person household, and 2 . the increase of the 'young' elder subset, both exerting a negative effect on the commuting motive. The recreation/sport activities (Figure 6.9) show a strong increase in the smaller households, 1-to 3person household, and a levelling off for the 3-or-more-person households. It is possible that the

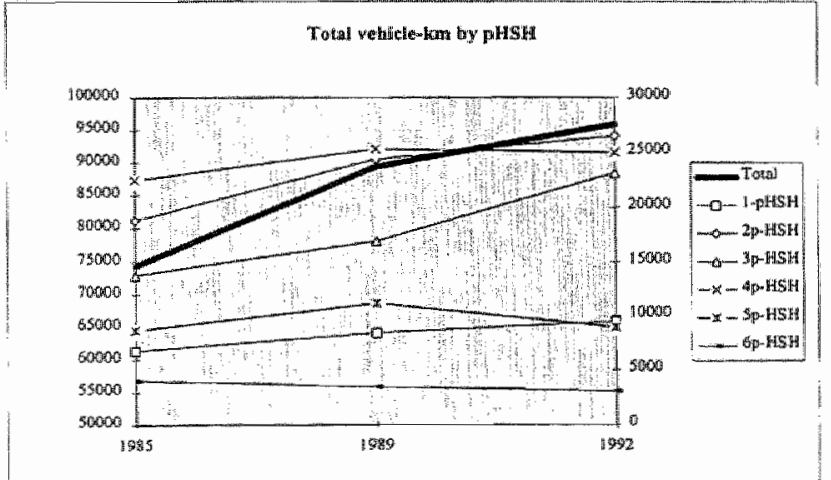

Figure 6.10 The total average car kilometrage $(\times 1000)$ per personday by n-person households penetration of the increased recreation/sport popularity in the $80 \mathrm{~s}$ starts with the small person households, and that the penetration over the 3-or-more households has been started in the 90 s. However, for the time being, it will be inconclusive if there is a convergence of the $n$ person households towards a single average figure or that the 1 - and 2 person households diverge from the remaining households. Examining the total wehicle kilometres by 1 - to 6-ormore person households (Figure 6.10) one sees a strong growth of the total 
kilometrage of all households. By decomposing this figure into the separate households, on can conclude that the smaller person households, 1- to 3-person households, take the greatest part to their account. The automobilism did increase most with these categories. The levelling off of the total vehicle kilometres came from the 4-to 6-or-more person households.

\subsection{The simulation results}

As we will disaggregate the total vehicle km per person per day by motive, as shown in the Figures $6.7-6.9$, we will simulate from the 8 motive data as basis and sum to the desired total vehicle kilometres. On the basis of expectations of the development of the 8 mobility motives plus the expected development of the number of n-person households in the future we arrive at the expected total kilometrage of the Dutch households.

Figure 6.12 shows the output plots of the total vehicle killometres under two assumptions:

1. a simulation run under the assumption of no change of the 8 mobility motives since 1992 (Test2), and

2. a simulation run under the assumption of an increase of $25 \%$ from 1993 to 2010 of the 8 mobility motives (Test 3 ), equally distributed over the $n$-person households,

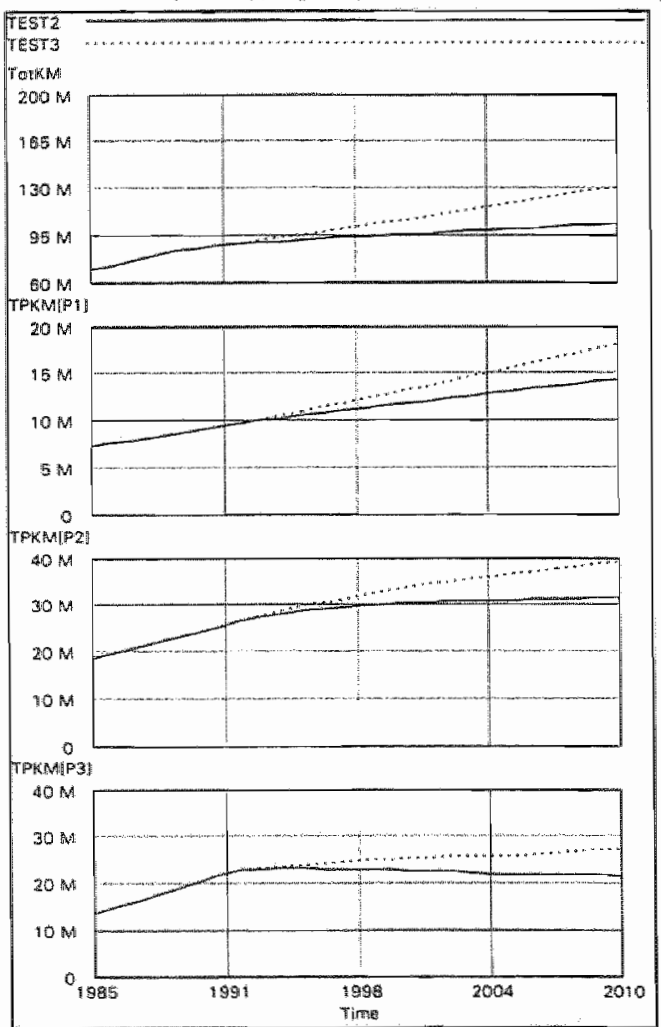

Figure 6.12 Two test runs of total veh-km (x) 1000 ) (Totkm) a. with no changes in mobility from 1992 on (run Tasc2),

b. with $25 \%$ increase of the mability to 2010 (Test 3 )
Ad. 1 depicted by Test2-run shows the change of total yearly vehicle kilometres and idem the vehicle kilometres of the 1- to 3-person households caused by changes of the number of households only.

Ad. 2. depicted by Test3-run shows the changes of total wehicle kilometres under the assumption of a $25 \%$ increase of the Dutch mobility from 1992 to 2010, as expected by some experts (RAI, 1993) plus the effect of the volume increase of the $n$ person households (assumption 1).

Looking at case $\mathbb{1}$ (run: Test2), the no change case, than the total vehicle kilometres TotKM of the Dutch households increases from \pm 69 billion (1985), \pm 93 billion (1995) to \pm 103 billion vehicle kilometres in 2010 . This is an increase of $50 \%$ base year 1985 or $20 \%$ base year 1995 only due to an increase in the number of the $n$-person households with the future mobility equal to those observed in 1992 (the latest available detailed kilometrage of $n$-person households by 8 motives). Case 2 (run: Test 3 ) the $25 \%$ increase case, the total vehicle kilometres increase to \pm 130 billion vehicle kilometres, again the 1-person households TPKM[P1] and 2-person households TPKM[P2] are the main drivers behind the increase of automobilism. As the after war baby-boomers will enter the age-class of 65-75 year ("young elder") during the end 2010 , the $25 \%$ increase of the mobility figure is doubtful. 


\subsection{Yearly wehicle killometrage by vintage by fuel type (Velh-Km[F,V])}

Up till now wo routes have been taken to arrive at the required data for the input of the emission model, to be developed in the next chapter. The comerstone is the car stock by vintage, by fuel type which can be modelled from

1. the household model via the household car ownership (chapter 6) to the total car stock, or

2. the stock-flow or logistic models of chapter 5 to the vintage car stock model by fuel type. In chapter 6 the robustmess of both methods will be confronted in order to determine and to compare both approaches. Here only the results will be presented.

Figure 6.5 showed the total car stocks of the two different approaches and describes their differences.
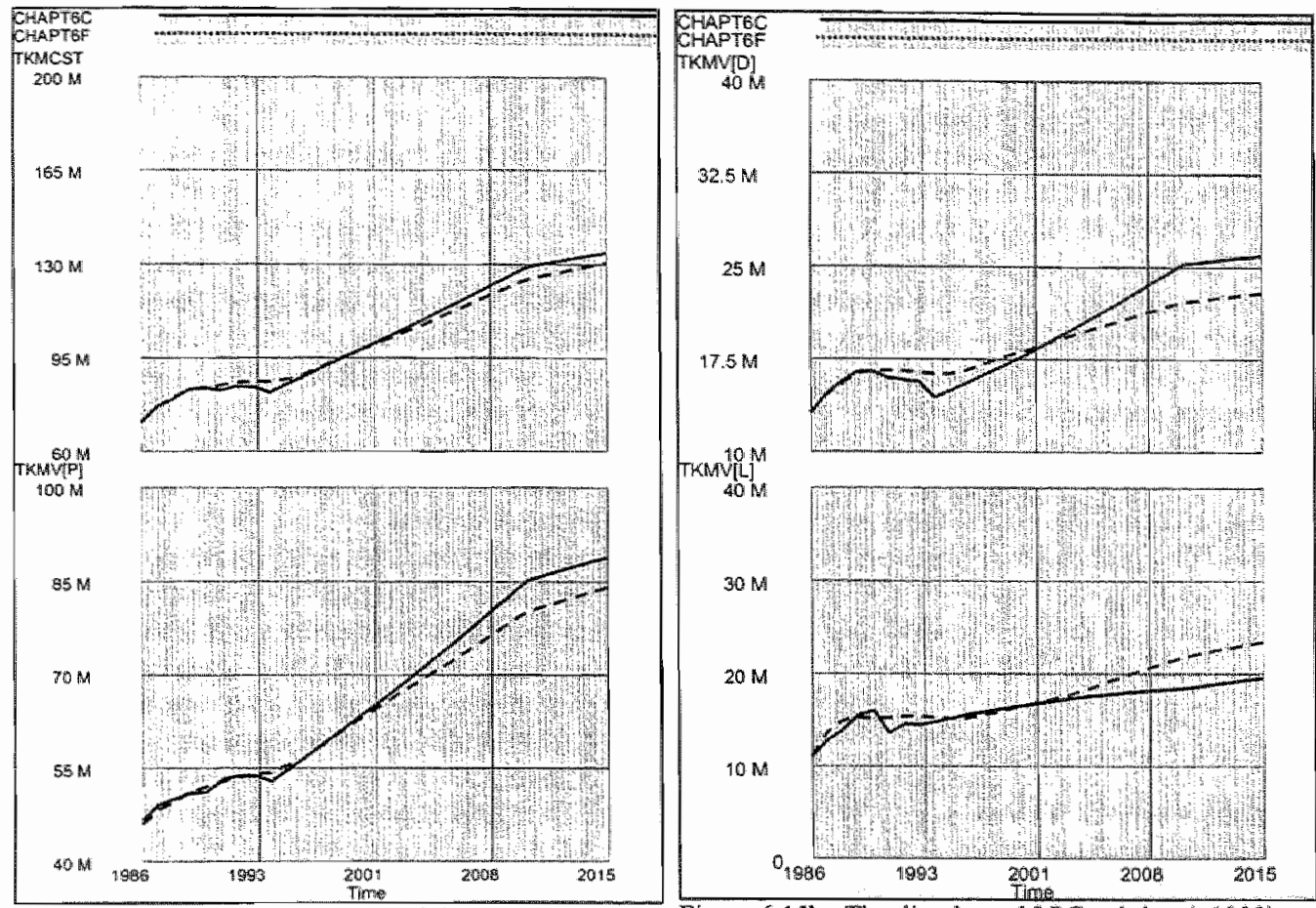

Figure 6.15a. The total veh-km and the gasoline veh-km Figure 6.15b. The diesel - and LPG veh-km (x1000) $(x 1000)$

Based on both car stock models the total vehicle kilometres will be shown in Figure 6.15. Note: the series CHAPT6C is derived from the household - car ownership model, developed in this chapter and CHAPT6F is based upon the vintage car stock model (SIGMOMD), developed in chapter 5 . The total vehicle kilometres in 2015 counts to \pm 133 billion, respectively \pm 130 billion vehicle kilometres, the difference has its cause in the difference of the car stock as depicted in Figure 6.15. However in view of the uncertainty it is quite close. The total vehicle kilometres (TKMCSI, upper graph of Figure $6.15 \mathrm{a}$ ) is the result of the summation of the kilometrage of the vintages respectively, the total vehicle kilometres of the gasoline- (TKMV[P]), diesel- (TKMV[D]), and LPG cars(TKMV[L]). The final multiplication to arrive at the vehicle kilometres by fuel by vintage equals the product of kilometrage by fuel by vintage and the car stock by fuel by vintage. Table 6.3 shows an example of the computation of the total veh-km of the year 1990, which is the input of the enission model to be dealt with in the next chapter.

Note: that the youngest vintages are the most advanced in input/output technology and take the highest kilometrage on their account. The columns vint-cars and vint-km have to be multiplied by 1000 


\begin{tabular}{|c|c|c|c|c|c|c|c|c|c|c|c|c|}
\hline \multicolumn{2}{|c|}{ GASOLIFE TSO } & \multicolumn{4}{|c|}{ DIRSEL 1954 } & & \multicolumn{3}{|c|}{ DFG ISG } & & \multirow{2}{*}{ 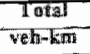 } \\
\hline Whitage & Whowmin & Whimeary & Whitl-1m & Virtige & Thmont & 7interars & Wint-knn & Wintage & Ykonotimi & Whitecars & Whin-kising & \\
\hline Tक्690 & 18130 & 325 & 58.2250 & 1990 & 32650 & 39 & 1271406 & 1690 & 36450 & 38 & 1.804540 & $(10000)$ \\
\hline 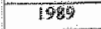 & 15830 & 353 & $358 \mathrm{795it5}$ & 4969 & $366: 0$ & 65 & 257650 & 1989 & $\$ 3780$ & 58 & 2075240 & \\
\hline 1928 & 15446 & 34 & $32952 \%$ & 1968 & $390 \%$ & 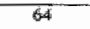 & 2499200 & 1988 & 31960 & 53 & 1661920 & \\
\hline 199\% & 144356 & 350 & 3583960 & 1987 & 26800 & 69 & 1842010 & 198 & 26990 & 56 & -1506400 & \\
\hline 1986 & 13160 & 400 & 526416000 & 1986 & 26560 & 71 & 1885760 & 19886 & 25470 & 57 & 1451790 & \\
\hline 1685 & 13126 & 343 & 4906460 & 685 & 25660 & 69 & 1719220 & 1988 & 26550 & 53 & 1401150 & \\
\hline 15864 & $122 \% 6$ & 320 & 3925600 & 19प्ष4 & 2728 & 35 & 1499500 & 19884 & 22180 & 45 & 1086800 & \\
\hline 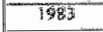 & 12056 & 327 & 3973450 & 1963 & 23170 & उद्य & 903630 & 16 & 23380 & 92 & 1215760 & \\
\hline 192 & 10920 & 274 & $20 \div 2018$ & 192 & 20970 & 31 & 650070 & 1982 & 9150 & 48 & 919200 & \\
\hline 1981 & 12150 & 226 & 274900 & 1981 & 17580 & 25 & $43550^{\circ}$ & 6981 & $19 \div 90$ & 39 & 760110 & \\
\hline REST & 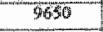 & 771 & 740150 & REST & 16960 & 53 & $100048 \times 4$ & REST & 20779 & 87 & 1806990 & \\
\hline & & 4080 & 53205040 & & & 578 & 16101810 & & & 589 & 15271920 & 578 \\
\hline
\end{tabular}

Table 6.3 An example of the computation of the total veh-km of 1990

\subsection{Monte-Carlo simulation}

As explained in chapter 6 the kilometrage of the Dutch households has been attained by two independent statistical sources:

1. The OVG survey (Qnderzoek VerplaatsingsGedrag wan de Nederlandse bevolking) period 1985 1995 furnishes us with the daily average distance travelled by car by motives by n-person households $(n=6$ ) which after multiplications and summing over $n$-person households comes up with the desired yearly auto-kilometrage of the Dutch households.

2. From the PAP survey (Personen Auto Panel) the average yearly kilometrage per fuel type per vintage is available and by the needed multiplication of these figures with the active vintage car

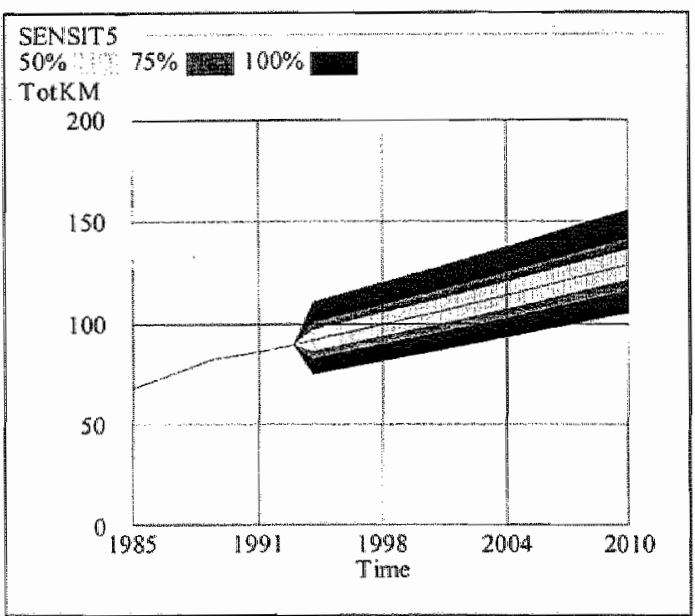
stock by fuel type we arrive at the desired average total yearly wehicle kilometres of the Dutch car fleet.

Both approaches comes up with equal figures and the only assumption to be stated are the future development of the $n$-person households ( ad 2.) and the future expected travell behaviour. Figure 6.16 shows a MonteCarlo simulation of the projected $n$-person households and car-use by these households. The 1 - to 6-or-more person households and the car use by morive ( 8 variables) are allowed to vary between t $10 \%$ and $-10 \%$, simultaneously and independently drawn from a uniform pseudo random generator during 1500 runs.

Figure 6.16 The average total vehicle kilometres ( $\mathrm{x}$ billion)

The numbers are random drawn from an uniform distribution. The results are shown in Figure 6.16 by graphical time plot with three confidence bounds including the mean value. Figure 8.15 shows the graph with the uncertainty in total vehicle kilometres, $T o t K M\left({ }^{*} E 9\right)$, as it changes over time. Half of the simulations (750) have generated a value within the $50 \%$ region, white band, around the mean value of \pm 130 billion vehicle kilometres, with $50 \%$ upper bound of \pm 135 billion vehicle kilometres and $50 \%$ lower bound of \pm 125 billion vehicle kilometres. Three quarters of the simulations (1000) have generated a value within the $75 \%$ region, grey shaded band plus the white band and all the simulations (1000) have generated a value within the $100 \%$ region, the black shaded bound with upper bound \pm 155 billion vehicle kilometres and lower bound \pm 115 billion vehicle kilometres. 


\section{Chapter 7. The emission modell}

\subsection{Introduction}

Road traffic is an emission source of high importance. Other important sources are the industry, electrical power stations, agriculture and households. Far most the largest part of the road traffic caused exhaust particles comes from the combustion of gasoline, diesel fuel and LPG.

- The exhaust of carbon oxide (CO) and hydrocarbons ( $/ O C$ ) arise from incomplete combustion. For diesel engines these emission are low, because they are working in an affluent oxide environment by which the combustion is practically complete. $C O$ is a toxic gas : it takes oxygen from the blood by the breathing process. $V O C$ is a set of volatile organic compounds containing particles with carcinogenous properties and are a precursor to forming ozone (smog)

- The exhaust of nitrogen oxide $N O_{x}$ is caused by the combustion of nitrogen, for the most part coming from the air and partly from the fuel. $N O_{x}$ consist of nitrogen monoxide (NO) and nitrogen dioxide $\left(\mathrm{NO}_{2}\right)$. The formation of $\mathrm{NO}_{x}$ increases when combustion temperatures are increasing.

- Particulates are fixed and/or fluent particles which be suspended (or float) in the air and consist for the greater part of soot. To the soot carcinogenic particles can be affixed. Diesel engines produce relatively a lot of particulates.

- $\mathrm{SO}_{2}$ arises by the combustion of the sulphur contained in the fuel. Only diesel fuel has a sulphur content of importance.

- The exhaust of lead compounds comes from the lead compounds added to the gasoline in order to get a better engine performance. During the last decade the lead content of gasoline has been decreased, among others, to introduce catalyst converter.

- $\mathrm{CO}_{3}$ and vapour arise by complete combustion of the fuel. They are not considered as pollutants, but have greenhouse properties which can have, among others, climatic consequences.

- The FOC emissions by road traffic are not only arising from combustion activities but also partly $(25 \%)$ by evaporation of the gasoline from the vehicles, by the intake of fuel and losses from the fuel control system during and after driving. The evaporation losses of diesel fuel and LPG are neglectable. For an integral effect of the emissions the activities of the manufacturing, repair, maintenance and demolition of vehicles and the emission of refinery and distribution of fuels has to be counted for.

\subsection{Methodology}

Starting from available test data a computational methodology has been chosen by which the emissions are being computed by multiplying the extent of the pollutant activities with the emission factors (emission per unit activity). The available test data coming from different sources as: CBS (CBS, 1993 C), RAI (RAI.1995), IW-TNO (Rijkeboer, et al, 1990, 1992) and UBA-TUV (UBA-TUV,1987). In case of road traffic the extent of the activity is being expressed or measured:

1. in traffic performance (kilometres per year or per drive);

2. fuel use, and

3. the number of cars in use (active cars stock).

The emission factors used by the computation of the combustion emissions depend among others of the vehicle category or car type and the type of fuel use (gasoline, diesel oil, LPG).

The combustion emissions are further influenced by the drive behaviour and speed, these facts provide, in principle, a nearly infinite number of drives with idem different emission factors. Therefore, to become manageable, three drive types/road classes have been separated :

1. inner city traffic or urban traffic $\left(R T_{1}\right)$

2. outer city traffic or rural traffic $\left(R T_{2}\right)$

3. high way traffic $\left(R T_{3}\right)$

The emission factors for $\mathrm{CO}, \mathrm{VOC}, N \mathrm{NO}_{x}$ and particulates are derived from the results of measurements of vehicles, by which, by means of drive (test) cycle, the different drive types are simulated. These measurements were performed by the Instituut woor Wegtransportmiddelen TNO (IW-TNO) in Delft, Holland and Technische Überwachung Verein (TÜV) Rheinland, Germany. 
The emission factors for $\mathrm{CO}_{2}$ and $\mathrm{SO}_{2}$ result from respectively the carbon, and sulphur contents of the fuels. The uncertainty margins for the emission factors $\mathrm{SO}_{2}$ and $\mathrm{CO}_{3}$ are small, because the sulphur and carbon contents are knowr. Also the data about the lead content are highly reliable and exact. For the evaporation emissions relatively few research results are available. Especially about the evaporation losses during a drive littlle research results are available. Exaporation emissions are being assumed to be caused by gasoline use, $90 \%$ being released by inner city traffic. The methodology has been developed by IW-TNO (CBS, $1993 \mathrm{C}$ ).

For these miain types of input parameters, additional information (e.g. on technological improvements and innovation, vintage (year of construction) profiles of the car stock is needed in order to evaluate the technological effects on imput-output, and combustion technologies. The introduction of technology will be locked to the yeat of construction (vintage), the penetration will therefore be dependent on the turnover of the car stock, that is, the ratio new car sales and scrap. Figure 7.10 shows the applied computation scheme.

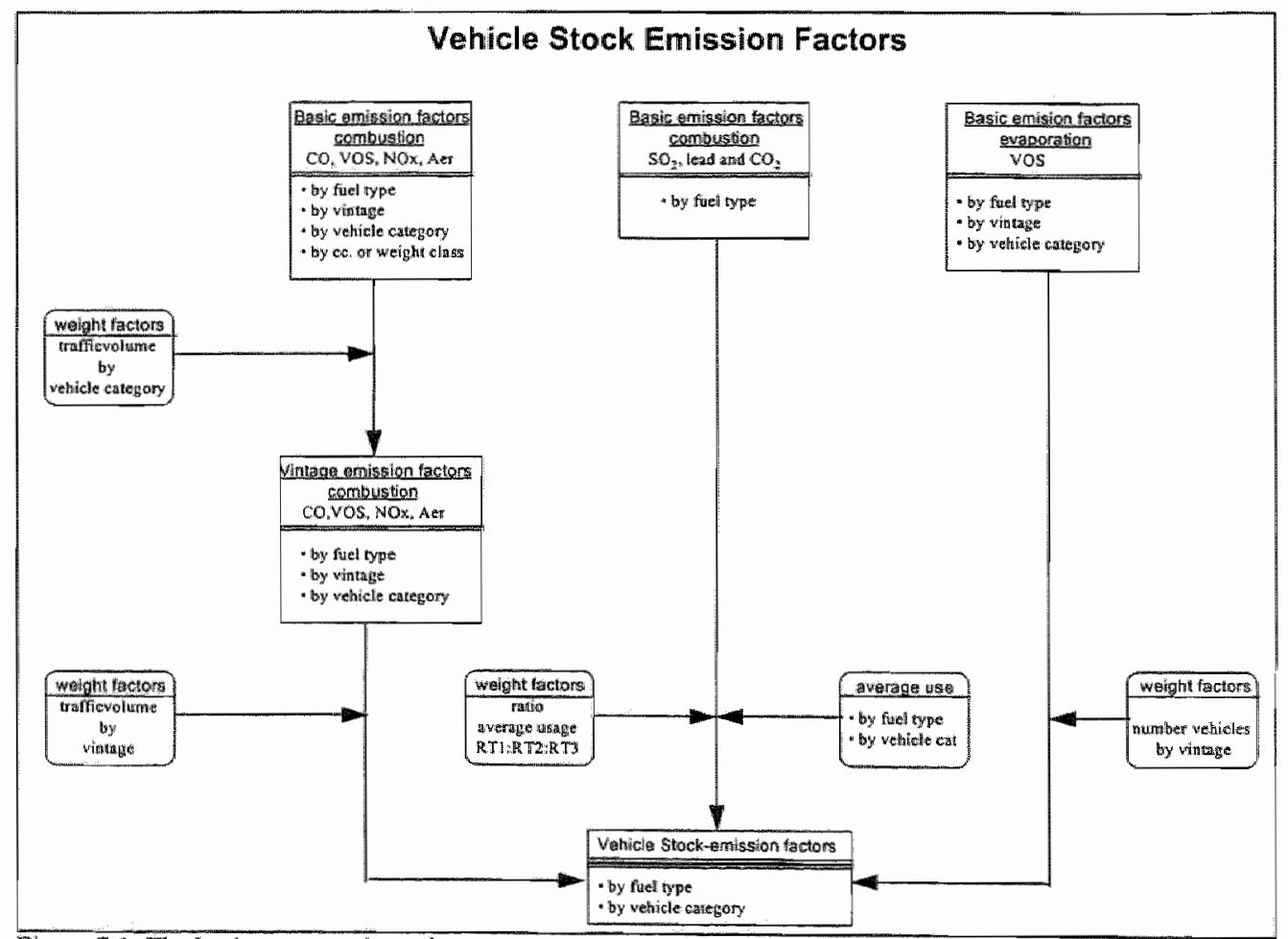

Figure 7.1 The basic computation scheme 


\subsection{From basic emission factors to vintage emission factors}

As explained above, the basic emission factors are completely detemined by technical and average driving conditions, and are the starting points to arrive at the yearly Dutch car fleet emission. The car fleet emission depends on the traffic performance of each vintage in the car stock and the technological composition of the car stock or vintage structure of the car stock, as shown in Figure 7.1. The vintage emission and fuel use factors will be treated hereafter, the car fleet emissions will be dealt with in the next chapter.

The vintage emission factors for gasoline (Figure 7.2) and LPG engines show impressive decreases for the period 1986-1992 due to:

- the introduction of the open loop and closed loop catalytic converter (output technology), and

- high penetration rate (high tumover or new car sales) of the new output technology

From 1993 on no new technological engine and/or design innovation has been assumed, only the continual technological improvement remains active. These technological improvements are described in section 7.3.2. The technological innovation in case of input and combustion processes will be described and simulated in the next chapter. Note as explained in section 7.1 the diesel engine follows a different combustion process and was from the beginning on a relative low emission process, reinforced by the introduction of the direct injection technique and catalytic converter. The dimension of the vintage emission factors are gram/veh- $\mathrm{km}(\mathrm{g} / \mathrm{km})$.
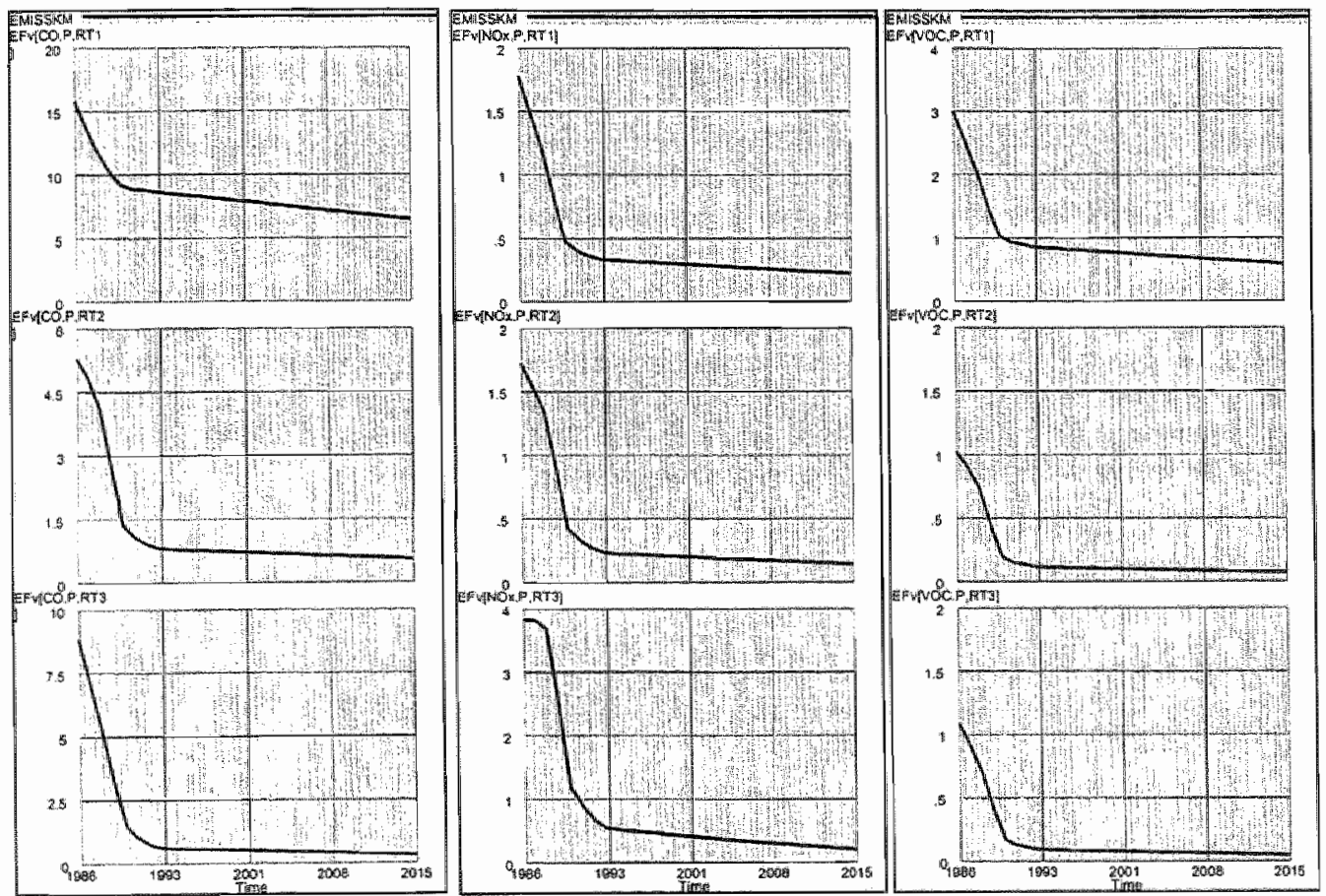

Figure $7.2 \mathrm{CO}, \mathrm{NO}_{x}, \mathrm{VOC}$ vintage emission factors for gasoline cars for 3 different road types

\subsection{The CO-emission in 1990 , a computational exercise and validation}

As referenced above the vintage-emission factors for $C O, W O C$, and $N O$, will be deduced from the basic-emission factors by applying weight factors. These weight factors represent the share of the several vehicle classes $(T)$ which participates in the traffic performance per vintage (year of construction) by the same wehicle categories. These shares are based upon the new car sales of each wehicle per class $T$ of Table 5.2 , chapter 5 . For the year 1990, Table 7.1 gives an example how to arrive at the vintage-emission factors for fuel type gasoline and urban road type RTI. 


\begin{tabular}{|c|c|c|c|c|}
\hline \multicolumn{2}{|c|}{ Fratage-Emission Factors 1990} & & & \\
\hline \multicolumn{2}{|l|}{ RTI } & Weight & Basic & Wintage - \\
\hline & Factor & Emission & Enmission \\
\hline Gasoline & & Vintage & Hactors & Factors \\
\hline \multirow[t]{4}{*}{ <1.4Iliter } & Conventional & 0.02 & 15.40 & 0.31 \\
\hline & Trmpoved cons. & 0.02 & 70.30 & 0.21 \\
\hline & Open loup Cat. & 0.07 & 8.90 & 0.62 \\
\hline & Cloped loop Cat & 0.31 & 7,70 & 239 \\
\hline \multirow[t]{4}{*}{ 1.4-201fter } & Coniventional & 0.0I & 78.700 & 0.18 \\
\hline & Improved conv. & 0.01 & 12.50 & 0.13 \\
\hline & Open loop Cait. & 0.10 & 960 & 0.96 \\
\hline & closed loop Cat & 0.42 & 9.20 & 3.86 \\
\hline \multirow[t]{4}{*}{$>2.0$ lifer } & Conventional & 0.00 & 21.00 & 0.00 \\
\hline & Improwed conv. & 0.00 & 0.00 & 0.00 \\
\hline & Open loop Cal & 0.00 & 0.000 & 0.00 \\
\hline & Closed loop Cat & 0,04 & 11.20 & 0.45 \\
\hline Total & & C.60 & & 9.70 \\
\hline
\end{tabular}

Table 7.1 The Vintage-emission factor CO for RT1 1990
The weight factors are from Table 5.2, chapter 5 and represent the share of the new car sales in 1990 of the possible classes $T$. By multiplying the weight factors (column 3 ) with the related basic-emission factors, computed by the emission model, one arrives at the vintageemission factor, which has to be summed. The value $9.10 \mathrm{~g} / \mathrm{km}$ returns in Table 7.2 in the 1990 row entry collumn 5.

Note: $9.1 \mathrm{~g} / \mathrm{km}$ will be labelled to the "vintage $1990^{\circ}$, for CO-emission road type $R T 7$, during the whole lifetime till the moment "vintage 1990" has been scrapped from the Dutch car stock. The analogous procedures take place for the $R T 2$ and $R T 3$ road types.

The same procedure holds for the diesel and

LPG cars. It is in this way that the vintage-emission factors are computed and applied in order to compute the total $\mathrm{CO}$-emission. In order to get more insight in the computational procedures the total CO-emission will be presented for the year 1990 , the figures will be checked against the official CBS (also computed, not observed) emission data. As noted above from the basic-emission factors we have to go to the vintage-emission factors (this is the weighted (by technology and by cc) emission factor per vintage) for three road types (as a proxy for drive behaviour). These vintage-emission factors should be multiplied by the traffic perfomance per vintage (kilometrage per vintage by fuel class). Table 7.2 shows the results of the computational procedures. The yearly kilometres per vintage (column 2) comes from the veh-km model developed in chapter 6, the car-vintage (column 3) are from the car models developed in chapter 5 , and multiplying column 2 by 3 one arrives at the kilometres of each vintage. The vintage-emission factors (collumn 5,6, and 7) are computed by the emission model developed in this chapter. The road type distribution (column 8,9 , and 10) is from the CBS and remains constant. To compute the overall emission on has to compute first the RT1, RT2, and the RT3 vintage-fleet-emission (column 12,13, and 14). This is performed by multiplying column 4, column 5 , and column 8 to get the result of column 12. After summation over all vintage and over the three road types one arrive at the total 1990 CO-emission for the several fuel types. 


\begin{tabular}{|c|c|c|c|c|c|c|c|c|c|c|c|c|c|}
\hline 3 & 2 & 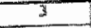 & 항 & 5 & 5 & 31 & 3 & 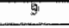 & 20 & III & 3 & $n_{1}$ & 14 \\
\hline \multirow{2}{*}{\multicolumn{2}{|c|}{ CASOLDVE }} & & \multicolumn{4}{|c|}{ 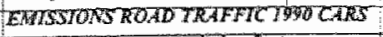 } & & & & RT: & RTI & NE2 & RTI \\
\hline & & & \multicolumn{4}{|c|}{ Wintage-erussion figetors } & \multicolumn{3}{|c|}{ Thosit type dishriberion } & \multicolumn{3}{|c|}{ 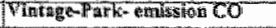 } & \\
\hline Vhatseg & Thanint: & vinal-cams & 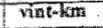 & $\mathbb{R T I}$ & RTI & RTS & RTi & RT2 & RTS & \multicolumn{3}{|c|}{ 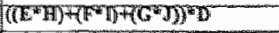 } & \\
\hline 2980 & 12336 & $3 \mathrm{x}^{\mathrm{E}}$ & 5892256 & 9.70 & $\frac{120}{3-\pi 0}$ & 4.58 & 2. 34 & 9.3 & 0.38 & $\frac{1}{2} \frac{3}{3} \cdot 36$ & 3 管 & B. 1.3 & 3.35 \\
\hline 7999 & 15830 & 353 & 5587990 & 10.00 & 3.50 & 3.80 & 6.24 & 9.3 & $0.3 \mathrm{~s}$ & 26.79 & $25: 4$ & 4.3 & 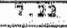 \\
\hline स9 & 15446 & 343 & $525 \$ 20$ & 42.00 & 4.00 & $5.3 \mathrm{a}$ & 0.24 & (1) 3 & 0.38 & $33,7 \frac{14}{3}$ & 15.25 & 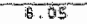 & 30.65 \\
\hline 2097 & 1.70 .36 & 358 & 5593540 & 79.60 & 4.80 & 7.36 & (4. & का & 0.39 & 46.61 & 29.56 & 10.19 & 15. \\
\hline र98 & 13360 & 400 & 526,4600 & 15.00 & 5.30 & 8.30 & 0.44 & 0.38 & 0.38 & 46.83 & 20.23 & $\mathrm{Da}, \mathrm{Et}$ & 17.45 \\
\hline 1925 & 73220 & 343 & 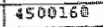 & $\$ 9.00$ & 6.00 & 11.06 & 6.24 & $0.3 \mathrm{~B}$ & 0.38 & 49.59 & 30.52 & 30.26 & 29.9 \\
\hline 2984 & 12280 & 320 & 329000 & 20.100 & 6.50 & 12.60 & 9.24 & 2. $3 \mathrm{E}$ & 0.38 & 45.45 & 1 त. & 9.21 & 27.93 \\
\hline $15 \mathrm{E3}$ & 2350 & 327 & 3973050 & 22.00 & 7.90 & 13, & 6.24 & 0.38 & 0.38 & $5 y+32$ & $20 . \mathrm{ge}$ & 10.72 & 39.63 \\
\hline 5982 & 25920 & $2 \%$ & 2942080 & 22.00 & 3.20 & 13.018 & Q. 24 & 0.38 & 0.39 & 35.65 & 正, 的 & 9.67 & 24.79 \\
\hline 198 & 12150 & 226 & 2745300 & 22.00 & 7.16 & 13.00 & 6.34 & 3.38 & 0.38 & 35.4 & 1.4 .50 & $7+91$ & 73,56 \\
\hline \multirow[t]{2}{*}{ RESE } & 56190 & 572 & 74 40450 & 40.00 & 8.80 & 13.00 & 9.24 & 9.38 & 0.38 & 130.20 & 71.4 & $22.0^{2}$ & 36.45 \\
\hline & & 4080 & 153205040 & & & \multicolumn{4}{|c|}{ 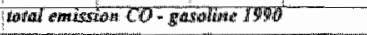 } & $32 \pi, 7$ & 24259 & 7029 & Trss? \\
\hline & & & & & & 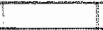 & & & & & & & \\
\hline \multicolumn{2}{|c|}{ DLESEL TSTI } & & \multicolumn{4}{|c|}{ Wintage-inisutan factors } & \multicolumn{3}{|c|}{ Ro:d type alstritsoton } & \multirow{2}{*}{\multicolumn{3}{|c|}{ 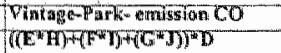 }} & \\
\hline Fintage & Mátivint & $\operatorname{vin} w \mathrm{Cd}_{2}$ & 7intem: & RTT & RT2 & RT3 & WTT & FT2 & TRT3 & & & & \\
\hline ह9so & $\$ 2500$ & 39 & 2277400 & 9.94 & 0.62 & 0.3 .8 & 6.24 & 0.38 & 0.38 & 0.6 .3 & . 29 & $0_{n} x_{1}$ & 0.24 \\
\hline 1989 & 35510 & 55 & 2373650 & 9.94 & $0, \sqrt{2}$ & 0.30 & 0.24 & 2.38 & 0.38 & i. 19 & 84 & 8,36 & 6.27 \\
\hline 1988 & 35050 & 64 & 248020 & 0.95 & 6. $\sin ^{2}$ & 0.30 & 6. 24 & 8.89 & 0.38 & 1.35 & 0.57 & 0.40 & 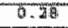 \\
\hline 1987 & 26600 & 69 & 1849200 & $\$ .95$ & 9.42 & 0.30 & 2.34 & 3. 3 & 0.38 & 0.93 & फ़. & 3.50 & 0.24 \\
\hline 198.6 & 26580 & 71 & 1895760 & 0.91 & 8.42 & 0.30 & 16. & 0.38 & 0.38 & 0.98 & 6.43 & 0.30 & a. 21 \\
\hline 1980 & 215600 & 67 & 1919220 & 3.26 & 0.50 & 0.55 & 0.24 & 6.38 & 0.39 & 3.15 & 5.50 & 0.33 & 0.33 \\
\hline 1904 & 27260 & 53 & 249300 & 9.50 & 0.60 & 6.60 & 0.24 & 0.39 & 0.30 & 1. 34 & 3.94 & 0.34 & 0.46 \\
\hline 1993 & 23170 & 39 & 993630 & 1.80 & 0,70 & 1.00 & 0.24 & 0.38 & 0.38 & 0.93 & 7. 39 & Q. शब & $\mathrm{O}_{n} 3 \mathrm{~s}$ \\
\hline $258: 2$ & 20530 & 31 & 650070 & 2.10 & 1.80 & 1.30 & 9.24 & 0.38 & 0.38 & 0.815 & 9.33 & 0.20 & 0.32 \\
\hline 1961 & 17580 & 25 & 439500 & 2.40 & 8.36 & 1.50 & 0.24 & 0.38 & 6.39 & 6,8 & 0.25 & 0.15 & 0.25 \\
\hline \multirow[t]{3}{*}{ REST } & 18960 & 33 & $20 \% 6800$ & 3.50 & $1: 20$ & 2.00 & 5.24 & 6.38 & 96 & 3.07 & 6.34 & 0.46 & $0.7 \mathrm{~V}$ \\
\hline & & 378 & 106201810 & & \multicolumn{4}{|c|}{ 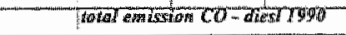 } & & M.97 & 500 & 3.99 & $3,39^{-1}$ \\
\hline & & & & & \multicolumn{2}{|c|}{ - } & & & & & & & \\
\hline $19 P G 990$ & & & & \multicolumn{3}{|c|}{ Whicage-emistan lactors } & \multicolumn{3}{|c|}{ Rotal type distingution } & \multicolumn{3}{|c|}{ Wintage-Park- enus on $\mathrm{CO}$} & \\
\hline Pintage & $\gamma \mathrm{km}$ ivint & vinte-exps & Nint-hm & RTI & RT2 & $\mathrm{kT}$ & RTI & $\mathrm{N} t 2$ & HTS & \multicolumn{3}{|c|}{ 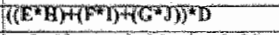 } & \\
\hline 1900 & 36330 & 38 & 1380540 & 2.60 & 0.70 & $0.4 B$ & 0.24 & C. & 0.39 & 2.40 & 0.86 & 8.37 & 0.25 \\
\hline 1989 & 15780 & 58 & स०तS240 & 3.20 & 1.00 & 0.66 & 0.24 & $2 \times 3.8$ & 0.38 & 2.90 & 1.50 & 0.79 & 0.52 \\
\hline 1968 & 31950 & 52 & 2661520 & 3.60 & $2 \cdot 30$ & 0.8 .8 & 0.24 & 0.38 & 6.39 & 2.78 & 1.49 & 0.82 & 0.32 \\
\hline 1989 & 26800 & 56 & 2506400 & 3.80 & 1.50 & 0.94 & $0.2 \pi$ & 0.38 & 0.38 & 2. & 2.37 & D. 要要 & 0.54 \\
\hline 2965 & 25470 & 57 & 1451790 & 0.00 & 1.78 & 2.10 & 0.2 .4 & 0.38 & 0.318 & $2 \cdot 5 \cdot 4$ & 1.39 & 0.94 & 8.62 \\
\hline 1965 & 26550 & 53 & 2407150 & 4.20 & 2.70 & 1.20 & 0.24 & 0.48 & 0.34 & $2 \times 22$ & 1.52 & 0.91 & 0.59 \\
\hline 3948 & 2286 & 49 & 1086020 & 4.20 & 1.70 & 1.10 & 0.2 .4 & 0.38 & 0.39 & 2.25 & 1.10 & 0.70 & 0.45 \\
\hline 1903 & 23380 & $5 / 2$ & 1215760 & 4.20 & 2.70 & 1.10 & 0.24 & 0.38 & D. 38 & 2.52 & 1. 13 & 0.99 & 0.51 \\
\hline 2562 & 19350 & 88 & 919200 & 1.20 & 3.70 & 2.10 & 0.26 & 0.38 & 0.38 & 1.90 & 0.93 & 0.69 & 0.36 \\
\hline प्र०2 & 39.800 & 39 & 360110 & 4.20 & 3.70 & 1.10 & 0.24 & 0.31 & 0.38 & 1.87 & 0.77 & 0.69 & 0.32 \\
\hline REST & 20770 & 87 & 1906950 & 4.20 & 1.70 & 1.110 & 0.24 & 0.38 & 0.36 & 3.74 & 1. 82 & 1.17 & 0.76 \\
\hline & $\because$ & 589 & 35271920 & & & tertal emissis & $\operatorname{enc} C O-L$ & $679 \%$ & & 27.78 & $T 3 M T$ & 8 & 5.85 \\
\hline
\end{tabular}

Table 7.2 An example of the simulated $C O$-enission for the year 1990

Comparison with CBS ngures:

\begin{tabular}{|r|r|r|}
\hline 1990 & CBS & Simulated \\
\hline Co (mif kg) & & \\
\hline Iotal & 565 & 565 \\
\hline or which & & \\
\hline RTI & 279 & 262 \\
\hline RT2 & 117 & 118 \\
\hline RT3 & 168 & 183 \\
\hline of which & & \\
\hline gasoline & 525 & 525 \\
\hline diesel & 12 & 12 \\
\hline LPG & 28 & 28 \\
\hline
\end{tabular}

The CBS computations (Table 29, page 49 , (CBS, 1992)) for $\mathrm{CO}$ by cars for the year 1990 (Table 7.3) arrive at $565 \mathrm{mln} \mathrm{kg}$, by summing column 11 we arrive at $564.6 \mathrm{~m} \mathrm{~kg}$, which is in the same order of magnitude. There are some differences in the urban road drives (RT1) and the RT3 (high way) emissions, but in view of the uncertainties of the distribution of the road type, the differences are negligible.

Table 7.3

\subsection{From basic fuel use factors to vintage fuel use factors}

The emission model computes the fuel use in $g / \mathrm{km}$ (Text table 7.3 , chapter 7), in order to arrive at the basic fuel use factor in litres per kilometre $(/ / \mathrm{km})$ we make use of conversion factors, Table 7.4, (CBS, $1992 \mathrm{C}$ ). Once again, as was the case of the emission factors, a correction has to be made for cold starts and warming-up phase during the first four kilometres. In order to get a general impression of the relationship between cold star and warming-up phase $(0-4 \mathrm{~km}$, average speed $22 \mathrm{~km} / \mathrm{h})$ and the fuel use, this relation can be approximated by the empirical relationship between average vehicle speed $(\mathrm{km} / \mathrm{h})$ and litres $/ 100 \mathrm{~km}$ (Redsell et al, 1988) depicted in figure 7.3 . Note: the function relates to a gasoline engine, $1600 \mathrm{cc}$, vintage 1985. 


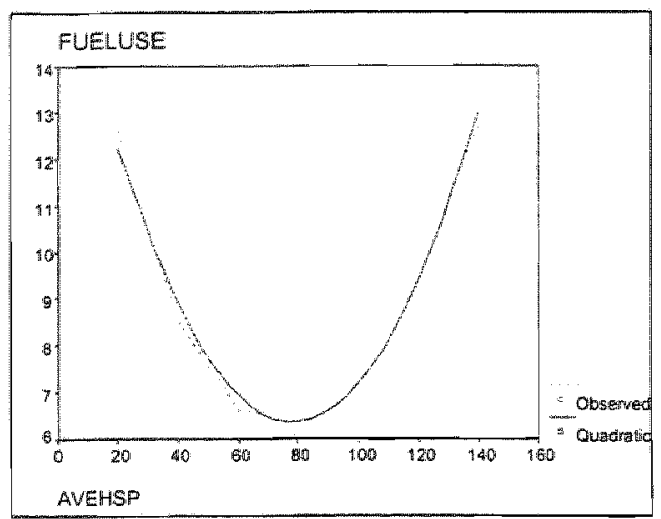

Figure 7.3 The curve fit of average veh- $\mathrm{km}(\mathrm{km} / \mathrm{h})$ and fuel use (L/100km)

The same relationship has been fitted with numerical output of the simulation model for all type of cars of vintage 1995 , where the average speed where set at $20,35,50,80,110,120 \mathrm{~km} / \mathrm{h}$. Figure 7.4 shows the comparison between the 1985 quadratic function and the 1995 on. It is the demonstration of incremental technological improvements.

Figure 7.4 shows the difference between the fuel use of an average gasoline car (1.4-2.0L) vintage 1985 and those of vintage 1995 . The same process of incremental technological improvements refers to the LPG cars and diesel engine cars ${ }_{p}$ with the exception that in the diesel case the introduction of the direct fuel injection technique was a technologicall innowation in the

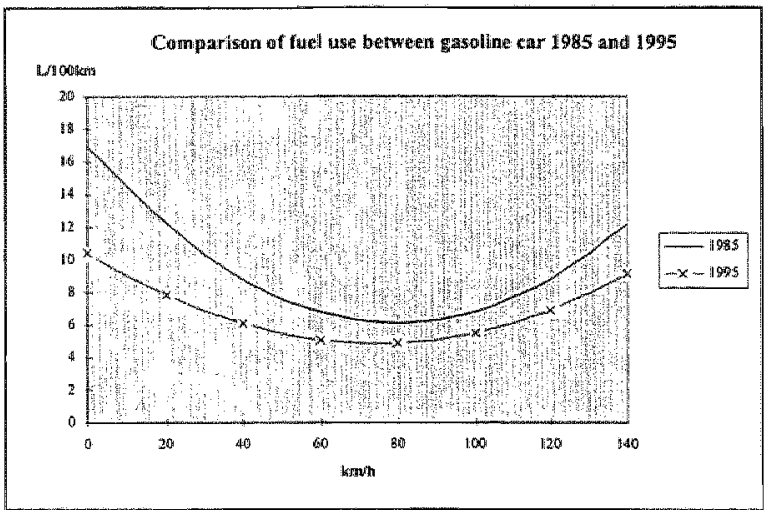

Figure 7.4 Comparison of the fuel use gasoline car 1985 and 1995

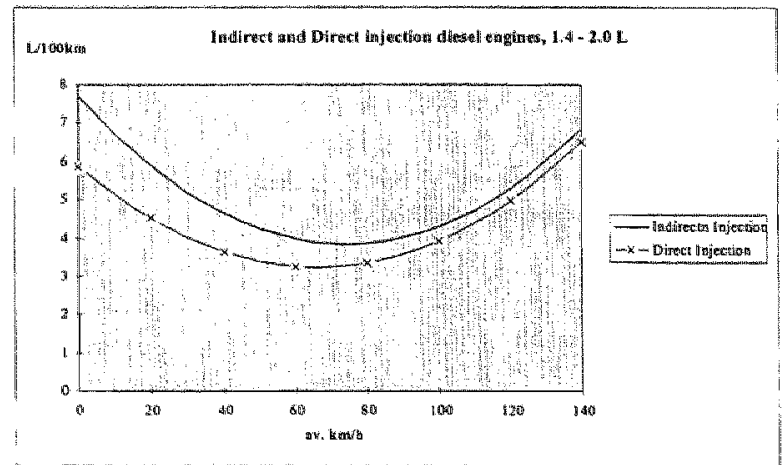
combustion process optimising the fuel use economy as can be seen by comparing the curves in Figure 7.5. The greatest impact of the direct injection technique occurs in the low speed trajectory where the fuel use and emissions of the direct injection technique (TDI) outperforms those of the indirect injection techniques. The same picture arise in the lower and upper ccclass.

From the figures shown above it will be clear how important a distinction by fuel type, by weight classes (cc-classes as a proxy) and technology is in case of emission abatement or control strategies. The vintage structure of car stock incorporates the time-related development of the qualitative aspects of the composition of the car stock. That is why the vintage fuel use factor is a consistent approach to deal with the exhaust of carbon dioxide, $\mathrm{CO}_{3}$, (a Greenhouse gas) and sulphur dioxide, $\mathrm{SO}_{2}$, (a Ozone gas).

Figure 7.5 


\section{Chapter 8. Scenario analysis}

In 1970, an EC policy on passenger car emissions was established by the introduction of a first EC Directive. That initiative has already been amended since than six times $(\mathrm{EC}, 1993)$. Each time more stringent limit values were announced which were met by the car manufacturers ${ }^{2}$ innovation potential. The 1990 amendment, which came into force by the end of 1992 , would lead to a total reduction in new car emission levels since 1970 of about:

- $90 \%$ for $\mathrm{CO}$ and

- $80 \%$ for $H C$ and $N O_{x}$

The most recent EC Directive states that in the year 2000 the emission norms should be lower by 20 to $40 \%$ than the 1996 standards. In 2010 this figure will be 50 to $70 \%$. The norm for the years 2000 and 2005 goes further than the US 1990 Clean Air Act standards and is comparable with the California norms. From 2000 on the fuels gasoline and diesel should be much cleaner, gasoline must completely unleaded and diesel oil is allowed to contain 500 ppm sulphur in 1997, against 2500 in 1995 and even $350 \mathrm{ppm}$ by the year 2000 . The last directive concerns the introduction of an electronic controlled catalytic converter (closed loop $+\lambda$-sensor) for all (old and new) gasoline/LPG cars in the year 2000 and the average fuel use will be 5.5 litre per $100 \mathrm{~km}$ for gasoline cars (12 L in 1995) and 4.5 litre per $100 \mathrm{~km}$ for diesel (14.5 L in 1995) cars in 2005. These stringent norms can only be reached by introducing the direct fuel injection technology for gasoline engines, which are, available for diesel engine cars and recently for gasoline cars.

As can be seen from this review, there has been a permanent pattem of reduction over the years, which has forced manufacturers to play a perpetual game of leapfrog with politicians and authorities. Every time a new standard has been set, the R\&D activities realised to meet it. But the moment it is met, than new, even higher ones are inposed. This trend has become virtually automatic. For example at the moment electronic engine management in combination with advanced mixture formation, advanced distributorless ignition systems and advanced combustion systems (in-cylinder geometry and in-cylinder flow) ensure improved combustion at all operating points. A closed loop (3-way catalyst) in combination with an exhaust oxygen sensor is effective to control and reduce the level of all 3 types of emission components in the exhaust. Exhaust gas re-circulation contributes to further $N \mathrm{O}_{x}$ reduction. Intake preheating and, if required, air-injection into the exhaust system helps to inprove emission behaviour during the warm-up phase after a cold start. A carbon canister stores the $H C$ emission, due to hot fuel vapour ventilation from the fuel tank when the engine is not running, and allows this fuel to be purged from the canister into the intake air during engine operation. However, it needs to be understood that further incremental technical improvements:

- will no longer result in the impressive achievements of the recent past (diminishing marginal improvements), and that

- these smaller more difficult improvements will involve disproportionately high additional cost, due to the growing sophistication of the technology required (increasing marginal cost),

- in addition, the improvements will be limited to specific aspects of overall motor vehicle performance.

These aspects concerns the incremental technical improvement whereas the expected introduction of the gasoline direct injection (GDD) marks a major technical improvement with a claimed one-time drop of fuel use of $\$ 20 \%$. In 1996 , experts did not expect a major technological breakthrough (electric, hydrogen or hybrid-fuelled cars) before the year 2005 with an additional time lag of 5-or-more years needed for the build-up of mass production facilities and relevant penetration in the car stock.

However, the technological process progress with increasing speed, in January 1997 an US automobile producer announced a fundamental breakthrough in the development of the electric car system, where hydrogen will be produced from gasoline, methanol, ethanol or natural gas. The system produces electricity by way of a chemical process which converts gasoline into hydrogen. In fact, the hydrogen will be bumed in a so called fuel cell, making the inefficient lead-sulphate batteries superfluous. Furthermore, it is claimed that the fuel use in comparison with the traditional gasoline engine will be halved, with the additional benefit that the emission of $\mathrm{CO}_{n} \mathrm{NO}, \mathrm{SO}$, and $\mathrm{VOC}$ will be 
reduced to $10 \%$ of the emissions of the traditional gasoline engine with the latest emission abatement technology. In October 1997 the US department of Energy confirmed the above mentioned discovery. Mass production of the electric car will probably take place in 2004. At the same time a Japanese automobile producer announced an efficient, clean 'hybride' car engine with a claimed fuel use of 1 litre gasoline upon 30 kilometres. Moreower, in combination with a new 3-way catalytic converter the exhaust of $C O$ will be reduced to 0.11 gram per kilometre!! Depending from the road type drive, the basic emission factor of $C O$ for a 1997 year of construction gasoline engine lies between 2 and 1 gram per kilometre. It is also claimed that the emission of $N O_{x}$ and hydrocarbons will be reduced to "uriknown low values', except for diesel cars.

However, as is the case with the $G D I$ engine the theoretical and partially lab-based results diverge from real life situations.

\section{Reference run}

The latest emission abatement technology in the reference run is the closed loop catalytic converter of which the penetration of the car stock will be completed after 2000 . It is assumed that the emission abatement technology is completed and not subject to incremental improvements as such. The observed and assumed future technical improvements refers only to design and engine (combustion) aspects of the new cars. Apart of the built-in incremental technical improvements, as explained in chapter 7, no break-through technological innovation has been assumed for the time being. The assumed incremental technical improvement refers to:

- traction efficiency $(+0.2 \% \Delta /$ year $)$

- roll resistance $(-5 \% \Delta /$ year $)$

- air resistance $(-2 \% \Delta$ year $)$

by summing over technology, cc and road - and fuel type we arrive at the total basic emission factor, as derived in chapter 7.4 :

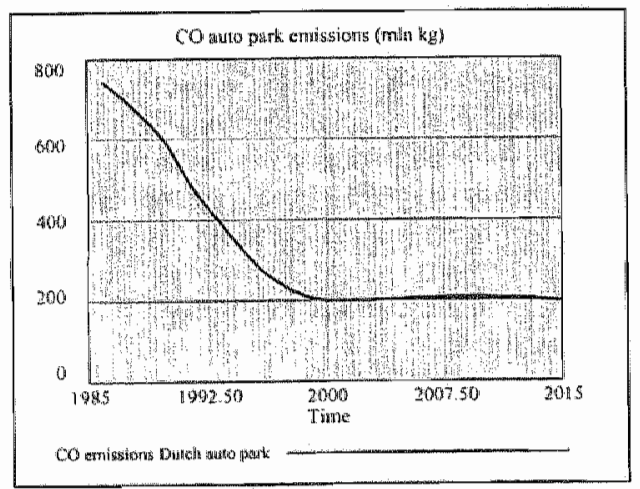

Figure 8.1 CO-car fleet emission.

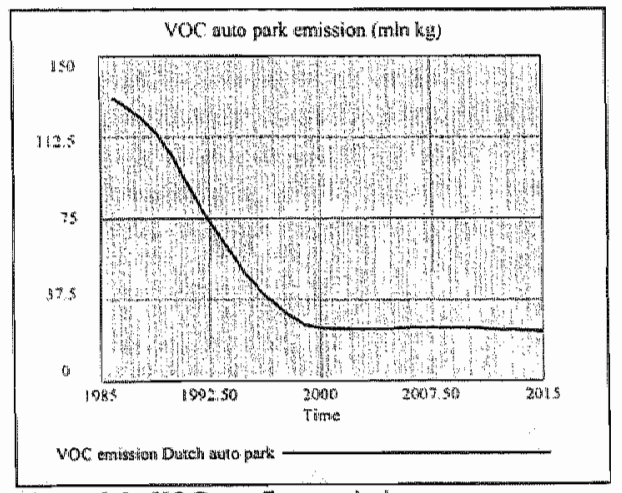

Figure 82 VOC-car flet emission

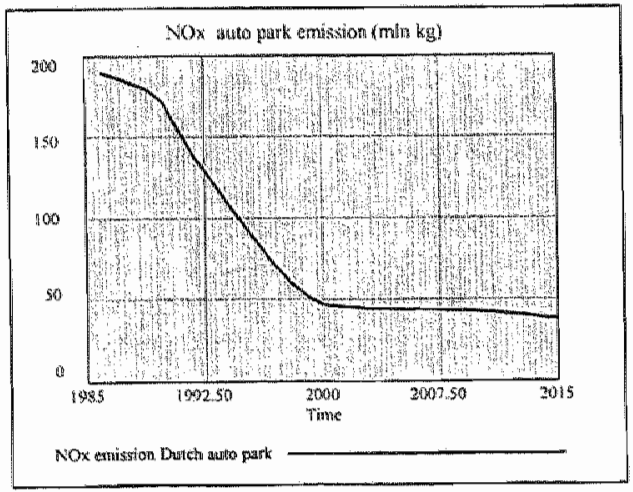

Figure $8.3 \mathrm{NO}_{x}$-car fleet emissions 


\section{Scenario 1. Stabilisation fuel efficiency}

During 1980 and 1995 the kilometrage increased $11 / 2$ time the energy use, indicating rising fuel efficiency. In the average the gasoline and LPG cars' fuel efficiency increased with $10 \%$ and for diesel cars even $20 \%$, however the largest part of the fuel efficiency has been realised in the period 19801990, after 1990 the fuel efficiency stabilised, except for the diesel cars.

For the period 1980-1990 the following assumptions holds:

- Traction efficiency $+0.2 \Delta \% /$ year

- Roll resistance $\quad-5.0 \Delta \% /$ year

- Air resistance

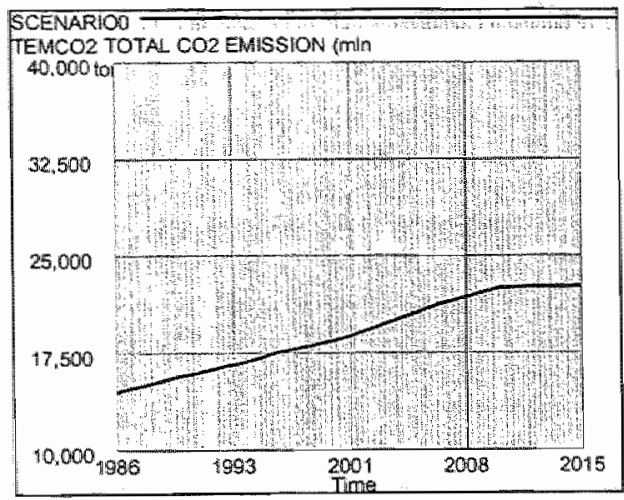

Figure 8.4
$-2.0 \Delta \% /$ year

Scenario 1 simulates these facts with the assumption of no future fuel efficiency improvements, except for the diesel engine with the introduction in the early 90 s of the direct injection (TDI) technology, with fuel efficiency of $\pm 30 \%$. The growth of the kilometrage (car use) and the car ownership are, for the gasoline and LPG cars, the ultimate active forces determining the future fuel use. So the simulated period shows a moderate increase of the gasoline fuel use for the period 1986-1990 and a strong increase for the period 1990-1995. For the period 1996-2015 the stabilisation of the fuel efficiency is maintained and the increase of the fuel use is caused by the increase of the veh-km. Figure 8.4 shows the equivalent $\mathrm{CO}_{2}$-emission trajectory.

Note the stabilisation of the fuel use after 2010 is determined by the assumptions that:

- the household formation by size saturates,

- mobility behaviour remains constant, and

- therefore the kilometrage will saturate after 2010 ,

however if one assumes a continuation of the 1980-90 fuel efficiency development, the picture will of course be totally different, as will be shown in the scenario $1 \mathrm{~A}$. 


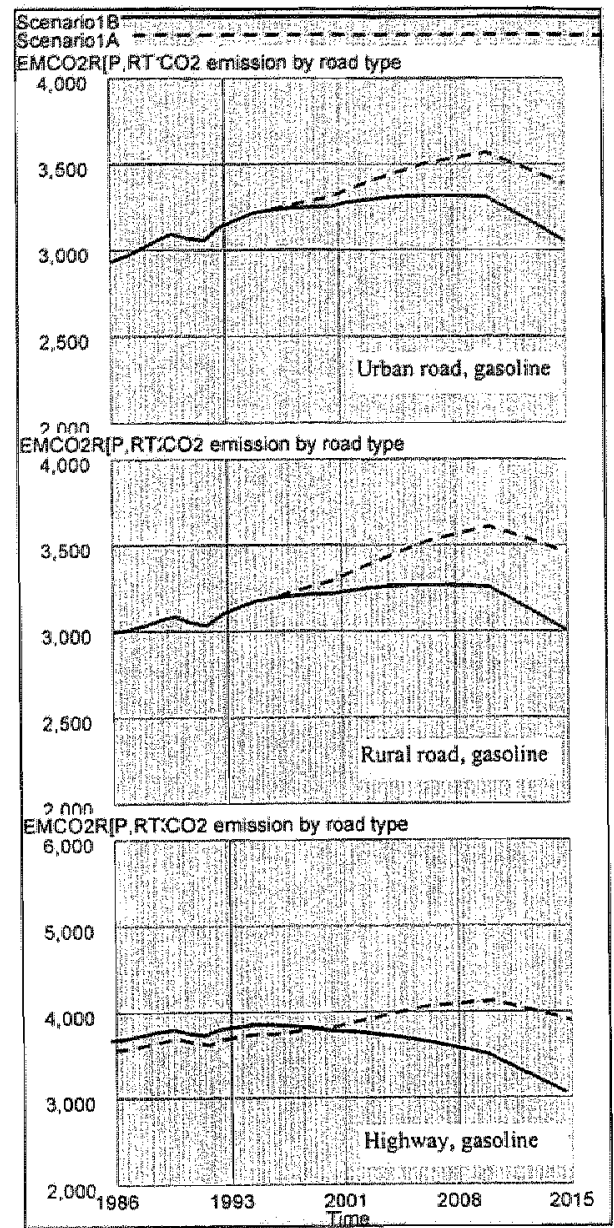

Figure $8.5 \quad C O_{n}$-emission by road type
Scenario 1A. (dotted line)

As indicated before incremental technical improvements of the fuel efficiency took place during the period 1980-90 and staggered during the period 1990-95. On can image two scenario's:

1. the fuel efficiency improvements are subject to diminishing marginal efficiency, therefore we assume that the incremental technical improvements are reduced by $50 \%$ for the period $1996-2015$ (Scenario 1A), or

2. the fuel efficiency pattern of the 80 s restart in 1996 till 2015 (Scenario 1B).

Figure 8.5 shows the resultant $\mathrm{CO}_{2}$-emission trajectories of gasoline cars by the 3 road types only. The other emission - and fuel use patterns show equivalent developments. The official Dutch government policy of reducing in 2010 the emission level to the 1990 levels will only be reached in 2015 (Scenario IB) if the kilometrage will be reduced sufficiently from 2010 on (as we do).

Note that besides the assumptions of the incremental technical improvements, the total car fleet emissions and fuel use of the Dutch car stock are computed under assumed development of national income, constant real oil prices in guilders, the households by size, the households" car ownership, the kilometrage of those households, and the auto mobility (car use). 


\section{Scenario 2. Automobility and household formation, the elderly case}

The mobility and especially the automobility of the elderly is of increasing importance in the near future. Because of the increased mobility of the elderly and the increased greying more and more elderly take part in the traffic. On $1 / 11995 \pm 3.5$ million Dutch inhabitants were over 55 years old, that is $22 \%$ of the total population. Since 1986 this is an increase of nearly $12 \%$, while the total population increased with $6 \%$. In the period $2010-15$ the strongest increase will come from the 2 person households of young elderly (65-74 years), followed by the 1-person households, both represent the baby boom after World War II. It will be plausible to assume their (auto)mobility to be greater than the contemporary elderly of the same age class. Not only the car ownership but also the displacement behaviour and distances travelled will increase. The reference run treated the elderly as a homogenous. group, in scenario 2 the elderly are divided in two groups, the 'young' elderly (65-74 years), and the "old" elderly $(75+)$, each with their own specific car ownership, displacement behaviour and distances travelled. However the kind of traffic participation within the age class $65+$ is rather diverse. In general, wealth and health conditions determine car ownership and car use. However health condition and not financial wealth determines the car ownership and car use for elderly people. Though the car ownership of elderly is on average less than with younger, during the period 1985 - 1995 it rose substantially, especially with men of age $65+$. Remarkable is the lower car ownership of women. The car ownership of women of age 55-65 years rose most, and seen the strong increase of car ownership of women aged 45-55 years, next decade more elder women will participate car driving. People aged. 55-65 years used most frequently the car, this age class is characterised by intensive and active leisure behaviour, and will continue this behaviour the next decade as $65+$. However, old elderly, 75+, have different leisure behaviour, and their share in car traffic as driver is lower than the share in the population. This reduced car use is compensated by using other means of transport, especially public traffic, bike and walking. Moreover elder car drivers make less kilometres, than the average of the Dutch per day per person, that is, in $1995 \pm 19 \mathrm{~km}$. The same distance holds for the age class $55-64$ year, however for the young elder (age-class $65-74$ years), on the average, less than $9.5 \mathrm{~km}$. For the old elder (age class $75+$ ) car drivers, the average distance per day is slight more than $4 \mathrm{~km}$, which is the cold start phase. However elder car drivers do no more short distance travels as youngsters do. About $60 \%$ of car using displacements are shorter than $10 \mathrm{~km}$, this about the same for elderly.

One can wonder how this picture will look like in 2010/15. Will the number of car using displacements change and in what direction? The same story holds for the average distances travelled per elder person. Car using displacements by motives in 1995 shows increasing percentages with older age classes $(55-64,65-74,75+)$, so for visits $(18.5 \%, 22 \%, 23.5 \%)$, for shopping $(25 \%, 29 \%, 32.5 \%)$, for recreation/sports $(12 \%, 14 \%, 10.5 \%)$, the commuting motive will of course show strong decreases, and the remainder is about $30 \%$ for the three age classes in question.

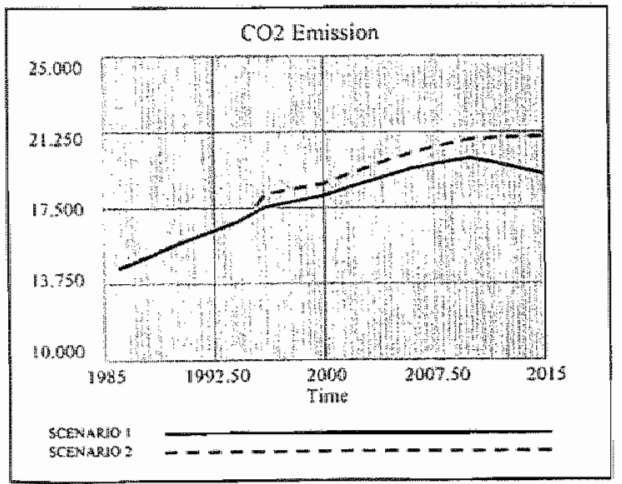

Figure 8.6
Again one can wonder how these figures will move with the cohorts through time, for example the recreation/sports motive in 1995 is lower for the 75 . than for the other age classes in question, but in view of the expected increasing life expectancies along with an expected improvement of the physical condition the 1995 situation can reverse. In the scenario 2 we assume:

- the displacements for three motives only (shopping, visits, and recreation/sports) will increase by $1 \%$ per year for the young elder and $1 / \%$ per year for the old elder from 1995 on. The average distance travelled per person remains constant. 


\section{Results}

The total vehicle killometrage will increase for the period $1995-2015$ from \pm 125 to \pm 137 billion $\mathrm{km}$, particular caused by an active leisure behaviour. As scenario 1 conditions remains active, the fuel use and the $\mathrm{CO}_{2}$ - and $\mathrm{SO}_{2}$ emissions increase proportionally more than the vehicle kilometres increase, counteracted by the fact that elderly"s car stock is of gasoline fuel type and on the average older, and therefore more polluting, than the rest of the car owners (Figure 8.6). Moreover urban - and rural road type drives are in the majority

\section{Scenario 3. Elimimating car use for the short distance traffic $(<7.5 \mathrm{~km})$}

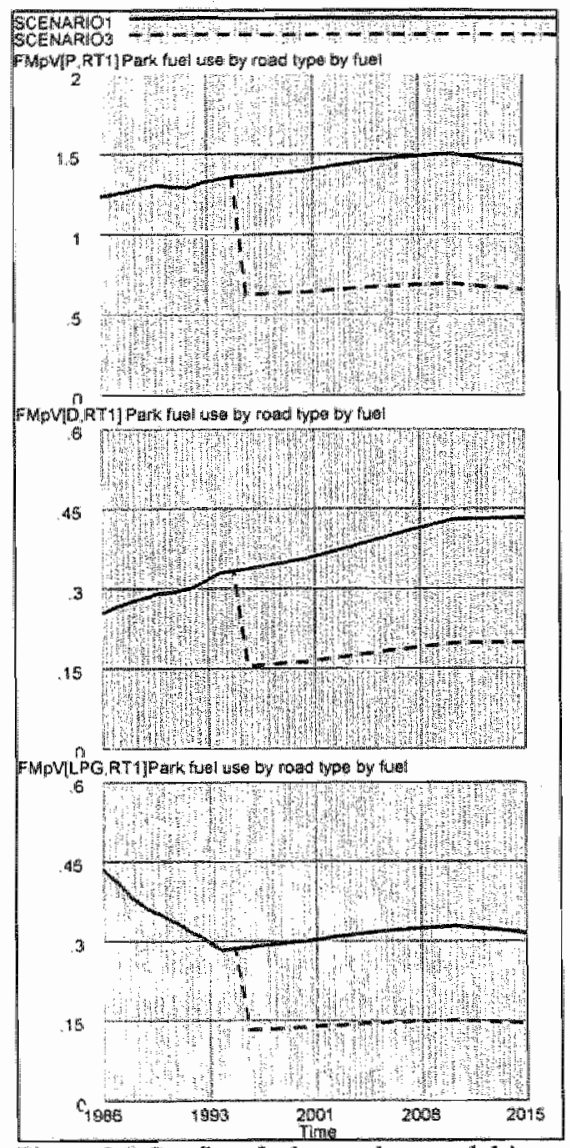

Figure 8.7 Car fleet fuel use urban road drive
As explained in chapter 3 men on average drive more kilometres than women. This is valid for the short $(<7.5$ $\mathrm{km}$ ) as for long distances. However women take more short distances for their account, two third $(2 / 3)$ of their car displacements are short distance travels. Two third. (2/3) of housekeepers' car use (as part of the home production) are for short distance travel. Daily activities like shopping, fetching and delivering of children, visiting friends, sport activities, cause short distance travels, and as the task combinations of the partners increase with increasing woman (often part-time) labour participation, these activities are taking place under increasing time pressure (time cost). Time-management of the housekeeping tasks + met leisure time ( $=$ non-labour time) are the driving forces of the car use for the increasing short distance travels. As explained in chapter 7 short distance travels by car (urban road type) are not only congesting, but extremely polluting and fuel using (cold starts, warming-up phase, stop-go runs), especially for gasoline engine cars, therefore the government policy could aim at restricting the car use in order to "save the environment" and to abate the silting up of the road infrastructure. The silting up of roads reinforce the pollution process by stop-go runs and low average speed. Short distance traffic policy is a potential source of reducing emissions and fuel use by substituting car use by other means of transport (preferably walking or biking). In 1995 short distance traffic accounts for 10.3 billion kilometres ( 93 billion $\mathrm{km}$ in total), however $1 / 9$ of the total kilometrage accounts for $4 / 9$ of the total $\mathrm{CO}$ and VOC emission as do show Figures 8.27 and 8.28 in chapter 8 .

\section{Scenario 4. Reducing average speed on highways.}

In chapter 7 the relationship between average speed and fuel use was examined and estimated. The fitted parabola indicates that the minimum fuel use will be reached at $\pm 80 \mathrm{~km} / \mathrm{h}$. After that point the fuel use rise substantially with increased average speed. Scenario 4 will consist of 4 runs with varying average speeds from $110-$ to $80 \mathrm{~km} / \mathrm{h}$ and the resulting effects on emissions and $\mathrm{CO}$, and $\mathrm{SO}_{2}$. The simulation runs show the impact of reducing average speed from 110-(Scenario 1), 100-(Scenario4) and $90 \mathrm{~km} / \mathrm{h}$ (Scenario4A). The greatest impact is on the gasoline and LPG cars, as the diesel engine is already fuel efficient, especially the TDI-diesel engine, therefore the reduction in $\mathrm{CO}_{2}$ and $\mathrm{SO}_{2}$ is substantial. The 1995 level of $\mathrm{CO}_{3}$ will be catch again in 2015 at an average speed of $80 \mathrm{~km} / \mathrm{h}$ (Figure 8.8). The $\mathrm{SO}_{2}$ figures are even more favourable (Figure 8.9). 


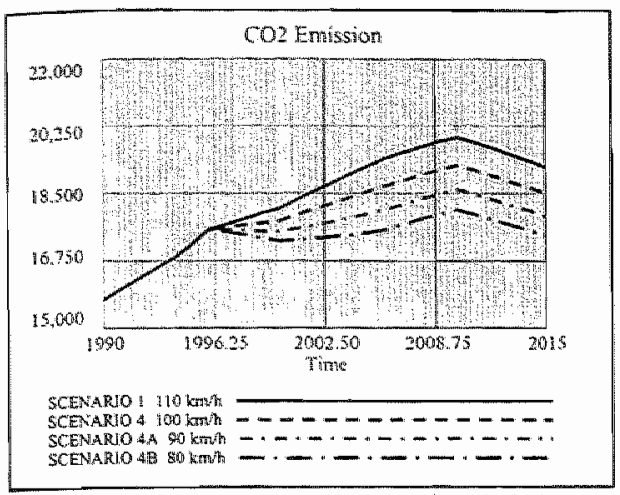

Figure 8.8 $\mathrm{CO}_{2}$-car fleet emission $(\mathrm{x}$ min $\mathrm{kg})$

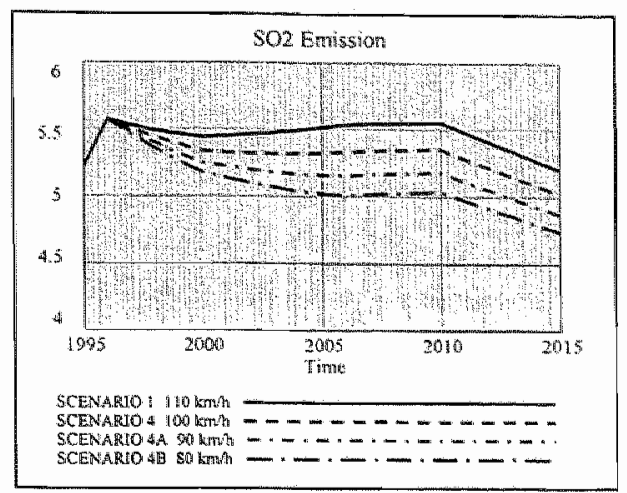

Figure $8.9 \mathrm{SO}_{2}$-car fleet enaission $(\mathrm{x} \mathrm{min} \mathrm{kg)}$

\section{Scenario 5. Indirect and direct injection diesel motor (TDI)}

In 1989 the direct injection (Turbo Direct Injection or TDD) for the diesel engine was introduced which improved the fuel efficiency about $\pm 30 \%$. In order to compare the emission performance of the injection systems we run two additional scenarios:

- In 1996 the diesel car stock is completely converted overnight from indirect into direct injection (Scenario 5), and

- the diesel new car sales are, from the year 2000 onwards, equipped with the direct injection (TDN) system (scenario 5a).

The effects are quite substantial especially for the $\mathrm{SO}_{2}$ (Figure 8.38). The unrealistic overnight conversion of the indirect injection into the direct injection in 1996 shows the opportunity losses of not using the alternative cleaner technology and can be computed as the integral (of the surface between the both eurves) of the difference of the fuel use between both technologies and is more or less an indication of the quality of the new TDI-technology.

\section{Results}

The introduction of the $T D I$-technology by way of the new car sales from the year 2000 on shows that the diesel car stock will be completely tumed over in TDI-diesel engine after 2008 . The figures for the $C O$ - and $V O C$ emissions shows a reduction of $\pm 30 \%$ after 2010 , however at the cost of an increase of the $\mathrm{NO}_{x}$ which should be abated among others by the introduction of a new $\mathrm{NO}_{x}$-catalytic converter.

(see also scenario 6 ).

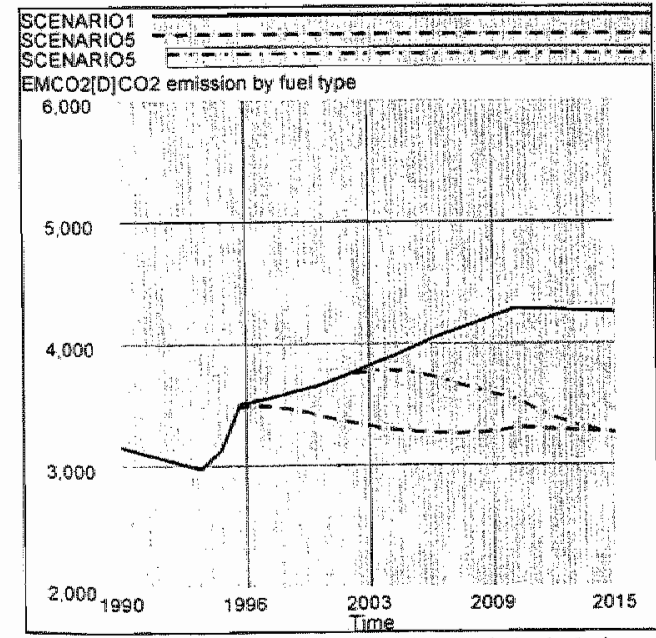

Figure 8.10 CO,-Diesel fleet emission ( $\mathrm{x} / \mathrm{min} \mathrm{kg})$

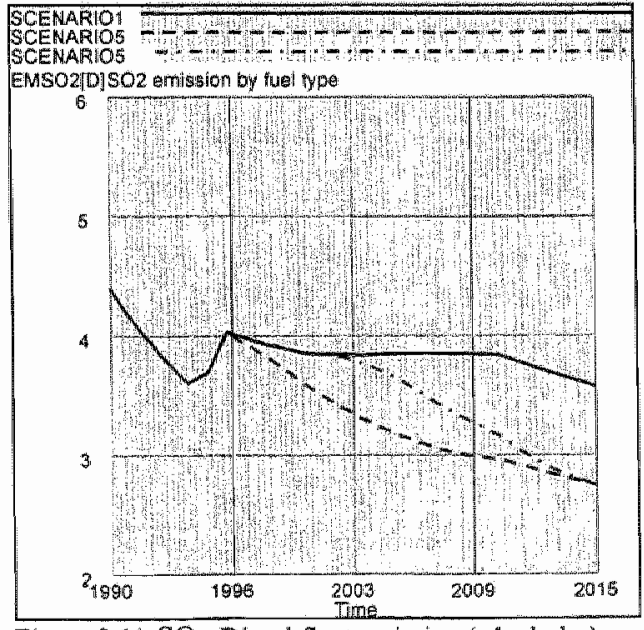

Figure $8.11 \mathrm{SO}_{2}-\mathrm{D}_{\text {inesel fleet emission }(\times 1 \mathrm{~min} \mathrm{~kg})}$ 


\section{Scenarion 6. Introduction of basic technical innovation : Gasoline Direct Injection (GDI)}

The GDI-engine is the furst offshoot of a new generation of gasoline engine which are more efficient and eleaner than the indirect imjection or conventional gasoline engine. The GDI-concept was developed 25 years ago after the first oil crises in order to search for more efficient combustion technology whereas the development phase started after 1985. GDI technology is really an analogy of the diesel direct injection (TDN), successfully introduced in 1989. In contrast to the conventional gasoline engine in the GDI-engine both air and fiel are injected into the cylinders where by way of intensive mixing an explosive mixture is formed. A direct injection into the cylinders has major pollution effects. Because the minuscule fuel drops (with a diameter $<20$ micrometer) are intensively and homogeneously mixed with affluent combustion air, the ignition temperature will be lower and in this situation the combustion process can not be integral combusted, and a phased process with oxygen near the walls and surface of the cylinders and an appropriate air/fuel mix around the ignition mechanism (spark plug) can be designed. The cylinder wall will therefore become less warm than in the conventional engine, with less heat losses: more avaliable energy content in the fuel will be applied for the ultimate target, the up- and down movement of the piston.

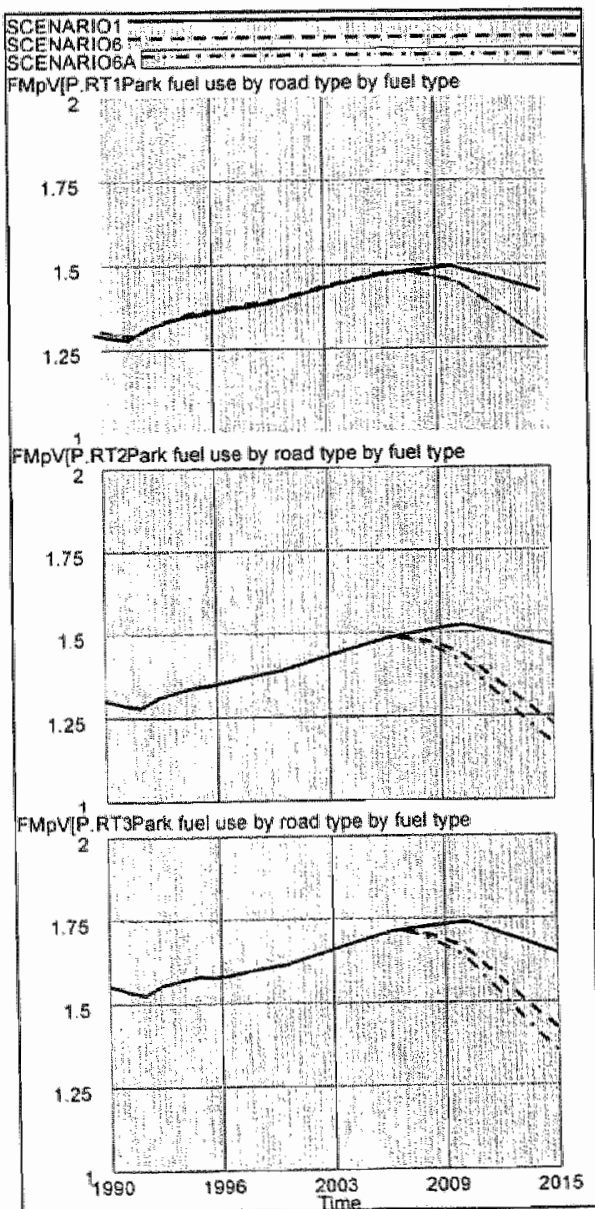

Figure 8.12 The gasoline car fleet fuel use by road type

\section{Results}

In order to analyse the effects of an introduction of a new injection technology one has to make an assumption about the diffusion speed and the fraction of new cars equipped with the new technology entering the car stock. The diffusion speed depends on the turnover of the car stock and can be policy relevant, for example, to speed up the scrap rate. Howewer in our case the tumover depends on the mean scrap rate measured in the past and on the new car sales, depending of the discrepancy between desired car ownership and the actual car ownership of the households by size.

Scenario 6 (Figure 8.12) runs under the assumption that from year 2005 on all gasoline and LPG new cars sales of all cc-categories are equipped with direct injection technology as described above.

As there exist for the time being no empirical measured (test cycle) results we have to assume the fuel efficiency for the three drive styles or road types. The following. assumptions about the fuel efficiency are:

$$
\begin{array}{ll}
\text { urban traffic } & \text { RT1 }=20 \% \text { (medium load) } \\
\text { rural traffic } & \text { RT2 }=30 \% \text { (low load) } \\
\text { highway traffic } & \text { RT3 }=35 \% \text { (high load) }
\end{array}
$$

However, Scenario $6 \mathrm{~A}$ assumes the following assumptions (with $100 \%$ of the new cars equipped with direct injection) :

$$
\begin{aligned}
& \text { urban traffic } \quad \mathrm{RT} 1=20 \% \text { (medium load) } \\
& \text { rural traffic } \quad \mathrm{RT} 2=35 \% \text { (low load) } \\
& \text { highway traffic RT3 }=30 \% \text { (high load) }
\end{aligned}
$$

These changes have a small effect on the volume $\mathrm{CO}_{2}$ and $\mathrm{SO}_{2}$ emissions (Figure 8.12 and 8.13) 


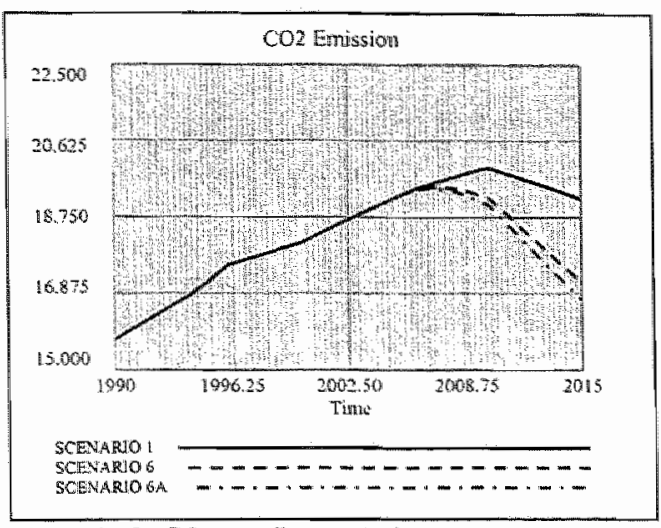

Figure 8.13 $\mathrm{CO}_{2}$-car fleet emission 


\section{Chapter 2}

\section{The Population Model}

\# Objective

Development of a six age-sex class population model ( $P_{1}^{6}$-model) for the period 1980-2015. The output of the modell will act as input driver for the household model to be developed in chapter 3. Three scenarios are computed and evaluated. The Low, Mid, and High scenarios (birth rates and migration) are evaluated by Monte Carlo simulations in order to test the sensitivity of the population dynamics.

\# Methods

Dynamic Markov chain analysis as a technique to deal with the transition of states governed by an ageing process. The resulting transition rates cascade through the population system with deaths as absorbing states. The transition rates are estimated for the period 1980-1989.

\# Data sources

Yearly population statistics and forecast (CBS), yearly household statistics and forecast (CBS). All years from 1980-1995. Population matrices men/women for the period 1980-1989, (CBS, unpublished).

\# Results

Projections of the Dutch population by 6 age classes by sex for the period 1980-2015 as input driver for the household model.

\# Conclusions

The developed parsimonious population model is a good representation of the complex CBS population model. The applied hill-climbing algorithm allows for a robust estimation of the transition rates. The trace- , vector search techniques allow for a local investigation of the optimum result, the grid - and random search for the global case. 


\subsection{Introduction}

In developing a dynamic household model a dynamic population model is needed as a driving input. The development of the population model is the aim of this chapter. A parsimonious population. model will be estimated against the CBS population model, which is far to complex for our purpose on hand. The CBS population matrices of the period 1980-89 are used as estimation benchmarks. On. the other hand the CBS population forecasts 1995-2015 are applied as a benchmark for the estimation of the levels of age classes and therefore indirect of the possible (unobservable) changing transition rates with regard to the base period 1980-1989. Given the inherent uncertainty the high -, mid - and low scenarios of birth rates and migration flows of the same CBS population forecasts are used in a Monte-Carlo simulation to test the sensitivities of the population dynamics. The structure of this chapter is as follows. Sections 2.2 through 2.7 are the core part of the development of the $P_{1}^{6}$. population model. The model equations and the application of indexed sets to compact formulation and computation of transition rates are formalised. The estimation and its performance are fully stated in maximum likelihood statements. The goodness of fit of the model is studied. Section 2.8 is an extension of the validation part with investigation of the local and global properties of the optimum, by applying trace -, vector -, grid -, and random search procedures respectively. Section 2.9 treats the forecast/prediction qualities of the parsimomious population model with respect to the official CBS population forecast. Finally, to cope with the inherent uncertainty, Section 2.10 treats the uncertainty of the population dynamics in a Monte Carlo simulation fashion.

\subsection{Population Model by age classes by sex}

The population of an area is the total number of inhabitants alive at a particular point in time. The population can be classified by sex, which provides information about the sex distribution of the population. The population can further be divided into age classes, in our case (0-3), (4-14), (15-24), (25-44), (45-64) and 65+, and, if each group is expressed as a fraction of the total, information is provided about the relative age composition of the population. Figure 2.1 gives an example of the age structure of total population of the Netherlands during the period 1980-1988.

Note the age class $65+$ are measured on the vertical right axis.

\section{Relative age composition Dutch population}

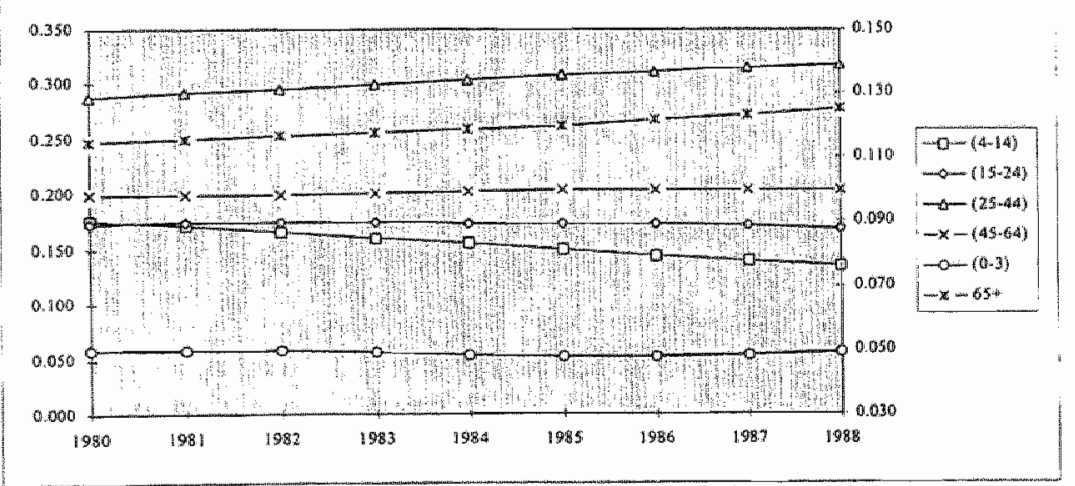

Figure 2.1 The relative age composition of the Dutch population

of course an 8 year overview does not easily allow to detect trends, but two changes can be distinguished:

1. The decrease of (4-14) age class, indicating a "degreening" of the population (rewersed in the 90 s), and

2. The slight but steady increase of the age classes (25-44) and $65+$, indicating a 'greying' of the population.

Crude birth rates, defined as live births per 1000 inhabitants, are at a certain point in time the result of an interaction of at least three factors (Lutz 1994): 


\section{Chapter 2}

\section{The Population Model}

\# Objective

Development of a six age-sex class population model ( $P_{1}^{6}$-model) for the period 1980-2015. The output of the model will act as input driver for the household model to be developed in chapter 3 . Three scenarios are computed and evaluated. The Low, Mid, and High scenarios (birth rates and migration) are evaluated by Monte Carlo simulations in order to test the sensitivity of the population dynamics.

\# Methods

Dynamic Markov chain analysis as a technique to deal with the transition of states governed by an ageing process. The resulting transition rates cascade through the population system with deaths as absorbing states. The transition rates are estimated for the period 1980-1989.

\#Data sources

Yearly population statistics and forecast (CBS), yearly household statistics and forecast (CBS). All years from 1980-1995. Population matrices men/women for the period 1980-1989, (CBS, unpublished).

\#Results

Projections of the Dutch population by 6 age classes by sex for the period 1980-2015 as input driver for the household model.

\# Conclusions The developed parsimonious population model is a good representation of the complex CBS population model. The applied hill-climbing algorithm allows for a robust estimation of the transition rates. The trace-, vector search techniques allow for a local investigation of the optimum result, the grid - and random search for the global case. 


\subsection{Introduction}

In developing a dynamic household model a dynamic population model is needed as a driving input. The development of the population model is the aim of this chapter. A parsimonious population model will be estimated against the CBS population model, which is far to complex for our purpose on hand. The CBS population matrices of the period $1980-89$ are used as estimation benchmarks. On the other hand the CBS population forecasts $1995-2015$ are applied as a benchmark for the estimation of the levels of age classes and therefore indirect of the possible (unobservable) changing transition rates with regard to the base period 1980-1989. Given the inhenent uncertainty the high -, mid - and low scenarios of birth rates and migration flows of the same CBS population forecasts are used in a Monte-Carlo simulation to test the sensitivities of the population dynamics. The structure of this chapter is as follows. Sections 2.2 through 2.7 are the core part of the development of the $P_{1}^{6}$ population model. The model equations and the application of indexed sets to compact formulation and computation of transition rates are formalised. The estimation and its performance are fully stated in maximum likelihood statements. The goodness of fit of the model is studied. Section 2.8 is an extension of the validation part with investigation of the local and global properties of the optimum, by applying trace -, vector -, grid -, and random search procedures respectively. Section 2.9 treats the forecast/prediction qualities of the parsimonious population model with respect to the official CBS population forecast. Finally, to cope with the inherent uncertainty, Section 2.10 treats the uncertainty of the population dynamics in a Monte Carlo simulation fashion.

\subsection{Population Model by age classes by sex}

The population of an area is the total number of inhabitants alive at a particular point in time. The population can be classified by sex, which provides information about the sex distribution of the population. The population can further be divided into age classes, in our case $(0-3)$, (4-14), (15-24), $(25-44),(45-64)$ and $65+$, and, if each group is expressed as a fraction of the total, information is provided about the relative age composition of the population. Figure 2.. 1 gives an example of the age structure of total population of the Netherlands during the period 1980-1988.

Note the age class $65+$ are measured on the vertical right axis.

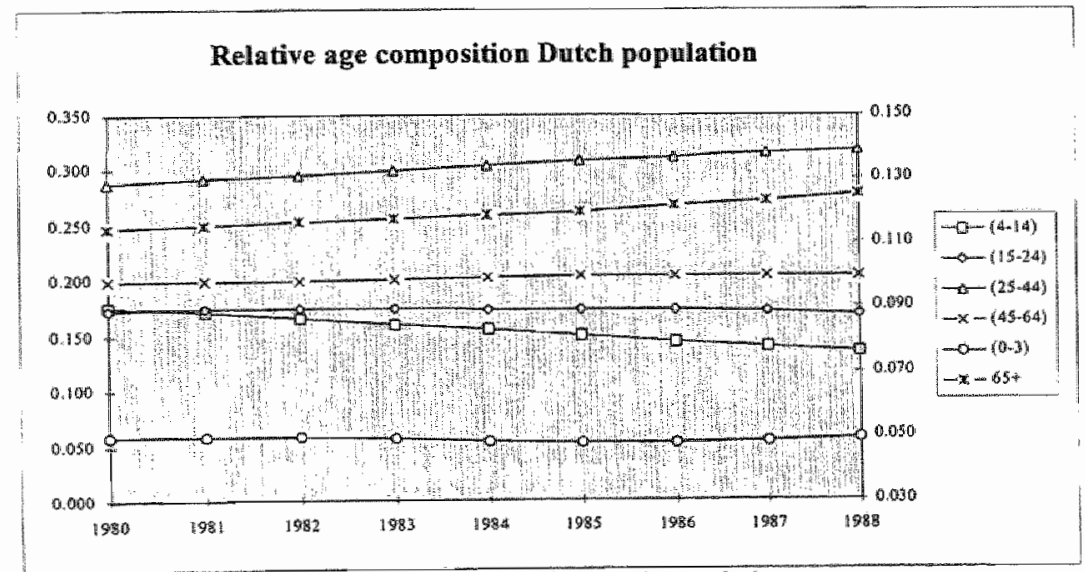

Figure 2.1 The relative age composition of the Dutch population

of course an 8 year overview does not easily allow to detect trends, but two changes can be distinguished:

1. The decrease of (4-14) age class, indicating a "degreening" of the population (reversed in the 90 s), and

2. The slight but steady increase of the age classes $(25-44)$ and $65+$, indicating a "greying" of the population.

Crude birth rates, defined as live births per 1000 inhabitants, are at a certain point in time the result of an interaction of at least three factors (Lutz 1994): 
- the level of fertility;

- the age structure of the population (especially of its female component); and

- the age distribution of fertility.

Of course, each of the factors mentioned can be subject to further investigation. For example, the level of total fertility can depend on marriage patterns and on fertility behaviour within marriages and other types of households. So a two-person household (2-pHSH) can be divided in married and nonmarried (living apart together), the total fertility level of both types of households are in fact very different. Next, what kind of observations can be made about changes of fertility measures through time? One could expect changes of fertility levels in time to be reflected in the crude birth rate. But how can changes of the age distribution of the population influence the crude birth rate trends? Will they reinforce or dampen trends of fertility? Can changes of the age patterns of fertility influence crude birth rates? In the long run the decisive factor shaping the crude birth rate seems to be the level of fertility. In other words, changes of the age structure and/or of age patterns of fertility alone can cause a decline or an increase in the crude birth rate, holding the level of fertility constant. In reality, changes of the age structure and of age patterns of fertility occur simultaneously with changes of fertility levels, and a separate analysis of each factor can provide information whether changes of the age structure, for example, have reinforced or cancelled a fertility level.

These complex interactions lie one layer beyond the level of interaction employed in the methodology of our present parsimonious $P_{1}^{6}$-population model, this is one drawback or better limitation of parsimony which should be completely known by the researcher and justified against the role parsimony should play in the study on hand. The same limitations are noted by T. Paul Schultz in his study on an applied reduced-form estimation of fertility, mortality and population growth (Schultz 1994). Another limitation which we will meet in section 2.9 is the impossibility of our parsimonious model to transfer discrete shock or pulses through the system network as we did choose for only 6 age classes with inherently long residence times acting as a filter and smoothing out shocks and pulses. If needed ad hoc model structure should be added in the form of dummy variables or table functions. The developed population module consists of 6 age-sex classes. The dynamic model is based on. stock-flow analysis, where each age class is treated as a stock - or level variable, integrating the inflow minus outflow per unit of time. The inflow in the first age class $(0-3)$ year equals the birth rate plus immigration. By ageing, for example, people becoming 4 year, those population flow into the (4-15) age class, staying there till the age of 16 and moves than into the (16-24) age class, etc. These transition rates can be captured in a transition matrix, showing the in-and outflows for each age class. In fact these population matrices are the database, they act as a benchmark for the $R_{2}$ population model to be estimated. The structure of the matrix is as follows:

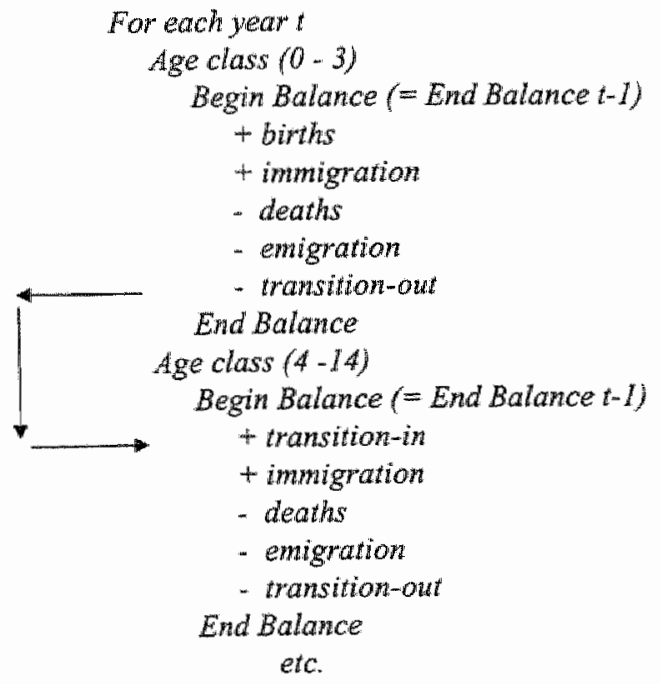


Note for the last age class $(65+)$ the transition-out flow collapsed in the death rate of the $65+s$.

Table 2. 1. shows the transitions for the Dutch female population for the period 1980-1989, Table 2.2. for the Dutch male population.

\begin{tabular}{|c|c|c|c|c|c|c|c|c|c|c|}
\hline \multicolumn{3}{|c|}{ 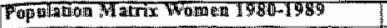 } & \multirow[b]{2}{*}{7958} & \multirow[b]{2}{*}{ Ty8 } & \multicolumn{3}{|l|}{ 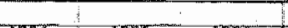 } & \multirow[b]{2}{*}{ rag? } & \multirow[b]{2}{*}{798,} & \multirow[b]{2}{*}{730} \\
\hline (त) & Tyso & 7प्र\$1 & & & rygs i & 7985 & 1938 & & & \\
\hline Wotal Population & mos & 759 & 205 & 1399 & 282 & 7304 & 73,46 & 79 & 9442 & 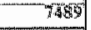 \\
\hline \multicolumn{11}{|l|}{$0-3$ yentr } \\
\hline Eegria balance & 342 & 346 & 349 & 347 & 34 & 340 & 340 & Wh & 735 & 36 ! \\
\hline birth & 8 & $8 \%$ & 89 & $82 !$ & 84 & 86 & rot & 90 & प्रत्: & 92 \\
\hline 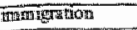 & 4 & 3 & 3 & 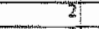 & 2 & 3 & 3 & $\sqrt[n]{3}$ & 3 & 3 \\
\hline dention & 7 & 0 & 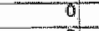 & 0 & 70 & OE! & 0 & J & 01 & o \\
\hline ensigaturol & 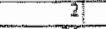 & 21 & 2 & 21 & 2 & 2 & 2 & 2 & 21 & 1 \\
\hline 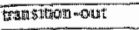 & 351 & 85 & 86 & 85 & 88 & $8 ?$ & 84 & $8 y$ & ESI & $\mathrm{ES}$ \\
\hline exd batiact & 375 & 329 & 347 & 344 & $360 ?$ & 30 & 947 & 35 & $360^{-}$ & 357 \\
\hline \multicolumn{11}{|l|}{ d-14 year } \\
\hline riegn billanes & 1213 & 1185 & 7103 & 1122 & 1058 & 1053 & 1021 & $\$ 95$ & 52 & 921 \\
\hline Thansinon-6 & $86 !$ & $85 i$ & 86 & 85 & r8s & 87 & 34 & 83 & 85 & 树 \\
\hline 20ก & II! & 7 & 16 & 5 & 5 & 6 & 61 & bis & bit & 7 \\
\hline esti & 1 & 6 & 0 & $8 i$ & 6 & 8 & 0 & 41 & 1 & 8 \\
\hline ambigntion & 4 & औ? & 3 & 61 & 5 & 4 & 4 & 4 & 4 & 2 \\
\hline 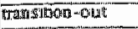 & $72 \pi$ & $m 9$ & 618 & $\pi s$ & 23 & T19 & חन & 708 & 38 & 9 \\
\hline end ba lasece & 1185 & 7153 & 112 & 108 & 10535 & Tors & \$5; & $9 / 2$ & 9601 & $\$ 960$ \\
\hline \multicolumn{11}{|l|}{ T524 heate } \\
\hline Geguil tal kunce & TIS4 & T208: & 1216 & 220 & 1223 & 1227 & 1228 & $\sqrt{2} 24$ & $12 L 4$ & $\Pi 5$ \\
\hline 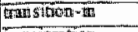 & $T M$ & $M$ & TाB & ThI & 723 & Tाक & TI4 & TUS: & 38 & 94 \\
\hline comingeration & 14 & 10 & $\mathrm{si}$ & 8 & 7 & 9 & 16 & TIT & II & 12 \\
\hline Geath & 1 & 9 & 0 & $0 !$ & 6 & 6 & 0 & 0 & 0 & 0 \\
\hline Emigrallow & 6 & 6 & 5 & 5 & $5:$ & 3 & 5 & 5 & 5 & 6 \\
\hline kTansition 0 out & T14 & $11 s_{1}$ & Til & 118 & 12]! & $12 \mathrm{~T}$ & 124 & 124 & 126 & $\mathrm{T27}$ \\
\hline Fand balawes & 1208 & 1216 & 1220 & 1253 & m2n & T2\% & 1224 & 7214 & T19? & T165 \\
\hline 25-4a yeare & & & & & 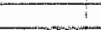 & & & & & \\
\hline began balance & 1964 & 2007 & 2045 & 2053 & 2120 & 2158 & 2796 & 2240 & 2264 & 2032 \\
\hline tratisitson n an & 114 & 175 & in & 118 & $121:$ & {$[21$} & 124 & 127 & 126 & T.2\% \\
\hline trmmigration & 16 & $\frac{75}{2}$ & 11. & 11 & $\pi$ & 13 & बा" & $|B|$ & TS & 76 \\
\hline Geatl? & 2 & 3 & 2 & 21 & 2 & 2 & 2 & 2 & 2. & 1 \\
\hline enmigration & 60 & 11 & $\sqrt{2}$ & 10 & 10 & To: & 11 & 5 & T. & 73 \\
\hline 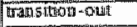 & 75 & 81 & 761 & 80 & 3 & 84 & 8I! & 74 & gr & 96 \\
\hline and billanoe & 2007 & 2045 & $20 \% 3$ & 2120 & 2138 & $2196 ;$ & 2340 & $22 \sqrt{4}$ & 2322 & 255 \\
\hline \multicolumn{11}{|l|}{$45-64$ year } \\
\hline begin balarter & 1434 & 1464 & 1455 & 14623 & 1476 & 1490 & T4DT & 1502 & TSTO" & 1523 \\
\hline 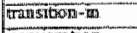 & 75 & 76 & 76 & 80 & $8 x^{2}$ & 84 & $8 T$ & 84 & 91 & 96 \\
\hline wim?gratanti & 4 & 3 & 2 & 2 & 2 & 3 & 3 & 3 & 3 & 3 \\
\hline teath & $7_{4}$ & 7 & 7 & 7 & 7 & 7 & 9 & 7 & 7 & \\
\hline entigrato in & 2 & 2 & 1. & 2 & 3 & 3 & 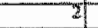 & 3 & 到? & 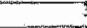 \\
\hline trate sition-oude & 60 & $6 T_{1}$ & $6 \pi$ & 59 & 601 & ग1 & 70 & 69 & 7 & 70 \\
\hline end balanes & 1644 & 1451 & 1462 & 1476 & $1490 !$ & TH9 & 1,502 & 15104 & 1323 & 1542 \\
\hline \multicolumn{11}{|l|}{$65+y+245$} \\
\hline 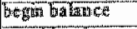 & s4at & $960^{\circ}$ & प्र85 & 1005 & 161 & 7656 & 10601 & Tors & Tin? & T130 \\
\hline 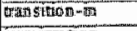 & 601 & 61 & 6! & $3 \%$ & 60 & $y T$ & 70 & 699 & $\pi 1$ & 70 \\
\hline Inmygaticen & 1 & II & 1 & $T$ & 1 & i & 11 & 7 & 7 & 1 \\
\hline$d e s$ & $4 \sqrt{11}$ & 4.2. & 49 & 43 & 45 & 5 & 78 & 17 & 48 & 51 \\
\hline 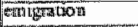 & 0 & 7 & 3 & 1 & 1 & $6 ?$ & $0 ?$ & 6 & 9 & 1 \\
\hline \multirow[t]{2}{*}{ end ofalatace } & 969 & 58 & 1605 & $102 \pi$ & Do 36 & 1061: & 1084 & 107 & 1130 & 714 \\
\hline & 1 & & & & & 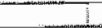 & & & & \\
\hline
\end{tabular}

Table 2.1. The Dutch female population matrix

The population matrices show the dynamics of the population as a system, the begin balance of each age class at each point in time equals the end balances of the same age class of the previous period. Starting with the begin balance of each age class the in- and outflows determine the end balance of each age class. The inflow of the first age class (0-3) year consists solely of birth and immigration of $(0-3)$ year, the outflow consists of death and 
emigration of the age class (0-3) plus the transition of children becoming 4 year old. The same outflow act as an inflows for the next age class beside the relevant immigration for that age class. Again the relewant deaths plus the emigration for that age class determines the transition rate going to the next age class, etc.

\begin{tabular}{|c|c|c|c|c|c|c|c|c|c|c|}
\hline \multicolumn{3}{|c|}{ 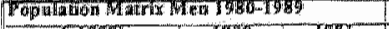 } & \multicolumn{3}{|c|}{$!$} & \multirow[b]{2}{*}{7983} & \multirow[b]{2}{*}{7986} & \multirow[b]{2}{*}{7987} & \multicolumn{2}{|l|}{ 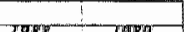 } \\
\hline 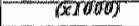 & 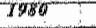 & Ty: & TyE & TEP : & $\gamma$ Wy & & & & 7988 & THY \\
\hline 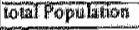 & 6929 & 704 & 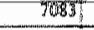 & Tol & 126 & TIStitit & 785 & 724 & 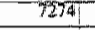 & 7319 \\
\hline \multicolumn{11}{|l|}{$0-3$ yetar } \\
\hline 5efyin brandace & 60 & $+6 x_{1}$ & 364 & $36 \mathrm{H}$ & 354 & 354 & 355 & 361 & $3 \%$ & 376 \\
\hline 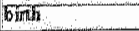 & 37 & 50 & 81 & 86 & 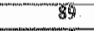 & 30 & 列? & 95 & 95: & 99 \\
\hline 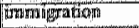 & 4 & 3 & 3 & 2 & $y$ & 3 & 3 & 3 & 3 & 3 \\
\hline rean & $\sqrt[7]{1}$ & 6 & 01 & $n$ & 7 & 0 & 5 & $0:$ & 0 & 9 \\
\hline 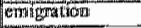 & 3 & 2 & i1 & 2 & 7 & 2 & 7 & 2 & 2 & 1 \\
\hline 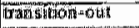 & 91 & 列 & अi & 5 & 92 & 90 & 881 & 87 & 701 & 91 \\
\hline Go bals co & 163 & 304 & $36 \pi$ & 358 & 354 & .955 & 361 & 376 & $36 !$ & 38 \\
\hline 414 gear & & & & 1 & & & & & & \\
\hline begem balsince & 1265 & 12160 & 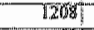 & 1194 & ती है? & 1103 & 100 & 1042 & 10201 & 1000 \\
\hline 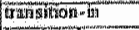 & 91 & 69 & 961 & 89 & 92 & 901 & 88 & 87 & 90 & 91 \\
\hline Entingrat lon: & 5 & 8 & 61 & 6 & 6 & 6 & 7 & 7 & 7 & 7 \\
\hline devilh & 9 & 6 & 6 & $0 !$ & 01 & 0 & 0 & 0 & a & (1) \\
\hline emtigratisti & 4 & 51 & 3 & 63 & 6 & 4 & 4 & 4 & 4 & 3 \\
\hline 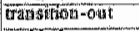 & IIT & $7 x$ & 124 & 23 & 129 & 125 & 19 & T12! & 102 & $9 \%$ \\
\hline cand Gotance & 1240 & 3208 & 112 & T16! & 1103 & 1070 & 1642 & 10203 & 1009 & 1006 \\
\hline \multicolumn{11}{|l|}{ S-24 yesar } \\
\hline begui billasince & IIAd4 & $128 \%$ & 1270 & 1272 & 7275 & 1277 & 1279 & 1274 & 1268 & 1239 \\
\hline 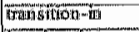 & Tes & 124 & 124 & {$[23$} & 129 & 25 & 19 & 112 & 02 & $9: 8$ \\
\hline whifnigratolosi & 1,1 & 1 & 7 & 6 & हाi & 8 & Tol & III & III & 13 \\
\hline décile & $T_{1}$ & I & if & 1 & 1 & 15 & 7 & II & 1 & (9) \\
\hline Emigration: & $6:$ & 5 & 6 & 5 & 3 & 3 & 4 & 3 & 3 & 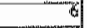 \\
\hline Trans & IHy & 120 & $12 !$ & 22 & 125 & $72 s^{4}$ & 129 & 129 & 732 & $\sqrt{33}$ \\
\hline end balance & 7263 & T2: & 1272 & 1273 & $12 \mathrm{~m}$ & 1279 & DTt & 1263 & 1239 & $12 \pi$ \\
\hline \multicolumn{11}{|l|}{2544 year } \\
\hline bengen bas arice & 2091 & 232 & 2109 & 2205 & $2237 ?$ & 2274 & 23II & 2354 & 2999 & 2435 \\
\hline 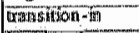 & 117 & 120 & $12 \pi$ & 122 & 125 & 125 & 129 & 129 & 132 & 133 \\
\hline iminingration & 18 & 10ी & 12 & 12 & Bi & 77 & 78 & 23 & 27 & 23 \\
\hline dew th & 3 & 3 & 3 & 3 & 31 & 3 & 3 & $\sqrt[3]{1}$ & 3 & 4 \\
\hline entigation & T3 & 14 & 7,6 & $74 i$ & 13 & 13 & T4 & 14 & 15 & $2: 1$ \\
\hline Transultron-0uth & 78 & 80 & 30 & 85 & 85 & 85 & 86 & 90 & 97 & To1 \\
\hline entabalance & 2132 & 2169 & 2203 & 2217 & 2274 & 2311 & 2355 & 2359 & 2435 & 2465 \\
\hline \multicolumn{11}{|l|}{4564 yeart } \\
\hline begin balance & 1363 & 7379 & 7301 & 14061 & $742 \pi$ & $76446:$ & 1द591 & 1.47 & $148 \div$ & 1308 \\
\hline 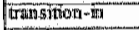 & 78 & 86 & 801 & 85 & 85 & 35 & 36 & 90 & 97 & 107 \\
\hline imimignigrat thot a & 3 & 2 & 2 & 3 & i & 3 & 3 & 3 & 3 & 4 \\
\hline deatli & 14 & 14 & 14 & $4 a$ & 14 & 14 & 14 & $\mid 4$ & $13 !$ & 14 \\
\hline emignatich & 3 & 3 & 2 & 3 & 3 & 4 & 4 & 4 & 5 & 4 \\
\hline Trans & $5 h$ & 32 & 5, & 50 & 31 & $81]$ & 60 & 59 & 61 & 59 \\
\hline Ent d bulinase & $13 y$ & 1391 & 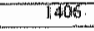 & 1427 & 1447 & 1459 & $1.47 \%$ & 1487 & 1508 & 1350 \\
\hline \multicolumn{11}{|l|}{$63+$ yelir } \\
\hline beforitance & 626 & 674 & 0 & $6 \mathrm{~S} 5 \mathrm{~s}$ & 690 & 694 & mit: & 722 & 735 & 729 \\
\hline moth & 31 & 52 & 31 & 50 & 31 & 61 & 60 & 5 का: & EII & $\$ 9$ \\
\hline im nigignation & T] & 0 & 01 & i & Ti & Ti & 1 & i & 1 & 7 \\
\hline denthi & 44 & 75 & 49 & 46 & $46:$ & A7. & 48 & 40 & 47 & 49 \\
\hline 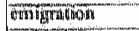 & 0 & 6 & 2 & $\sigma_{1}$ & 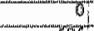 & 10! & 7 & 0 & (3) & 1 \\
\hline ond bithence & 62 & bot & 60 & 660 & 696 & $7 \pi$ & 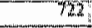 & 736 & 74 & 759 \\
\hline & & & & & & & & & & \\
\hline
\end{tabular}

Table 2.2 The Dutch male population matrix

Source: $\mathrm{CBS}_{n}$ unpublished 1994 


\subsection{Data Analysis}

Befone performing the estimations it will be desirable to get some insight about the peculiarities of the observed data. The observed data, measured per 1000 population, are the two transition matrices of Table 2.1 and 2.2. First of all, the birth rates (the exogenous transition-in) plotted with its related female age class (15 - 45) are very enatic and unstable as one can see in Figure 2.2

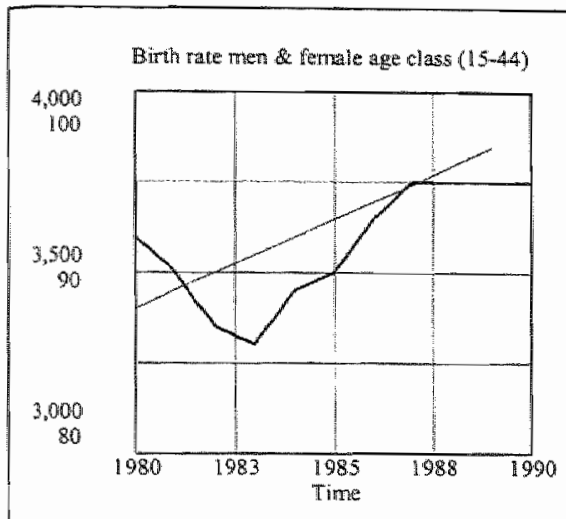

Actual female age class $(15-44)$

Birth rate ment

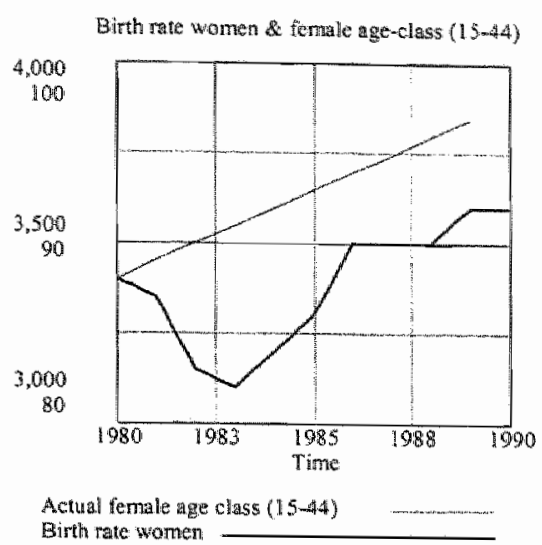

Age class $(0-3)$ \& transition rate $(0-3)>(4-15)$

Age-class (0-3) \& transition tate $(0-3) \rightarrow(4-15)$

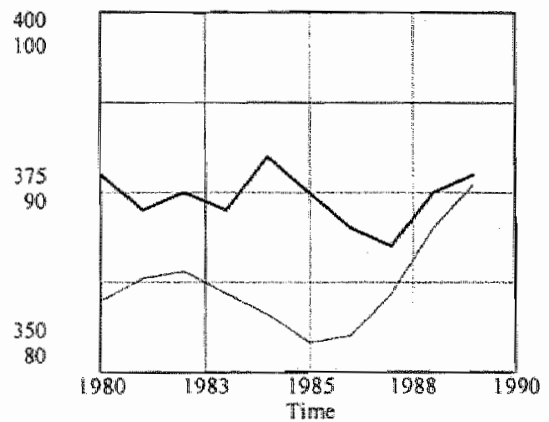

Mctual age-slass $(0-3)$ men

Actual rransition tate $(0-3) \rightarrow(4-15)$

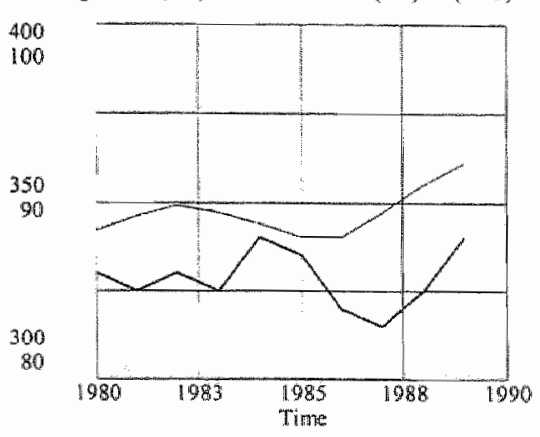

Actual a

Accuall transition rate $(0-3)>(4.75)$

Figure 2.2 Actual/obserwed birth rates and female fertile age class (upper figures) Actual age classes and transition rates (figures below)

(Note the bi-valued vertical axis, with the thin line measured by upper number and the bold line by the bottom number). It is observed that the birth rate change in $1983 / 84$ from a downward, started in the 70 s, into an upward direction, a reversal of the "degreening" phenomenon noted above. The transition between the first age class (0-3) and the second age class (4-14) shows most of the time a positive correlation. The decline in the age class (4-14) is largely due to the declining birth rates during the late 70 s and early $80 \mathrm{~s}$. That's why it hits both men and women. The abrupt decline in the age class (15-24) in 1986, men and women, is due to the decline in the birth rates in early 70 s. A complication arises as at the end of the 80 s and the early 90 s as the inflow of immigrants rose significant (see also Table 2.1 and 2.2 ).

In principle, migration can effect all age classes simultaneously. From the inspection of Figure box 2.2 one get an inturitive feeling of the stability of the transition rates. 
Age-class (4-14) \& transition rate $(4-14) \rightarrow(15-24)$

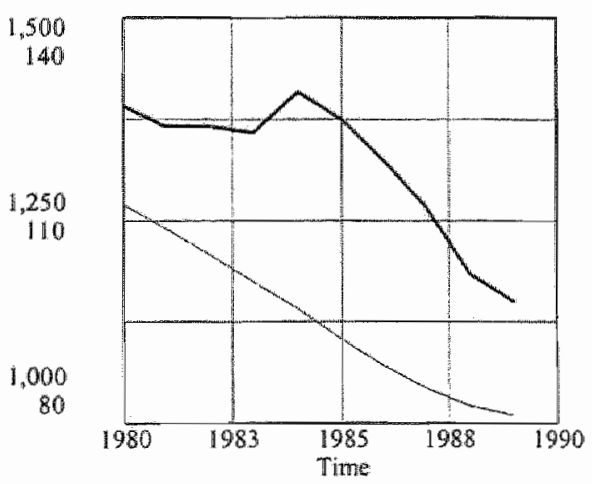

Auctual age-celass (4-14) men

Actual transition rate $(4-14)>(15-24)$

Age-class (15-24) \& transition rate $(15-24)>(25-44)$

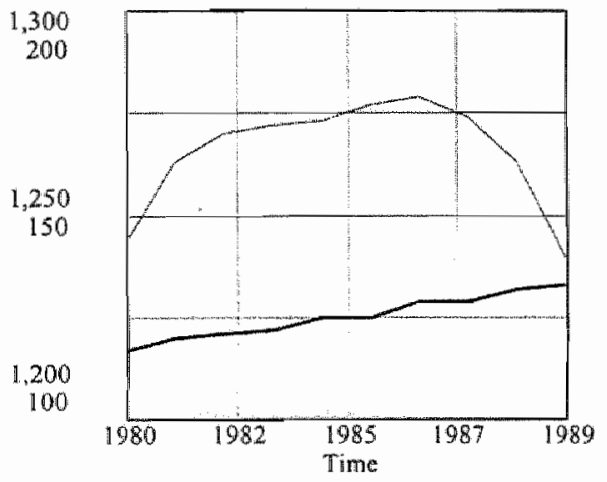

Actual age-class $(15-24)$ men

Actual transition rate $(15-24)>(25-44)$
Age-class $(4-14)$ \& transition rate $(4-14) \rightarrow(15-24)$

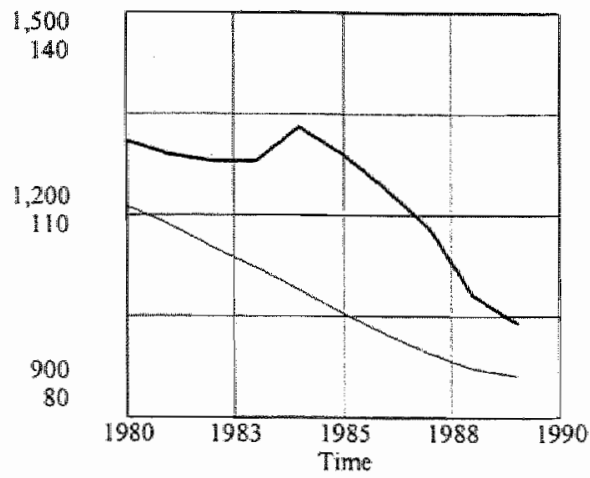

Actual age-class (4-14) women

Actual transition rate $(4-14)->(15-24)$

Age-class $(15-24)$ de tramsition rate $(15-24)>(25-44)$

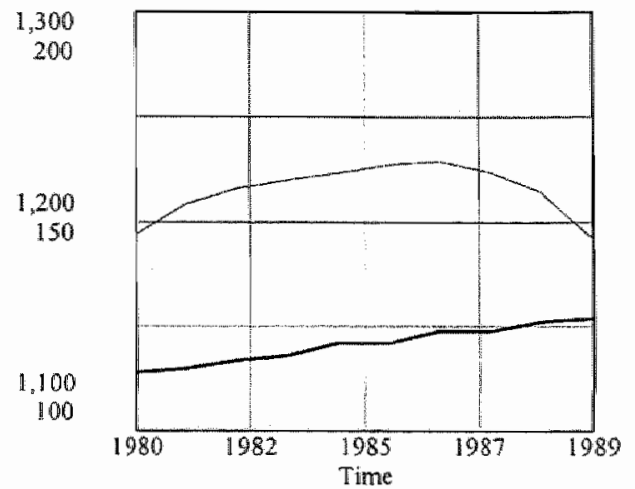

Actual agemelass (15.24) women

Actual transition rate $(15-24)>(25-44)$

Figure 2.2 cont. 
Age-class $(25-44)$ \& transition rate $(25-44) \rightarrow(45-64)$

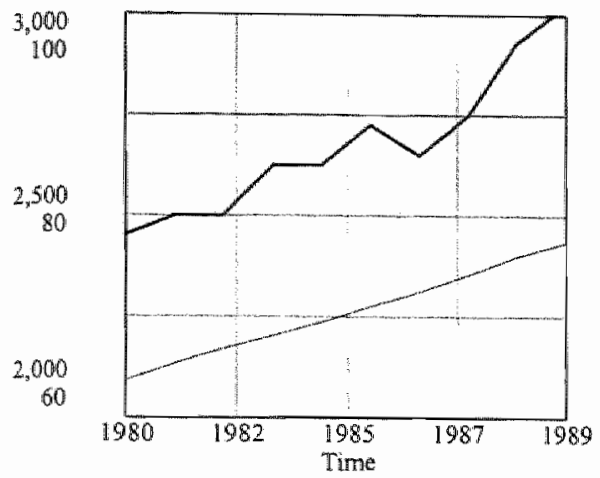

Actulal age-class $(25-44)$ men

Actual transition rate $(25-44) \rightarrow(45-64)$

Agewelass (45-64) \& transition rate $(45-64) \rightarrow(65+)$

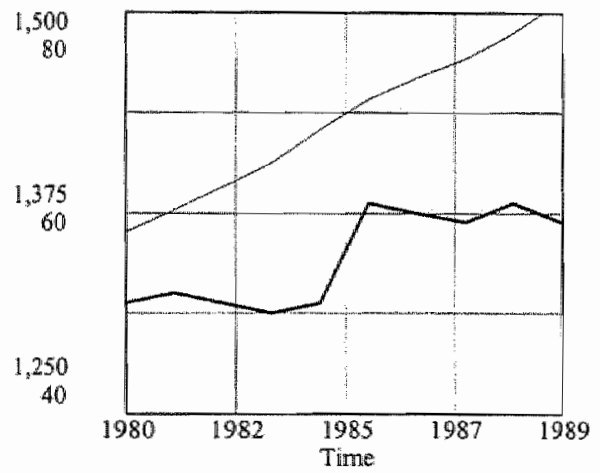

Actual age-class (45-64) men

Actural transition rate $(45-64)-(65+)$

Age-class $(65+)$ \& transinion rate $(65+) \rightarrow$ death rate

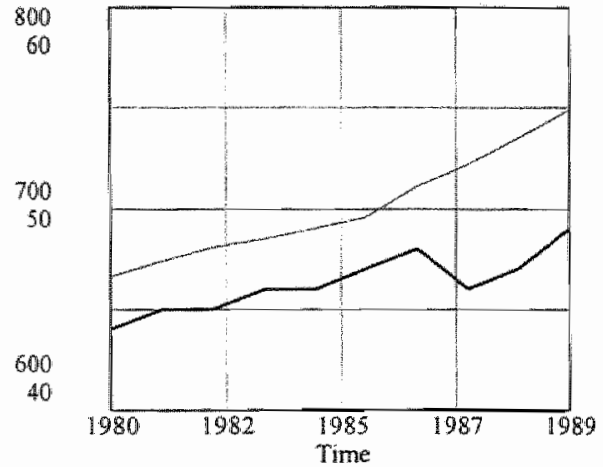

Actuall age-class $(65+)$ men

Actual transition rate $(65+)>$ death rate
Age-class $(25-44)$ \& transition rate $(25-44) \rightarrow(45-64)$

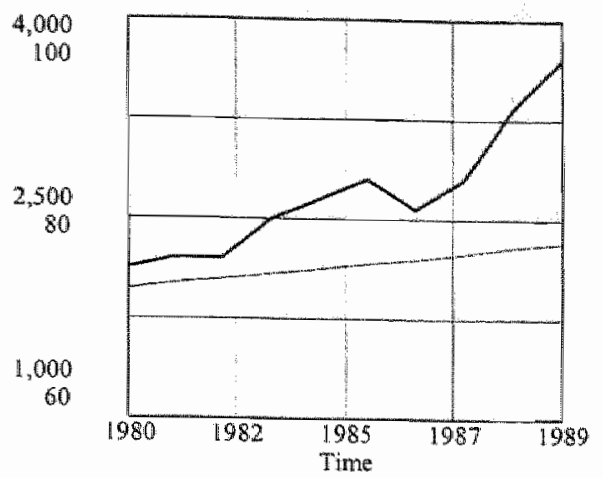

Actual age-chass $(25$-4) women

Actual transition rate $(25-44)->(45-64)$

Age-class $(45-64)$ \& transition rate $(45-64) \rightarrow(65$ th $)$

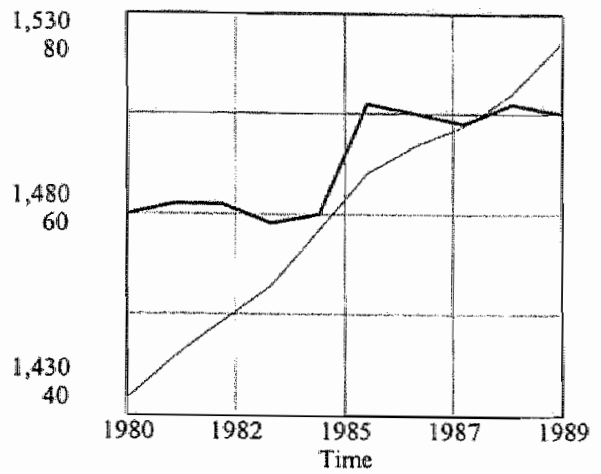

Actual age-class (45-64) wointen

Actual transition rate $(45-64)>(65+)$

Age-class $(65+)$ \& transition rate $(65+) \rightarrow$ death rate

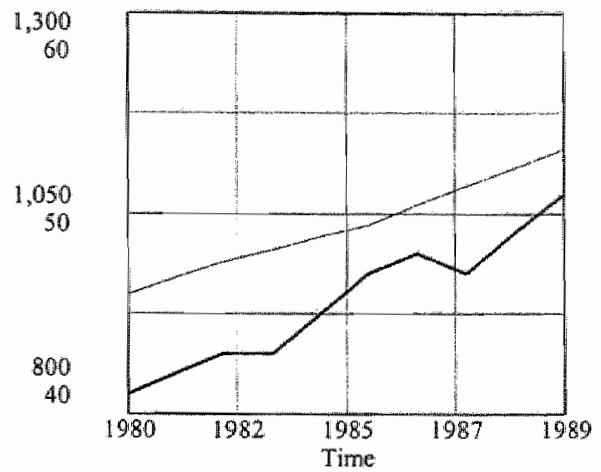

Actual age-class $(65+)$ women

Actual transition rate $\left(65 *^{\circ}\right)>>$ death rate 


\subsection{The $P_{1}^{6}$-population model}

The data of Table 2.1 and 2.2 are the basic database for the estimation of the transition rates, the birth rates are treated as exogenous perfectly known (zero measurement errors) input variables. Six transition or ageing rates ( $\left.\operatorname{TR}\left[A_{0}^{5}, S_{0}^{3}\right]\right)$ have to be estimated for each sex. The dynamic population model is a system of difference equations of $12^{\text {th }}$ order $(2.4 .1)$, which will be reduced to two equation (2.4.2) by the application of index(ed) set theoretical principles, to be explained in the next paragraph. The set of difference equations (2.4.1) represents the transition rates of the 6 age classes $\left(A_{0}, \ldots, A_{5}\right)$ defined in 2.4 .3 , for men $\left(S_{0}\right)$ only:

$$
\begin{aligned}
& P_{t}\left[A_{0}, S_{0}\right]=P_{t-1}\left[A_{0}, S_{0}\right]+\left(B_{i}\left[S_{0}\right]-T R_{t}\left[A_{0}, S_{0}\right]\right) \\
& P_{l}\left[A_{1}, S_{0}\right]=P_{t-1}\left[A_{1}, S_{0}\right]+\left(T R_{t}\left[A_{0}, S_{0}\right]-T R_{t}\left[A_{1}, S_{0}\right]\right) \\
& P_{t}\left[A_{2}, S_{0}\right]=P_{i-1}\left[A_{2}, S_{0}\right]+\left(T R_{t}\left[A_{1}, S_{0}\right]-T R_{i}\left[A_{2}, S_{0}\right]\right) \\
& P_{t}\left[A_{5}, S_{0}\right]=P_{t-1}\left[A_{5}, S_{0}\right]+\left(T R_{t}\left[A_{4}-T R_{t}\left[A_{5}, S_{0}\right]\right)\right.
\end{aligned}
$$

However by properly defining mappings of subscript ranges or vectors, one can reduce the number of equations to only two, regardless the number of age classes and sexes. In our case we have 6 age classes and two sexes.

$$
\begin{aligned}
& P_{t}\left[A_{0}, S_{0}^{1}\right]=P_{t-1}\left[A_{0}, S_{0}^{1}\right]+\left(B_{t}\left[S_{0}^{1}\right]-T R_{t}\left[A_{0}, S_{0}^{1}\right]\right) \\
& P_{t}\left[A_{1}^{5}, S_{0}^{1}\right]=P_{t-1}\left[A_{1}^{5}, S_{0}^{1}\right]+\left(T R_{t}\left[M_{1}^{5}, S_{0}^{1}\right]-T R_{t}\left[A_{1}^{5}, S_{0}^{1}\right]\right)
\end{aligned}
$$

where

$$
\begin{array}{ll}
P[\cdot, \cdot] & : \text { indexed population level }(\cdot \text { vector or subscript) } \\
P[A, S] & : \text { population level by age class } A \text { and sex } S \\
A_{0} & : \text { age class }(0-3) \text { year } \\
B\left[S_{0}^{1}\right] & : \text { birth rate male }(0) \text { and female }(1) \\
A_{1}^{5} & : \text { the computing sequence age class } 1, \ldots, \text { to age class } 5 \\
T R\left[A_{i}^{j}, S_{0]}^{1}\right]: \text { transition-out of age class } i, \ldots, j \text { over male and female } \\
M_{m}^{n} \quad: \text { mapping of age class } m \text { onto age class } m+I_{3} \ldots, n \\
T & : \text { time period }(1980-1989)
\end{array}
$$

The system of equations (2.4.2) is a concise description of a system which is characterise by the transition out-in. Only two equations describe the population dynamics regardless the number of age classes, or other population characteristics. Each population characteristic (age, age class, sex, income class, educational level, etc.) can be expressed as a vector and the vector space defines the dimension of the equation system. 


\subsubsection{Index(ed) set theory and subscript programming}

Consider the indexed set of age classes

$$
\begin{array}{ll}
A_{0}=\{1,2,3\} & :(0-3) \text { age }- \text { class } \\
A_{1}=\{4, \ldots, 14\} & :(4-14) \text { age -class } \\
A_{2}=\{15, \ldots, 24\} & :(15-24) \text { age-class } \\
A_{3}=\{25, \ldots, 44\} & :(25-44) \text { age-class } \\
A_{4}=\{45, \ldots, 64\} & :(45-64) \text { age-class } \\
A_{5}=\left\{65^{+}\right\} & :\left(65^{*}\right) \text { age-class }
\end{array}
$$

and the set

In general

$$
I=\{0,1,2,3,4,5\}: \text { a subset of non-negative integers }
$$

$$
I \in \mathbb{N} ; \text { is the set of non-negative integers or natural numbers }
$$

Notice that to each element $i \in I$ there corresponds a set $A_{i}$. In such a situation $I$ is the $i n d e x$ set, the sets $\left\{A_{0}, \ldots, A_{5}\right\}$ are the indexed sets, and the subscript $i$ of $A_{i}$, i.e. $i \in I$, is the index. Furthermore, the indexed class of sets is denoted with subscript 0 by superscript 5

$$
A_{0}^{5}=\left\{A_{0}, A_{1}, A_{2}, A_{3}, A_{4}, A_{5}\right\}
$$

or in general an indexed cllass of sets is denoted with subscript $i$ by superscript $j$ as

$$
A_{j}^{j}=\left\{A_{i}, \ldots, A_{j}\right\}_{i, j \in I}
$$

The indexed set sex is defined as

with

$$
S_{0}^{1}=\left\{S_{0}, S_{1}\right\}
$$

$$
\begin{array}{ll}
S_{0}=\{M\} & : \text { men } \\
S_{1}=(\text { W } & \text { : women }
\end{array}
$$

The variable birth rate has one dimensional data structure and is treated as an exogenous input wariable, coming from outside the boundary of the indexed transition set.

$$
B\left[S_{0}^{1}\right] \quad \text { : birth rate by sex class }
$$

The variable:

$$
P\left[A_{0}^{s}, S_{0}^{i}\right] \quad \text { : population by age-sex class }
$$

has a data structure in two dimensions with the indexed product set (space)

$$
A_{0}^{5} \otimes S_{0}^{1} \quad \text { :product space }
$$

as argument. The indexed product set can be illustrated as a tree structure with all possible combination as branches.

The same logic holds for

$$
\operatorname{TR}\left[A_{0}, S_{0}^{1}\right] \quad \text { : transition by }(0-3) \text { age-sex class }
$$


The variable which represents the transition through ageing can be stated in set theoretic terms as

$$
M\left[A_{1}^{5}\right] \quad: \text { Ageing by age- class }\left(A_{0} \rightarrow A_{1} \rightarrow \ldots \rightarrow A_{5}\right)
$$

The transition rate is a mapping onto (one-to-one relation or bijective function) and can be illustrated by Figure 2.3.

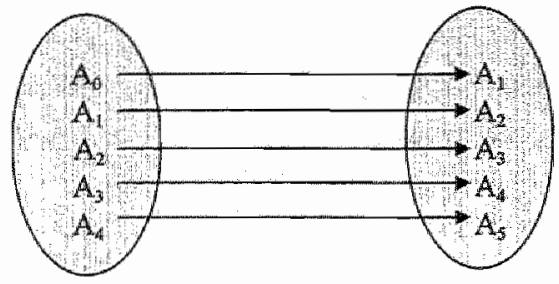

Figure 2.3 The mapping onto of age classes causing a transition

The mapping of $A_{0}^{4} \rightarrow A_{1}^{5}$ is an implicit dynamic transformation which means that the transition from one age class to the next age class occurs without the index set time as an additional dimension. This reduce the dimensionality of the representation space from 12 to 2 difference equations $(2.4 .1)$, irrespective the number of age classes.

In general

Definition 1.1 An indexed class of transition sets $M_{i}^{j}=\left\{M_{i}, \ldots, M_{j}\right\}_{i, j \in J}$ is a function

$$
m: A_{i}^{j-1} \stackrel{m}{\longrightarrow} A_{i+1}^{j}
$$

where the domain of $m$ is the indexed set $A_{i}^{j-1}$ and the range of $m$ is an indexed set $A_{i+1}^{j}$ and

$$
\begin{aligned}
& A_{i}^{j-1} \cup A_{i+1}^{j}=\left\{A_{i}^{j}\right\}_{i, j \in I} \\
& A_{i}^{j-1} \cap A_{i+1}^{j}=\left\{A_{i+1}^{j-1}\right\}_{i, j \in I}
\end{aligned}
$$

Now, with the concept of indexed class of transition sets a consistent expression and concise description of the dynamic transition structure are feasible and the set of equations (2.4.2) embodies these concepts.

\subsection{Estimation of the transition rates}

The transition rates between the age classes will be estimated and validated by optimisation procedures. First of all, a payoff function has to be defined which is a nornalised composite expression to measure the estimation performance and guides the search trajectories. The payoff (or objective function) for a model can be defined in terms of comparison of the simulated model variables $x_{i}(t)$ with the obserwed/measured data $x_{\Delta_{i}}(t)$ or as a combination of model variables only. These two types of payoffs are known as estimation payoff and policy payoffs.

The $i$-variable payoff can be defined as:

$$
\max _{x \in \Re^{n}} F(P)=\sum-\min \left(\frac{\left(x_{i}(t)-x_{\Delta_{i}}(t)\right)^{2}}{\sigma_{i}}\right)
$$

subject to

where

$$
L_{i} \leq s_{i} \leq U_{I}
$$

$$
x_{\hat{i}} \in X \quad \text { : the set of model variables }
$$




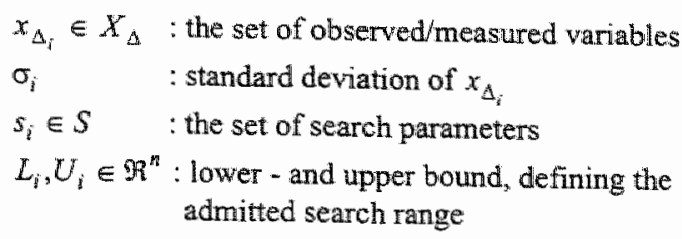

In the population model these model variables entering the payoff are:

where

$$
\begin{aligned}
& P\left[S_{0}\right]=\sum_{i=0}^{5} P\left(A_{i}, S_{0}\right) \\
& P\left[S_{1}\right]=\sum_{i=0}^{5} P\left(A_{i}, S_{1}\right) \\
& P=\sum_{j=0}^{1} P\left[S_{j}\right]=\sum_{i=0}^{5} \sum_{j=0}^{1} P\left(A_{i}, S_{j}\right) \\
& P\left[A_{0}^{5}, S_{0}^{1}\right]
\end{aligned}
$$

$$
\begin{array}{ll}
P & \text { : total population } \\
P\left[S_{0}\right] & : \text { total population men } \\
P\left[S_{1}\right] & : \text { total population women } \\
P\left[A_{0}^{5}, S_{0}^{1}\right] & : \text { sub-populations by age-sex subsets }
\end{array}
$$

Using this payoff, the difference between the different population subsets simulated by the model and the observed sub-population data (Table 2.1 and 2.2) will be used. The sum of squared errors will be computed, and weighted by $1 /$ standard deviation of each subset. In each case, the weight is squared, since it is used to compute the raw residual, which is then squared. Once the payoff has been defined, one has to select the search parameters (constants) which are dynamically changed (iterated) to maximise the payoff. A modified hill-climbing Poweil search algorithm will perform this maximisation task. The constants (fractions) to be estimated by search/iteration cycles are the transition rates:

$$
\operatorname{tr}\left[A_{0}^{5}, S_{0}^{1}\right]
$$

of each subset (age classes) which are then multiplied with the population levels of that subset to get the transition as

$$
\operatorname{TR}\left[A_{0}^{5}, S_{0}^{1}\right]=\operatorname{tr}\left[A_{0}^{5}, S_{0}^{1}\right] * P\left[A_{0}^{5}, S_{0}^{1}\right]
$$

In order to test the sensitivity to changes in search parameter values at an optimum, the search parameter list $t \hat{r}\left[A_{0}^{5}, S_{0}^{1}\right]$ will be rerun to determine how much each individual parameter would have to be changed to decrease the payoff by the desired confidence bounds (or intervalls). Positive and negative value changes are calculated separately, since no symmetry is expected. If the payoff is a true log likelihood or a properly weighted sum of squares different changes in the absolute value of the payoff, which is the same as the log likelihood, can be used to derive confidence bounds, for example, $95 \%(2 \sigma)$ or $99 \%(\sigma)$ on the search parameters. 


\subsubsection{The results}

In order to estimate and validate the transition rates for the period 1980-1989 an optimisation has been perfomed based on the model variables (2.5.1) and the search parameters (2.5.2). The control statements are presented in Box 2.1 and 2.2. The estimation control statements, Box 2.1, declares the first wariable as the modell variable followed by the observed data-variable and a value for the weight (1/standard deviation).

Format

(model variables | abserwed data/ / Hot)

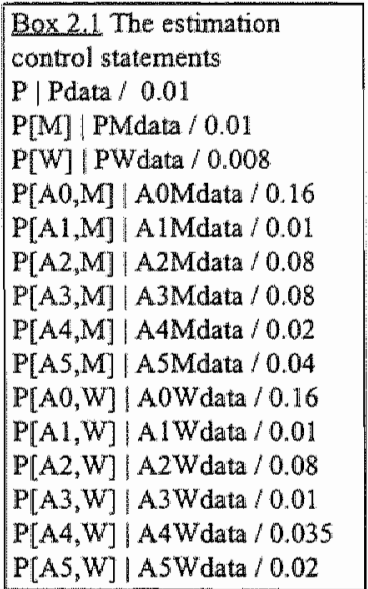

The optimisation control statements, Box 2.2 , declares the sensitivity option being set for computing confidence bounds or intervals at a $95 \%(2 \sigma)$ level, followed by the search parameters initial values bounded or restricted by lower- and/or upper bounds.

Format

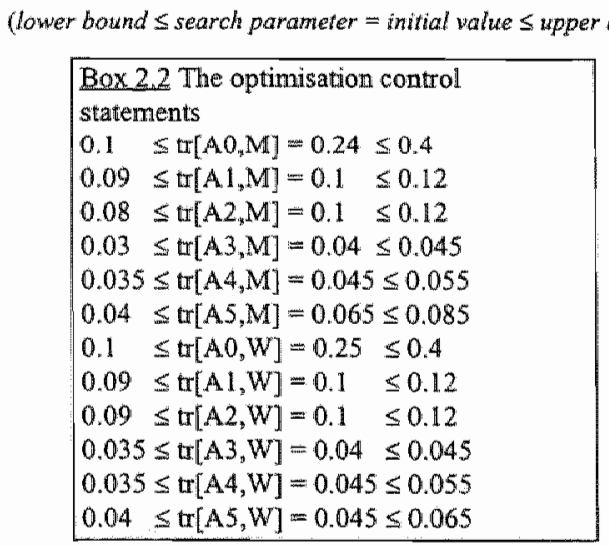

The results are shown in Box 2.3. The initial payoff (computed with the initial search parameter values) was -478 and improved after 435 simulations to -28 . The results will be validated in the next section after which it will be decided to perform additional estimations. Note that within each simulation (in order to compute the payoff), there will be the numerous iterations needed to search the surface. 
The format of the output file is:

Format

(lower bound $\leq$ search parameter = opthal wathe $\leq$ wpper bounds)

\begin{tabular}{|l|}
\hline Box 2.3 The output file \\
After 435 simulations \\
Best payoff is -27.9377 \\
Normally terminated optimisation \\
SENSITIVITY $=20$ \\
TRACE $=5$ \\
$0.1 \leq \operatorname{tr}[\mathrm{A} 0, \mathrm{M}]=0.246992 \quad \leq 0.4$ \\
$0.09 \leq \operatorname{tr}[\mathrm{A} 1, \mathrm{M}]=0.113788 \leq 0.12$ \\
$0.08 \leq \operatorname{tr}[\mathrm{A} 2, \mathrm{M}]=0.0977954 \leq 0.12$ \\
$0.03 \leq \operatorname{tr}[\mathrm{A} 3, \mathrm{M}]=0.0390872 \leq 0.045$ \\
$0.035 \leq \operatorname{tr}[\mathrm{A} 4, \mathrm{M}]=0.0476795 \leq 0.055$ \\
$0.04 \leq \operatorname{tr}[\mathrm{A} 5, \mathrm{M}]=0.0851186 \leq 0.1$ \\
$0.1 \leq \operatorname{tr}[\mathrm{A} 0, \mathrm{~W}]=0.246701 \quad \leq 0.4$ \\
$0.09 \leq \operatorname{tr}[\mathrm{A} 1, \mathrm{~W}]=0.115247 \leq 0.12$ \\
$0.09 \leq \operatorname{tr}[\mathrm{A} 2, \mathrm{~W}]=0.0984858 \leq 0.12$ \\
$0.035 \leq \operatorname{tr}[\mathrm{A} 3, \mathrm{~W}]=0.0363396 \leq 0.045$ \\
$0.035 \leq \operatorname{tr}[\mathrm{A} 4, \mathrm{~W}]=0.0453383 \leq 0.055$ \\
$0.04 \leq \operatorname{tr}[\mathrm{A} 5, \mathrm{~W}]=0.0450646 \leq 0.06$
\end{tabular}

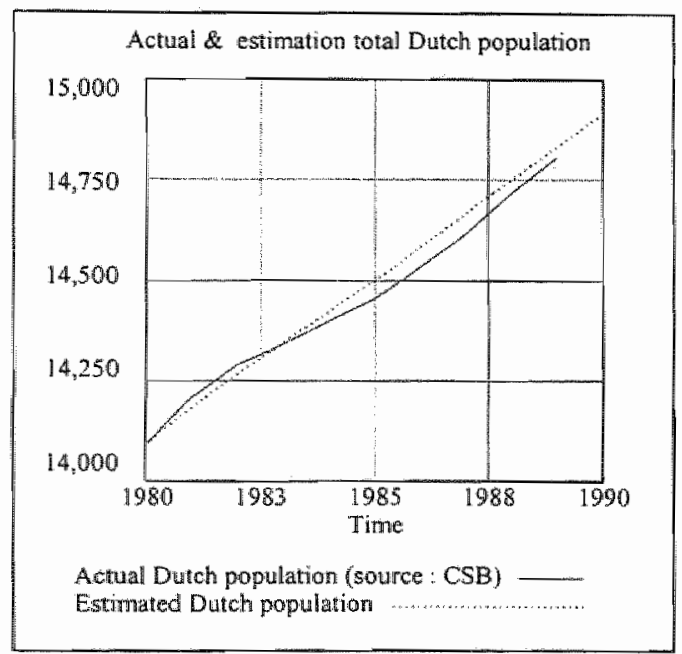

Figure 2.4

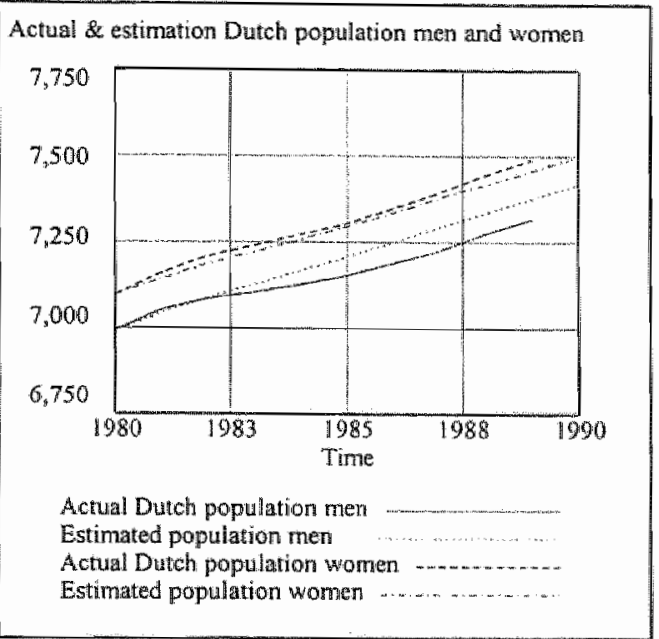

Figure 2.5

The model simulates the historical trajectories with the optimal parameter transition rates along with the observed/measured data series. Figure 2.4 illustrate the comparison of the simulated and the observed total Dutch population development during the 80 s, while Figure 2.5 compares the miale and female total population. The sensitivity analysis is performed by specifying the confidence bounds. Here twice the standard deviation has been chosen as indicating a $95 \%$ confidence bourds. 
The format of the sensitivity file is:

FORMAI (lower bound 5 search porcmeter = optimal value 5 upper bound)

\begin{tabular}{|c|c|}
\hline $\begin{array}{l}\text { Box } 2.4 \text { Log likelihood } 950 \\
\text { SFV }\end{array}$ & Confidence intervals \\
\hline SENSITIVITY $=20$ & \\
\hline $0.245058 \leq \operatorname{tr}[\mathrm{AO}, \mathrm{M}]=$ & $0.246992 \leq 0.246992$ \\
\hline $0.11206 \leq \mathrm{tr}[\mathrm{A} 1, \mathrm{M}]=$ & $0.113788 \leq 0.115556$ \\
\hline $0.0969277 \leq \operatorname{tr}[\mathrm{A} 2, \mathrm{M}]=$ & $0.0977954 \leq 0.0986219$ \\
\hline$? ? ? \leq \mathrm{t}[\mathrm{A} 3, \mathrm{M}]=$ & $0.0390872 \leq 0.0394167$ \\
\hline $0.0458699 \leq \pi[A 4, M]=$ & $0.0476795 \leq 0.049651$ \\
\hline $0.0818493 \leq \mathrm{U}[\mathrm{A} S, \mathrm{M}]=$ & $0.0851186 \leq 0.0894366$ \\
\hline$\eta g ? \mathrm{t}[\mathrm{AO}, \mathrm{W}]=$ & $0.246701 \leq 0.249408$ \\
\hline $0.11355 \leq \mathrm{th}[\mathrm{Al}, W]=$ & $0.115247 \leq 0.117562$ \\
\hline$? ? ? ? \leq \mathrm{tr}[\mathrm{A} 2, \mathrm{~W}]=$ & $0.0984858 \leq 0.0991543$ \\
\hline $0.035^{*} \leq \mathrm{tr}[\mathrm{A} 3, \mathrm{~W}]=$ & $0.0363396 \leq 0.0376468$ \\
\hline $0,0436764 \leq \pi[A 4, W]=$ & $0.0453383 \leq 0.0470883$ \\
\hline $0.040765 \leq \mathrm{tr}[\mathrm{AS}, \mathrm{W}]=$ & $0.0450646 \leq 0.0489794$ \\
\hline The base payoff is $\quad-27.9$ & 877 \\
\hline
\end{tabular}

The "????" -question marks indicate that a confidience bound could not be fixed for that particular element of the set of search parameters. In other word, the optimiser cannot find the appropriate point. There are two reasons this might happen:

1. the surface is (very) flat, there may be no way to change the sensitivity by the designed value (for example 20 or within $95 \%$ confidence bounds),

2. the surface is steep or ill-behaved, it may be hard to get the exact point.

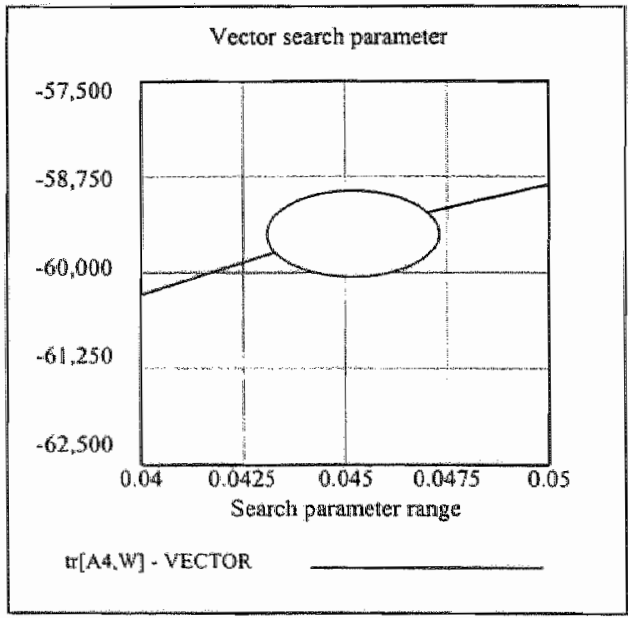

Figure 2.6 Example: correct sensitivity changing and searching the appropriate boundary points

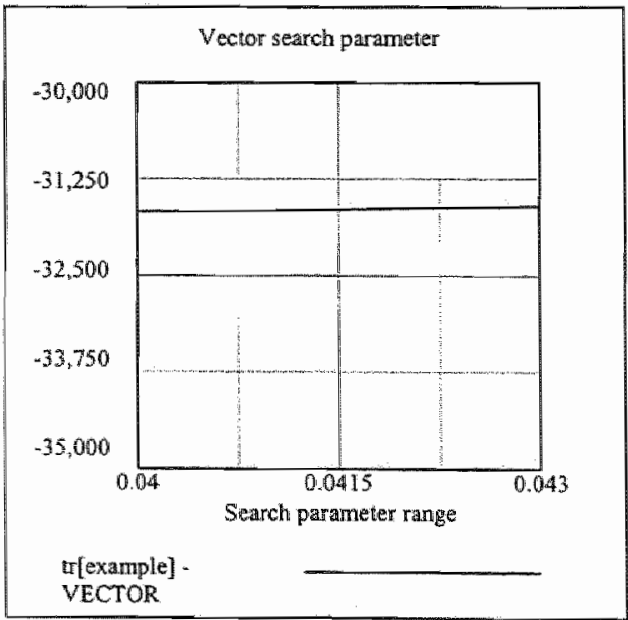

Figure 2.7 Example: too flat for changing the sensitivity by for example. $2 \%$

Figure 2.6 shows the result, taken from Box 2.4, of search parameter $\operatorname{tr}[\mathrm{A} 4$, W] with the $95 \%$ confidence bounds $(0.044,0.047)$, on the other hand Figure 2.7 shows a surface which is too flat to successfully change the sensitivity by $2 \sigma$. Figure 2.8 shows the surface of search parameter $\operatorname{tr}[A 3, M]$ $(? ? ? ?, 0.3941)$ which is too steep from the left to fix the exact point. Note the steep decrease of the values on the vertical axis, illustrative for the steepness of the slope. 


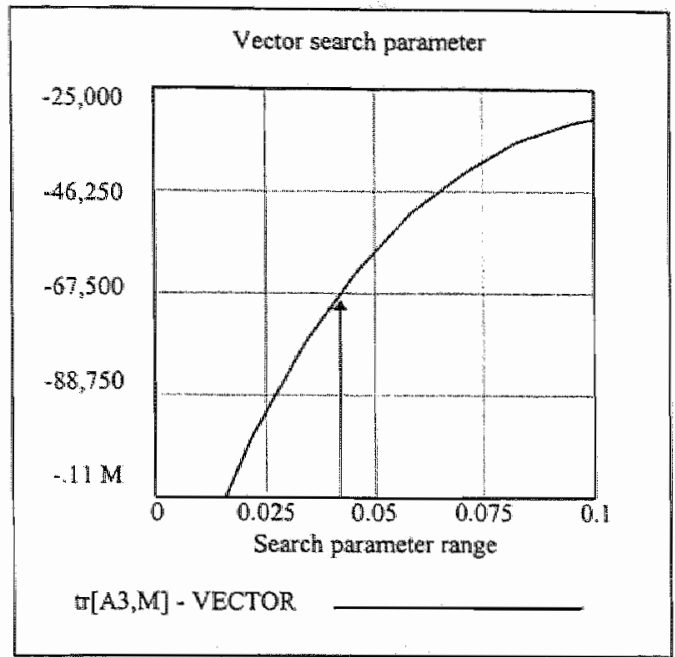

Figure 2.8 Example: surface too steep to get the exact point

\subsection{A second optimisation}

For reason of consistency the transition rates of the $65+$ age class are now treated as exogenous, because they are too high according to actual 1990 standards $(0.085$ versus 0.068$)$, indicating that during the 80 s the mean life expectancy of men increased from 77 year $(1 / 0.085=12$ year ( $=$ the mean residence time)) to 80 year (1/0.065). In other words, the $65+$ age class is still growing in the period under investigation (and for the next decades to come), not only in the absolute numbers of the transition-out entering the $65+$ age class (height), but also in the age expectancy or residence time, this means people becoming still older (length), so the volume (height * length) is extra growing. It is an evolution. Therefore an optimisation run was performed without the transition rates of men and women of the $65+$ age class in the optimisation process, conform the principle that death rates are partly technological dependent and therefore treated exegeneously. The remaining intemal transitions are strictly depended on the principle of balance relationship.

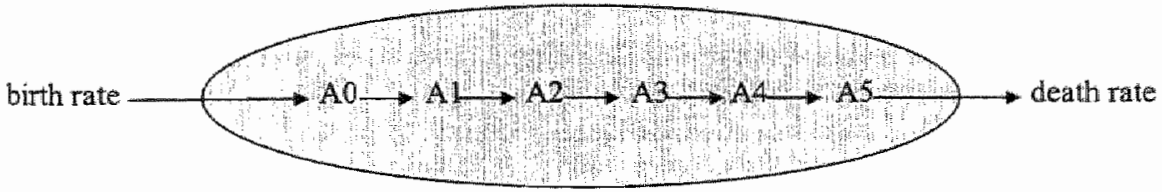

In fact, $t[A, M]$ and $t r[A 5, W]$ are now dropped as search parameter and becomes the death rates treated as constants $(0.07$ and 0.05 , respectively), incorporating the increase in the life expectancy in 1990. This means that the residence time of the last age class will be exogeneously controllable, in order to deal in a consistent way with increasing life expectancy The optimal results are shown in Box 2.5 


\begin{tabular}{|l|l|}
\hline Box 2.5 log likelihood 95\% Confidence intervals \\
SENSITTVY $=2 \sigma$ \\
$0.245029 \leq \operatorname{tr}[\mathrm{AO}, \mathrm{M}]=0.247976 \leq 0.250839$ \\
$0.102901 \leq \operatorname{tr}[\mathrm{A} 1, \mathrm{M}]=0.104548 \leq 0.106197$ \\
$0.091198 \leq \operatorname{tr}[\mathrm{A} 2, \mathrm{M}]=0.092066 \leq 0.092867$ \\
$0.0350084 \leq \operatorname{tr}[\mathrm{A} 3, \mathrm{M}]=0.03554 \leq 0.0360427$ \\
$0.0428516 \leq \operatorname{tr}[\mathrm{A4}, \mathrm{M}]=0.044816 \leq 0.0467008$ \\
$0.242861 \leq \operatorname{tr}[\mathrm{AO}, \mathrm{W}]=0.24588 \leq 0.248861$ \\
$0.103197 \leq \operatorname{tr}[\mathrm{A} 1, \mathrm{~W}]=0.105027 \leq 0.106852$ \\
$0.0906256 \leq \operatorname{tr}[\mathrm{A} 2, \mathrm{~W}]=0.0917588 \leq 0.0928706$ \\
$0.035 * \operatorname{tr}[\mathrm{A} 3, \mathrm{~W}]=0.0352812 \leq 0.0366809$ \\
$0.04197 \leq \leq \operatorname{tr}[\mathrm{A} 4, \mathrm{~W}]=0.0437848 \leq 0.0454964$ \\
The base payoff is -16.1828
\end{tabular}

Note that the payoff criteria remains unchanged! The payoff improves from -28 to -16 .

\subsection{A third optimisation}

As the end of the 80 s shows increased immigration rates the year 1988 and 1989 have been dropped from the base period which now account the period 1980-87. The estimation shows a payoff improvement from -16 to -7 with the following results (Box 2.6).

\begin{tabular}{|l} 
Box 2.6 log likelihood 95\% Confidence intervals \\
SENSITVTTY $=2 \sigma$ \\
$0.24562 \leq \operatorname{tr}[\mathrm{AO}, \mathrm{M}]=0.249312 \leq 0.253003$ \\
$0.100123 \leq \operatorname{tr}[\mathrm{A} 1, \mathrm{M}]=0.102139 \leq 0.104161$ \\
$0.088971 \leq \operatorname{tr}[\mathrm{A} 2, \mathrm{M}]=0.090108 \leq 0.091165$ \\
$0.0344175 \leq \operatorname{tr}[\mathrm{A} 3, \mathrm{M}]=0.035152 \leq 0.035869$ \\
$0.0414855 \leq \operatorname{tr}[\mathrm{A} 4, \mathrm{M}]=0.043973 \leq 0.046479$ \\
$0.24319 \leq \operatorname{tr}[\mathrm{A} 0, \mathrm{~W}]=0.24704 \leq 0.25088$ \\
$0.100583 \leq \operatorname{tr}[\mathrm{A} 1, \mathrm{~W}]=0.102799 \leq 0.104961$ \\
$2 ? 7 ? \leq \operatorname{tr}[\mathrm{A} 2, \mathrm{~W}]=0.090002 \leq 0.091531$ \\
$0.035 * \operatorname{tr}[\mathrm{A} 3, \mathrm{~W}]=0.035243 \leq 0.037159$ \\
$0.040617 \leq \operatorname{tr}[\mathrm{A} 4, \mathrm{~W}]=0.042958 \leq 0.045291$ \\
The base payoff is -7.00874
\end{tabular}

The global result is shown in Figure 2.9, the payoff improvements are also visible if one compares Figure 2.4 and 2.9 , the latter curve of observed population comes close to the estimated in 1989 , that means the gap in Figure 2.4 is now closed. This shows the improvement of treating the transition rates of the 65* age class as controllable constants. The parameter values of Box 2.6 will be applied in the $P_{1}^{6}$-population model which act as an input driver of the household model. The next section investigates in detail optimal properties of the results.

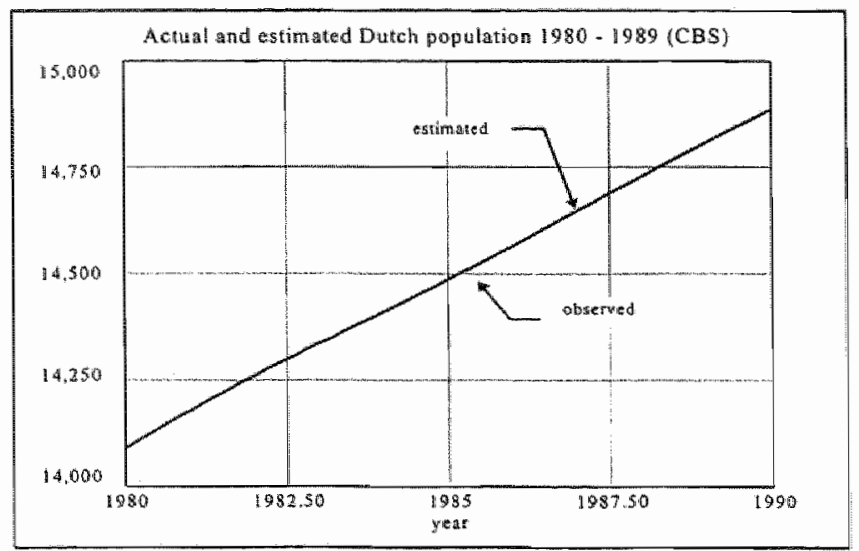

Figure 2.9 The observed and estimated total Dutch population 


\subsection{The optimisation results}

The estimation results will be evaluated at five levels:

1. The percentage deviation ( $\% \Delta$ ) of the observed and simulated population levels by age classes by sex. The transition rates applied for the computation of the new population levels are the estimated transition rates $\operatorname{tr}\left[A_{0}^{4}, S_{0}^{1}\right]$.

2. Decomposition of the payoff into the data variables entering the payoff and their individual support in the final payoff characterising the optimum.

3. The estimation trajectory of the individual search parameters $\operatorname{tr}\left[A_{0}^{4}, S_{0}^{1}\right]$ will be investigated (called tracing the search parameters)

4. Vector search will be performed defining the payoff as a function of each individual search parameter value in order to investigate its local optima.

5. Grid-and random search will be applied in order to investigate the global validity of the optima.

\subsubsection{The percentage deviation $(\% \Delta)$}

The percentage deviation of the observed population levels and the simulated levels gives a visual indication about the 'goodness of fit' and we will try to give an explanation if possible for the deviations. The percentage deviation are recorded on the $+5 \%,-5 \%$ vertical scale, however all deviations fall within the $2.5 \%,-2.5 \%$ range. The deviation of the upper left graphic (age class $(0-3)$ ) demonstrates the reversal of the birth rate mid $80 \mathrm{~s}$, as can be checked in Table 2.1. and 2.2, which after a delay of 3 years appears in the upper right graphic (age class (4-14)). The waves in the rest of the graphics are especially caused by birth rates variations in the 60 s and earlier. 
$\% \Delta$ observed versus simulated age-classes

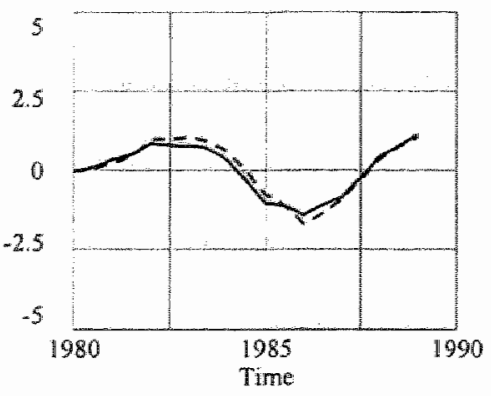

$\% \Delta$ age-class $(0-3)$ men $\% \Delta$ age-class $(0-3)$ women --

$\% \Delta$ observed versus simulatd age-classes

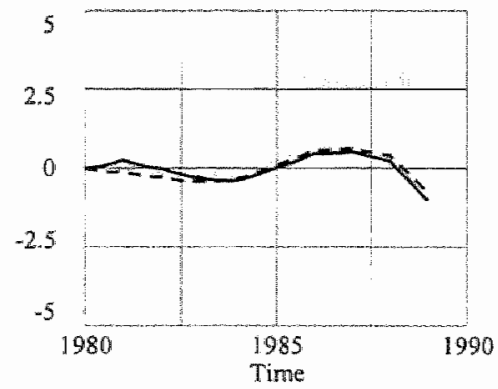

$\% \Delta$ age-class $(15-24)$ men
$\% \Delta$ age-class $(15-24)$ women
$\%$ observed versus simulated age-classes.

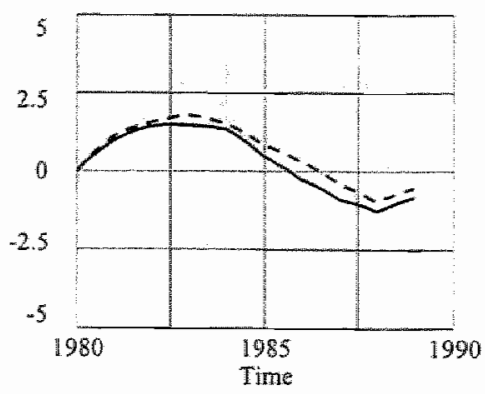

$\% \Delta$ age-class $(4-15)$ men
$\% \Delta$ age-class $(4-15)$ women

$\% \Delta$ observed versus simulated age-classes

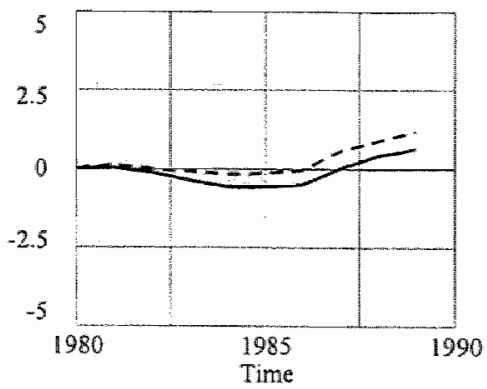

$\% \Delta$ age-class (25-44) men

$\% \Delta$ age-elass $(25-44)$ women - - -

$\% \Delta$ observed versus simulated age-classes

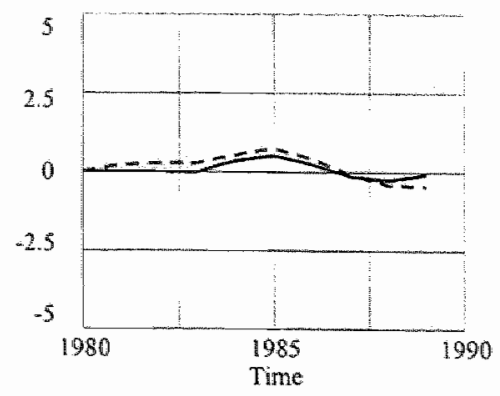

$\% \Delta$ age-class $(45-64)$ men
$\% \Delta$ age-class $(45-64)$ women

Figure Box 2.10 Percentage deviation observed age classes and simulated age classes 


\subsubsection{The decomposition of the payoff}

In analysing the decomposition of the payoff the first thing that strikes is the high value of -5.6 and the resultant percentage (34\%) of the data variable A $3 M D A T A$, that is the observed male population lewel of age class $(25-44)$. In fact it refers to the data in the row 'begin balance' 2544 year in table 2.2. Analogous to the data variable $A 3 M D A$ I $A$ is the model variable $P\left[A_{3}, S_{0}\right]$. Inspecting the database one sees immediately that it is due to the sharp rise $(+40 \%)$ of the immigration in 1989 in the age class (25-44) (see Table 2.2), the women part in the same age class on the contrary is smooth. The optimisation run based on the data of period 1980-1987 shows a halving of A3MDATA from 34\% to 17\% (Box 2.7) and a fall to the third position. Note the optimum values of the base period 1980-1987 are shown between squares [ ].

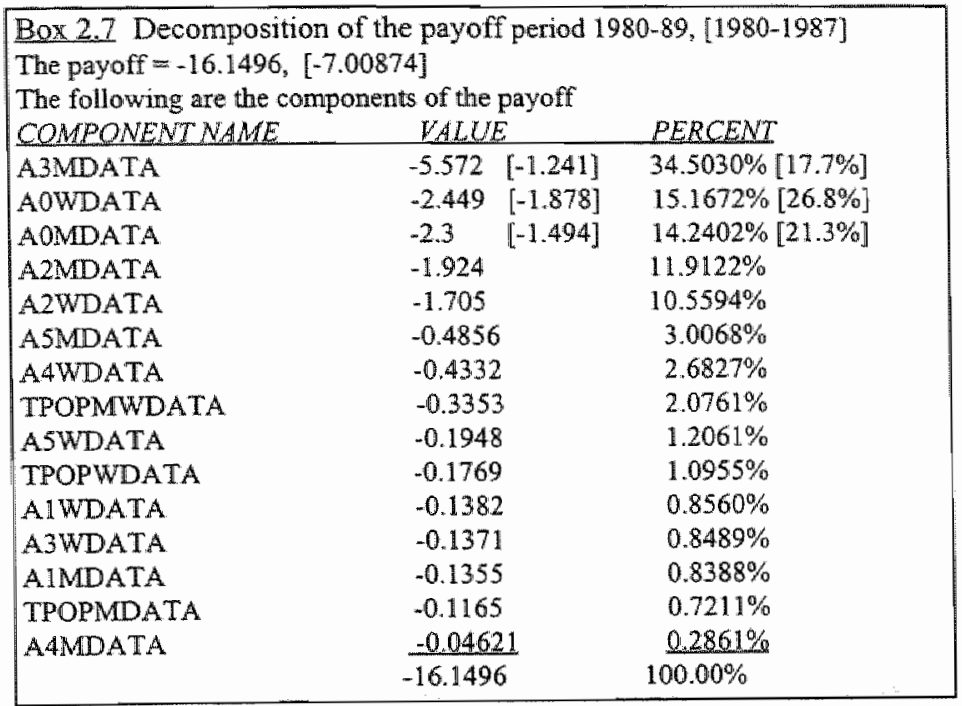

The birth related age classes (AOWDATA and AOMDATA) are in the top now due to the birth rate reversal after 1985 as noted above.

\footnotetext{
2 A3MDATA is composed of the following elements: A 3 is age class $3(25-44)$ year. M refers to male and DATA to the observed figures in table 2.1 and 2.2 So TPOPWDATA refers to the observed figures of total female population, etc.
} 


\subsubsection{Tracing the optimisation results}

Tracing is a procedure which determines the trajectory of the search parameter values and payoff at different iterations/simulations. It deals with the performance history (trajectory) of the payoff, as shown in Figure 2.12, and its constituent search parameters, as shown in the Figure box 2.13. It gives one an inside view of the optimising behaviour of the search parameters involved. Each search parameter starts with the initial value and ends, hopefully in an optimal way, with the optimal endvalue, as described before.

Note that the horizontal axes measures an index which is augmented by one with each simulation. The ongoing payoff trajectory, performed by simulations, shows the progress in the performance index as search parameters are changed after each iteration. Figure 2.12 shows the payoff which after two steps reaches smoothly its optimum value.

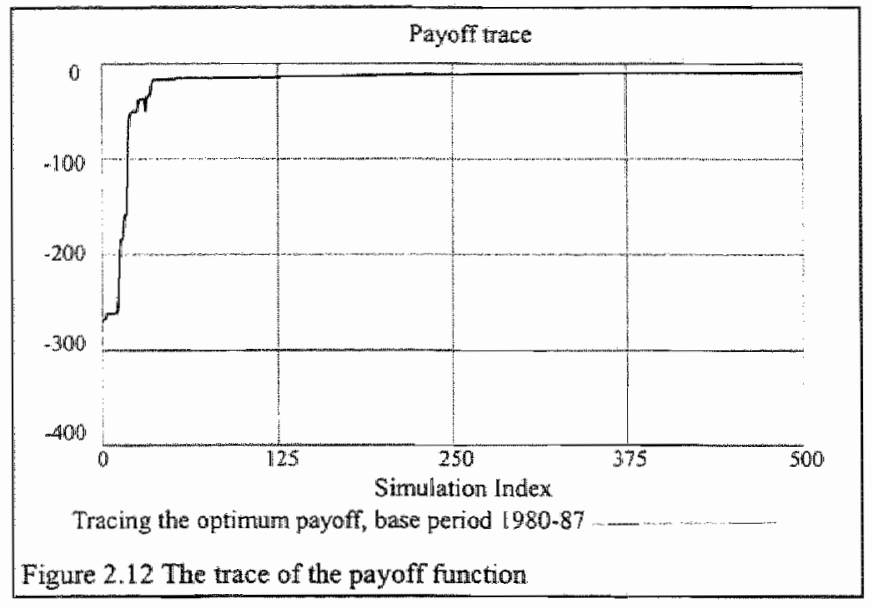

The initial payoff starts at -266 and ends at an optimum with a payoff of -7 (after 1645 simulations). For the sake of a clear visual representation only the first 500 simulation out of 1054 simulations are shown in Figure 2.12.

Note the simulation of payoff improvements only are shown in the picture.

Looking to the payoff trajectory of Figure 2.12 two jumps (at simulation 5 and 19) shows the steep increase in the performance. Which search parameter( $($ ) are accountable for the step improvements will be shown hereafter.

Examining the trace trajectories of the individual search parameters Figure box 2.12, then the dominant search parameters are the changes of transition rates of

- the age class (4-14) for men and women, $\operatorname{tr}[A 1, M]$ and $t r[A l, W]$,

- the age class (15-24) for men only, $\operatorname{tr}[A 2, M]$, and

- the age class $(25-44)$ for men and women, $\operatorname{tr}[A 3, M]$ and $\operatorname{tr}[A 3, W]$.

After the two jumps the improvement of the payoff takes place in a more gradual way where the algorithm or hill-climber is guided and directed by the payoff development and the value of the fractional tolerance, $7 O L$, which determine when to terminate an optimisation. The search is refined until the values for each parameter is within the fractional tolerance, $T O L$, times the value of the parameter (if the parameter is 0 then $+-T O L$ is used) In our research $T O L=0.0003$.

Examining the trace history of the search parameters, Figure box 2.13, one observes that the search parameters $m\left[A i_{1} M\right]$ of the men sub-population are the most to be changed and shows the most improvement during the optimisation. This is partly due to the immigration shocks especially of men end $80 \mathrm{~s}$.

Note that the vertical axis measures the (sub)range of the search parameter values, in agreement of coarse with Box 2.5 . 


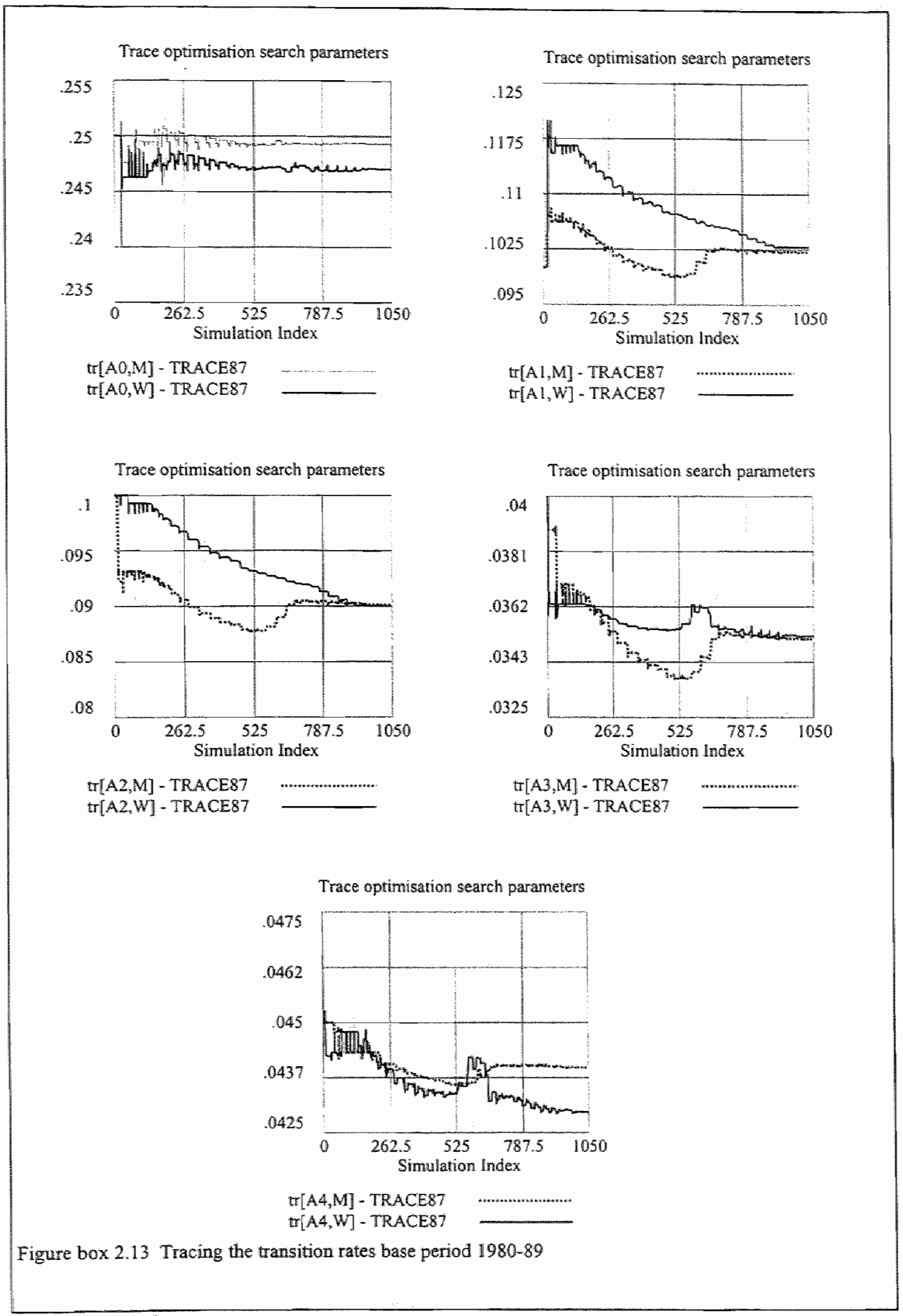




\subsubsection{Vector search}

The vector search changes only one parameter at a time. The wector search starts with the first parameter from its minimum to maximum declared values, then the second parameter, and so on. The partition is the maximum - minimum value over the setting of vector points (here 25 ). The ranges for parameters are specified as constraints on the parameters being optimised. The information from a vector search is very useful for viexwing separate cuts of the likelihood surface. This could be the case for search parameter $\operatorname{tr}[A 2, W]$ (Box 2.4 and 2.6) for which the surface from the left is too steep to compute the exact point, but there are no separate cuts. (see Figure 2.14 the vertical axis!) That is why the "????"-marks appear in the sensitivity output table (Box 2.5). The same holds true for search parameter $r[A 4, M]$ (Figure 2.15)

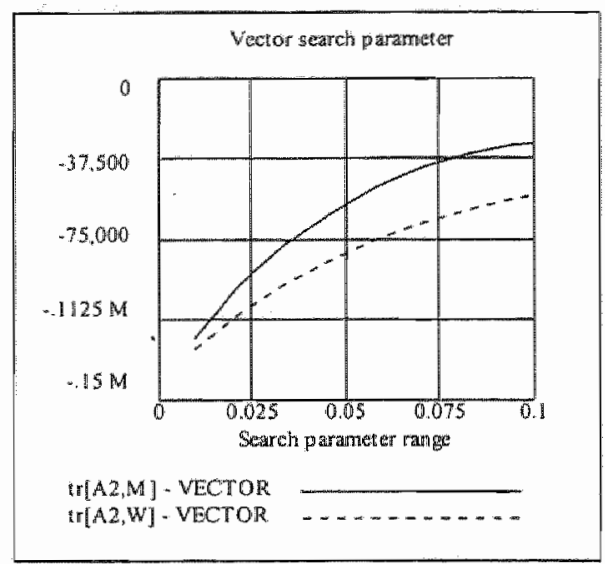

Figure 2.14 Vector search $\operatorname{tr}[A 2, M], \operatorname{tr}[A 2, W]$

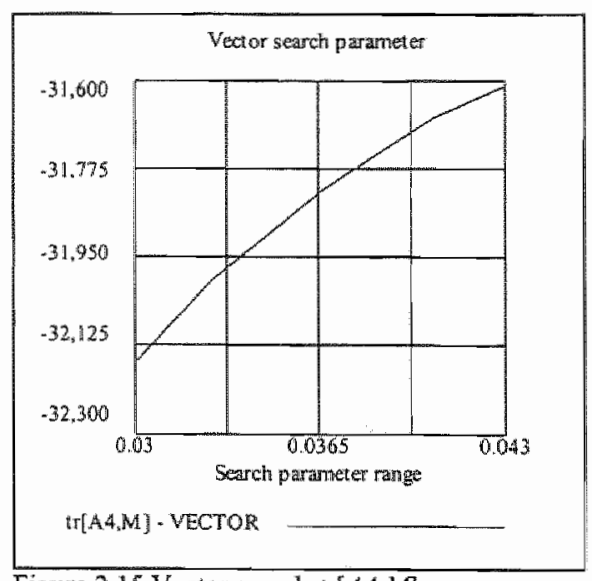

Figure 2.15 Vector search $t r[44, M]$

Looking at the search parameters $\operatorname{tr}[A I, M]$ and $\operatorname{tr}[A 1, W]$ in Figure 2.16 and 2.17 , one wonders why for $\operatorname{tr}[A I, W]$ no point can be fixed, and for $\operatorname{tr}[A l, M]$ it does, even if they are looking the same.

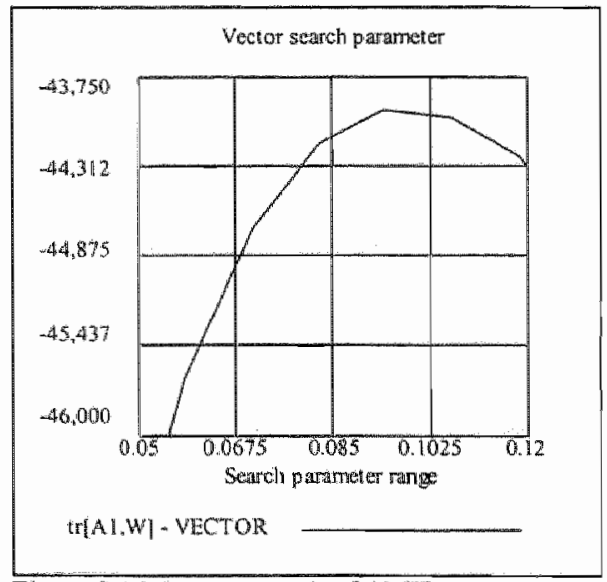

Figure 2.16 Vector search $t[A l, W]$

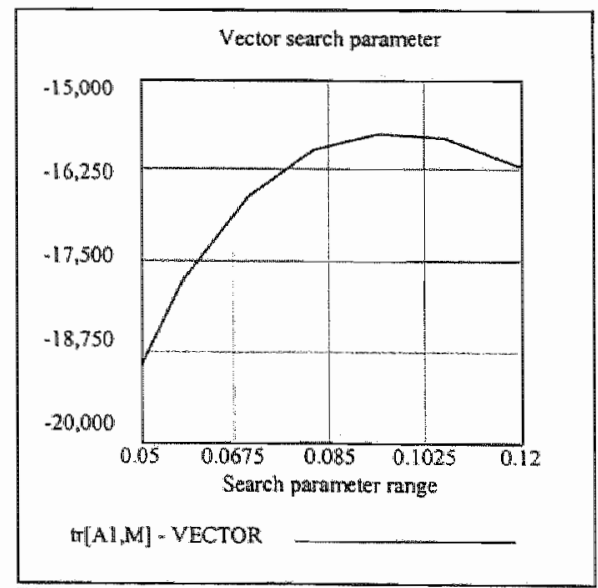

Figure 2.17 Vector search $\operatorname{tr}[A 1, M]$

Zooming-in more close around the boundary values shows that the surface of $t r[A 1, W]$ is more steep from the left than is the case for $\operatorname{tr}[A l, M]$. But again no separate cuts! The remaining parameters show also the correct confidence bounds. Moreover the search parameter with the '????'-marks, $\operatorname{tr}[A 2, W]$ in Box 26, for which no confidence bounds could be fixed will be further investigated in the 
next section by grid search procedures. Figure box 2.18 shows the complete vector search parameters.

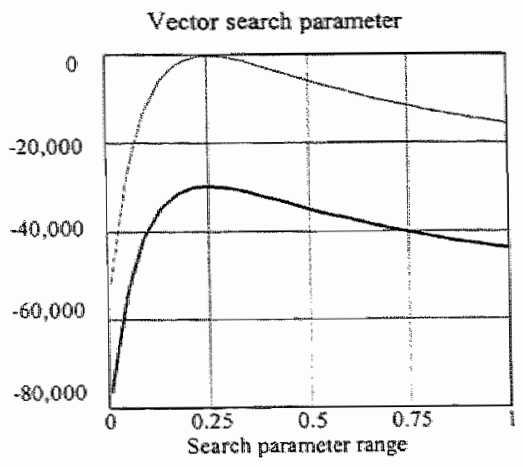

$\operatorname{sr}[\mathrm{AO}, \mathrm{M}]-\mathrm{VECTOR}$ $\operatorname{LA}[\mathrm{A}, W]$ - VECTOR

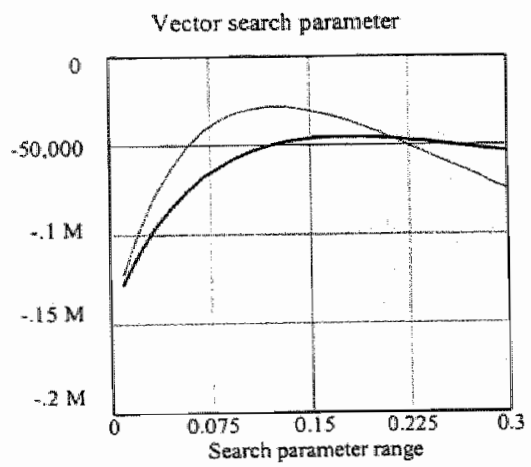

$\operatorname{tr}[\mathrm{A}, \mathrm{M}]$ - VECTOR TA2,W] VECTOR

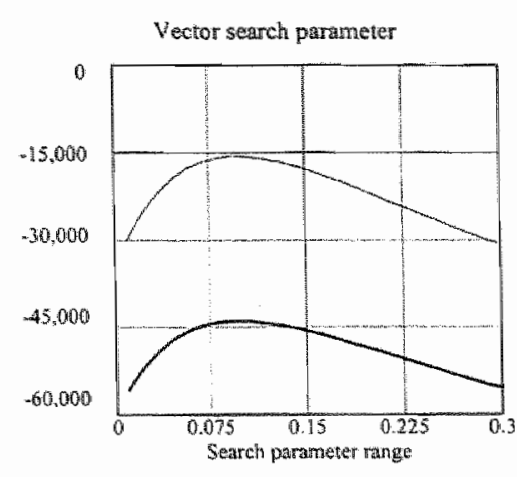

$\operatorname{Tr}[\mathrm{A}, \mathrm{M}]$ - VECTOR T[AI,W] - VECTOR

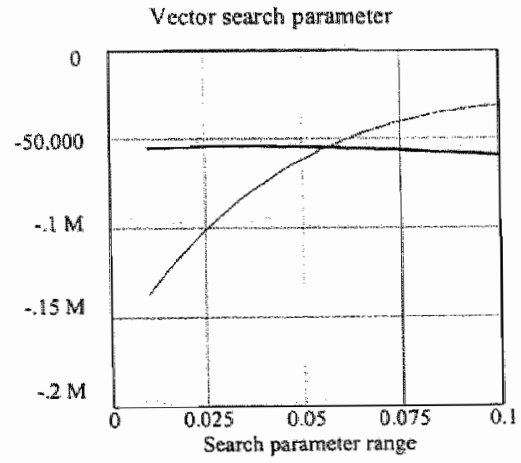

$\operatorname{tr}[\mathrm{A} 3, \mathrm{M}]-$ VECTOR

TIAB,W]- VECTOR:

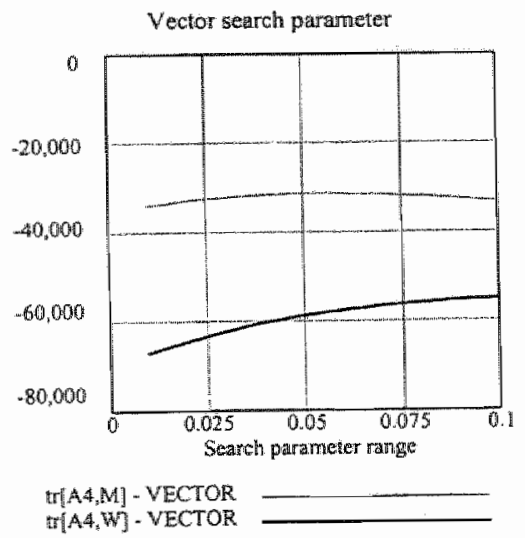

Figure box 2.18 The complete vector search parameters 


\subsubsection{Grid search}

As mentioned before grid - or random search are procedures to investigate the stability of local or global optima. The starting points are computed over successively finer grids over the range of each declared parameter. The first grid computes the endpoints of the ranges, the next grid also computes the midpoints, and each successive grid divides the previous grid by 2 . This continues for up to $2^{10}$ divisions. However, the potential number of simulations is 1024 to the power of the total number of search parameter. This induces wery fast a combinatorial explosion. For example, by selecting 5 search parameters for a grid search $1024^{5}$ simulations have to be performed !!!

The grid search algorithm explores combinations in the following way:

\section{$S T A R T$ \\ Cycle 1 \\ Cycle 2 \\ Cycle 3 \\ ... 0}

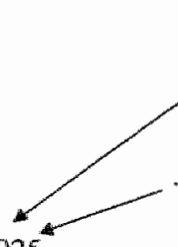
.0925

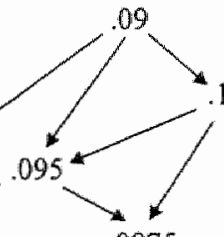

.0975

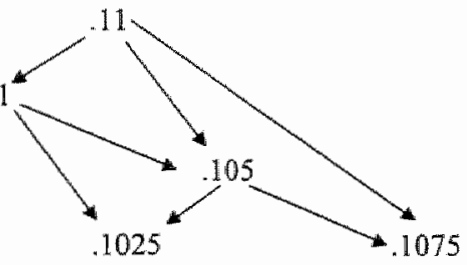

Cycle $\mathrm{n}=11$

$$
2^{n-1}=1024
$$

Starting with the declared boundary values the centroid, (minimum + maximum) $/ 2$, will be computed in the first cycle; in the second cycle the last computed value plus the former values account for two new centroids, etc. The grids becoming more and more finer, searching the surface all directions in order to get an evaluation of the stability of the local maximum, as shown in Figure 2.19

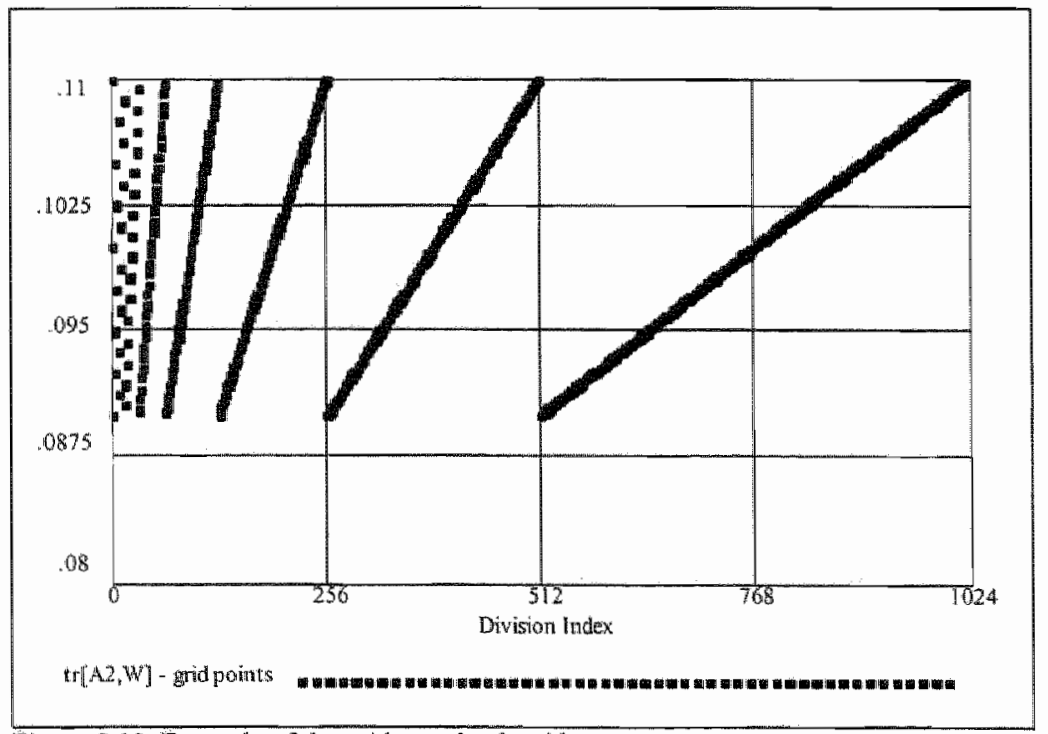

Figure 2.19 Example of the grid search algorithm

Take search parameter, $\operatorname{tr}[A 2, \mathrm{~W}]$, as an example: the grids will be computed over the range 0.08 $0.11(\mathrm{Box} 2.2$ and 2.5). Figure 2.20 shows that for parameter $\operatorname{tr}[A 2, W]$ the local maximum is stable 


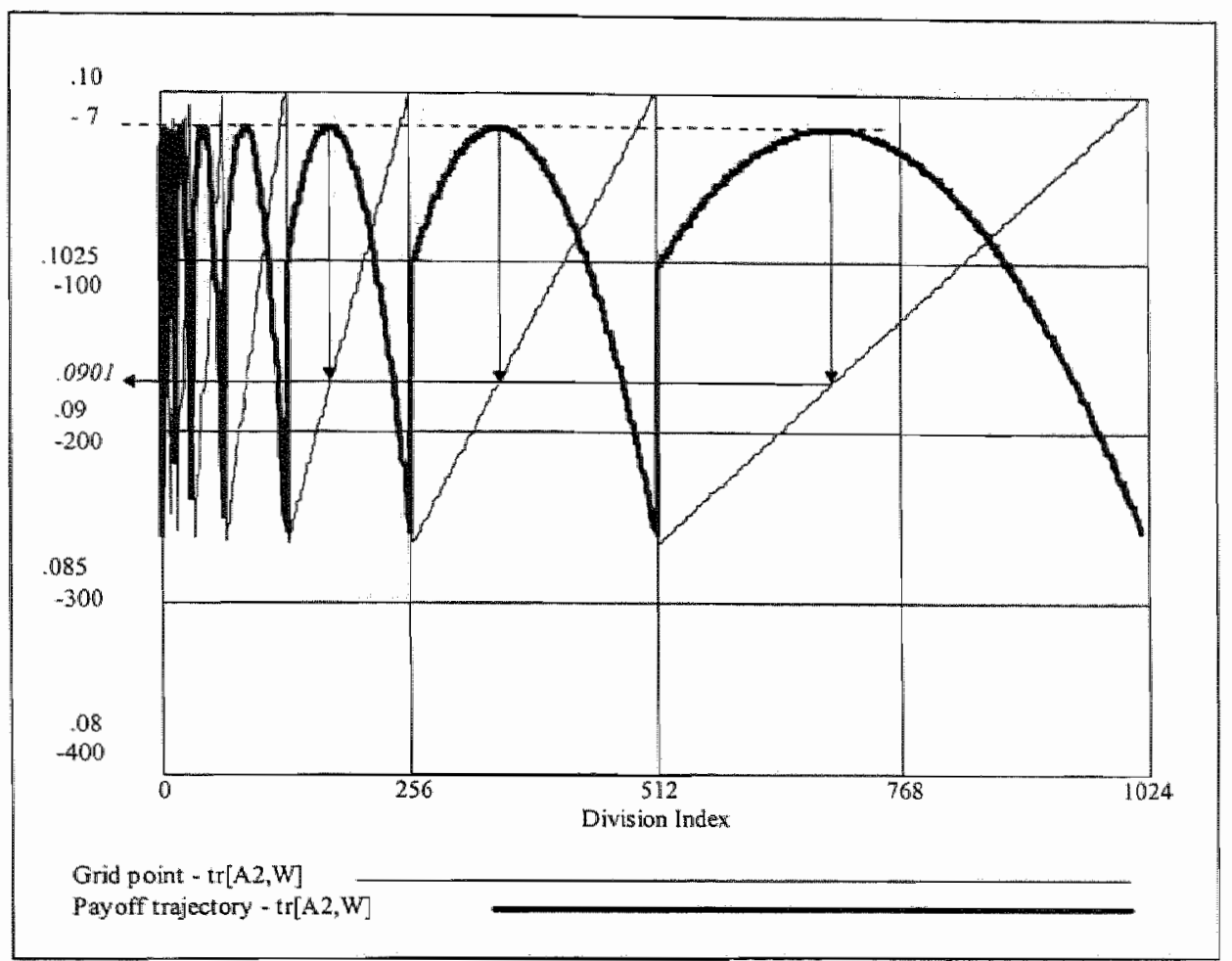

Figure 2.20 The grid search and payoff trajectory for $\operatorname{tr}[A 2, W]$

Note the upper thin line 'Grid points' are measured by the upper scale values of the vertical axis, thus the range $(0.08,0.11)$, albeit the lower bold line 'Payoff trajectory' is the individual support or composition of the total payoff, as explained in the decomposition of the payoff (section 2.8.2) and is measured on the vertical scale by the lower value with range $(-400,0)$. Each time the value of the search parameter come in the neighbourhood of 0.0901 .... (true optimum, see Bor 2.6) the maximum of the payoff parabolla has been reached (see the downward artows). As one can observe no saddle points or other local weak maximum appeared during the optimisation and the payoff never reached a better value then' $-7 \ldots$. ', the optimum value. The same conclusion holds for the other search parameters, a subset will be shown in the figures $2.21 \mathrm{a} . . \mathrm{c}$. 


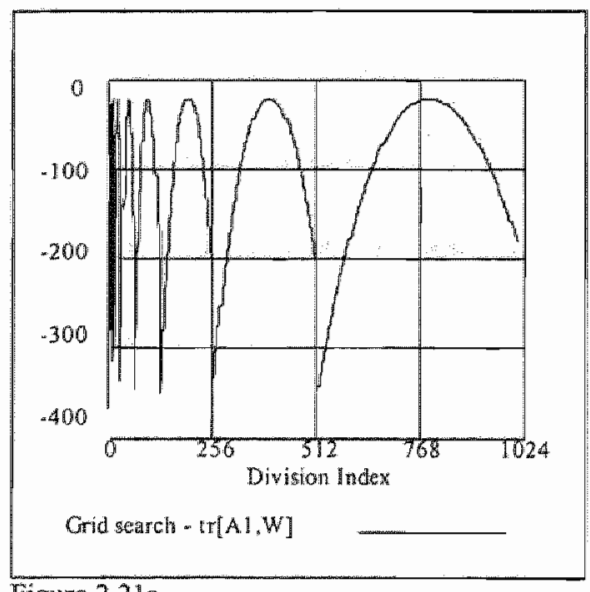

Figure $2.21 \mathrm{a}$

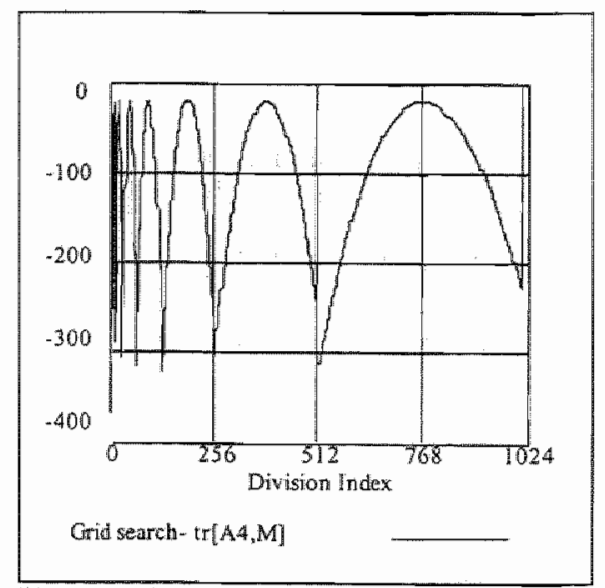

Figure $2.21 \mathrm{~b}$

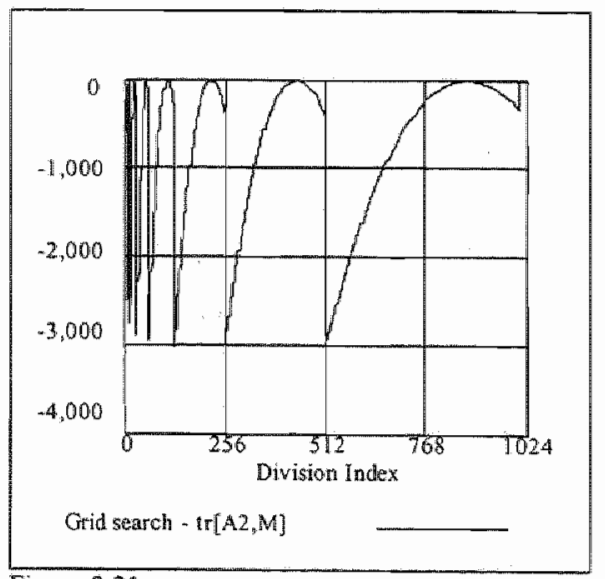

Figure 2.210 


\subsection{Projections: the $\mathbf{2 0 1 5}$ horizon}

After estimating the transition rates of the different age-sex classes the projections can be performed using the optimal transition rates, the exogenous birth rates (Figure 2.23) and migration rates (Figure 2.24). The transition rates of the third optimisation, section 2.7 , are chosen because more weight has been attached to the end years of the 80 s by treating the death rate of the age class $65+$ as exogenous. The simulated $P_{1}^{6}$-population projections are computed by the analogue model (2.1):

$$
\begin{aligned}
& P_{i}\left[A_{0}, S_{0}^{1}\right]=P_{t-1}\left[A_{0}, S_{0}^{1}\right]+\left(B_{t}\left[S_{0}^{1}\right]-I E_{t}\left[A_{0}, S_{0}^{1}\right]-T R_{t}\left[A_{0}, S_{0}^{1}\right]\right) \\
& P_{t}\left[A_{1}^{5}, S_{0}^{1}\right]=P_{t-1}\left[A_{1}^{5}, S_{0}^{1}\right]+\left(T R_{i}\left[M_{1}^{5}, S_{0}^{1}\right]+I E_{i}\left[A_{1}^{5}, S_{i}^{5}\right]-T R_{i}\left[A_{1}^{5}, S_{0}^{1}\right]\right) \\
& P_{t}=\sum_{i=0}^{5} \sum_{j=0}^{1} P_{i}\left(A_{i}, S_{j}\right)
\end{aligned}
$$

where

$$
\begin{array}{ll}
P & : \text { total population } \quad 1 / 1 \text { year } t \\
P\left[S_{0}\right] & : \text { total population men } \\
P\left[S_{1}\right] & : \text { total population women } \\
P\left[A_{0}^{5}, S_{0}^{11}\right] & : \text { sub-population by age-sex subsets } \\
I E\left[A_{0}^{5}, S_{0}^{1}\right] & : \text { net external migration by age-sex subsets } \\
t & : \text { start time } 1990 \\
T & : \text { end time } 2015
\end{array}
$$

Note the net migration (immigration - emigration), $I E[A, S]$, are now explicitly modelled in (2.9), however the age structure of the migration flows are assumed to be the same as in the $80 \mathrm{~s}$.

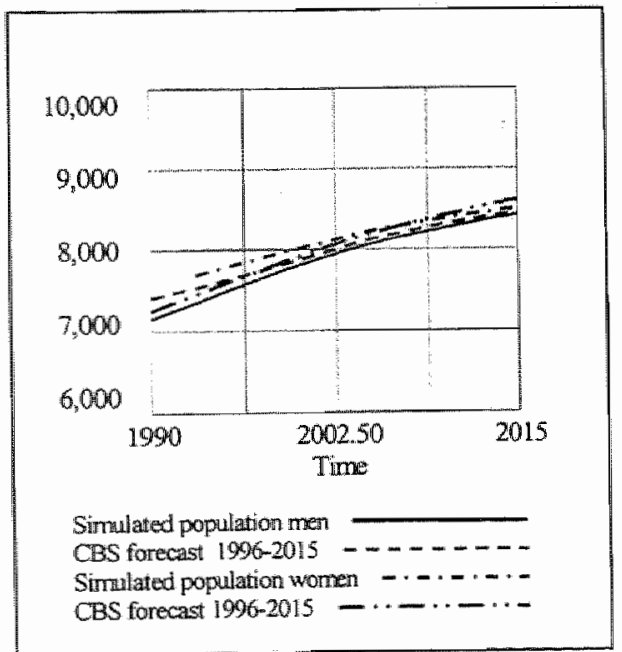

Figure 2.22 a The observed and simulated (fe)male sub-population.

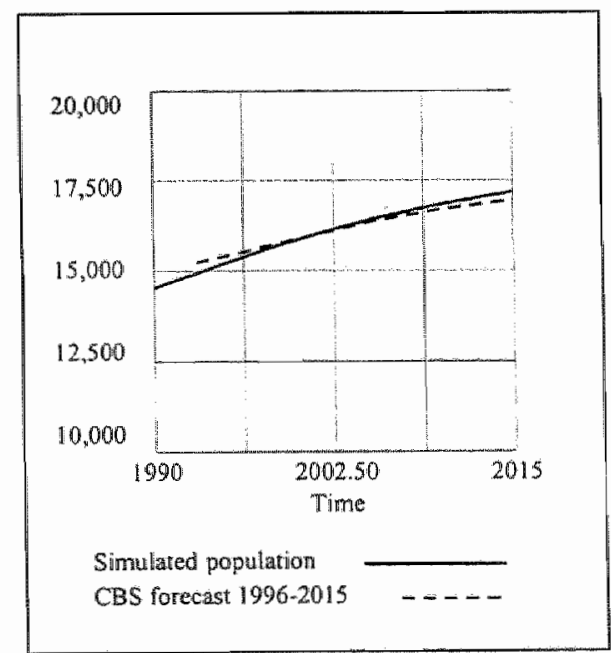

Figure $2.22 \mathrm{~b}$. The observed and simulated total Dutch propulation

The simulated forecast of \pm 17 million people in 2015 conforms to the official mid-variant CBS forecast ( 16.950 million) within $1.5 \%$ (CBS 1996). The birth and death rates (of the age class 65+) are the observed rates up to 1994 , from 1994 to 2015 the CBS forecast (Figure 2.23) have been used as exogenous input in the population model. The migration data and forecast are from CBS (Figure 2.24) and are also used as exogenous inputs to the simulation. 


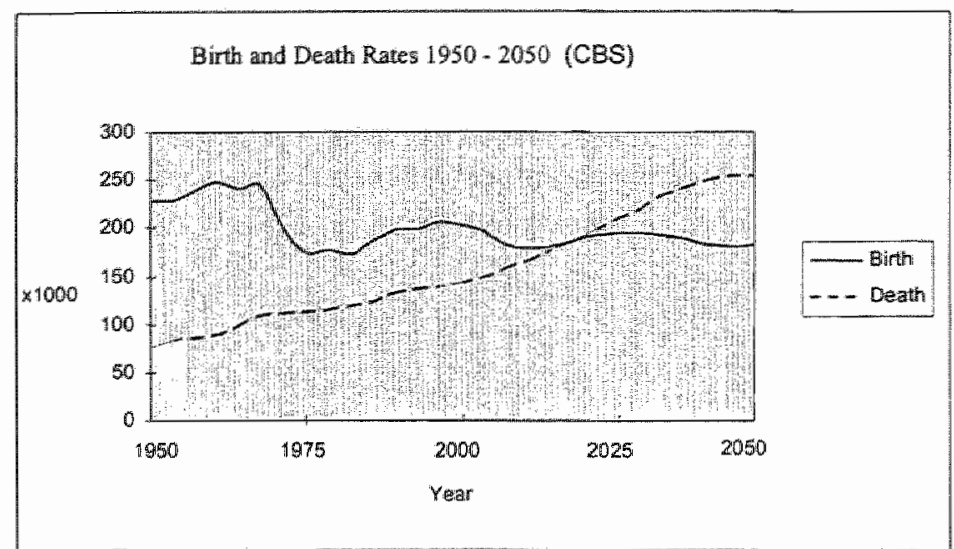

Figure 2.23. Birth and death rates observed 1950-1994, forecast 1994-2050

Also included in the population forecast are the migration flows. The net migration is the difference between immigration and emigration. The official Dutch forecast of the net migration in the new population forecast for the next 5 year amounts to 50.000 per year (CBS 1994 A). In the longer term (2010/15) a decrease of the net migration is assumed, not so much the immigration, but especially an increase of the emigration will account for it. The CBS assumed for the longer term a small decrease in the yearly immigration flow from 135 thousand to 123 thousand in $2010 / 15$. For the emigration an increase is assumed from 73 in 1993 to 88 thousand in $2010 / 15$.

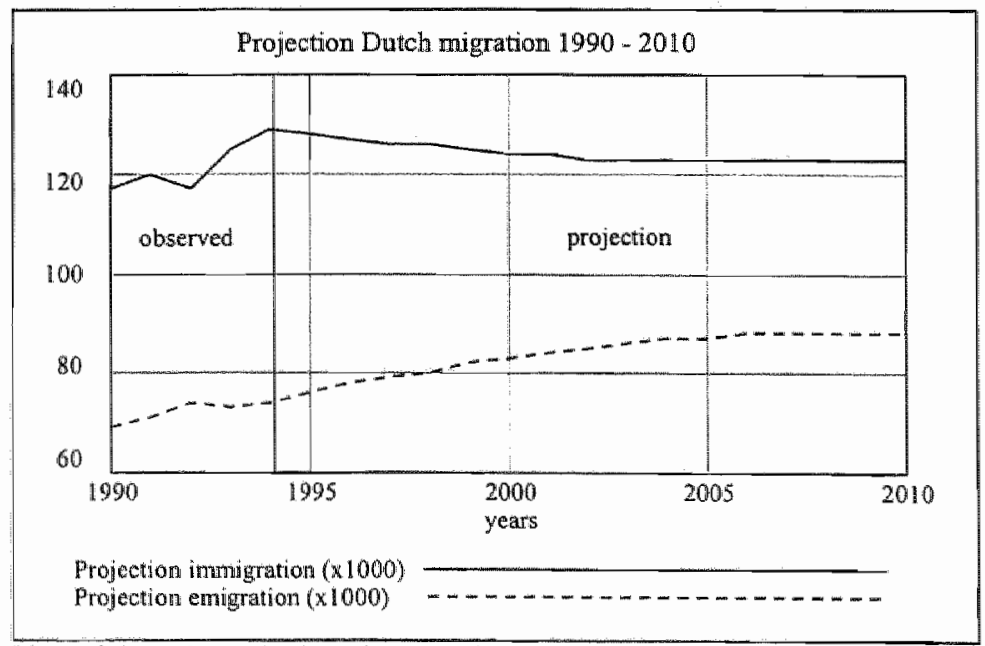

Figure 2.24 The projection of the Dutch migration 
The forecast migration flows are divided into age-sex classes conform the average age-sex ratio "s of the late 80 s.

\begin{tabular}{|ccc|}
\multicolumn{4}{c}{ Age-Sex Ratio's Immigration } \\
\hline \multirow{4}{*}{$\begin{array}{cc}\text { M } \\
(0-3)\end{array}$} & 7.29 & 7.92 \\
& $(0.75)$ & $(0.51)$ \\
$(4-14)$ & 18.08 & 17.67 \\
& $(1.95)$ & $(1.28)$ \\
$(15-24)$ & 23.42 & 27.19 \\
& $(1.71)$ & $(0.77)$ \\
$(25-44)$ & 41.87 & 36.80 \\
& $(2.4)$ & $(1.5)$ \\
$(45-64)$ & 7.35 & 7.60 \\
& $(0.95)$ & $(0.42)$ \\
$65+$ & 1.97 & 2.81 \\
& $(0.71)$ & $(0.3)$ \\
\hline Sum & 100 & 100 \\
\hline & & \\
\hline
\end{tabular}

Age-Sex Ratio"s Emigration
\begin{tabular}{|ccc|} 
& M & $W$ \\
$(0-3)$ & 6.3 & 7.64 \\
& $(1.11)$ & $(0.88)$ \\
$(4-14)$ & 14.99 & 17.18 \\
& $(2.19)$ & $(2.4)$ \\
$(15-24)$ & 17.52 & 21.26 \\
& $(1.23)$ & $(1.33)$ \\
$(25-44)$ & 48.31 & 42.38 \\
& $(2.35)$ & $(2.2)$ \\
$(45-64)$ & 11.65 & 9.29 \\
& $(1.85)$ & $(1.78)$ \\
$65+$ & 1.22 & 2.22 \\
& $(1.3)$ & $(2.16)$ \\
\hline Surn & lno & 100 \\
\hline
\end{tabular}

The figures within the parenthesis are estimates of the symmetric $95 \%$ confidence level.

\section{Conclusion}

The Dutch population remains growing. It is to be expected that in 2030 the maximum of 18 million will be reached. In 1990 the 15 million level was reached, the step from 14 to 15 million took nearly 11 year. The step towards the next million will go faster. In 1995 the 15.5 million will be reached and during the year 2000 the 16 million limit will be surpassed. From the population model the conclusion can be made that in the 90 s the average population growth will be higher than during the 80 s. This results from the combined effect of birth rates and the net migration which are substantial higher than in the 80 s. In the short run the major part of the population growth will be caused by the birth-surplus (the difference between birth and death). The remaining of the century the birth-surplus will be on average 70 thousand per year. That will be $\pm 65 \%$ of the total population growth of 110 thousand. The remaining $35 \%$ of the growth comes from the net migration (the balance of immigration and emigration).

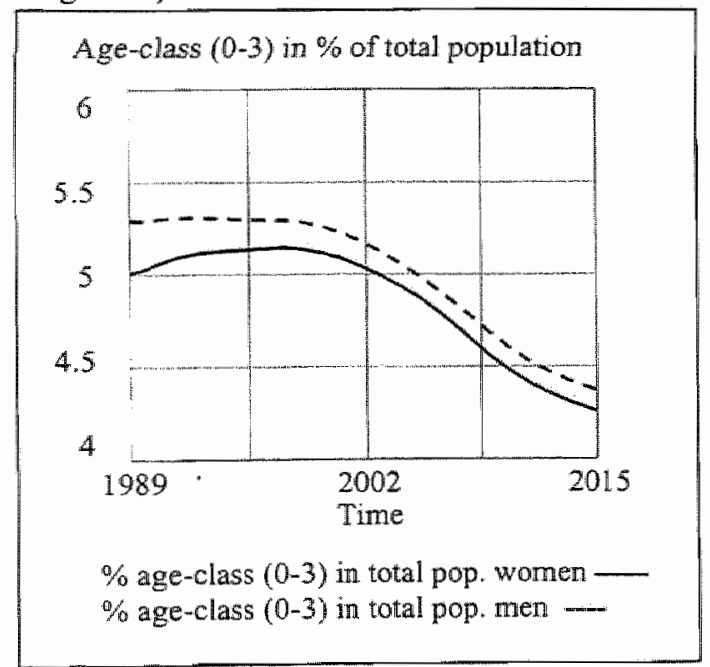

After 2000 it is to be expected that the speed of the population growth will retard. This can be shown by our forecast of the age class (0-3), Figure 2.25.

But the most important cause of the retardation of the population growth is the fact that the number of deaths will increase more and more. The cohorts of the baby boom generations after WWII are entering the age class of $65+$. From Figure 2.23 around the year 2020 it is to be expected that the number of deaths equals the number of births. After that point the number of deaths will increase. The birth-surplus will become negative. The population remains growing during some years due to a positive net migration.

Figure 2.25 Forecast of the age class $(0-3)$ year 
During the 90 s the changing age structure of the population comes from two processes, the 'degreening' (preople in the (0-14) age class) and the "greying'.

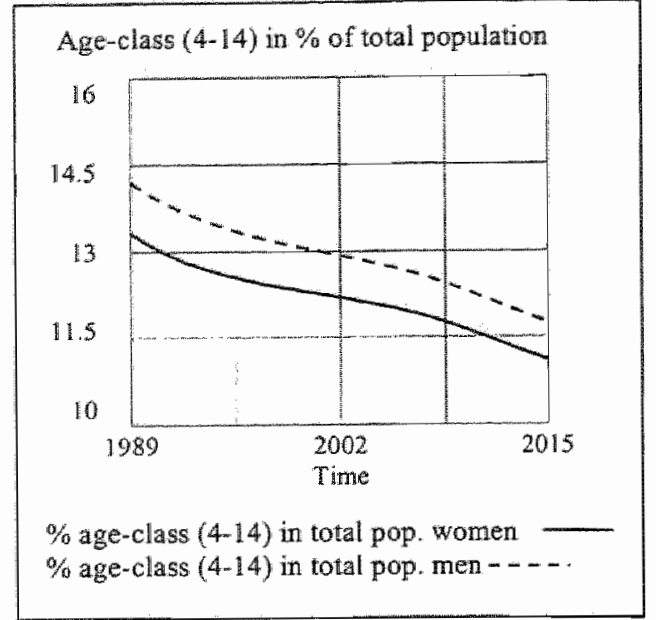

Figure 2.26 Stabilising 'degreening
The 'degreening' stabilises at the end $90 \mathrm{~s}$, as can be seen for the simulation nu in Figure 2.26, and its minimum can, according to the CBS forecast, be situated near 2020 . These effects are caused by the decrease in birth rate in the 70 's and early $80 \mathrm{~s}$, followed by a decade of birth rate increase, to decrease again from 1996 on (Figure 2.26). This last event did in fact occurred recently (CBS 1995), see Figure 2.25.

Greying in the long run can be characterised by the evolution of the age class $65+$. The actual percentage $65+$ of the total population is $\pm 13 \%$ and will gradually rise to $14.5 \%$ in 2015 . Figure box 2.27 shows the decomposition by sex and by

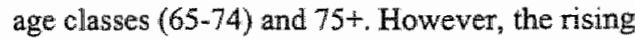
dynamics are seen after 2010 when the after-war birth wave becomes 65 year, see the left parts of the graphs in Figure box 2.27. The increase in the number of elders in the future is mainly caused by the fact of greater birth generations than by the increase of the average life expectation. Besides greying, the 'double greying' (for example, (65-74) called the 'young elder' and $75+$ the 'old elder') will be of importance. This means that within the $65+$ age class the number of high aged people increased relatively most. In $199423 \%$ of the $65+$ is elder than 80 year. This figure will increase very slowly the next 10 year.

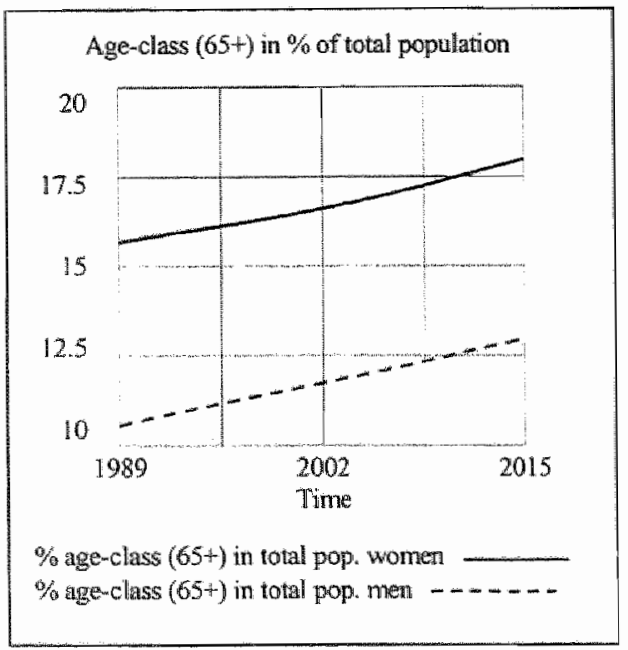

Figure $2.27 a$

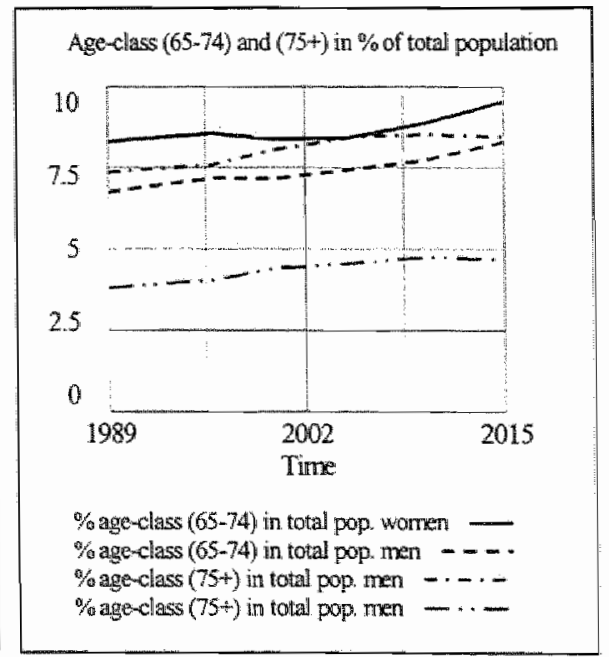

Figure 2.27b

Finally we show in Figure 2.28 the simulated $P_{1}^{6}$-results against the CBS forecasts, note the jump in the CBS forecast after 2010 when the birth wave of $1946 / 47$ enters the age class $65+$, as noted in section 2.2 these waves or shocks have to be treated by additional ad hoc model structures like dummy variables or table functions.

Note the series are valued in absolute numbers ( $\mathrm{x} 1000)$. 


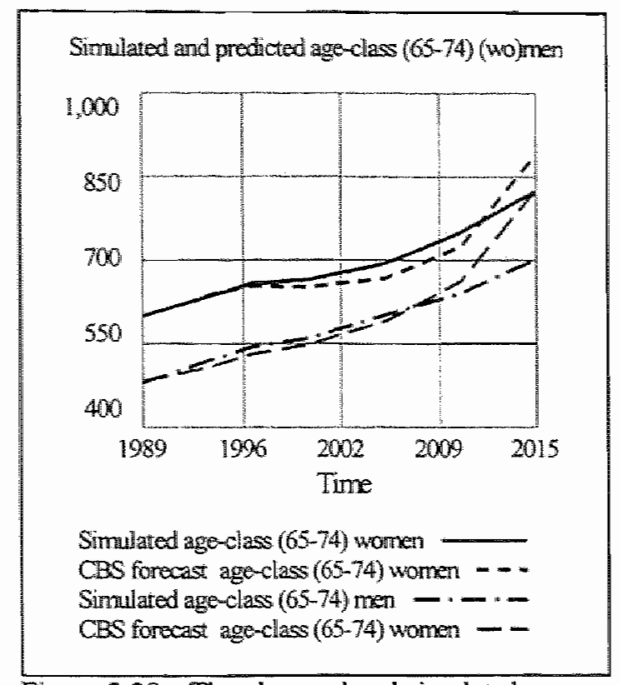

Figure 2.28a The observed and simulated 'young' elder

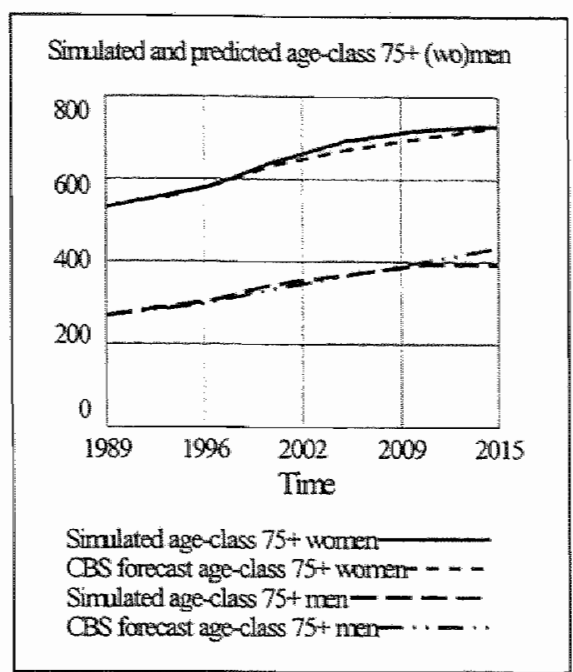

Figure $2.28 \mathrm{~b}$ The observed and simulated 'old' elder

\subsection{Scenario analysis and Monte-Carlo simulation}

In order to complete the analysis of the $P_{1}^{6}$-population model we will run some scenario's by referring to the CBS "low", 'medium" and 'high' variants (CBS 1995). The medium wariant describes the most probable (likely) future. In the low variant fertility, immigration and divorce are lower, whereas mortality, emigration and marriage are higher, than in the medium variant. The opposite applies to the high variant. The low and high variants are extreme variants, compared to the medium variant the low variant leads to a relatively small population and a low number of households (to be explained in chapter 3 ) whereas the high variant results in a relatively large population and a high number of households. Besides, extreme variants will have consequences for the random distribution to be chosen in the Monte-Carlo simulation. Figure 2.29 shows the three CBS variants.

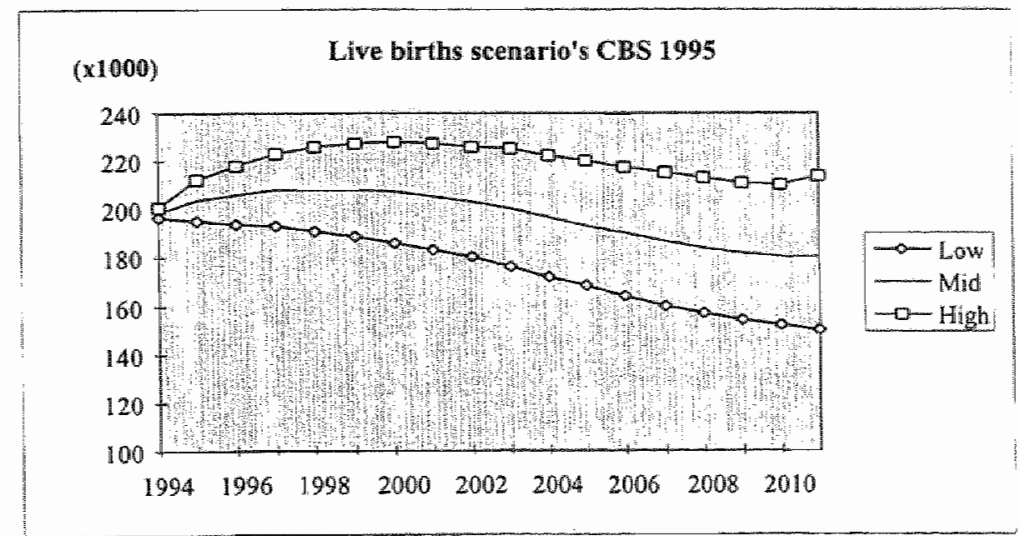

Figure 2.29 The liwe birth wariants of CBS 1995

For the net external migration, we use the CBS three variants forecast (Figure 2.30). Net external migration equals immigration minus emigration and is represented in the system of equations (2.9) by 
the variable $\operatorname{IE}\left[A_{0}^{5}, S_{10}^{1}\right]$. Note however that the forecast of the net external migration is far more uncertain than the crude birth rate forecast.

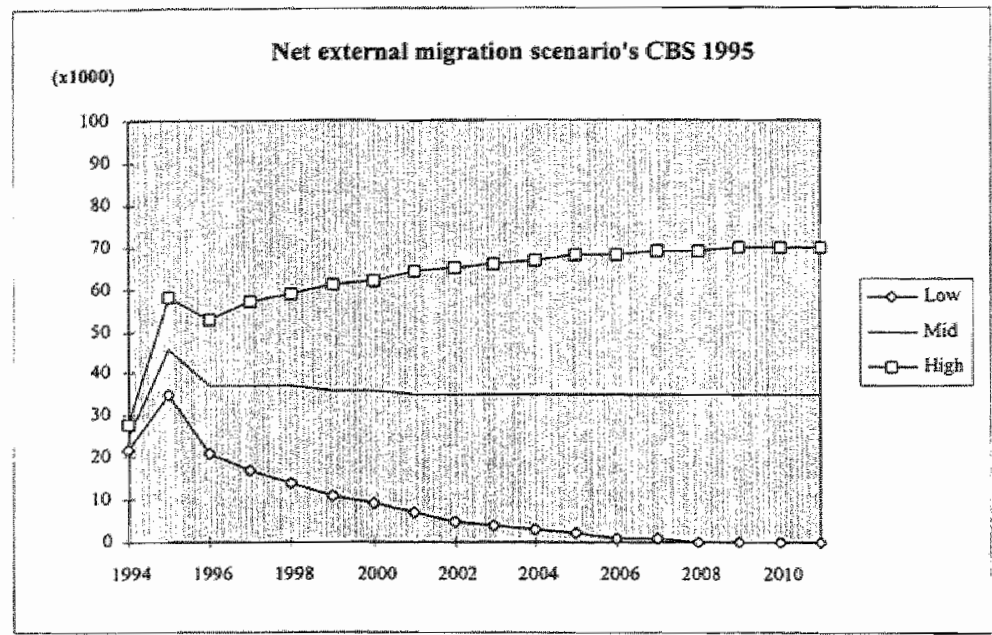

Figure 2.30 The net external migration variants of CBS $199 \overline{5}$

These two sets of variants will be treated as external inputs of the $p_{1}^{6}$-population model with an agestructure equal to those of the 80 s. The resulting simulation forecast for men and women are depicted in Figure box 2.31

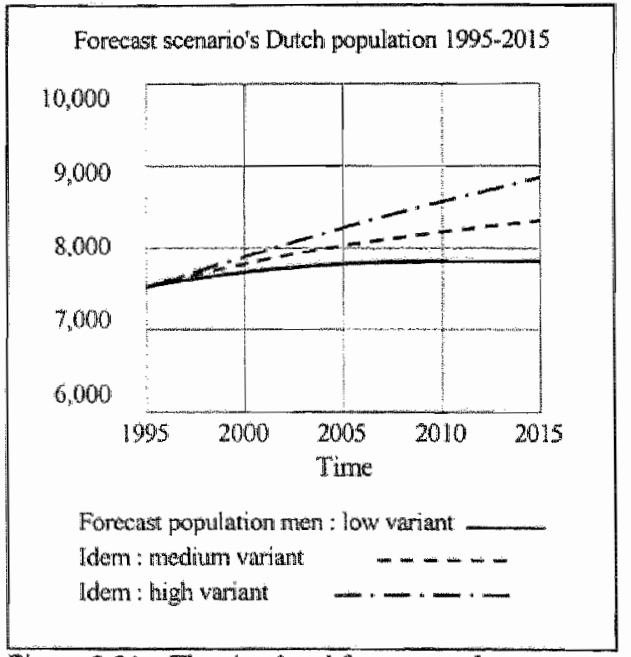

Figure 2.31a The simulated forecast male

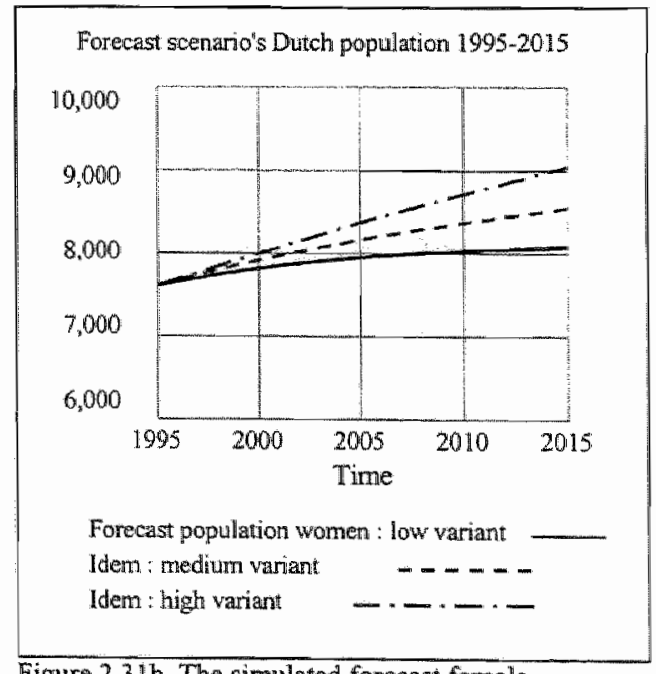

Figure $2.3 \mathrm{lb}$ The simulated forecast female 


\subsubsection{Monte-Carlo simulation.}

As the low and high variants are extreme values we do apply the triangular distribution in stead of the uniform distribution. The triangular distribution is a member of the family of continuous theoretical probability distributions which is easy to interpret and in case of skewed probability distributions it is a good approximation of the gamma or log normal distribution (Watson and Blackstone, 1989). Especially in scenario's or variants with three options as are most optimistic for thigh variant, most likely for medium (mid) variant and most pessimistic for low variant the triangular distribution is preferable. The following equation defines the triangular distribution:

$$
\begin{aligned}
p(x) & =\frac{2(x-\min )}{(\operatorname{mop}-\min )(\max -\min )} \text { for min } \leq x<10 p \\
& =\frac{2(\max -x)}{(\max -\operatorname{top})(\max -\min )} \text { for } \operatorname{top} \leq x \leq \max
\end{aligned}
$$

A process generator for the triangular distribution has been developed by using the inverse method. Because of the discontimuity of the function, however, (at $x=t o p$ with $p(x)=2 /(\max -\mathrm{min})$ ), two separate generators must be developed; one for $x<t o p$ and one for $x \geq$ top. To perform a Monte-Carlo simulation we start from the following assumptions:

Note MP, $M L, M O$ refer to the low, medium and high CBS variants in absolute numbers respectively, $x$ refer to the random variate, $p(x)$ is the probability of $x, 0 \leq p(x) \leq$

top : most likely $(M L)=x^{t} * M L$;

min : most pessimistic $(M P)=\left(x^{t}-x^{-}\right)^{*} M L$, where $x^{-}=(M L-M P) / M L$;

$\max :$ most optimistic $(M O)=\left(x^{+}+x^{t}\right)^{*} M L$, where $x^{+}=(M O-M L) / M L$;

In case of $x^{t}=$ and $x^{-}=x^{+}$then the distribution is symmetric (inverted $h$ )

Given the CBS variants as data we arrive to the following estimates of the crude living births:

top $=x^{t} * M L$ with $x^{t}=$ and $p\left(x^{t}\right) \approx 0.4$

min $=\left(x^{t}-x^{-}\right)^{*}$ ML with $x^{-}=0.1667$ and $p\left(x^{-}\right) \approx 0^{+}$

$\max =\left(x^{*}+x^{8}\right)^{*} M L$ with $x^{+}=0.1667$ and $p\left(x^{+}\right) \approx 0^{+}$(see Figure 2.31)

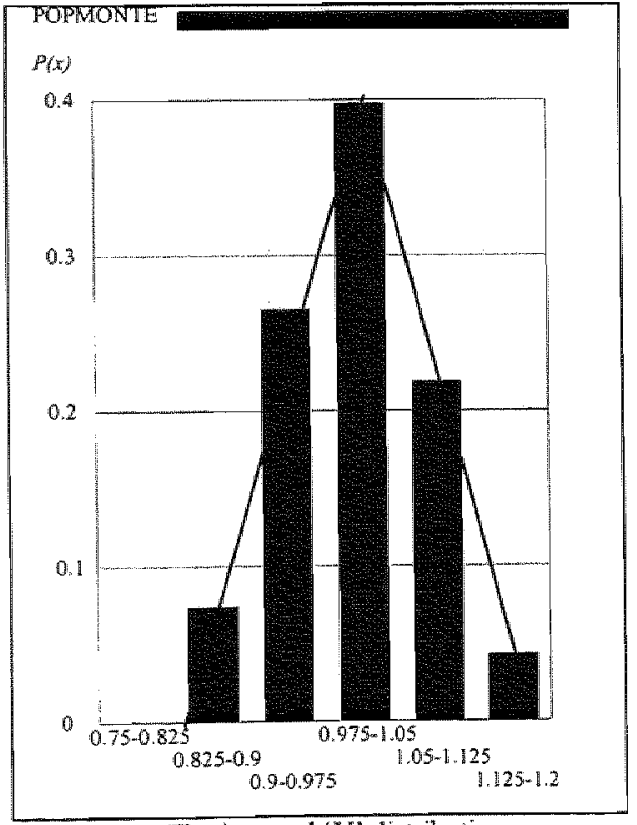

Figure 2.31 The inverted " " distribution $^{\prime}$
Figure 2.31 shows the triangular distribution after 1.000 simulations of the assumed 3 variants with $p\left(x^{t}\right)=0.4$ for $x^{t}=$ down to $p\left(x^{t}\right)-p\left(x^{-}\right)=0.833$ and $p\left(x^{t}\right)+p\left(x^{+}\right)=1.167$.

As we model population by sex the living births have to be divided up in men and women assuming the same relationship between both as in $80 \mathrm{~s}$. That is $\pm 51 \%$ of the liwing birth are boys and $\pm 49 \%$ girls.

The same logic holds true for the net external migration rate except that the uniform distribution has now been chosen due to the huge uncertainty about future immigration and emigration flows, so terms like most likely, most pessimistic and most optimistic are far more meaningless than in the case of living birth rate and only min and max values with equal change in the ( $\max$ - min) range (the uniform distribution) seems to be the best description of this process. The values chosen are: $\min =0.5$ and $\max =1.5$ 


\subsubsection{The results}

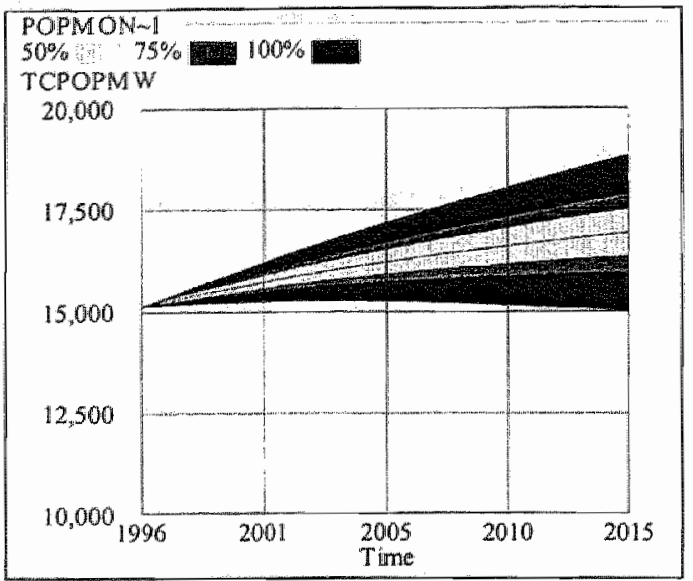

After 1000 simulation the TCPOPMW ${ }^{2.2}$ graph (Figure 2.32) shows the uncertainty in the population as it changes over time. At any time, half of the simulations have generated a value within the $50 \%$ region, three quarters within the $75 \%$ region and so on. If one compares the Monte-Carlo simulation results with the simulation of the 3-CES based variants (Figure 2.33) it seems clear that the 3variant simulation falls with the $75 \%$ range of Monte-Carlo simulation and that the additional $25 \%$ range (the black band) is mainly due to the uncertainty assumptions of the net external migration explained before.

Figure 2.32 The Monte-Carlo simulation

In fact $+20 \%$ of the simulation rums shows a negative net external migration, that means that the emigration is greater in numbers than the immigration with the net effect of zero population growth. In $\pm 50 \%$ of the simulation runs the net external migration is above its mean value of 35.000 a year (CBS medium variant), resulting in more high growth simulation runs.

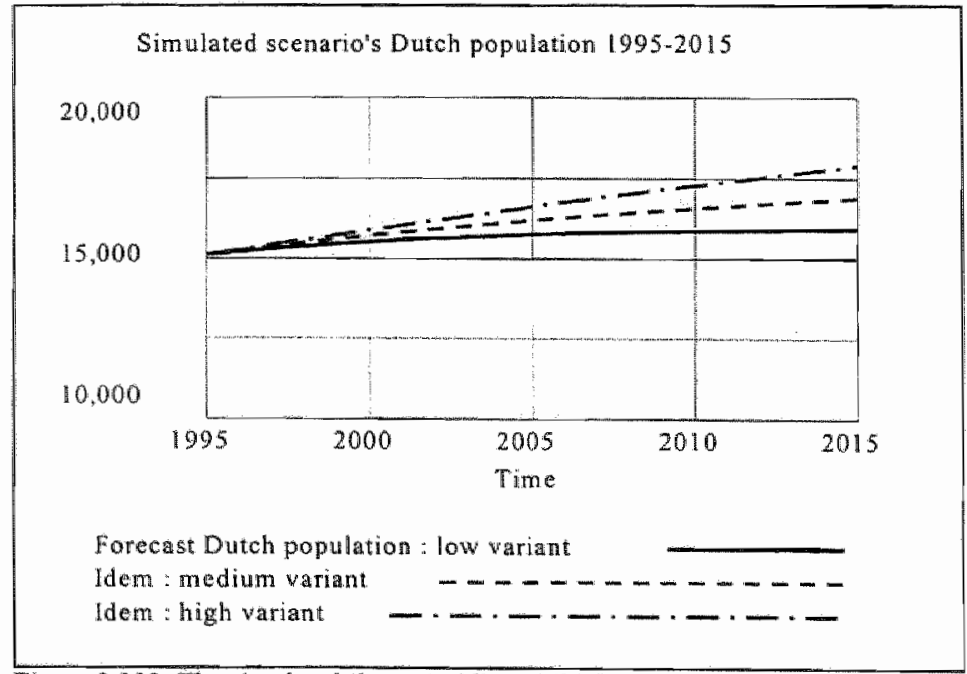

Figure 2.323 The simulated "low", "mid", and "high" variants

\footnotetext{
2.2 TCPOPMW stands for total (male and female) simulated population.
} 


\section{Chapter 3 \\ Households, mobility \\ and \\ consumer lifestyles}

\# Objective

\# Methods

\# Data sources

Results

\#anclusions
A. Development of a household by size model ( $H_{1}^{6}$-model) for the period 1980-2015. The household by size model is driven by the 6 agesex classes as output of the population model ( $P_{1}^{6}$-model) developed in chapter 2 . The output of the $H_{1}^{6}$-model will act as input driver for the mobility, kilometrage and car stock model.

$\mathrm{B}$. Time budget surveys (TBO) are examined in order to investigate the interrelationship between $n$-person households, (auto)mobility and lifestyle developments during the period 1975-1990 and its likely prospective into the future.

Fraction "household by size by age class" matrices model has been computed from the CBS household forecast which will be premultiplied by the row vector of population's age classes, inputted from the population model ( $P_{1}^{6}$-model), to forecast the development of the household size.

Population statistics and forecasts (CBS), Households statistics and forecast (CBS), Labour Force Surveys (CBS), Displacement of the Dutch population statistics, OGV (CBS), Time budget surveys, TBO (CBS)

A. Forecasts of the households by size (one to six persons) for the period 1980-2015. The 1- and 2 person households account for the increase of the future households.

B. Although the increase in car use can be attributed only to a limited extent to a growth of mobile life styles, the effect of these life styles is still stronger in relative terms than the demographic effect, i.e. the increase in the size of the active $(20-50)$ age class. On the whole, however, it was found that the past increase in car use was not for the most part due to composition changes and must therefore be accounted for autonomous growth: the habit of using the car has become more dominant everywhere, including also the inactive, like the young elderly, unemployed, etc.

The increase of households in 2015 is twice (17\%) the increase of the population ( $9 \%$ ) and acts consequently as a unfolding potential of consumer demand for transport service and among other for car use. 


\subsection{Household model}

\subsubsection{Introduction}

The dynamics of household formation, mobility and car ownership typically exhibited the features of a feedback system resulting in sigmoid growth paths of the three variables, without detecting an unidirectional or uni-causality between them. This evolution has a direct impact on space use, congestion, and emissions. The following topics will be elaborated in the remaining sections. In section 3.1 a short historical overview about the changing household formation and its underlying socio/demographic causes will be followed in section 3.2 by the development of the houseliold simulation model $H_{1}^{6}$, that is households by size, here 1 - 10 6-and-more persons. The output of the $P_{1}^{6}$-population model, developed in chapter 2, will be used as primary input to the $H_{1}^{\text {th }}$-household model. After short historical overview the households characterised by size will be the subject under investigation. Next the (inter)linkage of households, displacements and mobility will be investigated first on a theoretical level than its evolution during the last three decades will be dealt with. It is to be expected that mobility saturates end 90 s, the diffusion of the mobility behaviour has reached all strata of socicty, also the car ownership will be diffused at that time over the households, the only growth in car use and kilometrage will come from the growth of the one person - and two person household. In fact the development of one person - and two person households are a proxy of the structural changes in the Dutch lifestyles.

\subsubsection{Households 1960-1990}

The Anmual Household Statistics (JHS) are based on the Labour Force Survey (EBB) (CBS 1994 B). The data are yearly averages and refer only to private households, excluding institutional households. The data we use hereafter are presented on the person level as well as on the household level. On the person level the position held in relation to a reference person is indicated. Single persons live alone in a one person household. In multiple-person households the distinguished positions are cohabiting, living at parental home, lone parent and other. Any person not being a partner or child of the reference person nor a child of the partner, occupies the position 'other'. On the household level the household is charaterised by the positions the household member occupy with respect to each other. The position of the reference person plays an important role; households in which "others" reside are not separately indicated.

In this section the changes in households during the period 1960-1990 will be analysed. The number of households increased from \pm 3.1 million to \pm 6.0 million. This growth was partly caused by the population increase, but this was not the only reason. Also the size of the households became smaller. In 1990 the average Dutch household consists of 2.5 persons. In 1960 this figure was 3.6 person on average. This development is not unique for the period 1960-1990. The reduction of the household size started already in the end of the 19 th century. However the prime factors differs from period to period. Looking at the changes in household size since the end of the 19 th century three periods can be distinguished (SCP 1994):

- the period from the end of the 19 th century till the end of the $60 \mathrm{~s}$;

- the period from the end of the 60 s till 1980 ;

- the period of or since the 80 s.

The most remarkable development for the first period is that marriage and family plays an increasing role in the process of household formation. At the end of the 60 s the situation was that marriage and getting children was common place in society. Other lifestyles than marriage and family were not appreeiated or even not accepted. Stayng or living alone was in that period not an acceptable way of living. Living together unmarried was hardly tolerated by the society. The increased role of marriage and family as model for the individual life went hand in hand with the change in the expectations about marriage and family. Marriage and family were judged of their sense for the personal development. The logical counterpart of this evolution was a more tolerant consent about divorce. This greater tolerance became visible in the increasing number of divorces during the 60 s.

The second period starts at the end of the 60 s and continued till 1980. This period was marked by opposition and critical attitude against, among others, marriage and family and the discussions about alternative ways of life : as are living in community, living apart together and living alone. This 
discussion influenced the process of household formation. In general young people left on younger age the parental home and a marriage was delayed. Instead they liwed alone (temporally) or cohabiting: unmarried. A stagnation in the decreasing age of marriage took place. Postponement and abandonnement of getting children became increasingly popular. The increase of the divorces, starting in the 60 s, continued and even accelerated in the $70 \mathrm{~s}$.

The third period starts about 1980. The discussions of the 60 s and 70 s settled down and the unmarried cohabitation was accepted by society as a new lifestyle. The new ideas about postponement and abandonment of getting children became more and more popular and penetrated through all strata of society. The strong decrease of age at which to leave parental home stopped end 80 s and a small increase was observable. However the trend of increasing interest in leaving home under the youngsters and live alone or cohabiting ummarried continued. Initially this process went together for the continuing decreasing interest for the marriage. At the end of the $80 \mathrm{~s}$ an increase of the number of marriages was discernable, but this increase was more a catch up of the postponement of mamiage. The number of births increased from 1983 till 1995, probably also a catch up of earlier postponement. However the trend in postponement and abandonment of parentalship continued. The strong increase in divorce rates halted in this period.

\subsubsection{Composition of the households}

Changes in the composition of households are dominant in the period 1960-1990. The composition of household can be classified as

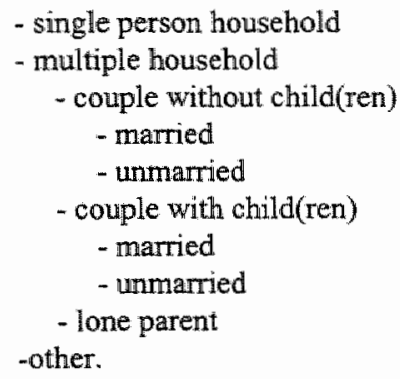

The data have been assembled of households by size and by composition (CBS 1993 A). Only from 1988 on are consistent data available (Table 3.1 and 3.2 )

\begin{tabular}{|c|c|c|c|c|c|c|c|}
\hline \multicolumn{3}{|c|}{ Hous eholds by size and comprasition (CBS) } & \multicolumn{2}{|c|}{ Year average } & \multirow[b]{2}{*}{ P5-pHLH } & \multirow[b]{2}{*}{ Total } & \multirow[b]{2}{*}{$\%$} \\
\hline 1988 & $1-\mathrm{pH}$ HSI & $2-$ PHSH & $3-\mathrm{pHSH}$ & 4-pHSH & & & \\
\hline Sungle-pers on hous ehold & 1677 & & & & 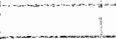 & 1677 & 29 \\
\hline Multiple-pers on household & & & & & $i$ & & \\
\hline Couple without child(ren) & & & & & 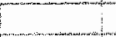 & & \\
\hline manied & & 1255 & 16 & & & 121 & 22 \\
\hline non-mainted & & 321 & & & 8 & 321 & 6 \\
\hline Couple with ofidd(ren) & & & & & & & \\
\hline manied & & & 706 & 989 & 736 & 2131 & 37 \\
\hline non inamied & & & 28 & 14 & 6 & 48 & 1 \\
\hline Loneparent & & 172 & 100 & 29 & 12 & 313 & 5 \\
\hline Other & & 56 & 12 & 4 & 3 & 75 & 1 \\
\hline Total & 1677 & 1804 & 862 & 1036 & 457 & 5836 & 100 \\
\hline
\end{tabular}

Table 3.1 Households by size by composition 1988 


\begin{tabular}{|c|c|c|c|c|c|c|}
\hline \multicolumn{7}{|c|}{ (Hous ehold by size and composition (CBS) } \\
\hline 1993 & I-pHSH & 2 pHSHI & $3-\mathrm{pHSW}$ & $4-\mathrm{pHSH}>5-\mathrm{NHSH}$ & Tolat & का \\
\hline Single-piers on hous ehold & 7968 & & & & 1968 & 31 \\
\hline Multple-persion household & & & & & 0 & \\
\hline Couple whthout child(ren) & & & & & 0 & \\
\hline maried & & 144 & T3 & & 1455 & 23 \\
\hline non-mamed & & 433 & & & 433 & 7 \\
\hline Conple whin chid(ren) & & & & & 0 & \\
\hline named & & & 724 & 412 & 2038 & 32 \\
\hline non-minartied & & & 45 & 27 & $8 !$ & 1 \\
\hline Cone parent & & -184 & 95 & 29 & 318 & 5 \\
\hline Other & & $6 I_{1}^{1}$ & 8 & 1 & -75 & 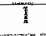 \\
\hline Total & 1968 & 2120 & 885 & 432 & 6368 & 100 \\
\hline
\end{tabular}

Table 3.2 Householde by size by composition 1993

The number of people living alone or better one person households ( $1 p H S H$ ) increased during the period $1960-1990$ from 373.000 to 1.813 million, to increase further to 1.970 million in 1993 . Their share in the total number of households has increased significantly from $10 \%$ in 1960 to $31 \%$ in 1993 . In $199325 \%$ of the one person household consists of people younger than 30 year. $26 \%$ is widowed and older than 65 year, most of them women. Because youngsters left parental home to become an one person household and by the increase of the divorces the mean age decreased during the period 1960-1990. In 196025\% was younger than 45 year, in 1990 nearly $50 \%$ was younger than 45 year.

The number of households consisting of married - and unmarried couples without children was in 1988 1.6 million (27\%) and increased to 1.85 million ( $30 \%)$ in 1993 . Most of these households consists of married people. The non-married couples are ir the minority. Within the class of couples without children living at home (two person household) the elder people are relatively strong represented. Unmarried couples without children are much younger aged. The share of couples without children living at home in the total number of households has been increased from $18 \%$ in 1960 to $30 \%$ in 1993 . Within the class of households with children the following distinction can be made:

$$
\begin{aligned}
& \text { - couples with child(ren) } \\
& \text { - married } \\
& \text { - non-married }
\end{aligned}
$$$$
\text { - lone parent }
$$

These three household types together counts in 1960 for more than $50 \%$ and decreased to $43 \%$ in 1988 to $38 \%$ in 1993. This mamied couples take the largest part for their account. The lone parent group is and remains modest, despite the doubling share since 1960 .

\subsubsection{Households by size}

The household by size (one to six-and-more person) will be the unit of analysis for our research, because household by size is an important element in the explanation of mobility and car use. Furthemore household formation and population growth are decoupled since the 60 s and the statistical recordings accordingly. For example, car ownership by households by size, displacement by household by size, etc. Figure 3.1 shows the dynamics of household by size for the period 1960-1990. Figure 3.1 confirms the continuing growth of the past decades of the number of two classes of household:

- one person household, and

- two person household 


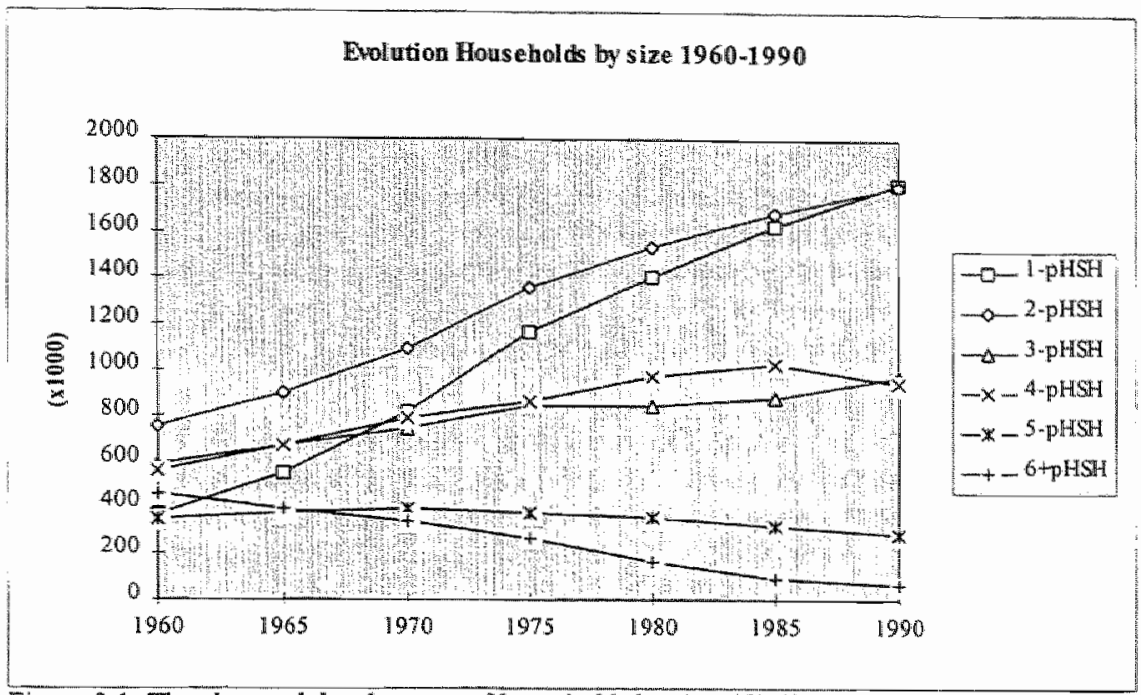

Figure 3.1 The observed development of households by size: (CBS)

The sharp growth or stated otherwise the positive feedback phase of both series lies in the $60 \mathrm{~s}$ and $70 \mathrm{~s}$, with the one person household exhibiting a prolonged (stretched) asymptotic growth path. The dominant loop shift, that is the shift from positive loop to negative loop or mathematically speaking the point of inflection in the sigmoid curve, is situated in the early 70 s for the two person household and in the mid of the 70 s for the one person households. From our simulation experiments the number of the two person households increase or growth rate saturates or comes to a maximum in the early 2000 , the number of the one person households saturates approximately two decades later. The number of the three and four person households stabilise in the 80 s after a modest growth in the $60 \mathrm{~s}$ and $70 \mathrm{~s}$. The number of the five and six person households stabilise also during end 80 s and early $90 \mathrm{~s}$, but after a decrease during the 60 s. and $70 \mathrm{~s}$.

\subsubsection{Demography and behaviour}

Changes in the number of households have two possible causes (CBS $1996 \mathrm{~A}$ ):

- a changing extent and age profile of the population, and

- a changing behaviour (lifestyle).

Changes in the age protile are of importance, because there exists great differences in the household situation of the different age classes. For example, three quarter of the 30 year old people are living together (couple) whether married or not, against one tenth of the 20 year old people. A changing extent of the different age classes will cause changes in the number of households. Changes in the extent and age profile of the population are the demographic changes, but behavioural changes are also of importance, think of the increase of the percentage singles. According to the CBS-household forecast the number of households amounts to \pm 7.5 million in the year 2015 , of which $80 \%$ can be ascribed to demographic developments. This percentage has been deduced by computing the increase of the number of households under the assumption of a constant percentage distribution between singles and couples for each age class. Note that singles refer to one person households and couples to married and non-married pairs living together.

If per age class the percentage singles remains constant, the total number one person household will increase with 200-210 thousand, whereas the total increase amounts to $560-580$ thousand. This means that less than half of the expected total increase of singles can be attributed to demographic developments only. Behavioural changes are therefore of more importance for the increase of singles 
than the changes in the age composition. The effect of changes in the age composition for the number of singles is expected to be limited, because the age classes with relative high percentage singles will decrease in extent the next decades.

For courples the image is quite different. On account of changes in the age profile an increase of the number of couples of $430-450$ thousand should be expected. In the CBS forecasts a decrease of the percentage people living together has been assumed. The increase of the number couples will therefore be estimated on $310-320$ thousand. Contrary to the singlles demographic developments and behavioural charges of couplles have an adverse effect. Because the demographic effect is stronger than the behavioural effect the total number of couples will on balance increase by $310-320$ thousand only.

\subsubsection{Effects of demographic changes}

The most important "source" of new households are children leaving parental home, further couples who diworce, and immigration forms a third source. The most important cause of the disappearance of households are the death of single-living widows and widowers. Furthermore the number of households is diminished because singles are going to live together, by emigration and people entering an elder or nursery home (institutional households ${ }^{3.3}$ ). Only by the fact that youngsters forming a new household are greater in extent than the number of deceased widows and widowers the number of households increases each year.

Changes in the age profile of the population are especially caused by development of the rumber of living births (Figure 3.2). Shortly after World War II there was a high birth peak, of which the effects are still noticeable in the age proffle. During the first half of the 60 s the number of births increased again with 1964 as top year with the effect that the 30-35 year old people are now the largest age class.

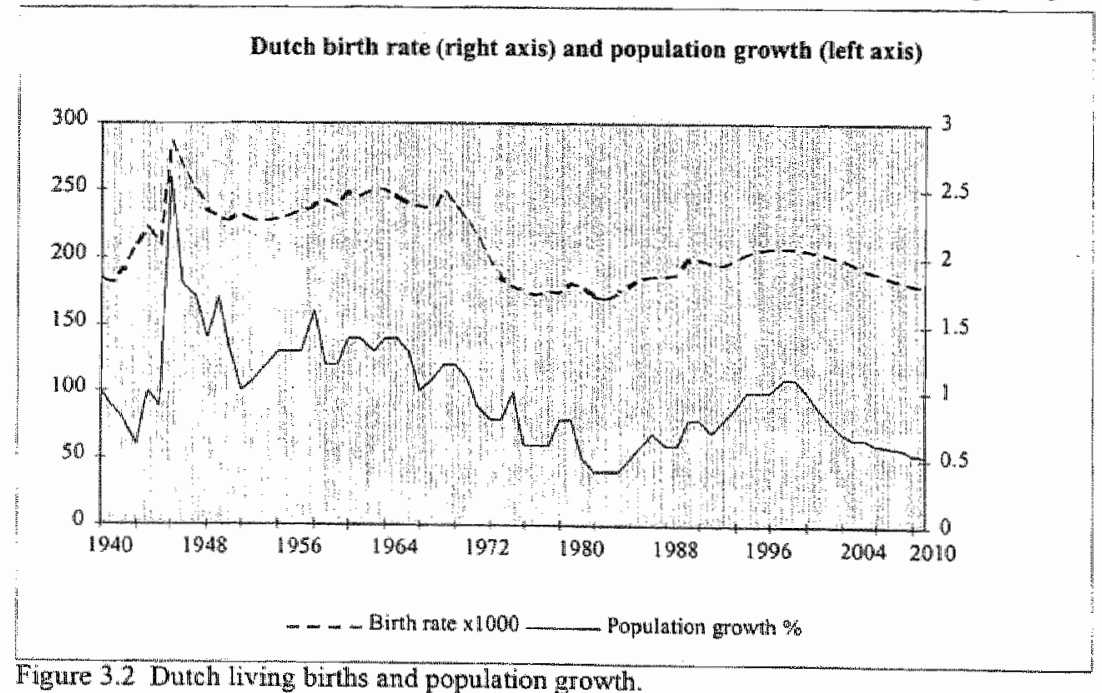

Figure 3.2 Dutch living births and population growth.

After 1970 the birth rate decreased very strong. The generations born after 1975 are therefore one quarter smaller than the generations born before 1970 . In the midst of the 80 s the birth rate increased again for wo reasons.

1. there was an increase of women around 30 year age giving birth to their first child (after postponing the first birth),

2. the extent of the new generation of new parents was large caused by the increased birth rate during the first haif of the $60 \mathrm{~s}$.

\footnotetext{
As private households only enter our analysis, the institutional households are expelled due to the low mobility
profile.
} 
Because the birth rates are not decreasing the last ten years, 'degreening" of the population has halled. Because of the fluctuations mentioned above the number of 20 and 30 year old people will be smaller in 2015 than now. The younger and older classes will on the contrary have a greater extent.

Table 3.3 shows the age profile and household positions during the period 1995-2015. Of the 40 and 50 year old people $\pm 12 \%$ lives as single. By the expected increase of this group of 4 million now to 5 million in 2015 the number of singles, will increase with \pm 125 thousand (see Table 3.3 ). If the share of singles also increases, the increase of the number of singles will of course be augmented.

\begin{tabular}{|c|c|c|c|c|c|}
\hline \multirow[t]{2}{*}{ Age } & \multicolumn{2}{|c|}{ Population size } & \multicolumn{3}{|c|}{ Change 1995-2015 } \\
\hline & 1995 & 2015 & total & single (1) & couple (1) \\
\hline $20-39$ & 4990 & 4125 & .865 & -148 & .558 \\
\hline $40-59$ & 3955 & 4986 & 103 & 125 & 850 \\
\hline $60+$ & 2730 & 3920 & 1190 & 315 & 753 \\
\hline
\end{tabular}

In the older age classes the percentage singles (26.5\%) will be higher than those of the (40-50) age class $(12.1 \%)$. Because women marry men who are on average two year older and because women live on average six year longer than men, these groups counts a large number of widows (singles). In 19952.7 million people of 60 year and over, against nearly 3.9 million in 2015 . The increase of the number elder will especially be caused by the great birth generations (1946 and after). The higher mean life expectancy has less influence. By this increase the number of singles of $60+$ will grow with \pm 315 thousand. Against the increase of the number singles of 40 there will be a smaller decrease caused by the decrease of the number of 20 and 30 year old people. Of the people of 20 year about $20 \%$ lives alone and of the 30 year old people about $15 \%$. The decrease of the number of 20 year and 30 year old people with \pm 865 thousand will cause a decrease of the number singles of \pm 140 thousand.

Changes in the age profile plays also an important role in the development of the number of people that lives together (couples). Because the percentage of couples will be greater than the percentage singles, it refers to greater numbers households than for singles. Changes in the age profile causes the number of couples of $40+$ to increase to 1.6 million, while the number of couples for 20 and 30 year old people will decrease with \pm 550 thousand. On balance the number of couples will increase with \pm 1.045 million as a result of demographic changes only. Note that these computations assume no behavioural change. Such changes can amplify or dampen the increase of the number of households.

\subsubsection{Changes of behaviour}

The number of households will be influenced by changing behaviour (lifestyle) (SCP 1994). Young people do create more and earlier in time an one person household (single) than those of earlier generations, therefore influencing more strongly the number of households. The development of the number of households will therefore be determined by choices made by successive generations during their different life cycles. Especially the choice to live alone or to marry while leaving parental home is of importance for the development of the number and size of households. Getting children has no immediate influence on the number of households, but on the household size.

Also the changing divorce behaviour', the partners remaining lone persons or when elder inhabitants remain independent persons, all influence the number of households. Divergence in the relative development of inhabitants and of households, as shown in Figure 1-1, is caused by the factors mentioned above. To sum up: 
Societal changes during the sixties influenced the changing household positions. The strong increase of the number of households was accompanied by:

- An increase of the dirorce rate causing many households to separate into two households (at least temporary, because some partners joining after some time an existing household);

- An increased popularity of living apart for youngsters;

- Emancipation developments causing more young women to live apart;

- Ageing population liwing (often necessarily) longer independent caused by capacity of intramural aid staying behind the potential demand.

\subsubsection{The near future}

The following social/cultural aspects dominate the behavioural changes in the near future:

- Leaving home

Living apart for youngsters was very popular during the 60 s and $70 \mathrm{~s}$, but reversed somewhat during the 80 s probably due to lengthening of the education and the increasing starting cost of one person households in a stagnant economic environment. During the early 90 s the age of leaving parental home did not change and stabilised at $50 \%$ for 21 year old women and 23 year old men. In the CBS forecasts it is assumed that the median age at which youngsters leave parental home do not change. Nonetheless by the growth of the number of youngsters the number of living-at-home increase from \pm 4.5 million in 1995 to \pm 4.7 million in 2015 .

- Living apart

More youngsters, while leaving parental home, become single, for the time being, before becoming a couple. In the CBS forecasts it is assumed that the percentage singles of youngsters will increase. So it is assumed that the percentage male singles less than thirty year will increase from $20 \%$ in 1995 to $25 \%$ in $2015^{5.2}$. For women of the same age category an increase from $13 \%$ to $16 \%$ will be expected. The difference between men and women lies in the fact that young women become earlier a couple than men and their number is smaller than that of men in the same age category. This last fact induced that the percentage men living-together is smaller than that of women living-together. In 1995 the inhabitants aged 20-30 years accounts for \pm 800 thousand singles. It is projected that this figure does not change in 2015 , nonetheless the increase of the percentage singles. This is caused by a decrease of the inhabitants aged $20-30$ years.

\section{- Living-together married and non-married}

During the 80 s the number of non-married couples has increased very strongly. More than half of the yourngsters lives, for some time, together. At least three quarter will chose for the martial status. According to the CBS forecasts the percentage unmarried couples of men aged 30 years will increase from $22 \%$ to $28 \%$ in 2015 . For wonen the increase will be $17 \%$ to $25 \%$. In $1995 \pm 900$ thousand people aged 20-30 years lives as unmarried couples. In 2015 it is to be expected to increase slight to \pm 950 thousand The slight increase is caused by the fact that the number of people aged 20 - 30 years decreases.
Table 3.4 summarise the parameter values.

\begin{tabular}{|c|c|c|c|c|c|c|}
\hline \multirow[t]{2}{*}{ Year } & \multicolumn{2}{|l|}{ Single } & \multicolumn{2}{|c|}{ Couples unmartied } & \multicolumn{2}{|c|}{ Couples married } \\
\hline & Men & Women & Men & Women & Men & Women \\
\hline 1995 & 20 & 13 & 22 & 17 & 49 & 63 \\
\hline 2015 & 25 & 16 & 28 & 25 & 39 & 53 \\
\hline
\end{tabular}

\footnotetext{
The reason for this assumption is unclear, probably it is an extrapolation of past and recent trend
} 


\section{- Chilldren}

Many men and women follow longer education, go later at work, live later together, marry later and get children later. The average number of children per woman has decreased strong during the last decades. Of the women born before WWII $50 \%$ bore 3 or more children, against $25 \%$ with younger generations. Beside more women are childless ( $12 \%$ against $20 \%$ ). The increasing childlessness is the most important cause of the decrease of the average number of children. Despite the expected increase of childlessness. the number of families with children increases somewhat. In $1995 \pm 2.1$ million families with two parents and child(ren), in $2015 \pm 2.25$ million are to be expected. The increase is due to the increase of the number of people of 40 years (from \pm 2.3 million in 1995 to \pm 2.75 million in 2015 ).

- Divorce

After a strongly increase during the 70 s the number of diworces has stabilised since the mid 80 s. Slight more than $25 \%$ of the marriages ends in divorce. In the forecasts it is assumed that the divorce rate will hardly change in the future. Partly this is assumption is based on the increase of the number of nonmarried couples. Less stable relations end sooner, before becoming a matrimony. Couples with children divorce less quickly than childless couples. Nonetheless in 1995 there were \pm 300 thousand one-parent families, $12 \%$ of the total families. It is to be expected that remains unchanged in the near future.

\section{- Life expectancy}

The life expectancy increases still further. The lengthening of the life expectancy is not caused in the first place by the elder people getting older, but especially by the fact that more people becoming elder. The most important reason is the decreasing death chance at middle age. It is to be expected that in the near future the life expectancy will further increase, but at a decreasing rate compared with the recent past. Of the 80 year old women more than $50 \%$ is single, against $20 \%$ of the 80 year old men. According to the CBS forecasts the one person households of age $65+$ will increase from \pm 700.000 in 1995 to $\$ 1.5$ million in 2015.

\section{Other scemarios}

The figures shown above are from the mid-variant of the CBS forecasts. In this variant it is assumed that the growth of the percentage singles will increase less the next 15 year than the past 15 year. (CBS 1996 A). Reason for this is the assumption of the mid-variant that singles for the most of the youngsters will be temporary. A further growth of singles will therefore be limited. For elder people living alone has often a permanent character.

However other scenarios are imaginable. For example the changes of the past 15 years will continue for the next 15 year or even at an increasing rate. In the age group 20-50 the percentage singles has been doubled the past 15 year. If an extreme individualisation scenario will be assumed that the next 15 year the percentage will double again then the number of one-person households will increase from \pm 2.6 million to \pm 3.3 million in 2010 . The number of couples will than decrease slightly from 4.3 to 4.1 million, due to the change of the age profile of the Dutch population.

On the other side one can imagine a family scenario, by which it is assumed that the percentage singles decreases and that an increasing percentage of the inhabitants will live together (married or unmarried). This should mean a trend reversal with respect to the developments of the last decade. If the percentage singles between the age of 20 and 50 decreases from $14 \%$ in 1995 to $9 \%$ in 2010 , then the total number of singles in 2010 will be equal to the number in 1995 . This means that if the percentage sirgles decreases by more than $5 \%$ then the number of singles also decreases. In this scenario the number of couples increases from 4.1 million in 1995 to 4.6 million in 2010 . In sum a strong trend reversal is needed in order to stabilise the number of singles the next 15 year.

The conclusion drawn from the alternative scenarios is that even under extreme future assumptions about living alone or together a fundamental different view of the future development of singles and couples does not arise. This is so because the strong influence of change in the future age profile on the household development are frozen (long gestation period) or fixed in the actual age profile. Uncertainty about the future number of births has for the period under investigation no influence on the number of households. 


\subsection{The household model ( $H_{1}^{6}$-model)}

\subsubsection{Introduction}

In 1992 the Netherlands Central Bureau of Statistics (CBS 1992) published its first household forecast, which provided information about the number of single and more person households. In the new household forecast, households are distinguished by size. Also information about parents by age of children living at home has become available. These extensions of the household forecasts are based on a model in which mothers can be paired with their children (headship rate method). First the model follows the process of childbearing per birth generation of women. Than it relates the age of the mothers to the age of their children by using information about the birth intervals between the children. It is than possible to follow the process of children leaving the parental home. As a result, the number of women by number of children living at home can be computed. The results of the model are now used in the forecast of households by size and type (Table 3.1 and 3.2). To make the forecast the numbers of women with children at home must be divided into cohabiting women and lone parents. The rates could be computed by relating these numbers to the number of persons per household position. These rates can be applied to people in these household position according to the forecasts.

Note the 1980-93 figures are partly observed partly interpolated data.

\begin{tabular}{|c|c|c|c|c|c|c|}
\hline Yeis & T-pHSH & ZFPHSH & उ-pसSTI & 4-PFISH & उ-pसSH & 6म्ब1HSH \\
\hline 7980 & TाMT & 17002 & $86_{2}$ & 876 & 795 & 279 \\
\hline $\mathrm{T} 9 \mathrm{gT}$ & 1252 & 1444 & 874 & 883 & 386 & 260 \\
\hline T:B2 & TआI & $748 T$ & 875 & 890 & प्या? & 24 \\
\hline 1983 & 7376 & 7529 & 897 & 897 & 368 & 222 \\
\hline Trod & 7438 & 1572 & 908 & 904 & 359 & 205 \\
\hline 1985 & 7500 & $\mathrm{Tr} 13$ & 920 & 912 & 350 & 184 \\
\hline 7986 & 7562 & 1657 & $9 \pi$ & 919 & 340 & 765 \\
\hline $\mathrm{f} 9 \mathrm{7}$ & 1624 & $\mathrm{~T} 700$ & 94 & 925 & $3 \pi$ & 146 \\
\hline $\mathrm{TS}$ & 7686 & 1742 & 951 & 933 & 322 & 127 \\
\hline 198 & 1748 & 1785 & 966 & 940 & 313 & 708 \\
\hline 799 & TII0 & T1828 & 977 & 347 & 3 Wh & 89 \\
\hline काग & $T 850$ & 1865 & 595 & 967 & आ० & पा \\
\hline 7992 & 1877 & 1904 & Tाग & 987 & 315 & 92 \\
\hline 7595 & 1934 & Tि56 & 1018 & 97 & 3054 & 98 \\
\hline 1994 & 1981 & 2104 & To23 & 955 & 3091 & प्वा \\
\hline $\mathrm{T} \times 95$ & 2027 & $20 \times 99$ & 1024 & 943 & 312 & 701 \\
\hline 1906 & 2072 & 2088 & Tr22 & 334 & 318 & 762 \\
\hline 19997 & $2 \pi$ & 212 & Tors & 928 & 390 & 703 \\
\hline 1998 & 8158 & 2147 & 7015 & 925 & 325 & 104 \\
\hline$T 929$ & 2360 & 2167 & 7610 & 925 & $33 !$ & 7104 \\
\hline 20001 & 2241 & 2783 & Tिय & 927 & 336 & 7104 \\
\hline 2001 & 2282 & $2 T 95$ & 997 & $53 !$ & 7ब1 & 7,04 \\
\hline 2002 & 2323 & 2204 & 90 & 957 & 347 & 703 \\
\hline 3003 & 2164 & $28 \pi$ & $9 \times 3$ & अव & 391 & 702 \\
\hline 2004 & 2405 & 2817 & 97 & T52 & 356 & TWT \\
\hline 2005 & $2+46$ & 2324 & 972 & 758 & 350 & 99 \\
\hline 2006 & 2488 & 2226 & 968 & 964 & 362 & 97 \\
\hline 2007 & $252 \%$ & 2235 & 965 & 960 & WI & $\$ 5$ \\
\hline 2008 & 257 & $224: 1$ & 963 & 913 & 364 & 93 \\
\hline 20018 & 2613 & 2247 & 962 & 976 & 96 & 9 \\
\hline 2010 & 2657 & 2235 & 962 & 977 & 367 & 89 \\
\hline
\end{tabular}

Table 3.3 The $n$-person household forecast (CBS several years)

A second household forecast model, PRIMOS, developed by INRO-TNO is a macro simulation model for forecasts of the household evolution in the Netherlands (CBS 1992 A). In PRTMOS the main categories of households distinguished are : single person, married/cohabiting couples and lone parent. The multi-person households (the latter two categories) are distinguished by household size. For these multi-person households relations between the members of the household are modelled by age-relation matrices. The initial values of these relation matrices are deduced from the WBO (Housing demand survey). Such matrices are defined for cohabiting partners and for mothers and their children living at home. To simulate the household evolution, transition rates between household positions are used. For the multimperson households the interaction between transitions of the members is explicitly modelled to assure consistency. When a child leaves the parental home a new household results but at the same time 
the household of his parent(s) changes in size and a cohabiting male cannot divoree without his partner doing the same. The structure makes it possible at any time to translate from the household position to the population by age and by sex. Therefore on this level a perfect consistency can be guaranteed with the CBS population forecasts, if for the population changes (birth, death, immigration and emigration) the parameters of the CBS forecast will be used.

The forecast results in an increasing number of households in the Netherlands, from 5.95 million in 1990 to 7.37 million in 2015 , hardly smaller than the CBS forecast mentioned above. The percentage of growth $(24 \%)$ of the number of households is almost twice that of the population.

\subsection{2.. The household modiel ( $H_{1}^{6}$-model)}

The $H_{1}^{6}$-model uses the projected age classes of the $P_{1}^{6}$-population model as input driver and the computed transition ratio's to compute the household formation by size. The observed and forecast data of households are used as bench marks in order to map the (causal) structure into a parsimonious set of relationships. The information available are the allocation of 16 age classes (from 15-19 to $90+$ ) to the 1 to $>6$ person households. After converting the 16 age classes into 6 age classes, the number of inhabitants in each separate age class $l\left(A_{l}\right)$ of the $k$-person household is computed $\left(p_{k} H_{i}\right)$. In our case $l$ $=1, \ldots, m$ and $k=1, \ldots, n$. In the example below for the 1-person household the official CBS population and household forecast delivers the data for column 1 and 2, Note A0, age class 0 (0-3) year, and Al,

\begin{tabular}{|c|c|c|c|c|c|}
\hline \multicolumn{3}{|c|}{ CES forecast $(\times 1000)$} & \multicolumn{3}{|c|}{ Population model $(\times 1000)$} \\
\hline 1 & 2 & 3 & 4 & 5 & 6 \\
\hline Age-class & $1 \mathrm{pHSH}$ & $\cos 2 / \operatorname{col} 1$ & Age-class & $\cos 3$ & col/4*cols \\
\hline A2 & $\mathrm{xH} 1$ & Y1 & A2 & $\mathrm{rg}_{9}$ & $x+y$ \\
\hline A3 & $x+12$ & $\gamma_{2}$ & A3 & $\mathrm{Y}_{2}$ & $x \mathrm{H}_{2}$ \\
\hline$\cdots$ & $\cdots$ & $\cdots$ & $\ldots$ & $\cdots$ & $\cdots$ \\
\hline A6 & $\mathrm{xH6}$ & Y6 & $A 6$ & $y_{6}$ & $\begin{array}{c}x H 6 \\
10 H S H\end{array}$ \\
\hline
\end{tabular}

age class (4-14) year does not enter the household computation) after dividing column 2 by column 1 one get the fractions, column 3 or the $p_{k} h_{l}$, which are the columns of matrix $H_{\text {mxn }}$. The $P_{1}^{6}$-model computes the row vector $A_{0 \times m}$ (column 4), which upon multiplication $H_{m \times n}$, gives the row vector of the number of the $n$-person households (the sum total of column 6). These operations are performed for all forecast years $1995,2000,2005,2010,2015$.

Therefore Table 3.3 can be conceived as the result of matrix product with the row wector population age classes $A_{0 x m}$ and the transition matrix $H_{m \times n}$ of transition ratio's of population of age class $m$ in a $n$ person household:

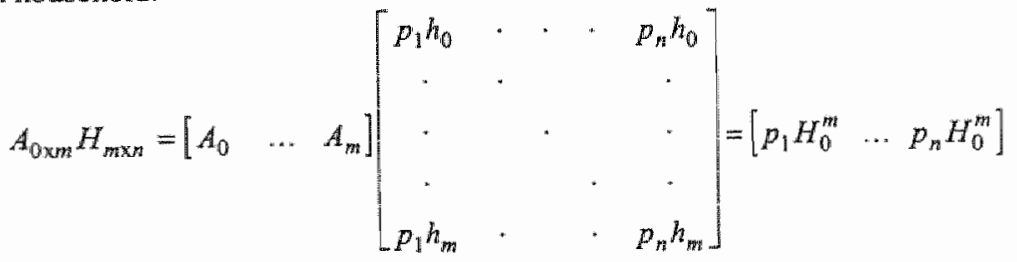

where

$$
\begin{aligned}
p_{k} h_{l}=\frac{p_{k} H_{l}}{A_{l}} & \\
p_{k} h_{l} & : \text { fraction of } k \text {-person household of age class } l \\
p_{k} H_{l} & : \text { number of } k \text {-people in household of age class } l \\
A_{l} & : \text { number of people in age class } l \\
n & : \text { number of household member }(\mathrm{s}) \\
m & : \text { number of age classes }
\end{aligned}
$$




$$
\begin{aligned}
p_{1} H_{0}^{m} & =\sum_{j=0}^{m} A_{j} p_{1} h_{j} \text { one-person household summed over } m \text { - age classes } \\
\ldots \ldots \ldots & \ldots \ldots \\
p_{n} H_{0}^{m} & =\sum_{j=0}^{m} A_{j} p_{n} h_{j} \quad n \text {-person household summed over } m \text { - age classes }
\end{aligned}
$$

sum to the total households

$$
H S H=\sum_{i=1}^{n} p_{i} H_{0}^{m}
$$

The $P_{1}^{6}$ population model consists of six $(m=6)$ age classes $\left\{A_{0}, \ldots, A_{5}\right\}$ with

$$
\begin{aligned}
& A_{0}:(0-3) \text { year } \\
& A_{1}:(4-14) \\
& A_{2}:(15-24) \\
& A_{3}:(25-44) \\
& A_{4}:(45-64) \\
& A_{5}:\left(65^{4}\right)
\end{aligned}
$$

\begin{tabular}{|c|c|c|c|c|c|c|}
\hline Trifus & & 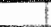 & & & & \\
\hline year & Was? & Tyen & 1495: & 204 & $200 s$ & 2010 \\
\hline \multicolumn{7}{|l|}{$(75 \times 30)$} \\
\hline ThSF & 32 & 271 & 275 & T185। & 787 & רoss: \\
\hline Fiti & 20,0 & 220 & 2036 & - $187 \pi$ & Toris & 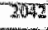 \\
\hline$(15-24)$ & 103 & 104 & 10,4 & 9 & 9.7 & 37 \\
\hline \multicolumn{7}{|l|}{ 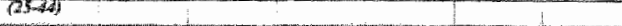 } \\
\hline "ISST" & 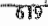 & 659 & 690 & $78 \%$ & EIS & wat \\
\hline POD & 7009 & -1922 & 4585 & - & 7869 & 456 \\
\hline ( $(1544)$ & 125 & Than: & $T .8$ & 5 & 764 & 17.6 \\
\hline \multicolumn{7}{|l|}{$7(160)$} \\
\hline $\mathrm{THSH}$ & 359 & mS & 40 & $5 x$ & 58 & 894 \\
\hline POPP & $32 \pi$ & $-3 x^{2}$ & $\mathrm{x} 50 \mathrm{y}$ & $-3 B 7$ & 488 & -4690 \\
\hline 485$)$ & T20 & 12.1 & 725 & MI.! & 16.5 & $77 \%$ \\
\hline \multicolumn{7}{|l|}{68} \\
\hline HSTI & 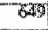 & 661 & 681 & 723 & 758 & BTR \\
\hline $\mathrm{OP}$ & 1953 & "19, & E034 & 278 & -298 & 2487 \\
\hline \multirow[t]{2}{*}{65} & -53 & 35 & 335 & $3 \pi, 4$ & -3.0 & $\$ 26$ \\
\hline & & & & & & \\
\hline year & 7952 & 194 & 1995: & 20100 & 2005 & 2010 \\
\hline$(15-2)$ & 103 & 104 & 704 & $97 \%$ & 9.7 & 9.7 \\
\hline 7549 & 212 & 13,0 & 138 & 75 & 76. & 77.6 \\
\hline$[45-601]$ & 725 & 72. & 126 & - & TS, & 779 \\
\hline 6504 & 337 & 3.3 & 35,5 & 334 & 33.04 & 32.6 \\
\hline
\end{tabular}

and $\operatorname{six}(n=6)$ person households

$$
\left\{p_{1} H, \ldots, p_{6} H\right\}
$$

\begin{tabular}{|c|c|c|c|c|c|c|}
\hline 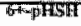 & & 7 & & & & \\
\hline year & TS\$: & ToNs: & $11955^{3}$ & 20000 & 20051 & 76100 \\
\hline$(15.261$ & & 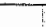 & & & & \\
\hline HIST & 时 & a & $\sigma$ & a & $\gamma$ & 物 \\
\hline POP & 2766 & 2705 & 20868 & "ד87 & $18 \%$ & 202 \\
\hline$(15-2 \pi)$ & $500 \%$ & 001 & 0.01 & 0,0 & 0.0 & 07 \\
\hline$(2580)$ & & & & & & \\
\hline BSIIT & 7 & 85 & $\$ 7$ & 88 & $8 T$ & 72 \\
\hline por & 400 & 402 & d98 & उत्का & 7469 & \$ उहा \\
\hline$(25-4)$ & T. & $T .7$ & $T, 7$ & $\pi$ & 1.7 & 5.6 \\
\hline$(35.60)$ & & & & & & \\
\hline FIST & $T$ & 13 & 7 id & 76 & 78 & $T 6$ \\
\hline POP & 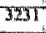 & 3398 & 3503 & 3873 & ज2Rs & 4635 \\
\hline $7(3564)$ & 0,43 & 0.38 & 8.40 & 0.41 & 0.42 & $6 \times$ \\
\hline 63 & & & & & & \\
\hline HSH & D. & (1) & 0) & 0 & (i) & 6 \\
\hline POP & 7958 & TwS: & 2014 & गाब & 2296 & 2487 \\
\hline $63 \%$ & 0,0 & Quini & 0.01 & 0.0 & कर & W, \\
\hline & & & & & & \\
\hline year & 7352 & $T 969$ & 7 ThS & $20 \%$ & 2 Fos: & 2010 \\
\hline$(\mathrm{TS}-26)$ & 0.8 & $D .0$ & 60 & 00 & $6 \pi$ & 50 \\
\hline$(25+4)$ & $\sqrt{1.6}$ & 77 & $T .7$ & $\pi$ & 5.5 & 7.6 \\
\hline$(45-6)$ & 0.4 & 0.4 & 0.4 & $m$ & व.4 & 0.3 \\
\hline 654 & 0,5 & $6 \pi$ & 8,6 & 00 & 0.6 & 00 \\
\hline
\end{tabular}

Table 2.1 can now be written in its final form as a set of $n x .1$ row vector, each row vector for each year. The 1992-and 2015 transition matrix $H$ has the following values structure

Note the age classes $A_{0}$ and $A_{1}$ are excluded in the household formation process, they are allocated to the $2^{*}$ pHSH conform the CBS statistics. That is why the first two rows are zeros.

$$
\left[\begin{array}{cccccc}
0 & 0 & 0 & 0 & 0 & 0 \\
0 & 0 & 0 & 0 & 0 & 0 \\
.103 & .085 & .03 & .005 & .001 & .0 \\
.126 & .116 & .096 & .151 & .051 & .016 \\
.12 & .217 & .123 & .071 & .019 & .004 \\
.33 & .225 & .036 & .002 & .0 & .0
\end{array}\right]^{1992}, \cdots=\left[\begin{array}{cccccc}
0 & 0 & 0 & 0 & 0 & 0 \\
0 & 0 & 0 & 0 & 0 & 0 \\
.097 & .077 & .024 & .005 & .0005 & .0 \\
.176 & .096 & .08 & .139 & .057 & .016 \\
.179 & .218 & .093 & .071 & .022 & .0034 \\
.326 & .257 & .016 & .0012 & .0 & .0
\end{array}\right]^{2010}
$$

Table 3.3 The forecast of household and transition factors computed
Table 3.4 The forecast of household forecast and transition factors computed 
The data base are the outcomes of the CBS household forecast which delivers, among other, the age sinucture of the person-households for each future year. Table 3.3 illustrates the p-HSH by age classes for 1992 and table 3.4 for the year 2010 . Note that 1992 and 1993 are observed or measured data.

Using the age classes from the $P_{1}^{6}$-population model ( $A_{0 x m}$ ) as input driver and equation $(3.2 .2)$ can be computed for each year with outcomes being the number of households by size.

where

$$
\left.p_{k} H S H\right|_{k=1} ^{n}=\left.h s_{k}^{*} p_{k} H_{0}^{m:}\right|_{k=1} ^{n}
$$

$$
\begin{aligned}
k & =1, \ldots, n \text { index number household members } \\
p_{k} H S H & =k \text {-person household } \\
h s_{k} & =\text { search parameter } \\
p_{k} H_{0}^{m i} & =k \text {-person household, computed from equation } 3.2 .2
\end{aligned}
$$

The computation of 3.2 .2 will be estimated (by estimating $\hbar s_{k}$ ) with the CBS $n$-person households forecast, that means, to bring them as near as possible to the CBS forecast figures. That is why the $h s_{i}$ values are \pm 1.0 (Box 3.1 ), it is a kind of fine tuning.

The initial payoff was -350.096 and after 589 simulation the optimiser could not improve the payoff of 49 anymore.

\begin{tabular}{|l} 
Box 3.1 Log Lkelihood 95\% Confidence interval \\
SENSTIILTT $=20$ \\
$1.00226 \leq \mathrm{hs} 1=1.00821 \leq 1.01353$ \\
$1.07138 \leq \mathrm{hs} 2=1.07811 \leq 1.08431$ \\
$0.917463 \leq \mathrm{hs} 3=0.93285 \leq 0.9474$ \\
$0.982614 \leq \mathrm{hs} 4=0.99699 \leq 1.0105$ \\
$0.955927 \leq \mathrm{hs} 5=0.99380 \leq 1.03099$ \\
$0.873889 \leq \mathrm{hs} 6=1.00992 \leq 1.14491$ \\
$0.996104 \leq \mathrm{hs}=1.00069 \leq 1.00467$ \\
The base payoff is -49.0111
\end{tabular}

\begin{tabular}{|lcc|}
\hline Box 3.2 & \\
The following are the components of payoff \\
COMPONENT NAME VALUE PERCENT \\
HSH1P & -16.7 & $34.2347 \%$ \\
HSH4P & -12.72 & $25.9447 \%$ \\
THSH & -8.551 & $17.4461 \%$ \\
HSH3P & -4.945 & $10.0899 \%$ \\
HSHSP & -3.387 & $6.9107 \%$ \\
HSH2P & -2.083 & $4.2499 \%$ \\
HSH6P & -0.5509 & $1.11239 \%$ \\
\end{tabular}

Note the component names in Box 3.2 are the data, in fact the CBS household forecast. Box 3.2 states that the one and four person households ( 1 -and 4 pHSH) take $60 \%$ of the payoff for their account, this means that the gap between simulated and observed values ate the largest (also dependent of the weights) for those variables. 


\subsubsection{The results}

After simulation the household model has been compared with the CBS forecast. The total number of households are compared in Figure 3.3 starting in 1995. The difference between both series are small and acceptable.

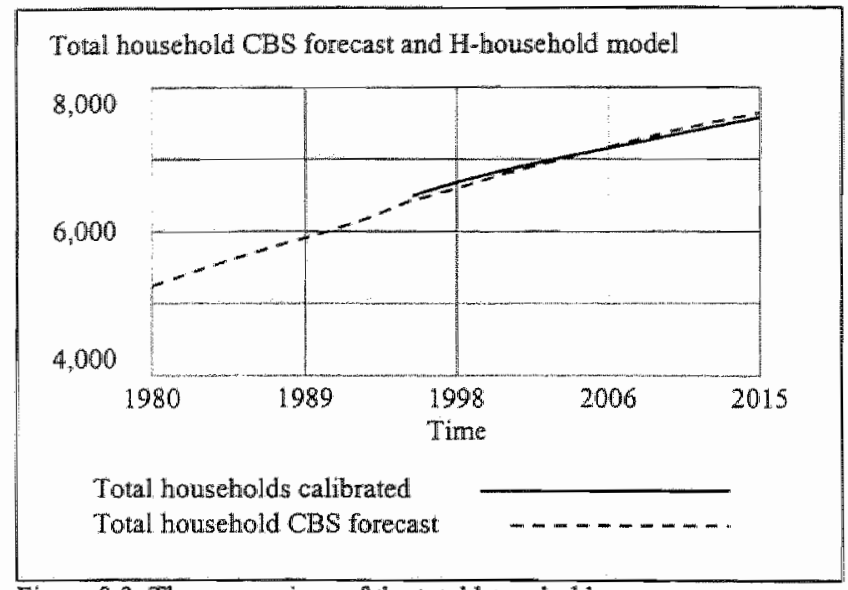

Figute 3.3 The comparison of the total households

Figure 3.4 shows the decomposition of the total household series estimated and the CBS forecast. From Figure 3.4 one sees at glance that the one person households $(I-p H S H)$ are not be expected to stabilise in 2015. CBS foresees this to be happen between 2020 and 2030

The other two to six person households $(2-6+p H S H)$ stabilise during next decade from above, for example, the 2-pHSH or from below, for example, the 5-6+pHSH.

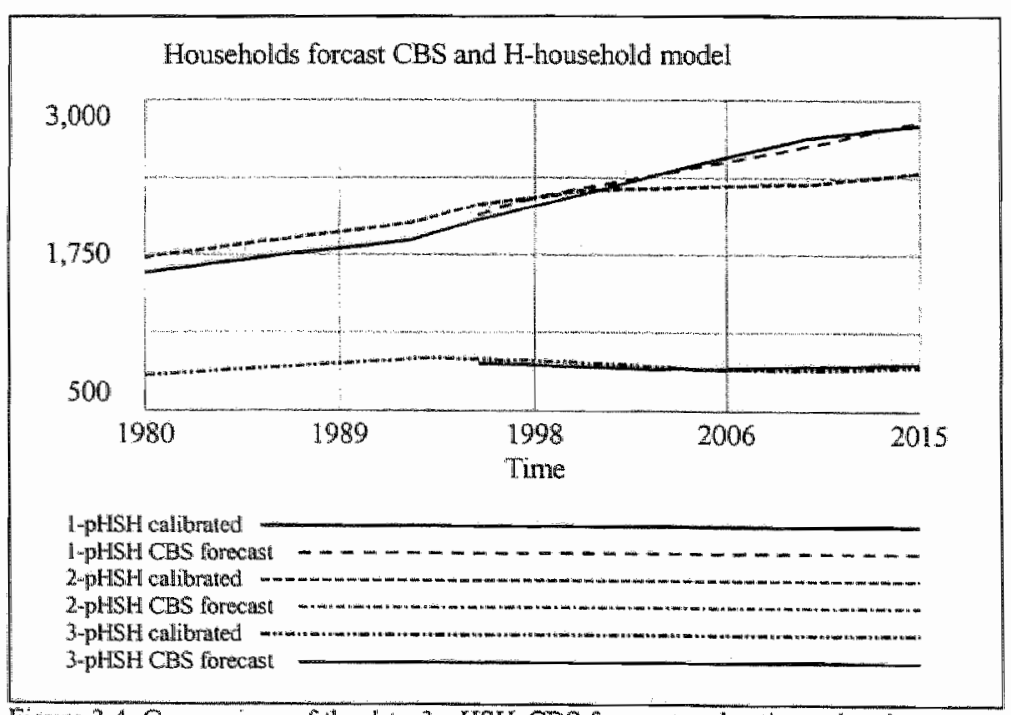

The one person and two person households are growing particularly by the 'greying' of the population which causes the widows (age $75+$ ) and the elder couples (age 65-80) to increase. For the four to five person households ( 4 to 5-pHSH) the increase is very small with regard to the 80 s, while the six and above person household $(6+p H S H)$ declines somewhat from the $80 \mathrm{~s}$ on.

Figure 3.4 Comparison of the $I$ to $3 p-H S H$ CBS forecast and estimated series 


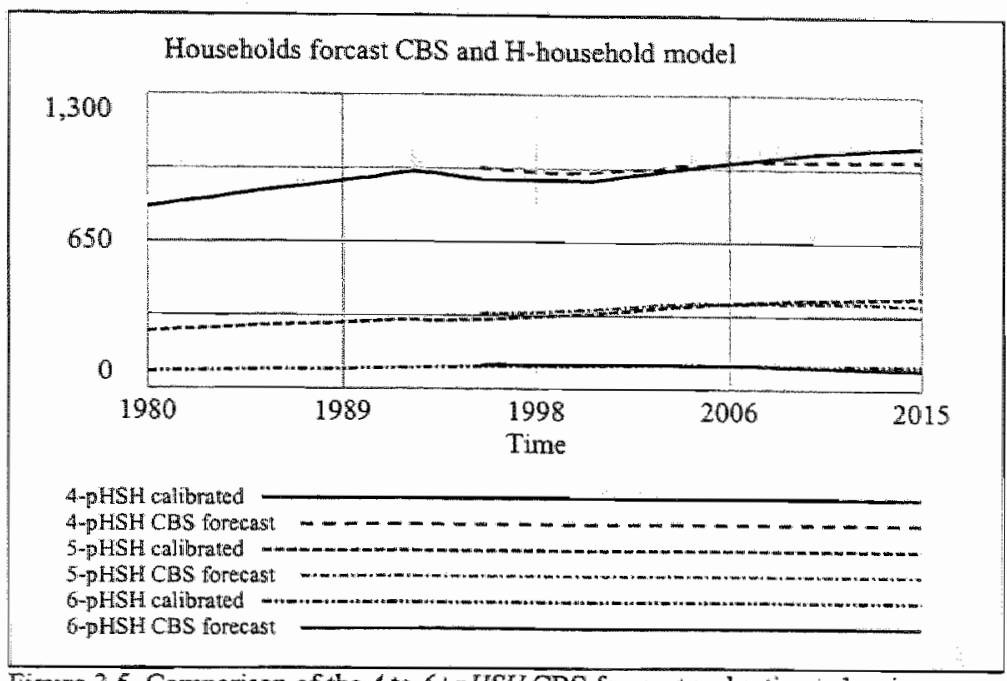

Figure 3.5 Comparison of the 4 to $6+p H S H$ CBS forecast and estimated series

Demographic scenarios are the same as applied in chapter 2 and the household formation are shown in Figure 3.6. Note no lifestyle changes are assumed, so only demographic changes are effective. If one add the three specific household formation scenario's (section 3.1.8), like individualisation- and family scenario, we arrive at 9 scenario runs.

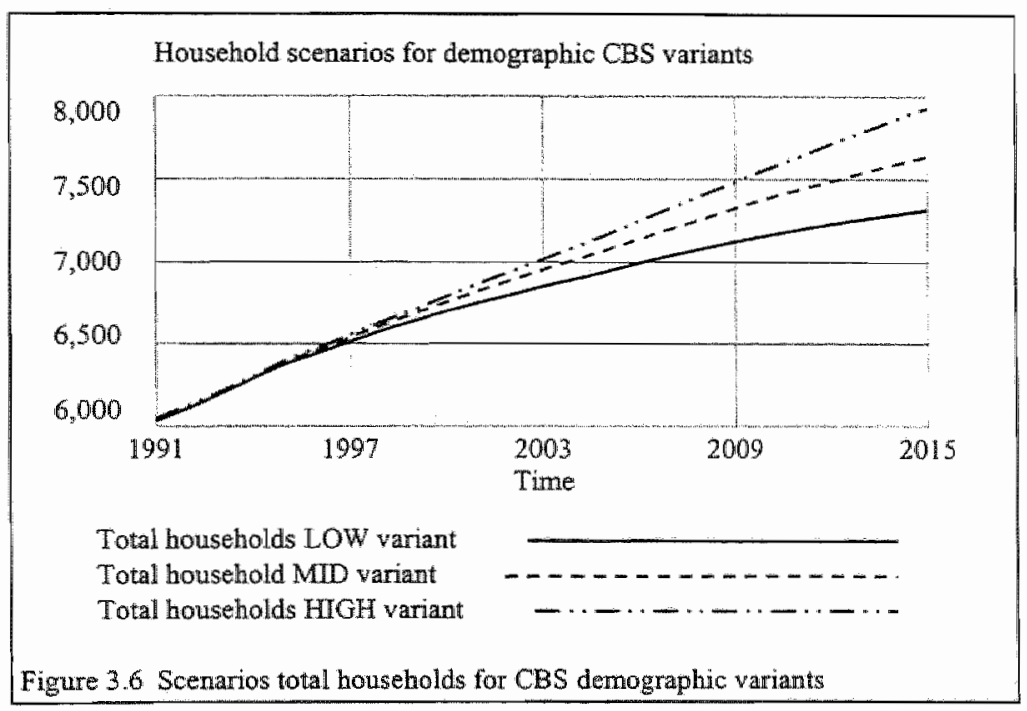

The demographic variants have of course the expected simulation results for the household formation, the stabilisation occurs earlier in time in the low variant and vice versa. Of interest are the underlying $n$. person households developments, Figure 3.7 shows the development of the one to three person households $(1-3 p H S H)$ in absolute and Figure $3.8 \mathrm{in}$ relative $($ in $\%)$ terms. The one person households ( 1 pHSH) grows the strongest in both senses, from $31 \%$ in 1990 to $37 \%$ in 2015 , stabilising after 2020 , whereas the two person households (2-pHSH) grows a little in absolute terms but hardly in relative terms, from $33 \%$ in 1990 to $32 \%$ in 2015. 


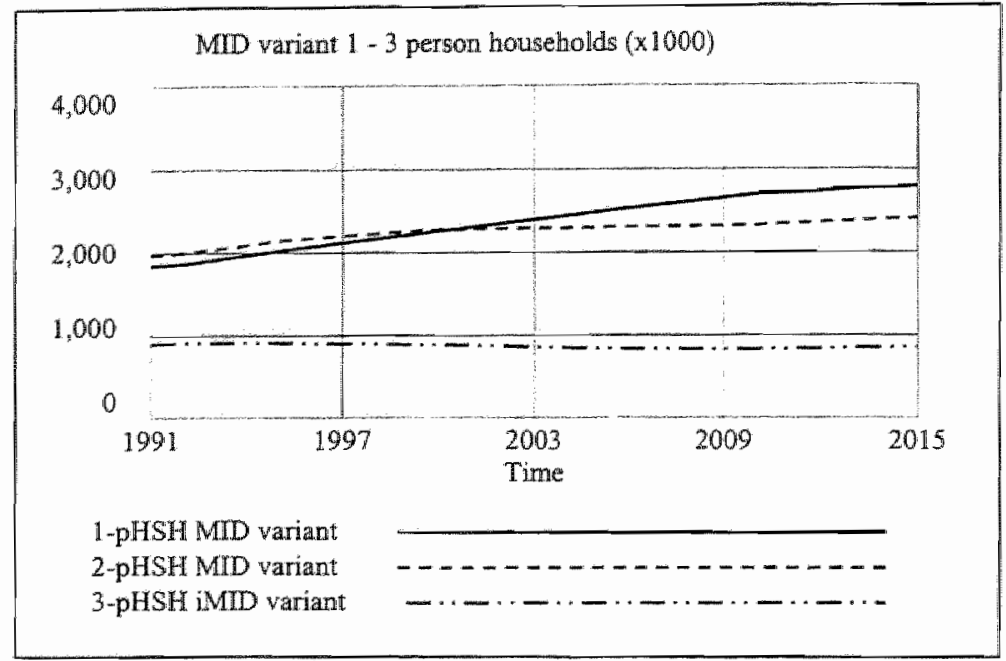

Figure 3.7 The absolute development $1-3 p H S H$ MD variant

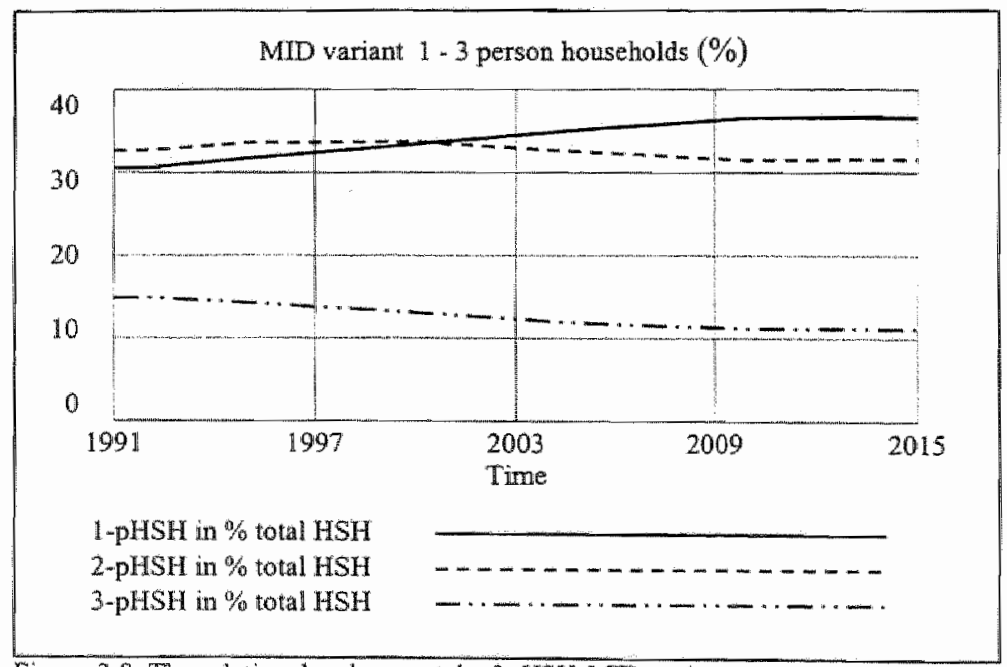

Figure 3,8 The relative development $/-3 p H S H$ MID wariant 


\subsection{Households, time allocation and time budget}

\subsubsection{Introduction}

Explaining the mobility development of the households in the modern westem societies it seems essential to state that the demand of mobility is more or less deduced from the spatial distribution of supply and demand of goods and services, labour supply and demand and finally of the production process itself. The first cluster determines the demand of displacements by the motives : shopping* education, recreation and entertainment, the second cluster the demand of commuting and the third cluster the demand of business traffic or visits. In section 3.3 .2 the concepts of time allocation, time budget and the transport systems will be elaborated, while section 3.3 .3 the motives will be further analysed. For each cluster not only the extent of the activities is of importance, but especially the spatial distribution between living place and the places where the activities take place (shopping, recreation/entertainment centre, schools, offices and enterprises, etc.). The historic growth of the mobility by motive is empirically (partial) linked with the increase of the number of households. On the other hand the growth of the commuting kilometres is mainly determined by the increase of the traversed distance per household - which in turn is determined by

- the kind of employment,

- social characteristics of the employees (for example married labour participating women with children have a quite distinct or unique mobility pattern), and

- spatial planning,

and less by the development of the number of employed persons per se.

In sum, the spatial distribution of the organisation of the consumption and production process tums out to be the cominant factor, but the spatial distribution is in turn dependent of the available transport system.

\subsubsection{Time allocation, time budget and transport systems}

In general the avallability of faster modes of transport has further increased the spatial distribution and the demand of mobility (Klaassen 1972). For example the introduction of the automobile has allowed a very fine and extreme sub-urbanisation, this in turn is supported by an active and anticipating public policy, for example the supply of infrastructure, a favourable tax/pricing system for car ownership and usage, increasing in stead of correcting for extemalities. All these processes caused a strong increase in the need of transport. These kind of processes are an example of positive feedback(s) causing initially exponential growth followed by negative feedback(s) as system boundaries become visible leading to a damping/retardation of the growth pattern. These processes can be described by sigmoid functions. The more efficient (in terms of km per time unit), the car-transport system did not lead to a shortening of the total travel times. On the contrary, the increase of mobility seems more desirable or attractive. In sum the technological development has changed the time restrictions : the availability of faster transport systems does increase the travel potentials within a fixed delimited time period ( 24 hours). Essential is the increase of the range or radius of action and the coupled increasing possibilities per addicional travelled kilometre.

With this process another essential aspect of the demand of mobility comes into view, the displacement causes time costs. Fixed delimited time budigets (up to 24 hours) are availlable to the consumers and members of the households and are therefore scarce. Persons don't only allocate their income over different goods and services, but also over the available time. As the referenced activities and the displacements to these activities cost time, not only the number of displacements but also the potential (but valued at a higher utility) locations for these activities are restricted. It is therefore quite possible that given the spatial distribution of the activities the introduction of a faster transport system causes longer travel distances by equal time costs to visit these locations giving a higher utility (Oort; 1969). Besides, seen in a dynamic perspective, the economic growth is attended by a process of specialisation and economics of scale which also has a spatial dimension. The developments in spatial distribution may be different per activity by which the demand of mobility has been stimulated. Simultaneously the government did and still does support actively the spatial distribution by official 
space planning. However the continuing spatial distribution is only possible by the increased transport potentials in water, rail, road and air.

The aggregate demand of mobility is a reflection of the spatial organisation of the society and economy which themselves again are determinate by the actual structure of transport systems. Increased spatial distribution was stimulated by endogenous processes - specialisation and economics of scale - and exogenous processes - government policy - and realised by the rapid diffusion of faster (efficient) transpont systems. After World War II the automobile (car and lomies) transport system showed a large scale diffusion (especially in the 60s) and was responsible for the strong increase of the mobility during and after that period, besides it made possible the increased spatial distribution which is one of the main determinant of economic growth. Mobility is a necessary but not sufficient condition of economic growth measured in conventional economic terms.

\subsubsection{The demand and supply of mobility}

The conventional theory of consumer behaviour indicates the way how a rational consumer spend his money income to different goods and services. Conventional economic wisdom states that: given the income and prices it can be shown that under the assumption of decreasing marginal utility the total satisfaction reaches a maximum, subject to the budget constraint, if for each good or service the marginal utility equals the utility of the money offered for the purchase of that marginal quantity. Stated in this form the marginal utility theory is subject to a number of restrictions (Klaassen 1972) 1. the theory is static, however dynamics versions including habit formation, changing tastes, and durability are formulated.

2. the spending of income is timeless, e.g. no time costs.

This means that only money is the restricting factor in the consumption process, but the consumption process has to be done within 24 hours a day and 365 days a year. So there exists a physical himit, within the consumption process has to be taken place. As will be shown later on the money budget restriction will be complemented explicit by the time budget restriction in the advanced western societies $^{3.3}$ (Becker, 1965). This implies a diminishing dominant role for the price mechanism in controlling the consumption process.

3. in addition to restriction 2 the mere act of consuming (to enjoy the utility of a good or service does not only cost money but also time, called consumption time, as a third time element next to labour time and leisure time. Like labour time and leisure time, consumption time often implies travelling time, as to bridge the distance between living place and the consumption location. In principle the consumer and member of a household has some alternatives at his disposal in order to bridge the distances depending of income, cost and speed of the travel time. A dynamic theory includes the time dimension, a spatial theory includes the distance, e.g. a spatial element.

4. the last restriction concerns the infinite divisibility in physical sense of the consumption goods and services. This restriction is important in the spatial sense of the consumption process. In bridging distances the consumers is not able to choose in an infinite divisible way an optimal mix of transport systems to bridge his wanted displacements, for example, own car system or public transport system. As the car-transport system is an investment in a consumer durable good, one has to separate owmership and usage each with its own, different, decision criteria. Decisions related to the choice of a transport. system have a discrete character, dominated by its fixed cost, its efficiency and related time cost struchure while usage and especially the intensity or frequencies of usage of consumer durable are among other factors partly determined by the ownership itself and partly by its variable cost structure. One can imagine that the household first chooses its transport systems, given the existing or expected infrastructure, for the different activities and then the living location (domicile) will be determined. Most of the time the number of altemative transport systems are very restricted to one or two. The concept of marginal utility becomes therefore an empty concept. The choice of the household takes place based on a comparison of his total utility in, for example, two situations, that is, assuming alternative 1 has been chosen and the remaining income and leisure time will be spent in an optimal

\footnotetext{
${ }^{33}$ However inplicit the time restriction appears in the money budget constraint through labour income or the allocation of labour time versus leisure time with leisure giving positive utility.
} 
way, or alternative 2 has been chosen and the remaining income and time will be spent in an optimal way. The next section a formal relationship will be developed between money budget and time budget originating by Oort and $\mathbb{K}$ laassen which we will extend and modify where necessary.

\subsubsection{Money budget and time budget}

The introduction of the element time in the theory of consumer behaviour is traditionally restricted to labour time $\left(T_{L}\right)$ versus leisure time $\left(T_{F}\right)$, suppose further that the total utility depends on the amount of goods and services enjoyed by the earned income, than we can formulate in static terms:

where

$$
\begin{array}{ll}
U=U\left(x_{1}, \ldots, x_{n}, T_{L}, T_{F}\right) & \\
T=T_{L}+T_{F} & \text { (time budget) } \\
Y=p_{l} T_{L}+V & \text { (money budget) } \\
Y=\sum_{i=1}^{n} p_{i} x_{i} &
\end{array}
$$

$$
\begin{aligned}
& U-\text { utility index (time/time) } \\
& T-\text { total (absolute) day time (time) } \\
& T_{L}-\text { labour time used-up (time) } \\
& T_{F} \text { - leisure time (time) } \\
& Y \text { - earned income (money/time) } \\
& V \text { - non-labour income (money/time) } \\
& p_{i} \text { - price of unit good } i \text { (money/good) } \\
& x_{i} \text { - quantity consumed of good } i \text { (good/time) } \\
& p_{l} \text { - wage rate (money/time) }
\end{aligned}
$$

From these equations the marginal utility of good $i$ obeys to equation (3.2.2) if the consumer seeks to maximise $U$.

$$
\frac{\partial U}{\partial x_{i}}=\left(\frac{\partial U}{\partial T_{F}}-\frac{\partial U}{\partial T_{L}}\right) \frac{p_{i}}{p_{l}}
$$

Formulated in this way $\frac{\partial U}{\partial T_{F}}$ (time/time) is the marginal utility of an unit leisure time and $\frac{p_{i}}{p_{i}}$

(time/good) the number time units which has to used up for an unit of good $i$. The product $\frac{p_{i}}{p_{i}} \frac{\partial U}{\partial T_{F}}$ (time/good) is therefore the marginal utility of the leisure time used up needed to acquire one unit of good $i$ or the (dis)utility of labour to be performed at the same time.

Expression (3.2.2) states that the marginal utility of each good is equated to the total leisure time and labour time used up in order to acquire a marginal unit of good $i$. The formulation conforms to the traditional theorema known as the second law of Gossen, that is,

$$
\frac{\partial U}{\partial x_{i}} / \frac{\partial U}{\partial x_{j}}=\frac{p_{i}}{p_{j}}
$$

the rate of the marginal utility between a pair of goods equals the rate of prices of the same goods. Rearranging (3.2.2) orie gets

$$
\frac{\partial U}{\partial T_{F}}=\frac{\partial U}{\partial x_{i}} \frac{p_{l}}{p_{i}}+\frac{\partial U}{\partial T_{L}}
$$

As this equation conforms to all its, it follows

\footnotetext{
1.* Expressions between brackets are dimension(s). Dimensional analysis is an often overlooked unit of measurement check of mathematical statements, e.g. the dimension of the left expression must be tin the same unit(s) as the dimension of the right expression. (de Jong 1967)
} 


$$
\frac{\partial U}{\partial x_{i} p_{i}}=\frac{\partial U}{\partial x_{j} p_{j}}=\frac{\partial U}{\partial Y}=\lambda
$$

The money budget equation in (3.3.1) can therefore be rewritten as

where

$$
\frac{\partial U}{\partial T_{F}}=\lambda p_{l}+\frac{\partial U}{\partial T_{L}}
$$

\section{A - marginal utility of money (time/money)}

This formulation conforms to the convential consumer behaviour theory by which the total incame deterrmines indirectly the satisfaction.

By introducing the third time element, total consumption time, $T_{C}$, as an attribute and consumption time or time intensity of the consumption process, $t_{i}$, as a non-linear function of the stock of durables, $K$, more reality is added to the theory of consumer/household behaviour. The amortised capital depreciation, $\delta K$, has been added to the budget equation, $Q$. In order to arrive at a clear cut exposition we make a distinction between tied time, $T_{C}$, or must time (bounded, as commuting, task combining, eating, sleeping, etc.) and untied time or net leisure time, $T_{F}$ (SCP 1995). So we can formulate the following general household time-allocation model

$$
\begin{aligned}
& U=U\left(x_{1}, \ldots, x_{n}, T_{L}, T_{F}, T_{C}\right) \\
& T=T_{L}+T_{C}+T_{F} \\
& T_{C}=\sum_{i=1}^{n} t_{i} x_{i} \\
& t_{i}=f(K) ; f(\cdot) \text { is an inverted sigmoid function. } \\
& Y=p_{i} T_{L}+V \\
& Q=\sum_{i=1}^{m} p_{i} x_{i}+8 K
\end{aligned}
$$

s.t.

$$
\begin{aligned}
& T \geq T_{L}+T_{C} \\
& Q \leq Y
\end{aligned}
$$

Hence

$$
\frac{\partial U}{\partial x_{i}}=\left(\frac{\partial U}{\partial T_{F}}-\frac{\partial U}{\partial T_{L}}\right) \frac{p_{i}}{p_{i}}+\frac{\partial U}{\partial T_{F}} t_{i}
$$

where

$$
t_{i} \text { - consumption time or time intensity of good or service } i \text { (time/good) }
$$

Note that the variables $T, T_{L}, T_{F}, T_{C}$ are stock variable (time), whereas the remaining are flow variables (unit/time), $T_{k=}$ is a "fiee" variable, in fact a balance variable.

The first term represents the well known used-up of leisure time plus the disutility of labour time. The second term represents the value of leisure time sacrificed or transformed in consumption time.

${ }^{3.5}$ The inverted sigmoid function has like the original sigmoid function an exponential region where $\frac{\partial t}{\partial K}<-1 . \frac{\partial^{2} t}{\partial K^{2}}<0$, an asymptotic region where $\frac{\partial^{\partial}}{\partial K}>-1, \frac{\partial^{2} a}{\partial K^{2}}>0$, and a mode shift point where $\frac{\partial r}{\partial K}=-1, \frac{\partial^{2} t}{\partial K^{2}}=0$. Moreover $\operatorname{limin}_{K \rightarrow \infty} \neq 0$ 
An interesting feature of $(3.2 .8)$ is introduced by the time budget. In the extreme, suppose that $\frac{p_{i}}{p_{l}}$, by rising $p_{i}$, approaches zero, than the marginal utility of good $i$ equals the time used-up by the act of consuming.

For the marginal rate of utility then applies:

$$
\frac{\partial U}{\partial x_{i}} / \frac{\partial U}{\partial x_{j}}=\frac{t_{i}}{t_{j}}
$$

In other words, the rate of the marginal utility of a couple of goods equals the rate of their consumption times. This implies that with increasing wealth the traditional role of prices in controlling the demand diminish in favour of the consumption times.

The formulation of the marginal utility of leisure time can be deduced from (3.2.8) as follows

$$
\frac{\partial U}{\partial T_{F}}=\frac{p_{l}}{p_{i}+t_{i} p_{l}} \frac{\partial U}{\partial x_{i}}+\frac{p_{i}}{p_{i}+t_{i} p_{l}} \frac{\partial U}{\partial T_{L}}
$$

The denominator $p_{i}+t_{i} p_{l}^{3.6}$ is the price paid in acquiring of one unit of good $i$ (money/good) plus the consumption time of one unit of good $i$ (time/good) valued at the wage rate per time unit (money/time).

From (3.2.10) it follows for $p_{l} \rightarrow \infty$

$$
\lim _{p l \rightarrow \infty} \frac{\partial U}{\partial T_{F}}=\frac{1}{t_{i}} \frac{\partial U}{\partial x_{i}}=\frac{1}{t} \frac{\partial U}{\partial x}=\frac{\partial U}{\partial T_{C}}
$$

In other words, in the limit the marginal value of utility of leisure time equals that of the consumption time, $T_{C}$, as stated in equation 3.2.9.

Note that the formulation stated above holds for the time activities in a time budget framework with a disjoint character, work versus non-work, consuming versus non-consuming. In this way the absolute physical time limit adds up to 24 hours a day, denoted by $T$. But going deeper in detail, it will be possible to do different activities within the same time unit, for example dish washing while cooking with or without a magnetron during a musical intermezzo on radio or $\mathrm{CD}$ player. This simultaneity of activities introduces the relative or flexible time limit, denoted by $\widetilde{T}$, and the total available activity time could be larger than (added to) 24 hours. So, if $\widetilde{T}>T$, then the consumption intensity per unit of time increases (or equivalent the time intensity decreases as a function of the capital intensity) and the greater this gap the greater the time productivity, $\frac{1}{l_{i}}$, of the consumption process. Now the relative time can be expressed as $\widetilde{T}=\frac{T_{C}}{t_{i}}+T_{L}$, with relative or effective consumption time equals absolute consumption time times time productivity or $\widetilde{T}_{C}=\frac{T_{C}}{t_{i}}$.

However it will be fruitful to broaden the concept of consumption to the concept of homeproduction in a production function approach (Becker 1965, Muth 1966 and Cigno 1991). The household is viewed as an organisation producing goods of various kinds for the benefit of its $n$ members. The efficiency of this productive process in households of different type and size can be compared and differences in efficiency by technological progress (transport systems included) can explain the development of different household type and size during the past decades.

${ }^{3.6}\left(p_{i}+t_{i} p_{l}\right)$ has the following dimension $\frac{\text { money }}{\text { gaod }}+\left(\frac{\text { time }}{\text { good }}\right)\left(\frac{\text { money }}{\text { time }}\right)=\frac{\text { money }}{\text { good }}$ 
This approach originates from Becker's notion that market goods are not consumed in their original state, but transformed into utility-giving final goods by the application of the consumer's own time (that is $T_{F}+T_{C}$ ). The final goods are not transferable from one household to another. The home production approach has more generality and includes

- the standard consumer model of micro economic theory as a special case, where goods bought from the market are assumed to be consumed without any further processing and without any expenditure of the consumer's own time.

- the standard income-leisure model according to which the good 'leisure" is domestically produced by time alone, without any imput of market goods. By allowing negative inputs of goods, the homeproduction approach can be extended to households producing commodities for the market along with goods for own consumption.

The household production possibilities can be summarised by a home-production function X( • ), such that

where

$$
X=X\left(K, T_{C}, Q\right)
$$

$X$ - aggregate measure of domestic output (leisure time $T_{F}$ included)

$K$ - capital stock or stock of durables

$T_{C}-$ consumption time or time dedicated to domestic production activities.

$Q$-aggregate measure of the quantities of market goods and services

It will be assumed that the function has nice mathematically properties like twice differentiable, quasiconcave, and that the isoquants do not cut the axes - in other words both time and goods are essential to the domestic production of goods, but substitutable at a diminishing marginal rate. If the capital stock will be replaced by its serwices $(k)$ delivered to the home-production process then linear-homogeneity can be assumed and constant returns to scale characterise the home-production function. However, the possibility of economies or diseconomies of scale are open, if scale is expressed in number of household members ( $n-p H S H)$.

The choice of $T_{C}$ and $Q$ is subject to the following restrictions: Note $T_{F} \subseteq X$.
1. $k, T_{C}, Q \geq 0$
2. $T_{C} \leq T$
3. $Q \leq Y^{\prime \prime}$
4. $T_{L}=T-T_{C}$

The households will be interested in both the size and the composition of the home-product. Since households utility will rise with $X$, then $T_{C}$ and $Q$ will be chosen so as to maximise 3.2 .11 , subject to 3.2 .11 , where the budget constraint can be reformulated as

$$
p_{l} T_{C}+Q \leq p_{l} T+Y=Y^{*}
$$

where $Y^{*}$ is the full time income if $T_{L}=T$ or $T_{C}=0$.

Now if one assumes that the rate of return to $T_{L}$ is given by the market wage rate $p_{l}$ and the rate of return to $T_{C}$ by the shadow-wage rate $p_{c}=\frac{\partial U}{\partial T_{C}} / \frac{\partial U}{\partial Q}=\frac{p_{i}}{t_{i}}$. So the shadow-wage rate equals the marginal rate of technical substitution of market goods for home-time (or consumption time). It depends on the ratio $p_{J} / p_{c}$ how the households will (re)allocate their time, between $T_{L}$ and $T_{C}$ up to the point where $p_{l} / p_{c}=1$. This process is especially effective in case of two-or-more person households where, for example, in case of two wage-eamers (both full-time or part-time or full time and part time) the household task combination will cause leisure time, $T_{F}$, to be balanced in downward direction and in effect decreases. One has, of course, to differentiate between the possible combinations

$3.7 p_{\mathrm{c}}=\frac{p_{i}}{t_{i}}=\frac{\text { money }}{\text { good }} \frac{\text { fonte }}{\text { good }}=\frac{\text { money }}{\text { that }}$ 
between both full-time wage-earners at one extreme, and one wage-earner and house (wo)man at the other, representing differences in the pressure on the leisure time, $T_{F}{ }^{3 . s}$.

On the other hand, the consumption intensity can only be increased by augmenting the capital intensity, $k=\frac{K}{X}$, (capital deepening) of the household activities (home-production), so the capital intensity will increase by investing in consumer durables, as wash (dishing) machines, refrigerators, freezers, magnetrons, first or second car, etc. From time budget surveys (see next section) it can be concluded that the free variable leisure time, $T_{F}=T-T_{L}-T_{C}$, comes increasingly under pressure, in effect it declines, depending among others on the wage-eamer position(s) as mentioned before, and this dewelopment has far reaching consequences for the consumerhousehold behaviour and therefore consumer lifestyle, especially for the mobility, the chosen transport systems and in our case car ownership and car use on the one hand and the price mechanism on the other hand. The price mechanism as regulatory mechanism becomes less and less effective in controlling the mobility demand. This has indeed far reaching consequences for the effectiveness of the traditional public policy in the area of (public) transportation.

\section{Summary}

Starting from a given living location and labour market participation(s) the $n$-person household has to take into account, in order to maximise its satisfaction or utility, four cost components:

a. the supply price of the good or service,

b. the consumption time of the good or service,

c. the transport cost to and from the supply side of the good or service,

d. the transport time needed to and from the demand side (home side).

The physical consumption time, travel time as a subset of $T_{C}$ included, becomes the additional variable to be minimised, beside the traditional household expenditures per se. Pressure on leisure time results, next to scale effects of the more-person households, in choosing the most efficient or optimal transport system. A transport systems consists of all types of means of transport available, broadly divided into collective means of transport, like train, busses, etc., and private means of transport, like bicyclle, automobille, etc. The private means of transport are the most flexible in the time-distance space and can satisfy more or less all the displacement motives of the $n$-person households. The collective means of transport are fixed in the same time-distance space and can therefore satisfy some displacement motives only. The n-person household chooses its optimal transport systems given the assumptions and conditions stated above, and it is evident that their exists a range of optimal transport systems for the Iperson and 4 person household or in general for the $n$-person households. The more efficient the transport system the more kilometres can be done per unit of time or more displacements within the given available travel time. If the free time, or net leisure time comes under pressure the choice of more displacements within the available travel time is more likely then the same displacements within less travel time. Travel time will not be minimised, the number of displacements will be maximised. These propositions are theoretically based on the general model of household's time-allocation described before and will be (indirectly) scrutinised in the next section(s).

${ }^{38}$ The case of unemployed household member(s) is quite different and will not treated here. 


\subsection{Mobility and time budget surveys}

\subsubsection{Introduction}

Analyse of traffic and transport often link the development of mobility to factors such as economic growth, population growth, sub-urbanisation and scale increase. There are indications that, in conjunction with these factors, changes in lifestyle too affect mobility. Surveys have made frequent reference to the number of married or cohabiting women entering the labour market and to the number of one and two person households. An analysis of time budget data also shows that arrangements made within households regarding the division of home-production (task combinations) and the use of met leisure time ( $T_{F}$ ) affect the need for displacements (trips). Much of this information is derived from research in which individual differences in the extent of mobility were measured at one particular point in time or part of a year (two weeks in October). A recent Dutch research (SCP 1993) investigated the question whether mobility has also increased over time (19751990 ) because lifestyle changes are now diffused in the society. The statistical sources are the time budget surveys (TBO) for the period 1975-1990. The findings support the thesis that the characteristic "household by size' (or n-phSH) is an important element in the explanation of mobility and car use. Four aspects of a modern life style proved to be important in explaining mobility and the growth of mobility:2

- reduction in the size of households;"

- women emancipation;

- the combination of various tasks;

- the diversity of leisure behaviour.

These factors refer to different aspects but are not completely disjoint and therefore overlaps only partially. It was also first established that the effect of these factors on the number of individual trips is partly due, if at all, to the effects of differences in age, income, education or car ownership. The main problem examined may be stated as follows :

- What influence do the reduction in the size of households, emancipation, task combination, and leisure time have on the transport system used for these purposes.

\subsubsection{Changes in activities and displacement (trips)}

\subsubsection{Changes in the ratio of obligatory activities to leisure activities in hours}

The shifts in the use of time observed during the period 1975-1990 have mainly led to greater contrasts between younger and older age-classes and, accordingly, to greater changes too between employed people and non-employed (unemployed plus those in retirement or early retirement). Since 1975 people in the (20-50) age-class have for various reasons spent an increasing amount of time on all their activities (labour $T L$ and home-production TC) together and therefore had less leisure time $(T F)$ in 1990 than in the 70 s (Figure 3.9 and 3.10).

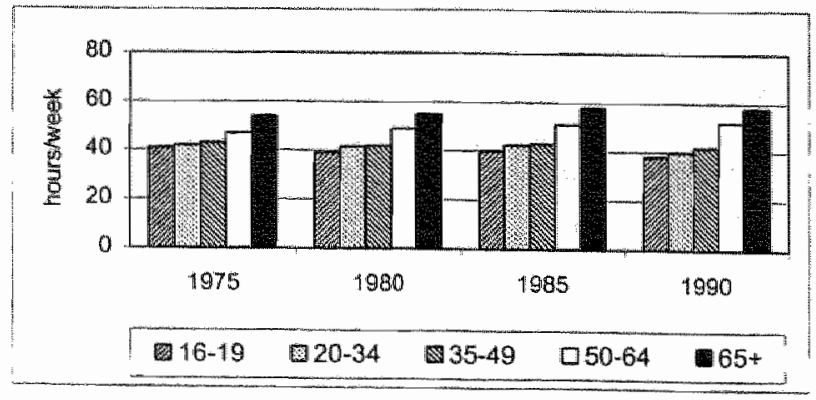

Figure 3.9 Average time spent on leisure activities by age-class 


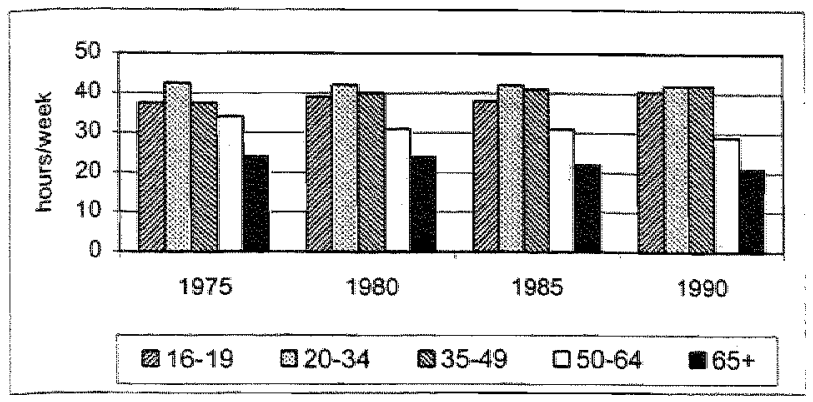

Figure 3.10 Average time spent on obligatory activities by age-class

By contrast, the $50^{+}$, particularly the men, now have much less labour work than in 1975 and considerably more leisure time.s. The extra leisure time for middle-aged and old people means that the differences in leisure time from age-class to age-class have broaden further since 1975. Besides the contrast between young and old, the division of work and leisure time among the various educational categories has also become more unequal: the lower the educational level, the less busy the person is (Figure 3.11). Note the percentage difference increases with higher educational levels. The same conclusion holds for the kilometrage per person per day by car (Figure 3.12).

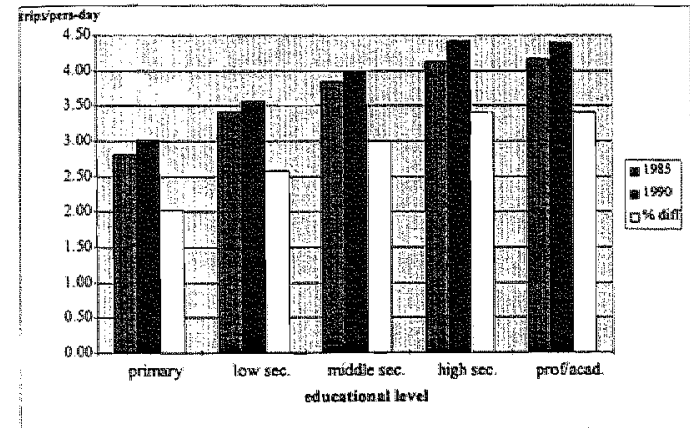

Figure 3.11 Total trips by educational level 1985-1990

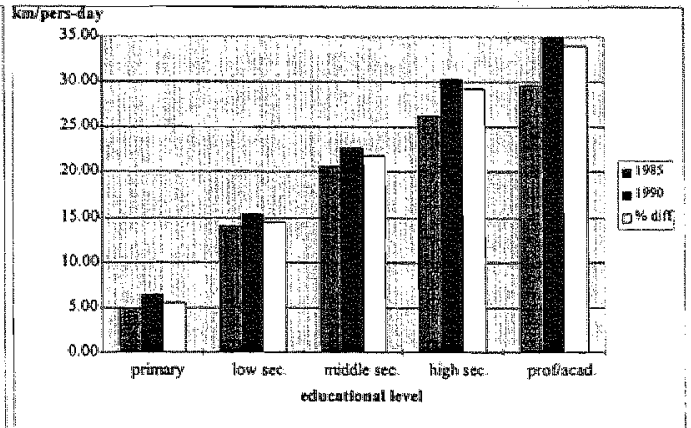

Figure 3 12 Car trips by educational level $1985-1990$

The idea that everyone is getting more and more leisure time is based on a misunderstanding, in any event, if one takes a normal working week. Although the number of days during which a person need not work has increased for some employees when calculated on a year scale (due to more days" leave and shorter working hours), data recorded during a week in which all activities take place as normal (a normal working week) provide the best information about the possible causes of the increased mobility.

\subsubsection{General view of changes in displacement reasons and mode of transport}

People whose obligation(s) are largely outside the home (i.e. people following courses, working men and women) make more trips in a week then those who have no daily duties outside the home (housewives, non-employed people). Young people make more trips than elder people, and people with a higher educational level more trips than people with a lower educational level.

\footnotetext{
${ }^{3.0}$ Leisure time has to be understood as net leisure time. The concept of net leisure time $\left(T_{F}\right)$ is defined as that part of the week what remains after deduction of all duties (labour work, education or household activities) and after deduction of the time allocated to personal care (sleeping. washing, clothing, etc.).
} 
The increase in the number of trips between 1975 and 1990 is most apparent among the group who were initially least mobile: women (particulariy housewives), non-employed and elder people aged over 65. These shifts (behavioural changes) point to a levelling off of the differences in the extent of mobility: groups whose activities consists mainly of home tasks and leisure pursuits have become more mobile.

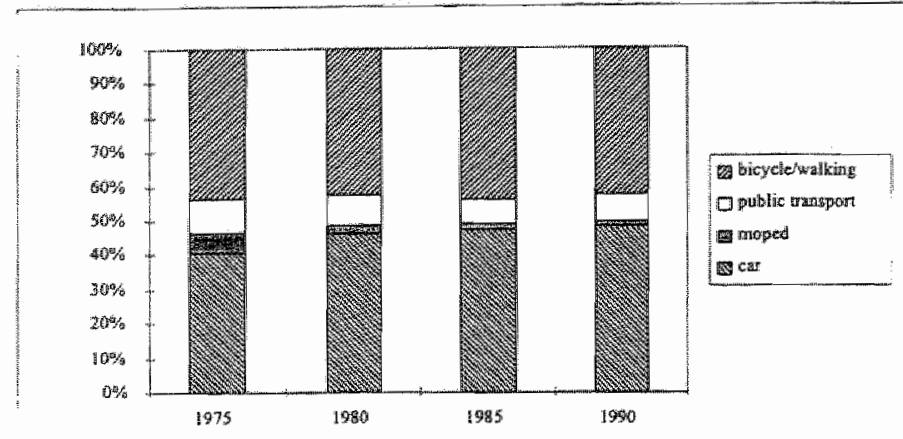

Figure 3.13 Average number of trips per week by means of transport
The car was the mode of transport whose use increased the most between 1975 and 1990 (Figure 3.13). The rise between 1975 and 1990 was $30 \%$ (from 6.7 to 8.8 trips per week) which was almost three times the average tise in overall mobility (from 16.5 to 18.3 trips per week). In addition, walking and cycling increased, albeit to a much lesser extent $(+8 \%)$. The use of public tramsport decreased between 1975 and 1990, as did the use of mopeds. The share of public transport in the total number of trips declined from $10 \%$ in 1975 to $8 \%$ in 1990 , whille the share of the car increased from $41 \%$ to $48 \%$. The time spend to car use (hours per week) rose from 3.3 in 1975 to 4.2 in 1990, an increase of 27\%. Although people on the whole made less frequent use of the train, bus, tram and metro, they did spend more time in them on average.

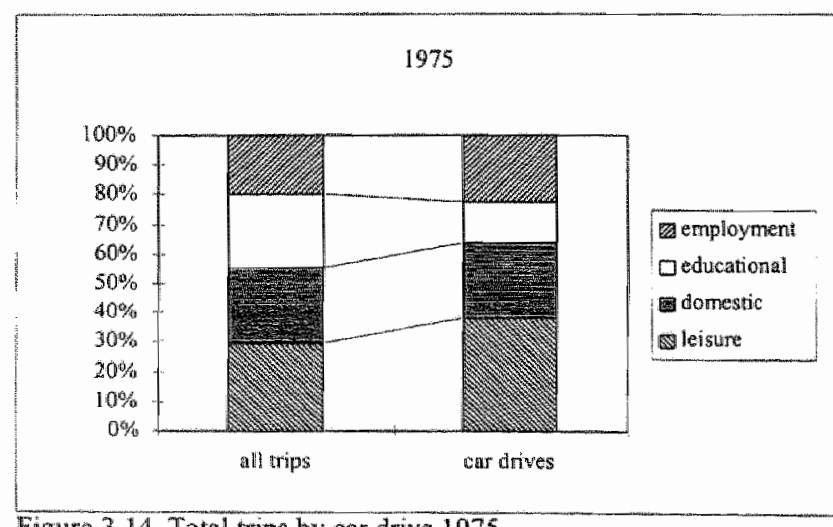

Figure 3.14 Total trips by car drive 1975

1990

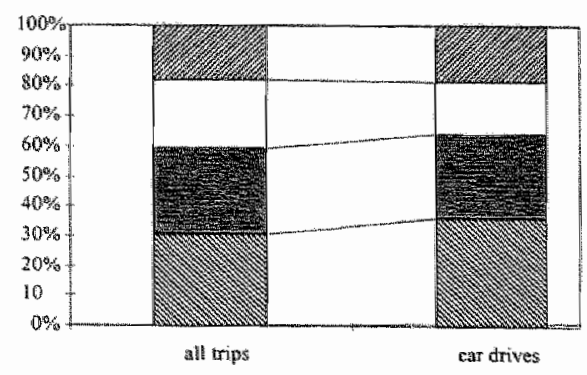

The use of leisure time (recreation and entertaimment) is the most frequently quoted reason for trips and the category on which the most time is spent. People leave home \pm 6 times a week to visit friends and relatives, play sport, attend a club, do woluntary activities and/or take part in an activity involving politics, religion, etc. Home-production (in particular shopping) also accounts for trips by a larger number of people, although the number of trips is still smaller than due to leisure activities.

Nonetheless, the number of trips made in connection with homeproduction in 1990 (Figure 3.15) already exceeded the number made in connection with employment. This was not the case in 1975 (Figure 3.14). Figure 3.14 and 3.15 shows the number of trips and car drives per week by motive (in \%) for 1975 and 1990 
The figures from the TBO surveys on the modes of transport used and the reasons given for the trips agree closely with those obtained from the special OV G transport surveys. As regards the absolute extent of the number of recorded trips and the trend since 1975 , the similarities between the two surveys are less great. It remains unclear, however, to what extent this can be attributed to differences in the method of measurement or different weights, therefore from 1995 on the weights are modified in order to match both surveys and to correct for differences in population, different minimum time needed for the definition of a trip, etc.

\subsubsection{Changes in activities in connection with changes in travel patterns}

Between 1975 and 1990 there was an increase in the number of people in puid employment, particular those in part-time jobs or people with a second job. This type of work is most common among women and students. The time spent at work declined on average among all the participants, those working short and long hours. Transport to and from the work location generally required more time in 1990 than in 1975. For every 8 hours a person was away from home for employment activities, \pm 1 hour was spent on commuting in 1990 , whereas in 1975 around 50 minutes' travelling time was still sufficient for an 8-hour working day. Note that commuting people in the (20-35) age-class exceeds the average share by $1 / 8$ part in 1990 .

Although travelling to and from work is taking more and more time on average (1.4 hours per week in 1975 to 1.6 in 1990, Figure 3.17), the number of trips per person per week has declined (3.5 1975 to 3.3 1990, Figure 3.16). This may be attributed to the fact that on average working people lived further from their work place in 1990 than in 1975 , as a tesult of which many of them no longer had the opportunity to return at home at noon. In these cases, the number of trips to and from work each day has therefore declined from 4 to 2 . The trip frequency is the highest (measured per 10 working hours) among groups who work only a limited number of hours. The car is still used the most in travel to and from work. In 1990 almost half (48\%) of all trips were made by car. In $43 \%$ of the cases the distance was done walking or by bicycle. Public transport was the least used mode of transport in 1990 and also lost ground in connection with commuting in comparison with 1975.

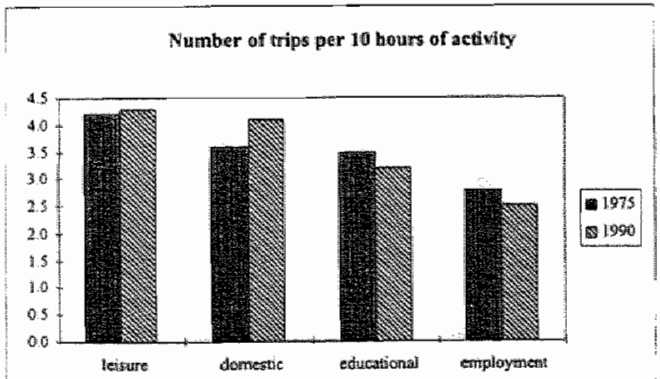

Figure 3.16 The number of trips per 10 hour of activity

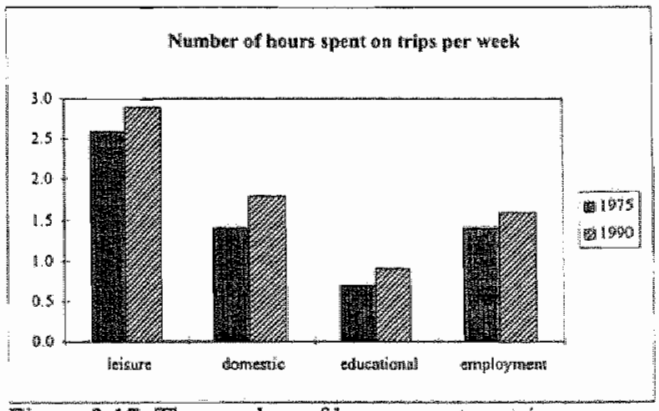

Figure 3.17 The number of hours spent on trips per week:

The number of people attending (participation rate) educational institutions increased between 1975 $(28 \%)$ and $1990(33 \%)$, although the average time spent (in hours per week) on this activity declined $(22.2 \%$ in 1975 and $18.9 \%$ in 1990 ). As in the case of employment, there was an increase in the number of people participating in educational activities as a secondary activity. This was increasingly the case among better educated adults in the (20-50) age-class. People engaged in educational activities spend a lot of time travelling compared with people travelling to and from work: on both survey sources travel accounted for about $1 / 6$ of all the time spent on education. Groups who take part in education but spend relatively little time on it, such as adults and in particular housewives following part-time courses, travell more frequently in relative terms than those groups in full-time education. Full-time educational participants travel on average (displacement fiequency) 2.8 times in 
1975 and 2.8 times in 1990 and part-time participants 3.4 in 1975 and 5 times in 1990 for each 10 hours of educational activity.

For the most full-time educational participants travel by bicycle or by walk to the institution. Nonetheless, both these slow modes of transport and public transport too are losing its share in favour of the car. The car is most used by participants in employment (trip frequency per car 1.3 in 1975 and 1.4 in 1990) and by housewives who are attending an educational institution or following a course as a secondary activity (trip frequency per car 1.7 in 1975 and 2.9 in 1990).

The number of persons who do home-production for at least 1 hour has increased substantially, especially the employed ( $89 \%$ in 1975 to $93 \% \mathrm{n} 1990$ ). Home-production has been done as a secondary activity more frequently since 1975. Although this image corresponds with trends in employment and education, there is also a clear difference. Unilike in the case of employment and education, the number of people for whom home-production constitutes the principal activity - i.e. housewives - is diminishing (task-specialisation). Home-production which is performed as a secondary activity also necessitate a relatively large number of trips. The male partners (or nonemployed or one-parent) often do the shopping or take and fetch the children, as a result of which they are high mobile. Employed, unemployed men and retired persons spend between 1/5 and 1/4 of the time they are engaged in home-production on transport; for housewives the figure is only $1 / 11$. The task combiners make 5 trips for every 10 hours of home-production (4.6 in 1975 and 4.7 in 1990), whereas task specialists (housewives) make on average just over 2 trips in the same period (1.6 in 1975 and 2.3 in 1990 ).

In sum, more trips are now made in connection with home-production than in 1975. These trips are often in the nature of short and frequent displacements $(1.5-2 \mathrm{~km}$ and to $5-7 \mathrm{~km})$. Nonetheless, the car use penetrated further in the home-production sector too. The increase in the number of trips (probably an irreversible phenomenon) in this sector is attributable almost entirely to an increased use of the car. Car ownership tends to encourage intensive travel patterns (positive feedback). Member of households which have a car at their disposal make trips for home production purpose more frequently than people who have no car at theirs disposal (trip frequency ${ }^{3.10}$ per car 2.1 in 1975 and 2.5 in 1990). This applies above all to shopping trips, taking and fetching (school) children; it also explains why public transport occupies an even more modest position than in the case of employment and education. The increase in car use has not been limited to groups who use the car often for getting to work or courses. Housewives and non-employed persons - two groups who did not frequently use the car in 1975 - are now catching up in terms of car use (change in behaviour). For the housewives trip frequency per car was 0.5 in 1975 and 0.8 in 1990 , for unemployed (those declared unfit included) 1.1 in 1975 and 2.1 in 1990, for retired people 1.4 in 1975 and 1.6 in 1990.

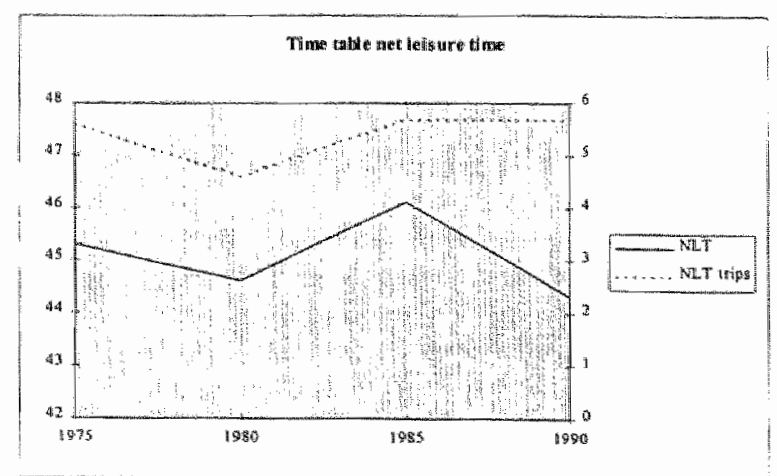

Figure 3.18 Time table net leisure time 1975-1990
During a normal work week in the auturn, the sample period, the great majority of net leisure time is spent at home. The figure is about 2 out of every 3 free hours. Since the 1980 survey and in line with the economic business cycle, the proportion of leisure time spend. outdoors has increased again. The same picture energes in respect of the average number of trips for leisure activities (NLT trip)" ; this too has increased since 1980. However the number of net leisure hours excluded transport (NLT in Figure 3.18) decreases. Since 1975 rather more time has been spent on

\footnotetext{
3. Trip fiequency per car is defined as the number of trips per 10 hour home-production

3. The NLT top variable is measured on the right axis in Figure 3.18
} 
outdoors activities, but also on watching TV, playing sports and participating. For information about trends in holidays and excursions, data from other sources were consulted. These shows among other things that the number of Dutch people visiting recreational or cultural events has increased since 1979 and even more since 1987.

\subsubsection{Conclusion}

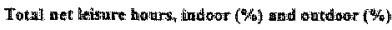

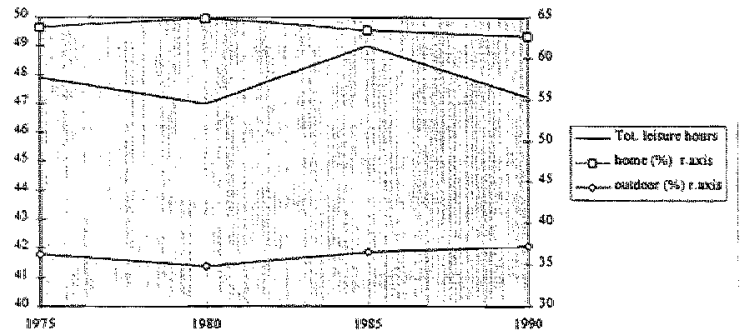

Figure 3.20 Total absolute leisure time, in and outdoor (\%)
It is often said that the more net leisure time people have the more likely they are performing outdoors activities. This common sense statements is not supported by the facts. Indeed, the converse is true since in general the less net leisure time people have the greater percentage of such time is spent in outdoors activities (Figure 3.20). People under 35 and also people at educational institutions have fewer net leisure hours, but spend a higher than average proportion of them $( \pm 40 \%)$ in outdoors activities. There is also a comnection between social status and the extent to which people invest in outdoors activities: the higher the educational level the more time is allocated to outdoors activities. Leisure time spent outdoors (sports, entertainment, visits to friends etc.) belongs to the category of actiwity which generates a relatively large number of trips: in 1990 on average every 2.3 hours (4.3 trips per 10 hours spent outdoor). As many more people are actively engaged in leisure activities than in employment or education, net leisure time has generated more trips then employment and education together since 1985. Employed, middle and high educated between 20 and 50, people make: the most trips in their leisure time. The changes between 1975 and 1990 indicate that there has been some levelling off of the initial differences regarding age and the nature of the activities: older people and/or non-employed and housewives became more mobile in their leisure time. However, the differences in terms of social status remain considerable: employed people are more mobile (went out more frequently) in their net leisure time then people economically non-active, and people with a medium or high level of education are more mobile (went out more often) then people with a lower level of education.

The car is the most used mode of transport for leisure time activities: cycling and walking come second. In leisure time means of transport also serve mainly as recreational aids. This explains the modest position of public transport now and in the future. The relationship between the various modes of transport did not alter greatly between 1975 and 1990.

The (20-50) age-class makes the most frequent use of the car for leisure activities. Once again, this especially true of employed people and the more highly educated in this age-class. But here too, groups such as housewives and retired people who in 1975 could still make little use of a car in their leisure time are catching up.

Car ownership is once again accompanied not only by the more frequent use of the car but also and more generally by higher frequency of trips. Public transport has not lost ground on average, but it has done so among those groups who still made little use of the car in 1975 (housewives and retired persons). It is striking that the use made of public transport has even declined among the inhabitants of the three major Dutch cities, who have a comprehensive public transport network at their disposal. 


\subsubsection{The influence of modern lifestyles on mobility growth}

The general notion is that the more people are engaged in actiwities which are connected with varying locations the greater the number of trips they will made (SCP 1994, 1992). At the same time, the need for individual modes of transport will be greater if the activities are determined by personal arrangements in terms of location, starting time, duration or order of events. One may wonder whether there are reasons for assuming that there are now more people with "individualised" lifestyle than some decades ago. Four of these possible reasons will be elaborated hereafter. It will be assumed that:

- reductions in the size of the households;

- emancipation;

- task combination, and

- diversification of leisure activities.

determine the increase in demand for transport, i.e. for individual forms of transport.

Before the actual influence of these phenomena is analysed, they are discussed briefly below.

\subsubsection{Reduction in the size of households}

Since the 1960 s the average size of households has been declining. This has been due among other things to:

1. a decline in the average number of children per family in which children are still present;

2. an increase in the number of households consisting of two adult partners only, and

3. an increase in the number of people living apart (and people living temporarily separated). Reduction in the size of households signifies a decline in the scale of production and consumption of 'household care'. In 1960 there were on average \pm 28 households for every 100 Dutch inhabitants. By 1990 the figure was \pm 42 . This means that the shopping for 100 people involved 42 trips in 1990 compared with an average of $28 \mathrm{in} 1960$. It is also reasonable to assume that members of "minihouseholds" are more dependent on third parties for human contact and entertainment and that they therefore have more ontdoor activities. The effect of this reduction in the size of households on the need for transport has been investigated by comparing the travel patterns of members of a one or two person household $(1-2 p H S H)$ with those of three to six person households (3-6pHSH). The population of the "mini-households" consists of people up to the age of 50, because these people - unlike older single people - can serve as an indicator for a modem, individualistic way of life. The number of people aged under 50 living in "mini-households" increased by $9 \%$ in 1975 to almost $19 \%$ in 1990 . The number of children living at home declined from $24 \%$ in 1975 to just under $19 \%$ in 1990. Oneperson and two-person households are increasingly common in the (20-35) age-class. "Minihouseholds" are more and more likely to consist of either a working woman or unemployed or retired people (housewives are not often members of this kind of household). In addition, "mini-households" are over -represented among people with a medium or high level of education. As might be expected, children living at home are generally still at school or college.

\subsubsection{Emancipation}

The traditional role pattems between men and women have largely disappeared especially among the post-war generations. These generations include many more women who, like men, are following higher education, developing a professional career and choosing their leisure activities according to their personal preferences. The participation of women in the labour market has risen from $25 \%$ to $56 \%$ since 1960 . In the same period the participation among men, especially those $50^{+}$, declined. Moreover, this catch-up process gained momentum after the $70 \mathrm{~s}$. The percentage of married women among working women has continually risen, which explains why women tend above all to take parttime jobs. The move towards equal relations between men and women is much further advanced in terms of participation in education and the level of education than in the labour market or the homeproduction sector. Emancipation is important in this connection because the greater participation of 
women in outdoors activities is accompanied by a greater need to make trips. Two key variables can be selected as an indicator for the degree of emancipation:

1. the number of married or cohabiting women who are working full or part-time in a profession or business;

2. the number of married or cohabiting men who spent at least 10 hours on home-production (including looking after the children or other members of the household) during the week under review.

The second indicator points to equal rights within the household, in particular to the presence of male partners who spend more than the average amount of time on home-production. The group of married or cohabiting women who perform paid work rose from almost $5 \%$ in 1975 to over $10 \%$ of the sample in 1990 (10\% and $20 \%$ respectively of the total number of women). The number of married or cohabiting men who spent more than the average amount of time on home-production increased from $11.5 \%$ to $15 \%(23 \%$ and $30 \%$ respectively of all men).

The number of working mamied or cohabiting women appears to have increased most in the ( 35 50 age-class and among people with a medium or high level education. In comparison with 1975 , there were more working married or cohabiting women in the category who work over 20 hours a week. Married or cohabiting men who spend more than the average amount of time on homeproduction are now more common in all various age-classes, but in particular in the $50+$ age-class. Although this phenomenon is also increasingly found among employed men, it is still the most common among the non-employed. In 1990 this phenomenon was no longer typical for men with a low educational background, and gained ground in particular among men with a medium or high level of education. Both the categories in question, but in particular married or cohabiting women working outside the home, already made more trips than average in 1975. In that year car use by working. married women was almost twice as high as the average.

\subsubsection{Combination of tasks}

More and more people are combining on a weekly basis a principal activity with study, work or home-production with a secondary activity in one or two of these fields. One of the reasons why the traditional division of labour or responsibilities is gradually giving way to task combination is the women emancipation. However, this is by no means the only reason (CBS 1992). The most important one is that to an increasing extent paid jobs are held by that part of the population who are at a stage in their lives when not only their professional career but also other factors such as dwelling, interior decorating and having and raising children demand a lot of time and energy. This is the case for both women and men in the age-class (25-45). Another factor is the period of study for young people, which is tending to last longer and longer. An increasing number of young people become adult long before their education is finished. Although the percentage of students under the age of 20 who live away from home has stabilised in recent years, the absolute number of students living outside their homes is now much greater than in the 70 s. As the occupants of a room or flat, this group have a "mini-household" and are therefore obliged to combine home-productions with studying and often also with a part-time job on the side. After finishing the study the combination of employment and home-production, as many young adults continue to live alone for a considerable time thereafter.

The increased participation in forms of adult education also leads to task combination. More and more people whose principal activity is in the field of employment or home-production subsequently go on to follow courses. In these cases task combinations of employment with study or of homeproduction with study occur. And in many cases there are combinations of all three. When people spend at least 5 hours a week on each separate obligation, i.e. paid work, study and/or homeproduction, this will be treated as a task in the time budget surveys. This operational definition was felt to be the best way of obtaining an adequate description of the phenomenon. Task combination has an important bearing on mobility because, as mentioned before, those involwed in such combinations tend on average to make more trips than people with a single task. There were strong indications therefore that the persons concerned also combine the travel requirements of the various tasks. The 
number of people with two/three tasks increased from $37 \%$ in 1975 to $48 \%$ in 1990 . The combination of tasks increased among all categories, except in the (50-65) age-class and among people of the lowest educational level. The average trip frequency of the group with two/three tasks was over 18 per week in 1975 (almost 4 mips more than the sample average). People who combined tasks also made higher-then-average use of the car.

\subsubsection{Diversiffication of leisure activities}

Since the time budget survey (TBO) was first conducted in 1975 Dutch people have tended on average to take part in increasingly varied activities but within a slightly smaller amount of leisure time. The variety of the individual range of activities, which indicates how many different leisure activities people generally take part in, has grown by $9 \%$ between 1975 and 1990 . The diversification of individuals leisure activities points to a prosperous pattern in which the opportunities for consumption (equipment, apparatus, subscription, membership etc.) have grown more strongly than the avallable time. Time and money are spread more thinly over more and more things: as a result people take part infrequently in a wide range of activities. Quite independently of this, there is also a growing desire to have a wariety of experiences and impressions. Travelling and moving around mobility for mobility"s sake - are in keeping with these feeling. As people do more and more different activities in their leisure time, they have to be in different locations more frequently and hence have to travel from one location to another more frequently too.

The diversity of leisure activities is a concept that has been operationally defined by reference to observations. On the basis of TBO survey replies, it has been established that on average respondents took part in 8.8 activities (out of a total of 30 different kinds of activities on the list) in 1975 and in 9.6 activities in 1990. People who gave 10 or more positive replies were counted as belonging to the group having a wide range of leisure activities. Over $41 \%$ of the sample complied with this criterion in 1975 and over $50 \%$ in 1990. The (20-35) and $50^{*}$ age-classes accounted for the greatest increase in people with a wide range of leisure activities. Nowadays economically unemployed and retired people are also more likely to have a wide range of leisure activities. Young people and people at school or studying are less likely now than in 1975 to have a wide range of leisure activities. As in 1975 the higher the educational level of the people concemed the more diversified were their leisure activities in 1990. In 1975 the group with a wide wariety of leisure activities made more trips than average, over 16 trips a week. Car use was only slightly higher than average.

\subsubsection{Analysis of the effects of the variation in life styles between 1975 and 1990}

The TBO survey examined to what extent the greater mobility among the population was attributable to an increase in the number of people with a mobile life style of the kind described above. Mobility could be expected to have increased since 1975 because the population in 1990 included more people with a mobile way of life than was the case in 1975. Private transport (all registered trips less trips for employment/business purpose) rose by a modest amount on a per capita basis. Owing to the growth of the population, this naturally resulted in a sharp increase in the total number of trips. In 197514.5 of these trips per person per week were made on average for private purposes; in 1990 the figure was 15.4. The modest increase of $6 \%$ has to be seen as the result of contrary changes : both in and decreases of mobile population segments and an increase of less mobile population segments accounted for this. To what extent can this $6 \%$ increase be attributed to the growth of the groups with a more-than-average mobile lifestyle? This method concentrates on the effect of the change in the composition of a sample of the population, and is therefore called a study of the composition effect (no behavioural changes). The calculation corresponds to the calculation of a weighted average. The percentage of representatiwes of the relevant groups in the populations in 1990 serves as the weighting in a calculation in which the trip frequencies (travel habits) in 1975 are assumed to be constant for each group. Allowance is made in this analysis for the partial overlapping of the groups. If it is assumed that the composition changes (no behavioural changes) were responsible for the slight 
increase in private trips, a major part of the observed increase in mobility can be attributed to the combined effect of the changed composition of the sample (Table 3.5).

\begin{tabular}{|lccc|}
\hline Observed and forecast displacement frequencies in the whole sample in 1990 \\
\hline & observed & forecast & difference \\
& B & B-A & B \\
\hline $\begin{array}{l}\text { forecast based on changes of: } \\
\text { I-2pHSH }\end{array}$ & 15.4 & 1.4 .6 & -0.8 \\
home-living child(ren) & 15.4 & 14.2 & -1.2 \\
women, mamied and outdoor working & 15.4 & 14.6 & -0.8 \\
men, married and with home-production tasks & 15.4 & 14.5 & -0.9 \\
task combiners & 15.4 & 15.1 & -0.3 \\
persons with broad leisure time scala & 15.4 & 14.7 & -0.7 \\
forecast based on the combined effect of the changes & & & \\
in the sample composition & 15.4 & 15.3 & -0.1 \\
forecast based on the growth of the (20-50) age-class & 15.4 & 14.6 & -0.8 \\
\hline
\end{tabular}

Table 3.5 Observed trip frequencies in 1990 and those based on changed sample composition

The group which has combined tasks has the greatest impact in this connection. The effect of the greater variety of leisure activities is less strong but still considerable. The other factors (decline in the size of households, emancipation) have had little effect. Although not all the selected variables play a substantial role, the applied procedure does allow a better explanation of the increase in mobility than would have been possible if only the demographic effect had been calculated. The increase in the size of the active part of the population aged 20-50 (demographic effect) would not completely explain the increase in mobility. In this sense a more specific calculation allows a better estimate.

The question of the relative effect of the various life styles was examined in the same way in respect of car use. The increase of the phenomenon task combination and of the diversification of leisure time behaviour would be the most responsible for the increase of the mobility between 1975 and 1990. It concems all kind of person transport: slow traffic, public traffic and car traffic. However to what extent car the observed increase in car use from an average of 4.4 trips in 1975 to 7.4 trips in 1990 be attributed to changes in composition of the population? This involves a much stronger rate of growth $(+68 \%)$ than that of all private trips $(+6 \%)$.

\begin{tabular}{|lrrr|}
\hline Observed and forecast displacement frequencies per car in the whole sample in 1990 \\
\hline & observed forecast & difference \\
forecast based on changes of : & A & B & B-A \\
I-2pHSH & 7.4 & 4.3 & -3.1 \\
home-living child(ren) & 7.4 & 4.4 & -3.0 \\
women, married and outdoor working & 7.4 & 4.6 & -2.8 \\
men, married and with home-production tasks & 7.4 & 4.5 & -2.9 \\
task combiners & 7.4 & 4.8 & -2.6 \\
persons with broad leisure time scala & 7.4 & 4.5 & -2.9 \\
forecast based on the combined effect of the changes & & & \\
in the sample composition & 7.4 & 4.9 & -2.4 \\
forecast based on the growth of the (20-50) age-class & 7.4 & 4.5 & -2.8 \\
\hline
\end{tabular}

Table 3.6 Observed trip frequencies in 1990 and those based on changed sample cornposition 
Only a modest part of the observed increase in car use can be explained by the combined effect of the composition of the sample (Table 3.6). If the effects are taken separately, the increase in the number of people with combined tasks is once again found to be the main factor. A much more modest part of the growth in car use is attributable to the increase in the number of working married or cohabiting women. The effect of the other factors is very small. Since the members of "mini-households" made less-than-average use of the car 1975, the growth in the number of "mini-households" since then might be expected to have reduced car use. When the analysis was continued, this assumption was found to be untenable with regard to the continuity of travel pattems and the increased car ownership from $1980(27 \%)$ to $1993(40 \%)$.

Although the increase in car use can be attributed only to a limited extent to a growth of mobile life styles, the effect of these life styles is still stronger in rellative terms than the demographic effect, i.e. the increase in the size of the active (20-50) age-class. On the whole, however, it was found that the increase in car use was not for the most part due to composition changes and must therefore be accounted for autonomous growth: the habit of using the car has become mote dominant everywhere.

\subsubsection{Analysis of the differences in changing travel habits}

A second question was whether a change in travel patterns among the relevant categories differed from the trend observed among the rest of the sample. For this purpose the TBO study compared the figures on the trip frequency of the relevant categories in 1975 and 1990 with the trend among the rest of the sample (Figure 3.21 ).

Note Figure 3.21 and 3.22 show the total number of trips and car drives by relevant background data $1975-1990^{3.12}$.

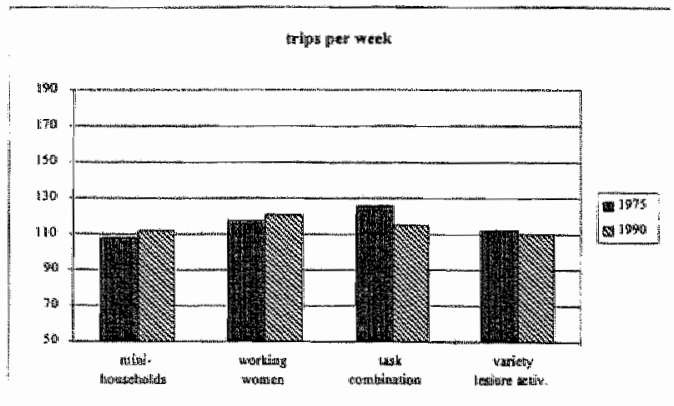

Figure 3.21 Total number of trips by relevant background data (1975/90 sample average index $=100)$

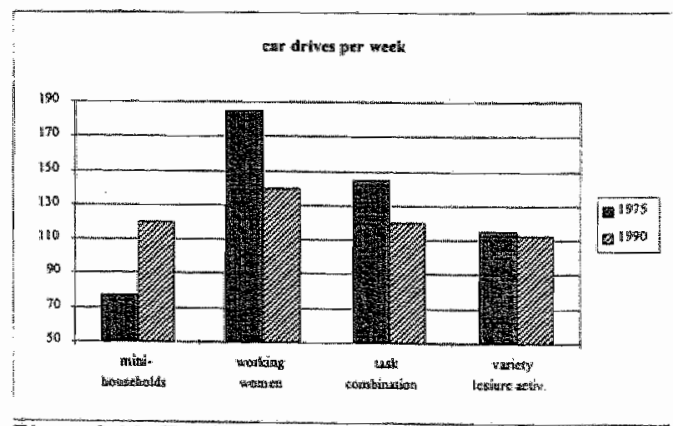

Figure 3.22 Total number of car drives by relevant background data (1975/90 sample average index $=100)$

The mobility of only one of the relewant categories has changed significantly since 1975: members of one atid two person households $(1-2 p H S H)$ were markedly more automobile in 1990 than in 1975 . Although changes also took place in the automobility of the other categories, none of the changes reached a level of any significance (i.e. the $5 \%$ level). With this one exception, the most significant increases in mobility occurred among the remaining, unspecified part of the sample. The assumption that the travel pattems of the categories that were specified would have remained more or less constant did prove to be correct in the majority of cases. The second (implicit) assumption that the travel patterns of non-specified rest groups would also have remained constant proved ir retrospect not to have been correct.

Although people with combined tasks made roughly the same number of trips in 1975 as in 1990 , their counterpart (i.e. people with no task or a single task) made appreciably more trips in 1990 than in 1975. This residual group consists mainly of housewives, the unemployed and retired people (nonemployed). A multiple regression analysis of the 1975 and 1990 data separately, performed by the 
TBO study, also suggests that differences in the extent of mobility are levelling out. Individual differences in trip frequency are explained to a lesser extent by background characteristics (age, income and education), car ownership and the four life style characteristics than in 1975. Car use shows sharp autonomous growth between 1975 and 1990. This change in travel habits occurred for the most part both among the specified groups and the residual groups. The assumption that the pattern of car use by each group would remain largely the same therefore proved to be mantenable. Indeed, the trend towards more intensive use of the car was even stronger (indeed markedly stronger) among members of one and two person households than among the rest of the population.

The same multiple regression analysis shows that the independent effect of car ownership on the extent of car use in 1990 was much stronger than in 1975. People who has a car at his or her disposal tends to used it more frequently. This points to a levelling out of the differences, particularly since wealthy car owners hardly make any more use of their cars than people with a modest household income, however the kilometrage is different. The other category who made frequent use of their cars in 1990 were the older car owners, especially the younger elder (65-74) year old. What is noteworthy about this is that although mobility as a whole decreases significantly as people become older, car use accounts for an increasing share of this decreasing mobility. In other words, the likelihood that old people will travel only by car increases with age.

As against this, people with combined tasks, members of "mini-households" and people with a wide range of leisure activities use the car more frequently than other car owners. There are therefore various signs suggesting that the differences in car use are levelling out, but the trend is less markedly than in the case of mobility. Differences in the extent of mobility or car use can be better deduced from the 1975 characteristics then from the 1990 one. However the characteristic referring to household by size (n-pHSH) became a better forecaster for car use in 1990 then in 1975 .

\subsubsection{Changes in the separate types of trips}

Possible changes in the motive of the various categories for making trips were also examined. The results of this analysis do not indicate that the increase in mobility is due to a particular type of activity. All four types of activity, i.e. employment, education, home-production and leisure activities, have contributed to it. People who combined tasks in the fields of employment, education or homeproduction, made more trips for home purpose in 1990 than in 1975. Although the same applied to people with a wide range of leisure activities, it is hard to see why this group should have made more frequent trips for home purposes and less frequent trips for educational purposes. One explanation could be that the group with a wide range of leisure activities in 1990 contained fewer people at school or college than in 1975. This would also help to explain why children living at home (mainly school children and students) made fewer trips in connection with leisure activities than in 1975 . The increase among the "mini-household" group in the number of people studying could explain why this group made more frequent trips to and from educational institutions in 1990 than in 1975 . 


\section{Chapter 4 \\ New car sales \\ and \\ the Dutch car stock}

\# Objective

\# Methods

\# Data sources

\# Restilts

\# Conclusions
To develop a new car sale (or purchase) system of equation in order to predict the long-run new car sales. New cars entering the car stock are important because they cause qualitative changes of the actual care stock. Qualitative changes refer to fuel efficiency, emission reduction and heavier engine cars.

Stock-flow dynamics based on stock-adjustment process derived from the desired or plamned car stock which is determined by the permanent income.

Car sales data for the period 1960-1994 from CBS and RAI, car stock data for the period 1961-1994 from RDW. Income data from CBS for the period 1961-1994.

The estimation of three models enabled us to chose two models as candidates for the simulation model. The delay-model (in continuous sense) and the lag-model (discrete sense) show remarkable features asking for more research. The first results of locality and locked-in phenomena are investigated.

The car market changed during the last 30 years after an accelerated growth in the $60 \mathrm{~s}$ and $70 \mathrm{~s}$, the car market changed during the $80 \mathrm{~s}$, it became a replacement market (buyers market) with its inherent short-run instability. The penetration or diffusion rate is not still completed in the 90 s. So the car stock will still growing (in an asymptotic fashion) with increasing income and the number of households. 


\subsection{New car sales $1970-1995$}

\subsubsection{Introduction}

In this paragraph some background features of the deteminants of car purchases (new and used cars) will be discussed in a qualitative way before a quantitative analysis will be performed. The data originates from three CBS statistical sources and one of the State Office of Road traffic (Rijksdienst yoor Wegwerkeer (RDW)). The first two sources, which offer data of consumer confidence of different kind, are taken from representative samples of private households: the Consumer behaviour research (CCO) and the Social-economic panel research (SEP), the third source, which offers data of the new car sales, is the statistic of Dutch vehicles (Statistiek van de motorvoertuigen) and the $\mathrm{RAI}_{\text {s }}$ the data of the used-car sales are offered by the RDW. In this paragraph the car buying plans will be related, based on aggregated data, to the development of the observed car ownership, the car stock. and fluctuations of consumer confidence. From recent Dutch research (CBS, 1991 a) the car buying plans are related to household income, the age of the head of the household, the level of consumer confidence and buying willingness. An important part of the differences between private households can therefore be explained by a few household features. On the aggregate level as well on individual household level changes of consumer confidence corresponds with changes in "buying plan of a car within 2 years'. This last phrase is a question of the CCO questionnaire. Whether the buying plans are realised depends, among others, of 'the expected (un)employment situation the next year', also at question of the $\mathrm{CCO}$ questionnaire.

\subsubsection{Car buying plans by households at an aggregate level}

Car buying plans by households at an aggregate level means that households are treated as a set consisting of homogeneous elements: the household, not further characterised. The household is the basic unit of analysis. If one wants to investigate the car buying plans sec then the households should. be divided up according to a well chosen characterisation, for example, households by size, by composition, by income classes of the head of the household or by employed or non-employed by the same head, etc. As we are investigating the long term determination of the active cat stock (fleet) in relation to consumer lifestyles and emissions, we will not pursue this topic further and stick to the household at an aggregate level.

The published data of car sales (new- as well used-cars) refers to the integral Dutch economy, e.g. all sectors of the economy. In our scope the economy consists of the sectors households and nonhouseholds. The sector non-households refers to firms, enterprises, local and central government (included the army). The sector households is further divided into private households and instinutional howseholds. Private households is a set consisting of one or more members (elements) of persons, living in a particular (living) space, with the goal to stay there and to meet the daily livelihood or the necessities of life. Institutional households refer to inhabitants which stay and lives at elderly or nursery homes. The private household is the basic unit of analysis.

\subsubsection{Car sales}

In dealing with car buying plans one has to distinguish two series:

- new car sales, and

- used-car sales

summing to total car sales. New car sales directly influence positively the level of the car stock, usedcar sales redistribute only the existing car stock, it changes only the car ownership. Scrapping, on the contrary, influences the car stock negatively, it diminish the car stock. Figure 4.1 shows the three series for the period 1976-1994.

Note that the new car sales are measured on the right axis, the total and used car siales on the left axis. The ratio is 1:3 to 1:4. The co-movement of new car and used-car sales applies for the end $70 \mathrm{~s}$, the mild recession in 1986/87 caused new car sales to decline, but used-car sales filled up the gap, in contrast to the '92/93' dramatic decline of the new car sales, the decline was hardly compensated by the used-car sales increase. 


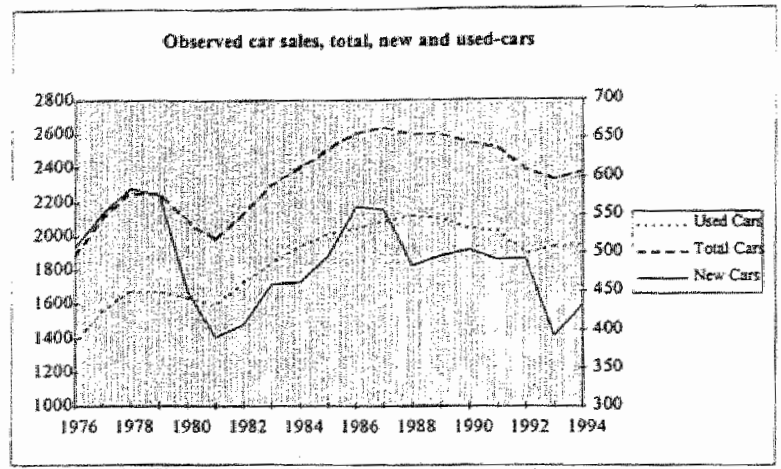

Figure 4.1 The observed total, new and used cars

The "92/93" decline in new car sales was mainly caused by a sharp decline of the non-household new car purchases. Non-households, as noted above, refer to business, firms and government organisations. Indication for this cause is the decline of the non-household car stock during the early 90 's, in contrast with the slight increase of the household car stock, the increase in the car stock was mainly due to importation of used-cars from Germany and an ageing of the car stock. (The phenomenon of the ageing of the car stork will be explained in the next section). Figure 4.2 shows the rates of change of new car sales (NCgr) and the used-car sales (UCgr) explaining the underlying behaviour of both series during the last 20 year. The series of the new car sale is very erratic and is subject to influences of changing buying plans caused by plan revision resulting in a possible backlogging or abandoning of the demand for new cars.

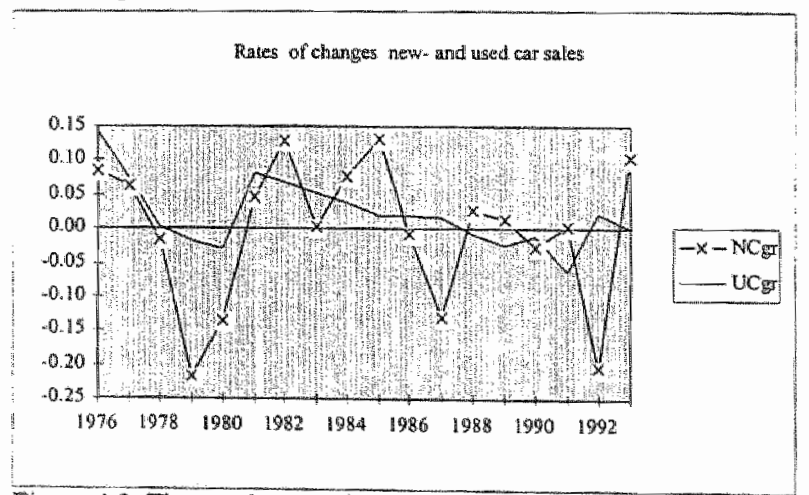

Figure 4.2 The yearly growth rates of the new cars and used cars $1976 \cdot 1993$

For an indication of the potential future car stock or car ownership it makes sense to investigate:

a) the relationship between planned car purchase (a llow variable) and the actual car stock (a level variable),

b) the household income and financial situation, determining the planned or desired car stock,

c) the index of consumer confidence and 'the buying willingness of cars within two years', explaining the new car sales (observed), while the buying willingness of cars will be determined by "the unemployment expectations the coming year", a proxy for the perceived state of the economy.

ad a. The planned or desired car purchase within 2 year is a question in the consumer behaviour survey (CCO) and has 5 possible answers: "Yes, sure", "Yes, maybe", "Not, likely", "No, sure", "Do not know", adding to 100. In Figure 2 the percentage households is shown which have answered 
positively the question of car buying plans with 'Yes, sure', and 'Yes, maybe', with the observed actual car stock of households. Figure 4.3 shows the observed car stock of Dutch households wersus the planned car purchases in 2 year. Note, the series of 'planned car purchases in 2 year" (Car Purch*) is measured on the right axis, the observed car stock of the households (Car Stock HSH) on the left axis. ${ }^{\text {* }}$

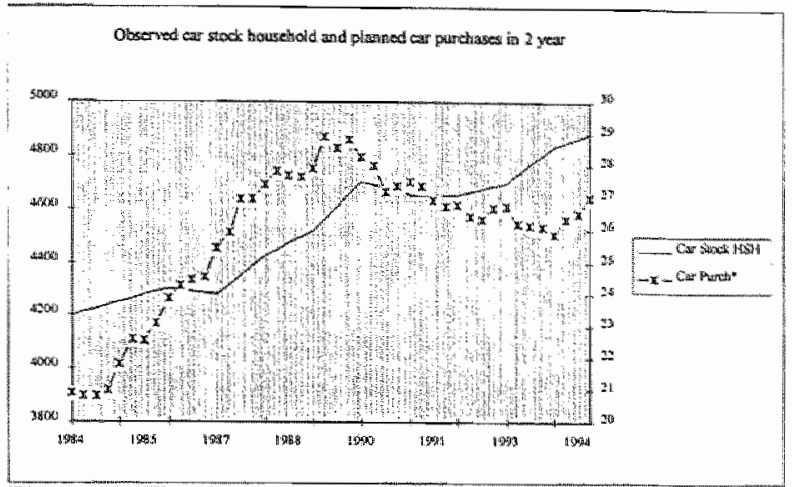

Figure 4.3 The observed car stock of the Dutch bouseholds compared with the planned car purchases in 2 year.

As can be seen in Figure 4.3 there is co-movement of observed or actual car stock and the "planned car purchases in 2 year' during 1985-1990. During the early 90's the relationship is distorted by the (unexpected) sharp economic recession in analogy with the deep recession during end 70 s/early 80 s. The 'planned car purchases in 2 year' is treated as a proxy for the planned or desired car stock by households. If understood in this way the relationship between the two series during the early $90^{\prime}$ 's can be explained by the short term distuption of the perceived state of the economy or consumer confidence, causing a sudden revision of the new car sales. This disruption causes that in the short run the actual car stock is not equal to the planned car stock (in quantitative and/or qualitative way), or a backlogging or abandoning of the demand for new cars.

$a d b$. Another indicator for the planned or desired car stock is the household income in a more or less medium or long term sense. This theme will be treated in detail in section 4.2 .2 . where the permanent income hypothesis will be explained.

ad c. The index of consumer confidence originates (like "the car buying willingness within 2 year' and 'the expected unemployment next year') from the consumer confidence research (CCO). As the composite confidence index and the single 'expected unemployment in 1 year' index practically coincides, we take "the expected unemployment next year" index in the analysis. Figuur 4.4 shows the evolution of "the index of expected unemployment next year" (Exp Employm*) and the observed car sales (TOT.Car sales). The co-movement is nearly perfect, indicating that short term unemployment expectations directly influence buying plans and that unemployment expectations do revise buying plans although the planned car purchases in 2 year are still positive during the period 1990-94. Figure 4.5 shows the divergence between the two series.

Although households are positive with regard to 'the car buying plans within two year" (Car. Purch*), at the same time "the expected unemployment next year" (Exp Employm*) declines very strong, causing a revision of the actual new car sales and a partial switching to used-car purchases or a backlogging/abandoning of the demand for new car sales, causing the aging of the car stock.

4.t The series of the planned car purchases starts in fact in 1972 , but the question was changed between 1979 and 1984 to 1 year in stead of 2 year, so the series is not homogeneous and therefore not comparable and it is decided to start with 1984. 


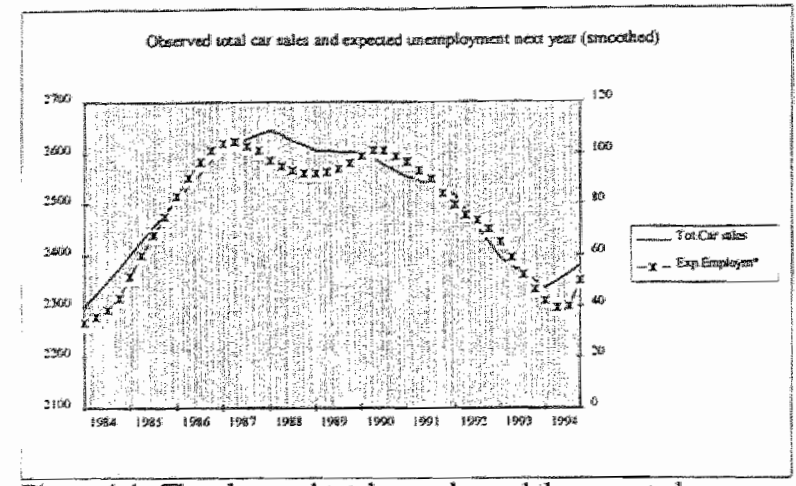

Figure 4.4. The observed total car sales and the expected unemployment next year

Note the series expected unemployment next year is measured on the right axis in percentages. The planned car purchases (left axis) is measured as the sum of the two 'Yes' answers minus the two 'No' answers plus 100 , in order to omit negative figures.

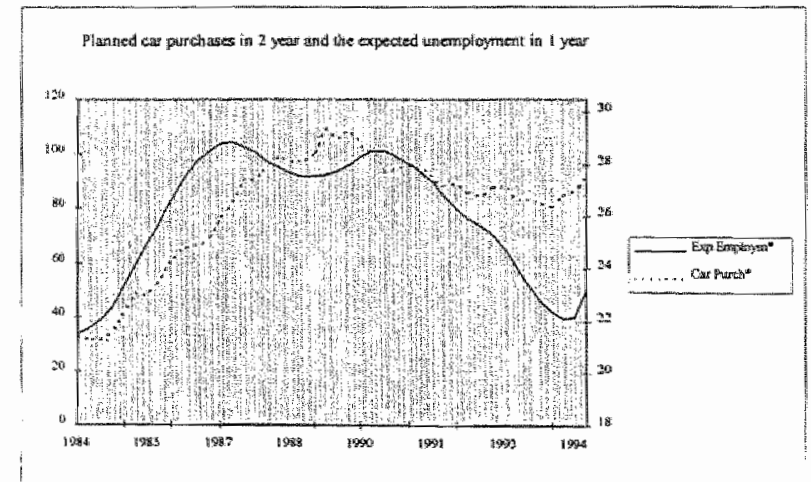

Figure 4.5. The comparison of the planned car purchases in 2 year and the expected unemployment next year.

In sum, the slight decline of the consumer confidence (or the proxy "expected unemployment next year") in 1987/88 did not coincide with and was not followed by a reduction in the "planned car purchases in 2 year" as a proxy for the car buying plans. During the deep recession during 70 s/ early 80 s and early 90 s both series did show a co-movement, that is to say the decline of the consumer confidence or its proxy 'the expectation of unemployment next year' continued to decrease long enough to start the process of buying plans revision. During the mild recession of the mid 80 s (in fact an inventory-correction recession) the decline in consumer confidence or the expectation of unemployment did not last enough for the car buying plans to be revised and so the buying plans were not revised. During the period end 70 s/early 80 s and 90 s the deep recession (an investment and inventory-correction recession) caused the revision of the car buying plans. 


\subsection{New Car Sales: An aggregate new car salles model}

\subsubsection{Introduction}

In the past many relationships explaining car sales include both demand (often total sales in monetary terms) and supply elements without distinguishing which variables serve to explain short-run fluctuations and which to explain long-run developments. Moreover, most of the research is focused on total automobile demand without taking into account differences in quality chatacteristics of different model types, fuel type and cylinder content class. In these studies, the depreciation level of the currently held car stock is usually related to the demand for new stock. This approach leads to a very general stock of adjustment (Griliches 1963) or generalised acceleration framework (Jorgenson and Siebert 1968). The best known aggregate automobile demand studies using this approach in timeseries context are those of Roos and von Szeliski (1939), Chow (1957), Suits (1958), Wykoff (1973), Rippe and Feldman (1976) and Blomqvist and Haessel (1978). The estimates of price elasticities from these studies range from -1 to -1.5 , and the estimates of income elasticities range from 1.5 to 4 (Bajic 1993).

The second approach is based on viewing automobiles as bundles of individual attributes (Lancaster 1966) for which no explicit markets exists. Rosen (1974) provided the theoretical base of this model. The difficulty with this approach is that the prices of individual characteristics are not abserved but must be imputed from differences in prices of otherwise identical bundles, albeit with different characteristics. The implicit prices of automobile characteristics are obtained from the hedonic regression, and then used, free of quality-differences, in the second-stage estimation of demand parameters. Cowling and Cubbin (1971) explain market-share movements by changes in quality adjusted prices. The residuals from hedonic price regressions are used as a price adjusted for quality differences. The idea that the residuals from the regression of prices of differentiated goods on their qualitative attributes are the quality adjusted prices was suggested by Griliches (1971). The main advantage of this approach over the aggregate demand is its treatment of the automobile as a differentiated good. This allows the investigation of the influence that model characteristics will have on automobile demand. However seen our goal we need a differentiation of new versus used automobiles, by year of construction (vintage), by fuel type, and cylinder content. Differentiation by fuel type leads to two main branches gasoline versus diesel oil or LPG (liquefied petrol gas), the cylinder content in three 3 classes ( $c c<1399,1400<\mathrm{cc}<2000, \mathrm{cc} \geq 2000)$. Ideally applying the ideas of Rosen (1974) one needs a four-stage discrete choice model in stead of the two-stage procedure as the first choice will be between new or used automobiles, the second choice is gasoline wersus nongasoline engine system based mainly on the break-even point of total yearly user cost versus yearly average kilometrage, for example in 1995 (1991) the break-even point for a LPG automobile was $27000(20000) \mathrm{km} /$ year, for diesel $25000(24000) \mathrm{km}$, so consumers with a yearly kilometrage < $20000 \mathrm{~km}$ will likely chose for the gasoline automobile system with a third choice of the cc-classes and the fourth choice the remaining difference in attributes. Due to lack of avallable data we are abliged to take a different route. As Roos and Szieliski we will relate directly the long-run dynamics of demand to the stock of cars and permanent income, rather than account for in proxy fashion by the rate of change of income. The supply of new cars at retail can be modelled as depended on sale price, the wholesale price of the car, and on dealer's cost of operations, however seen the aim of our study we take the simple assumption that the supply of new cars will be derived from the sale of new cars, this is justified in a buyers market (or replacement market) environment.

Therefore only long-run determinants will be analysed and estimated in this section. The long-run determinants of purchases of consumer durables are much different from those of other consumption and investment in residential construction. From the consumer durables the new car sales will be treated separately, because of the mobility aspects and the emission factors determined by car type, wintage and fuel use. Because of the particular nature of durables (new car sales included), it has sometimes been suggested that a function explaining these purchases or sales should be an adaptation of functions explaining consumption of nondurables and services and fixed business investment. But this would give a misleading impression of the type of consumer durables function that we want apply. In particular, the lag structures of the other functions are quite inappropriate. In the function for 
consumption of nondurables and services, lagged consumption is an important determinant of present consumption. This is explained through habit persistence or irrewersibility of consumption patterns. In the fixed business investment function, there is a lag of a year or more between the time when cconomic variables change and the bulk of investment actually undertaken. However, neither of these important relationships is found in a function explaining consumer durables. First durable purchases are by their nature made only at long unequal time intervals, unlike those purchases such as food, rent, and so on, which must made frequently at evenly spaced intervals. Second, past purchases of durables tend to have a negative rather a positive effect on present purchases. Third, purchases of most durables can be made almost immediately, unlike fixed business investment, so that a long gestation lag between income and purchases does not occur.

\subsubsection{Developing and estimating long-run new car sales functions}

A framework for analysing consumer behaviour is the stock adjustment model, viewing the households as attempting to adjust actual to desired (or planned) stocks of assets. Within this framework, survey measures of consumer purchase expectations (section 4.1.1) can be interpreted as a subjective estimate of the difference between actual and desired stock, with reported purchase expectation reflecting the speed of the adjustment process as well as the underlying determinants of desired stock. And survey measures of consumer attitudes (optimism, pessimism) might be interpreted as one of the arguments in the desired stock function. It should be pointed out that by their nature, durables goods are not purchased to be used up themselves but for the flow of services received from these goods until the product is fully depreciated. The analysis of demand for consumer durables focuses on the demand for durable goods stock, and only indirectly examines purchases. In the next section a model will be developed that relates several aspects of purchase behaviour to stock demand. The model has to take provision for the lagged adjustment of the stock of automobiles to changes in the equilibrium level of stocks, for the expectational basis of stock demand, and for the distinction between transitory and permanent influences on demand. In general terms, the model views consumers as having a 'target' or 'desired' value of durables stocks to which they adjust gradually. Adjustments are not made instantaneously partly because of decision and purchasing lags, partly because the level of desired stock represents a target demand about which there exists some uncertainty, and partly because of transaction costs. Household investment decisions are sensitive to uncertainty because resale markets are imperfect; a decision to invest represents a commitment to consume a certain level of services wel』 into the future. Net imvestment is viexred as having a 'permanent' or 'planned' component and also an 'unforeseen' or 'transitory" components. In general the distinction between permanent and transitory investment may come from an unexpected but permanent income change which alters the rate of consumption and therefore the level of durable stock helld. However, the permanent component depends on long-run expectations and average adjustment lags, while the transitory component represents the inmediate reaction to unexpected income flows. The transitory component accounts for the volatile behaviour of investment because of unforeseen economic phenomena (expected unemployment, and related consumer sentiment) alter the time pattern of stock adjustment.

The flow of services received from these goods is not the definition of consumption entered in the national income accounts. The national income definition refers to gross additions to the stock of durables in much the same way that fixed business investment refers to gross additions to the stock of business capital. Just as the stock of capital is proportional to the firm's full capacity output, the stock of durables will be proportional to an individual's income, if population is the unit of analysis, or household's income, if the household is the unit of analysis. Furthermore, just as both present and lagged output are important determinants of investment, both present and lagged income will be used to explain the level of the stock of consumer durables. The concept of permanent income, developed by M Friedman (1958) enters our analysis, because this concept is of importance not only for determining new cars sales, but also for other consumer durables and nondurables and possible investment in residential construction. Also, just as the purchases of consumer nondurables and 
services can be treated as being proportional to permanent income, the stock of consumer durables is also proportional to permanent income.

\subsubsection{Permanent Income}

The question of lags in consumer behaviour was investigated from a rigorous point of view by Friedman. Friedman approaches the problem by making a distinction between income actually received, called measured income (a flow variable) and the income on which the consumer actually base their behaviour, called ummeasured or permanent incomes.2 (a stock or level variable). A similar distinction can be drawn between measured and permanent consumption. However, following Friedman, one can define permanent income as the amount a consumer unit (be an individual or a household) could consume (or believes that it could) while maintaining its wealth intact. Similarly, permanent consumption is the value of the services that it is planned to consume during the period of interest.

The principal hypothesis of the permanent income theory states that the ratio of permanent consumption to permanent income is independent of the level of permanent income. Since permanent consumption is also taken to be proportional to permanent income, the long-rum marginal propensity to consume (mpc) for each consumer unit is equal to their average propensity to consume (apc), and thus the aggregate long-run mpc is equal to the aggregate apc. The apc's need not be the same for all individuals or types of households or for all time periods, in particular, they may depend on the interest rate, the ratio of non-human wealth to permanent income, the dispersion of measured income around its mean value, or the age and composition of the consumer unit. However, the value of the ape"s are independent of the level of permanent income.

In formal statements:

where

$$
\begin{array}{lll}
C_{p}=k(i, w, u) Y_{p} & \\
Y=Y_{p}+Y_{t r} & \rho\left(Y_{p}, Y_{t r}\right)=0 & \bar{Y}_{t r}=0 \\
C=C_{p}+C_{t_{r}} & \rho\left(C_{p}, C_{t r}\right)=0 & \bar{C}_{t r}=0 \\
\rho\left(Y_{t r}, C_{t r}\right)=0 & &
\end{array}
$$

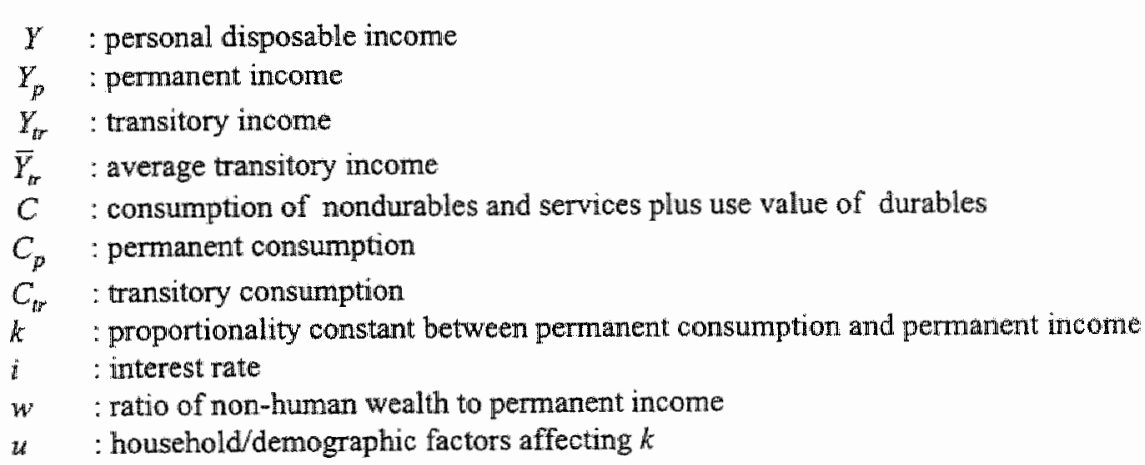

In addition, $p$ is the correlation coefficient and the barted variables represent mean values. Equation (4.2.1) explains that $C_{p}$ is proportional to $Y_{p}$, with the proportionality factor depending on various economic and demographic factors. Equations (4.2.2) and (4.2.3) state that measured income and consumption can each be divided into a permanent and a transitory component, that these components are independent, and that the mean value of transitory component is zero. Equation (4.2.5) states that the transitory components of income and consumption are independent. If $i, w$, and 
u remain constant over time, then the ratio of $C_{p} / Y_{p}$ will will be constant over time. If short-run fluctuations in $C$ and $Y$ are averaged over time (for example, by taking business cycle averages so that $C_{r r} \equiv Y_{t r} \cong 0$, then the long-run $C r Y$ ratio will remain constant and will exhibit any trend. Furthemore, the long-run constancy of the $C / Y$ ratio implies that consumption and income are proportional in the long-run and that the long-run mpc is equal to the apc.

Although permanent income is an unobservable variable, Friedman approximated it by a weighted average of present and past measured income with the weights declining exponentially. Such weights are exponentially distributed for the continuous case and geometrically distributed for the discrete case, as we applied it:

$$
Y_{p}=\sum_{i=0}^{\infty} \lambda Y_{i-i} .
$$

The above weighting structure implies that consumption plans are influenced more by recent than past income (declining in importance). We can apply directly the continuous case in our simulation model for modelling $C_{t}=k\left(Y_{p}\right)_{t}$ or since the weights for the measured income terms decline geometrically, the equation can be transformed into a simpler relationship proposed by Koyck with respect to the investment functions. It is designed for expressions with an infinite number of terms, although the modification for a finite number of terms is rather easy. In general terms,

then

$$
Y_{t}=k \sum_{i=0}^{\infty} \lambda^{i} X_{i-i}
$$

or, in general.,

$$
\lambda Y_{t-1}=k\left(\lambda X_{t-1}+\lambda^{2} X_{t-2}+\ldots+\ldots . .\right)
$$

Subtracting (4.2.7) from (4.2.6) gives

$$
h_{i-1}=k \sum_{i=0}^{\infty} \lambda^{i+1} X_{t-i-1}
$$

$$
Y_{t}-\lambda Y_{l-1}=k X_{t} \text { or } Y_{t}=k X_{t}+\lambda Y_{t-1}
$$

Applying to the car sales, CS, and car stock, CST, we state that the planned or desired car stock CST* is proportional to permanent income, that is to say to some weighted average of previous income which extends over many years. After a certain point, each previous year has a declining weight in this average. There are any number of particular lag structures that could express this fact. As stated abowe, Koyck chose a structure with a series of geometrically declining weights.

That is, if the state variables are in equilibrium, that is $\operatorname{CST}_{t}^{*}=C S T_{1}$, and $0<\lambda<1$, then

By the Koyck transformation

$$
C S T_{t}=\alpha\left(Y_{t}+\lambda Y_{t-1}+\lambda^{2} Y_{t-2}+\ldots+\lambda^{k} Y_{t-k}+\ldots\right)
$$

Subtracting

$$
\lambda C S T_{t-1}=\alpha\left(\lambda Y_{i-1}+\lambda^{2} Y_{t-2}+\ldots+\lambda^{k} Y_{t-k}+\ldots\right)
$$

$$
C S T_{t}=\alpha Y_{t}+\lambda C S T_{t-1}
$$

Now by definition the car stock at time $t^{4.3}$ equals the car stock at $t-l$ plus the summation of car sales and scrapping, $S C R$, during the time period $t-(t-1)$, so in the simulation model the general model 4.4 description of the car stock with simulation time step, $0<\Delta<t$, is as follows:

$$
C S T_{t}=C S T_{r-1}+\sum_{a}^{t}\left(C S_{\Delta}-S C R_{\Delta}\right)
$$

\footnotetext{
4subscript $t$ refers in the simulation model to the end-year situation, $\Delta$ can refer to daily $(\Delta=t / 365)$, weekly $(\Delta=t / 52)$, monthly $(\Delta=t / 12)$, etc. periods.

4. The discrete simulation model is in fact a discretised continuous state space model. It approaches the continuous formulation when $\Delta \rightarrow 0$.
} 
where

$$
S C R_{\unlhd}=\delta C S T_{p-1}
$$

$C S_{\Delta}$ : simulated new car sales at time step $\triangle$

$S C R_{\Delta}$ : simulated scrap at time step $\Delta$

However investigating long term developments we set $\Delta=f$ and by the Koyck transformation this our model 4.2 .10 to be estimated is:

with

$$
\begin{gathered}
C S_{t}=\hat{\alpha} Y p_{t}+\hat{\beta} C S T_{t-1} \\
C S T_{t}=C S T_{t-1}+C S_{t}-\hat{\delta} C S T_{t-1} \\
\hat{\beta}=\lambda-1, \hat{\beta}<0 \\
\hat{\delta}=1 / \rho_{0}, 0<\hat{\delta}<1
\end{gathered}
$$

where

$$
\begin{aligned}
& C S: \text { Car Sales (units/year), observed } \\
& C S T: \text { Car Stock (units), observed } \\
& S C R: \text { Scrapping (units/year), observed } \\
& Y P: \text { Permanent income } \\
& \hat{\delta}=1 / \rho: \text { Scrapping Rate (1/time) to be estimated }
\end{aligned}
$$

which states that the long-run new car purchases depend positively on income and negatively on existing car stock.

\subsubsection{Estimating lagged variables}

Lagged terms can be modelled and estimated in a continuous ${ }^{4.5}$ (delays) or discrete formalism (lags).

- Delays are symbolised by the delay-operator $D_{\theta}^{m}(*)$. This symbolises a delay of order $m_{\text {, with }}$ $m>0, m \in \mathbb{N}$ and time constant $\theta, \theta \in \mathbb{R}$.

In practice the order $m$ will be in the range of $0<m<9$, with $m=1$ or 3 as the most practical order or shape, each order has its own behavioural justification.

Note that $D_{\theta}^{\mathrm{l}}(\bullet)$ stands for the first-order delay, that is the continuous lag with exponentially declining weights, as referred above, giving the largest weights to the most recent events. This form of delay-operator is equixalent as:

$$
D_{\theta}^{1}(Y(t))=\int_{0}^{\pi a t} \frac{Y(t)-Y_{y}}{\theta} d t
$$

Higher-order delays are modelled as cascaded first-order delays, giving rise to two different basic behavioural reaction pattems. Delays can be estimated by estimating the time constant $\theta$ for a fixed integer $m$-order delay, say $m=1$ and estimate $\theta$, the same holds for $m=3$, etc.

- Lagss.6, symbolised by the lag-operator $L^{n}(\bullet)$ of order $n$, can be estimated, in two ways:

1. estimating the lag coefficients $\omega_{l}$ of the $\hat{\omega}_{l} L^{\frac{1}{n}}(\bullet)$ operators, $\bar{n}$ is a prefixed integer, $0<\bar{n}<T, \bar{n} \in \mathbb{N}$ or

2. estimating the order $n$ of the lag operator $L^{\hat{n}}(\bullet)$, where $\hat{n}$ is a real number $\hat{n}>0, \hat{n} \in \mathbb{R}$, $\bar{\omega}_{n}=\mathbb{1}$ and $\hat{n}>\Delta(\Delta$ is the simulation time step $)$

Note that $L^{n}=\lim _{m \rightarrow \infty} D_{\theta}^{m}$, the delay approaches the lag (like an impulse) as $m$ increases, in the limit as $m \rightarrow \infty$ the delay equals the lag operator with $n=\theta$.

\footnotetext{
${ }^{45}$ An important class of continuous time delays are the exponential smoothing representations.

4.5 For the properties of the lag operators, see W. Enders 1995
} 
- Distributed lags, $L_{D}^{p}$, of order $D: L_{D}^{p}=\sum_{n=1}^{P} \hat{\omega}_{p} L^{p}(\cdot)$

The discrete lag model can be formulated as follows:

$$
C S_{i}=\hat{\alpha} Y p_{s}+\hat{\beta} C S T_{i-1}+\hat{\omega} L^{n}\left(C S_{i}\right)
$$

or

$$
\begin{aligned}
& C S_{t}=\hat{\alpha} Y p_{t}+\hat{\beta} C S T_{t-1}+L^{\tilde{n}}\left(C S_{i}\right) \\
& C S T_{t}=C S T_{t-1}+C S_{t}-\hat{\delta} \operatorname{CST} T_{t-1} \\
& \hat{\beta}=\lambda-1 \\
& \hat{\delta}=1 / \rho
\end{aligned}
$$

with

\subsubsection{Some final remarks}

A relative price component has not been inserted in the equation $(4.2 .10),(4.2 .11)$ and $(4.2 .12)$, because of the premise that relative price considerations do not determine directly the car ownership but the choice of car type (by cc or by fuel) and/or new or used-cars consideration. The credit terms are very important in the short run, but we assume that in the long-run, in an assumed growing econorny, credit availability poses no constraints on 'the expectation of a car purchase within 2 years' (planned car purchases), this holds also true for car supply. Both variables being determined by competiriwe market forces, by which supply and demand interaction determines an equilibrium price. Debt burden act in the model as a financial constraint in the case of new car purchases. If the actual debt burden exceeds the equilibrium debt burden then the actual car buyers will become potential car buyers, this means that the car purchase will be temporarily postponed, and enter a backlog of postponed demand, till better market conditions returns. The same holds true for short-term labour market conditions, in case of unemployment or better 'the expected unemployment next year' or labour time reduction. The last consumer expectations influence directly the buying willingness of cars. As is the case with all durable goods cars purchase can easily be postponed, causing erratic and short-run unstable behaviour, see Figure (2.1). These phenomena can be explained by the changes in short-run expectations. Looking to the long-run car ownership, this will be determined by household type, permanent income and the actual car stock, the debt burden approaching or exceeding the equilibrium debt burden acting more or less as a short term financial constraint. 


\subsection{Estimation $1961-1994$}

\subsubsection{Introduction}

The data of new car sales and active car stock are compiled from CBS statistics (CBS 1994 A) Figure 4.6 illustrates the time series from 1960 to 1994 . Note the new car sales (x 1000) and real disposable income ${ }^{4.6}(\mathrm{x} \mathrm{mln})$ are measured on the right axis, the car stock ( $\left.\mathrm{x} 1000\right)$ on the left axis. Of interest are the sales figures of the period $60 \mathrm{~s}-70 \mathrm{~s}$. Unprecedented car sales resulting in an exponential growth of the car stock, closing the gap of the relation of the real disposable income and the desired car stock (not shown). The same development is depicted very clearly in Figure 4.7 This development is based on strong income growth effects (with a accelerating desired car stock levels) and a starting diffusion effect, both signalling the erea of automobilism, supporting the exponential increase of mobility of the Dutch society.

\section{New car sales, car stock and real disposable income 1960-1994}

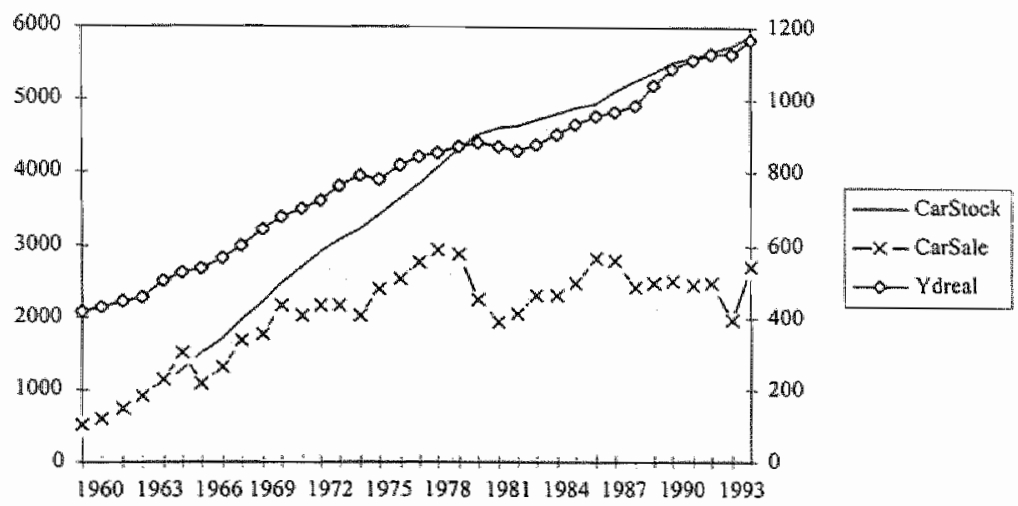

Figure 4.6 Real disposable income, Ydreal ( $\mathrm{x}$ mln), left axis; new car sales, Carsale ( $\mathrm{x} 1000$ ), right axis and car stock, CarStack (x 1000), right axis.

During the period 1972 and 1979 the number of cars increases with 1.4 million to 4.3 million, an increase of $48 \%$. Round 1980 a point of inflection occurred introducing the beginning of a new growth area or regime, the accelerated growth rate of the car stock changes into more moderate growth rates. The rate of growth of the car stock in 1990 was $29 \%$ for the period $1979-1990$ (from 4.3 to 5.5 million). This increase of the number of cars did not involve corresponding increase of the diffusion rate of the car ownership in the private households (an analysis of the diffusion rate of the car stock and car ownership will be presented in chapter 6).

Since the 80 s the growth rates follows those of the real disposable income and of the number of households. Probably giving more weight to the household development in the recent and next decade(s), than to the development of real disposable income. After 1980 the new car sales undergo eratic up and downs, following or preceding the recession of the early $80 \mathrm{~s}$ and $90 \mathrm{~s}$. The steep drop of car sales in the early 80 s was followed by a remarkable recovery in the mid 80 s. These instabilities characterise the car market's change into a replacement (buyers) market. At the moment experts in the car market do not expect the same pattern (resurgence) will happen in the mid $90 \mathrm{~s}$ after the steep decline of the early 90 s.

\footnotetext{
4.6 The real disposable income has been deflated for the "volume" component. The volume-changes are determind according to the formular of Laspeyres. The weighting scheme referred to the data of the preceding year and wot to the data of a particular basis year. As the development of the "volume" over time is the topic under inwestigation the mutations are coupled with the help of a chain index to a chain index number.
} 
Real disposal income (\%A) and Car stock ( $\% \Delta)$

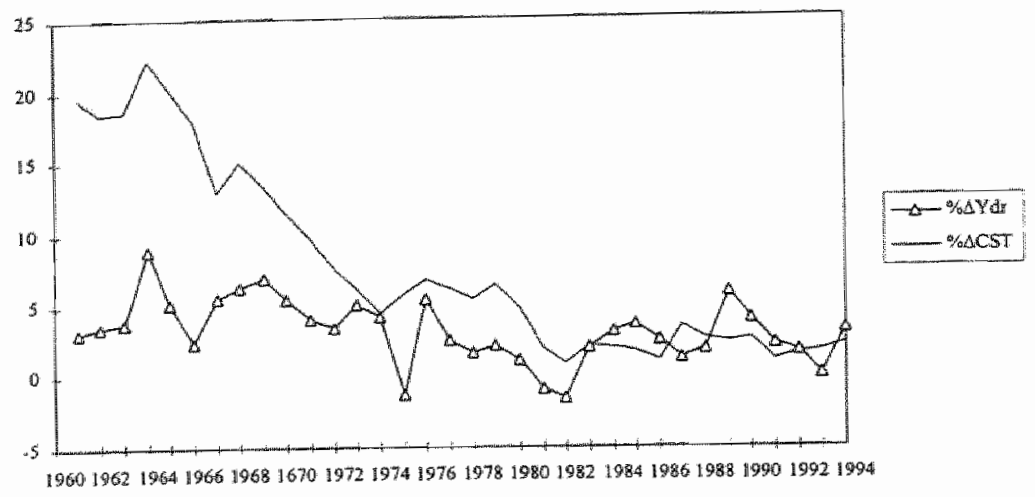

Figure 4.7 Real disposable income $(\% \Delta)$ and car stock $(\% \Delta)$

In sum, the percentage growth figures, defined as $\left(\frac{x_{t+1}}{x_{t}}-1\right) * 100$, show the eratic character of the new car sales time serie. In Figure 4.8 the 1993 figure shows a $20 \%$ decrease in new car sales comparable with the 1979/81 decline and somewhat less than the $30 \%$ drop in 1966/67. It suggests a $11 / 13$ year cyclic character of the new car sales. The frequencie domain analysis below will confirm this periodic character.

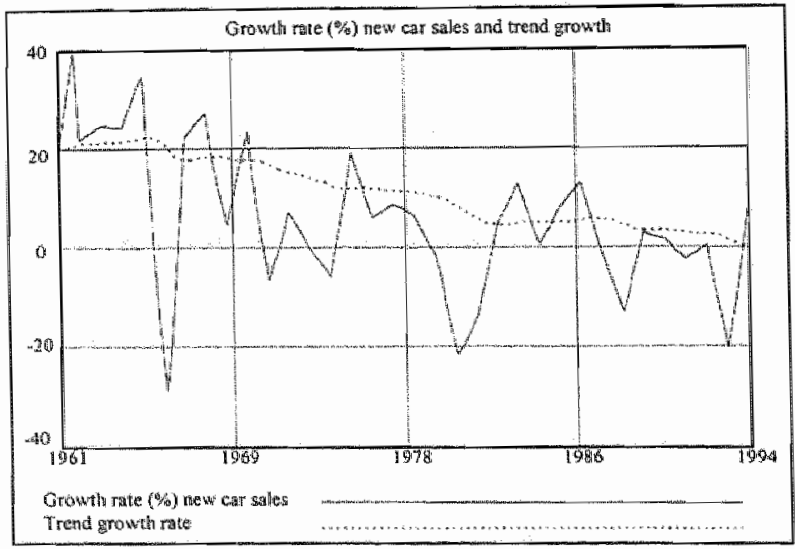

Figure 4.8 Percentage growth rate new car sales $1961-1994$

As we are interested in longe-run relationships, we have to filter out the short term fluctuations and the random noise. The resulting trend growth curve shows a settling down of the growth rate. The expected growth rates the next two decades will follow the growth rates of the households and that the car penetration rate in households now between 0.65 and 0.7 has reached its maximum value and less of the real disposable income. 


\subsubsection{Periodic analysïs}

The frequency domain plot (Figure 4.9 ) has a horizontal-axis labeled "Frequency". Frequency is measured in the units of the selected time base (years); power is measured in the square of the units for the variable "new car sales". The detrended variable "new car sales" (NCS) exhibited a mean periodicity of $11 / 13$ year, with frequency $=I /$ period $(\omega \approx 0.08-0.1)$. It coincides with the four investment recession of the last 35 year. A second periodicity, $4 / 6$ year, follows the milder inventory. correction recessions. An autocorrelation plot (Figure 4. 10) shows the autocorrelation of the variable "new car sales" (NCS) with the variable's value at a prewious time. The horizontal-axis represents the number of lags, where a lag is determined by the model $\Delta:$. From the autocorrelation plot one can infer that the distance from the mean occured, from below, Jong periods ago $32(1961) \Rightarrow 11$ (1983) and recently $10(1984) \Rightarrow 0$ (1994), 'from above' the mean, indicating a new lower growth trend of new car sales.

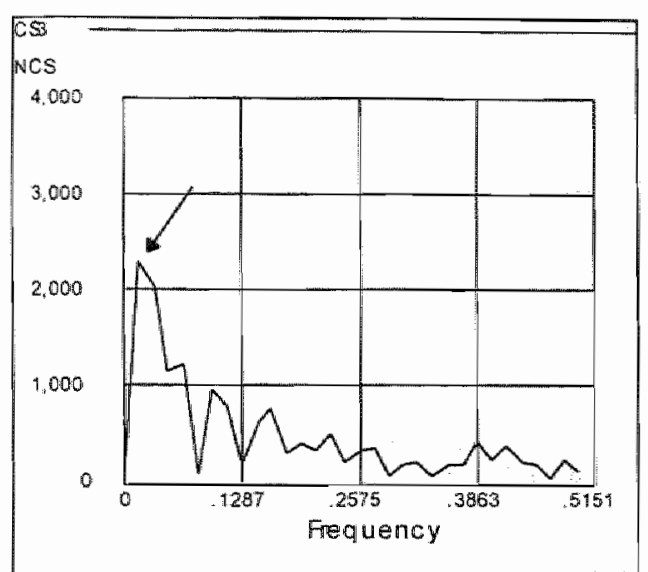

Figure 4.9 Power Spectrum

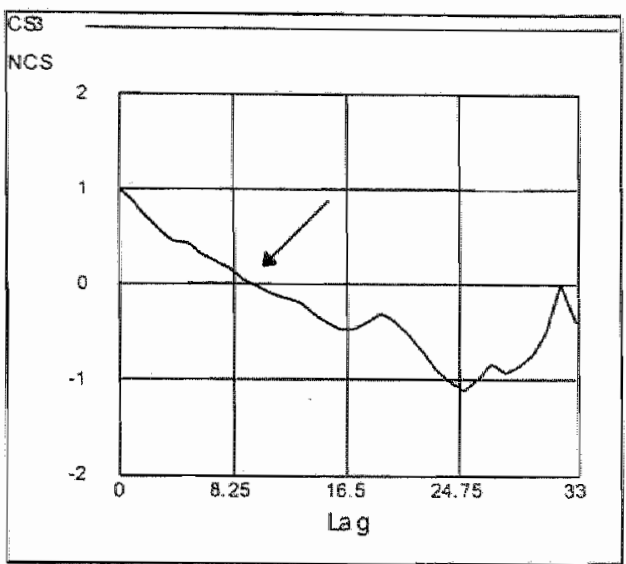

Figure 4.10 Autocorrelation Plot

\subsubsection{Estimation analysis}

Model 2.10 will be estimated using the hill-climbing procedures. The payoff $P(\cdot)$ (also called loss or objective function) of the model has been defined in terms of a combination of the simulated model variables, car sales, CS, and car stock, CST, with the corresponding observed data series for new car salies, $C S_{\Delta}$, and car stock, $C S T_{\Delta,}$, Using this payoff, the squared difference between the simulated model variables car sales, $C S_{t}$ and car stock, $C S T_{\text {w }}$ and the observed variables car sales, $C S_{A}$, and car stock, $C S T_{\Delta}$, will be minimised. The sum of the squared errors will be computed, and each weighted by the quotient of the standard deviation. In each case, the weight is squared, since it is used to compute the raw residual, which is then squared. Data points are compared to the model at the nearest time step $\Delta t$, regardless of the integration technique used. Values for variables on time step intervals, $t-\Delta t$, will always be computed. If there are more then two data points within a single time step, both are compared. As the hill-climbing algorithm (modified or extended Powell search) minimise the distance, we have to maximise the negative of this minimisation problem.

$$
\begin{aligned}
\max P(U) & =\sum-\min \left[\psi_{1}\left(C S^{*}-C S_{i}\right)^{2}+\psi_{2}\left(C S T^{*}-C S T_{i}\right)^{2}\right] \\
\psi_{1} & =0.008 \\
\psi_{2} & =0.0006
\end{aligned}
$$

where

$$
\begin{array}{ll}
C S^{\#} & \text { : observed car sales } \\
C S_{t} & \text { : simulated new car sales } \\
C S T^{\phi} & \text { : observed car stock } \\
C S T_{t} & \text { : simulated car stock }
\end{array}
$$




\subsubsection{Estimation results}

The estimation results will be reported in numerical form e.g. in boxes. In the first box the optimised parameters are displayed with their initial (or starting values) values while in the second box the log likelihood $95 \%$ confidence interval are displayed for left and right side, because no symmetry is to be expected in a non-lineair procedure. The log likelihood confidence intervals are to be understood as a case of parametric sensitivity. The other sensitivity procedures, optimum sensitivity, will provide information about the global versus local optimal solutions and will be presented in graphical form in order to improve the understanding of the likelyhood surface images.

First, their will be the tracing procedure. The tracing results of each optimised parameter will be performed and plotted in order to follow the course of the optimisation process of the search parameters in question. Note that the horizontal axis is an index that increases by one on each simulation.

Second, procedures which restarts the optimisation process multiple times from different starting points, to be determined by different procedures, like random -, vector - and grid search procedures, or (in case of no optimisation) simulates the model for different values of the search parameter(s). The vector search procedure typically changes only one parameter at a time. The vector search procedure can be applied in two fashions:

1. in an optimisation setting. The vector search procedure searches the first search parameter from its (user defined) minimum to maximum values, then the second, and so on. The partition is the maximum - minimum value over the setting of vector points (here chosen at 25 ). The ranges for the search parameters are specified as constraints on the parameters being optimised.

2. in a non-optimisation (simulation) setting, a vector search procedure will computes the payoff as a function of the optimised parameter value in question. Note this is in effect no optimisation but an analysis in retrospect, after the optimistion has been performed. The staring points are computed over uniformly partitioned values of each parameter. The information is quite useful for viewing separate cuts of the likelihood surface.

In contrast to the vector search procedure the grid search changes all search parameters at a time, simultaneously. The grid search procedure computes the starting point for each optimisation over successively funer grids over the range of each search parameter. The range for the search parameter are specified as constraints on the search parameters being optimised. The first grid computes the endpoints of the range, the next grid also computes the midpoints, and each successive grid divides the previous grid by 2 . This continues for up to 1024 divisions. The potential number of simulations is 1024 to the power of the total number of search parameters. (In aur case explained hereafter with 3 search parameters this will be $1.024^{3}=1.073 .741 .824$ simulations)

\subsubsection{Estimation Model 4.2.10}

Model 4.2.10 has been estimated for the periad 1961-1994,

$$
\begin{aligned}
& C S_{t}=\hat{\alpha} Y p_{t}+\hat{\beta} C S T_{t} \\
& C S T_{t}=C S T_{t-1}+C S_{t}-\hat{\delta} C S T_{t-1} \\
& Y p_{t}=Y p_{t-1}+Y_{t}^{*}-\bar{\psi} Y p_{t-1}
\end{aligned}
$$

with

$$
\begin{aligned}
& \hat{\beta}=\lambda-1, \hat{\beta}<0 \\
& \dot{\delta}=1 / \rho, 0<\hat{\delta}<1 \\
& \bar{\psi}=0.377 \\
& T=33
\end{aligned}
$$

where

$$
\begin{array}{ll}
C S: \text { new car sales } & C S^{\prime \prime}: \text { observed new car sales } \\
\text { CST : car stock } & Y^{* *}: \text { observed real national income }
\end{array}
$$




\section{$Y_{p} \quad$ : permanent income}

The parameter optimisation results and the payoff value are displayed in Box 4.1. The true log likelihood with $95 \%$ confidence bounds is displayed in Box 4.2 .

\begin{tabular}{l} 
Box 4.1 Estimation Model 4.2.10 \\
Initial point of search. \\
$\alpha=1.000000$. \\
$\beta=-0.010000$. \\
$\rho=12.000000$. \\
Simulations $=1$. \\
Pass $=0$. \\
Payoff $=-35.5564$ \\
\hdashline Maximum payoff found at:. \\
$\alpha=1.50392$. \\
$\beta=-0.0364667$. \\
$p=13.4422$. \\
Simulations $=305$. \\
Pass $=3$. \\
Payoff $=-8.44016$. \\
Prid $=-8.437891$.
\end{tabular}

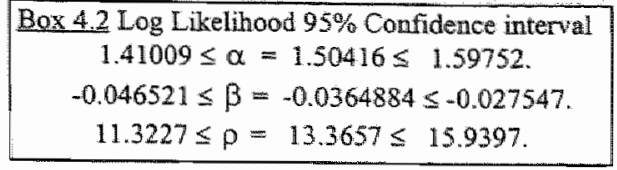

Constraints ( $\min , \max$ ) and the initial values of the search parameters are set at:

$$
\begin{gathered}
0 \leq \alpha=1.0 \leq 2.0 \\
-0.1 \leq \beta=-0.01 \leq-0.001 \\
11 \leq p=12.0 \leq 16
\end{gathered}
$$

\subsubsection{Simulation results}

The simulation runs are performed with the Model 2.10 (displayed in Box 4.3), and gives a visual or pictural image of the estimation performance it is a first impression of the 'goodness of the fit'. In order to get an impression about the giobal versus local properties of the optimisation results one has to rely on additional (sensitivity) analysis procedures. The random-, vector -, and grid search procedures are very powerful in order to get information about the global optimal characteristics of the search parameters and the resulting payoff function. The description and apllication of the sensitvity procedures will be treated in the last part of this section

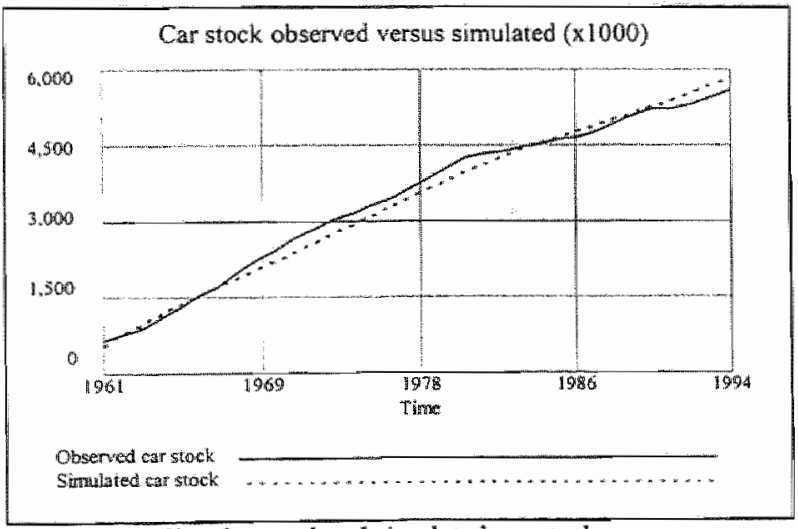

Fignure 4.1 il The observed and simulated car stock
Figure 4.11 shows the course or evolution of the car stock observed and simulated by model 2.10 . The fit between observed and simulated car stock is reasonable, but the right end point (1994) is somewhat to high, indicating that the most recent information of the new car sales thas not been incorporated. This fact can be demonstrated by Figure 4.7 which shows the trend course of "new car sales'. "The endpoint mismatch demonstrates this more clearly. 
Figure 4.12 show the simulation results of 'new car sales" in the form of a plot, one can observe that the startpoint and endpoint conditons are poorly simulated. This is partly due to the eratic but steep growths figures of "new car sales", followed in 1980 by a declining trend of the "new car sales". A. solution can be the use of first differences or the insertion of a autocorrelated term on the right hand. side (RHS) of the "new car sales' (CS) equation in Model 4.2.10. The poor estimation results, especially the mismatch of the start- and end phase, necessitates us to look after an adapted model structure which describes the characteristics of typically stock - or accumulation processes with long residence times.

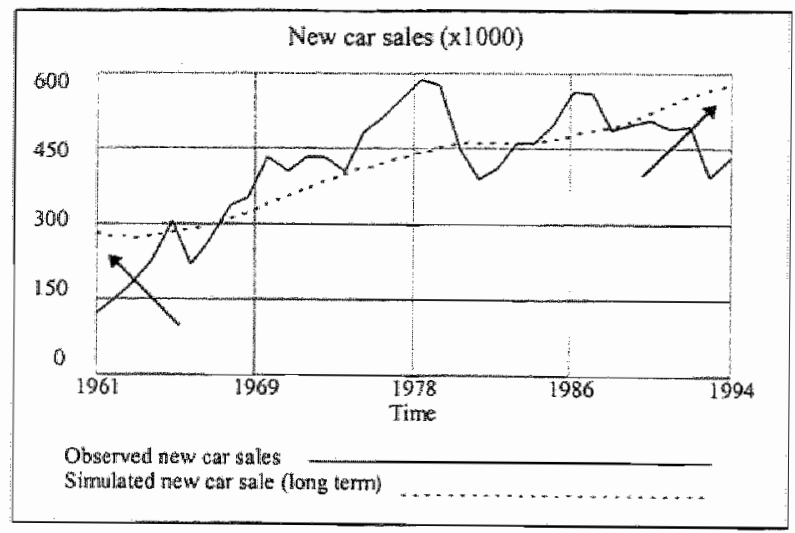

Figure 4. 12 The observed and simulated trew car sales after optimisation of model 2.10 


\subsubsection{Estimation model 4.2.11a}

The second estimation will contain a delayed term of CS on the right hand side (RHS) of equation (4.2.11a). In fact the delay used here is a first-order delay or exponential smoothing of the variable new car sales CS. $D F(*)$ stands for the delay operator of order $p$ and time constant $\theta$. A delay of order $p=1$ is also known as exponential smoothing. For $p=2,3, \ldots$ one can speak of double, triple, etc.

exponential smoothing. Smoothing is a continuous concept in contrast to the discrete time lag $L_{n}(\cdot)$, to be applied in model (4.2.11b). In fact one can think of a system of equations of the mixed firstdifferential/difference type:

with

$$
\begin{aligned}
C S_{t}= & \hat{\alpha} Y p_{t}+\hat{\beta} C S T_{t-1}+D_{\hat{\theta}}^{\mathbb{I}}\left(C S_{i}\right) \\
C S T_{t} & =C S T_{t-1}+C S-\hat{\delta} C S T_{t-1} \\
Y p_{\sharp} & =Y p_{t-1}+Y_{t}^{t}-\bar{\psi} Y p_{t-1} \\
& \hat{\beta}=\lambda-1, \hat{\beta}<0 \\
& \hat{\delta}=1 / \rho, 0<\hat{\delta}<1 \\
& \hat{\theta}>0 \\
& \bar{\psi}=0.377
\end{aligned}
$$

where

$$
\text { CS: new car sales }
$$

CST : car stock

Yp : permanent income

$Y^{*} \quad$ " observed real national income

Note the payoff defined (4.3.3) remains unchanged. The results are improved as the payoffs shows. The results shown in Box 4.4-5 indicate a dedicated improvement of model (4.211a) with regard to model (4.2.10). The time constant of the delay $D_{\theta}^{p}(\bullet)$ will be estimated, $\hat{\theta}$, allong with $\hat{\alpha}, \hat{\beta}$ and $\hat{\delta}$. Box 4.4 and 4.5 shows the estimates of the four parameters and the log likelihood of the $95 \%$ confidence intervals. The improvement of the payoff, from -8.5 to -3.8 , and therefore the improvement of the fit is substantial and the end point has been estimated fairly well. Otre can think of the simulated car sales series as a trend series.

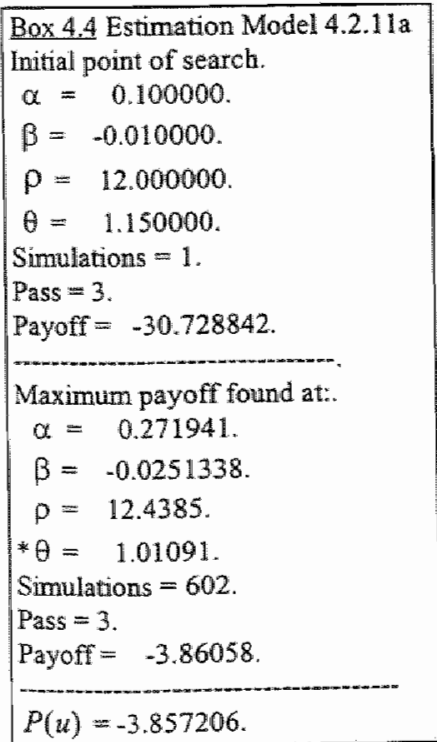

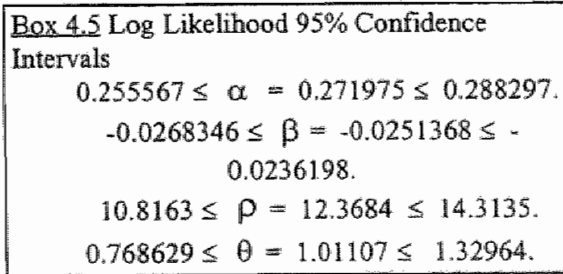

Constraints and initial values are set at:

$$
\begin{gathered}
0 \leq \alpha=0.1 \leq 1 \\
-0.1 \leq \beta=-0.01 \leq-0.001 \\
10 \leq \rho=12 \leq 15 \\
0.75 \leq \theta=1.15 \leq 2.0
\end{gathered}
$$

Box 4.6Estimated Model 4.2.11a
$C S_{t}=0.27 Y_{p_{t}}-0.025 C S T_{t}+D_{\mathrm{t} Q \mathrm{l}}^{\mathrm{a}}\left(C S_{t}\right)$
$C S T_{t}=C S T_{t-1}+C S_{t}-0.08 C S T_{t-1}$
$Y_{p_{t}}=Y_{p_{t-1}}+Y^{i t}-0.377 Y_{p_{t-1}}$




\subsubsection{Simulation results}

Figure 4.13 shows the trend of the "new car sales' which is the best fit under minimisation of both "new car sales" and the car stock, as defined in the payoff function guiding the estimation process.

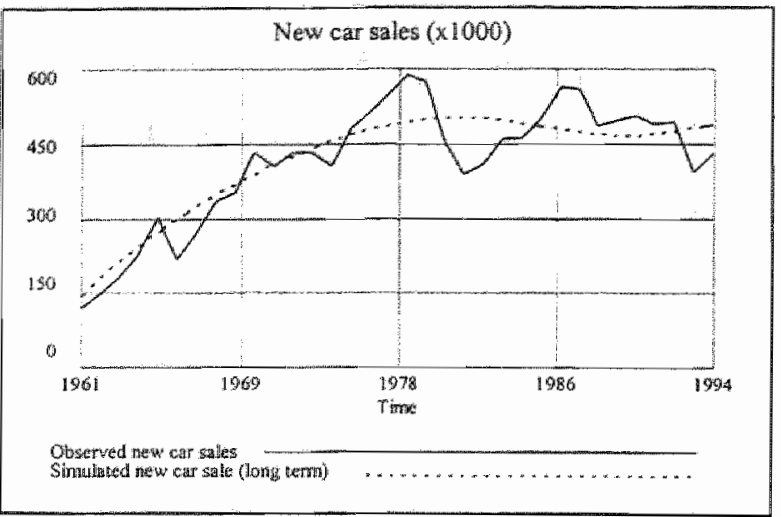

Figure 4.13 New car sales and its simulated trend

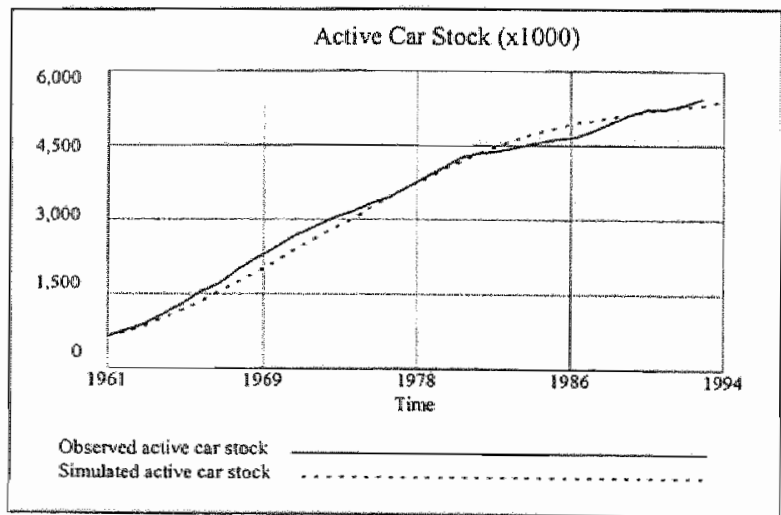

Figure 4.14 The observed - and simulated car stock

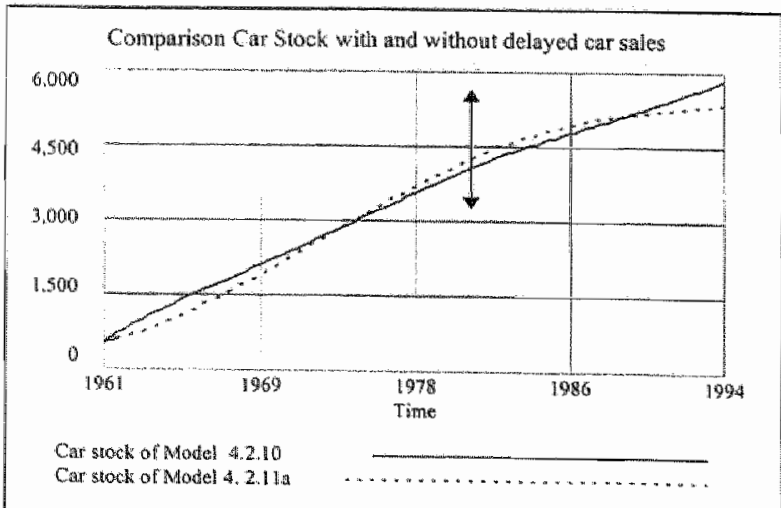

Figure 4.15 The simulated car stock series conform model 4.2 .10 and $4.2 .11 \mathrm{a}$
The start and endpoints are now in a better fit with the observed data. The payoff drops more than $50 \%$ as the result of simultaneously improvement of the fit of the simulated 'new car sales" and the car stock with the observed series. The simulated car stock is now closer to the observed car stock as can be seen from Figure 4.14 , especially the 1994 and point.

To get an understanding of the difference between the non-delayed model (4.2.10) and the delayed (auto-correlated) model (4.2.11a), both simulation series are shown in Figure 4.15. The simulated car stock with the delayed 'new car sales' in the RHS of model (4.2.1 la) takes the latest infor-mation available to mitigate the simula-ted car stock by the corresponding latest observed new car sales. Especially the end point in 1994 estimation is conclusive in this respect. The end points of the simulated car stock of model (4.2.10) are higher than the observed car stock (Figure 4.11). The simulated car stock of model (4.2.10) shows two linear segments, the first from the 60 s till 1,980 and the second from 1980 on with a less steeper slope than the first segment, indicating a slower growth rate of the car stock. But the simulated car stock of model (4.2.11a) fits the observed car stock as a logistic path in a correct way, with the first stage 1960-1972 exhibiting an exponential phase with a point of inflection around 1973 followed by a asymptotic growth path toward an unspecified (moving) saturation or maximum level. 


\subsubsection{Prediction error analysis}

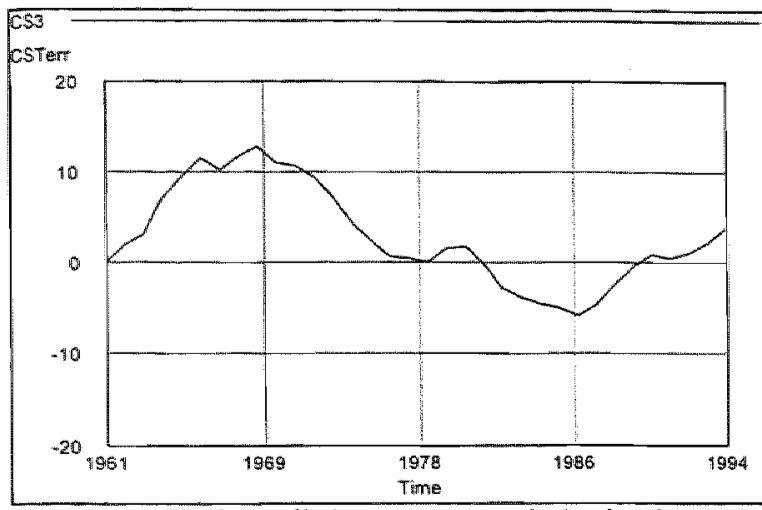

Figure 4.16 The $\%$ prediction error car stock simulated and observed
The prediction error of Figure 4.16 shows the exponential growth phase in the $60 \mathrm{~s}$ followed by an improvement of the fit. The endpoint fit illustrates the strong decline of 'new car sales' in 1992/93. The prediction error process can be explained as a damped sinus function. Figure 4.17 illustrates the damped periodic or sin-wave function

with

$$
y=D / \sqrt{t} * \operatorname{SN}\left(\frac{2 \pi * t}{E}\right)
$$

$$
D=30, E=30
$$

guessed by trial and error (non-optimised) and the optimised case, with $D=25.37, E=32.1285$

using the guesses as initial value. As the damping factor $1 / \sqrt{t}$ converged very quick to zero, the prediction process is stable, and improves over time. Although starting in or during a process, in place

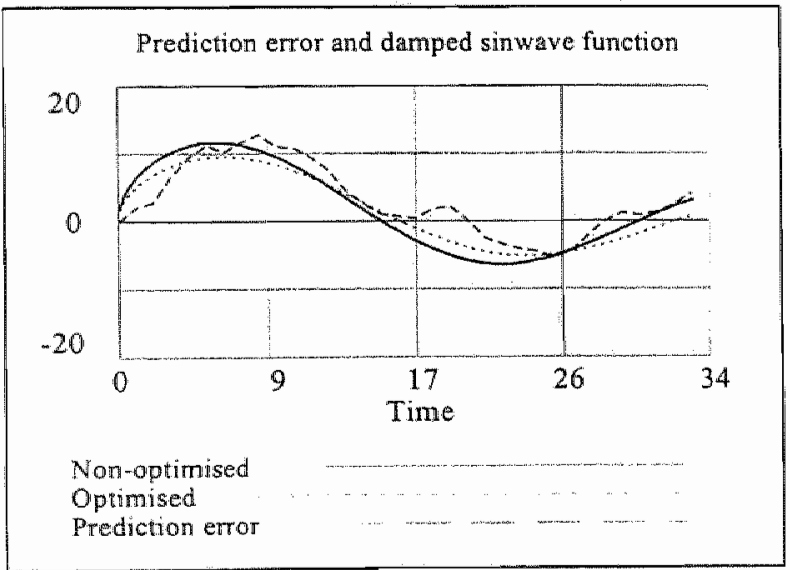

Figure 4.17 of starting from an equilibrium position, the convergence path is rather straightforward and therefore the error-reduction process is effective. This conclusion can also be deduced from the Fourier plot 4.18 , where there is only a small indication of periodicity. Note the frequency domain is a subset of full frequency domain as shown in Figure 4.14.

The autocorrelation plot 4.19 shows in contrast to those of model (4.2.10) in Figure 4.15 that the initial or start point mismatich is much less. The power spectra of new car sales "NCS" in Figure 4.8 and of Figure 4.18 are equivalent, the same conclusion holds for the autocorrelation

plot of Figure 4.9 and 4.19 . The mixed first-differential/difference approach tracks the original power spectrum.
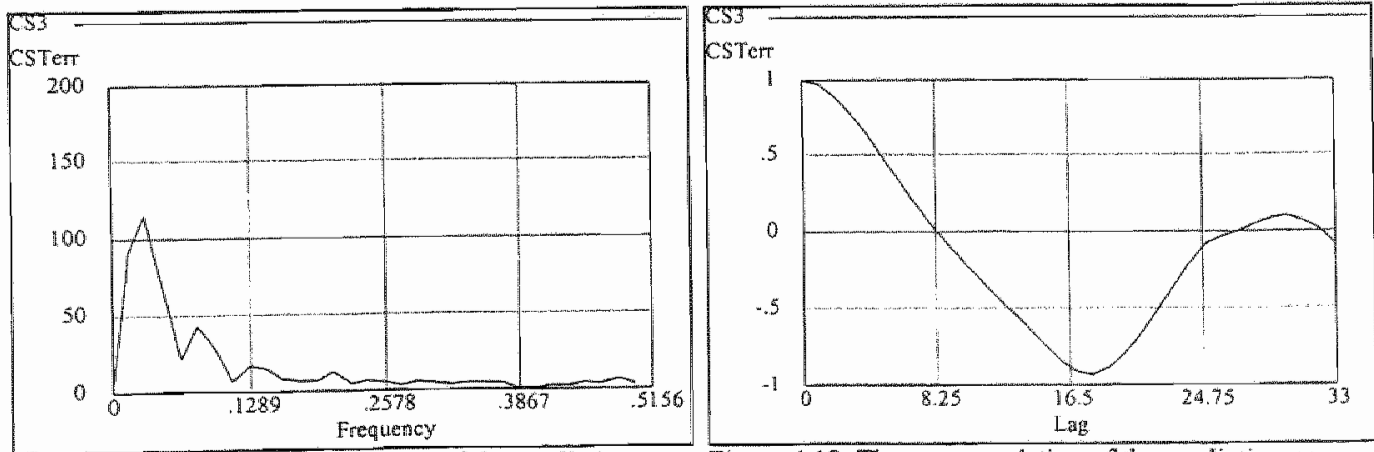

Figure 4.18 The frequency domain of the prediction error Figure 4.19 The autocorrelation of the prediction error 


\subsubsection{Trace results}

Tracing the search parameter provides us information about the estimation course of the parameters involved. The payoff trace (Figure 4.24) shows two major step increases, the first step was caused by

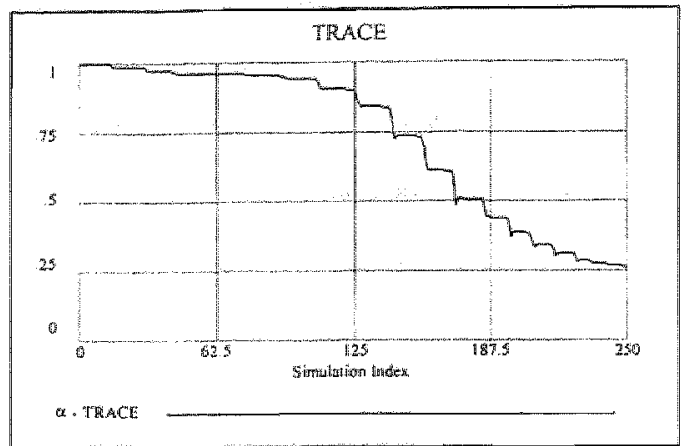

Figure 4.20 The trace trajectory of the $\alpha$-parameter

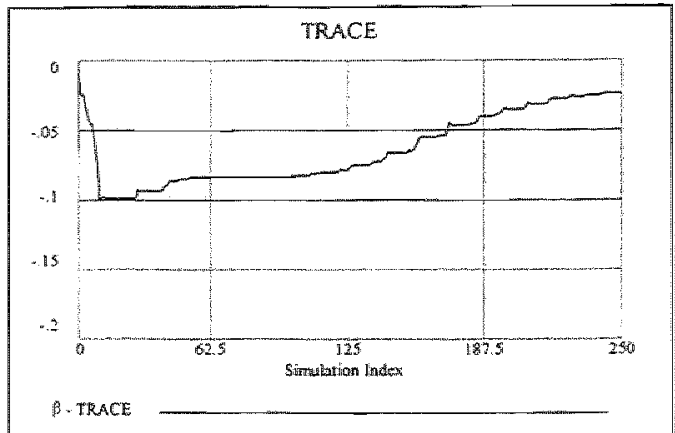

Figure 4.21 The trace trajectory of the $\beta$-parameter the decrease of

the $\beta$-search parameter of car stock variable (Figure 4.21) followed by the second step increase of the payoff caused by an increase of the delay time constant (residence time) ' $\theta$ ', (Figure 4.23). However the search process reversed its route by moving the $\alpha$-parameter of the permanent income variable downwards step by step (Figure 4.20) transfering the weight from permanent income to the delayed car sales.

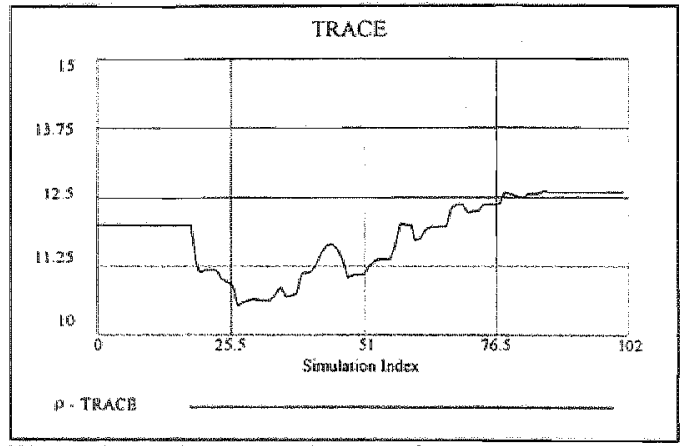

Figure 4.22 The trace trajectory of the p-parameter

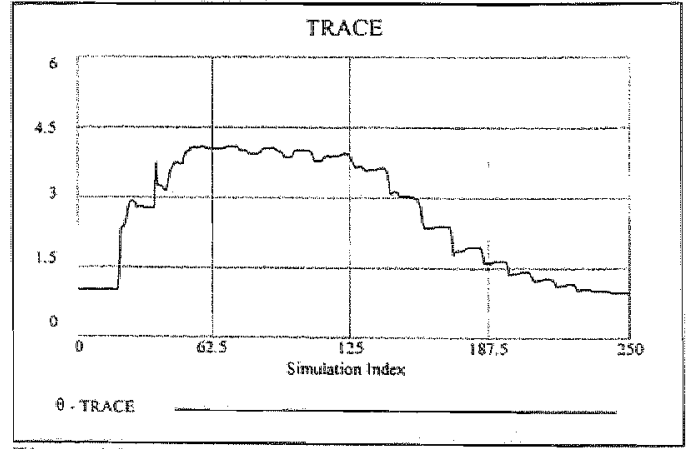

Figure 4.23 The trace trajectory of the $\theta$-parameter

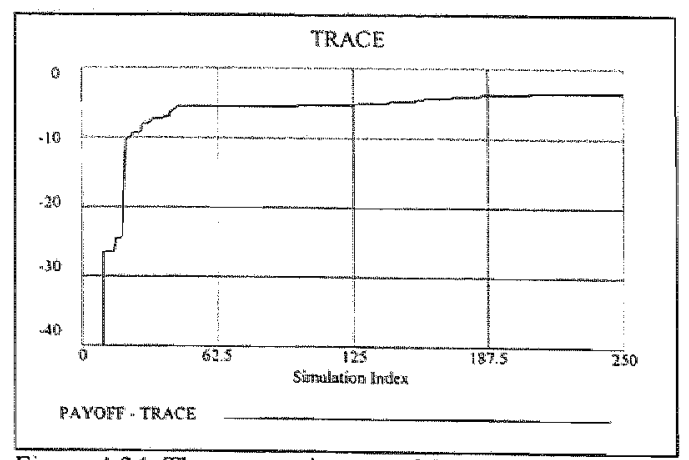

Figure 4.24 The trace trajectory of the payoff function 


\subsubsection{Vector search with no optimisations.7}

The vector search with no optimisation (simulation only) provides information for viewing possible separate cuts of the likelihood surface. Taking the log likelihood confidence intervals (Box 4.5)

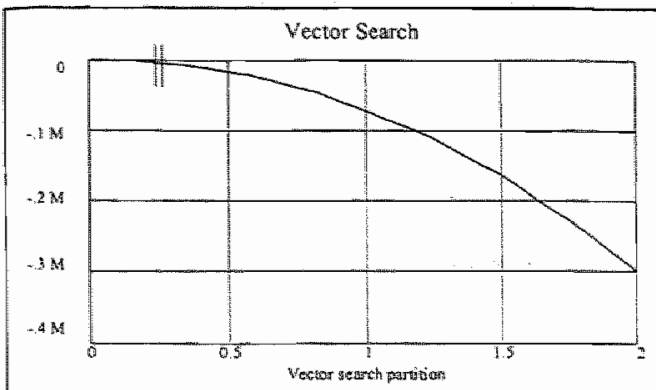

2. WECTOS

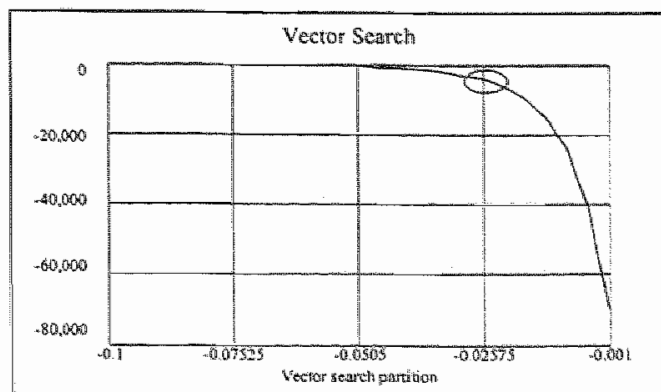

B. . WE:CTOR

Figure 4.25 The log likelihood surface of the $\alpha$-parameter Figure 4.26 The log likelihood surface of the $\beta$-parameter

into account and inspecting the four vector search plots (Figure 4.25-28) than the likelihood surface shows no unexpected or surprising traps. However inspecting the range of the wertical axis of Figure 4.25 one sees the enormous support of the $\alpha$-parameter in the payoff function, cet. par., from $(0,0)$ to $(2,-300.000)$. We will use this information when examining the influence of the individual search parameters upon the payoff function (Figure 4.62).
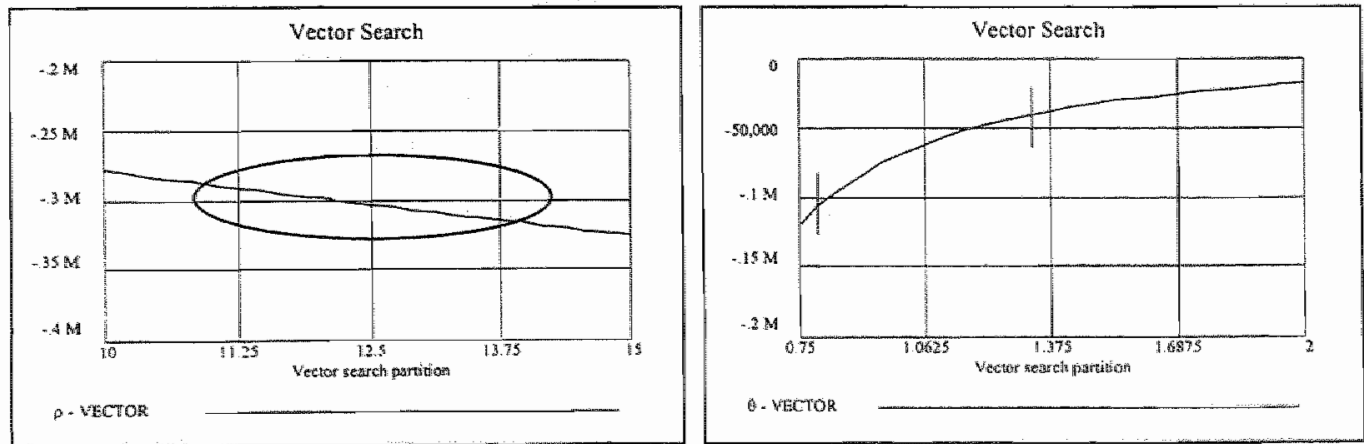

Figure 4.27 The log likelihood surface of the p-parameter Figure 4.28 The log likelihood surface of the $\theta$-parameter

${ }^{47}$ Note the grid search with and without optimisation have been omitted due to lack of space. However the grid searches did not reveal any complications. 


\subsubsection{Randlom search with optimisation}

As explained in chapter 2 the random search procedure give information about the global optimum solution, in fact it shows the global properties of the payoff function.

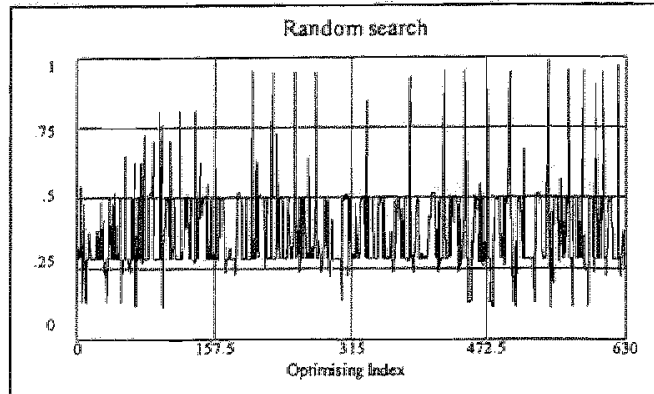

D. EADPOAY

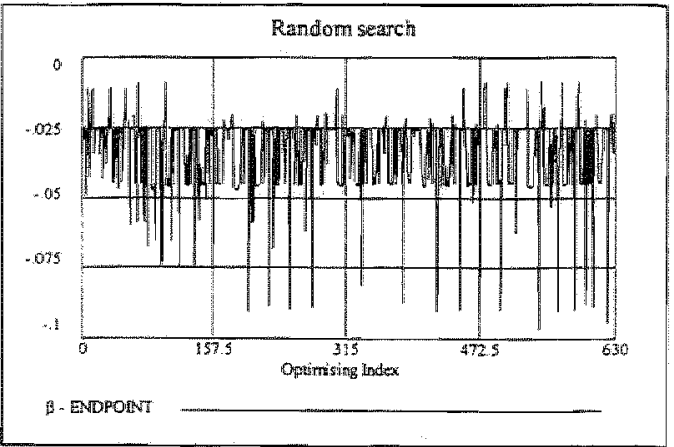

Figure 4.30

Figure 4.29

As can be shown in Figure 4.33 the optimum payoff value has not been surpassed by any lower payoff value. Note the $\alpha$ - and $\beta$-search parameter shows again an opposite course, but we do not know which

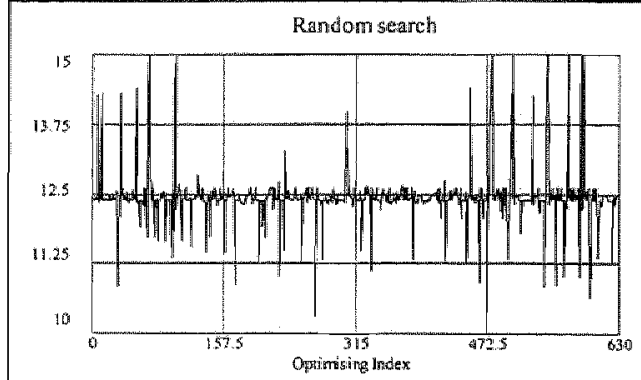

D. ENDAOINT

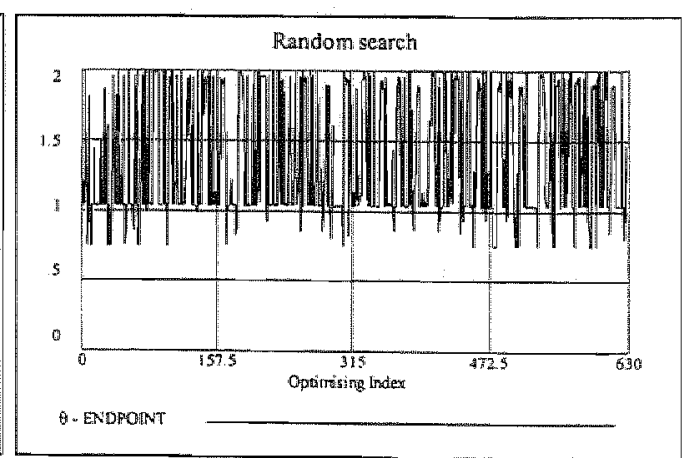

Figure 4.32

rigure 4.31

parameter causes (independent) and which follows (dependent), vector search with optimisation should provide that intormation (next section).

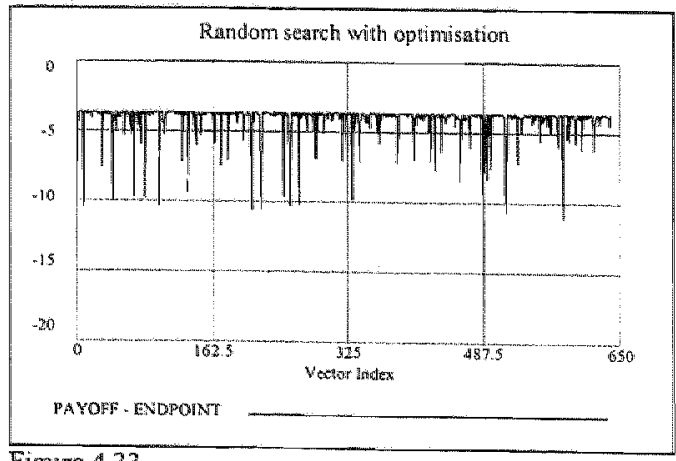

Figure 4.33 


\subsubsection{Vector search with optimisation}

As has been explained in chapter 2 vector search explores the optimisation process by changes the search parameters within the user defined range. For example, in Figure 4.34 the $\beta$-parameter has been changed with increments of $1 / 25$ of the domain segment $[0,25)$ with allowable range values $[-0.1,0]$, the remaining domain segments $[25,50),[50,75)$ and $[75,100)$ gives the optimal end values of the $\beta$-parameter cet. par, given 1) the change of the $\theta$-parameter in the domain segment $[25,50)$ (Figure 4.34) with the allowable range values $[0,2]$,

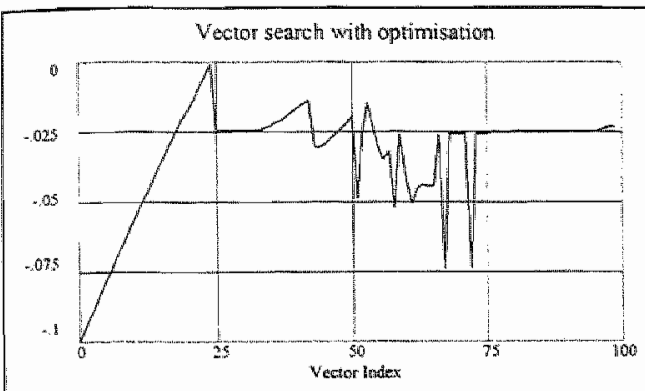

B- STARTPOORT

Figure 4.34

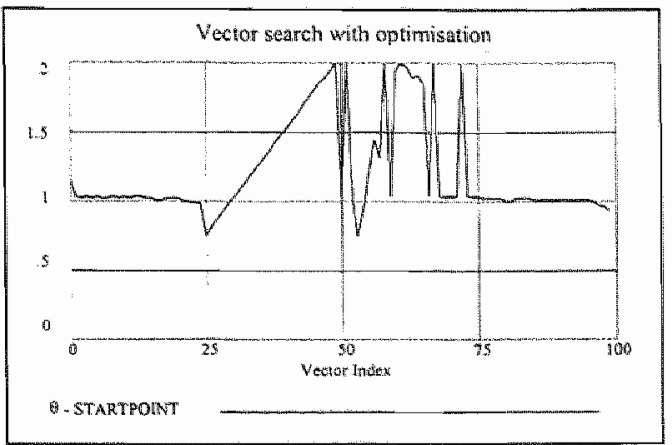

Figure 4.35

then 2) the change of the $\alpha$-parameter in the domain segment $[50,75$ ),(Figure 4.36), and 3) ending with the change of the $\rho$-parameter in the domain segment $[75,100)$ with allowable range values $[10,15]$.

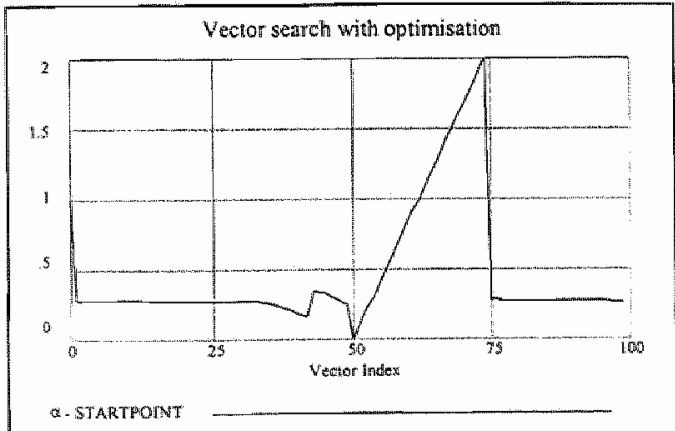

Figure 4.36

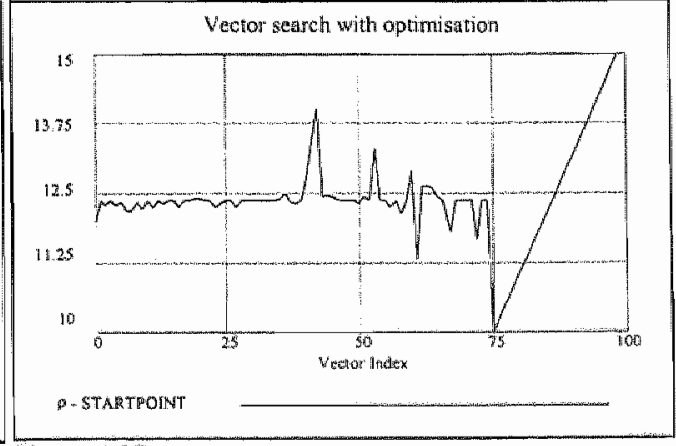

Figure 4.37

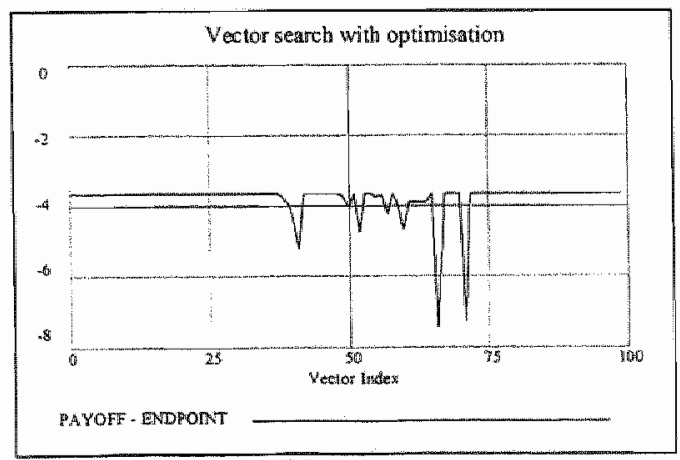

Figure 4.38 The payoff function 
From the five figures shown above the following conclusions can be drawn:

1. the incremental change $(1 / 25)$ in the domain segment $[0,25)$ of the $\beta$-search parameter, cet. par, over the range $[-0.1,0]$ has no impact on the remaining search parameters end values. The payoff function hardly changes in a significant way. Note the sharp decline of the $\alpha$-parameter in the time domain $[0,0.25$ ) is a first rigorous, coarse, step (trajectory) of the hill-climber toward the optimal walue, irrespective of the changing $\beta$-parameter.

2. the vector search of the $\alpha$-parameter has the most impact of the search parameters. Follow the reaction of the remaining search parameter (Figure $4.34,4.35,4.37$ and the payoff (Figure 4.38), when the $\alpha$-parameter changes its value from $[0,2]$ in the domain segment $[50,75)$.

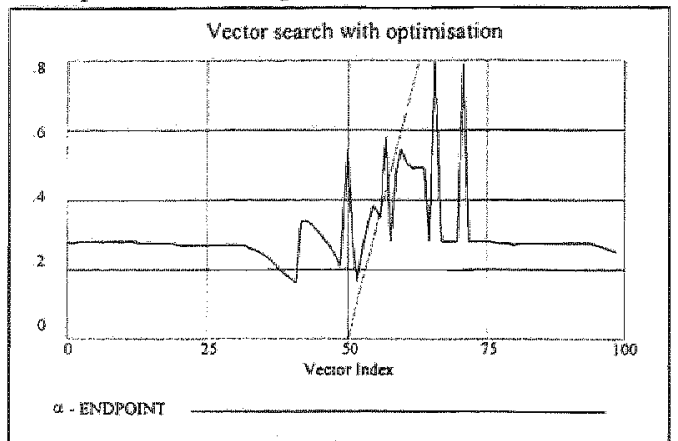

In Figure 4.39 the start values of the $\alpha$-parameter are plotted as a straight line (sloped) in the domain $[50,75)$ ranges from $[0,0.8)$ and its endvalues (after optimisation). The two peaks ( $\alpha \approx$ $1.25,1.8$ ) cause the system, that means the remaining search parameters to be dragged to a worse position, confirmed by the decrease of the payoff function from $\approx 0.38$ to $\approx 0.75$. Note however the log likelihood $95 \%$ confidence interval was:

$$
0.255 \leq \alpha^{*}=0.27 \leq 0.29
$$

Figure 4.39 The end-values of the $\alpha$-parameter 


\subsubsection{Estimation Model 4.2.11b}

The third estimation contains a lagged term of new car sales CS in the hand right side (RHS) of model $(4.2 .11 \mathrm{~b})$. The applied lagged term is the well known discrete time lag, $L^{\theta}(\bullet)$, for $\theta>0, \theta \in \mathbb{N}$. But we are not restricted by $\theta$ being an element only of the set of positive integers, $\theta \in \mathbb{1}$, we can admit $\theta$ being element of the set of positive real numbers, $\theta$ 还 and $\theta>\Delta>0$.

with

$$
\begin{aligned}
& C S_{t}=\hat{\alpha} Y p_{t}+\hat{\beta} C S T_{t}+L^{\hat{\theta}}\left(C S_{t}\right) \\
& C S T_{t}=C S T_{t-1}+C S_{t}-\hat{\delta} C S T_{t-1} \\
& Y p_{t}=Y p_{t-1}+Y_{t}^{\#}-\bar{\psi} Y p_{t-1}
\end{aligned}
$$

$$
\begin{aligned}
& \hat{\beta}=\lambda-1, \hat{\beta}<0 \\
& \hat{\delta}=1 / \rho, 0<\hat{\delta}<1 \\
& \bar{\Psi}=0.377
\end{aligned}
$$

where

$$
\begin{array}{ll}
C S & : \text { new car sales } \\
C S T & : \text { car stock } \\
Y_{P}: \text { permanent income } & \\
Y^{\text {H }}: \text { observed real national income }
\end{array}
$$

The first experiment with the discrete lag structure $L^{\theta}(\bullet)$ is to fix the lagged time period $\theta$ to 1 year period and to estimate the time-lag parameter $\theta$. The results are equivalent with the delayed model (4.2.11a) although the discrete lag model exhibits local minima, to be explained in the next section. The numerical parameter values are displayed in Box 4.7 with the $95 \%$ confidence interval displayed in Box 4.8 .

\begin{tabular}{l} 
Box 4.7 Estimation model 2.116 \\
Initial point of search. \\
$\alpha=0.100000$. \\
$\beta=-0.010000$. \\
$\rho=12.000000$. \\
$\theta=1.000000$. \\
Simulations $=1$. \\
Pass $=3$. \\
Payoff $=-42.937$. \\
Maximum payoff found at:. \\
$\alpha=0.31153$. \\
$\beta=-0.0291109$. \\
$* P=12.183$. \\
$\theta=1.18682$. \\
Simulations $=513$. \\
Pass $=3$. \\
Payoff $=-3.20102$. \\
\hline$P(u)=-3.201004$. \\
\hline
\end{tabular}

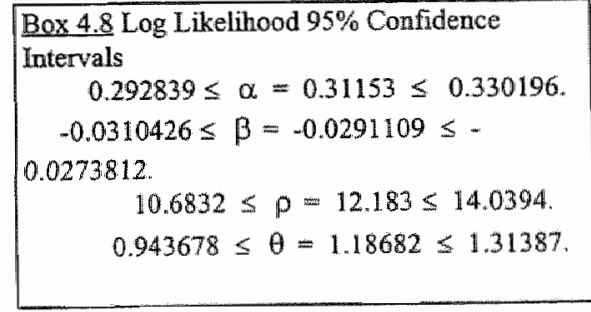

Constraints and initial values are set at:

$$
\begin{gathered}
0 \leq \alpha=0.1 \leq 1 \\
-0.1 \leq \beta=-0.01 \leq-0.001 \\
10 \leq p=12 \leq 15 \\
0.4 \leq \theta=1.15 \leq 2.0
\end{gathered}
$$

$$
\begin{aligned}
& \text { Box 4.2 Estimated model } 4.2 .11 \mathrm{~b} \\
& C S_{t}=0.31 Y_{p}-0.03 C S T_{t}+L^{1.2}\left(C S_{t}\right) \\
& C S T_{t}=C S T_{t-1}+C S_{t}-0.08 C S T_{t-1} \\
& Y p_{f}=Y p_{t-1}+Y^{t}-0.377 Y_{t-1}
\end{aligned}
$$




\subsubsection{Simulation results}

The model simulation results are of the same kind and order as the model (4.2.11 a). The trend (Figure 4.40) has been tracked very well and the plot is in correspondence with Figure 4.37 of model

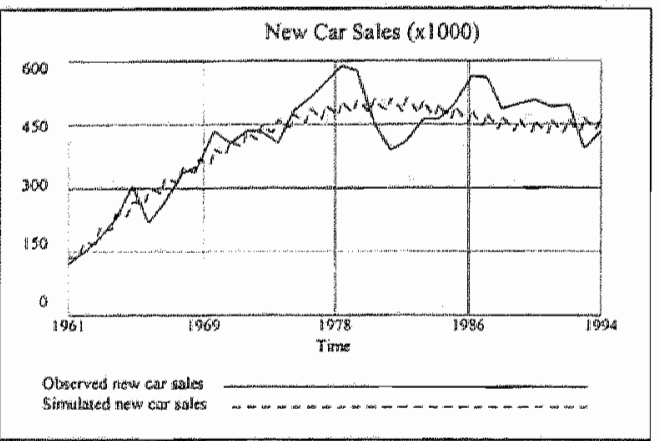

Figure 4.40 The new car sales observed and simulated

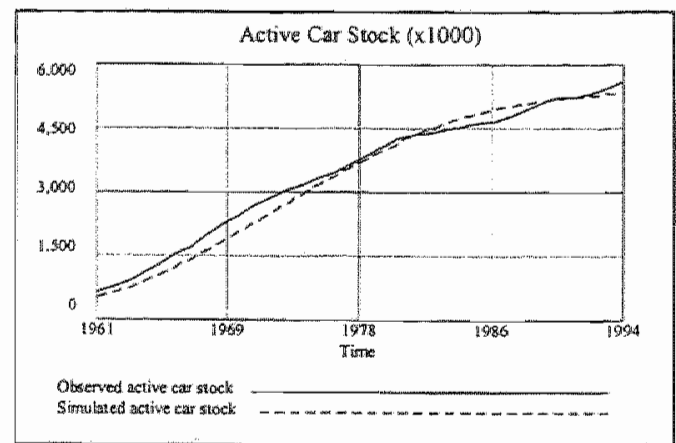

Figure 4.41 The observed and simulated car stock

(4.2.1 1a). The same can, of course, be said about the simulated car stock (Figure 4.41). This should not be a surprise seen the values of the search parameters in Box 4.7 .

\subsubsection{Prediction error analysis}

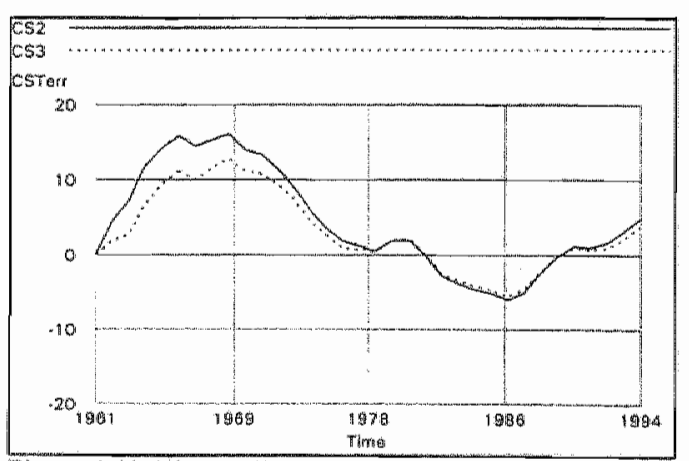

Figure 4.42 The prediction error plots of model $4.2 .11 \mathrm{a}$ and $4.2 .11 \mathrm{~b}$

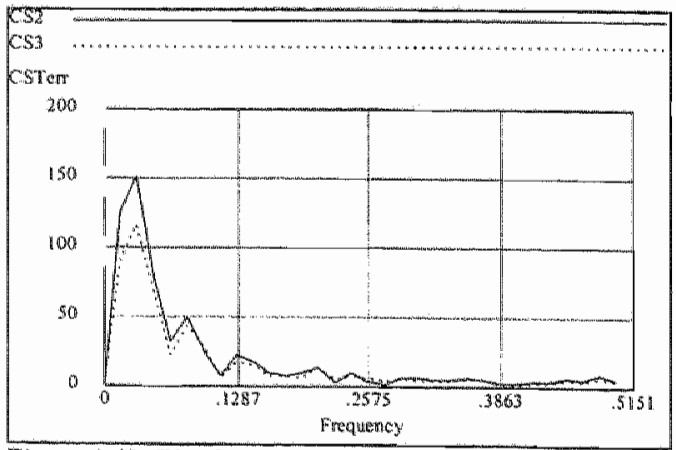

Figure 4.43 The frequency domain of the error plots
Figure 4.42 shows the comparison of the prediction error of model $(4.2 .11 \mathrm{~b})$, the dashed line CS2 and of thodel (4.2.11 b), the dotted line CS3. The CS3 line or the delay form performed a slight better than the discrete lag form. This can also be checked in the frequency domain. plot (Figure 4.43) where periodicity is hardly present. In general both the delay and lag function tracks correctly the periodicity of the new car sales NCS.

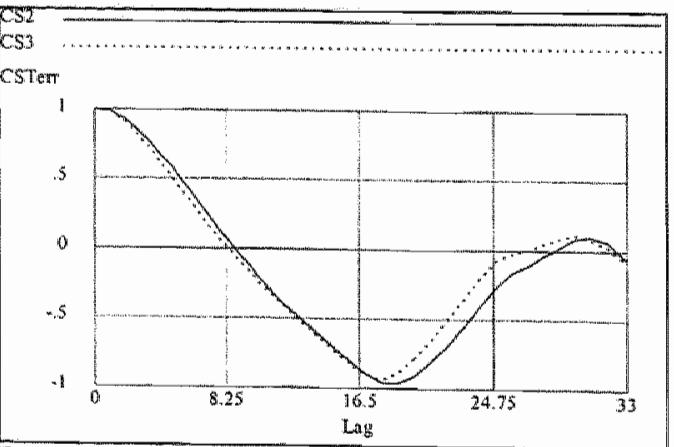

Figure 4.44 The autoconelation of the error plots 


\subsubsection{Trace results}

The trace results of the search parameters shows clearly the opposite relationship between the $\alpha$ - and the $\beta$ parameter, in three steps the search parameters reach or settle down to their optimum values $(\alpha=0.3$, Figure 4.46 and $\beta=-0.03$, Figure 4.45 , see also Box 4.7$)$.

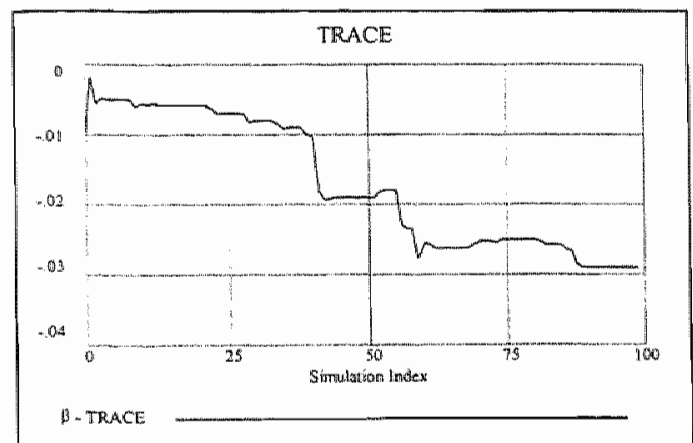

Figure 4.45

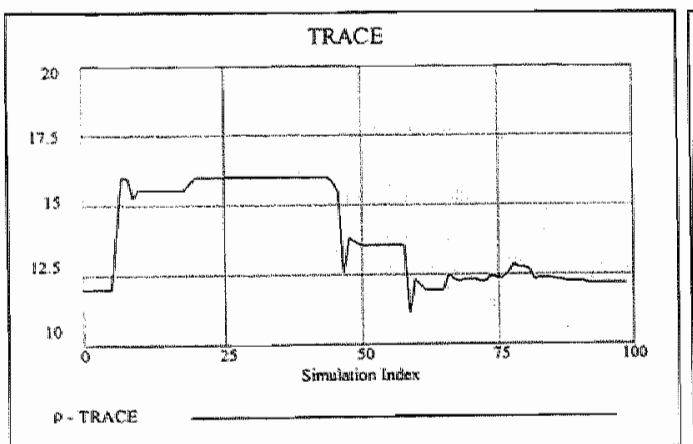

Figure 4.47

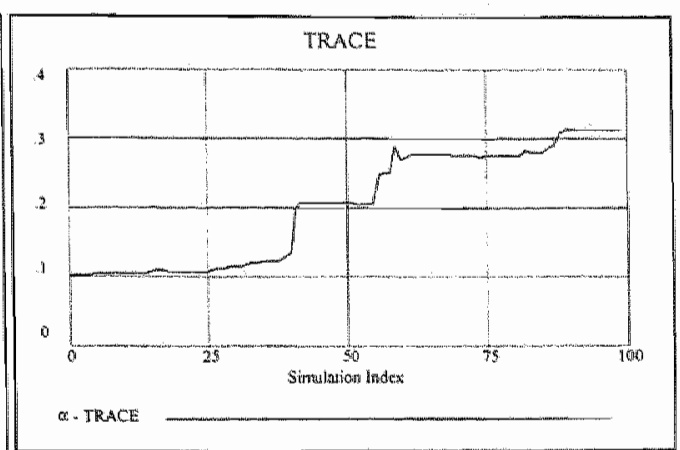

Figure 4.46

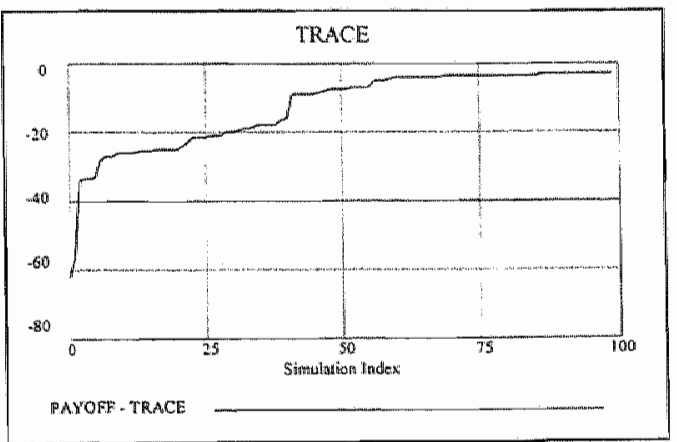

Figure 4.48

The depreciation time constant $\rho$ returns more or less to their initiali value after making a small trip early in the simulation. Note the first 100 simulation out of 513 are shown here in order to improve the interpretation of the plots. 


\subsubsection{Vector search without optimisation ${ }^{4.8}$}

As noted before vector search with no optimisation computes over the range of the partitioned search parameter space the payoff, $P(U)$, in order to investigate possible cuts of the likelihood surface. The dotted ellipses in the figures below show the log likelihood of $95 \%$ confidence interval. The horizontal axis measured the partitioned vector domain of the search parameter in question, which endpoints are the constraints applied in the optimisation process. The vertical axis measures the payoff value of the single search parameter under review.

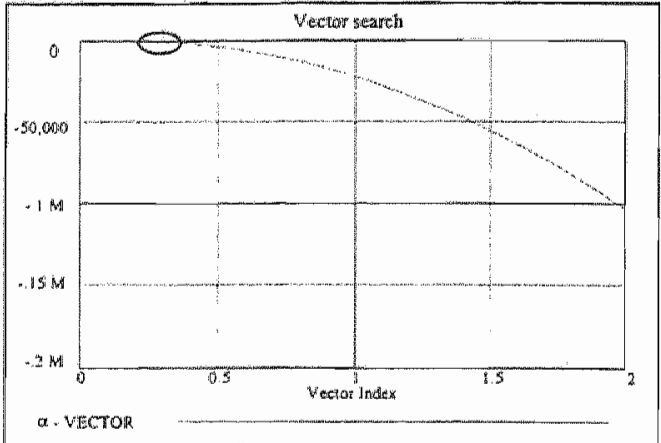

Figure 4.49

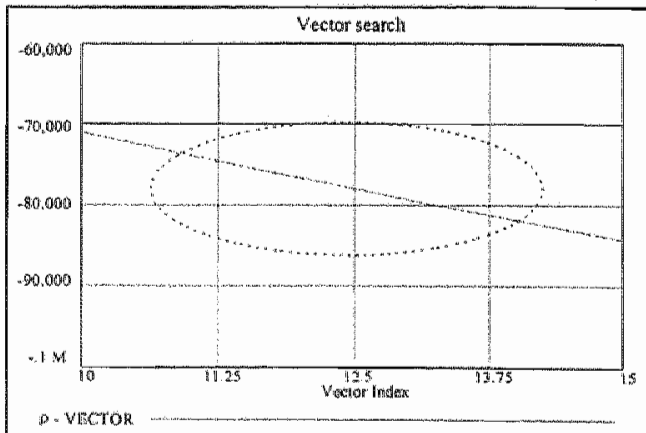

Figure 4.51

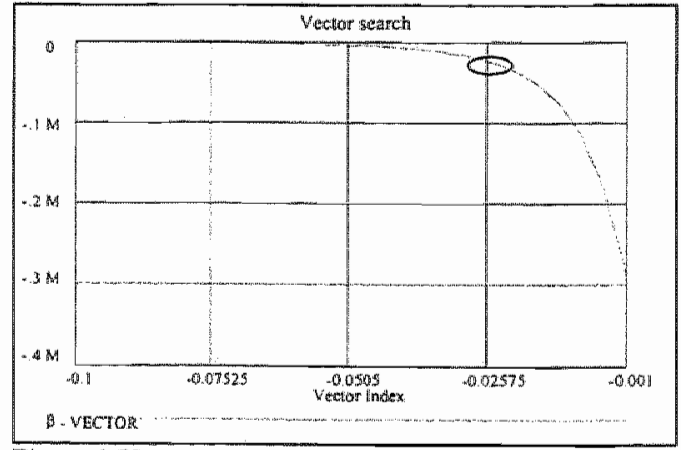

Figure 4.50

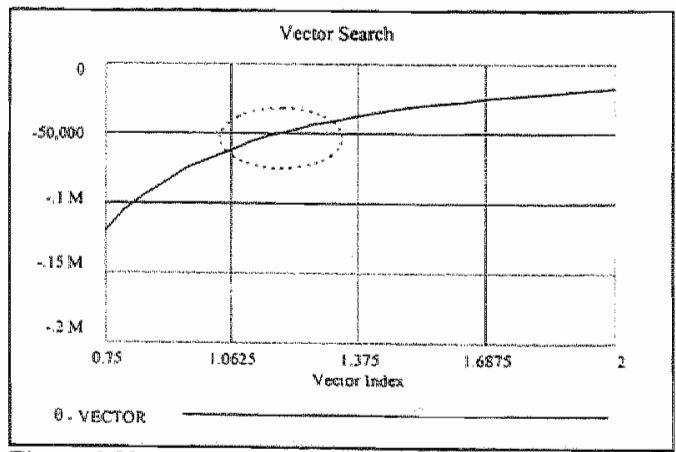

Figure 4.52

The likelihood surface of the $\alpha$-parameter (Figure 4.49) is less steep to the right than in Figure 4.49 , the delay version, however those of the $\beta$-parameter (Figure 4.50 ) is steeper to the right than in Figure 4.50 . This is so because the relationship between permanent income and the actual car stock is an inversely proportionate one. The log likelihood $95 \%$ confidence intervals for the $\alpha-$ and $\beta$ parameters shows comparable distances, this means that both parameters are tied together in an negative way, like specified in the equations of model $(4.2 .1 \mathrm{lb})$, even the numerical weights are comparable in value. Note the log likelihood intervals are:

$$
0.29 \leq \alpha^{*}=0.3 \leq 0.33 \text { and }-0.03 \leq \beta^{*}=-0.029 \leq-0.027 \text {. }
$$

This confirms the conclusions of model $(4.2 .11 \mathrm{a})$, the delayed version.

\footnotetext{
4.8 Note due to lack of space the grid search with and without optimisation has been omitted. However no complication revealed when inspecting the grid search results.
} 


\subsubsection{Vector search with optimisation}

The same domain segment and range values are applied hereafter as we did in section 4.3.17. The four plots with the start-points are complemented with those of the end-points after optinisation.

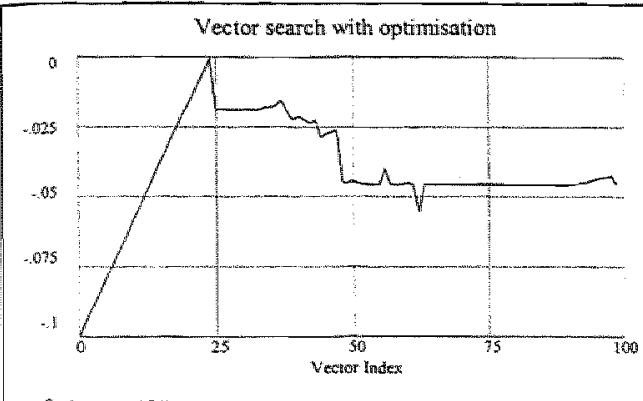

P. STARTPOIN

\section{Figure 4.53}

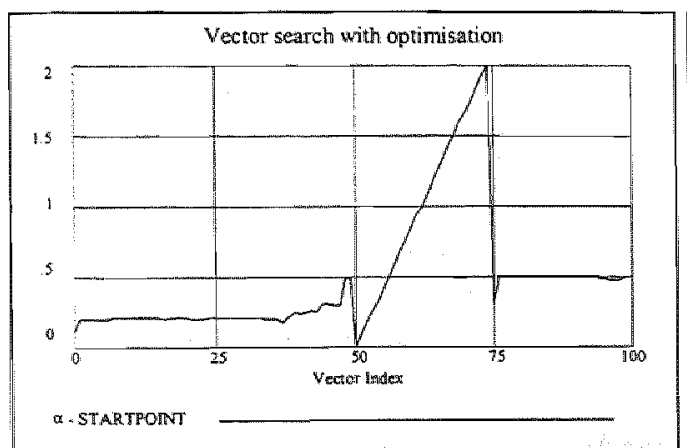

\section{Figure 4.55}

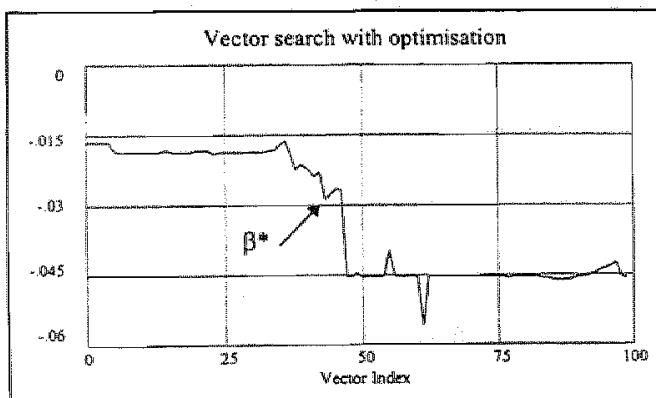

B. ENDPONT

\section{Figure 4.57}

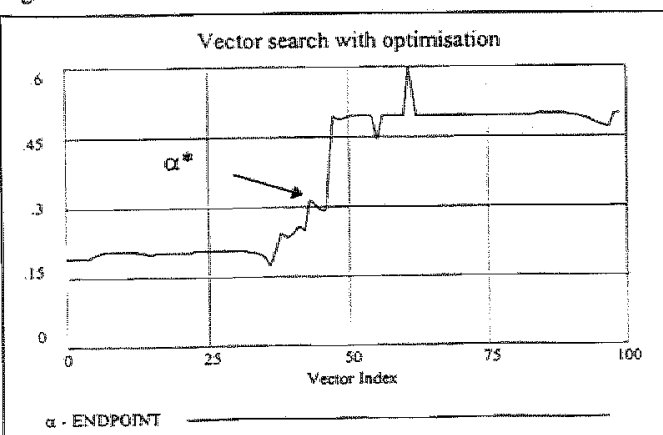

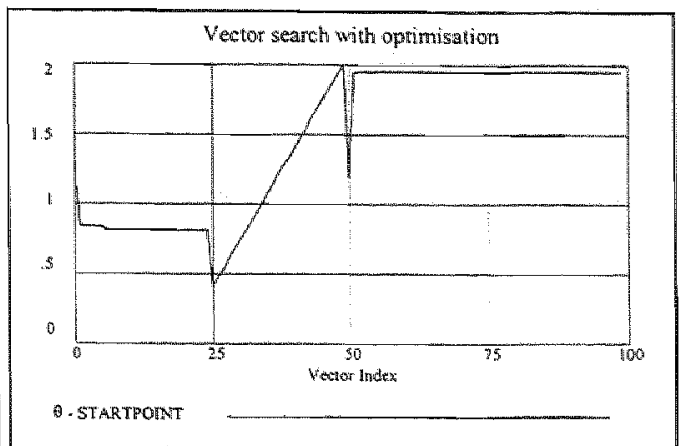

Figure 4.54

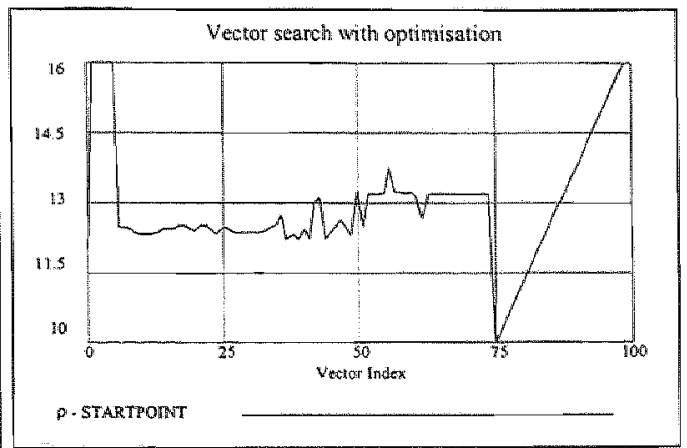

Figure 4.56

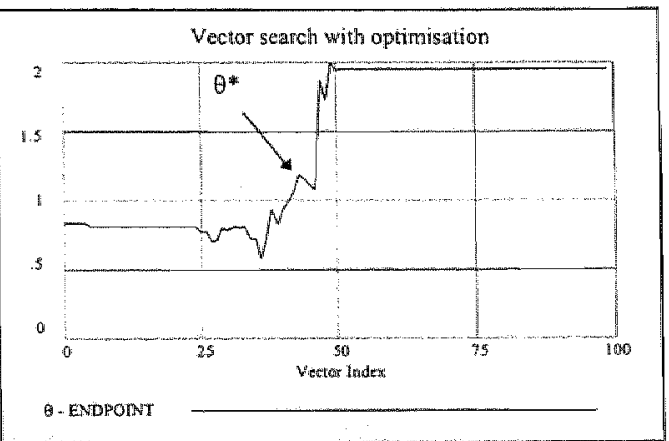

Figure 4.58

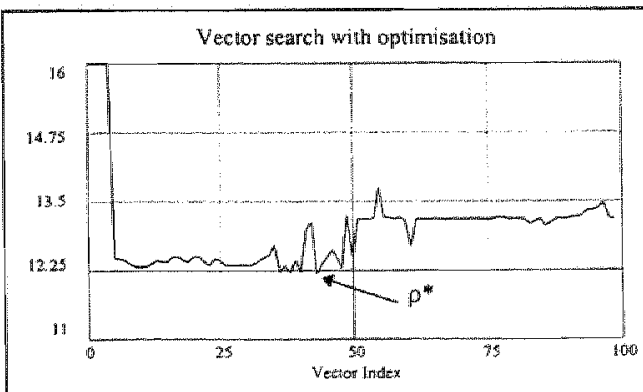

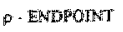


Note that the $\beta$-search parameter (Figure 4.57) and the $\alpha$-search parameter (Figure 4.59) forms a mirtor image. During the vector search of the time lag coefficient $\theta$ in the domain segment $[25,50]$ with range $[0.4,2]$ in the neighbourbood of $\theta \cong 1.8$, the $\alpha$ - and $\beta$-parameters in- and decreases in stepwise fashion. Furthemore, the $\theta$-parameter is nearly invariant for the changes of the remaining three parameters. Compare Figure 4.59 (the delay case) and. Figure 4.54 (the lag case). Notice the sensitivity of the time constant $\theta$ in the delay case (Figure 4.59 ) during the vector search of the $\alpha$ parameter of the permanent income variable.

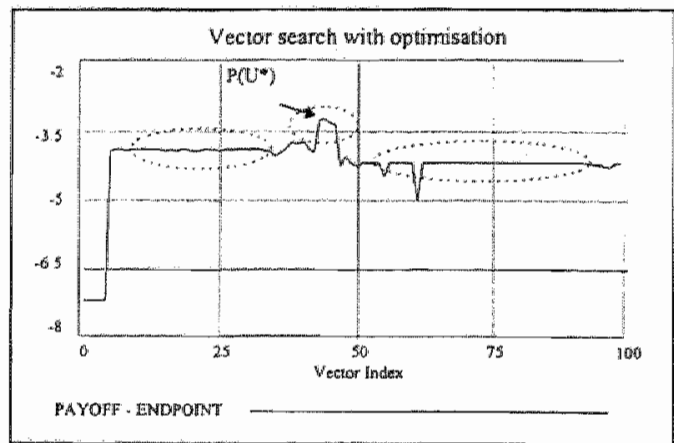

Figure 4.6!
The vector search with optimisation of the search parameters indicate the complexity of the discrete lag estimation, where phenomena of local and locked-in optima can arise. Three regions in Figure 4.61 of local optima of the payoff function can be separated by the dotted ellipses. Figures 4.53 to 4.60 provides us information which on the other hands were not possible to acquire. Once the initial $\theta$ parameter searches in the interval $0.4<\theta<1.4$ with $\Delta t=$ 0.125 then the maximum payoff settles down to a sub-optimal situation: $P(U) \cong-3.9$ and optimal $\theta^{*} \cong 0.5$. It is not possible to 'improve' out of the interval, because the surfaces especially of the $\alpha$ - and $\beta$ parameters are too flat. The hill-climber has entered a saddle point and is locked-in. This is shown in Figure 4.62 in point B. Ones the initial value forces the hill-climber to enter the regions characterised by the interval $1.5<\theta$ the optimal parameters values and the maximum payoff, $P\left(U^{*}\right) \cong-3.2$, are reached in point $\mathrm{A}$ with optimal $\theta^{*} \cong$ 1.15. When $\theta$ reach the neighbourhood of 1.8 than the $\alpha$-and $\beta$-parameters stepwise (in)decrease to $\approx$ 0.5 respectively $\approx-0.05$ and the $\theta$-parameters stay at $\approx 1.9$. Figure $4.57,4.58$ and 4.59 illustrates this phenomenon very clear.

Future research should investigate this complexity more deeply. The following questions should be posed and hopefully answered : is this sensitivity of initial value and optimal value due to the artefact of discrete or sampled data series and the interpolation algorithm applied versus the use of optimal smoothing algorithms? Also, the question of an optimal fixed-interval smoother, optimal fixed-point smoother or optimal fixed-lag smoother should furnish the question of estimation the time constant, $\theta$, of the discrete lag operator $L^{\theta}(\bullet)$.

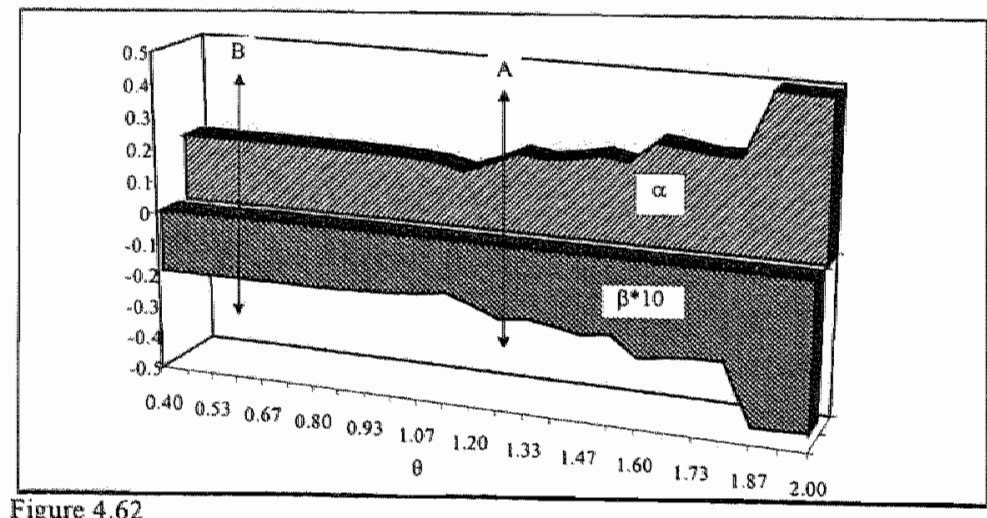

Figure 4.62 


\section{Chapter 5 \\ Vintage car stock models}

\# Objective

\# Methods

\# Data sources

\# Results

\# Conclusions
1. Development of vintage total car stock model by 15 vintages (or year of construction), in order to estimate the scrap/decay function.

2. Development of vintage car stock model by fuel type by 10 vintages.

3. By applying empirical weight coefficients the car stock by fuel type will be further divided up into 3 cylinder-content (cc) classes and 3 (4) input/output technologies of the new car engines. The reason for developing such a des-aggregated car stock model lies in the fact that each vintage of each fuel type, of each $c c$-class with each technology has its own emission spectrum and its own yearly kilometrage!

Estimation of the cleaned-up scrap data for the total car stock and for the car stock by fuel type. Dynamic simulations of the resultant active car stock model by vintage, by fuel type, by cc, and by technology.

Wrecks data from CBS, car registration data from RDW-'Rijksdienst voor wegverkeer'. New car sales data 1980-1994/5 from RAU/CBS, car stock data 1980-1995 form CBS.

Estimations of past scrap figures for the Dutch car market and projection to 2015. The structural changes are investigated and high lighted by means of statistical data available. The idiosyncrasies of the $90 \mathrm{~s}$ are illuminated as well as its repercussions for forecasting.

By investigating the dynamics of the car market the conclusion can be drawn that the reference period 1980-1995 is structural unstable as to serve for a base for forecasting or prediction. A sub period (1.986-1995) was chosen to serve as a base period. 


\subsection{Modelling Car Stock Vintage Model}

\subsubsection{Introduction}

Data Analysis (1961-1992)

In order to examine and anallyse the composition or quality of the car stock the car's year of construction (or vintage) should be tracked in the car stock during car"s lifetime.

This chapter uses the survey data of the so-called registered stock of vehicles. This applies to all motor-vehicles with car registration documents (Part I, II and III) issued by the "Rijksdienst woor het Wegverkeer" (RDW) after October Ist of the year $t$ involved and still in the motor-vehicle file at the 1 th of August year $t+1$.

Not accounted are vehicles whose registration documents are retumed to the RDW, because the vehicles involved have been demolished or permanently set out of use in another way. These cases will be assembled on behalf of the demolition or scrap of the vehicles.

\section{Basic Documents.}

The statistics are based upon the vehicle registration documents issued by the RDW, on the understanding that only are accounted those vehicles with valid and complete registration documents.

\section{Limits of observation}

In the statistics are not recorded:

1. military vehicles;

2. vehicles of foreign diplomatic and consular personnel;

3. vehicles of non-residents with $\mathrm{GN}$ - or BN-license plates;

4. new vehicles which are still in stock at the manufactures and dealers;

5. vehicles for which no license plate is needed, as are farm tractors, road building equipment, etc.

\section{Definitions}

In the statistics the class vehicles are subdivided by:

1. Passenger cars :

motor vehicles suited for the transport of a maximum of 9 persons (driver included), station cars included.

2. Delivery vans:

3- and 4-wheeled wans of which the empty weight and load exceeds $3500 \mathrm{kgs}$.

3. Lorries:

4- and more-wheeled lorries of which the empty weight and load exceeds 3500 kgs.

4. Tractors:

motor vehicles suited for the hauling of trailers.

5. Special vehicles:

motor vehicles for special purposes such as fire engines, dust lorries, pick-up lorries, etc.

6. Buses and coaches:

motor vehicles suited for the transport of 9 and more persons (driver not included).

7. Twow wheelers:

motor cycles, motor scooters, motor carrier, etc.

For tractors total weight is defined as the weight of the vehicle increased by the maxiximum permitted load on the trailercoupling. 


\subsubsection{Serap}

Since 1983, the "Centraal Bureau voor Statistiek" (CBS) conducts yearly surveys with respect to the number of vehicle wrecks. It concerns motor vehicles (with more than fwo wheels) with a legal registration document wich become available for dismantling within the Netherlands during the calander year. Excluded are military vehicles and cars of non-residents. The statistics are of interest for estimating, among others, the amount of waste materials and recycling. Furthermore, these statistics are of prime interest for mutation in the vehicle stock in our model. No information is given about the actual scrap of the wrecks, as this would require an inquiry into the chain of dismantling/scrap/shredding activities which were not feasible for the moment. Therefore the estimated scrap has to be deferred from diverse statistical sources. Starting point will be the automated registration, called administrative car stock (in case of automobiles), this registration is to raw and noisy to be usefull for our estimation purpose. For example, scrap of between times accruals of the vehicle stock can not be measured; and the mutations contain a source of noise. The resulting data are only indicative and unrehable for our modelling purpose. Kalman filtering techniques to account for measurement errors can be applied, unless more reliable data are available. CBS applies a cleaning process (CBS 1986), called here 'correction process I and II', in order to update the gross vehicle stock to a net wehicle stock (correction process D) and than to a perceived or estimated physical vehicle stock (correcition process II).

\subsubsection{Observation}

For the observation the legal registration document is (Part I, II and III) the starting point, with the advantage of direct entry to the automated registration data bank of the RDW and of other CBS statistics (foreign trade statistics). In this case the supply of vehicle wrecks over a period of a year can be defined as:

the number of administratively Dutch vehicles scrapped from the gross wehicle stock (by returning part III of the legal registration documents, minus the number of velticles not yet intended for dismantling (the merchant stock of wehicles, export of used vehicles, etc), plus the import of foreign vehicles to be dismantled in the Netherlands.

Note the fact that only legal registration documents are the source of the raw data; see the limits of observation noted above.

\subsubsection{Raw Data}

The measurement date for the registration is the 1 th of august each year $t$. The measurement consist of those vehicles, which:

a) during the 12 months preceding the measurement date have been announced to be permanently out of use by the RDW. This measurement will be called registered scrap ( $X$-units of velhicles in Diagram 1) from the vehicle stock. Owing to the delays in announcement, only $36 \%$ of car owners filfill the announcements, additional vehicles have to be selected which :

b) during the 12 month preceding the 1 th of octobre of year $t-1$ had a legal part III of the registration document and of which part III since the 1 th of october year $t-I$ till the measuremnt date have not been renewed with the exclusion of those vehicles which applies to criterium a). The resulting data will be called non-registered scrap ( $\mathrm{P}$-units of vehicles in Diagram 2). This process is called comection process $\mathrm{I}$. The resultant set has to corrected for the register numbers which are declared non-valid or incomplete by the RDW because of actual remaining out-of-use position of the vehicle (Q-units of vehicles). This to avoid double counting.

The second subset exist of the remaing set and contains $P-Q=Y$-units of vehicles. This is called the non-registered scrap from the wehicle stock. 

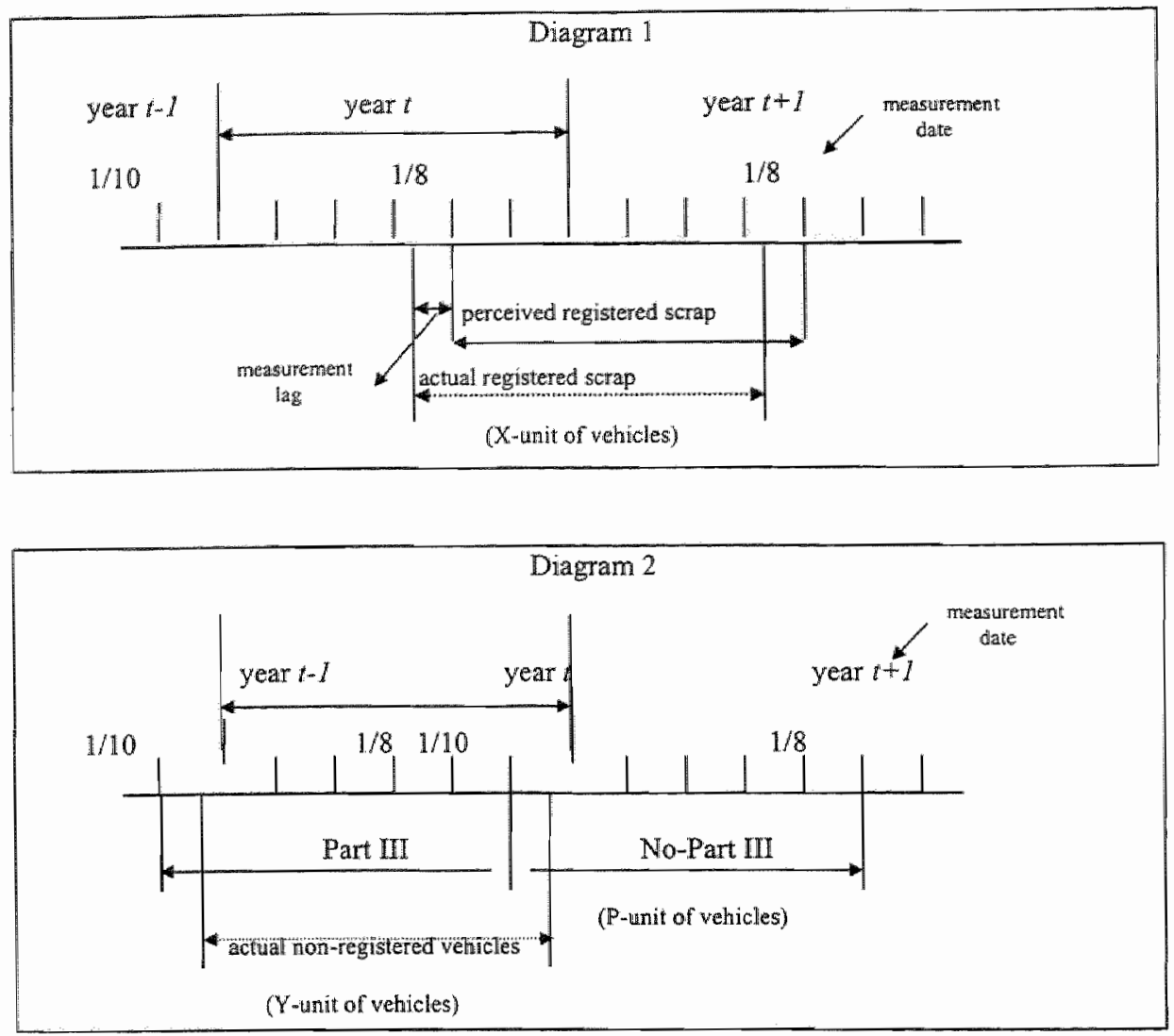

In order to obtain an estimate of the number of vehicles, intended for dismantling the scrap data have to be corrected for those vehicles which are likely not intended for dismantling, for example :

1. the dealer's merchant stock of used vehicles (Part III has not be renewed),

2. the export of wsed vehicles to be dismantled abroad and

3. the import of foreign vehicles to be dismantled in the Netherlands.

This process is called 'correction process II'.

The detailed results are published in the statistic "Afvalstoffen voertuigvakken 1983" (Waste

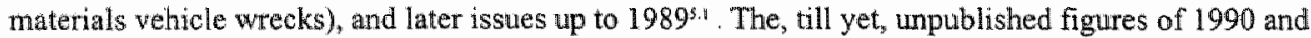
1991 have been kindly supplied by the CBS.

The following additional remarks may be of use: Estimates of the export of used registered vehicles are used (correction process II), because of the fact that these cars will not be dismantled in the Netherlands. This export mainly involves cars construeted in recent years (joung vintages). Similarly estimation of foreign vehules to be dismantled in the Netherlands will be applited.

The process of administratively observation of the supply side of wehiele wrecks means that some aspects are not explicite dealt with when looking to the environmental impact of the transport activities. Not explicitely considered are: the process of collecting, inventory holding and transport, the location of dismantling and the possibility of recycling of components and materials. Data about these aspects can only be observed on the demond side, the real dismantling chain. With the rate of throughput of wrecksin the dismantling chain being dependent of the scrap price.

\footnotetext{
5.1 Data of the year 1984 to 1990 are te be found in the issues Kwartaabericht Milieustatistieken $87 / 1,87 / 4$, $89 / 2,89 / 4,90 / 4,91 / 3$ and $92 / 4$
} 


\subsubsection{Estimation of the scrap rate of the car stock by vintage}

Tabel 5.1 displays the data of the scrap rate of the car stock $1983-1992$ by 20 vintages (V0-V20)

\begin{tabular}{|c|c|c|c|c|c|c|c|c|c|c|}
\hline Year & 1992 & 1991 & 119990 & 1989 & 1988 & 61987 & 19886 & 19.85 & 1984 & 11923 \\
\hline 10 & 0.6003 & 0.008 & 0.027 & 0049 & 0.008 & 0.006 & 0.005 & 0,005 & 0.011 & 0.037 \\
\hline$\| 1$ & 0.019 & 0.0231 & 0.035 & 0,020 & 0.0201 & 0.024 & 0.017 & 0.0115 & 0.020 & 0,017 \\
\hline 82 & 0.013 & 0.014 & $\$ 0.011$ & 0,009 & 0.012 & 0.014 & 0.009 & 0.000 & 0,008 & 0.007 \\
\hline$\sqrt{3}$ & 0.016 & $0.020 ?$ & 0.021 & 0.015 & 0.015 & 0.015 & $0.01 \mathrm{in}$ & 0.012 & 0,010 & 0.010 \\
\hline 14 & 0.021 & $0.025^{\circ}$ & 0.032 & 0.018 & 0.016 & 0,015 & 0.013 & 0.912 & 0013 & 0017 \\
\hline W5 & 0.022 & 0.028 & 0.035 & 0.018 & 0.016 & 0,017 & 0.013 & 0.014 & 0.02201 & 0.029 \\
\hline 816 & 0.029 & 0,034 & 0.036 & 0.021 & 0.021 & 0.019 & 0.017 & 0.022 & 0.034 & 0.045 \\
\hline 17 & 0.039 & 0.039 & 0.040 & 0031 & 0.029 & 0,034 & 0.035 & 0.043 & 0.061 & 0,79 \\
\hline$\sqrt{28}$ & 0.046 & 0.050 & 0.055 & 0,047 & 0.056 & 0.080 & 0.086 & 0.102 & 0.121 & 0.136 \\
\hline$M$ & 0.060 & 0.074 & 0.072 & 0,086 & 0.108 & 0.160 & 0.175 & 0.167 & 0.169 & 0.174 \\
\hline vig & 0.090 & 0.094 & 0.101 & 0.136 & 0.171 & 0.194 & 0.213 & 0.186 & a.18 & 0.156 \\
\hline V11 & 0.106 & 0.115 & 0.131 & 0.130 & 0.1901 & 0.171 & 0.174 & 6164 & 0.135 & 0.1010 \\
\hline V12 & 0.117 & 0.131 & 0.143 & 0.154 & 0.149 & 0.108 & 0.410 & 0.102 & 0.093 & 0.084 \\
\hline 113 & 0.122 & $0 . \mathrm{M}$ & 0.312 & 0.115 & 0.087 & 0,060 & 0.047 & 0.061 & $0,05 \%$ & 0.046 \\
\hline $\mathrm{V} 14$ & 0.120 & 0.094 & 0020 & 0.057 & 0,044 & 0.030 & 0.029 & 0.037 & 0029 & 0.024 \\
\hline v1.5 & 0.080 & 0.054 & 0.032 & 0.028 & 0.020 & 0.019 & 0.018 & 0.019 & 0.015 & 0010 \\
\hline$\sqrt{16}$ & 0.043 & 0.023 & 0.015 & 0.013 & 0.0131 & $0,0,2$ & 0.050 & 0.011 & 0.007 & 0.0066 \\
\hline v17 & 0.018 & 0.012 & 0.008 & 0.009 & 0,009 & 0.006 & 0.006 & 0.0005 & 0.004 & 0.002 \\
\hline$V 18$ & 0.010 & 0.006 & 0.006 & 0.006 & 0005 & 0.004 & 0,003 & 0,003 & 0.002 & 0001 \\
\hline V19 & 0.006 & 0.005 & 0.005 & 0.004 & 0003 & 0.002 & 0.002 & 0.0011 & 0,001 & 0.001 \\
\hline $\mathrm{V}_{20}$ & 0.005 & 0.004 & 0.003 & 0,003 & 0.002 & 0.002 & 0.001 & 0,001 & 0.001 & 0,001 \\
\hline Rest & 0.016 & 0.0121 & 0.009 & 0.0008 & $0,00 \%$ & 0.007 & 0.006 & 10.005 & 0,004 & 0.004 \\
\hline Total & 1.000 & 1000 & 1.000 & 1.000 & 1.090 & 1.0001 & 1.000 & 1.000 & $\|, 000$ & 1.0 \\
\hline
\end{tabular}

Table 5.1 The scraps by 20 vintages

The series have been computed from the raw yearly data taken from the statistic : Afvalstoffer: voertuigwrakken $1983 \mathrm{t} / \mathrm{m} \mathrm{1989}$, (Waste Materials vehicle wrecks), the data for the year 1990-1992 have been kindly supplied by the CBS.

Before applying a mean scrap rate by vintage, we will fit a gamma distribution to the data in order to look for consistency and reliability of the data. The gamma distribution was chosen because the distribution is remarkable flexible with two parameters to be estimated simultaneously.

The gamma distibution has the following density function:

Density:

$$
f(t)=\frac{\beta^{\alpha} t^{(\alpha-1)} e^{-\beta t}}{(\alpha-1) !}
$$

where

$$
\alpha>0, \beta>0, t \geq 0
$$

Ss

Normally, due to difficulties in the estimation procedure the scale factor $\alpha$ will be preset to an integer number and the order $\beta$ will be estimated. By our approach both parameters will be simultaneously estimated the iterative hill climbing algorithm. The results and the $95 \%$ confidence intervals for the year 1983-1992 are summurised in Box 5.1. The density functions are perfectly estimated as can be seen by some plots of for example 1983, 1990 and 1992, the other years show the same fit. If $\alpha$ is a positive integer, the gamma distribution is identical to the Erlang distribution with expectation $\mathbb{E}[t]=1 / \beta$ and variance $\operatorname{Var}[t]=1 / \alpha \beta^{2}$. In our case we set $\alpha=2$ and $\beta=0.1$. Inspecting Figures 5.1 to 5.3 shows an increase of cars' lifetime from $\approx 8.5$ year in 1983 to $\approx 12$ year in the 90 s. This conforms the observed ageing of the car fleet during the last decade. 


\begin{tabular}{|c|c|}
\hline \multicolumn{2}{|c|}{ Box $51 \quad 95 \%$ Confidence interval } \\
\hline 1983 & $1.972<=\alpha=1.9994<=2.03698$ \\
\hline & $0.0912<=\beta=0.1005<0.1093$ \\
\hline 1984 & $192<\alpha=1.9994<=2.03996$ \\
\hline & $0.0914<\beta=0.1005<=0.10918$ \\
\hline 1985 & $1.983<a=1.9994<-2.03571$ \\
\hline & $0.0916<=\beta=0.1005<=0.10907$ \\
\hline 1986 & $1.974<a=2.0000<=2.03395$ \\
\hline & $0.0922<\beta=0.1008<0.10879$ \\
\hline 1987 & $\begin{array}{l}1.959<\alpha=1.9994<=2.03577 \\
0.0916<\beta=0.1005<=0.109108\end{array}$ \\
\hline 1988 & $\begin{array}{l}1.972<\alpha=1.9994<2.03727 \\
0.09114<=\beta=0.1005<0.109424\end{array}$ \\
\hline 1989 & $\begin{array}{l}1.977<\alpha=1.9994<=2.03728 \\
0.09115<=\beta=0.1005<0.109421\end{array}$ \\
\hline 1990 & $\begin{array}{l}1.966<\alpha=2.000<=2.036971 \\
0.0923<\beta=0.1005<=0.11034\end{array}$ \\
\hline $199 \pi$ & $\begin{array}{l}1.9736<\alpha=2.0072<=2.04752 \\
0.09147<=\beta=0.1026<=0.112601\end{array}$ \\
\hline 1992 & $\begin{array}{l}1.97289<\approx \alpha=2.0065<=2.0468 \\
0.09118<=\beta=0.1023<0.11243\end{array}$ \\
\hline
\end{tabular}

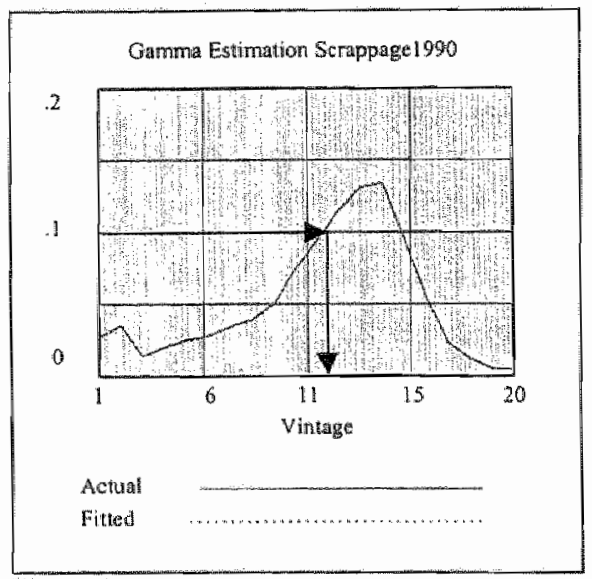

Figure 5.3

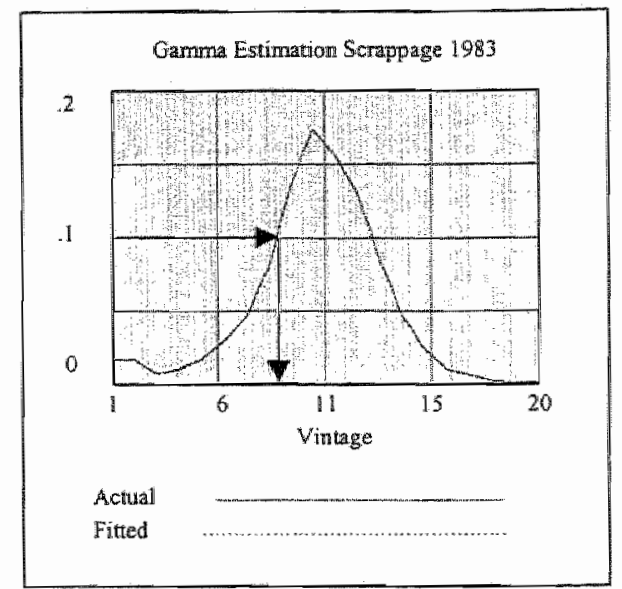

Figure 5.1

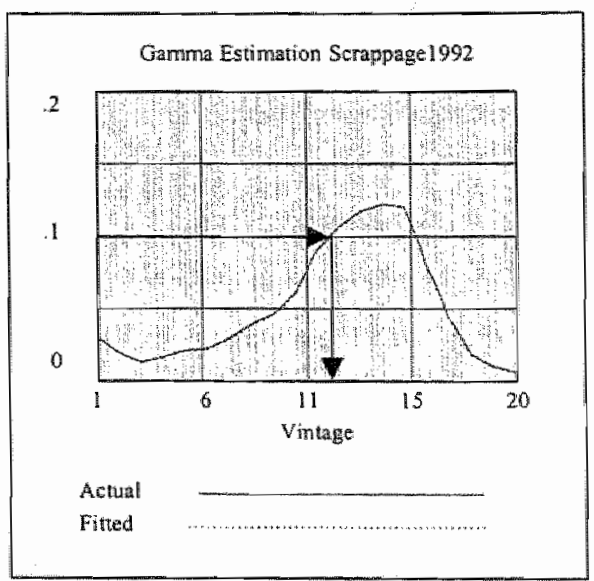

Figure 5.2

\subsection{Administrative and active car stock data by vintages}

The basic data are selected from the central wehicle-registration data base of the Dutch Ministry of Transport. A distinction should be made between administrative vehicle stock and the active (in-use) vehicle stock and this for the following reason. For some applications the extent of the active vehicle stock is a better indicator than the administrative stock. So will the computation of traffic performance, as well the determination of energy-use and the computation of emission factors of the raod traffic, be based on the active vehicle stock.

The difference between administrative and active vehicle stock exists of two subset:

A. On the one side a part of the vehicle stock belongs to the merchant inventory of dealer's and garage entreprises and for this purpose temporarely not in active-in-use;

B. On the other side the register documents per 1 th of August af each year contains vehicles which are scrapped (out-of-use), but of which the register documents are not yet returned to the "Rijksdienst voor Wegverkeer" (RDW). So the administrative vehicle stock is rather noisy and over-estimates the 
life time of the vehicles. This cleaning process has recently been started at the RDW, and this is the reason that estimates of the active vehicle stock by vintage (year of construction) are awailable from 1988 on and estimates of the active vehicle stock from 1970 till 1992.

$[1] \cong 0.01$
$[2] \cong 0.02$
$[3] \cong 0.03$
$[4] \cong 0.04$
$[5] \cong 0.05$
$[6] \cong 0.05$
$[7] \cong 0.06$
$[14] \cong 0.06$

As the administrative aggregated car stock differs on average by $6 \%$ from the active aggregate car stock, the comparison with the vintage structure between both concepts. looks like the following figures (rounded). The first 6 year the difference increases till year 7 then it stabilise at $6 \%$. Table 2 . shows the deviation of the administrative and active vintages

Table 5.2

\subsubsection{Estimation of active car stock by vintages}

As described before the legal inspection procedures were drastically changed in 1985 , with the effect that great parts of old 10-year vintages (> $/ 10]$ ) were inmediately removed or scrapped from the car stock, from 1988 on the inspection year of construction was dropped to 4 year (>M[4]). So 1985/86 marks a trend break with less high scrap rates for the elder vintages from 1987 on. So we estimated from 1987 till 1992 the car stock with 15 vintages structures. The best fit (but not in an optimal way) was perceived in a three stage way with the following scrap rates by vintages:

The first stage consist of estimating that part of the vintages that has the largest quantitative impact on the scrap. This part is the range of $V[5], \ldots, V[10]$. The other classes of vintages have been set to their empirical mean values. After estimating $\nu[5], \ldots, V[10]$, the other classes $V[1], \ldots, K[4]$ and $V[11], \ldots$, $V[15]$ were sequentially estimated, with the estimated data of $V[5], \ldots, V[10]$ holding fixed, replacing the old mean value.

Note the input to the active car stock was the actual new car sales.

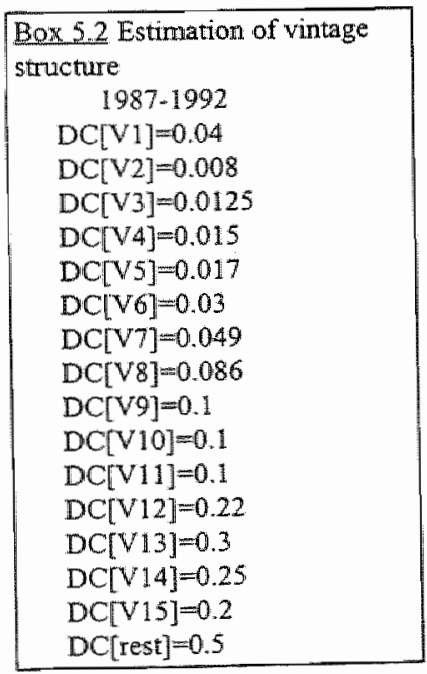

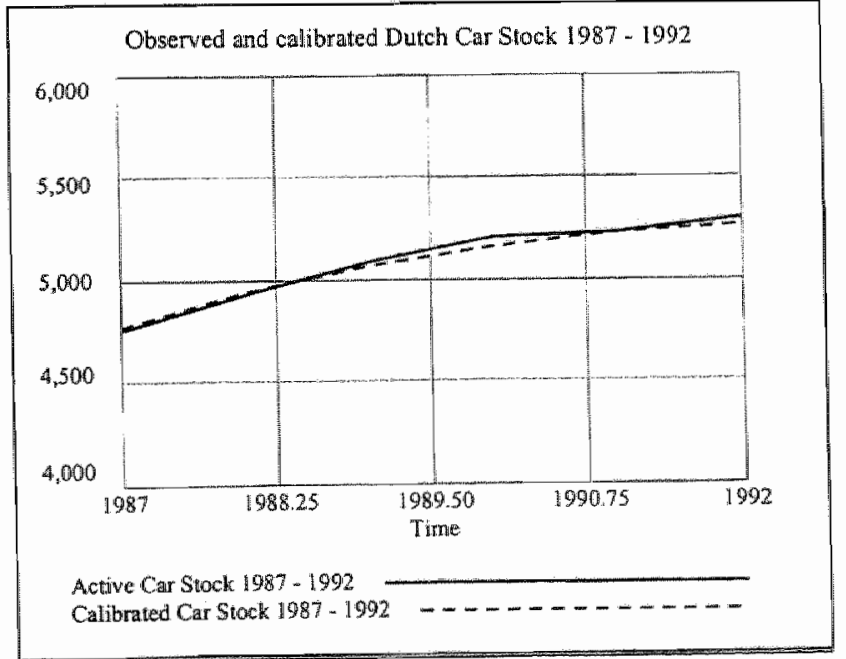

Figure 5.4 The observed active car stock and the estimated active car stock $(x 1000)$ 


\subsection{Estimation vintage structures car stock by fuel type}

\subsubsection{Introduction}

As the emission module uses, among others, cars by fuel type as input, we have to divide up the total active car stock into gasoline, diesel, and LPG driven cars and investigate the new car sales and the scrap by fuel type. Inspecting Figure 5.5 it is remarkable that the LPG cars are declining since 1990. The reason is the introduction of more expensive emission control devices for LPG type cars, which increase the user cost and the break-even point from $17500 \mathrm{~km} / \mathrm{year}$ in 1990 to $27000 \mathrm{~km} / \mathrm{year}$ since 1991. So there was and still is a switch from LPG to diesel or gasoline, depending among others from the yearly kilometrage. The gasoline shows a moderate recovery the mid 80s, and diesel exhibited a stretched sigmoidal growth curve. Note the gasoline -, diesel - and LPG car stock ( 1000$)$ is measured on the right axis, the total car stock, Total, (x.1000) on the left axis.

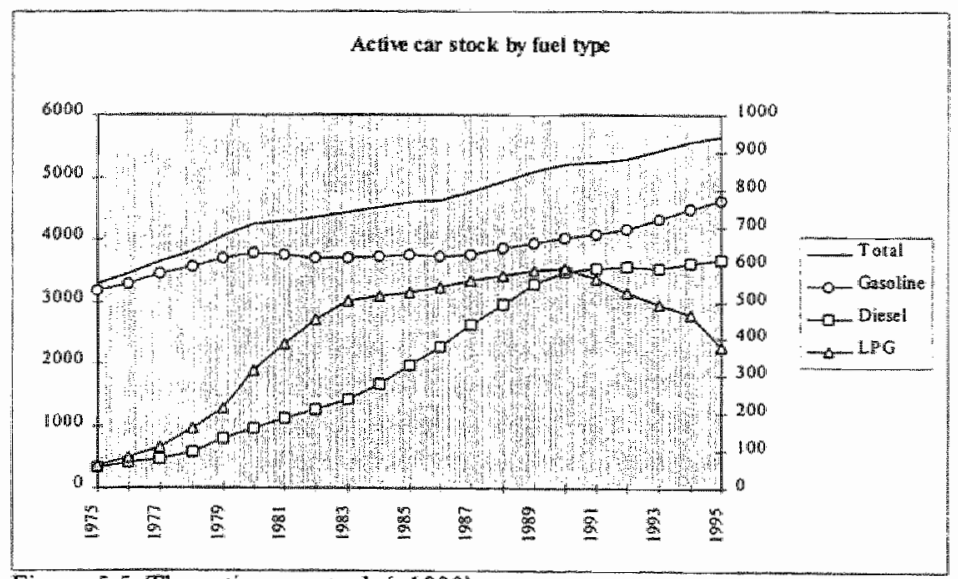

Figure 5.5 The active car stock (x1000)

Another view furnish a fractional distribution of the total car stock over the fuel type. Note in Figure 5.6 CSTP is the fraction gasoline cars in the car stock, CSTD, and CSTLPG respectively diesel and LPG car stock. CSTD and CSTLPG are measured on the right axis.

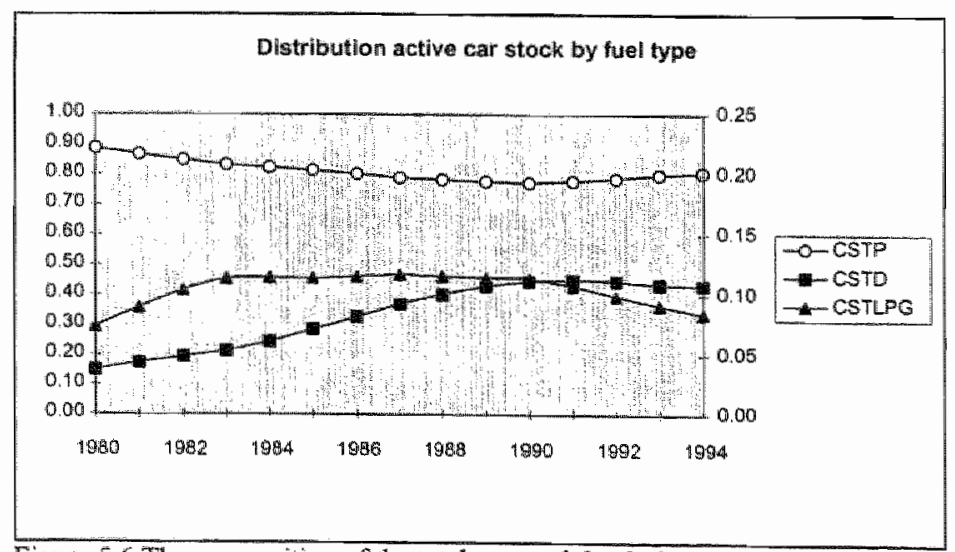

Figure 5.6 The composition of the total car stock by fuel type 


\subsubsection{The gasoline car stock}

As explained before the gasoline car stock shows a moderate steady growth during the 80 s after a strong increase in the $70 \mathrm{~s}$, however the new car sales shows very eratic movements following the business cycle. Exploring the vintage car stock data for the period 1980-1994 reveals among others an interesting side information: the aging of the Dutch car stock. The aging coefficient, $r_{z}$, has been measured as the share of the elder vintages, e.g. the vintages older then 10 years, as a fraction of the total car stock by fuel type. There exists an increasing rest sum from 1980 on. Figure 5.7 shows the recent evolution of the aging phenomenon of the Dutch gasoline car stock from 0.052 in 1980 to 0.243 in 1994 . This conforms the increasing average lifetime of the Dutch cars.

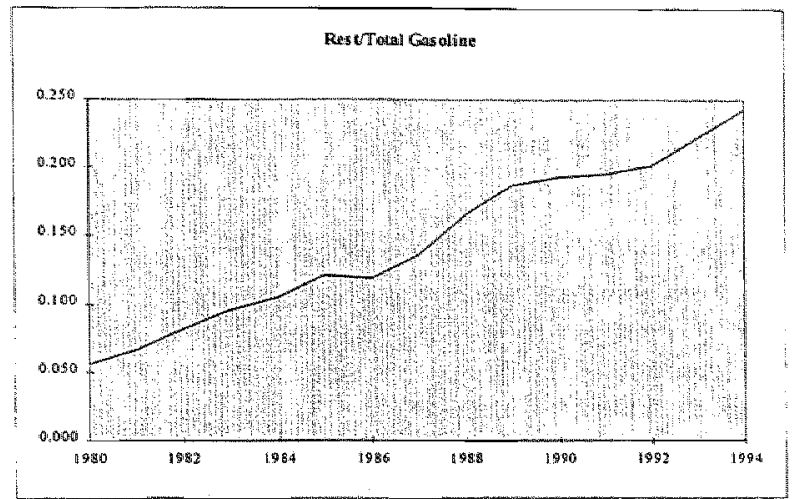

Figure 5.7 The ageing evolution of the Dutch gasoline car stock

In order to execute the correct estimation of the first 10 vintages scrap coefficients,

$$
\begin{aligned}
& D C[F, V] \\
& F=\{P, D, L\} \\
& \text { where } F: \text { fuel type } \\
& P: \text { petrol or gasoline, } \\
& D: \text { diesel and } \\
& L: L P G ; \\
& V=\left\{V_{1}, \ldots, V_{10}\right\}
\end{aligned}
$$

where

$$
\text { V: vintage or year of construction }
$$

the total car stock, CST, has been divided into the sum of the first 10 vintages $\{V l, \ldots, V 10\}$ and the sum-rest of the elder vintages, $R=\Sigma(V I 1, \ldots V r)$.

In general:

$$
\begin{aligned}
& \operatorname{CST}_{i}[F]=\sum_{k=1}^{10} \operatorname{CST}\left[\left[F, V_{k}\right]+R_{f}[F]\right. \\
& R_{i}[F]=r_{i}^{*} \operatorname{CST}_{i}[F]
\end{aligned}
$$

The observed total car stock, CST weighted by $1 /$ standard deviation, $1 / \sigma$, in order to measure the goodness of the fit. The sum-rest, $\mathbb{R}_{l}$, is treated as a time dependent variable added to the simulated car stock, CST. The observed yearly scrap coefficient $D C$ of vintage $k, D C^{*}\left[F, V_{k}\right]$, has been computed as :

$$
\operatorname{DC}_{i}^{3}\left[F, V_{k}\right]=\frac{\operatorname{CST}_{t-1}^{\sharp}\left[F, V_{k-1}\right]-\operatorname{CST}_{t}^{k}\left[F, V_{k}\right]}{\operatorname{CST}_{t-1}^{\#}\left[F, V_{k-1}\right]}
$$


The simulated scrap rate is computed as:

$$
S C R,\left[F, V_{k}\right]=\hat{D C}\left[F, V_{k}\right] * C S T\left[F, V_{k}\right]
$$

The estimation of the vintage scrap structure, $D C\left[F, V_{k}\right]$, pursues in general (e.g for $F=\{P, D, L\}$ ) the following steps. First the initial walues are set at the mean value for the period 1986-1994 with 10 as upper and lower constraint. Second the 10 parameters are entered in two blocks of 5 parameters, each with their mean values, $\mu$, as initial value. The first block $\{D C[F, V]\}, D C[F, V 5]\}$ is, in the furst instance, treated as consisting of model constants, $\overline{D C}\left[F, V_{1}^{5}\right]$, e.g. not yet treated as search parameters, the second block $\{D C[F, V 6], \ldots, D C[F, V I 0]\}$ are the search parameters, $D C\left[F, V_{6}^{10}\right]$. Then the search processes will be started and guided by the payoff fille criteria. The maximisation of the payoff or objective function in case of the gasoline vintage car stock can be expressed as:

$$
\max P(O)=\sum\left(-\min \left(\left(D C^{\prime}\left[F, V_{k}\right]-\hat{D C}\left[F, V_{k}\right]\right) / \sigma\right)\right.
$$

for $P, D, L \in F$

If for one (more) search parameter(s), $D_{C}\left[F, V_{6}^{10}\right]$, a bound has been reached, e.g. the payoff is not at criterium, the upper or lower constraint will be increased to $\pm 2 \sigma$, (marked with *), the other search parameters are transformed to constants and the search process restarts with the bounded search parameter (rellaxation). This procedure continues untill no bounds are hit.

The payoff improved from -0.01598 after 572 iterations to -0.01305

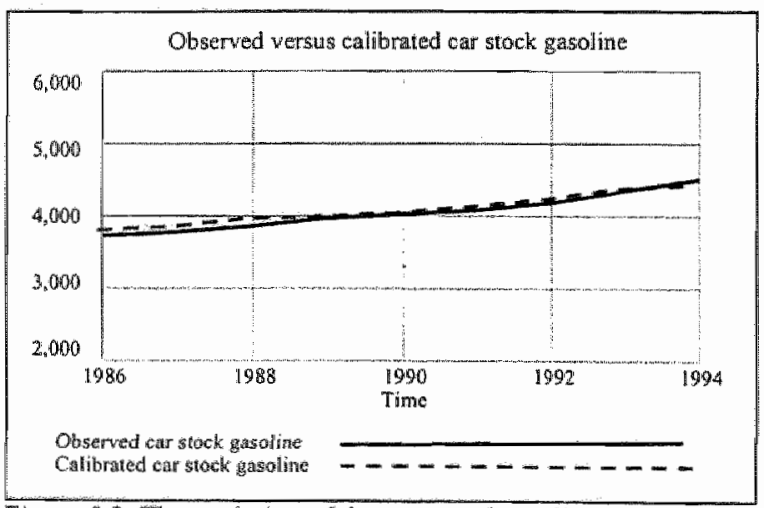

\begin{tabular}{l} 
Box 5.3 \\
$D C[P, V 1]=0.012 *$ \\
$D C[P, V 2]=0.016$ \\
$D C[P, V 3]=0.022$ \\
$D C[P, V 4]=0.025$ \\
$D C[P, V 5]=0.072$ \\
$D C[P, V 6]=0.082$ \\
$D C[P, V 7]=0.085$ \\
$D C[P, V 8]=0.124$ \\
$D C[P, V 9]=0.14$ \\
$D C[P, V 10]=0.24$ \\
\hline
\end{tabular}

Figure 5.8 The evolution of the measured gasoline car stock and the estimated car stock $(x 1000)$

The fit is renarkable good, but it should be alleged that the " $D C$ " -values do not represent a true unique optinum, it is more or less the 'best" guided estimation, because the search process will be guided by the choice of the input of the number or size of blocks of search parameters, $\hat{D C}\left[F, V_{1}^{10}\right]$, the initial values and the upper and lower constraints. 


\subsubsection{The diesel car stock}

The diesel car stock has since the mid 80 s till early 90 s shown a strong increase, as can be seen in Figure $4 .{ }^{5.2}$ The new diesel car sales increased exponential in the end $70 \mathrm{~s}$ and accounts now for $12 \%$ of the total car stock. The diesel car stock reveals also an increasing ageing phenomenon. Figure 5.9 shows clearly the increase, but is the ageing fraction is lower than in the case of the gasoline car stock. (15\% versus $23 \%)$.

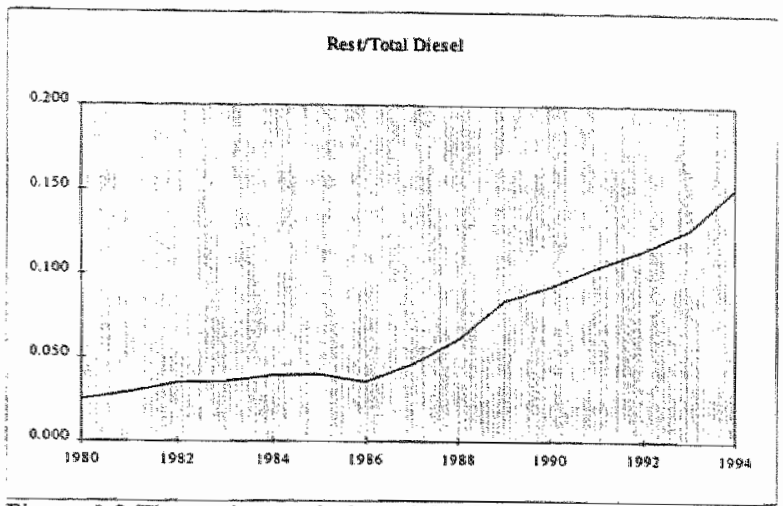

The same procedure, as explained above, has been applied to the estimation of the scrap coefficients, $D C\left[D, V_{k}\right]$.

Figure 5.9 The ageing evolution of the Dutch diesel car stock

The best fit of the vintage scrap structure is shown in Box 5.4

\begin{tabular}{|l|}
\hline Box 5.4 \\
$D C[D, v 1]=0.001$ \\
$D C[D, V 2]=0.011$ \\
$D C[D, V 3]=0.096^{*}$ \\
$D C[D, V 4]=0.093$ \\
$D C[D, V 5]=0.078$ \\
$D C[D, V 6]=0.074$ \\
$D C[D, V 7]=0.087$ \\
$D C[D, V 8]=0.009$ \\
$D C[D, V 9]=0.011$ \\
$D C[D, V 10] 0.014^{*}$ \\
\hline
\end{tabular}

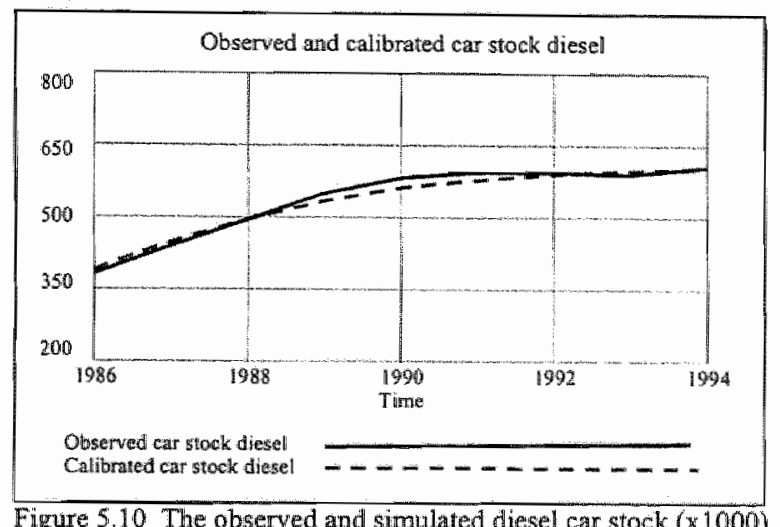

Figure 5.10 The observed and simulated diesel car stock ( 1000$)$

\subsubsection{The LPG car stock}

The LPG car stock is composed of a very eratic vintage structure, end 80 s (1988-1990) some vintages V2, V3, V4 show increases, with regard to the $V_{1}, V_{2}, V_{3}$, which is unusual, e.gegative sorap values which can be explained as an unusual high transformation from gasoline cars into LPG cars. Figure 3 shows this phenomenon. From the 90 s the LPG car stock decreased caused by a combination of two reasons: 1. the shift towards gasoline cars and to a lesser part to diesel cars and 2 . decrease of new car sales due to the recession in 1991-1993. In 1990 the emission criteria were sharpened. LPG installations were equipped with a micro processor which did rise the average build-in cost from fl 3000 in 1990 to 3800 in 1994 . This means that the break-even kilometrage of LPG versus gasoline cars rose from 22000 to $27000 \mathrm{~km} /$ year for an average $1800 \mathrm{cc}$ diesel car. Therefore from 1990 on the

2. There has been a substitution from LPG to diesel cars since the doubling of the road tax $1983 / 4$. 
LPG cars moved in a disadwantage position with regards to the gasoline and diesel cars, in $199015 \%$ of the new cars were equipped with a LPG-installation, $10 \%$ in 1995, and to end up in 1996 to $7 \%$ ! For the forecast purpose the unique transformation shift has been removed in order to get consistent estimates which ends up with the correct end-year 1994 LPG car stock. ${ }^{5.5}$ Figure 5.11 shows the resulting effect of the adapted procedure. The same estimation procedure as with gasoline and diesel cars, has been performed with the scrap coefficients shown in Box 5.5.

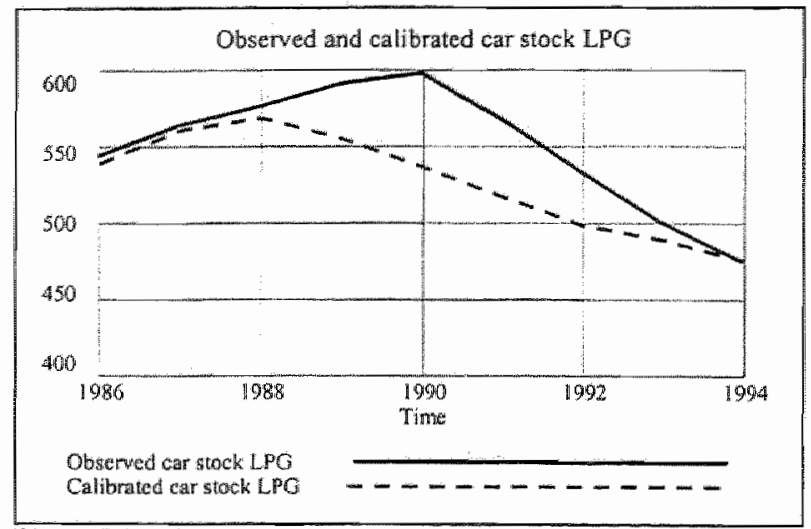

$B Q x, 5.5$
$D C[L, V 1]=0.004$
$D C[L, V 2]=0.016$
$D C[L, V 3]=0.013$
$D C[L, V 4]=0.006$
$D C[L, V 5]=0.004$
$D C[L, V 6]=0.015$
$D C[L, V 7]=0.045$
$D C[L, V 8]=0.084$
$D C[L, V 9]=0.16$
$D C[L, V 10]=0.13$

Figure 5.11 The observed and estimated LPG ear stock (x1000)

Like the gasoline and diesel cars stock the LPG car stock is also aging as can be seen from Figure 5.12 , but remains constant in the 90 s.

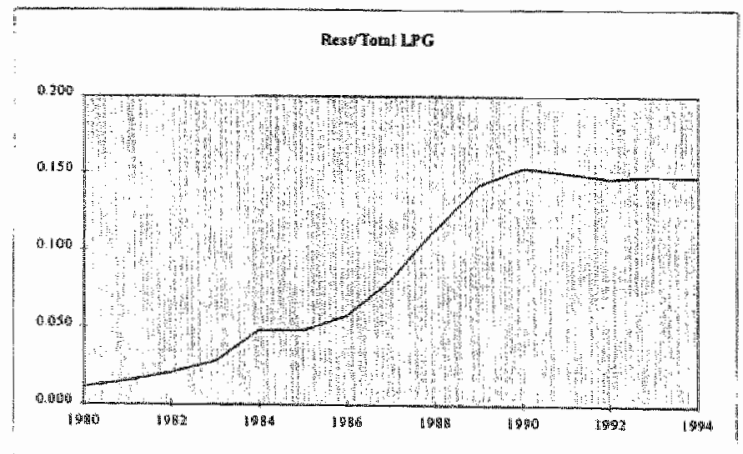

Figure 5.12 The ageing of car stock $\mathrm{LPG}$

\footnotetext{
5." During the very final stage of this research the information of a trend break was published (Kwartaalbericht Milieu (CBS) 96/3) indicating that LPG cars was 15-20\% overestimated form the late 80 s on!!! This conforms our findings when estimating the problematic LPG car stock. The surface between the observed (overestimated!!) and our estimated PLG car stock corresponds to the $15-20 \%$ overestimation.
} 


\subsection{Vintage car stock model by fuel type}

\subsubsection{Introduction}

The aggregate car stock model 4.2 .11 as developed in chapter 4 , will be used to generate an aggregate desired car stock and new car sales of the Dutch households which again will be applied as an input driver for a sequence of desaggregated vintage car stock models characterised by :

- fuel type (gasoline, diesel and LPG),

- cylinder content ( $c c<1.4 \mathrm{~L}, 1.4-2.0 \mathrm{~L},>2.0 \mathrm{~L})$, and

- technology (conventional engine, clean engine, open loop catalytic and closed loop catalytic).

The plan of action consists of the following steps:

1. estimating the car stock models by fuel type, e.g. by gasoline, diesel and LPG with the observed data, and

2. taking the total (future) desired car stock model (output from the $4.2 .11 \mathrm{a}$-model) and multiply it by the time-varying estimated weight coefficients, being the share of each fuel type in the forecast car stock series.

Ad. 1. Three altemative models will be evaluated and estimated with observed data series of the period 1980-1994. The first model consists of the standard formulation as applied in the aggregate car stock model 4.2.11a, but now estimated to the new car sales and car stocks by fuel type. The second model applies a differential equation which exhibited asymptotic growth near saturation levels. The justification for applying the (strong) sigmoid or logistic function models lies in the fact that the car stock market can be regarded as a replacement - or substitution market, e.g. the diffusion or penetration of cars over the households is almost completed, only the absolute growth of the number of households (especially the 1 - and 2 person households) is the major growth driver. The third model is a VerhulstPearl logistic function, which is an explicit solution form of the car stock model, formalised in the second model. The models referred above formalise a direct wealth component in its specification, e.g. (lagged) real disposable income or permanent income, etc., in order to partially determine the desired car stock.

Ad. 2. The next model has no direct wealth component it only applies the weight coefficients of the fuel type to the already estimated long term aggregate car stack model 4.2.1 la.

\subsubsection{Data and statistical somrces}

The data about new car sales are provided by RAI, the car stock by fuel type data are prowided by the CBS statistical source 'Statistiek van Motorvoertuigen' (Statistics of Vehicles). However, the new car sales are only published for diesel (CSD) and the rest (gasoline (CSP) and LPG (CSLPG)). The fact that the new car salles figures are not measured for LPG has to do with empirical fact that gasoline cars can be transformed at any time into a LPG type car. So new LPG car sales cannot properly reflect the integral LPG car stock dynamics. Some LPG vintages have an additional inflow and/or outflow from the transformation process explained above. So additional measures have to be taken in order to cope with this complication. The car stock by fuel type are available by 10 year vintages. The period of observation is 1980-1994. Table 5.2 shows the aggregate data. Note due to lack of space the additional data of the 10-vintages by fuel type are not reproduced here.

\begin{tabular}{|c|c|c|c|c|c|c|c|c|}
\hline YEAR & CSD & $\mathrm{CSP}$ & CSLPC & $\mathrm{CSI}$ & CST? & CISTD & CSITLCF & $\mathrm{TCS}$ \\
\hline 1980 & 30 & 378 & 42 & 430 & 3768 & 159 & 313 & 4240 \\
\hline 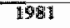 & 37 & 377 & 35 & 389 & 374 & 187 & 36 & +4314 \\
\hline 11982 & 36 & 342 & 38 & 416 & 3689 & 210 & क्ता151 & 4350 \\
\hline 1983 & 44 & 373 & 42 & 459 & $\$ 697$ & 237 & 504 & 44,38 \\
\hline 1984 & 61 & 360 & 40 & 461 & 3725 & $27 \%$ & 517 & 4519 \\
\hline 1985 & 74 & $38 !$ & 42 & 496 & 3748 & 328 & 524 & 4600 \\
\hline 1986 & 74 & 438 & 47 & 560 & 3725 & 30 & 537 & 4642 \\
\hline 1987 & 72 & 435 & 48 & 556 & 3759 & 430 & S5y & 4753 \\
\hline 1988 & 67 & 374 & 42 & 483 & 3857 & 495 & 589 & 4911 \\
\hline 1989 & 60 & 36 & 43 & 496 & 3950 & 547 & 584 & 3090 \\
\hline 99910 & 53 & 403 & 45 & 503 & 4025 & 580 & 391 & 5196 \\
\hline 1991 & 54 & 393 & 44 & 490 & 4073 & 590 & 561 & 5224 \\
\hline$\$ 992$ & 54 & 357 & 4 & 452 & $417 \%$ & 592 & 527 & 5250 \\
\hline 1993 & 48 & 346 & 30 & 432 & 4328 & 589 & 494 & 5411 \\
\hline 1595 & $5 \overline{3}$ & 3.43 & 37 & 433 & 4887 & 602 & 468 & 5557 \\
\hline
\end{tabular}

Table 5.2 The Dutch aggregate new car sales and car stock data 1980-1994 
where:
CSD : Car sales diesel
CSTD : Car stock diesel
CSP: Car sales gasoline
CSTP : Car stock gasoline
CSL : Car sales LPG
CSTL : Car stock LPG
CST : Total car sales
TCST : Total car stock

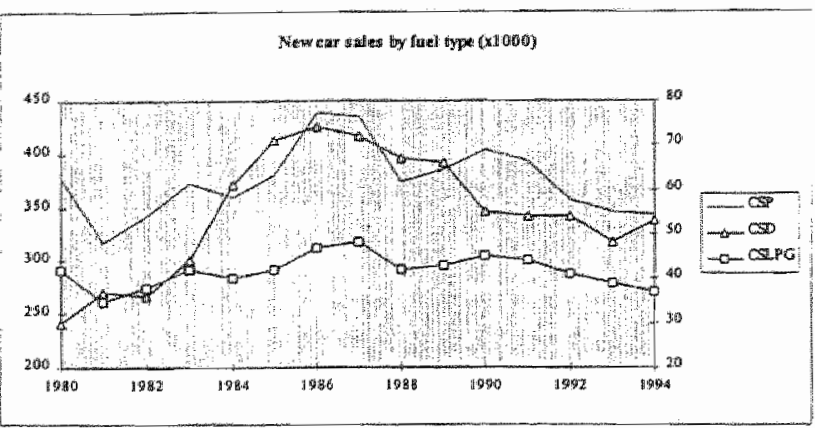

Figure 5.13 New car sales by fuel type
The data reflect the turbulence in the 80 s and early 90 s. Two severe recessions (1980/82 and 1991/93), a mild recession $1985 / 86$ and $a$ boom during $86-88 \mathrm{~s}$ are reflected in the new car sales data. Figure 5.13 shows the figure of new car sales by fuel type during the period 1980-1994. Note that the new diesel car sales (CSD) and new LPG car sales (CSLPG) are measured on the right vertical axis. Figure 5.14 shows the car stock by fuel type for the same period under inwestigation. Note that, again the diesel car stock, CSTD, and the LPG car stock, CSTLPG, are
measured on the right vertical axis. For the diesel car stock the period can be described as a sigmoidal (or logistic) growth process, with an exponential growth in the early 80 s, the reason is the additional

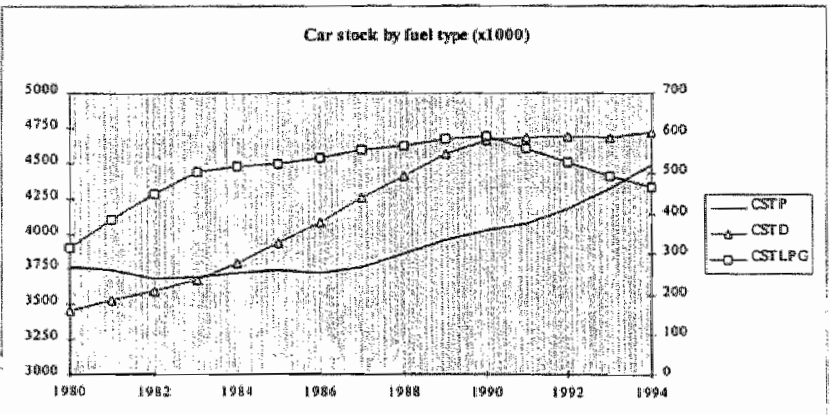

Figure 5.14 Car stack by fuel type evolution substitution from LPG to diesel cars. This was due to a doubling of the $L P G$ road-tax in 1983. Figure 5.13 and 5.14 shows very clear this break-point in 1983. The doubling of the LPG roadtax fuelled the diesel new car sales. The asymptotic growth of the diesel market (new car sales and the stock) started in 1986 and the saturation level was reached (for the time being) in 1990. This phase can be described as a decreasing (1986-1990) and zerogrowth phase in the early 90 s, followed by a positive nom zero-growth phase from 1994 on. Interesting also is the steady increase of the gasoline car stock, a second moderate sigmoid process (a short-run sigmoid process superimposed on the long-run sigmoid process started in the 50 s and ended in the early 80 s. This re-growth of the

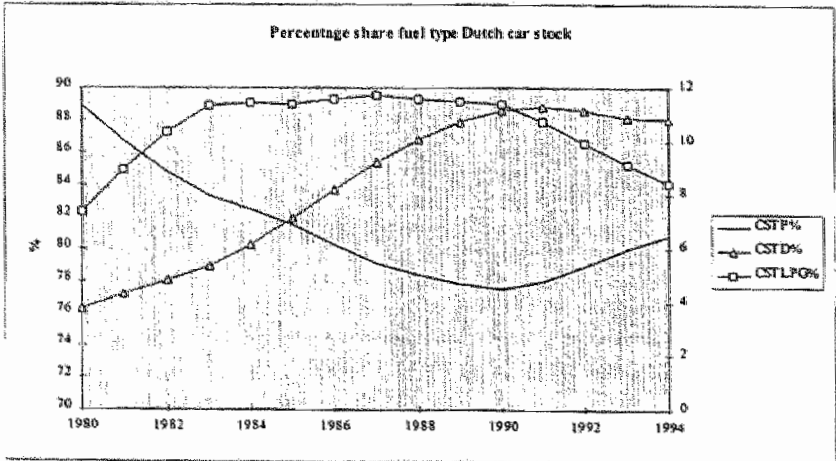

Figure 5.15 The percentage share car stock by fuel type gasoline market is partly realised at the expense of the $\mathrm{LPG}$ car sales from 1990 on. The reason is the change in the relative user costs of three fuel type cars. Since 1990 the price of build-in LPG devices increased substantially $(+30 \%)$ due to new stattutory technical requirements (emission decrease controlled by a micro-processor). Therefore the break-even user cost gasoline-IPG in average yearly km's for $\mathrm{LPG}$ cars, $1400 \mathrm{cc}$, rose to $27000 \mathrm{~km} /$ year against $25000 \mathrm{~km} / \mathrm{year}$ for diesel cars, 
$1400 \mathrm{Cc}_{y}$ (gasoline-diesel break-ewen point). So potential. LPG car demand was partly redistributed over gasoline and especially to diesel cars. The drop of LPG cars sales continued from 9\% (1990) to 7\% (1995) of the total new car sales. Note the same development is, of course, reflected in the percentage distribution of the car stock. The resurgence of the gasoline car stock can be expressed by the fact that in 1995 the 1984 percentage level $(82 \%)$ has been reached again. The LPG share drops to 1980 levels (7\%) and the diesel share remains around a $11 \%$ level from 1989 on. In section 5.5 .1 the substitution of fuel type cars will be further analysed. Note the years $1985 / 86$ shows a moderate decrease of the gasoline car stock due to the introduction of the obligatory periodic inspection (APK) which caused many ten thousands of car to be scrapped at once.

\subsection{Estimation the modell 4.2.11 a by fuel type}

All estimation tests in this chapter occur under the condition of maximising the payoff function e.g. $^{\circ}$ minimising the weighted squared difference between

a. the observed new car sales by fuel type $\left(C S^{*}[F]\right)$ and the simulated new car sales by fuel type $(C S[F]$ ), and

b. the observed car stock by fuel type $\left(T C^{\text {ti }}[F]\right)$ and the simulated car stock by fuel type $(T C[F])$. $\max P(U)=\sum-\min \left(\psi_{1}\left(C S^{*}[F]-C S[F]\right)^{2}+\psi_{2}\left(T C^{*}[F]-T C[F]\right)^{2}\right)$

\subsubsection{The gasoline car stock}

The formulation of the 4.2.11a-model was described in chapter 4. The specification of model 4.2.11a will be used in order to estimate model $(5.5 .1)$, with $\alpha, \beta$ to be estimated $\left({ }^{4}{ }^{\prime \prime}\right)$, and the remainder parameters already estimated $\left({ }^{c-c}\right)$ :

$$
\begin{aligned}
& C S_{t}[F]=\hat{\alpha} Y p_{t}+\hat{\beta} T C_{i}[F]+D \frac{1}{\theta}(C S[F]) \\
& \operatorname{CST}_{i}\left[F, V_{k}\right]=C S T_{i-1}[F, V]+C S_{i}[F]-S C R_{t}\left[F, V_{k}\right] \\
& T C_{t}[F]=\sum_{k=1}^{N\left(V_{k}\right)} \operatorname{CST}_{i}\left[F, V_{k}\right]+R_{t}[F] \\
& Y p_{t}=Y p_{i-1}+Y_{t}^{* \#}-\bar{\psi} Y P_{t-1}=D_{y_{W}}^{1}\left(Y_{r}^{*+}\right) \\
& \operatorname{SCR}_{i}\left[F, V_{k}\right]=\overline{\mathcal{D C}}\left[F, V_{k}\right]^{*} \operatorname{CST}\left[F, V_{k}\right] \\
& R_{r}[F]=\bar{r}_{r}[F] * T C_{r}[F]
\end{aligned}
$$

where

$$
\begin{aligned}
& F=\{P, D, L\} \\
& V=\left\{V_{k}, R\right\} \\
& V_{k}=\left\{V_{1}, \ldots, V_{10}\right\} \subset V \\
& R=\sum_{\left.k=1 V_{i}\right)}^{\infty} V_{k} \subset V \\
& F \text { : fuel } \\
& P: \text { gasoline } \\
& V \text { : vintage (year of construction) } \\
& D: \text { diesel oil } \\
& R \text { : remaining vintages ( }>10 \text { vintages) } \\
& L: \mathrm{LPG}
\end{aligned}
$$

$$
\begin{aligned}
& \bar{\Psi}=0.377 \text { (estimated } 1 / \text { time constant) } \\
& \bar{\theta}=1.6 \text { (estimated time constant) }
\end{aligned}
$$

$D_{\theta}^{1}(\bullet) \quad$ : delay operator (first order and $\theta$ time constant)

$N(\bullet) \quad$ : enumerate function, (enumerate the elements in a set)

$C S[F] \quad:$ simulated new car sales by fuel type

$T C[F] \quad$ : simulated total car stock by fuel type 


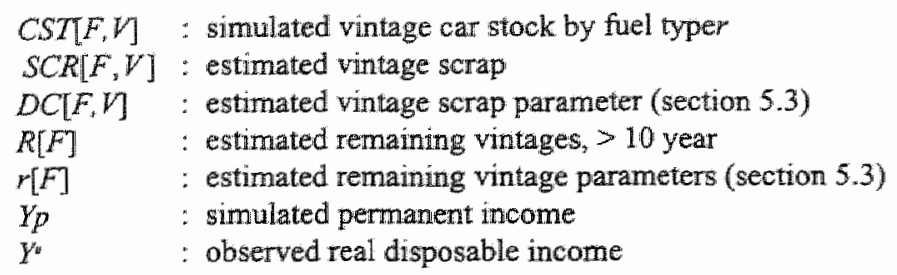

Note the vintage scrap rate has been estimated in paragraph 5.3. Model formulation (5.5.1) has been developed upon a wealth and a physical component. The influence of the wealth component will be named income effect, those of the physical component the stock effect. The income and stock effect can be defined in nominal and in relative terms.
nominal incorne effect $-\eta_{l}=\alpha Y p$
nominal stock effect $-\eta_{S}=\beta T C$
relative income effect $-\tilde{\eta}_{j}=\alpha Y_{p} / C S$ relative stock effect $-\tilde{\eta}_{s}=\beta T C / C S$

Estimating the model to the observed data for the period 1980-1994 means incorporating the turbulence of the $80 \mathrm{~s}$ and early $90 \mathrm{~s}$. The signs of the parameters (Box 5.6) suggest a nominal negative income effect (measured by the factor $\alpha Y_{p}^{\prime}$ ) and a nominal positive stock effect (measured by the factor

\begin{tabular}{|l|l|}
\hline Box 5.6 Log likelihood $95 \%$ Confidence interwals \\
$-0.0681407 \leq \alpha[\mathrm{P}]=-0.0626464$ & $\leq-0.0571923$ \\
$0.00409225 \leq \beta[\mathrm{P}]=0.00448486$ & $\leq 0.00486905$ \\
The base payoff is -17.9666 & \\
\hline
\end{tabular}

BCST) on new gasoline car sales. Moreover, the negative income effect dominates the positive stock effect, as shown in Figure 5.16. This is inconsistent with the premise of the theory of consumption of durables, as explained in chapter 4 . This is an indication that the demand for new cars by fuel type for the period under consideration, 1980-1994, is structural unstable, e.g. structural changes have taken place, and a search after tuming point or turn rounds will be needed.

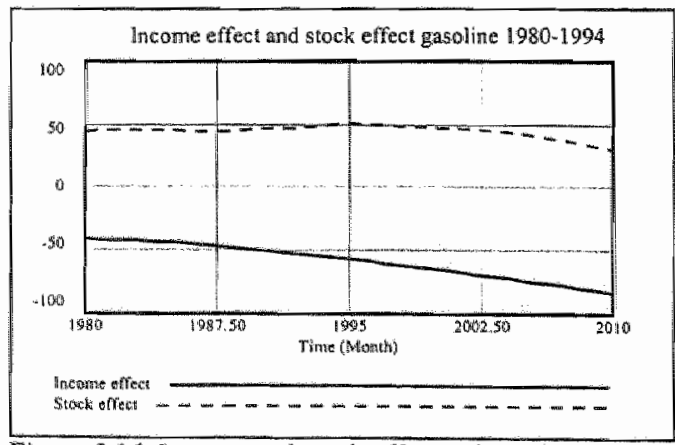

Figure 5.16 Income and stock effects of gasoline car stock

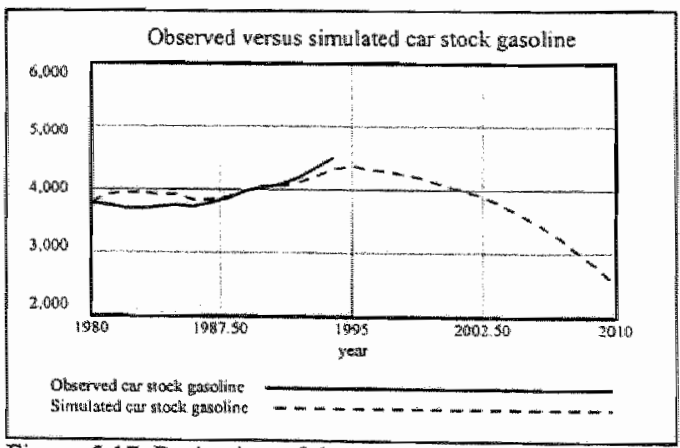

Figure 5.17 Projection of the gasoline car stock 
Disposable income (observed or expected) by households or disposable national income as a proxy, and actual car stock are sufficient in explaining the desired total car stock. Taking desired car stock by fuel type, this no longer can be maintained. The period under investigation can be qualitatively described as consisting of, at least, five periods (Figure 5.18): However for gasoline and IPG there is a co-

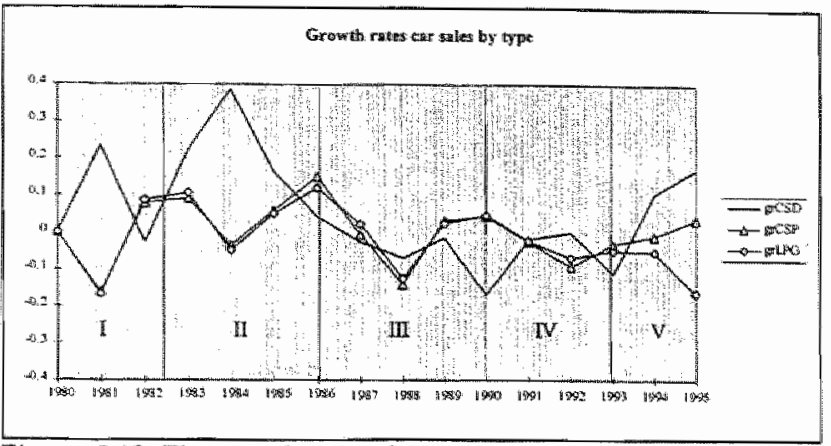

Figure 5.18 The growth rates of the mew car sales by fuel type

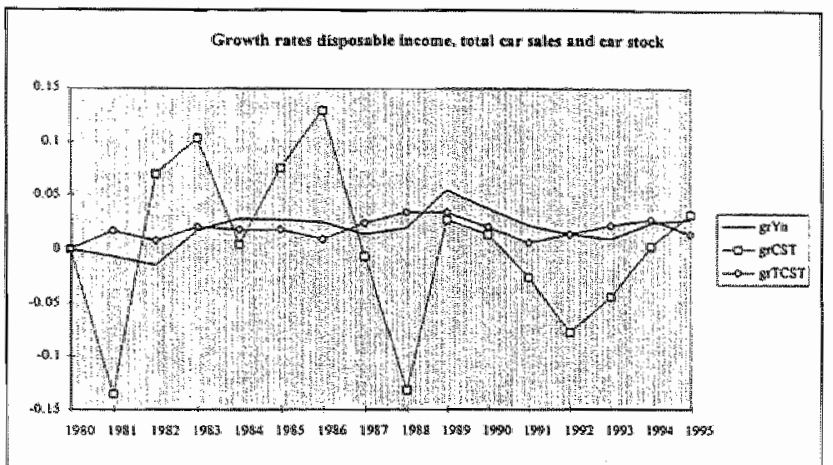

Figure 5.19 The growth rates of the disposable income, total new car sales and car stock movement from 1980 to 1993 (period I to IV) and an opposite direction from 1993 on (period V). The growth rates of diesel and gasoline/LPG are opposite in period I, II and IV, comovement in period III and comovement of diesel /gasoline opposite to $\mathrm{LPG}$ in period $\mathrm{V}$. This last development was due to user cost (price effect) change in 1990 as described above. ${ }^{5.4}$

In sum the period under investiga-tion can be characterised by a combination of short-run business fluctuation (buyers strike) and/or changing user cost between the fuel types. The last component is largely due to govemment policies.

Figure 5.19 shows the macro economic time series of disposable income, total new car sales and total car stock. Both figures, 5.18 and 5.19 are important reference frameworks for analysing the income and stock effects of the period under investigation.

The combination of the movements. described above results in the estimated parameters shown in Box

5.6, which badly describe the forces in the car market. Moreover, extrapolating the model with the assumption of $2 \%$ growth in disposable income leads to contra intuitive results as the desired gasoline car stock declines continuously, as shown in Figure 5.17. The same reason holds when starting the model in 1986. Looking after reasons one can state that business cycles, replacement market dynamics and substitution possibilities are the main teasons. Substitution is the outcome a very complex decision-making process, as a lot of factors enters the scene, e.g. relative supply prices, actual and expected (relative) fuel prices, different fiscal regimes and environmental legislation by the EC, in sum changing user costs. The share of gasoline car stock in the total Dutch car stock shed some light in this question. It declines from $89 \%$ in 1980 to $77.5 \%$ in 1990 and increases to $84 \%$ in 1995 . A complication of LPG cars is that conversion from existing gasoline cars in LPG and vice wersa is technically al ways possible.

Seen the frequent mode shifts a simple macro system formulation cannot be applied in order to get a valid basis for estimation purpose. What can be done is to inspect the growth rates $(X / X)$ and its interrelationship during the different periods. The following model structure for gasoline $(P)$ cars will be applied: Note: the superscript "means abserved" or measured" and the " means first difference.

9.4 Note the growth rate of total new car sales, will not be shown in Figure 5.18 because it practically coincide with new gasoline car sales, which account for $78-84 \%$ of total new car sales. 


$$
\begin{aligned}
& \Delta(\dot{C S} / C S)_{t}^{p}=\hat{\alpha}(\dot{Y} / M h)^{p}+\hat{\beta}(\dot{C S T} / \operatorname{CST})_{t}^{p}+\hat{\varphi}(C S T / C S T)_{\Delta}^{D} \\
& C S_{t}^{p}=C S_{t-1}^{p}\left(1+(\dot{C S} / C S)_{t}^{p}\right) \\
& C S T_{t}^{p}=C S T_{i-1}^{p}+C S_{t}^{p}-S C R_{t}^{p} \\
& S C R_{t}^{p}=C S T_{t}^{p} / \hat{\theta}
\end{aligned}
$$

where

$$
\begin{aligned}
& C S^{F}: \text { simullated new car sales by fuel type } F \\
& C S T^{F}: \text { simulated car stock by fuel type } F \\
& S C R^{F}: \text { scrap rate by fuel type } F \\
& Y h^{*}: \text { observed real disposable income } \\
& F=\{P, D, L\} \\
& P: \text { gasoline } \\
& D: \text { diesel } \\
& L: L P G
\end{aligned}
$$

Given the model 5.5.2 the diesel car stock effect (the changes in the diesel car stock) dominates, for the period 1980-1985, the changes in gasoline new car sales growth rates, moreover the effect of the

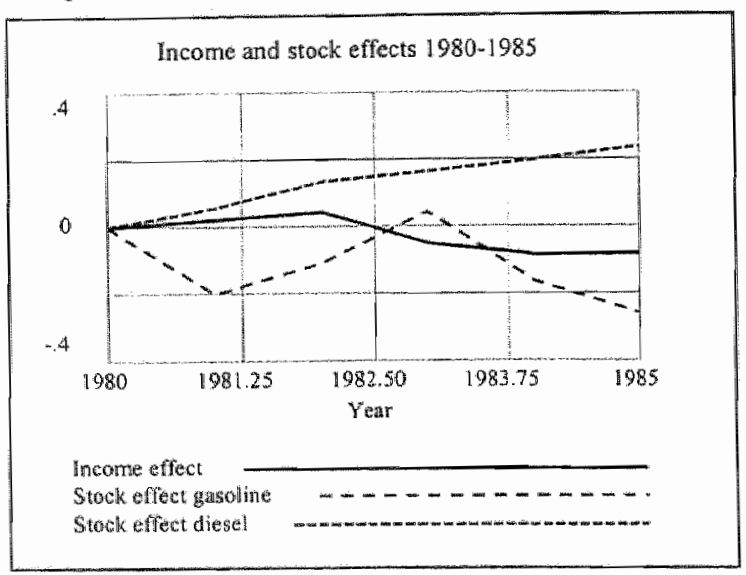

Figure 5.20 gasoline car stock changes cycles during the period under investigation and the income effect changes sign after 1982 (the start of the recovery). Figure 5.20 shows these movements. The exponential increase of the diesel car stock is straightforward during 1980-82. Note the point of inflection of the diesel car stack occurs during 1982, which is the starting point of the asymptotic growth path. However the period 1980-1985 was hit by a severe recession and a recovery, but the overall changes of the diesel car stock outperforms the changes $(+/-)$ of the growth rates of the disposable income. These movements are visualised in Figure 5.21 in 3 dimensional surface plot.

The 3 dimensional plot, Figure 5.21 , shows the inter relationship between the three effects with the changing effect of the gasoline car stock $v i s-\dot{a}$-vis the other effects. The two holes foms two separate regions with distinct structural features. Changing income figures, accelerating diesel new car sales, diminishing growth LPG car sales and a stagnant gasoline car stock. At first sight one suppose that there has been a substitution between gasoline, LPG and diesel cars as the diesel user cost turns out to be favourable at the expense of the gasoline and LPG cars. However growth rates are dimensionless figures and a confrontation of the absolute figures are needed, because the share of the diesel car stock in the total stock was only $7 \%$ against $10 \% \mathrm{LPG}$ and $83 \%$ gasoline in the early 80 s. 


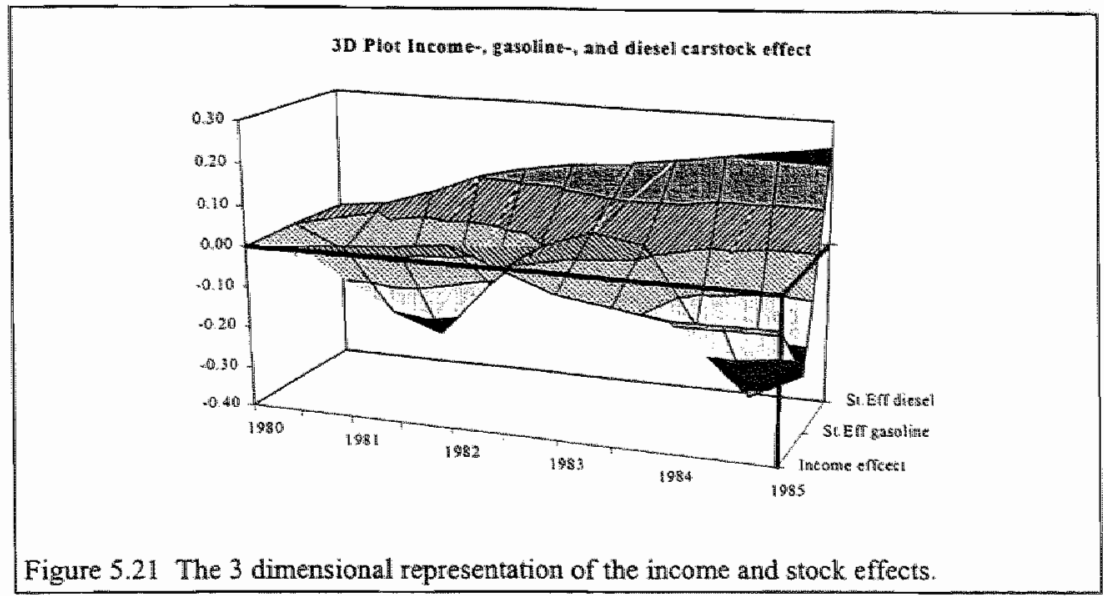

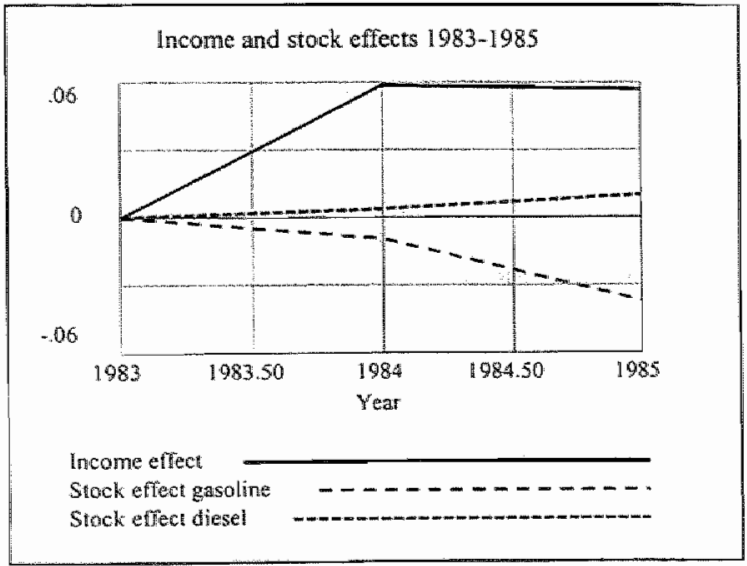

Figure 5.22

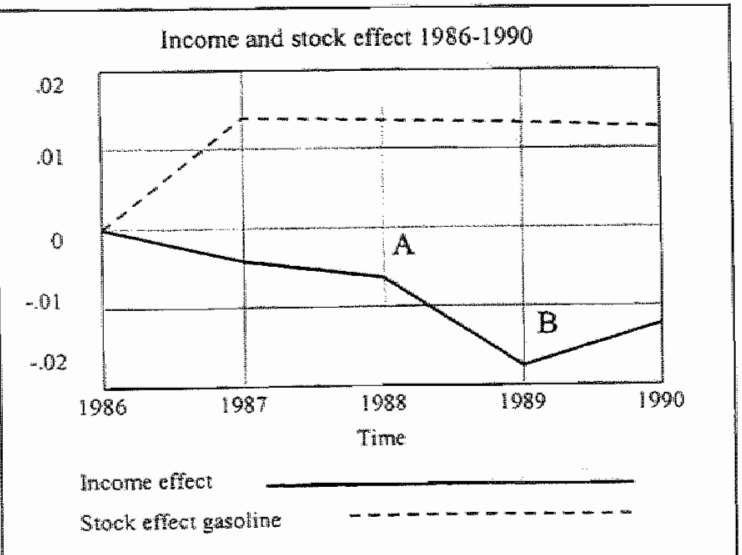

By dropping the recession years (1980-82) one can see the disposable income recovery gets more influence (the income effect switches in 1984) in the ultimate growth rates of the new car sales (Figure 5.20,5.21, and 5.22). The traditional role of the income increase has been taken over, while the changes of the gasoline car stock exerts a damping effect on the changes of the growth rates of gasoline new car sales. The influence of the changes of the diesel car stock is moderate positive with regard to the income effect. The estimated parameter and the payoff are:

$$
\begin{aligned}
\alpha & =2.049 \\
\beta & =-10.585 \\
\phi & =0.111 \\
P(U) & =-0.0346
\end{aligned}
$$

The period 1986-1990 can be characterised by a co-movement of the slowing-down growth rates of the three fuel types, gasoline, diesel and LPG (see also Figure 5.18 and 5.19). As the growth rates of disposable income can be characterised by nondecreasing rates the $\alpha$-parameter is negative ( the break-point A marks a increase in growth rate of disposable income during 1.988 , followed by a slowdown of the growth rates from 1989 on (point B). The influence of the gasoline car stock is very prominent during $1986 / 87$ as the one-time scrap in 1985/86 exerts a negative effect on the gasoline car stock level (Figure 5.23 and 5.24). 


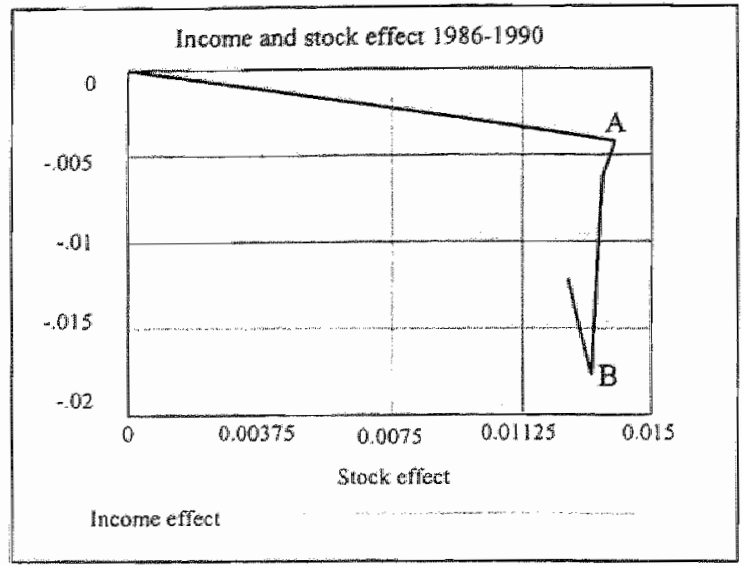

Piglure 5.24
The parameter walues are:

$$
\begin{aligned}
\alpha & =-0.319 \\
\beta & =0.702 \\
\theta & =12.22 \\
P(U) & =-0.22
\end{aligned}
$$

Note an one-year severe drop in new car sales (1988) causes the worsening of the payoff.

The period 1990-1995 can be characterised by two sub-periods of distinct features, 1990 93 and 1993-95. The period 1990-1993 shows slowing-down growth rates of both gasoline and LPG new car sales and a more or less stable diesel growth rates. The two relevant opposing forces are the growth rates of disposable income (0) and gasoline car stock ( $*$ ) (Figure 5.25/6, also Figure 5.18 and 5.19). The year 1993 can be described as a "buyer-strike" year, as explained in Chapter 3. The year 1993 is also the year were the LPG installation device cost rose with $30 \%$, this fact translates immediately into a new break-even kilometrage for gasoline from 20000 to $27000 \mathrm{~km}^{5.5}$. So potential buyers will chose gasoline cars till the first limit of average yearly kilometrage of $25000 \mathrm{~km}$, after which the diesel type car become profitable. The effect are clearly observable in that the LPG new car sales drops from $14 \% 1989$ to $10-7 \%$ in $1995 / 96$ leaving room for traditionally LPG buyers to switch to gasoline if they have an average yearly kilometrage of less then $25 / 27000 \mathrm{~km} / \mathrm{y}$. By inspecting the Figures 5.25 and 5.26 one sees at one strike the different features of both sub-periods. (Note for the purpose of a clear presentation the category-axis has been reversed !). For the period 1990-93 the role of LPG was negligible for explaining the growth rate of gasoline new car sales (co-movement with gasoline), but for the period 1993-95 this role is reversed caused by the rise of the user cost of $L P G$ cars.

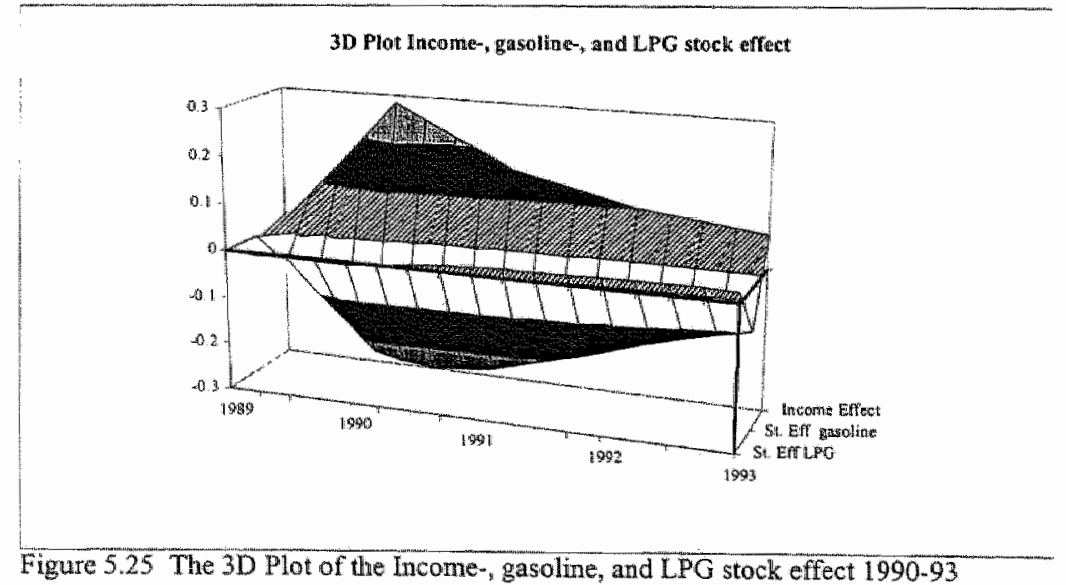

Figure 5.25 The $3 \mathrm{D}$ Plot of the Income- gasoline, and LPG stock effect 1990.93

\footnotetext{
5.5 This statement applies for medium size cars, in our models the cc-class 1.4-2.0L is used as a proxy for the medium size cars.
} 


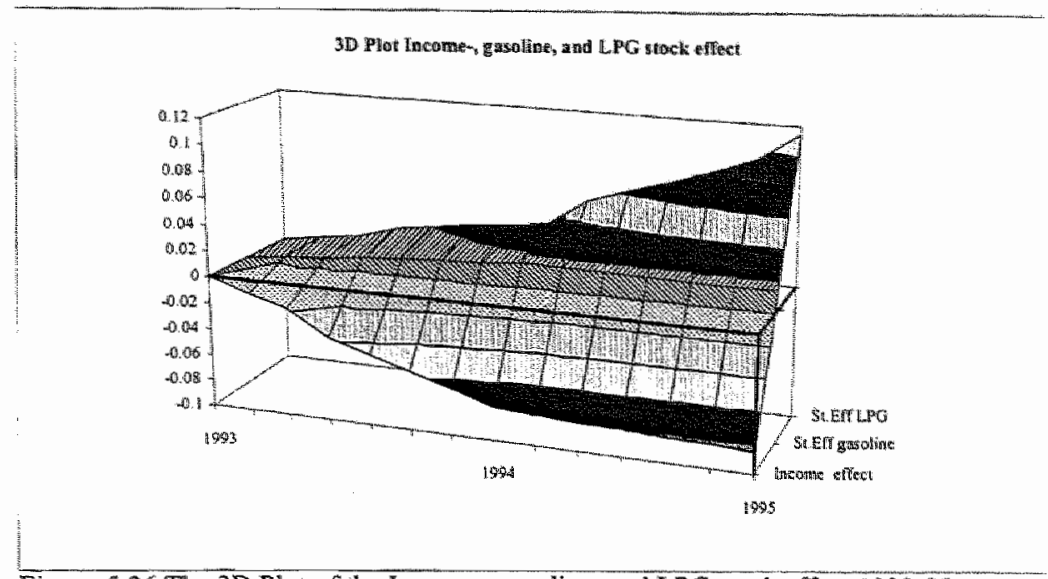

Figure 5.26 The 3D Plot of the Income-, gasoline, and LPG stock effect 1993-95

Note the change of the sequence of the categories of the $z$-axis in Figure 5.26 .

\subsubsection{The dilesel car stock}

For the period 1980-1994 the diesel car stock shows mixed results: the income effect doninates the stock effect and both parameter signs are positive, that why it is impossible to reproduce a logistic or sigmoid process. The estimated trend line is of a parabolic type and does not reproduce the growth dynamics of the diesel car stock in a correct manner. From the observed data it concerns here of a logistic growth process (Figure 5.28) with a point of inflection in 1986.

\begin{tabular}{|l|}
\hline Box 59 Log likelihood $95 \%$ Confidence intervals \\
$0.111988 \leq \alpha[D]=0.119173 \leq 0.126293$ \\
$0.00140311 \leq \beta[D]=0.00720349 \leq 0.0151204$ \\
The base payoff is -18.3534
\end{tabular}

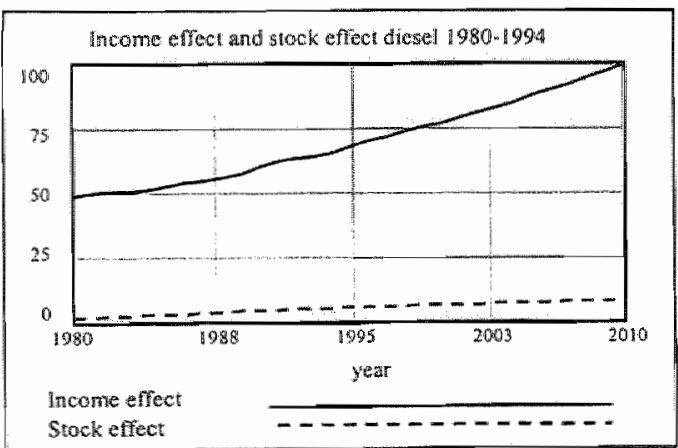

Figure 5.27 The nominal income and stock effect diesel $\operatorname{cars}(\mathrm{x} 1000)$

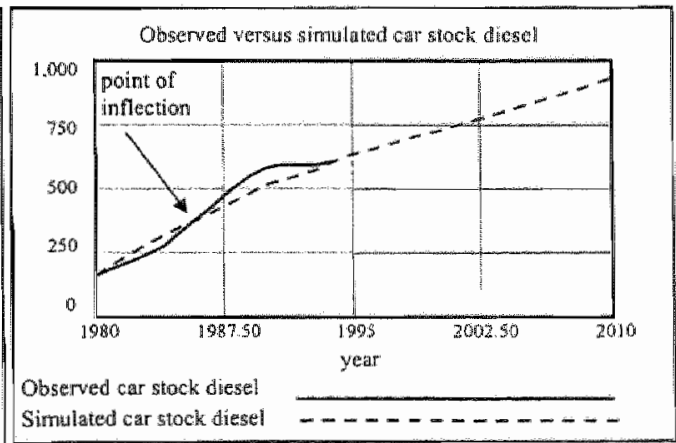

Figure 5.28 The diesel car stock, obseryed and simulated $(\times 1000)$

As explained before a sigmoid or logistic function can be separated into two regions:

1. from the origin to the point of inflection, where the exponential growth occurs, and

2. from the point of inflection to the maximum or saturation level.

The first region is dominated by the positive feedback loop from the stock variable(s), here a littie hampered by the flow variable, the period 1980-1986 can be described by such exponential growth-like development of the diesel car stock; the second region can be described by a negative feedback loop 
dominance, where the stock variable(s) take over the negative loop dominance by changing signs form "t' to " $"$ " the period 1986-1994 can be described by such a negative loop dominance.

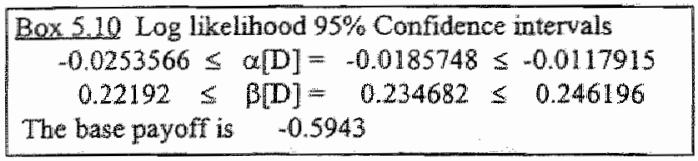

Box 5.10 shows the results of the estimation of the period 1980-1986 diesel car stock dynamics and Box 5.11 shows the results for the period 1986-1994. Note the levelling off around the 90 s is to sharp to obtain a better fit given both end points. However the overall results confirm the changing loop dominance for a sigmoid or logistic curve process. Figure 5.29 and 5.30 confirm the goodness-of-thefit for both periods

\begin{tabular}{|l|}
\hline Box 5.11 Log likelihood $95 \%$ Confidence intervals \\
$0.380058 \leq \alpha[D]=0.400512 \leq 0.420765$ \\
$-0.287793 \leq \beta[D]=-0.266955 \leq-0.2477$ \\
The base payoff is $\quad-3.30919$ \\
\hline
\end{tabular}

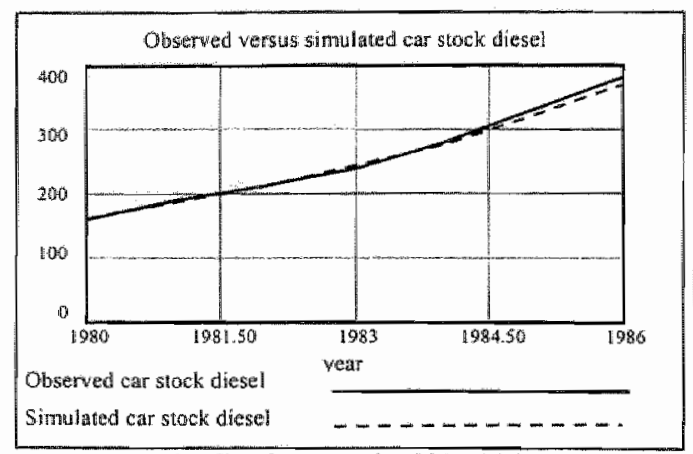

Figure 5.29 The diesel car stock $1980-1986$ (x1000)

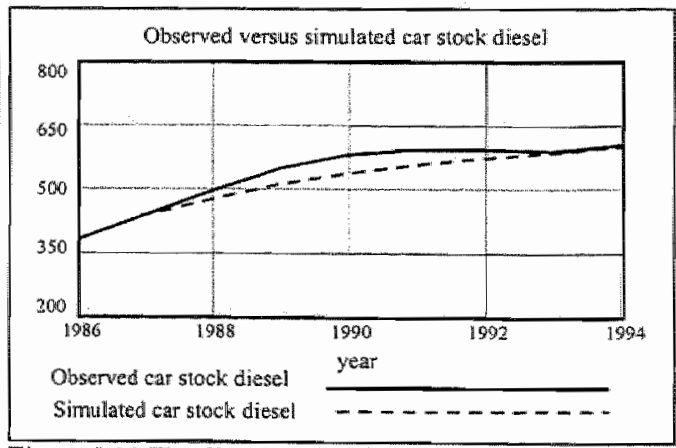

Figure 5.30 The diesel car stock 1986-1994 (x.1000)

\subsection{Conclusion}

Not only the problem of initial value but also the base or reference period is of key importance for inference of structural changes. However the period 1980-1995 is not stable enough for being a basis for future car stock projections, the start year 1980 means to start in the midst of the recession with a strong collapse of new car sales $(30 \%)$ followed by a boom in new car sales in $1987 / 88$ and a severe drop again in 1992/93, for worst, in the period 1985/86 an autonomous compulsory periodic inspection policy (APK) reduced significantly in one time the car stock. All this has been explained in the

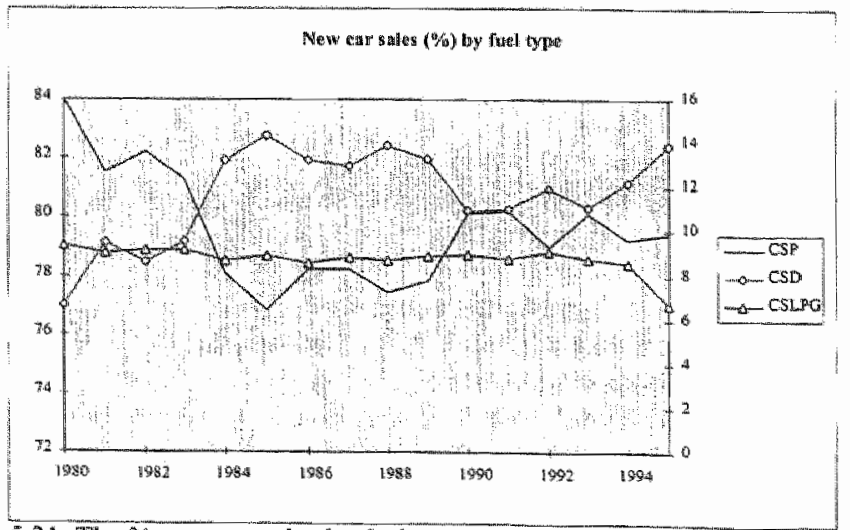
subsequent sections. Moreover, substitution effects between fuel types, especially between gasoline, LPG and diesel are probable of importance. Figure 5.24 provide some evidence for the possibilities of substitution.

In sum, the period 1980-1995 is too heterogeneous, and characterised by structural changes. Another reference period has to be chosen and/or an alternative functional relationship like the sigmoid model and the Verhulst-Pearl functions. 


\subsection{Sigmoid and the Verhulst-Pearl logistic function imodel}

\subsubsection{Introduction}

Referring to the exponential growth of the Dutch car fleet in the 60 s and the diesel cars in the 80 s, the number $C$ of cars in a car stock at time $t$ did follow an exponential law of growth, characterised by

where

$$
C=C_{0} e^{x^{t}}
$$

$$
z>0 \text { and } C_{0} \text { is the car stock at } t=0 .
$$

This law assumes that at time the rate of growth, $d C / d t$, of the car stock is proportional to the number of cars in the car stock. That is, $d C / d t=\chi C$. However, under exponential growth, a car stock would get infinitely large as time goes on. In reality, however, when the car stock gets large enough there are environmental factors that slow down the rate of growth, like biologicial growth processes. For example, lack of space, congestion, emission, etc. These factors cause $d C / d t$ eventually to decrease. The car market becomes a replace market, the diffusion or penetration has been completed, and the growth comes only from the growth in the absolute level of households. It is reasonable to assume that the level of the car stock is limited to some maximum number $M$, where $0<C<M$, and as $C \rightarrow M$, then $d C / d t \rightarrow 0$ and the car stock tends to be stable, however not in an absolute sense, but relative stable. In sum, we want develop and estimate three models consisting of the

1. sigmoid model

2. symmetric Verhulst-Pearl function, and

3. asymmetric Verhulst-Pearl function

which exhibit exponential growth initially but which also includes the effects of saturation and erivironmental resistance to too large car stock growth. The fist model incorporating the sigmoid function, is obtained by multiplying the right side of $d C / d t=\chi C$ by the factor $(M-C) / M$ :

$$
\frac{d C}{d t}=\chi C\left(\frac{M-C}{M}\right)
$$

If $C$ is small, then ( $M-C) M$ is close to 1 and we have a growth process that is dominated by positive feedback, $d C / d t>$ (the income effect) with $\chi$ as the growth factor that is approximately exponential like equation 5.6.1. As $C \rightarrow M$, then $M-C \rightarrow 0$ and $d C / d t \rightarrow 0$, in other words the negative feedback ${ }^{5.6}$ dominates, $d C / d t<$, (the stock effect), as we wanted in our model.

After solving the differential equation 5.6.2. for $C$ by the method of separation of variables one obtains the well known logistic function:

$$
C=\frac{M}{1+\varphi e^{-\beta t}}
$$

Equation (5.6.3) is called the symmetric logistic function or the Verhulst-Pearl logistic function. As we want explicitly model the new car sales we have to differentiate equation (5.6.3)

$$
\frac{d C}{d t}=\frac{\varphi \beta e^{\beta t} M}{\left(\varphi+e^{\beta t}\right)^{2}}
$$

The asymmetric logistic function is as follows:

$$
C=\frac{M}{\left(1+\varphi e^{-\beta t}\right)^{x}}
$$

\footnotetext{
${ }^{56}$ The negative feedback starts gradually after the point of inflection, $d C / d t=$, increasing its dominance as $d C / d t \rightarrow 0$.
} 
where

$x<\rrbracket$ is the megative asymmetry, the point of inflection is situated to the right towards the saturation level $M$;

$\chi=1$ is the symmetric case equation 5.6 .5 , and

$\chi>1$ is the positive asymmetn, the point of inflection is situated left towards the origin

The first derivative is

$$
\frac{d C}{d t}=\frac{\varphi \beta x\left(1+\varphi e^{-\beta t}\right)^{-(1+x)} M}{e^{\beta t}}
$$

Note for $\chi=1$ equation 5.6 .6 equals 5.6 .4 .

In the next section the three functions will be estimated, the sigmoid function is a process estimation. of the interplay between positive and negative feedback, whereas the estimation of the Verhulst-Pearl symmetric and asymmetric function can be defined as curve fitting. In our models the first derivative of the Verhulst-Pearl functions (equation 5.6.4 and 5.6.6) are estimated which, after integration, gives or simulates the car stock.

\subsubsection{Model formulation of the sigmoid process}

Equation 5.6.2 will replace the new car sales function in model 5.5.1, with the additional income effect as a second argument. The model test in the first place whether the desired car stock, $M$, is greater then the actual car stock, $T C$, if so the new car sales function, $C S$, equation (5.6.2) is active, if not only the scrapped cars, $S C R$, are replaced. The total car stock by fuel type, $C S T$, equals the summation of its vintages, $V$, plus the remainder, $R$, which summed over the fuel types equals the total car stock, TC. The desired car stock, $M$, depends of the maximum share quote, $\phi$, times the car stock, CST. The maximum share quote is a policy variable to express the desired composition by fuel type of the car stock. The model formulation is:

$$
\begin{aligned}
& \text { if } \\
& M_{t}[F]-T C_{s}[F]>0 \\
& \text { then } \\
& C S_{t}[F]=\hat{\alpha} Y p_{t}+\hat{\beta} T C_{r}[F]\left(\left(M_{t}[F]-T C_{t}[F]\right) / M_{t}[F]\right) \\
& \text { else } \\
& C S_{t}[F]=S C R_{t}[F] \\
& \operatorname{CST}_{i}\left[F, V_{k}\right]=\operatorname{CST}_{i-1}\left[F, V_{k}\right]+\operatorname{CS}_{i}[F]-\overline{S C_{i}}\left[F, V_{k}\right] \\
& T C_{f}[F]=\sum_{k=1}^{N\left(V_{k}\right)} C S T_{f}\left[F, V_{k}\right]+R_{f}[F] \\
& T C_{s}=\sum_{F} T C_{t}[F] \\
& Y_{p_{t}}=Y p_{r-1}+Y_{t}^{*}-\bar{\psi} Y p_{t-1} \equiv D_{1 / \psi}^{1}\left(Y_{t}^{*}\right) \\
& M_{i}[F]=\phi_{F} T C_{i}[F] \\
& S C R_{i}[F]=\sum_{k=1}^{N\left(Y_{k}\right)} \overline{S C_{i}}\left[F_{i}, V_{k}\right] \\
& R_{\mathrm{if}}[F]=\tilde{F}_{\mathrm{i}} * T C_{\mathrm{i}}[F]
\end{aligned}
$$


where

$$
\begin{aligned}
& F=\{P, D, L\} \quad V=\left\{V_{k}, R\right\} \\
& F_{k}=\left\{V_{1}, \ldots, Y_{10}\right\} \subset V \\
& F: \text { fuel } \\
& P \text { : gasoline } \\
& D \text { : diesel oil } \\
& L: \mathrm{LPG} \\
& R=\sum_{k=N\left(F_{k}\right)+1}^{\infty} V_{k} \subset V \\
& V \text { : vintage (year of constuction) } \\
& \bar{\psi}=0.377 \\
& \bar{\theta}=1.6 \\
& \phi_{F}=\phi_{P}+\phi_{L}+\phi_{D}=1 \\
& \phi_{\neg D}=\phi_{P}+\phi_{L}=0.85 \text { (non-diesel share of car stock) } \\
& \phi_{D}=0.15
\end{aligned}
$$$$
R^{\prime} \text { : remaining vintages ( }>10 \text { vintages) }
$$

Note the interpretation of the logistic function has been changed, in the traditional ecological/ biological sciences, $M$, refers to a static maximum, carrying capacity or surviving population, however in our sense, $M_{s}$, refers to the desired toral car stock (a dynamic policy variable), for example, in the gasoline case: $\quad M_{i}[P]=0.85 * T C_{t}$

this means, the penetration rate of gasoline cars is $85 \%$ of the desired total car stock. If the actual gasoline car stock, $C S T_{n}[P]$, approach the upper bound of $M[P], C S T_{l}[P] \rightarrow M_{n}[P]$, then the gasoline new car sales, $C S_{*}$, decreases. As the numerator $(M-C)$ is not allowed to be come negative, the maximum function, $\max ((M-C), 0)$ take care for this inconvenience, setting the new car sales, $C S$, equal to zero.

\subsubsection{The gasoline car stock base period 1980-1994}

The first estimation test refers to the period 1980-1994 and the signs of parameters have an interpretative meaning. But the same problems arise as with model 5.5.1, for the period 1980-1986. Note beyond the 1994 horizon, no governmental policy change, nor price changes are assumed in the simulation runs

\begin{tabular}{|l}
\hline Box 5.10 Log likelihood 95\% Confidence intervals \\
$1.09114 \leq a[\mathrm{P}]=1.10002 \leq 1.10833$ \\
$-0.206486 \leq \beta[\mathrm{P}]=\quad-0.2 \leq 5-0.193418$ \\
The base payoff is -32.5975
\end{tabular}


In order to detect the sigmoid or logistic features of the new car sales function the time horizon has been enlarged to 2020 in Figure 5.33 under the assumption that disposable income grows with $2.5 \%$

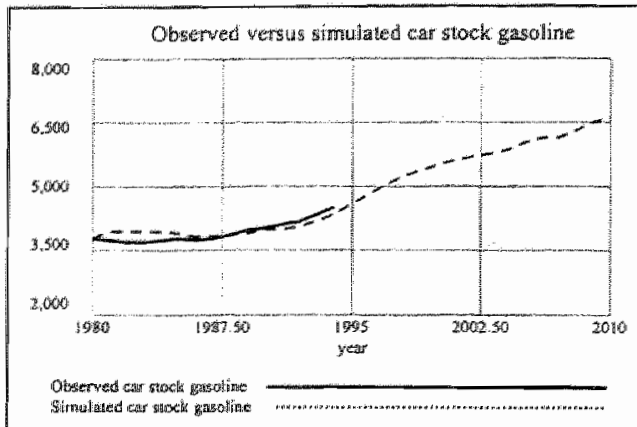

Figure 5.32 The gasoline car stock $19809-2010$

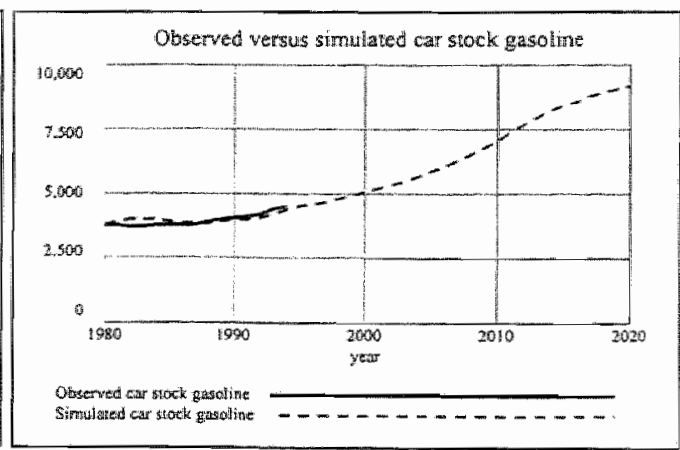

Figure 5.33 The gasoline car stock 1980-2020

Just after 1995 the $85 \%$ limit has been approached, CST[P] $\rightarrow M_{t}[P]$, (see arrow in Figure 5.34) the gasoline car stock slows down somewhat.

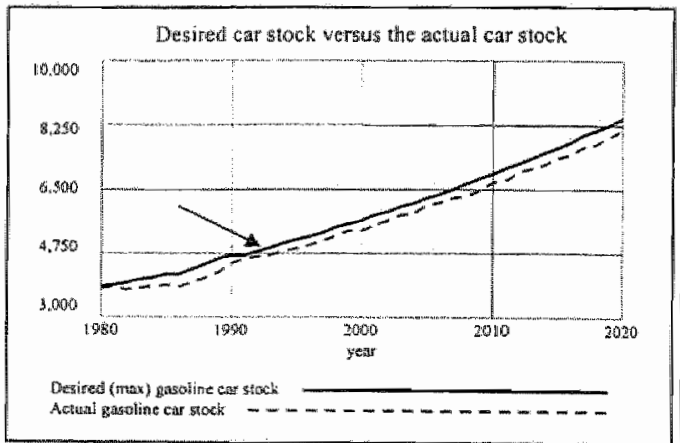

Figure 5.34 The desired versus actual car stock

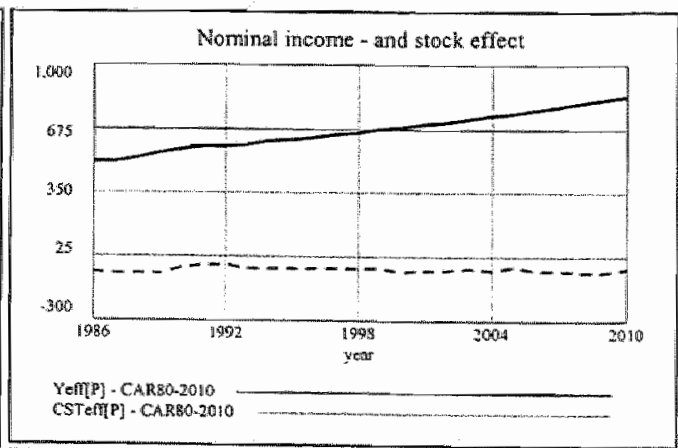

Figure 5.35 The nominal income and stock effect

In fact, the approximation prewents the relative stock effect to become positive, $\tilde{\eta}_{S}<0$, and simultaneously the relative income effect to fall below 1 , $\pi i_{\gamma}>1$. In our model with two explaining variables causing the gasoline car stock to slow down.

\subsubsection{The gasoline car stock base period 1986-1994}

In the last sections the period 1986-1994 was chosen as the period of reference, the estimation results implies a lower gasoline car stock, than in the 1980-1994 case (Figure 5.33 and 5.34). As 1986 forms an absolute lowest level of the gasoline car stock (for reasons explained in the last sections) the growth rates accelerated somewhat in the second part of the 80 s and will dampen somewhat during the second part of the $90 \mathrm{~s}$, implying a lower growth rate of the gasoline car stock.

\begin{tabular}{|c|}
\hline Box 5.11 Log dikelihood $95 \%$ Confidence intervals \\
$1.6064 \leq \alpha[\mathrm{P}]=1.61427 \leq 1.6212$ \\
$-0.495867 \leq \beta[\mathrm{P}]=-0.491543 \leq-0.487424$ \\
The base payoff is -27.1067
\end{tabular}

From the second part of the 90 s and through the year 2000 and thereafter a continuous tension arise between the desired and actual car stock, with the stock effect exerting more influence than in the case of period 1980-1994 (compare Figure 5.35 and 5.39). 
The growth potential will be determined by the income and stock effect. As the stock effect is negative, the stock effect exert a damping effect on the income effect as consumer theory explains (chapter 3).

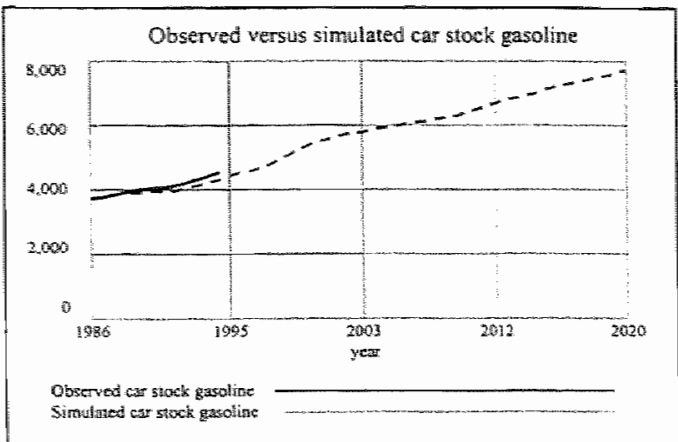

Figure 5.36 The gasoline car stock 1986-2020

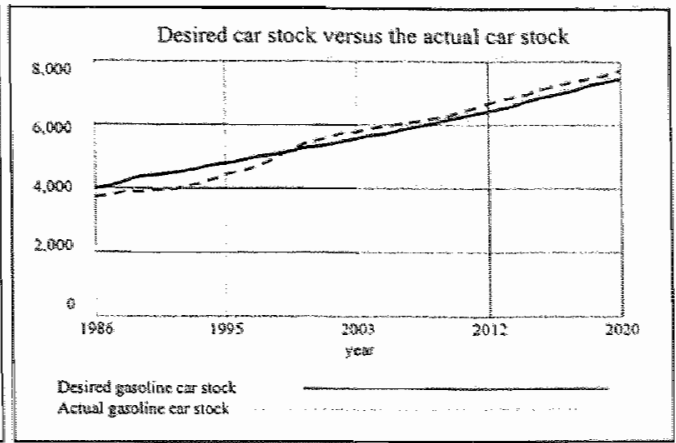

Figure 5.37 The desired and actual gasoline car stock

The next Figure 5.40 shows three test runs with altemative growth figures of the real disposable. household income, $0,1,2,3 \%$, from 1995 on. With a zero growth of disposable income the saturation level has soon be reached, around 2000 , of course the higher the growth rate the later the saturation level. Note that the saturation level should include a congestion effect, shortening in time the saturation level.

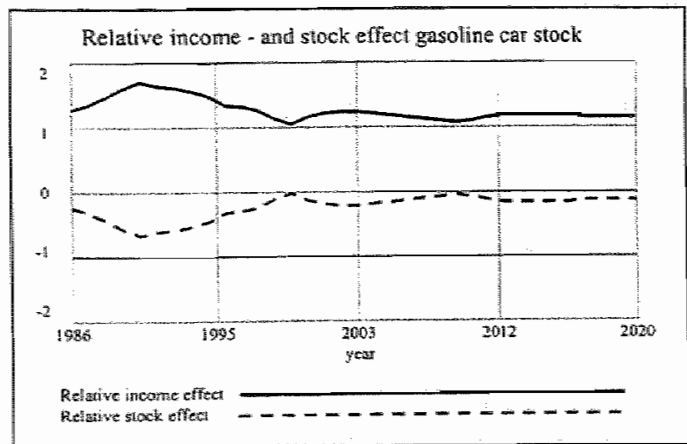

Figure 5.38 The relative income and stock effect

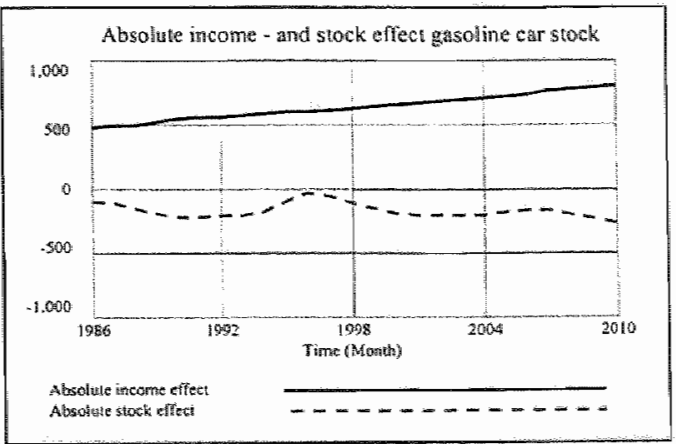

Figure 5.39 The nominal income and stock effect

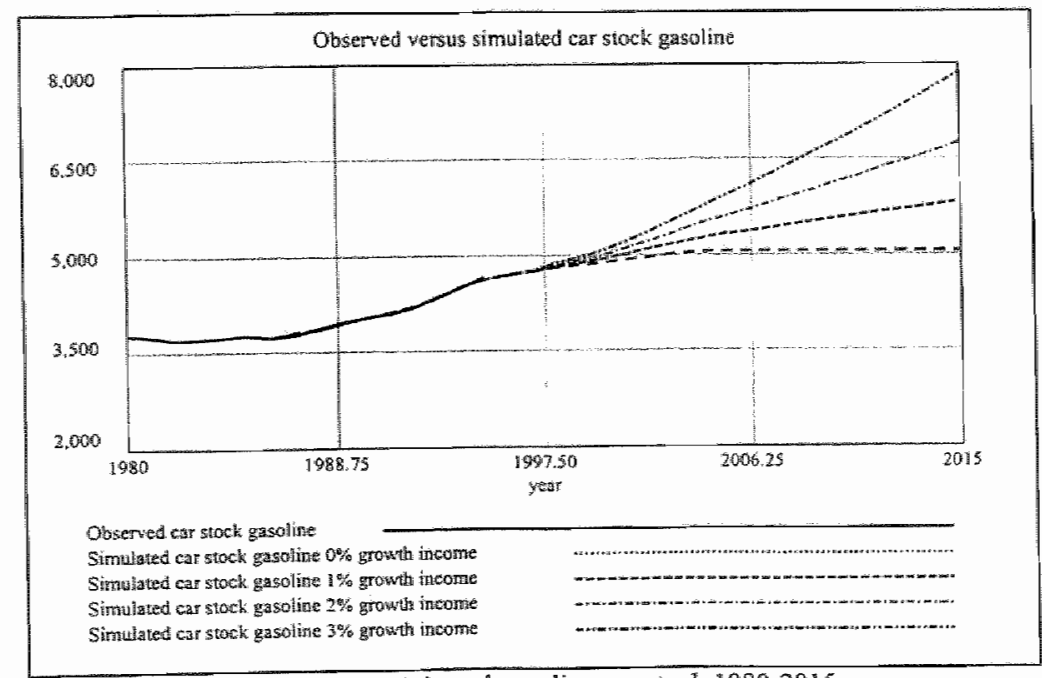

Figure 5.40 Growth rate scenario"s and gasoline car stock 1980-2015 


\subsubsection{The diesel car stock base period 1980-1994}

For the diesel car stock the estimation of the strong logistic curve is not quite accurate, it underestimates the strong increase phase, partially due to the ageing of the diesel car stock but mainly to the stock effect in the period 1986-93. For example, figure 5.42 shows the improved effect of the decreased $(0.83)$ vintage scrapping rate.

\begin{tabular}{|c|}
\hline Box $5.12 \log$ likelihood $95 \%$ Confidence intervals \\
$? ? ? ? \mathrm{q} ? \mathrm{D}]=-0.265583 \leq-0.258405$ \\
$? ? \mathrm{~g} ? \mathrm{~B}] \mathrm{D}]=1.00376 \leq 1.00376$ \\
The base payoff is -6.20955
\end{tabular}

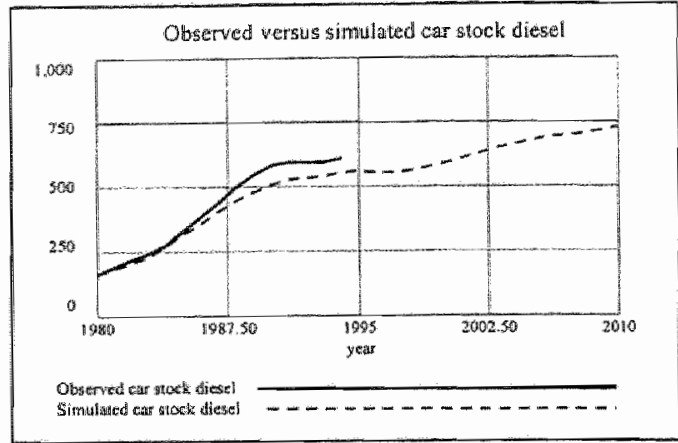

Figure 5.41 The fixed scrapping rate

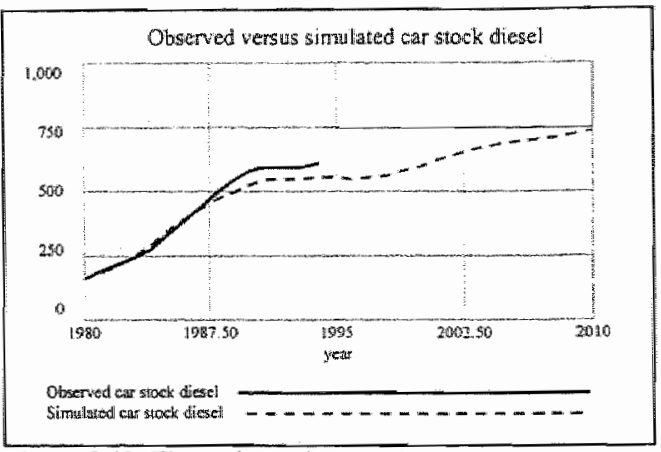

Figure 5.42 The estimated scrapping rate

From the experiments it is clear that this growth process can be described by a positive asymmetric logistic process, where the point of inflection lies near the origin (to the left). The largest increase did occur in the year 1982-84 (growth rates up to 35\%), slowing down to negative growth rates in the end 80 s. However, in case of consumer durables the positive asymmetric function is plausible, as a positive asymmetry will cause (by different economic control variables) a systematic increase of the potential market. This means a positive asymmetric process can be characterised by a relative smooth expansion of the market of the second growth phase (after the point of inflection). This progressive expansion will be calused by the enlargement of the potential market due to a positive development of economic welfare and/or to a decrease of the relative prices.

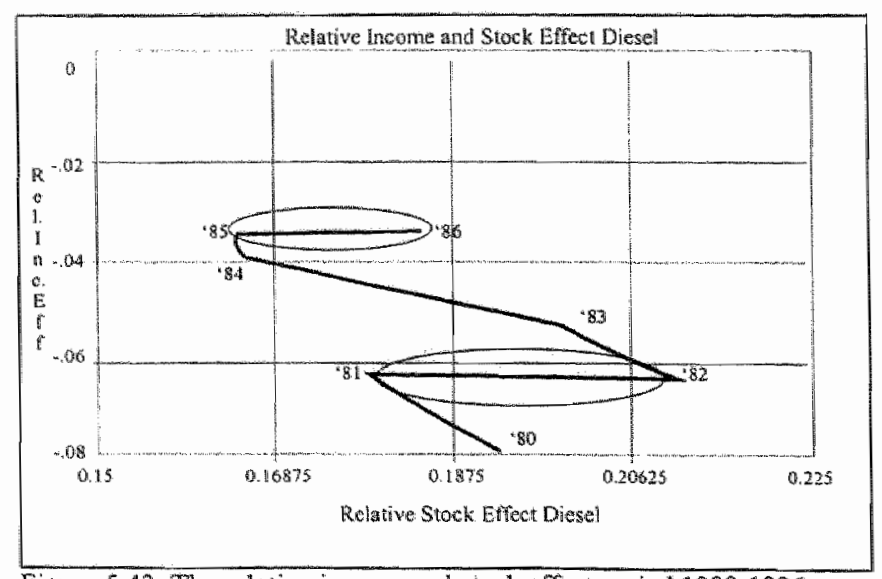

Figure 5.43 The relative income and stock effect period 1980-1986
As was the case with the gasoline car market the diesel market has also been divided in two phases. Phase $1(1980-86$, Figure 5.43) can be described by two periods dominated by the stock effect (1981-82 and 198486 ) and two periods by a mixed income/stock effect (1980-81 and 1982-84). It mirrors the erratic dynamics of the car market during the period 1980 86. 


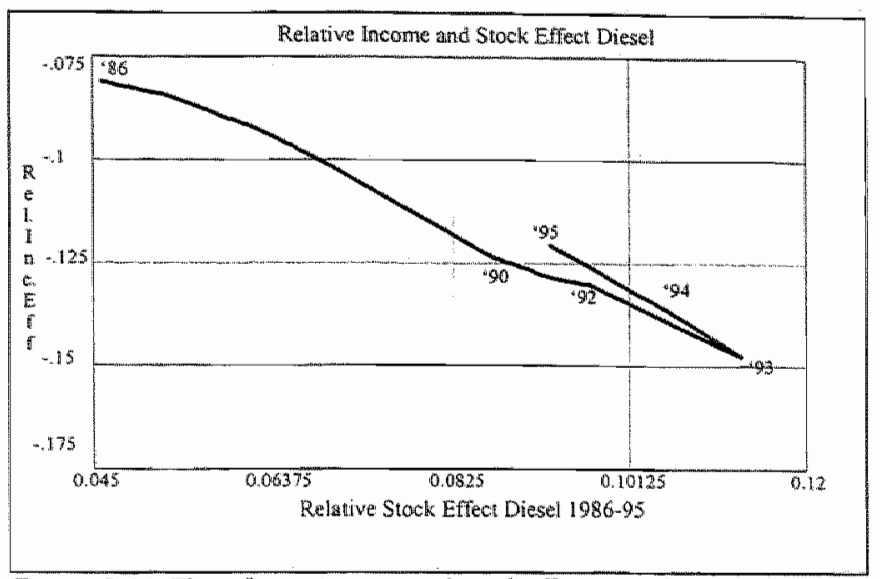

Figure 5.44 The relative income and stock effect period 1986-1995
The second phase is the period 1986-1995 and can be subdivided by another two phases, the period $1986-93$ and 1993-95, as explained before. These characteristics are clearly detected in Figure 5.44. The asymptotic growth process has been dominated by the combined income/stock effect. The period $1993-95$ is a reversed move with an increase of the diesel car sales, partly at the expense of the $\mathrm{LPG}$ new car sales.

\subsubsection{The diesel car stock base period 1986-1994}

As expected the estimation results of the second period (1986-1994) performs much better than the first period (1980-1994). Compare Table box 5.12 and 5.13. The simulation shown in Figure 5.45 assumed a net yearly growth rate of disposable income of $2.5 \%$ from 1994 on.

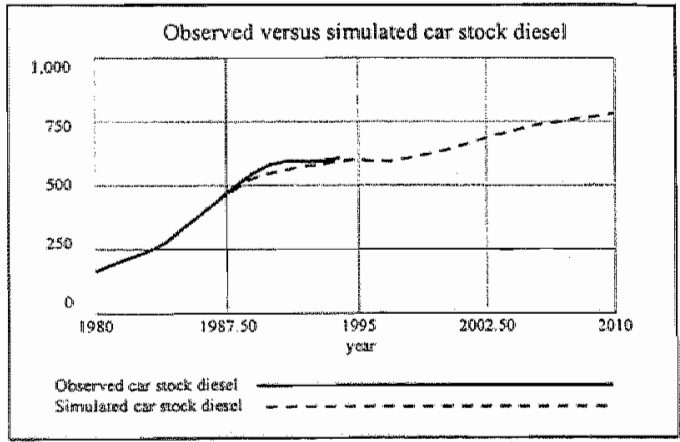

Figure 5.45 The observed and simulated diesel car stock 1986/94-2010

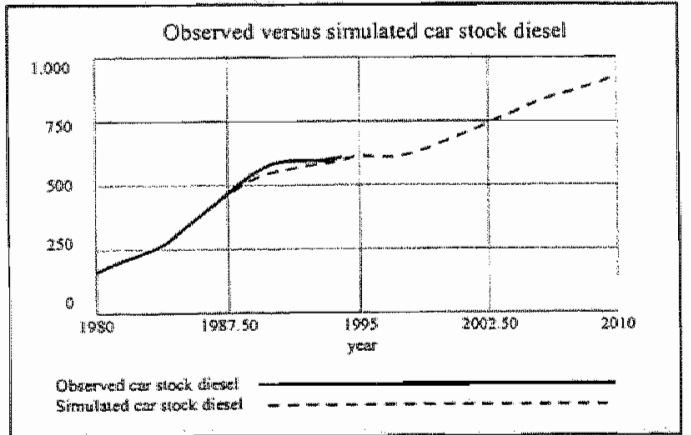

Figure 5.46 The simulated diesel car stock with $3 \%$ yearly growth rateof disposable income.
Box 5.13 Log likelihood $95 \%$ Confidence intervals $\begin{aligned}-0.139423 \leq \alpha[D] & =-0.11814 \leq-0.0954346 \\ 0.670597 \leq & B[D]=0.728134 \leq 0.792164\end{aligned}$ The base payoff is -1.8685

Note $M=0.15 * T \mathrm{C}$

The simulation shown in Figure 5.46 was performed under the assumption of a $3 \%$ yearly growth rate, the corresponding increase of diesel new car sales and the diesel car stock are calculated under the restriction that $15 \%$ of the total car stock will be maximum diffusion rate of the diesel cars. This distribution parameter was in $199511 \%$ of the total car stock and depends heavily of the public tax policy. However this figure will be changed with the scenario analysis to be performed in chapter 8 . 


\subsubsection{The LPG car stock base period 1986-1994"}

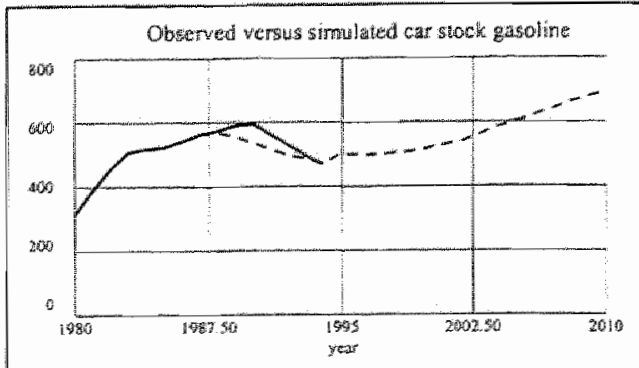

Ditwersed cos sidech $\mathrm{LPG}$

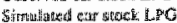

The development of the LPG car stock is and was heavily dependent of the public policy (road) tax policy, as explained in section 5.3 . However as with the diesel new car sales the LPG new car sales will be subject to scenario analysis. Note that since 1990 the scrapping has decreased significantly. The forecast starts with the following distribution of the observed car stock:

Gasoline $82 \%$, Diesel $11 \%$ and LPG $7 \%$ and this remained so for the whole period till $2010 / 20$.

Figure 5.47 The obserwed and simulated LPG car stock

\subsubsection{The totall car stock}

By summing the car stock by fuel type one arrive at the total car stock of a particular year. For the forecast we used a growth rate of $3 \%$ of the disposable income, and arrive at a total of $8-8.5$ million cars in 2010 (Figure 5.48)

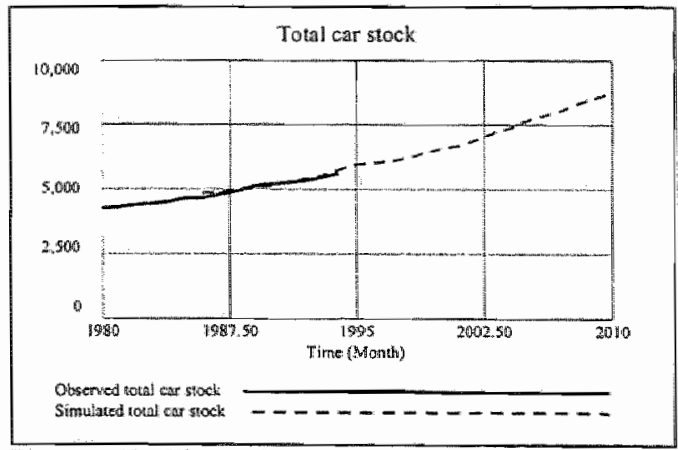

Figure 5.48 The total car stock observed (1980-1994) and simulated (1986-2010)

\footnotetext{
5." During the very final stage of this research the information of a trend break was published (Kwartaglbericht Milieu (CBS) 96/3) indicating that LPG cars was 15-20\% overestimated form the late 80 s on !"! This conforms our findings when estimating the problematic LPG car stock. The surface between the observed (overestimated!!) and our estimated PLG car stock corresponds to the 15-20\% overestimation.
} 


\subsubsection{Modell formulation symmetric Verhulst-Pearl logistic function}

Equation (5.6.6) will replace the new car sales function in model 5.5.1. Now the estimation is in fact a curve fitting of the new car salles function, $C S$,

$$
\begin{aligned}
& C S_{t}[F]=\hat{\alpha} D_{\theta}^{1}\left(Y h_{t}\right)+\frac{\hat{\phi} \hat{\beta} e^{\hat{\beta} t}}{\left(\hat{\varphi}+e_{t}[F]\right.} \\
& C S T_{k}\left[F, W_{k}\right]=C S T_{t-1}\left[F, V_{k}\right]+C S_{f}[F]-\overline{S C_{k}}\left[F_{k}, V_{k}\right] \\
& T C_{k}[F]=\sum_{k=1}^{N\left(V_{k}\right)} C S S T_{k}\left[F, V_{k}\right]+R_{r}[F] \\
& T C_{\mathrm{g}}=\sum_{F} T C_{\mathrm{r}}[F] \\
& M_{t}[F]=\phi_{F} T C_{t}[F] \\
& S C R_{t}[F]=\sum_{k=1}^{N\left(V_{k}\right)} \overline{S C}\left[F, V_{k}\right]
\end{aligned}
$$

where

$$
\begin{array}{cc}
F=\{P, D, L\} & V=\left\{V_{k}, R\right\} \\
& V_{k}=\left\{V_{1}, \ldots, V_{10}\right\} \subset V \\
& R=\sum_{k=\sum_{\left(V_{k},+1\right.}^{\infty} V_{k} \subset V} \\
F: \text { fuel } & V: \text { vintage (year of construction) } \\
P: \text { gasoline } & R: \text { remaining vintages }(P 10 \text { vinages) } \\
D: \text { diesel oil } & \\
L: \text { LPG } &
\end{array}
$$

$$
\begin{aligned}
& \bar{\Psi}=0.377 \\
& \bar{\theta}=1.6 \\
& \phi_{F}=\phi_{P}+\phi_{L}+\phi_{D}=1 \\
& \phi_{D}=\phi_{P}+\phi_{L}=0.85 \text { (non-diesel share of car stock) } \\
& \phi_{D}=0.15
\end{aligned}
$$

$N(*) \quad$ : enumeration function

$C S[F] \quad$ : simulated new car sales by fuel type

$T C[F]$ : simulated total car stock by fuel type

$\operatorname{CST}[F, M]$ : simulated vintage car stock by fuel type

$M[F] \quad$ : maximum share of fuel type $F$ of total car stock

$\overline{S C} F, V]$ : estimated vintage scrap parameter (section 5.3)

$Y_{p} \quad:$ simulated permanent income

$Y^{*} \quad$ : observed real disposable income

The new car sales function has now been modified by inserting the first derivative of the VerhulstPearl logistic function. The parameters to be estimated are now, $\widetilde{\alpha}$, the income parameter, $\widetilde{\beta}$, the growth constant and $\widetilde{\varphi}$, the scale parameter. 


\subsubsection{The gaseline cars symmetric Verhulst-Pearl function base period 1986-1994}

The symmetric Verhulst-Pearl function $\frac{d C}{d t}=\frac{\varphi \beta e^{\beta g} M}{\left(\varphi+e^{\beta r}\right)^{2}}(5.6 .4)$ has been estimated for the gasoline

(Box 5.14) and diesel case (Box 5.15). The asymmetric function $\frac{d C}{d t}=\frac{\varphi \beta \chi\left(1+\varphi e^{-\beta t}\right)^{-(1+x)} M}{e^{\beta t}}$

$(5.6 .6)$ has been estimated for the diesel case only (Box 5.16), as there was no improwement for the gasoline case.

\begin{tabular}{|l|l|}
\hline Box 5.14 Log likelihood $95 \%$ Condidence intervals \\
$-2.50271 \leq \alpha[\mathrm{P}]=-2.4743 \leq$ & $\leq-2.44739$ \\
$1.62462 \leq \beta[\mathrm{P}]=$ & $1.65501 \leq 1.687$ \\
$2.55474 \leq \varphi[\mathrm{P}]=2.62071 \leq 2.6884$ \\
The base payoff is -13.4575
\end{tabular}

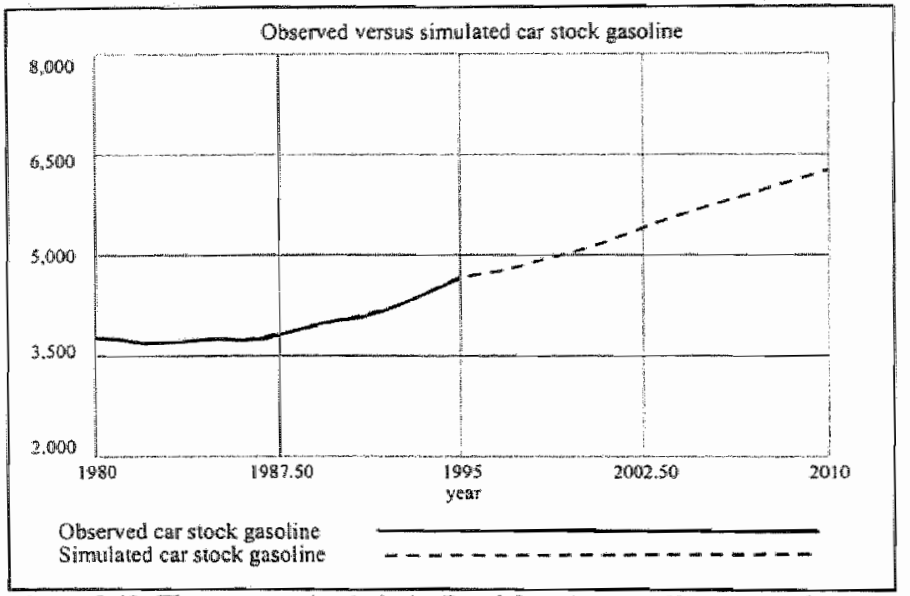

Figure 5.49 The symmetric Verhulst-Pearl function gasoline car stock

As can be seen from Figure 5.49 the fit is quite close and the forecast is based on a $2 \%$ growth rate of net disposable income.

\subsubsection{The diesel car stock symmetric Verhulst-Pearl base period 1986-1994}

The symmetric Verhutst-Pearl function 5.6.2 performed a reasonable fit as can be shown in Box 5.14.

\begin{tabular}{|c|c|c|c|}
\hline \multicolumn{4}{|c|}{ Box 5,14 Log likelihood $95 \%$ Confidence intervals } \\
\hline$-0.766204 \leq \alpha[D]=$ & -0.755269 & $\leq$ & -0.744693 \\
\hline $2.23405 \leq \rho[\mathrm{D}]=$ & 2.26884 & $\leq$ & 2.30475 \\
\hline $7.22091 \leq \varphi[\mathrm{D}]=$ & 8.00704 & $\leq$ & 9.66615 \\
\hline \multicolumn{3}{|c|}{ The base payolf is $\quad-2.77056$} & \\
\hline
\end{tabular}




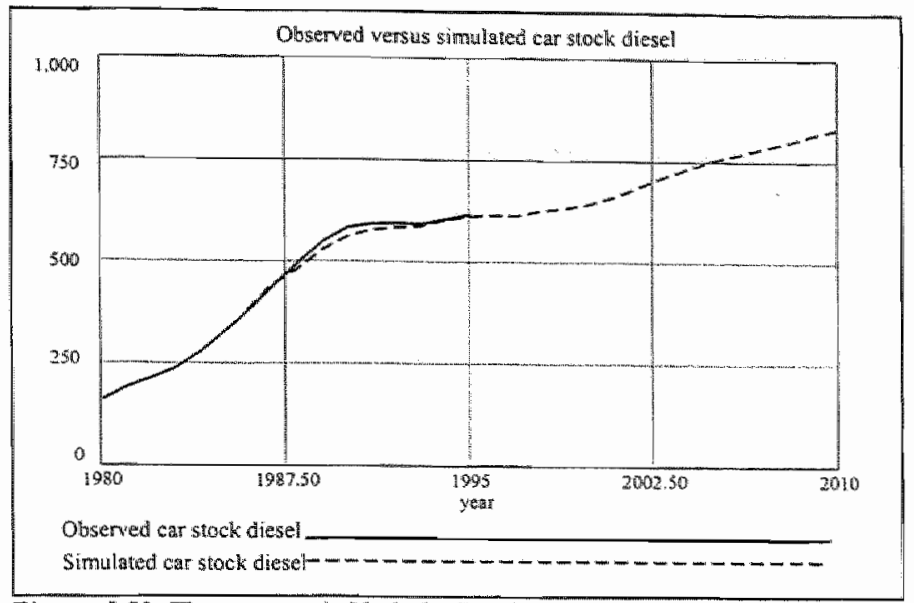

Figure 5.50 The symmetric Verhulst-Pearl function

\subsubsection{The diesel car stock asymmetric Verhulst-Pearl base period 1986-1994}

The asymmetric Verhulst-Pearl function:

$$
\frac{d C}{d t}=\frac{\varphi \beta \chi\left(1+\varphi e^{-\infty \beta t}\right)^{-(1+\gamma)} M}{e^{\beta t}}
$$

performs somewhat better then the symmetric one (Box 5.15). As there is an identification problem the scale parameter $\chi$ has been estimated first, simultaneously with $\alpha[D]$ and $\varphi[D$, setting the $\beta[D]=$ 0.5 exogenous; this resulted in the optimal value $\chi[\mathrm{D}]=2.015$. In a second round the scale parameter $\chi$ is set exogenous and the $\beta[D]$ enters with $\alpha[D]$ and $\varphi[D]$ in the estimation process. As the scalle parameter $\chi[D]=2.015$ it is a question of a positive asymmetry, as explained before. The positive asymmetry is typically for consumer durables where economic and demographic variables push up the potential market.

\begin{tabular}{|l} 
Box $5.15 \mathrm{Log}$ likelihood $95 \%$ Confidence intervals \\
$-0.99475 \leq \alpha[D]=-0.98224 \leq-0.96957$ \\
$0.49708 \leq[\mathrm{D}]=0.502 \mathrm{D}]=0.502759$ \\
$0.50254 \leq \varphi[D]=0.505 .495 \leq 0.5083$ \\
The base payoff is -2.58915
\end{tabular}

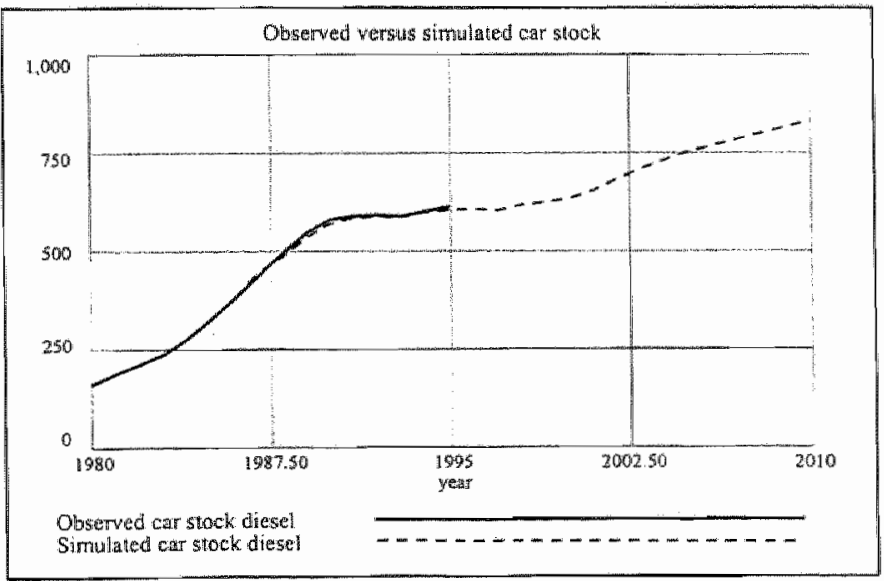

Format 5.51 Asymmetric Verhulst-Pearl function 


\subsection{The vintage car stock model by fuel type, by ce and by technology}

\subsubsection{Introduction}

After examining and testing different models of car stock by fuel type $(F)$ we want a further digression by dividing the car stock by cylinder content (cc) and by input-output technology (Tc). By oc (cyllinder content, measured in litres (L) or $1000 \mathrm{cc}$ ) three cc classes will be distinguished:

$$
\begin{array}{ll}
<1.4 \mathrm{~L}, & (S) \\
-1.4-2.0, & (M) \\
->2.0 \mathrm{~L} & (L)
\end{array}
$$

for technology four classes will be distinguished on behalf of the gasoline and LPG cars:

$$
\begin{aligned}
& \text { - conventional engine, (NB) } \\
& \text { - clean engine, } \\
& \text { - open-loop catalytic, (OLB) } \\
& \text { - closed-loop catalytic. (CL) }
\end{aligned}
$$

for the diesel cars the following distinction has been made:

\subsubsection{Data sources}

- indirect injection: without catalytic

$($ IND)

- indirect injection: with catalytic

- direct injection

\begin{tabular}{|c|c|c|c|c|c|c|c|c|c|c|}
\hline $\mathrm{CC}$ & Technodogy & 1986 & 1987 & 1908 & 1959 & 1990 & 19911 & 1992 & 1993 & $1994 \%$ \\
\hline \multirow[t]{5}{*}{$<1.4 \mathrm{~L}$} & Comyentitonial & 244568 & 97813 & 28964 & 14150 & 8253 & 4915 & 7511 & 36 & 17 \\
\hline & Clear Engine & 56973 & 160706 & $157 \times 53$ & 89395 & 10071 & 7295 & 5455 & 1090 & 9 \\
\hline & Open loop CaL & 4285 & 31684 & 39305 & $451 \% 0 !$ & 33690 & 17696 & 6450 & 2656 & 3365 \\
\hline & Closd loop Cat & $0 \frac{3}{3}$ & 0 & (2) & 63925: & 146630 & 158804 & 161403 & 143668 & 163429 \\
\hline & & 305926 & 290.209 & 226122 & 212700 & 108584 & 108100 & 194059 & $14740^{11}$ & 160819 \\
\hline \multirow[t]{5}{*}{$1.4-2+0 !$} & Converitianal & 156775 & 115012 & 41628 & 14427 & 5398 & 1022 & 357 & 118 & 100 \\
\hline & Clatin Engyine & 3180 & 12688 & 25861 & 13089 & 1943 & 149 & $y$ & 2 & 0 \\
\hline & Open logp Coa & 4112 & 47824 & 102232 & 87431 & 37555 & 23571 & 9091 & 489 & 5 \\
\hline & Closd boes Cat & 9 & & का & 78831 & 197860 & 190447 & 220381 & 177896 & 21347 \\
\hline & & 164006 & IPSST & 169719 & 193829 & 22269 & 220199 & 220837 & 178490 & $2 / 3582$ \\
\hline \multirow[t]{6}{*}{$22.0 \mathrm{~L}$} & Gonverndonal & 15597 & 12959 & 8065 & $3816:$ & 274 & 64 & 36 & 38 & 5 \\
\hline & Ctean Enginhe & 0 & 0 & 0 & 91 & 0 & of & 0 & Q & (9) \\
\hline & Open lowper R & 380 & 3867 & 1025 4 & 5743 & 237 & 15 & 8 & 3 & 的 \\
\hline & Closd loom Cnt & 0 & 0 & 6 & 11330 & $2 \$ 056$ & 2719 & 29972 & $2 ! 7 ! 4$ & 25276 \\
\hline & & 15977 & 16926 & 18426 & 21380 & $2556 \%$ & 27272 & 256161 & 21759 & 25282 \\
\hline & Subtota! & 485870 & 482553 & 414267 & 427902 & 446847 & 435591 & 433507 & 347701 & 405683 \\
\hline Ditusell & & Tolal & & & & & & & & 0 \\
\hline \multirow[t]{3}{*}{ Iryjectioni } & lindirect & 736111 & 72208 & 6.6478 & 66650 & 51605 & 52066 & 49893 & 32706 & 32049 \\
\hline & $\operatorname{lng}, \mathrm{Ca}$ & 0 & & & & 3104 & $1: 803$ & 7344 & 10580 & 21460 \\
\hline & Dired & & & & & & & & & 0 \\
\hline \multirow[t]{2}{*}{ wnkinatw } & & 1031 & 982 & 1872 & & 115 & 967 & 13,36 & 947 & 802 \\
\hline & Total & $\$ 60512$ & 585743 & 49251 ? & 494562 & 502671 & 90407 & 492130 & 391934 & 460000 \\
\hline
\end{tabular}

The sales data of new car sales by fuel type, by $\mathrm{cc}$ and by technology are supplied by the RAI, recorded from 1986 on. The administrative car stock data by fuel type, by ce and by technology are published from CBS from 1990 on. From these two basic sources weight coefficients are computed and shown hereafter. Table 5.3 illustrates a subset of the data to be applied in our vintage car stock model by fuel type by cc by technology. 


\subsection{Diffasion of technology}

Figure 5.52 shows the new car sales by fuel type and by technology during the period 1986-1994. Note that the diesel car sales are measured along the vertical right axis. The conventional motor type technology is losing very quick its share, starting in 1986 with $75 \%$ of the new car sales, and ends-up with $0.0 \%$ in 1992 . At the same time two interim technologies started during the mid-80s, the clean engine motor and the open-loop catalytic device.

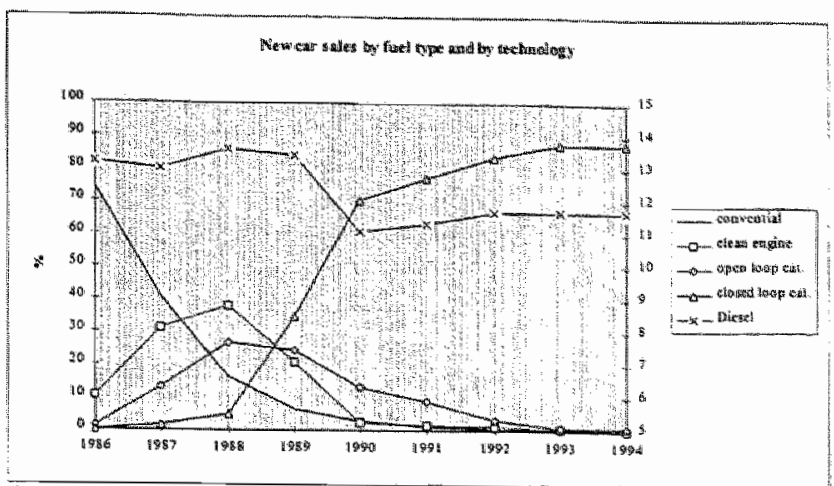

Figure 5.52 The new car sales by fuel by technology

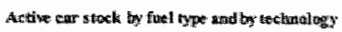

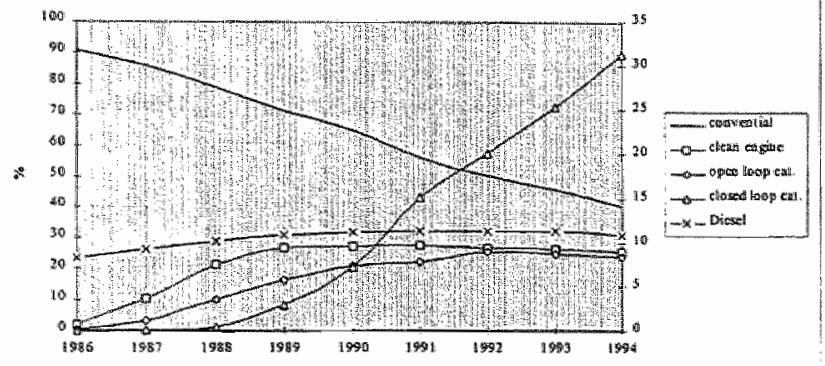

From 1988 on engine equipped with the closed-loop catalytic device takes over the lead and accounts for $85 \%$ and more in 1994 . This diffusion process has its repercussions for the composition of the car stock. Note in Figure 5.53 the conventional car stock only has been measured along the vertical left axis $(\%)$. The four other car stocks are measured along the vertical right axis $(\%)$.

Figure 5.53 The active car stock by fuel by technology

The conventional car stock decays continuously from $90 \%$ in 1986 to $\pm 40 \%$ in 1994 (Figure 5.53 ). In 1994 already about $30 \%$ of the car stock consists of the closed-loop catalytic type cars. The interim technologies, clean engine and the open-loop catalytic car stock are decaying slowly after their maximum in 1989, and 1992. The diffusion shown is almost identical for the three cc-classes and will therefore not shown here.

Apart from the fuel/technology type, another development took place during the period under investigation: the trend towards heavier motors, measured by their cylinder-content (Figure 5.54) Note that the big cars, class " $>2.0$ L." has been measured along the wertical right axis (measured in fractions).

The share of small cars, ' $<1.4 \mathrm{~L}$ ', cars in the new car sales is decreasing from $65 \%$ in 1986 towards $40 \%$ in 1994 .

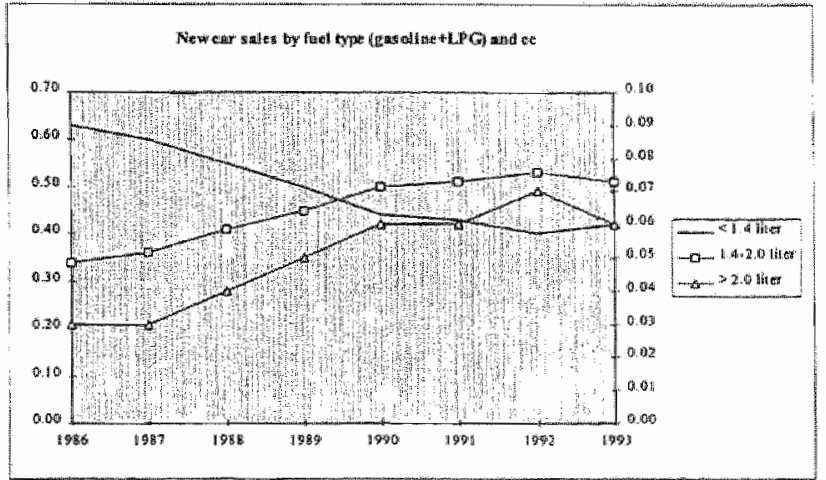

Figure 5.54 New car sales by fuel type and ce (fractions) 
The opposite development occurs of course for the medium cars, ${ }^{4}, 4-2.01$ ', chass and to a lesser extent to '>2.0L' class. The '1.4-2.0 L' class increases from $35 \%$ in 1986 towards $45 / 50 \%$ during the 90\%. For our basic reference runs the 1995 figures are treated as constants during the perod 1995 $2010 / 15$.

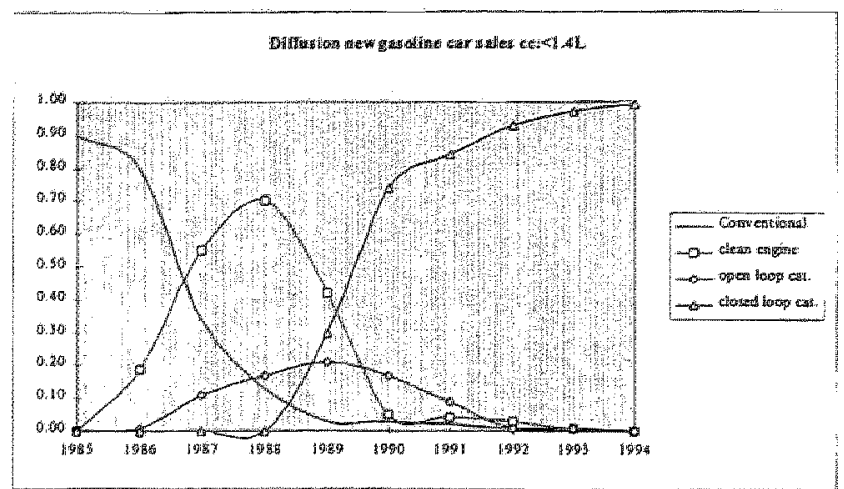

A further dignession of the diffusion of technology is attained by looking to the cc-classes. The small cars, " $<1.4 L$ L", (Figure 5.55) and the medium cars, "1.42.0 L', class (Figure 5.56) shows the same diffusion paths but the clean engine technology was first introduced and far more penetrated in the " $<1.4 \mathrm{~L}$ " class (small cars) than in the "1.42.0 L" class (medium cars).

Figure 5.55 The diffusion or penetration rates for the $<1.4 \mathrm{~L}^{3}$ class (fractions)

The opposite development occurs for the open-loop catalytic device which was first introduced in the "1.4-2.0 L' class and perietrated much deeper in that class as in the ' $<1.4 \mathrm{~L}$ ' class. The introduction and penetration of the closed-loop catalytic device occurred at the same point in time and shows the same penetration shape.

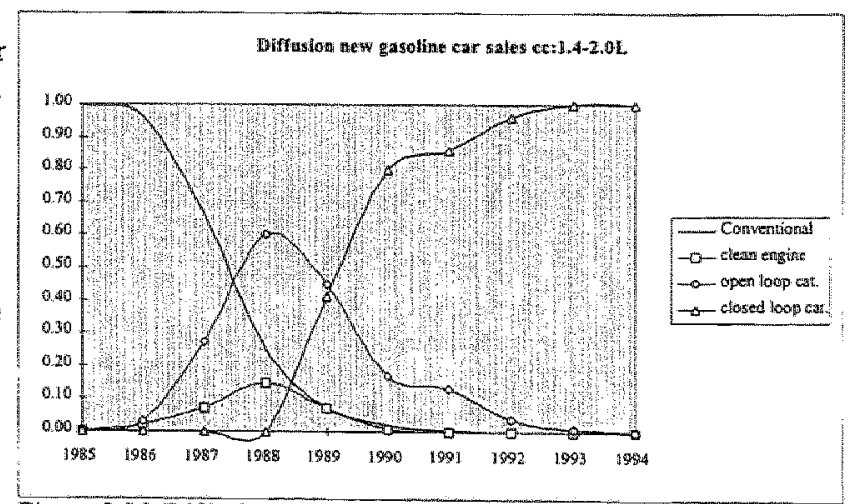

Figure 5.56 Diffusion or penetration rate "1.4-2.0 L" class (fractions)

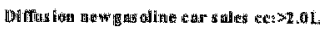

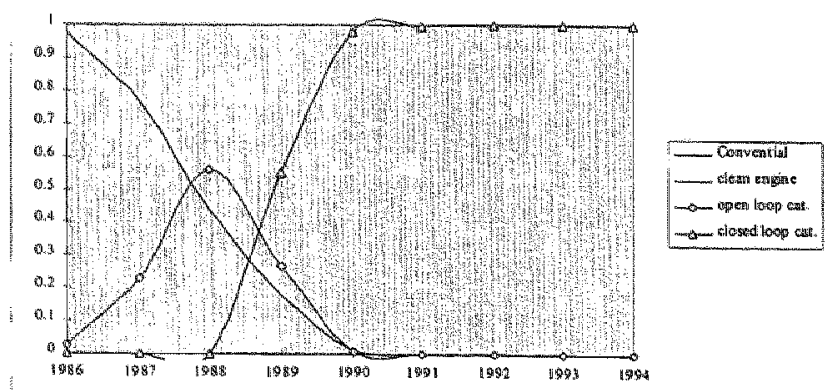

Figure 5.57 The diffusion or penetration rate $>2.0 \mathrm{~L}$ ' class (fractions)
The clean engine technology surpassed the big car, " $>2.0 \mathrm{~L}$ " class (Figure 5.57), where the open-lowp catalytic device was first introduced in 1985. The follow-up closed-loop catalytic device did penetrate very fast, up to $100 \%$, within two years. The diesel car stock can be divided in indirect and direct injection (Figure 5.58). However, the last class is for the Netherlands up to 1996 negligible. The medium diesel cars count for $75 \%$ of the diesel car stock, and the big diesel cars $24 \%$

The catalytic device for the indirect injection class was introduced in 1989 and made first momentum in 1991/92. It is to be expected that the full diffusion will be completed in $1996 / 97$. 


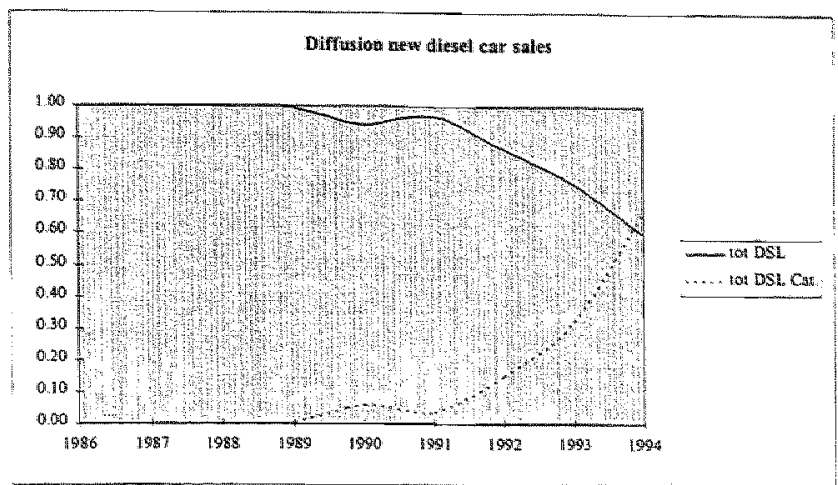

Figure 5.58 The diffusion or penetration rate of diesel indirect injections with catalytic device (fractions)

5.8.4. The formalised car stock model by vintage, by fuel, by ce, and by technology In section 5.6 .2 the logistic car stock model (called sigmoid) by fuel type had been developed and estimated, in section 5.7.1 and 5.7.4 this was done for the symmetric and asymmetric Verhulst-Pearl logistic function. All these exercises were performed with the aim to estimate a consistent and reliable new car sales function by fuel type, $C S[F]$. In order to compute the desired four (three) technology classes of gasoline/LPG (diesel) for three cylinder-content classes ( $c c$ ), the yearly simulated car sales by fuel type, $C S[F]$, has to be multiplied by the weight coefficients, $[[F, T, C C]$, Table 5.4 , deduced. from Table 5.3 for the period 1986-1994 (equation 5.8.1).

\begin{tabular}{|c|c|c|c|c|c|c|c|c|c|c|}
\hline We thg ht co: & thelentes & 1 & & & & & & & & \\
\hline Gasabinet & $\mathrm{CPG}$ & & & & & & & & & \\
\hline $\mathrm{CC}$ & Texhanology. & 1986 & 1987 & 79885 & 19.99 & 1996 & 1,591 & 1092 & TS13 & TSP \\
\hline CWB & Cosivential & $0.5103 !$ & 0.201 & $0.0 \% 0$ & 0.033 & 0,018 & 0.010 & 0.1002 & 0,000 & 0.0030 \\
\hline & Clenn Engue & ont & 0.33 & 0.381 & 0209 & Ro23 & 0.017 & 0.019 & 0005 & 0.0000 \\
\hline & Open loop C C. & 0.609 & 0.066 & 70.095 & 0106 & $60 \% 5$ & $0,04 \pi$ & 0.015 & 7.0008 & 0.65018 \\
\hline & Closdloop CaL & 0.000 & 0,009 & 7.07\% & 0130 & $0,3,25$ & 60365 & 0.372 & 1.4T3 & 0.467 \\
\hline & & 0.639 & 0.601 & 0.546 & 0.497 & 19.44 & $6 \mathrm{Ax}$ & 0.402 & (12.24 & $0.4 \pi 1$ \\
\hline (1.4-2. 201 & Convertal & 0.935 & 0.238 & 0.100 & 0.0034 & $0.012^{5}$ & 7,0002 & $8.00 \Gamma_{i}^{-}$ & 00005 & 0.000 \\
\hline & Clean Engine & 0.007 & 0.026 & 0.062 & 0.0091 & 0.064 & 0.000 & 0.090 & n. & 0.000 \\
\hline & Cpen loop Cat & 0.008 & 0769 & 0.247 & 0.304 & 0.084 & 0.066 & 0.021 & 9.071 & 0.000 \\
\hline & Closd loop Cal & $0.0 \% \%$ & 6.600 & $40000^{\circ}$ & 0.154 & $0.3 \times 58$ & 0.497 & $0.505^{3}$ & 6.512 & 0.526 \\
\hline & & 70.358 & 8364 & 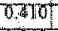 & 6.453 & 0.498 & 0.508 & 0.530 & 0.513 & 6,425 \\
\hline $201 \mathrm{C}$ & Comykentait & 0.052 & $0.02 \%$ & 0.018 & 0.009 & 0.001 & 0.0001 & $0000 \%$ & 0.000 & 0,000 \\
\hline & Chetan Engine & 0,0001 & 0,000 & 0.1000 & 0.000 & $0.60 \%$ & 0.0000 & - $60.7 \mathrm{~m}$ & 0.0001 & Trom \\
\hline & Opeen lowp Cal & 0.001 & $0,60 \mathrm{~B}$ & 0.025 & odTs & 0.001 & $7,0,000$ & astotion & 0,400 & onche \\
\hline & Closd loop Cat & 0000 & 0.0000 & 0.600 & 0.028 & 6056 & 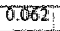 & atsos & $0.082:$ & 酷, \\
\hline & & 10.033 & 0.035 & 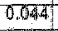 & 0.050 & 0.65 & 0.260 .1 & 7. & $0.06 \%$ & 4.072 \\
\hline & Subten & $T .000$ & 10000 & Thoo & 1.200 & 1.600 & 77600 & 1.605 & 1.000 & D.600 \\
\hline Diest & & & & & & & & & & \\
\hline Trujection & hitarent & T.,ot: & 1000 & $7.0 \% 0$ & 1.000 & Q.514 I & 6967 & $0.8 \% 1$ & -0.556 & 0.509 \\
\hline & Ivdent & 6001 & 0.070 & 0.000 & 0,0001 & T. $\mathrm{CF}^{2}$ & 0.031 & 0.129 & 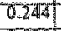 & $75.45 T$ \\
\hline & Direc: & $0,00 \%$ & 0.000 & 9.600 & Q. & 6.000 & 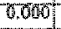 & 0.60 & 770050 & 0.0070 \\
\hline & 5 Witotat & 1.600 & 1000 & 1.000 & D.0701 & $\pi 00$ & 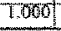 & 7.000 & T.TOC & Thon \\
\hline
\end{tabular}

Table 5.4 The weight coefficients for car sales by fuel type

Note the diesel cylinder content classes are approximated (CBS 1994) by the following fractions:

$$
\begin{array}{cc}
<1.4 \mathrm{~L} & --0.01 \\
1.42 .0 \mathrm{~L} & -0.75 \\
>2.0 \mathrm{~L} & -0.24
\end{array}
$$

The computational sequence is as follows, for example, in 1990 the new car sales (gasoline and LPG) mounted to 446.847 of which : in the cylinder-content class less than 1.4 litres $(c c<1.4 \mathrm{~L})$

$$
\begin{aligned}
& 0.018 * 46.847=8.250 \text { conventional (falling) } \\
& 0.023 * \text { * }=10.250 \text { cleam engine (falling) } \\
& 0.075^{*} \text { " }=33.600 \text { open-loop catalytic (falling) } \\
& 0.328 * " \quad=146.000 \text { closed-loop catalytic (rising) }
\end{aligned}
$$


so for the year 1990 new car sales of gasoline $(F=P)$ of the conventional type $(T C=N B)$ less then $1.4 \mathrm{~L}(\mathrm{CC}=\mathrm{S})$

$$
C S_{9900}[P, N B, S]=8250 \text {, equation } 5.8 .1 \text {, }
$$

this flow variable diminished with the scrapping of 1990 will enter the stock or state variable

$$
C S T_{1990}[P, N B, S, V] \text {, equation } 5.8 .2 \text {, }
$$

the same sequence is taken for the other cc-classes, technology classes as well as for the other fuel type new car sales. However the diesel category distinguishes three different technology classes:

- indirect injection (conventional)

- indirect injection with catalytic device

- direct injection

These yearly sales (a vintage) are separately integrated into state variables, equation 8.5 .2 , and added to the total car stock composed of earlier remaining 9 vintages (year of construction) plus a remaining wintage (older than 10 year), equation 8.5.3. This remaining number of cars became more and more important during the 80 s and 90 s. If we take the fully integrated car stock by fuel type, by technology, by $\mathrm{cc}_{\text {, }}$ and by wintage, equation 5.8 .4 , we come up to $(2 * 4 * 3 * 11) 264$ integrals for the gasoline and LPG cars and for diesel cars (1*3*3*11) 99 integrals, summing up to 363 integral computations each time step $(\Delta t=0.125)$. So the state space adds up to 363 dimensions, without the time dimension, $\Delta t$. The diffusion level (diffusion coefficient times total actual car stock) determines the potential car market, $M$, for each fuel type, equation 5.8.5. Having qualitatively described the formalised model and some computational aspect the complete formal model $(5.8 .4)$ is:

Full integrated car stock model 5.8.4.

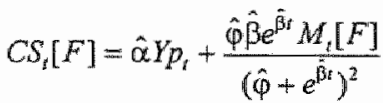

$$
\begin{aligned}
& C S_{r}[F, T c, C C]=\bar{\omega}[F, T c, C C]^{*} C S_{f}[F] \\
& \left.\operatorname{CST}_{l}\left[F, T_{C}, C C_{3} V_{k}\right]=\operatorname{CST}_{a}\left[F, T_{c}, C C, V_{k}\right]+C S[F, T c, C C]-\overline{S C}\left[F, V_{k}\right]\right) \\
& T C_{i}[F]=\sum_{T_{c}} \sum_{C C} \sum_{k=1}^{N\left(V_{k}\right)}\left(C S T_{i}\left[F, T c, C C, V_{k}\right]+R_{i}[F]\right) \\
& T C_{t}=\sum_{F} T C_{t}[F] \\
& Y_{p_{t}}=Y_{p_{t-1}}+Y_{t}^{*}-\tilde{\psi} Y_{p_{t-1}}=D_{l i \psi}^{l}\left(Y_{q}^{*}\right) \\
& M_{r}[F]=\phi_{F} T C_{\gamma}[F] \\
& R_{t}[F]=\vec{r}_{r}^{*} T C_{r}[F]
\end{aligned}
$$

where

$$
\begin{array}{lc}
F=\{P, D, L\} & V=\left\{V_{k}, R\right\} \\
& V_{k}=\left\{V_{1}, \ldots, V_{10}\right\} \subset V \\
& R=\sum_{k=N_{N}\left(P_{k}\right),+1}^{\infty} V_{k} \subset V \\
F: \text { fuel } & V: \text { vintage (year of construction) } \\
P: \text { gasoline } & R: \text { remaining vintages }(P 10 \text { vinages) } \\
D: \text { diesel oill } & \\
L: \mathbb{L P G} &
\end{array}
$$

$$
\begin{aligned}
& b \\
& \bar{\psi}=0.377 \\
& \bar{\theta}=1.6
\end{aligned}
$$




$$
\begin{aligned}
& \phi_{F}=\phi_{P}+\phi_{L}+\phi_{D}=1 \\
& \phi_{D}=\phi_{P}+\phi_{L}=0.85 \text { (non-diesel share of car stock) } \\
& \phi_{D}=0.15
\end{aligned}
$$

$D_{\theta}^{3}(\bullet) \quad$ : delay operator (first order and $\theta$ time constant)

$N(\bullet) \quad$ : enumeration function

$C S[F] \quad$ : simulated new car sales by fuel type

$T C[F] \quad$ : simulated total car stock by fuel type

$C S T[F, V]$ : simulated vintage car stock by fuel type

$M[F] \quad$ : maximum share of fuel type $F$ of total car stock

$\overline{S C}[F, V]$ : estimated vintage scrap parameter (section 5.3 )

$R[F] \quad$ : estimated remaining vintages, $>10$ year

$r[F] \quad:$ estimated remaining vintage parameters (section 5.3 )

$Y_{p} \quad:$ simulated permanent income

$Y^{*} \quad$ : observed real disposable income

The new car sales function 5.7.6 is one of the three alternative formulations, in this case the symmetric Verhulst-Pearl type, the other are the asymmetric Verhulst-Pearl:

$$
C S_{i}[F]=\hat{\alpha} D_{\hat{\theta}}^{1}\left(Y_{t}^{*}\right)+\frac{\hat{\varphi} \hat{\beta} \hat{\chi}\left(1+\hat{\varphi} e^{-\hat{\beta} t}\right)^{-(\hat{\imath}+\hat{\chi})} M_{t}[F)}{e^{\hat{\beta} t}}
$$

and the sigmoid formulation

$$
C S_{n}[F]=\hat{\alpha} D_{\hat{\theta}}^{\frac{1}{t}}(Y h)+\hat{\beta} T C_{i}[F]\left(\left(M_{t}[F]-T C_{t}[F]\right) / M_{t}[F]\right)
$$

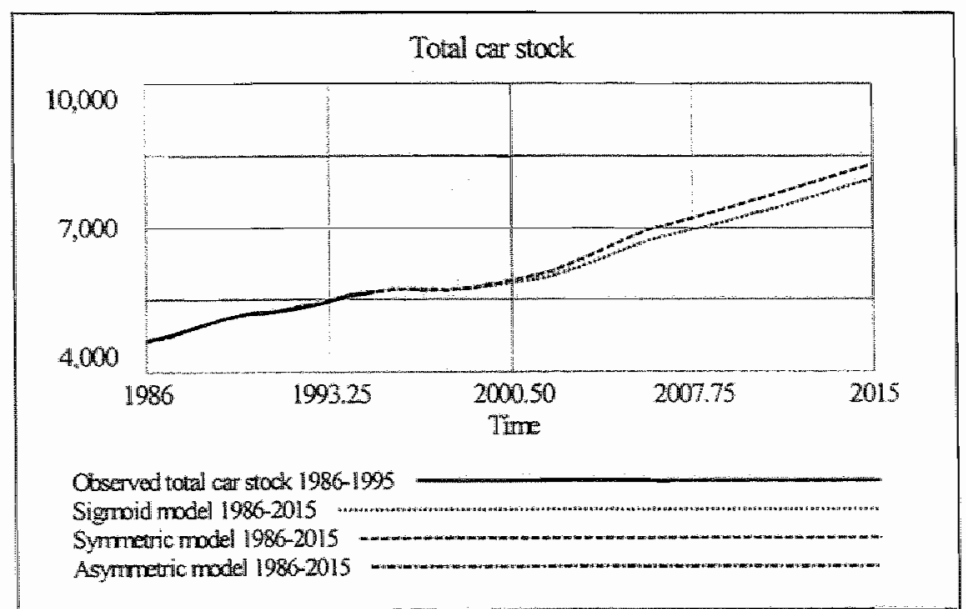

The three new car sales functions will be compared in their forecast behaviour in the next section. Note that the scrapping function for the three fuel types has already been estimated in chapter 4 , and are the same for cylinder-content and technology within each fuel type.

Figure 5.59 The observed (1986-1995) and predicted (1986-2015) total car stock $(\times 1000)$

In sum, we can track the (future) vintages of the above defined car stock, this is of importance because each vintage (defined by fuel, by technology, and by cc) has its own, specific, emission spectrum and its own average yearly kilometrage. 


\subsubsection{The results}

Some reference future runs will be shown for the total car stock by fuel type and, for illustratiwe purpose, a specific vintage will be shown during its lifetime.

Figure 5.59 shows the total car stock for the three model developed before. The estimation was performed for the period 1986-1995. The forecast based on the estimation assumes:

- a ret growth of disposable income of $2 \%$ for the period $1996-2015$;

- the diffusion rate of fuel type remains fixed at its 1995 levels, that means the diffusion parameter for gasoline $(82 \%)$ and $L P G(7 \%)$ remains $89 \%(M[P L]=0.89)$ for the forecast period and $11 \%$ $(M[D]=0.11)$ for the diesel cars;

- the weight distribution of the new car sales over the cylinder-content classes remains fixed at its 1995 level, that means the weight parameter $\omega$ for the small cars, class $<1.4 \mathrm{~L}$ is 0.41 ( $41 \%$ of the new car sales gasoline plus LPG), between 1.4-2.0 L, the medium cars, is .526 and for the big cars, $>2.0 \mathrm{~L}$ class the weight -parameter is 0.062 .

- the break-even kilometrage of LPG is $27.000 \mathrm{~km} /$ year and for diesel $25.000 \mathrm{~km} / \mathrm{year}$ remain fixed. for the period 1995-2015.

However the parameter and constants settings will be changed in the scenario runs to be performed in chapter 8 . The reference run show that in 2010 the car stock will be $7.2-7.5$ million cars, mounted to 8.0-8.3 million in 2015.

What the figures show (Figure 5.59,5.60, and 5.61) is the smoothing during the period 1995-2000 of the gasoline and LPG new car stock, this partly due to the idiosyncrasies of the period 1990 -1995 and especially after 1993 which shows a divergence of the almost constant sales/stock ratio of \pm 0.10 for the 80 s but deteriorates to 0.077 in 1995 . This means that 1 t the scrapping of vintages is delayed for that time being but will probably be reversed in end of 90 s and/or 2 . the imports of used-cars increased significantly.

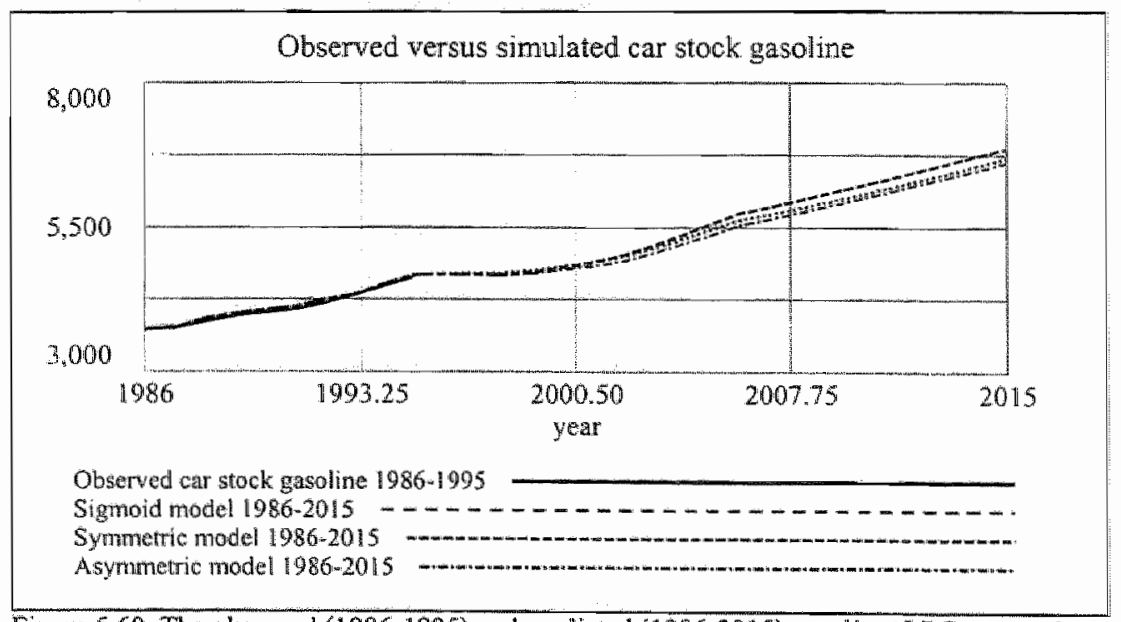

Figure 5.60 The observed (1986-1995) and predicted (1986-2015) gasoline+LPG car stock (x1000) 


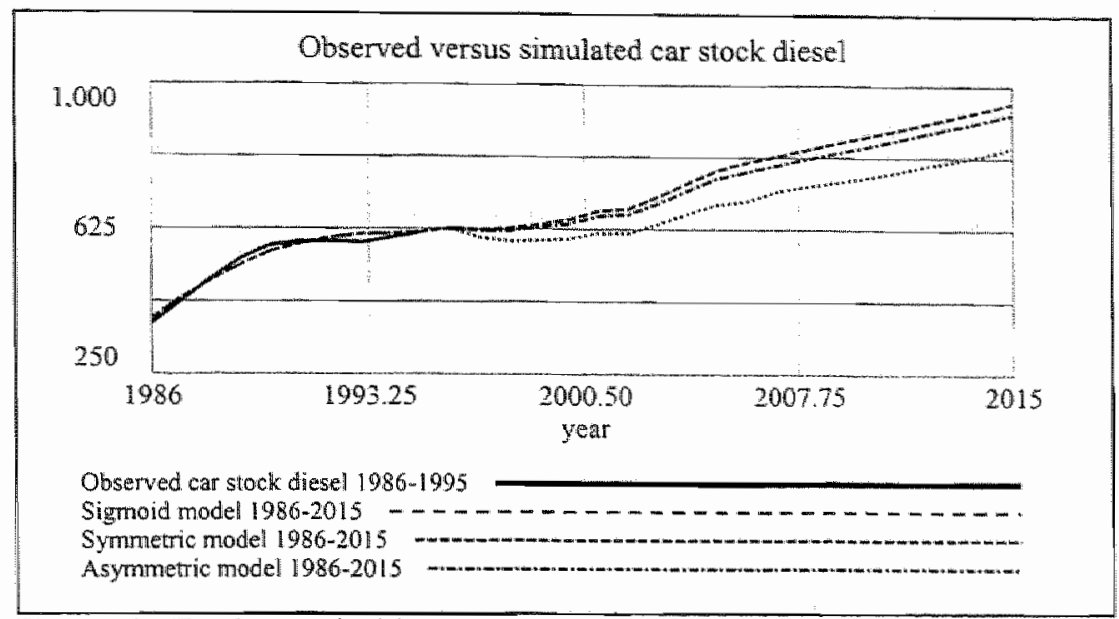

Figure 5.61 The observed (1986-1995) and the predicted (1986-2015) diesel car stock $(\mathrm{x} 1000)$

The diesel car stock has its own idiosyncrasies, as shown before, as the exponential growths in the mid 80 s levels out during the early $90 \mathrm{~s}$, but for the years $1994 / 95$ the diesel new car sales did grow significantly probably with the support of LPG substitutes. What strikes further is the sigmoid curve in Figure 5.61, this due to the fact that diffusion rate of the diesel is in the neighbourhood of the actual diffusion rate of the diesel cars $\pm 11 \%$, which hampers heavily the income effect of the growth process. The symmetric and asymmetric models give less weight to the narrowing of the maximum and the actual diffusion rate.

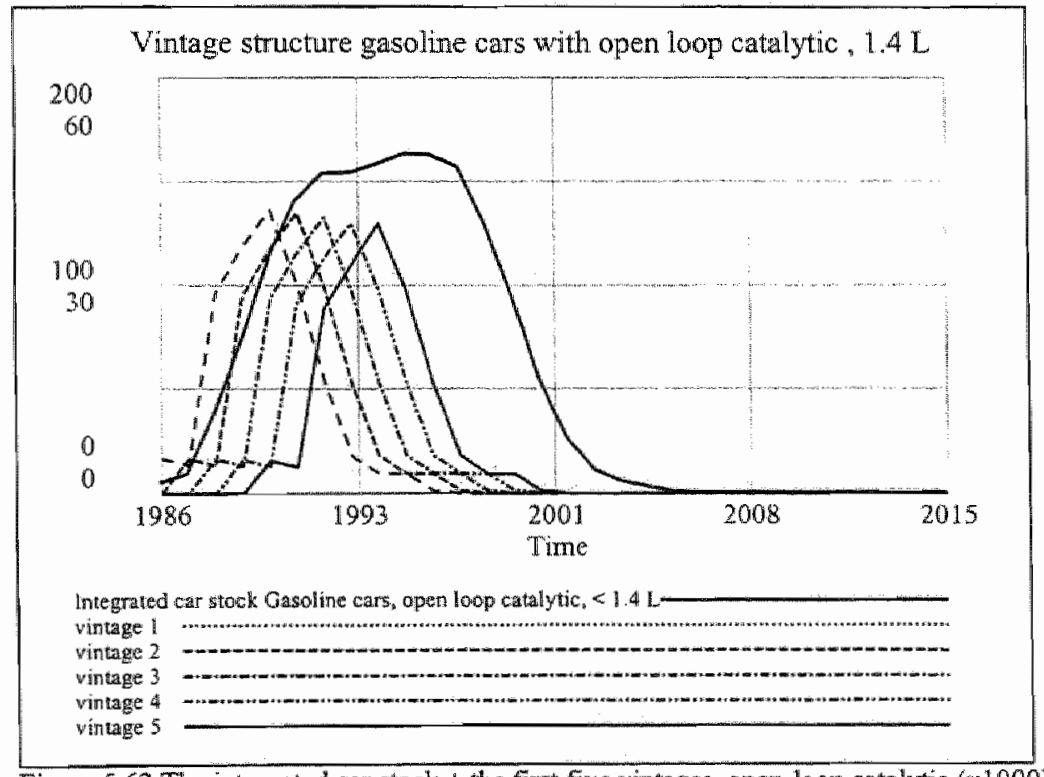

Figure 5.62 The integrated car stock + the first five wintages, open-loop catalytic ( $\times 1000)$

The last two figures 5.62 and 5.63 shows the integrated car stock of gasoline cars with open-loop catalytic devices and the first five wintages. It is an example of a declining (or dying) technology with 
the peak in 1989 (Table 5.3 ) and in 1996 practically zero. Figure 5.62 shows very cleat the residence time of the open $100 p$ cars in the total car stock which will be near zero in 2003.

Figure 5.63 shows the integrated car stock of the closed-loop catalytic gasoline cars and the first five vintages. The full diffusion of the closed-loop technology will be completed after 2000 .

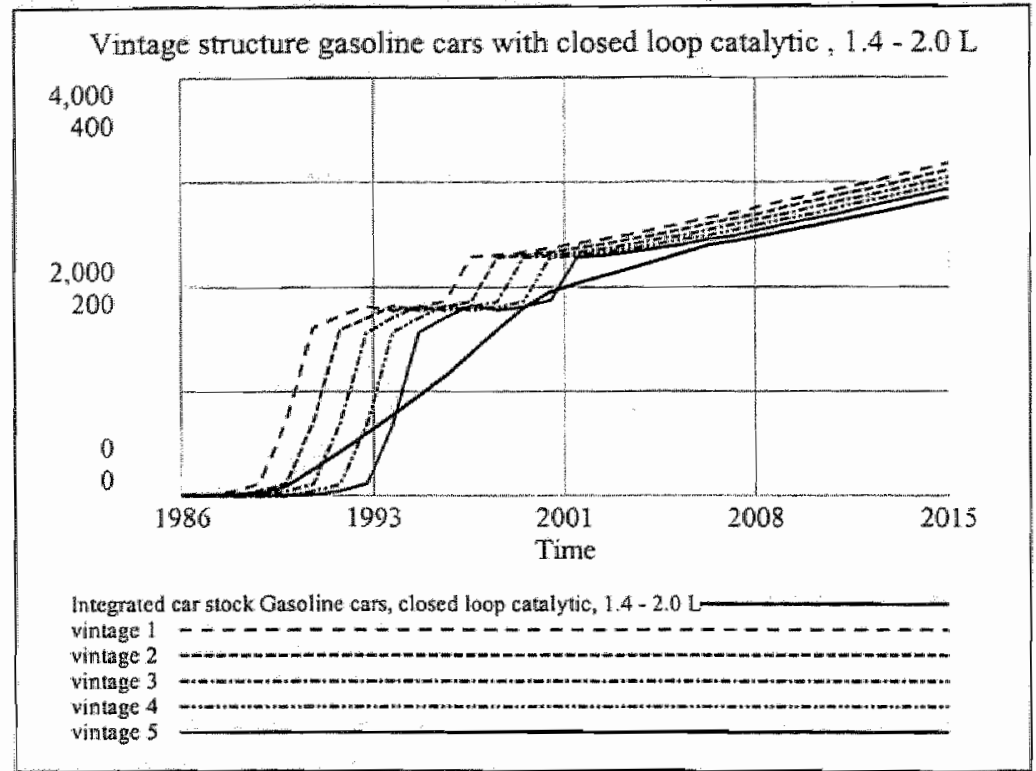

Figure 5.63 The integrated car stock t the first five vintages, closed-loop catalytic (x1000)

Note the car stock of Figure 5.62 and 5.63 are measured by the first indices of the vertical axis, the vintages by the second indices. 


\section{Chapter 6 \\ Car ownership, car use \\ and \\ kilometrage \\ from micro - to macro analysis}

\#Objective

\# Methods

\# Data sources

\#Rsults

\#Conclusions
Examination of past car ownership patterns of households by size, to confront the results with the outcomes of chapter 4 . The past development of car use as a representation of mobility of the households by size. This micro analysis will be followed by a macro analysis of kilometrage of the Dutch car stock. From the examinations of the past development one can make projections of the future impact of mobility on the kilometrage and the car use.

Using household by size projections (output of the $H_{1}^{6}$-model) as input driver for the car ownership and car use model, together with the observed penetration of the car stock over the 1- to 6-person households and assumptions about the expected car penetration rate over the households by size, one obtain projections about the mobility by motive, car use and vehicle kilometrage for the period 1995-2015. Survey displacement behaviour of the Dutch population (OV G, CBS, yearly from 1979 on), and private car panel (PAP, CBS, yearly from 1970 on, Wrecks statistics, CBS, yearly from 1986 on)

Projections of household car ownership, car use, vehicle kilometrage and vehicle kilometres for the period 1995-2015

From the projections and scenario runs it is to be expected that the car stock will increase from $4.6 \mathrm{mln}$ (1985), $5.6 \mathrm{mln}$ (1995) by $30-45 \%$ to $7.5-8.25 \mathrm{mln}$ in 2015 . These figures from a micro analysis confirms the results of the macro analysis of chapter 4 . However, the number of cars increases stronger than the car use. This is due to:

1. the greying of the Dutch population. Car ownership remains important but car use decreases by elder people;

2. increase of number of cars per household, with the average car use declining;

3. increasing participation of cohabiting partner in the labour market. It is to be expected that the average yearly vehicle kilometrage (veh- $\mathrm{km})$ will stabilise around $16000 \mathrm{~km}(15380$ in 1985,16560 in 1995). The yearly vehicle-kilometres will increase from 70.7 billion in $1985,93.3$ billion in 1995 to 133 billion in 2015. 


\subsection{Household car ownership, new car sales and car use. 1980-1995 6.1.1. Introduction}

The relationship between the development of car ownership and new car sales of private households between 1970 and 1995 will be analysed. The development of buying plans of cars will be analysed both on an aggregated level and on household level. At the same time the background features of households on individual level will be determined and linked with buying plans. Based on these analysis the determinants of the buying plans and the observed new car sales will be confronted. It seems clear that buying plans are related to household income level, the age of the head of the household, the level of consumer confidence and the kind of buying willingness. From this analysis it reveals that only a small subset of background features explains the most important part of the car buying plans of the households. Car use attracts increasing interest from many sides, especially the environmental effects of car use, the congestion in or near the cities and the scarce land use in the Netherlands for new infrastructure.

\subsubsection{Car ownership and households}

During the last two decades the Dutch car fleet has increased substantial. Figure 6.1 shows the 34 year evolution of the new car sales and the resulting car stock development. Note the volume of the car stock has been measured on the left axis (1.a.), the new car sales on the right axis (r.a.).

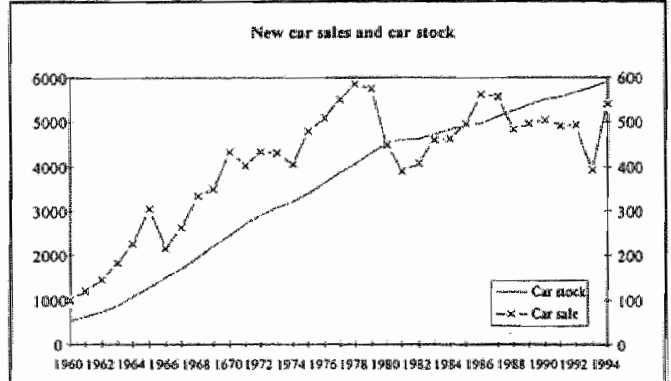

Figure 6.1 The Dutch car stock (l.a.), car sales

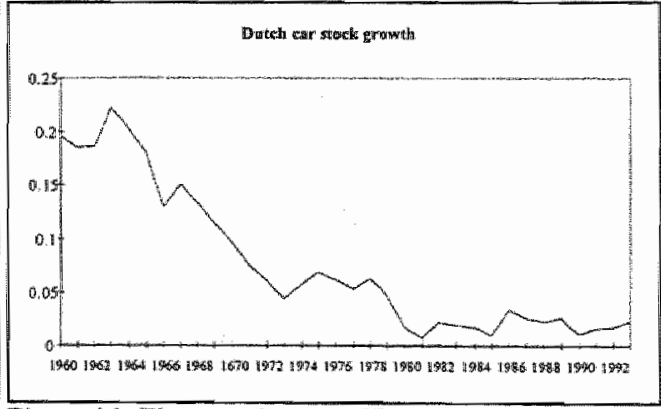

Figure 6.2 The growth rates of Dutch car stock

The past three and a half decades the Dutch automobile car fleet (or stock) has experienced in the early sixties an (declining) exponential growth with 1971/72 the first minor point of inflexion and a major inflexion point in 1980 . Between 1960 and 1972 the number of cars increased from 0.5 to 3 mln in 1972 an increase of $464 \%$ (Figure 6.2). Between 1972 and 1980 the increase was reduced to

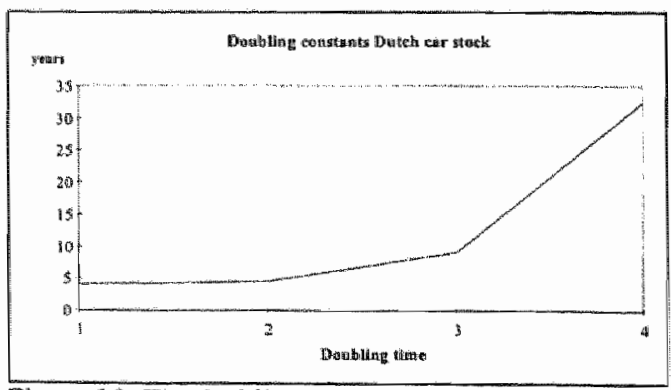

Figure 6.3 The doubling time curve
$56 \%$ and from 1980 till 1994 the increase was further reduced to $30 \%$. Expressed in doubling constants, the doubling from $0.5 \mathrm{mln}$ cars (during the period 1960) to $1 \mathrm{mln}$ occurred in 4 years (1964), the next doubling from $1 \mathrm{~min}$ to 2 min cars lasted 4.5 years from 1964 till medium 1968 and the next doubling from $2 \mathrm{mln}$ to 4 min cars lasted 9 year's from medium 1968 till medium 1977. The next expected doubling will run from 1978 till 2010 in fact \pm 30 year. Figuur 6.3 shows this dynamic process 


\subsubsection{Penetration rate of cars over Dutch households}

During the two decades $1960-1980$ the strong increase of the number of cars was not matched with a corresponding strong increase in the number of households. In 196016\% of the households owned a car, in 1972 this was increased to $62 \%$, and in 1979 to $69 \%$. As detailed survey data are available from 1979 on, the car owmership over more person households are known. First we show the car ownership over the total household followed by car ownership over more person households. Figure 6.4 shows the car ownership over total households, the " 0 -car' and ' $1-$ car ' measured on the left axis, the '2-cars' and '3-cars ' series on the right axis. The car ownership is still slight increasing, in 1979 '0-car households', or '0-carHSH', accounted for 30\%, in 1994 it decreased to $23 \%$. The '1-car households', stabilise at $61 \%$ from 1985 on, the '2-car households" on the contrary increases from $10 \%$ in 1985 to $14.5 \%$ in 1994 . The '>2-car households' shows no definitive trend an oscillates between $11 \%$ and $17 \%$.

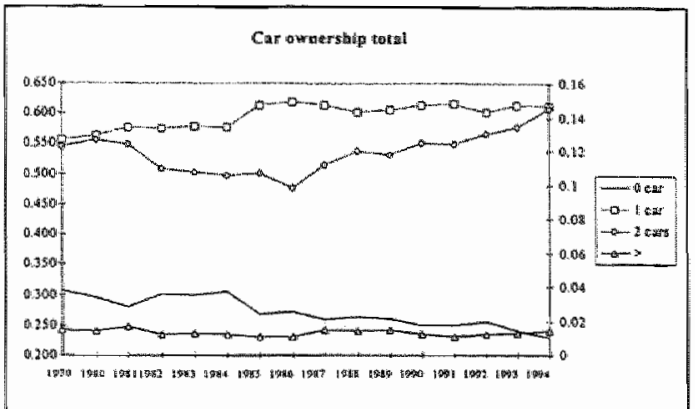

Figure 6.4 The car ownership by total households

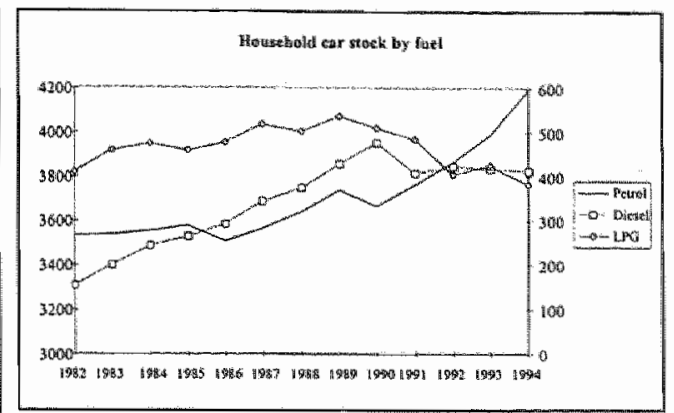

Figure 6.5 Honseholds car stock by fuel type

Of interest is also the division of car stock by household and non-household (government and enterprises and by fuel type. Figure 6.5 shows some interesting developments, first the rising share of the gasoline cars, from $3.530 \mathrm{~min}$ in 1979 to $4.200 \mathrm{mln}$ in 1994 , second an exponential increase of the diesel car in the $80 \mathrm{~s}$ but from 1990 on with $0.477 \mathrm{mln}$ a decrease which hollds on to 1994 to $0.410 \mathrm{mln}$ diesel cars (in 1995 the diesel car sales and therefore also the diesel stock resume the growth process) third the LPG cars (which exhibited exponential growth in the 70s) shows in the 80 s a moderate increase till 1990, with $0.591 \mathrm{~min}$ LPG cars, from 1990 on the LPG car stock decreased continuously to $0.380 \mathrm{~min}$ in 1995 . In order to complete the picture of the development of the Dutch car fleet the "non-household" car stock will also be shown in Figure 6.6. The "non-household' car stock by fuel type shows quit opposite developments. Figure 6 shows a temporary? decline of the gasoline car stock, an increasing share of the diesel cars and an unsure development of the LPG car stock.

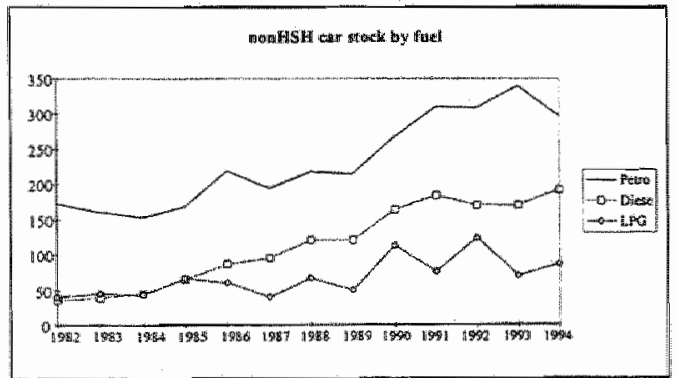

Figure 6.6 The non-household car stock by fuel type
The above elaborated dynamics hide some important background developments within the household sector, especially bousehold characterised by size, e.g. 1 to 6 - or more person households (1-6pHSH). The most important development during the $80 \mathrm{~s}$ is the strong increase of the 1- and 2-person households $(1-, 2 p H S H)$ as explained in chapter 3 . The 1-car ownership of 1-person households rose from $24.8 \% \mathrm{in} 1979$ (the first observed year) to $44.9 \%$ in 1995 (Figure $6.7)$ a $68 \%$ relative increase in 15 year. The 1-car ownership of 2-person households increased from $57 \%$ in 1979 to $69 \%$ in 1995 , a moderate $21 \%$ relative increase in 15 year. 


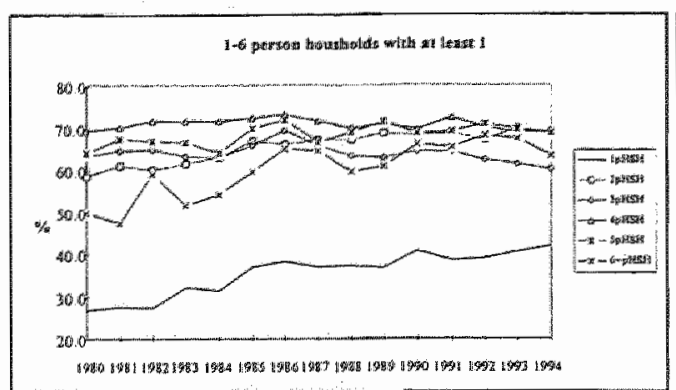

Figure 6.7 1.6 person households with 1 car.

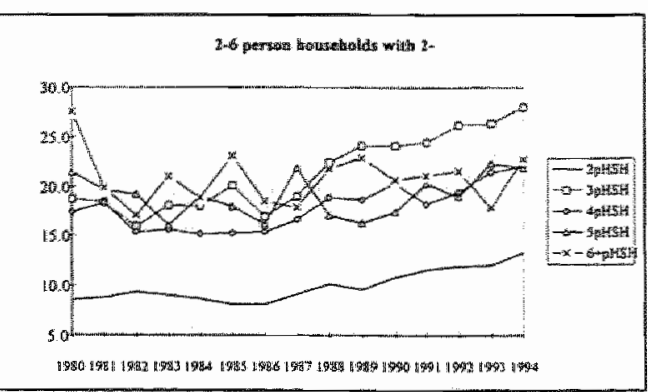

Figure $6.8 \quad 1-6$ person households with 2 cars

The 2-car ownership of 2person households rose from $7.4 \%$ in 1979 to $13.3 \%$ in 1994 (Figure 6.8 ), 2 $80 \%$ relatiwe increase over 15 year, for the 3 -person households the following figures applies: from $17.5 \%$ in 1979 to $28 \%$ in 1994 , a $60 \%$ relative increase; for the 4 -person households from $18.4 \%$ in 1979 to $22 \%$ in 1994 , a $20 \%$ relative increase. The other household types remains nearly constant around $20-22 \%$.

The car ownership of households has been approximated from two different statistical sources:

1. the private car panel (PAP) for the total households, and

2. the displacement behaviour survey (OVG) for the 1.6person households

The objective of the private car panel research (PAP) is the investigation of ownership and use of private cars and the determination of the relationship existing between ownership- and use features. The sample population is the legally recorded cars and the sample unit is the private car. The a-select (random) sample of car owners/users are asked during four sequential months to the killometrage recorded by their cars. From the difference between these kilometrages the month-kilometrage will be deduced. Each average month-kilometrage is based on \pm 1.000 observations. The data collection consists of a. person-, household- and car data and b. kilometrage The survey of displacement behaviour (OVG) investigates yearly the mobility of the Dutch population. The objective of the OVG is to describe the mobility pattern of the Dutch population. In case of displacement, information is collected about origin and destination, departure - and arrival time, the use of mode of transport and the motive of displacement. The sample population is Dutch population, sample size is \pm 10.000 and the sample unit is the household. The households are, among others, characterised by size.

\begin{tabular}{|c|c|c|c|c|c|c|c|c|c|}
\hline$T$ & 2 & 3 & 4 & 3 & 5 & 7 & \& & H & 16 \\
\hline \multicolumn{10}{|c|}{ Car Owhershlp } \\
\hline Vear & Theremek & Car Sions & Active & BSE & & & DUan-ASIT & & \\
\hline & Ist & now-1HSA & 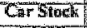 & Petmol & 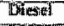 & DF & Hetrol & Desol & Lis \\
\hline & $(7000)$ & (3)odo) & 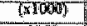 & $(\mathrm{x} / \mathrm{W})$ & (AI TOEY & TITELO; & WTED & 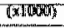 & $0 \times 10040$ \\
\hline "7974 & 37.48 & 344 & 4652 & & & & & & \\
\hline 1980 & 304 & $20 \%$ & $-1,201$ & & & & & & \\
\hline 7801 & 495 & 263 & 4314 & & & & & & \\
\hline 1082 & 405 & 232 & 450 & 39.31 & 755 & $4 \pi$ & 173 & 36 & 40 \\
\hline 90 & 46 & 242 & 4438 & 344 & 159 & 460 & 160 & 38 & 44 \\
\hline 1904 & 4352 & 26 & $4 \$ 89^{\circ}$ & 3594 & 34 & 404 & 152 & 45 & 47 \\
\hline 1985 & $\$ 301$ & 290 & 600 & 380 & 283 & 458 & 168 & 64 & 65 \\
\hline 1986 & 4216 & 366 & 460 & 3506 & 293 & 49 & 219 & 7 & 60 \\
\hline 1987 & 420 & 320 & 4759 & 3565 & 344 & 587 & 194 & \$is & 40 \\
\hline 7985 & 4518 & 405 & 4921 & 3640 & 374 & 502 & 217 & 121 & 67 \\
\hline 1989 & 4703 & 383 & $\$ 086$ & 374 & 427 & 35 & 215 & 120 & 4 \\
\hline 1990 & 445 & 542 & 9796 & 3657 & 417 & 510 & 266 & 1.64 & 112 \\
\hline 7961 & 695 & 570 & 5225 & 378 & 407 & 485 & 30 & I. & 76 \\
\hline 7902 & 46,08 & 60.1 & 5397 & 7889 & 813 & $4 f 4$ & 309 & 169 & 723 \\
\hline 1893 & 4835 & 926 & 5411 & 3989 & 419 & 425 & 399 & 170 & 69 \\
\hline 8994 & 498 & 576 & 558 & 4190 & 412 & 381 & $\not 158$ & $16 \mathrm{O}$ & $88^{\circ}$ \\
\hline
\end{tabular}

Table 6.1 Car stock by fuel type and total householl

Source PAP

Note that column 3, Table 6.1, labelled 'Car Stock non-HSH' represents the car stock owned by enterprises, central and local government (police included) 


\begin{tabular}{|c|c|c|c|c|c|c|}
\hline Car Owron & $\frac{2}{2}$ & 芶 & 4 & 3 & 6 & HSOH $C \mathrm{Er}$ \\
\hline Carowater & dip Hish & & & & & HSEM-CET \\
\hline Tear & HSH & 0-car & I- & 2 mars & $>3+4 \sqrt{n s}$ & 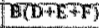 \\
\hline & $(x 1069)$ & & & & & (I) \\
\hline 1979 & 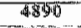 & 0.306 & 0556 & 0.12 .3 & 0.055 & 3334 \\
\hline 1980 & 5005 & 0.295 & 0.564 & 0,127 & 0.014 & 3529 \\
\hline 7981 & 5090 & 0.281 & 0.578 & 0.12 & 0.017 & जot. \\
\hline 1982 & 5194 & 0302 & $0.3 \% 6$ & Q. & 0012 & 3625 \\
\hline 1985 & 3289 & 0.298 & 0.58 & 0.168 & 0,079 & 3905 \\
\hline 1984 & 5384 & 0.905 & 0.37 & 0.168 & 0.0 .2 & 372 \\
\hline 198 & 5481 & 0.268 & 0,614 & 0.107 & 0.011 & 4012 \\
\hline 1586 & 3574 & 0.272 & 10619 & 0.098 & 0.01 & 4tos \\
\hline 1987 & 5670 & 0.260 & 0.613 & 0.112 & 0.015 & 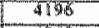 \\
\hline 7988 & 3764 & 0.263 & 0.603 & 0.120 & G.014 & 4245 \\
\hline T989 & 5860 & 0.201 & 0.606 & 0.178 & 0.015 & कीजा \\
\hline 1990 & 5955 & 0.250 & 0.613 & 0.125 & 0,012 & 4466 \\
\hline 1991 & 6079 & 0.250 & 0.675 & 0.124 & 0.017 & 3559 \\
\hline 1992 & 6198 & 0.255 & 0.003 & 0.130 & 0.012 & $46 \mathrm{TS}$ \\
\hline 1993 & 6285 & 0.240 & 0.015 & 0.134 & $3.0 \mathrm{~L}$ & का7 \\
\hline 1994 & 6371 & 0.229 & 0.612 & 0.145 & 0.01 .4 & $\$ 112$ \\
\hline
\end{tabular}

Table 6.2 Total household car oxmership

Source OVG

We will confront both approximations of the car ownership and try to explain the differences. The PAP survey records, among others, the car(s) ownership of the interviewed persons and the car(s) by fuel type (Table 6.1). The OVG survey records, among others, the private household characteristics (of which household size or n-person households is only one possible characteristic), the car ownership as "1-car', '2-cars' and 'more than 2-cars'(Table 6.2). The direct observable PAP total household car stock, labelled 'Car Stock HSH', is shown in column 2, Table 6.1, the computed OVG total household car stock, labelled 'HSH-CST' in column 7, Table 6.2, is computed as follows:

$H S H-C S T(7)=H S H(2) *(1 \operatorname{car}(4)+2 \operatorname{cars}(5)+3 \operatorname{cars}(5))$.

Note the number between parenthesis are the column numbers of Table 6.2 .

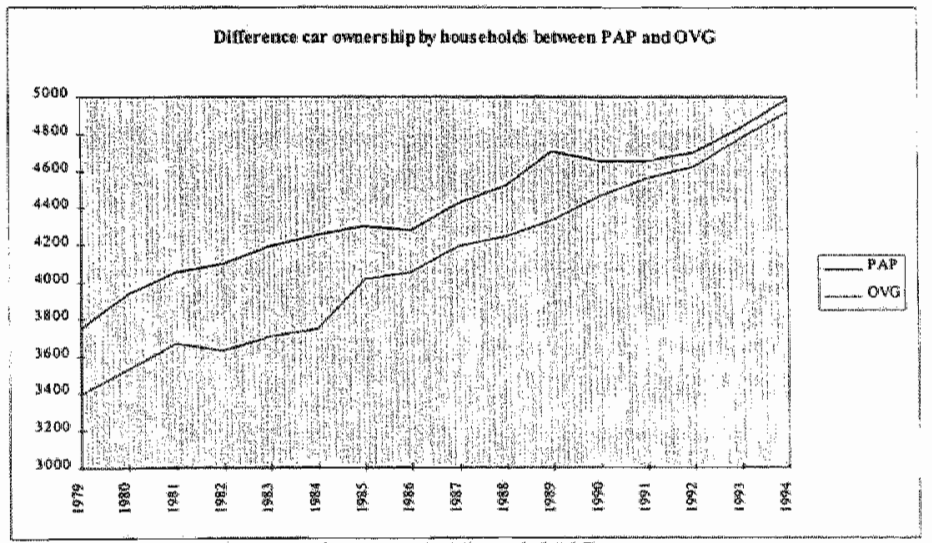

Figure 6.9 The difference between PAP and. OVG survey

Figure 6.9 shows the difference of car ownership of households between the PAP and the OVG survey. In 1990 the PAP sample design or stratification has been changed to cope with the structural changes during the $80 \mathrm{~s}$. Since 1990 the difference is close to a constant, being, among others, the institutional households, which are not in the OVG sample (only private households). The set of institutional households contain nursing and elderly homes.

In sum : From the OVG survey two statistical data types are available:

1. the total fraction car ownership of ' 1 -car', "2-cars", "more then 2 -cars",

$$
T C S T^{m} \text { for } m=1,2,3
$$

(the last row of Table 6.4 and 6.5) and the total households, $H S H$ of column 2, Table 6.2.

The total household car stock will be computed according to formula: 


$$
\left(\sum_{m=1}^{3} \mathrm{TCST}_{t}^{m}\right) \mathrm{HSH}_{\mathrm{s}} \quad \text { for } t=1979, \ldots, 1994
$$

2. the 1-6 person household, $p_{n} H S H$, fraction car ownership of "1-car", "2-cars", "more than 2-cars"

\begin{tabular}{|c|c|c|c|c|c|c|c|c|}
\hline \multicolumn{4}{|c|}{ Car Orwners Hifo of Howeholds by size: 1979 } & & & Car Stotid & Carstock & Active \\
\hline PHSTr & TST & \%甚SH & Icar & 2 cars & 32 cars & MSH & non-1:BST & Carstuck \\
\hline Imp MTR & 1042 & 0.212 & $\sqrt{248}$ & 0.0606 & 8000 & 259 & & \\
\hline $2-p H S H$ & 1470 & 0.299 & 0.570 & 0.074 & 60.000 & 947 & & \\
\hline $3 \mathrm{pHSH}$ & 771 & $0.15 \%$ & 0.631 & 0.175 & 6ीा & 6.50 & & \\
\hline 4pसSH & 1020 & 0208 & 0.688 & 0.184 & 0.022 & 912 & & \\
\hline 5-pसSH & 38 & 0079 & 6.64 & 8277 & 0.033 & 346 & & \\
\hline$>y-p$ AISI & 220 & 10.045 & 1).525 & 0.220 & 0.101 & 186 & & \\
\hline Total & बाबा & 1.000 & & & & 3279 & 773 & 4052 \\
\hline
\end{tabular}

$$
\begin{aligned}
& C S T_{n}^{m} \\
& \sum_{m=1}^{3}\left(\sum_{n=1}^{G} p H S H, \operatorname{CST}_{m n^{m}}^{m}\right) \\
& \text { for } m=1,2,3 ; n=1, \ldots, 6 \text {; } \\
& \text { sfor } t=1979, \ldots, 1994
\end{aligned}
$$

\begin{tabular}{|c|c|c|c|c|c|c|c|}
\hline \multicolumn{4}{|c|}{ 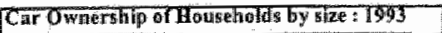 } & \multirow[b]{2}{*}{2 ents } & \multirow[b]{2}{*}{$32 \cos$} & \multirow{2}{*}{$\frac{\text { Can Stock }}{\text { HSHI }}$} & \multirow{2}{*}{$\begin{array}{l}\text { Car Stock Actule } \\
\text { non-HSH Car Stae }\end{array}$} \\
\hline PASII & MISUI & WHSE & T car & & & & \\
\hline mpHSH & 1934 & 0.368 & 0.400 & 0,000 & 0.000 & 78,5 & \\
\hline $2-p H S H$ & 195 & 0.311 & 0.699 & 0.120 & 0,000 & 1602 & \\
\hline 3-pHISH & 1018 & 0.162 & 0.613 & 0.282 & 0.025 & 916 & \\
\hline 4p/IIST & का & 0.154 & 0.639 & 0214 & 0.035 & 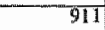 & \\
\hline Swp] & $\$ 05$ & 0.079 & 0.695 & 0.223 & 0.030 & 29.3 & 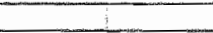 \\
\hline$>$ S-jMHSH & 92 & 0.016 & 0.673 & 0.178 & 0.077 & Q & \\
\hline Total & 6286 & 1.000 & & & & 4598 & 813 \\
\hline
\end{tabular}

\begin{tabular}{|c|c|c|c|}
\hline \multicolumn{3}{|c|}{ Hotseholds by size and car ownership } & \multirow[b]{2}{*}{$>2$ cars } \\
\hline 1980 & $1 \mathrm{car}$ & 2 cars & \\
\hline IpHSH & 26.8 & & \\
\hline $2 \mathrm{pHS}$ & 58.6 & 86 & \\
\hline 3pHSA & 63.3 & 18.7 & 1.0 \\
\hline 4pHSH & 69.4 & 17.4 & 2.0 \\
\hline SpHSH & 64.1 & 21.4 & 4.3 \\
\hline $6+\mathrm{pHSH}$ & 50.0 & 27.6 & 8.6 \\
\hline Total & 56.4 & 12.7 & 11.4 \\
\hline
\end{tabular}

Table 6.3 Car owmership of households by size 1979 and 1993

Table 6.4 and 6.5 show the penetration of the car ownership over the households by size during the 80 s and early 90 s. Only the penetration of the car ownership for the year 1980 and 1994 will be illustrated in Table 6.4 and 6.5

\begin{tabular}{|c|c|c|c|}
\hline Households by size and car ownership & \\
\hline 1994 & 1 car & 2 cars & $>2$ cars \\
\hline 1 pHSH & 41.7 & & \\
\hline $2 p H I S H$ & 68.8 & 13.3 & \\
\hline $3 p H S H$ & 60.1 & 28.0 & 2.4 \\
\hline pHISH & 68.8 & 22.0 & 3.6 \\
\hline 5pHSH & 68.6 & 21.8 & 4.5 \\
\hline $6+p H S H I$ & 63.2 & 22.7 & 7.0 \\
\hline Total & 61.2 & 14.5 & 11.4 \\
\hline
\end{tabular}

Table 6.4 Penetration of cars over the househoids by size

Table 6.5 The penetration of cars $1994(\%)$

The evolution of the car ownership during the period 1980-1994 is most impressive for the 1- and 2 . person households. Figure 1.10 illustrates the penetration of the car ownership for 1 -and 2 cars ower the $1 p H S H$ and $2 p H S H$.

Note that the 2 car serie is measured on the right vertical axis. 


\subsubsection{The futwre household car owbership}

\subsubsection{A general long term total household car ownership modiel}

One can assume that there exists a relationship between the growth of car stock, renewal of scrapping, growth of the number of households, and the growth of car ownership per household. In this section two functional relations will be calibrated expressing the above mentioned statement. At the onset the car stock has to be divided between private or household (CHSH)and non-household car stock

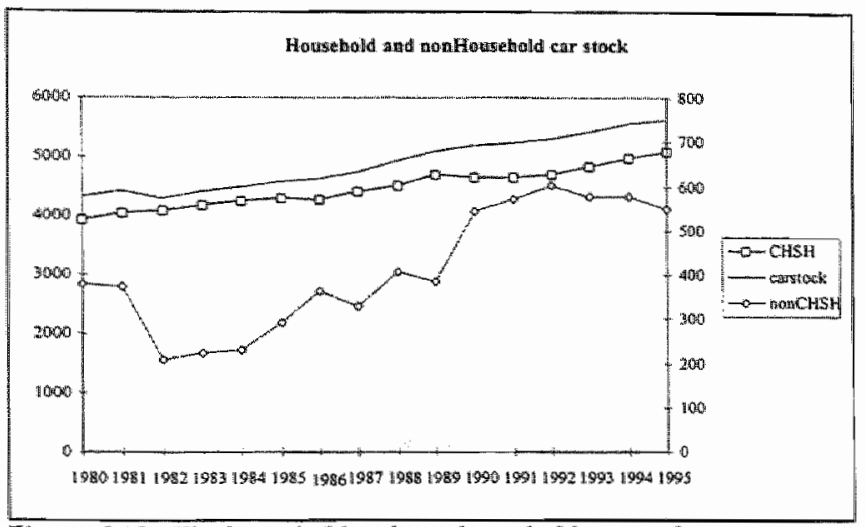

Figure 6.10 The household and mon-housenold car stock
(nonCHSH). In Figure 6.10 the non-household car stock (measured on the right axis) shows two changing patterns. In the early $80 \mathrm{~s}$ there is a sharp drop during the sewere recession of $81 / 83$ and during the end of the 80 s a sharp increase indicating the booming of the economy (recovery) and the introduction of a new ownership feature, that of leasing new cars by enterprises. In coping with these new structural features we estimate first the household car stock (ownership) and in a second round the non-household car stock vis-ä-

wis the total car stock. Two model formulations are developed for the period 1986 1995;

$$
\begin{aligned}
& C S T_{t}^{H}=C S T_{t-1}^{H}+C S_{f}^{H t}-S C R_{t} \\
& S C R_{t}=\hat{\delta} C S T_{t}^{H} \\
& C S_{t}^{H}=\hat{\alpha} S C R_{t}+\hat{\beta} H S H_{t}+\hat{\chi}\left(C S T^{H t} / H S H\right)_{t}
\end{aligned}
$$

The household car ownership, $C S T_{i}^{H}$, is the result of the accumulation of the difference between new car sales, $C S_{t}^{H}$, and the scrapping of cars, $S C R_{t}$, by households. The scrapping will be determined by the product of a decay fraction, $\delta$, and the household car stock. A fraction of the scrapping, $\alpha$, will be renewed into new car sales, moreover the growth of household car stock will be influenced by the growth of those households, expressed by the parameter $\beta$ and by the growth of the number of cars per household, expressed by the parameter $\chi$.

The estimation of the household car stock of ownership model, 6.1.4.a, takes place in $n$-steps in order to cope with overidentification problems:

1. the parameters $\beta$ and $\chi$ will be calibrated, the remaining parameters $\alpha$ and $\delta$ are prefixed at their mean values of the period $1982-1992(\alpha=0.873(\sigma=0.08) ; \delta=0.089(\alpha=0.013))$;

2. the prefixed parameters $\alpha$ and $\delta$ will be calibrated with the parameters $\beta$ and $\chi$ set at their first cycle values;

3. the parameters $\beta$ and $\chi$ will be calibrated again, the parameters $\alpha$ and $\delta$ are set their second cycle values; etc.

After a number of cycles the convergence assures us of a stable solution, which will be checked by the grid, vector and random search procedures with and without optimisation as explained in chapter 2 .

The results are:

\begin{tabular}{|c|}
\hline Box $6.1 \log$ likelihood $95 \%$ Confidence intervals \\
$0.8084 \leq \alpha=0.85 \quad \leq 0.8902$ \\
$0.0087 \leq \beta=0.011 \leq 0.0133$ \\
$0.0813 \leq \chi=0.1005 \leq 0.118$ \\
$0.0552 \leq \delta=0.075 \leq 0.0965$
\end{tabular}


initial -1.6157 to -0.67129 . Figure 6.11 shows the observed and the calibrated household car stock, the fit is quite close.

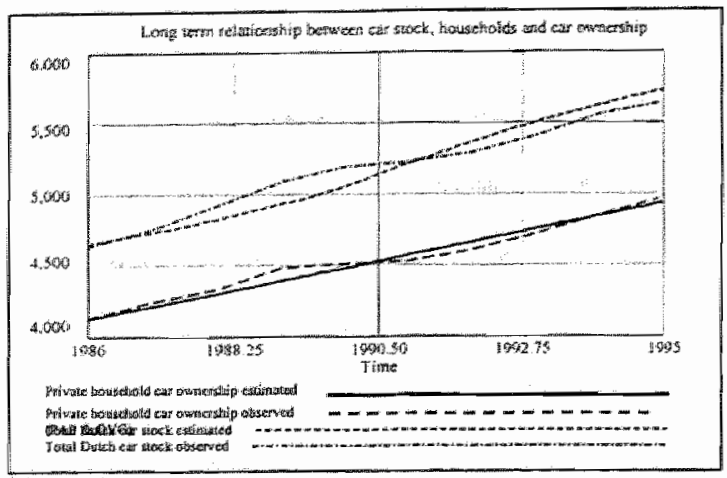

Figure 6.11

The last step is the calibration of the nonhousehold car stock according to the following formulation:

where

$$
\begin{aligned}
& \mathrm{CST}_{t}=\mathrm{CST}_{\mathrm{q}}^{H}+\mathrm{CST}_{\mathrm{r}}^{\mathrm{NHH}}
\end{aligned}
$$

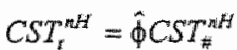

$$
\begin{aligned}
& \text { CST - estimated total car stock } \\
& \mathrm{CST}^{H} \text {-- estimated car stock } \\
& \text { households } \\
& C S T^{n H} \text { - estimated car stock mon- } \\
& \text { households }
\end{aligned}
$$

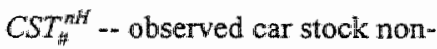

$$
\begin{aligned}
& \text { households }
\end{aligned}
$$

The estimation, with the estimated and observed total car stock in the payoff function, results in $\phi=1.456$. This long term relationship levels out the short term wings as seen in Figure 6.11

The second model formulation defined the new car sales function, CS, as being dependent of the renewal of the scrapped cars, plus a term consisting of the product of households, $H$, and car ownership per household, $C$.

$$
C S_{t}=\hat{\alpha} S C R+H^{\hat{\beta}} C^{\hat{x}}
$$

The remaining formulations remains the same. The (quasi) optimal parameter values are :

$$
\begin{aligned}
& \alpha=0.850 \\
& \beta=0.565 \\
& \chi=-0.033 \\
& \delta=0.0756
\end{aligned}
$$

The payoff is -0.71781 , and did not improve the payoff of model 6.4 .1 .a, however the difference is very small.

As the aim of this section is to detect future possible trajectories we will use the household model of chapter 3 to generate the input of future households to compute series based on the models calibrated

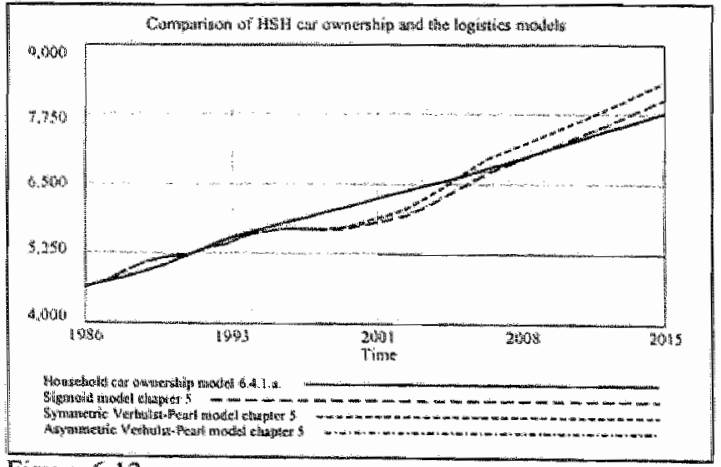

Figure 6.12 above. Moreover we assume that the average car ownership per household will be grow to 1.0 in $2010 / 15$ (was 0.87 in 1995). Figure 6.12 shows the household car ownership model 6.4.1.a. with the sigmoid, symmetric, and asymmetric Verhulst-Pearl modlels of chapter 5 . The dynamics and therefore the trajectories originates from quite different sources. The logistic models of chapter 5 are heavily influenced by the structural instabilities and jdiosyncrasies of the short term car market in the $80 \mathrm{~s}$ and $90 \mathrm{~s}$, as explained in chapter 5 . On the other hand the household formation shows long term developments which are driven primarily by the lagged population dynamics and behavioural changes as explained in chapter 2 and 3 .

In the next section we will analyse the households by size and by 1 to 3 -or-more car ownership, their dynamics will show different future trajectories. 


\subsubsection{A general llong term in-person household car ownership model}

As the future is born in the past, analysing and interpreting of (recent) past developments is of uttermost importance. Therefore trend analysis is most of the time the basis of scenario analysis. Most of the time linear trend analysis is the favourite trend method, however as will be shown linear trend analysis is valid in the asymptotic growth region only. For example, take the oar ownership of the 1. person households which exhibits in the early 80 s exponential growth characteristics. By taking a linear trend one can get into trouble as can be shown in Figure 6.13, how impressive the statistical

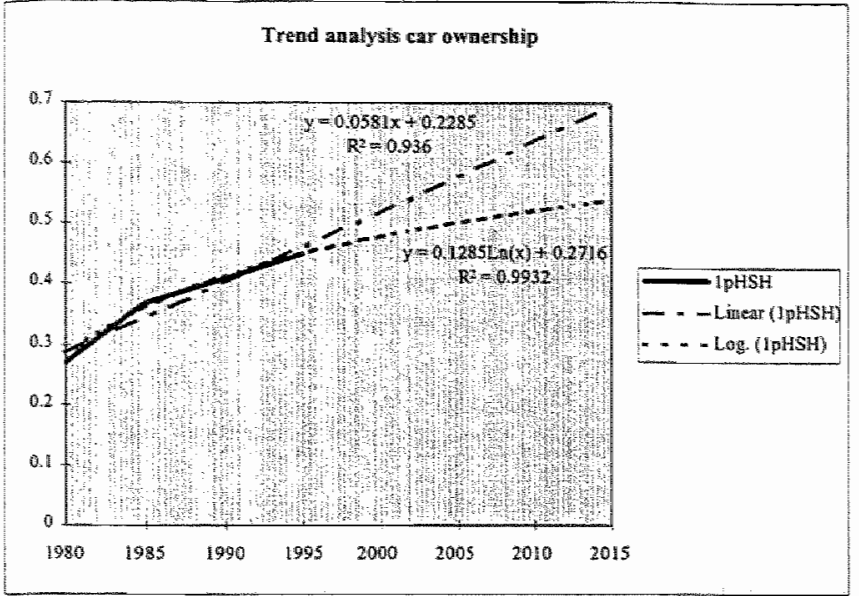

Figure 6.13 Trend analysis of car ownership IpHSH measure of goodness - of -fit may be. In our example the year 1985 or 1990 might be good candidates of initial (staring) point of time for linear trend curves.

However, one can take the linear trend curve as an upper limit case in a Monte-Carlo simulation or as the most-wnlikely figure in a triangular distribution case. On the other hand using a logarithmic trend method on get a more or less a valid description of the damped growth phase,

this is the phase from the point of inflection to the asymptotic growth phase.

It is to be expected that the car ownership of the 1-person households, lcarlpHSH (Figure 6.14), will not stop at the 1995 figure of $44.9 \%$, the same holds true for the 2-car ownership of the 2-person households, 2 car $2 p H S H$, which increases from $7.4 \%$ (1979) to $15 \%$ (1995). However the 2 -car ownership of the n-person households shows similar logarithmic trend features, except for the 2-car 2-person households, 2 car $2 p H S H$, which shows increased growth rates in the recent past. Therefore a logistic ourve (or $S$-growth curve) has been calibrated as : $y=\frac{M}{\left(1+A e^{B i}\right)}$

with $M=0.30$ (saturation level), $A=4.1634$, and $B=-0.1314$.

This means that $30 \%$ of the 2 -persons households will be the approximated penetration rates of the second car of the 2-person household, 2car2pHSH (Figure 6.14) in 2015. Note the saturation level, $M$, has been set exogeneously.

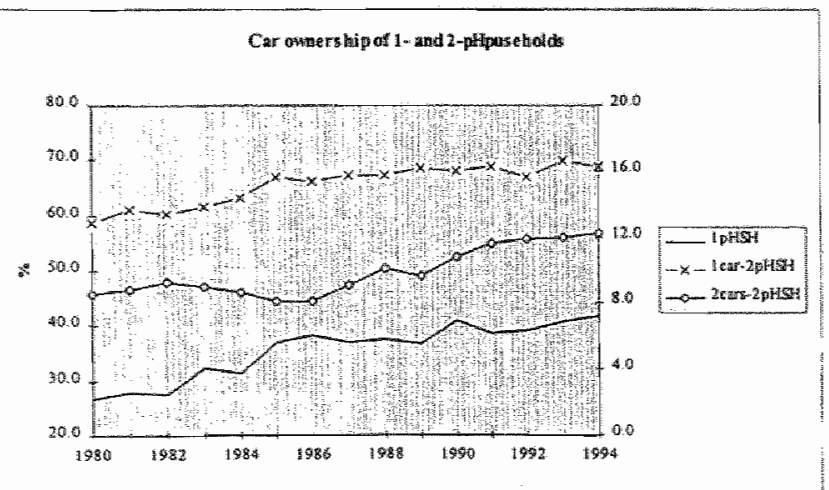

Figure 6.14 The penetration of $l$-and 2 cars over the $l$-and $2 \mathrm{pHSH}$
Examining the data of table 6.6 (next page) one can expect that the penetration of 1-car ownership over the more-person households, $>1$ pHSH, will saturate at $70 \%$. For the 2- and 3-car owmership the outcome of the future development is more uncertain. We will assume that the second car ownership of the 2-person household will increase to $30 \%$ in $2010 / 15$, for the 3 or-more-person household,

this will be also $30 \%$ in $2010 / 15$ and the 2 -or-more car ownership for the 2-or-more-person household 
Will increase to $5 \%$ in $2010 / 15$. However the strongest growth impulse will come from the guantitative devellopment of the 1 -and 2 -person households, as explained in chapter 3 .

\begin{tabular}{|c|c|c|c|c|c|c|c|}
\hline \multicolumn{8}{|c|}{ Houlseholds by size and car ownership } \\
\hline 1995 & 1 car & 2 cars & S2 ears & $2010 / 2015$ & 1 car & 2 cars & 32 cars \\
\hline IpHSH & 44.9 & & & IpHSH & 55.0 & & \\
\hline $2 \mathrm{pHsH}$ & 68.3 & 14.9 & & $2 \mathrm{pHSH}$ & 70.0 & 30.0 & \\
\hline $3 \mathrm{pHSH}$ & 60.5 & 27.9 & 2.2 & 3pHSH & 70.0 & 30.0 & 5.0 \\
\hline $4 \mathrm{pHSH}$ & 68.9 & 21.6 & 3.1 & 4pHSH & 70.0 & 30.0 & 5.0 \\
\hline SpHSH & 67.7 & 22.9 & 3.2 & SpHSH & 70.0 & 30.0 & 5.0 \\
\hline $6 \mathrm{pHSH}$ & 63.8 & 21.8 & 5.0 & 6pHSH & 70.0 & 30.0 & 5.0 \\
\hline
\end{tabular}

Table 6.6 The actual 1995 data and the assumed $2010 / 15$ data

In sum, in the simulation runs we assume that the penetration of the car in the 1 -person households follows the logarithmic trend function as described in Figure 6.13 (the 1-car ownership of the 1 person household increases to $\pm 50 \%$ in 2010 and to $\pm 55 \%$ in 2015 ). The remaining 1 -car ownership by 2- to 6-person households are also logarithmic trend functions of the type $y=A+B \operatorname{Ln}(t)$. The 2car ownership of the 2-person households follows a logistic growth process with the maximum penetration level set at $30 \%$.

\subsubsection{Comparing the car stock derived from the logistic model (chapter 4 and 5) with the car owmership of the n-person households.}

As can be seen from Figure 6.12 the total car stock arrives at $\pm 7.75 \mathrm{mln}$ in 2010 and $\pm 8.25 \mathrm{mln}$ in 2015 for the car ownership model of section 6.1 .4 . The models of chapter 5 arrives at $8.00-8.25 \mathrm{mln}$ in 2015 . Seen the different underlying dynamic processes of the logistic model and the populationhousehold model their trajectories are different, albeit approximating the upper limit of $8.5 \mathrm{~min}$ cars

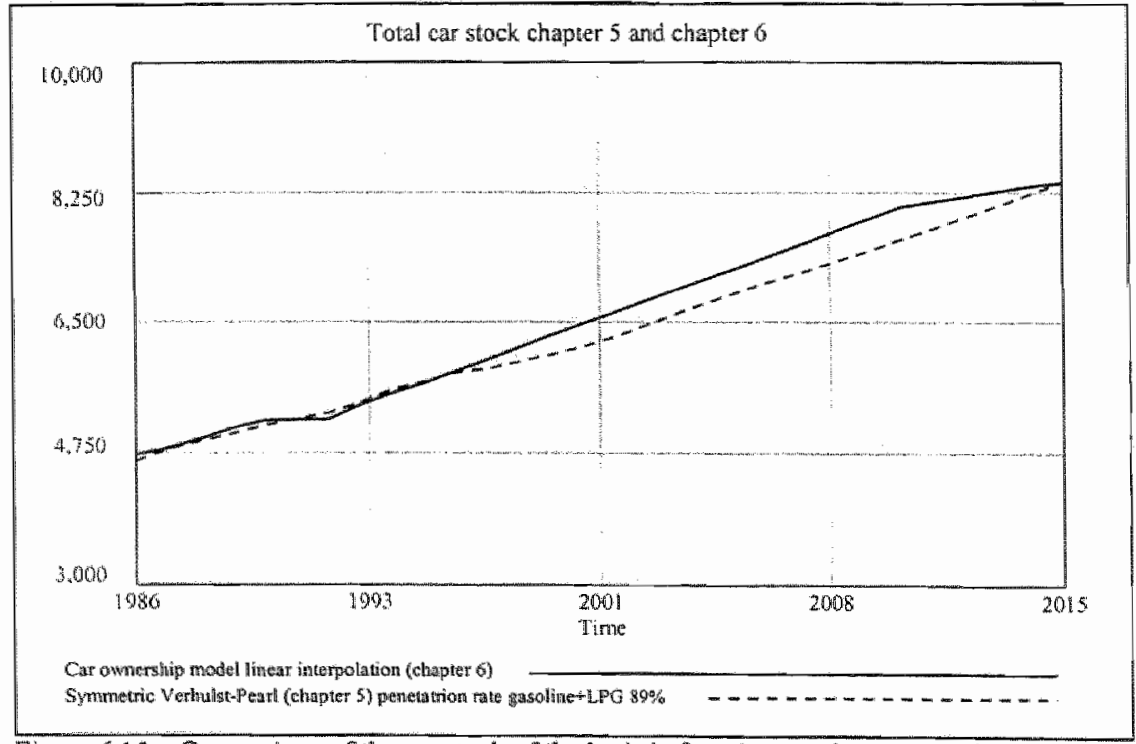

Figure 6.15 Comparison of the car stock of the logistic function - and car ownership model

in 2015. The dynamics of the population-houselyolds model has been dealt with in chapter 2 and 3 , the dynamics of the logistic model in chapter 5 . However it is interesting to notice the difference between the trajectories of the total household model car ownership and the 1-to 6-person household by 1 - to 3-or-more car owmership. This is due to the aggregation in the total household model which has a smoothing effect on its dynamic interaction, as in the n-person household model the development of the 1- and 2-person households and their assumed saturation levels of car ownership are decisive (see 
Figure 6.16). The growing influence comes from the 1- and 2-person households and the 1 - and 2 car ownership similar relative growth paths, as can be seen in Figure 6.17.

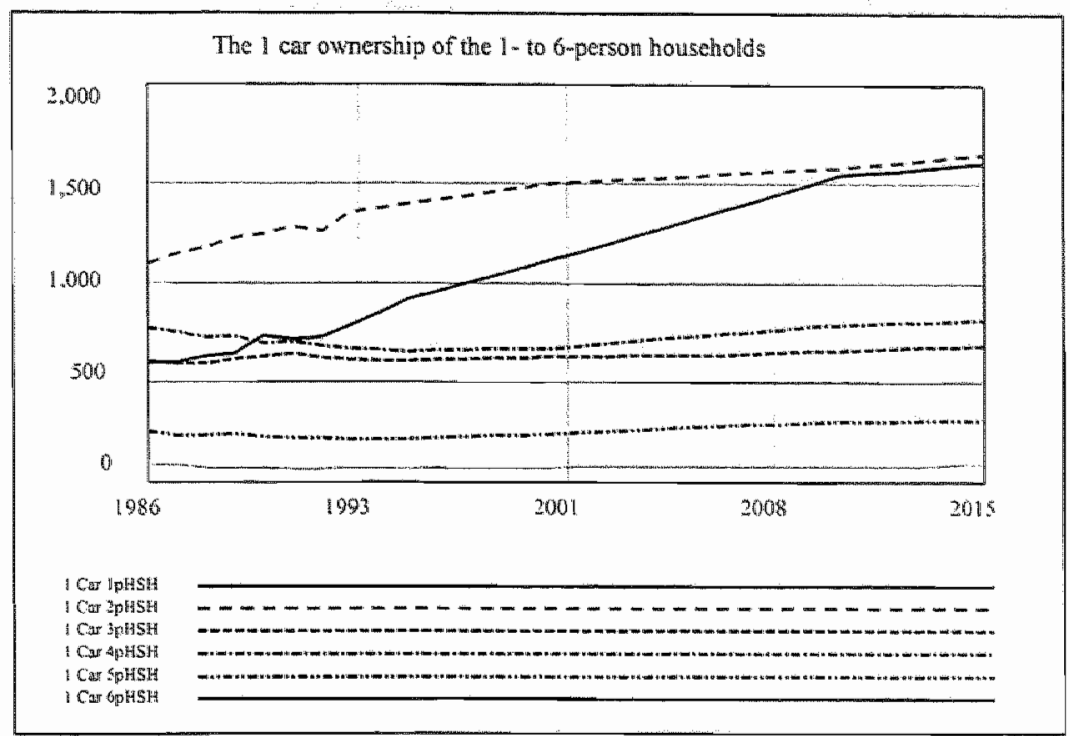

Figure 6.16 The 1 car ownership by 1- to 6-person households

We will interpret the car ownership figures as upper limits and the asymmetric Verhulst-Pearl as under limits in the Monte-Carlo simulation of the next section.

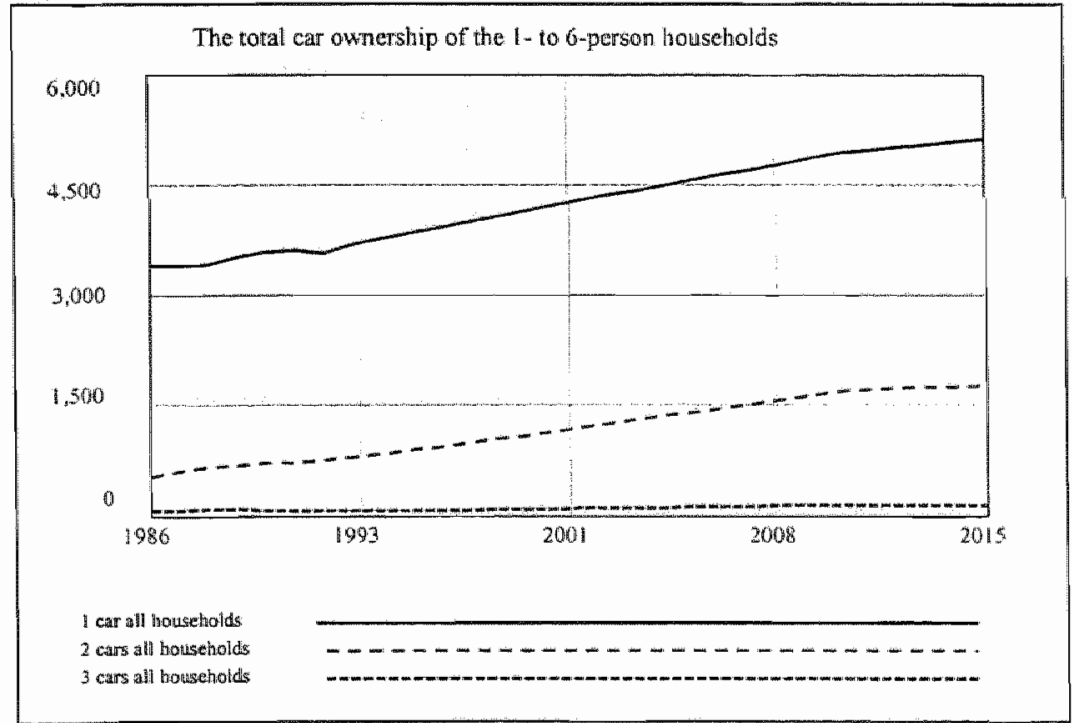

Figure 6.17 The 1- to $>2$ car ownership by all households 


\subsubsection{Sensitivity analysis (Monte-Carlo)}

In order to cope with uncertainty and to test the robustress of the households car ownership model 6.1.4.a, sensitivity simulations were performed under the following conditions : the parameters distributing the $m$-car $(s)$ over $n$-pHSH for $m=1,2,3$ and $n=1, \ldots, 6$ has been allowed to vary $\pm 10 \%$.

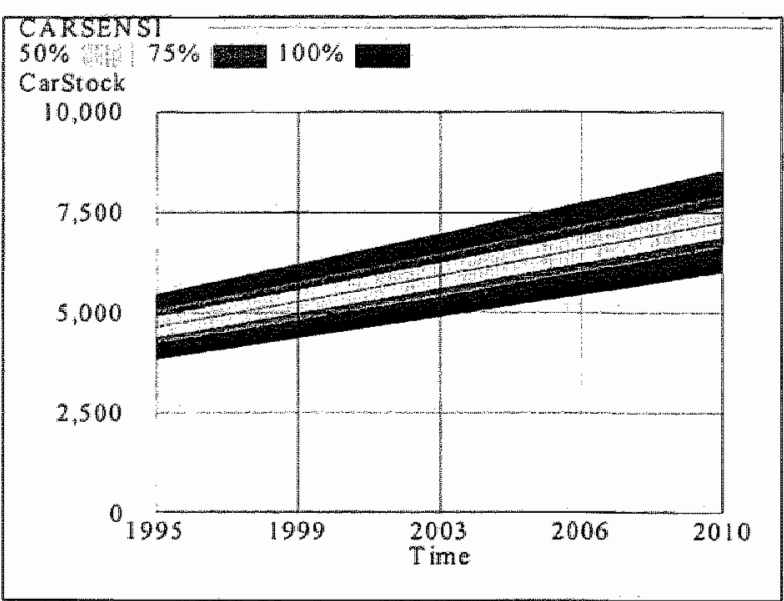

Figure 6.18 The multivariate sensifivity simulation The generation of the random series are controlled by a uniform random distribution. Two sensitivity simulations were performed under the following methods:

1. Multivariate method, this means all parameters are changed together, in a simultaneously way;

2. Latin hypercube method. The number of simulations was set at 1500 . Figure 6.18 and 6.19 shows the uncertainty in the total Dutch car stock as it changes over time.

At any time, half of the simulations have generated a value within the $50 \%$ region (7.35-7.5 mln), three quarters within the $75 \%$ region $(7.2-8.2 \mathrm{mln})$ and all simulations within the $100 \%$

region or band.

Figure 6.118 shows the sensitivity results when the multivariate method has been applied, Figure 6.19 shows the same results when the Latin. hypercube method has been applied. There is a negligible difference between the results of both methods as the $50 \%$ and $75 \%$ ranges are somewhat smaller in the Latin Hyper cube case.

Three remarks can be made about Figures 6.18-19. First the uncertainty grows over time, which is a plausible result of the accumulated nature of households and car stock. Secondly, the percentiles as shown in Figure 6.20 are not evenly spaced, even

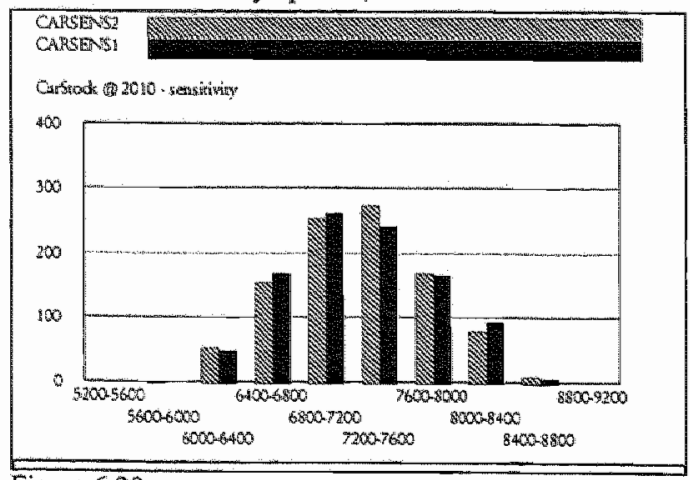

Figure 6.20

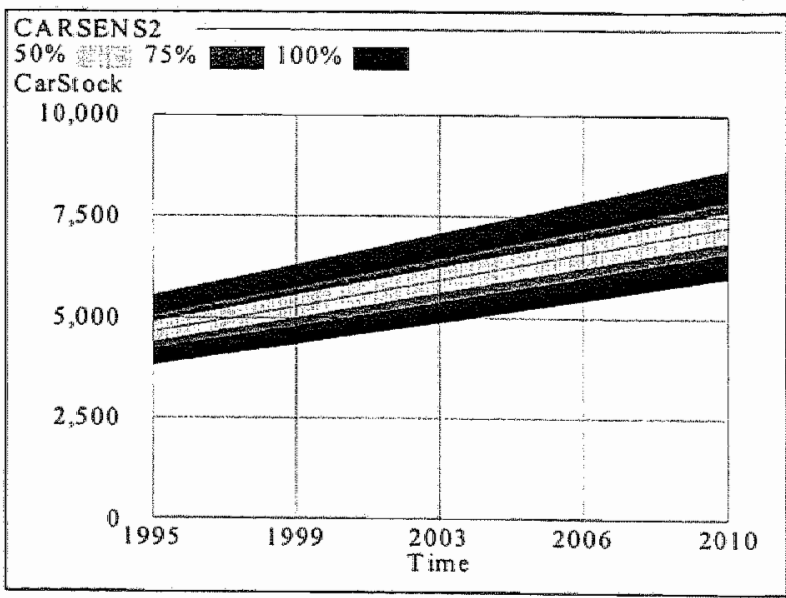

Figure 6.19 The latin hypercube sensitivity simulation though we have applied a unform (flat) distribution of uncertainty inputs. The graph of Figure 6.20 indicates that both series are distributed in a bell shaped curve. This is because a number of different independent sources of error are combined together in the model. A well known result from statistics is that combining different independent error sources tends to lead to variables which are normally distributed. Thirdly, the differences between the two methods are negligible, as can also be illustrated by Figure 6.20 where both methods are compared by a histogram. 


\subsection{Households and car use}

From the consumer time budget surveys of chapter 3 the social cultural causes of the mobility changes during the 80 s were explained. Now we start from the person households, pHSH, and look after their car use by motive. The statistical source supplying these figures is the survey of the mobility behaviour of the Dutch population (OGV) available from 1979-1995. Figure 6.21 shows the development during the 80 s and early 90 s of distance travelled by car driwer by motive (subset only). The distance is measured as average $\mathrm{km}$ per person per day. Note that the Total distance travelled is measured on the left vertical axis. All motives (exept visiting family/friends) show an increase. The

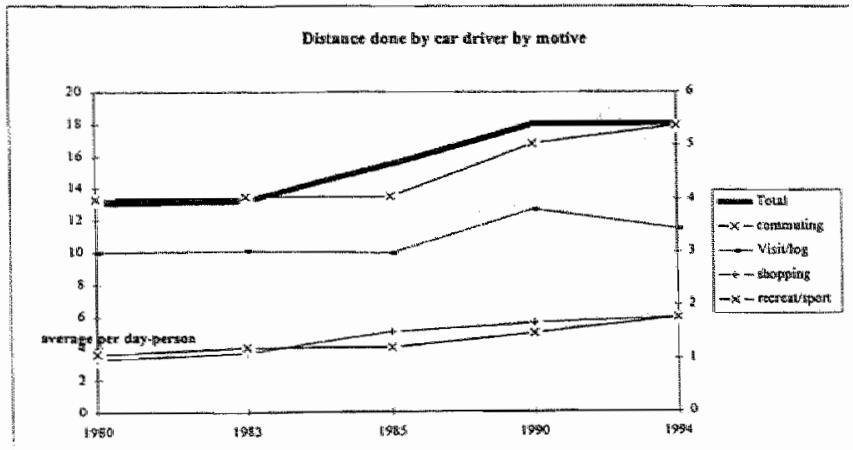

Figure 6.21 Distance travelled by car driver by motives small decrease in 1994 can be due to random error, within the confidence bounds). By multiplying the figures with total Dutch population and 365 days one arrives at the yearly total vehicle-km. The vehicle-km times the awerage occupation tate per vehic equals the traveller-km. As we are using the pHSH as unit of analysis we will look after figures which

distributes the distance travelled by car driver by motive.

The motive for car use are classified as: 1. Commuting; 2. Business wisit; 3. Family visit; 4. Shopping; 5. Education; 6. Trip; 7. Recreation/sport; 8. Rest

Tables 6.7-6.9 give for the years 1985,1989 and 1992 the car use measured in average $\mathrm{km}$ per personday by 1 - to 6-person household by motive. A pictorial representation of these data are shown in. Figures 6.22-6.24. These data forms the basis to link the n-person household(s) to the total vehicle kilometrage using equation $(6.3 .1)$ of the next section.

\begin{tabular}{|c|c|c|c|c|c|c|c|c|c|c|c|}
\hline \multicolumn{12}{|c|}{ 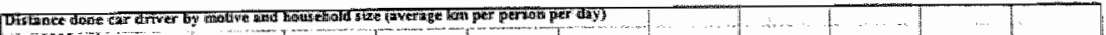 } \\
\hline year $39: 8.5$ & $\begin{array}{c}\text { Conmonto } \\
\text { grize. }\end{array}$ & "Evisinies: & $\begin{array}{l}\text { Fiminily } \\
\text { Vligid }\end{array}$ & StEoptal & Edinceatina & Tripip & $\begin{array}{c}\text { Rocrestion } \\
\text { Spiouint }\end{array}$ & Fkesit & Tritis: & $\begin{array}{c}\text { Tot HSH } \\
(x 1000)\end{array}$ & $\begin{array}{l}\text { Tutsil Kimi } \\
(11080)\end{array}$ \\
\hline Tocall" & 4,05 & $1.94^{-1}$ & 2.98 & “1.71 & 0.98 & $0 . \$ 7^{\circ}$ & $-1+23$ & 132 & 14,59 & 5475 & $743: 43$ \\
\hline 1).yPH & 2.45 & $1.5 i$ & $3: 63$ & 189 & 079 & 0.43 & 0.95 & 1.30 & 10.00 & : 45,5 & 6927 \\
\hline sipuntist & 05 & 20 a & 375 & 191 & $a x$ & 0.65 & 10 & 1.86 & 9565 & $36: 5$ & 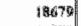 \\
\hline JW-HSH & 4.76 & 1. .94 & 270 & 1272 & 010 & 072 & 1.15 & 175 & 眖: 6 & 850 & $607 x$ \\
\hline H FW FST & 23 & 213 & 2,49 & 155 & 0.40 & 0.50 & 180 & 1.20 & H. $60:$ & $10 \leq 6$ & 2218 \\
\hline Sow & 3.45 & 2,25 & 2300 & 1,45 & 62 & 0.47 & 1.06 & 1.283 & d $32 n$ & 360 & : \\
\hline ISp HISET & 443 & 203 & 1.44 & 132 & 020 & 156 & tas 4 & $\$ .95$ & $j+4,1+1$ & 100 & 4ny \\
\hline
\end{tabular}

Table 6.7 The distance travelled observed as average km per person per day 1985

\begin{tabular}{|c|c|c|c|c|c|c|c|c|c|c|c|}
\hline \multicolumn{12}{|c|}{ 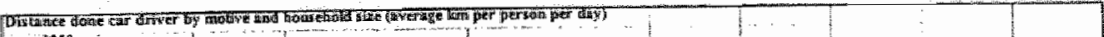 } \\
\hline 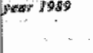 & Cominit & 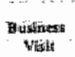 & Familat & 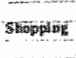 & - Eusuritutin- & Trip & $\begin{array}{c}\text { hecreation } \\
\text { Spart }\end{array}$ & Pitit & Thioxil & 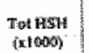 & 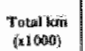 \\
\hline Tetal & 5.14 & 221 & 343 & 90 & 0.43 & 0.55 & 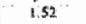 & 167 & $1, \gamma, 4,5$ & $50 \xi \xi$ & s0dila \\
\hline I mpiASHE & 3.12 & 1.79 & 3.90 & $1988^{\circ}$ & 0.14 & $0.2 \mathrm{a}$ & $11.20^{-}$ & 1.56 & -19.37 & \pm 450 & and \\
\hline 2PHSH & 89 & 1. & 4. 2. & 2.27 & 085 & $6.78^{-}$ & 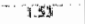 & 2.7 & thats & $18 \% 9$ & $24 \times 5.5$ \\
\hline ]phast & 6.57 & 217 & 3.49 & $T, 65$ & $039^{-}$ & 0,4 & 1.25 & 1.94 & 18.6\% & 890 & 40 \\
\hline 4 MFESAI & 5.5 & 2.63 & 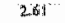 & 1.54 & 6.68 & -0.46 & (.63 & $182^{\circ}$ & 1600 & 1025 & 2509 \\
\hline Sp- & 5.4 ? & 256 & 2 . & 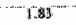 & 1,57 & 10.56 & 66 & 240 & 18.40 & 3440 & $1110 \%$ \\
\hline betas & 364 & 3,02 & $26 \%$ & 164 & 450 & 0.48 & 0.81 & 1. $9 y$ & 14.1 & 40 & 3405 \\
\hline
\end{tabular}

Table 6.8 The distance travelled observed as average km per person per day 1989

\begin{tabular}{|c|c|c|c|c|c|c|c|c|c|c|c|}
\hline \multicolumn{12}{|c|}{ 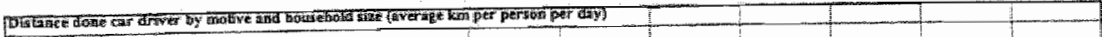 } \\
\hline pos J 32 & Ceringinit- & Wustintis & Fiaming & \$tiphopiag: & dacklom & Trip & Plencratitions & 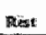 & Todal & "Tat HSI & 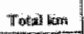 \\
\hline & "ring & VERT: & Fintit & & & & mast & & & [E] & 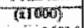 \\
\hline Toual & $\$ 3$ & 2.85 & 3.64 & 1.76 & it.24 & 0,37 & 149 & 2.17 & 17.9195 & 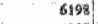 & 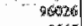 \\
\hline 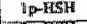 & 20 & 1.76 & 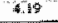 & 1,220 & a & $0,4 y$ & 1.34 & $\$ 268$ & iji, & 1804 & 9867 \\
\hline (3p-15sh & $3,1,6$ & 3000 & 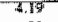 & 20 & 75290 & -0.18 & Ted & $2 \times 3$ & 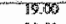 & og: & 76468 \\
\hline 3,p-EISH & 6.6̈ & 3.40 & 4.39 & $1 \pi$ & ay & 0.57 & $1.5 \%$ & 2.25 & 20.62 & 16013 & 20094 \\
\hline $4 \mathrm{p}$ FSH & 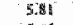 & 3.14 & 3.6 & Tits & 521 & 0.26 & 134 & $20 \%$ & 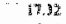 & $9 y_{6} 7$ & 24958 \\
\hline SPMETH & 5. & 218 & 2.42 & $14 \%$ & 0.17 & 0.318 & 1.22 & 2118 & 35.49 & 3.15 & 8.0005 \\
\hline Gowners & 3,36 & 236 & $2 . \mathrm{mil}$ & Tा10 & 0.78 & 635 & 757 & 228 & 15.35 & 55 & $5 \%$ \\
\hline
\end{tabular}

Table 6.9 The distance travelled observed as average $\mathrm{km}$ per person per day 1992 
As can be seen in Figure 6.24 the (average) total kilometrage per person-day increased in the midst of the 80 s to change again during the period $1989 / 90$ to a lower growth pattern. By decomposing the total figure into the underlying motiwe commuting and to a lesser extent shopping and recreation/sport are the dominant factors influencing the growth of mobility in the $80 \mathrm{~s}$.

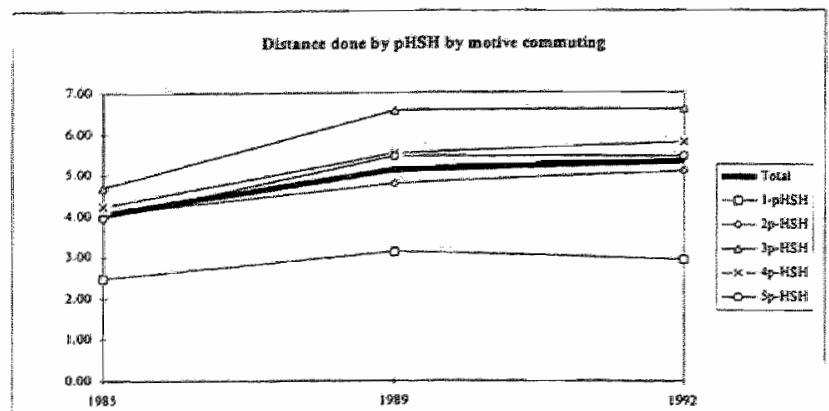

Figure 6.22 The car kilometrage per person-day by commuting motive
Looking at the person household level as reproduced in the Figures $6.22-6.24$ the commuting motive of car use increases for all person households, with the 1-person. household, $1 \mathrm{pHSH}$, as an exception (Figure 6.22). The reason will be the introduction of free public transport permits for the students in 1989 , as the student population forms an important subset of the IPHSH.

The recreation/sport activities (Figure 6.23) show a strong increase in the smaller households, 1-to3person household $(1-3 p H S H)$, and a levelling off for the 3-or-moreperson households. It is possible that the penetration of the increased recreation/sport popularity in the $80 \mathrm{~s}$ starts with the small person households, $1-3 p H S H$, and that the penetration over the 3-or-more households has been started in the 90 s. However, for the time being, it will be inconclusive if there is a

Total wehicle-kme by pHSH

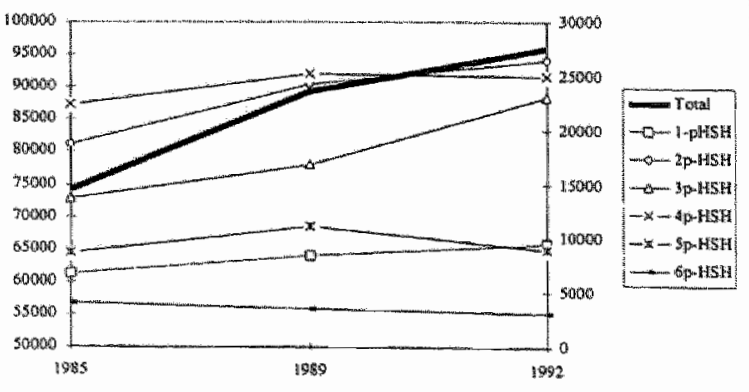

Figure 6.24 The total average car kilometrage $(\times 1000)$ per person-dlay by n-person households

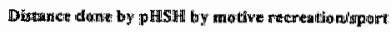

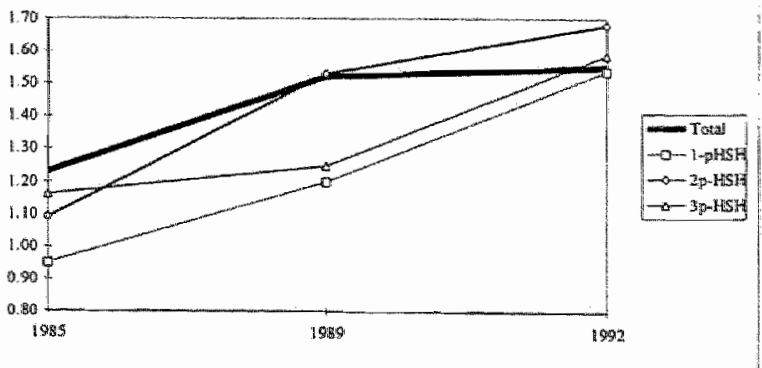

Figure 6.23 The car kilometrage per person-day recreation/sport motive convergence of the n-person households towards a single average figure or that the 1 - and 2 person households diverge from the remaining households.

Examining the total vehicle kilometres by 1 - to 6-person households (Figure 6.24) one sees a strong growth of the total. kilometrage of all households. By decomposing this figure into the separate households, on can conclude that the smaller person households, 1 - to 3 -person households, take the greatest part to their account. The automobilism did increase most with these categories.

The levelling out of the total vehicle kilometers came from the 4 - to 6 person households. 


\subsubsection{The estimation simulation results}

The yearly total average household vehicle-km has been computed applying formula (6.3.1)

$$
\begin{aligned}
& \text { whonHSH } H_{n}=\widetilde{D}_{n} * Y * n * \sum_{m=1}^{5} n H S H \\
& \text { TvknHSH }=\sum_{n=1}^{6} \text { vehkmHSH } H_{n}
\end{aligned}
$$

where

$$
\begin{aligned}
\text { vkmpHSH } & : \text { vehicle-km n-person household } \\
\widetilde{D}_{n} & : \text { average distance travelled per person per day } \\
\gamma & : 365 \text { days } \\
\text { TwknHSH } & : \text { total vehicle-km all households }
\end{aligned}
$$

\begin{tabular}{|c|c|c|c|c|c|}
\hline 1992 & total & & mo.HSH & sett-km/yr & carrection \\
\hline 1-pHSH & 43.89 & 365 & 1887 & 9566807 & $9 \%$ \\
\hline 2-pHSH & 19,00 & 2 & 1904 & 2640480 & \\
\hline 3-pHSH & $20.82:$ & 3 & 1013 & 23094274 & \\
\hline 4 pHSH & 17,32 & 4 & 987 & 24958466 & \\
\hline 5pHSH & 15.49 & 5 & $\$ 15$ & 8904817 & \\
\hline 6-pHSH & 15.36 & 6 & 92 & 3094733 & \\
\hline & & & & 96027573 & 893.4365 .7 \\
\hline
\end{tabular}

The simulation of the total vehicle $\mathrm{km}$ applies equation (6.3.1) with the 1 -to 6-person households as input from the $p H S H$-model, while the total vehicle $\mathrm{km}$ from the PAP act as benchmark. Table 6.10 give an example of the computation sequence for the year 1992, see also Table 6.9.

Table 6.10 An example of the computation sequence of equation (6.3.1)

summing to the total vehicle kilometer of 96 billion veh-km.

The number of 1 . 6 HHSH (column 5 $(\mathrm{x} 1000))$ are multiplied by total average $\mathrm{km}$ per person per day (column 2) times 1-6 person(s) (column 4) times 365 (days),

Note that the OVG-survey data claim to record an overestimation of $\pm 8 \%$ as people overestimate their real kilometrage. After the correction of $8 \%$ this figure is reduced to 88 billion. The observed vehicle $\mathrm{km}$ of the $P A P$ amounts to 87 billion. After estimating the $O V G$-based simulation with the $P A P$ data as benchmark the optimal correction was 0.914 , e.g. a correction factor of $8.6 \%$.

Figure 6.25 illustrates the fit of the simulated and the observed PAP vehicle killometer data. Note that the number of households in the mid 80 s are less reliable (not measured) than the $H S H$ data from 1990 on, this might explain the gap between the simulated data and the observed PAP data. The CBS started in 1992 with formal modelling and forecasting the households by many characteristics. See also the remarks with Figure 6.9 in section 6.1.3.

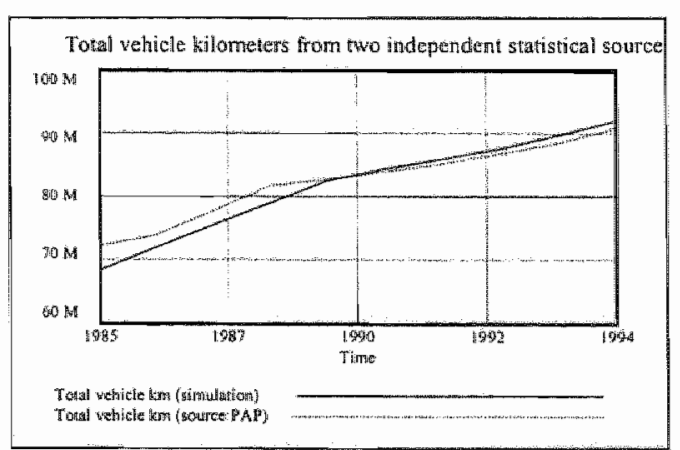

Figure 6.25 The simulated - and observed total vehicle kilometers

As we will desaggregate the total vehicle $\mathrm{km}$ per person per day by motive, as shown in the Tables 6.7-6.9 we will simulate from the 8 motive data as basis and summing to the desired total vehicle kilometers, using equation (6.3.1). On the basis of expectations of the development of the 8 mobility motives plus the expected development of the number of n-person households in the future we arrive to the expected total kilometrage of the Dutch households. 


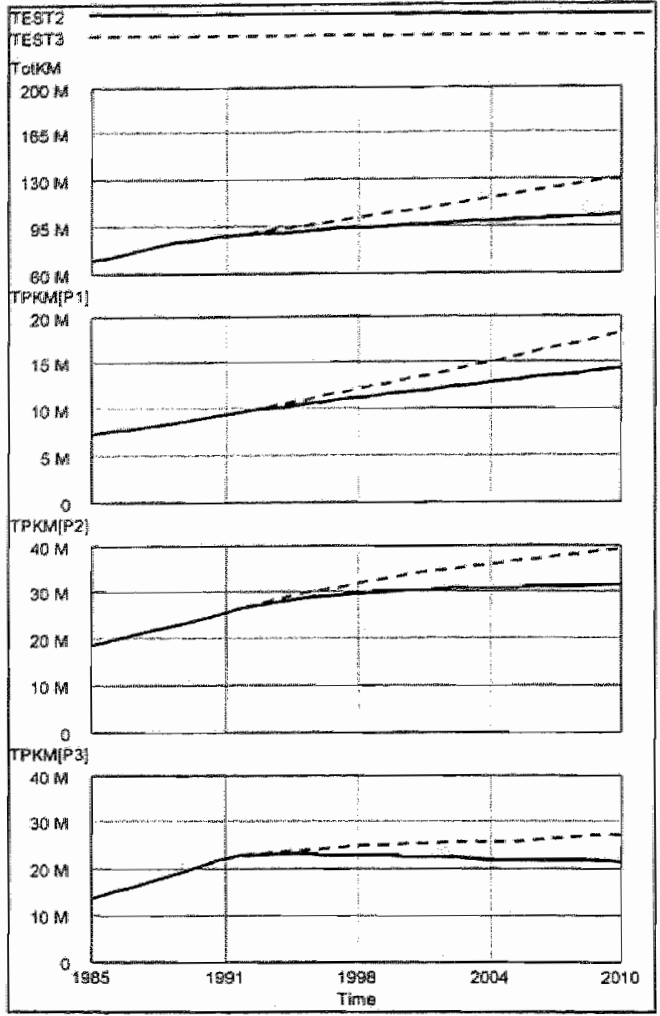

Figure 6.26 Two test runs of total veh-km (x 1000) (Tothon) a. with no changes in mobility from 1992 on (nn Test2), b. with $25 \%$ increase of the mobility to 2010 (Test3)

Looking to the second case the $25 \%$ change of the mobility motives from 1992 to 2010 , the increase is recorded as 69 billion (1985), 88 billion (1992) to 130 billion veh- $\mathrm{km}$ in 2010 . The percentage changes are : $88 \%$ base year 1985 or $48 \%$ base year 1992 . Figure 6.27 (upper plot) shows the perunages $(\triangle \mathrm{Y} / \mathrm{Y})$ of both test runs. The $88 \%$ increase in 2010 is 1.88 in perunage expression. The lower plot shows the nominal value trajectories of both cases. Taking 1992 as base year and examinating the figures then one can distinguish two effects :

Total effect $=1^{\text {th }}$ order effect $+2^{\text {nd }}$ order effect;

1. first order effect: $(H S H+\triangle H S H)$ and $(M O B+\triangle M O B)$, and

2. second onder effect : $\triangle^{2}(H S H \cdot M O B)$ Now looking to the total veh-km the following conclusions can be stated (1992 as basis): The order effect: $(H S H+\triangle H S H)$ and $M O B$ accounts for $+17 \%$ increase (with $\triangle M O B=0$ ),
Figure 6.26 shows the output plots of the total vehicle kilometers under two assumptions :

1. a simulation run under the assumption of no change of the 8 mobility motives since 1992 (Test2), and

2. a simulation run under the assumption of an increase of $25 \%$ from 1993 to 2010 of the 8 mobility motives (Test 3 )

Ad. 1 depicted by Test2-run shows the change of total yearly vehicle kilometres (veh-km) and idem the veh-km of the $1-$ to 3 person households caused by changes of the volume of households only.

Ad. 2. depicted by Test3-run shows the changes of total veh-km under the assumption of a $25 \%$ increase of the Dutch mobility from 1992 to 2010 , as expected by some experts $(R A I, 1993)$ plus the effect of the wollume increase of the n-person households.

Looking at case 1 , the no change case, then the total wehicle kilometers of the Dutch households (HSH) increases from 69 billion (1985), 88 billion (1992) to 103 billion veh$\mathrm{km}$ in 2010 . This is an increase of $50 \%$ base year 1985 or $17 \%$ base year 1992 anly due to an increase in the volume of the n-person households with the future mobility equal to those observed in 1992.

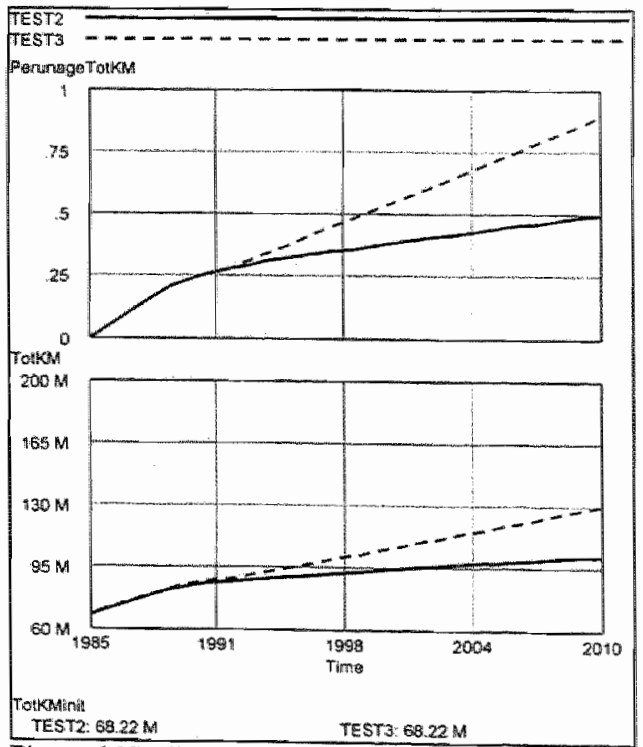

Figure 6.27 The perunage - and nominal volume total weln-km $\left(x_{1000}\right)$ 
the assumed increase in mobility was $+25 \%$, the total effect was $+48 \%$, therefore, the interaction between growth of HSH and MOB ( $2{ }^{\text {mb }}$ order effect) accounts to $+6 \%$. Till now only the total veh- $\mathrm{km}$ came into picture, however looking the 1-to 6-person households the view is quite different, we will Illustrate this by showing the nominal volume plot (Figure 6.28) and perunage plot (Figure 6.29). Note the legenda shows the computer program variables which are to be read as follows:

TPKM[P1] : Total veh-km $l p H S H$, etc.

Test 2: test run with expected development of the $1-6 p H S H$ only $(\triangle M O B=0)$

Test3: test num with expected development of the $1-6 p H S H$ and $\triangle M O B=25 \%$

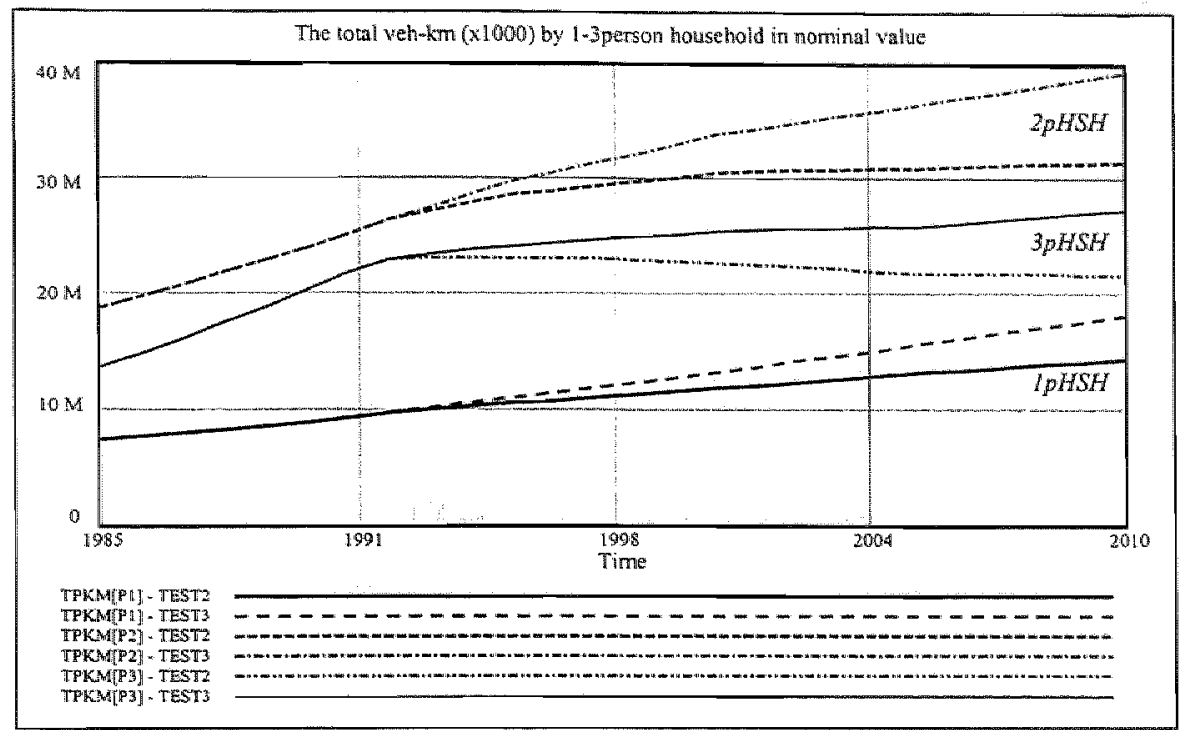

Figure 6.28 The nominal volume evolution of veh-km by 1- to 3-pHSH 1985-2010

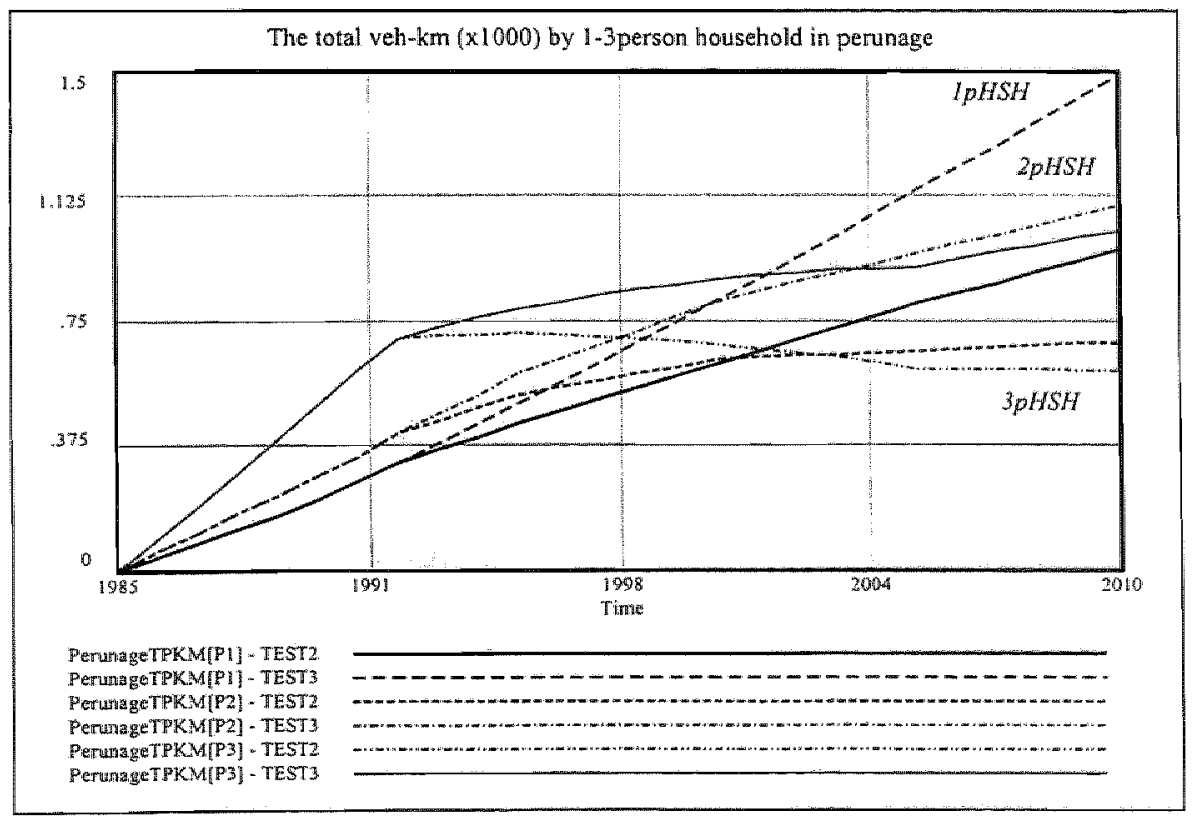

Figure 6.29 The perunages of the weh-km by 1- to 3-pHSH 1985-2010 
From Figure 6.28 one can conclude, given the assumptions mentioned above, that the relative strongest increase comes from the 1-person households veh-km which is expected to grow from 7 billion (1985) to 18 billion ( 2010$)$ veh- $\mathrm{km}$, an increase of $150 \%$. This is the result of the combined effect of wolume growth of the 1 -person household and the $25 \%$ increase of the mobility. The 2person and 3-person households increases from 18.5 and 13.5 billion (1985) to 39 reps. 27 billion (2010) nearly an increase of $100 \%$ both. Note the expected development of the 1 - to 6-person households, 1-6pHSH, (Figure 6.29), as explained in chapter 3. Its clear that the growth path of the 1person household, IpHSH, is a stretched one, with the point of inflection in the years 1992-94, but with a relative maximum after 2020 . However, the 2-person household, $2 p H S H$, is expected to reach the relative maximum around the year 2000. The remaining 3- to 6-person households stabilise (some modest in-or decrease) to the 1994 figures.

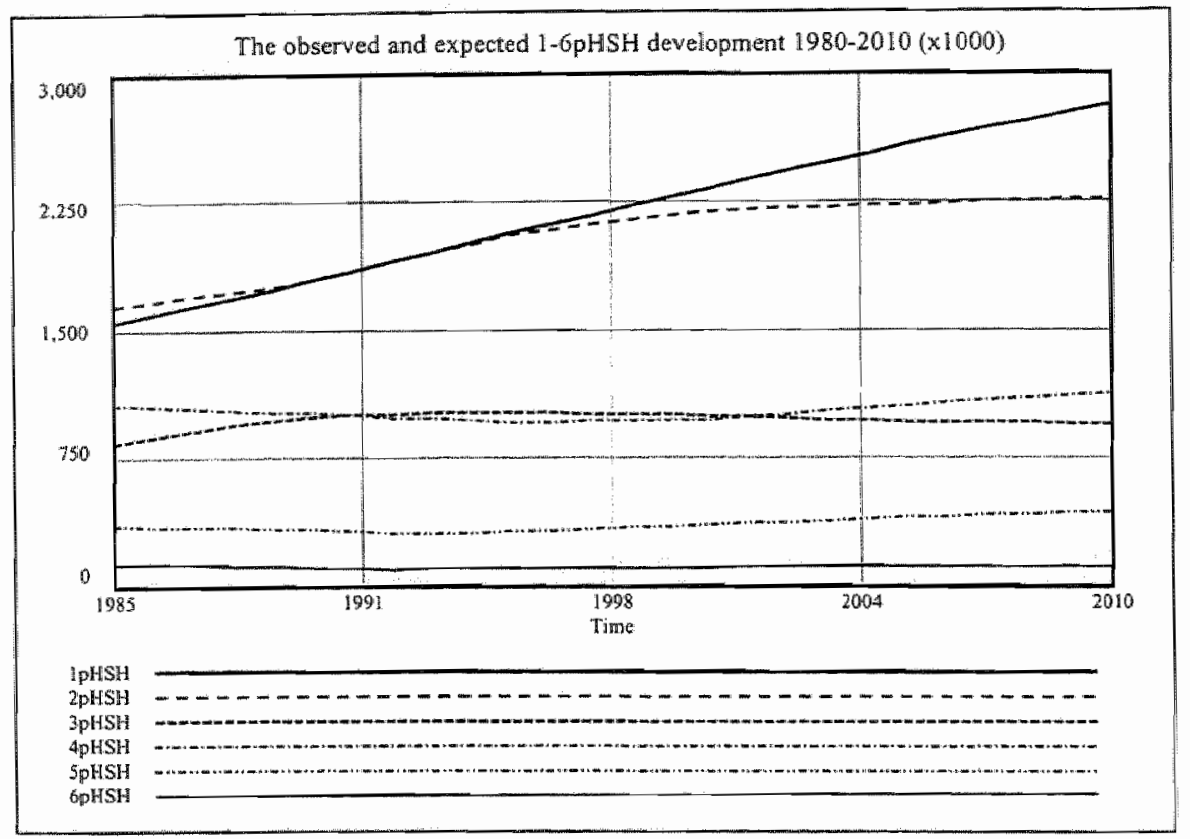

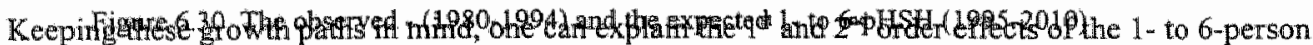
household 1 weh-km with 1992 as base year. Table 6.10 gives an overview of the $1^{\text {st }}$ order, $2^{\text {ad }}$ order and total order effect. The volume expansion of the 1-person household is decisive for the total effect, this is less for the 2-person household which reach saturation around 2000. For the 3-person household the situation is opposite, there is to be expected a small decrease in volume with regard to 1992. The number of 4-person household again is to be expected to increase slight, as will be the case for the 6mperson household.

\begin{tabular}{|c|c|c|c|c|c|c|}
\hline \multicolumn{6}{|c|}{ 1-6person Houlsetholds vehiclo kilometers $(x$ min $)$} & \multirow[b]{2}{*}{ total effect } \\
\hline & & & 1-order effer & & 2=0nder effect & \\
\hline & 1992 & 2010 & Wol. $\mathrm{PSH}$ & vol. MOB & & \\
\hline MpKSH & 9.6 & 18 & $45 \%$ & $25 \%$ & $28 \%$ & $88 \%$ \\
\hline $2 p H S H$ & 26.4 & 391 & $19 \%$ & $25 \%$ & $4 \%$ & $48 \%$ \\
\hline JpHSH & 23 & 27.2 & $-6 \%$ & $25 \%$ & $-0.01 \%$ & $19 \%$ \\
\hline dpHSH & 24.7 & 35.6 & $14 \%$ & $25 \%$ & $5 \%$ & $44 \%$ \\
\hline SpHSh & 8.8 & 16 & $38 \%$ & $25 \%$ & $19 \%$ & $82 \%$ \\
\hline 6pHSH & 3 & 5 & 296 & $25 \%$ & $19 \%$ & $67 \%$ \\
\hline
\end{tabular}

Table 6.11 The total veh-km (billion) of 1-to 6-pirSH divided up by 1-order and 2-order effust 


\subsubsection{Sensitivity analysis (Monte Carlo)}

So far we treated the parameters as known and certain, however to examine the sensitivity of the 1 - to 6-person households veh-km and the total veh-km output upon changing parameters we performed a number of sensitvity test runs. The 1-6pHSH (6 variables) and the car use by motive ( 8 variables) are allowed to vary $+10 \%$ and $-10 \%$ during 1500 nus. The numbers are random drawn from an uniform distribution. The results are displayed in two ways: 1 . by graphical time plot with three confidence bounds included the mean value, and 2 . by a histogram plot. Figure 6.31 shows the graph with the uncertainty in total veh-km, TotKM, as it changes over time. Half of the simulations $(500)$ have generated a value within the $50 \%$ region, white band, around the mean value of \pm 130 billion velb-km, with $50 \%$ upper boud of \pm 135 billion veh- $\mathrm{km}$ and $50 \%$ lower bound of \pm 125 billion weh-km. Three quarters of the simulations $(750)$ have generated a value within the $75 \%$ region, gray shaded band plus the white band and all the simulations (1000) have generated a value within the $100 \%$ region, the black shaded bound with upper bound \pm 155 billion veh-km and lower bound \pm 115 billion veh-km. One conclusion is the increasing uncertainty, due to the cumulative development of households. Secondly, again the percentiles are not evenly spaced (Figure 6.32), albeit the random process is based on an uniform distribution.

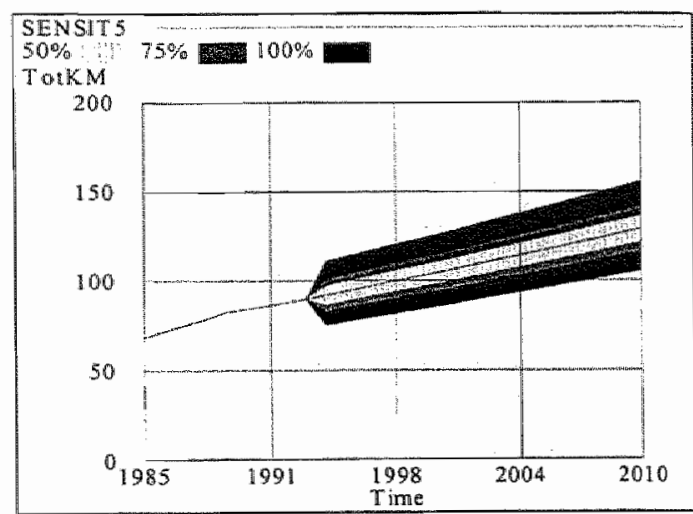

Figure 6.31 The sensitivity of total veln- $\mathrm{km}$ based on an uniform distribution

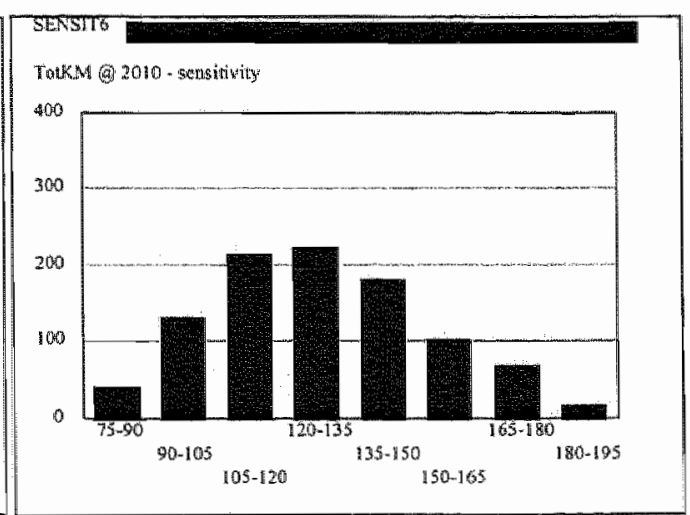

Figure 6.34 The bar graph of the sensirivity results

Note the vertical axis of Figure 6.32 and 6.34 measures the number of simulations.

If the variations are allowed to become $+25 \%$ and $-25 \%$ for the $I-6 p H S H$ weh $k m$ and $\pm 20 \%$ for the $I$ $6 p H S H$ then the sensitivity has of course broader ranges as Figure 6.28 shows.

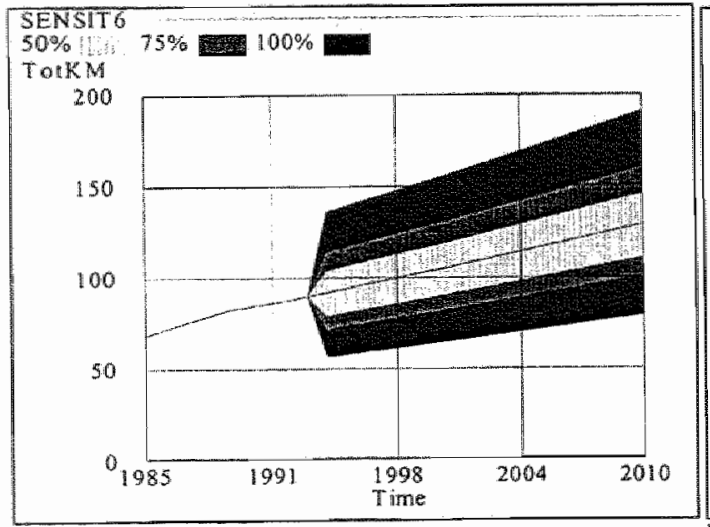

Figure 6.33 The $\pm 25 \%$ sensitivity of total veh-km

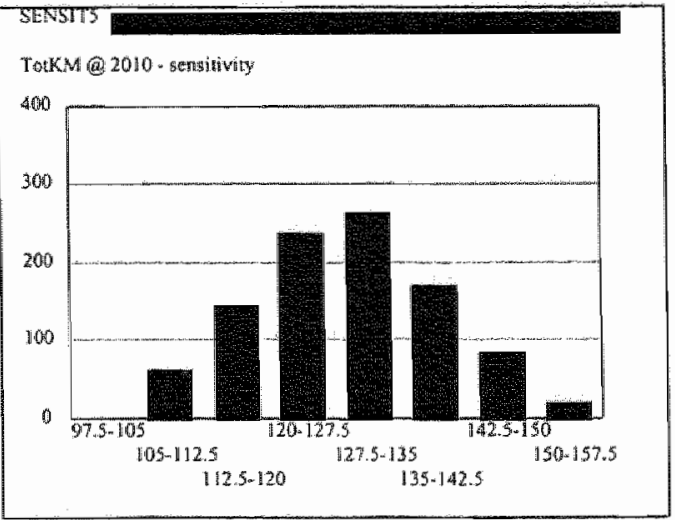

Figure 6.32 The bar graph of the sensitivity results

The dispersion has, of course, become greater, but the central moments remains stable around, $105-150$ billion weh-km per year. 
The sensitivity graphs of the underlying I- to 6-person households shows the 3-person household, $3 p H S H$, to be the most sensitive, due to the expected trajectory of the $3 p H S H$ from 1994-2010, with during the 80 s a mild increase then, during the $90 \mathrm{~s}$, a stabilisation.

\subsection{Automobile kilometrage of the Person Automobile Panel (PAP)}

\subsubsection{Introduction}

A second independent statistical source supplies information about kilometrage of the Dutch car stock is the Personen-Auto-Panel (PAP). We will confront the results of the OVG-source with the PAPsource and can conclude that the results are comparable within a $1 \%$ range. This means that for future projections one can take two routes : from the households by size or from the car stock, but the household by size and their evolution during the past two decades offer much more empirical evidence or explanations (among others, automobilism by motive), than the mere registration of the kilometrage of the PAP by car users. We succeeded in linking the households by size via the $O V G$ survey figures to arrive at the total yearly vehicle-kilometrage needed as input for the emission model. However, an additional transformation is needed because the emission model needs car stock by fuel type by vintage and the average vehicle kilometres by fuel type by vintage. The $P A P$-surveys fumish the needed data for the calibration and for the benchmarks..

\subsubsection{Kilometrage of the period 1980-1994}

Again in the midst of the 80 s the average kilometrage of the LPG cars are declining in favour of the

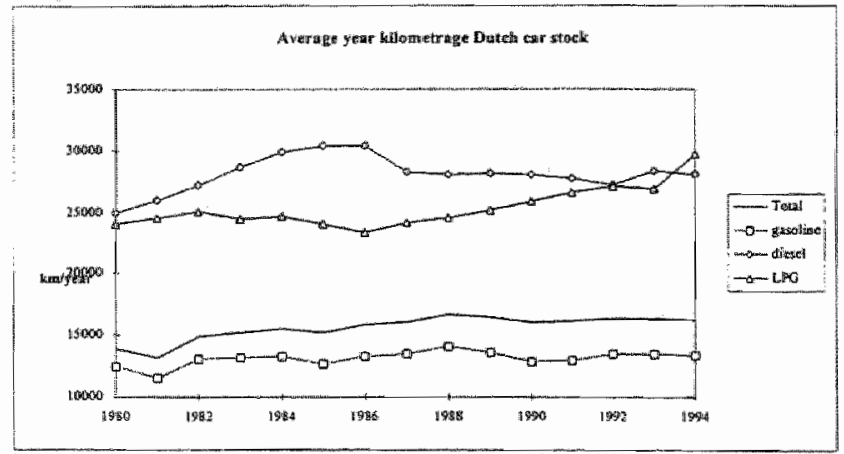

Figure 6.35 The average year kilometrage of the Dutch car stock diesel car (Figure 6.35). After 1987 this development reversed. This trend continues till 1993, the year of the chanced break-even kilometrage of the LPG cars. Is it a one time jump or a reversal of the trend? The figures of the coming years have to illuminate this question. The average kilometrage of the gasoline cars stabilises around $13000 \mathrm{~km} /$ year. The same conclusion holds for the total average kilometrage of the Dutch car stock around $15500 / 16500 \mathrm{~km} /$ year.
The $P A P$-survey decompose the kilometrage by 4 motive categories, comnuting, business visit, holidays and a rest category. However due to deviations in definitions the $P A P$ motives are not comparable with the $O V G$ motives. Note the Total and the Rest average kilometrage is measured on the left axis, the other categories on the right axis. As already observed in the $O V G$ survey the commuting kilometrage shows (Figure 6.36) a modest increase during the period $1982(3500 \mathrm{~km} / \mathrm{year})$ to 1994 (4350 km/year). The development of the other categories (Business visits : $2750 \mathrm{~km} / \mathrm{year}$ and Holidays : $1500 \mathrm{~km} / \mathrm{year}$ ) stabilise and the direction of the future development is inconclusive, therefore they are treated as constants in the base simulation runs, but treated as seasitivity test variables in the scenario runs. 
6.4.3. Average year kilometrage by vintage

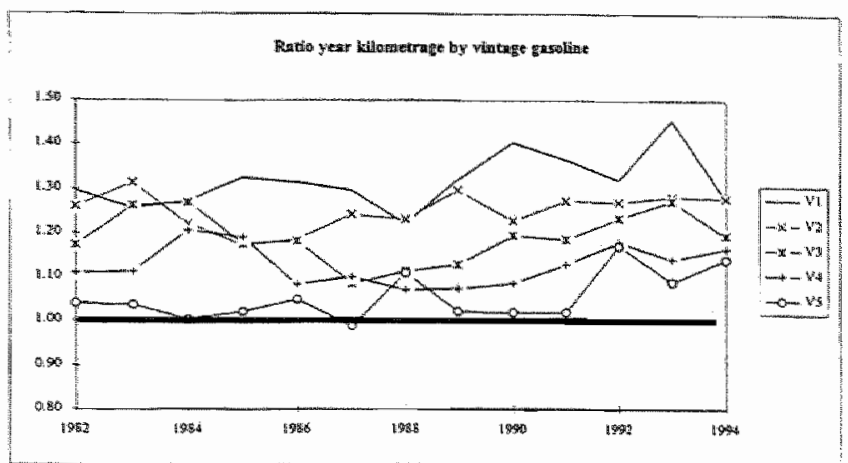

Figure 6.37 Ratio average total $\mathrm{km} /$ year of V1-V5 gasoline cars

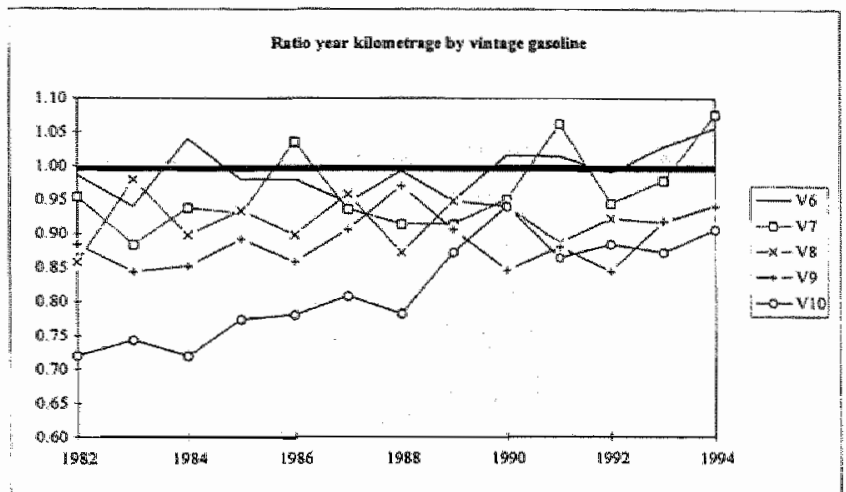

Figure 6.38 Ratio average total veh- $\mathrm{km}$ of V6-V10 gasoline cars

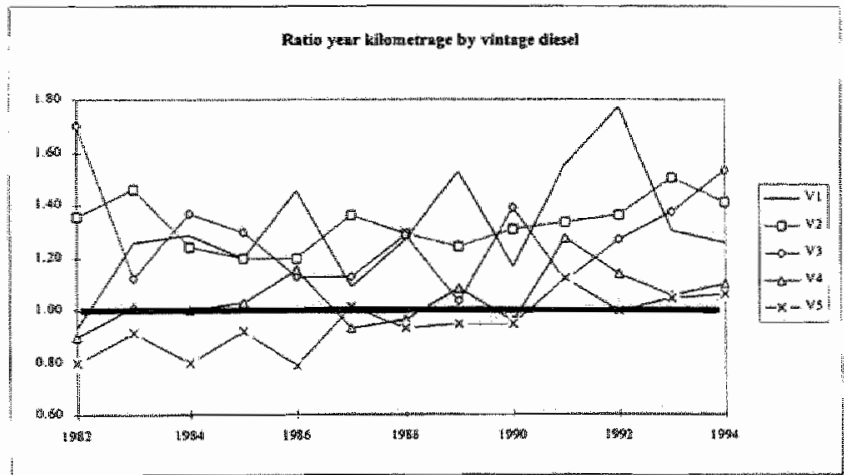

Figure 6.39 Ratio's of the diesel cars
The last interesting data measured by the PAP is the year kilometrage by fuel type by vintage. The data are measured from 1982 on.

The average veh-km of the vintages are compared with the average total veh-km $(=1$, bold line) by computing a ratio average vintage- $1 \mathrm{~km} /$ average total $\mathrm{km}$ (Figure 6.37).

In Figure 6.37 and 6.38 all the vintage V1-V5 of gasoline cars are above the average total weh$\mathrm{km}(=1.0$, bold line) and $\mathrm{V} 6 \mathrm{~V} 7$ are oscillating upward around the bold line. "The remainder wintages are below, but upward. the average total veh-km.

Note the upward direction of the older vintages V5-V10 of the average veh- $\mathrm{km}$. The is in agreement with the fact of the ageing of the car stock.

The diesel car use deviates from the gasoline car use in that the first three vintages, V1-V3, are above the average total veh- $\mathrm{km}$, bold line and that V4, V5 oscillates upward around the bold line (Figure 6.34). The elder vintages, V6-V 10 , are below the average total veh-km, bold line (Figure 6.40).

Note again the upward direction of the elder wintages, V4-V10, again indicating the ageing of the diesel car stock (Figure 6.40) 


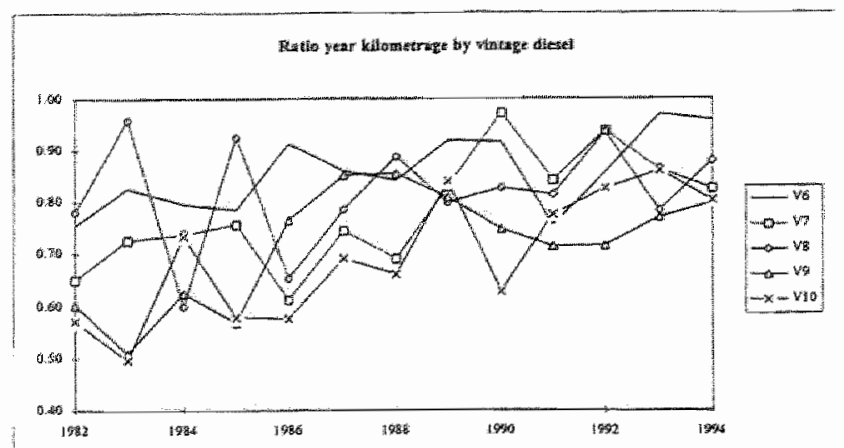

The sarme picture (not shown), as the diesel case, holds for the LPG cars except that the V4, V5 are oscillating stable around the average total veh- $\mathrm{km}$ line 1.0 . Again the ageing induces an upward direction of the elder vintages

Figure 6.40 Ratio's of the diesel cars older vintages

\subsection{Yearly vehicle kilometrage by vintage by fuel type (Veh-Km[F,V])}

Up till now two ways have been taken to arrive at the required data for the input of the emission model, to be developed in the next chapter. The comerstone is the car stock by vintage, by fuel type which can be modelled from

1. the household model via the household car ownership (chapter 6) to the total car stack, or

2. the stock-flow (or logistic) models of chapter 5 to the vintage car stock model by fuel type. In this section we will confront and compare both approaches in order to determine the robustness of both methods.

Ad 1. To arrive at the average total yearly vehicle kilometrage of the Dutch population $(\mathrm{Veh}-\mathrm{Km})$ we start with the OVG survey by the required summations ( $\Sigma$ ) over the 8 motives per pHSH ( $\Sigma A k m / 1$ $6 \mathrm{pHSH})$ and summation over the $6 \mathrm{pHSH}$ amiving at the total average kilometrage $(\Sigma T A K m)$.

Dividing ( $\varnothing)$ this total average vehicle kilometrage by the car stock (ICSTOT) one arrives at the average kilometrage per car $(\mathrm{Akm} / \mathrm{Car})$ which is also available by the PAP survey which will be used as a check.

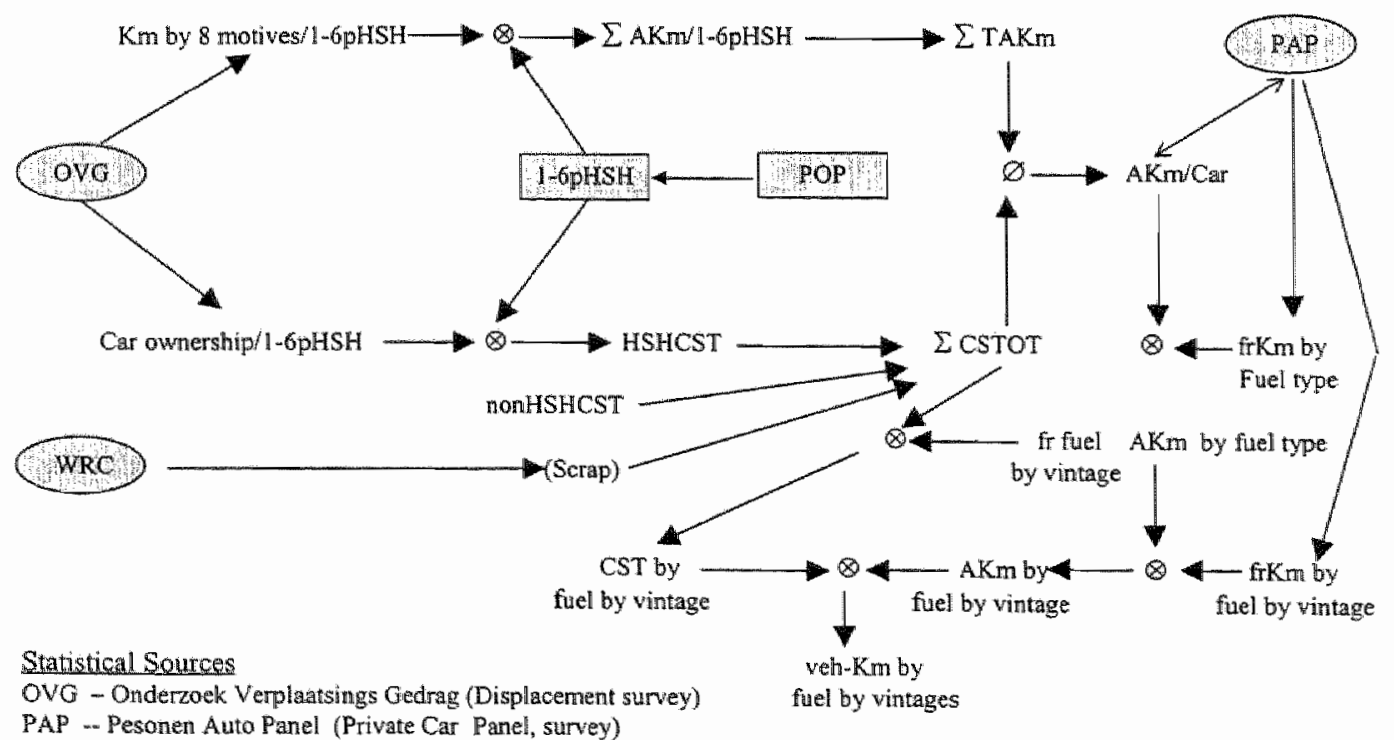

PAP -.. Pesonen Auto Panel (Private Car Panel, survey)

WRC - Wrecks Statistics

Figure 6.41 The computing sequence of the vehicle kilometrage of the household car ownership model 
The PAP survey also furnishes us with the average kilometrage per car by fuel type (gasoline, LPG and diesel), as explained in section 6.4.3. From the fraction of fuel type in average $\mathrm{Km}$ (frKm by fuel type) during the period (1982-1994) the Jogarithmic, LN( $)$, trend has been computed:

$$
\begin{aligned}
& \text { FRKm }[\mathrm{P}]=0.84+0.0263 \mathrm{LN}(\mathrm{t}) \\
& \text { FRKm[L] }=1.39+0.3923 \mathrm{LN}(\mathrm{t}) \\
& \text { FRKm[D }]=2.064-0.1 \mathrm{LN}(\mathrm{t})
\end{aligned}
$$

By multiplying the average kilometrage per car $(\mathrm{Akm} / \mathrm{Car})$ with the fraction of fuel type $(\mathrm{fr} K \mathrm{~K}$ by fuel type) one gets the average kilometrage per car by fuel type (AKm by fuel type). By multiplying the average kilometrage per car by fuel type (Akm by fuel type) with the normed fraction of the vintages (fr Km by fue! by vintage) vis-à-vis the average kilometrage per car by fuel type, one arrives at the awerage kilometrage per car by fuel type and by vintage (Akm by fuel by vintage). This is the first phase of the computation, the second phase is the computation of the car stock by fuel type and by vintage (CST by fuel by vintage). From the OVG survey the 1-, 2- and more-than-2 cars of the 1- to 6 person households are available, by multiplying out and the required summations of these two data series one arrives at the total car stock of the Dutch households (HSHCST). The household car stock has to be added with the non-household car stock (nonHSHCST) to arrive at the total car stock (ICSTON) which has to be divided over the fuel types and the vintages (frfitel by vintage). ${ }^{6.1}$ The result is desired figure of the total car stock by fuel type and by vintages (CST by fuel by vintage). This last figure has to be multiplied with the average kilometrage per car by fuel type and by vintages ( $A \mathrm{~km}$ by fuel by vintage), from the first phase, to arrive at the required vehicle-kilometrage per fuel type and per vintage (veh-Km by fuel by vintage). An alternative way is also possible to compute the total car stock, as explained in section 6.1.4. The functional relationship between total households, average car ownership per household and the renewal of the scraps (or wrecks) indicated by the dotted arrows.

Ad 2. The second way (Figure 6.42) to arrive at the desired yearly vehicle kilometrage takes the first phase of the computing sequence of the model, as explained above, and the vintage car stock model by fuel type, as developed in chapter 5 . The permanent income (GDP) and the scrap from the car

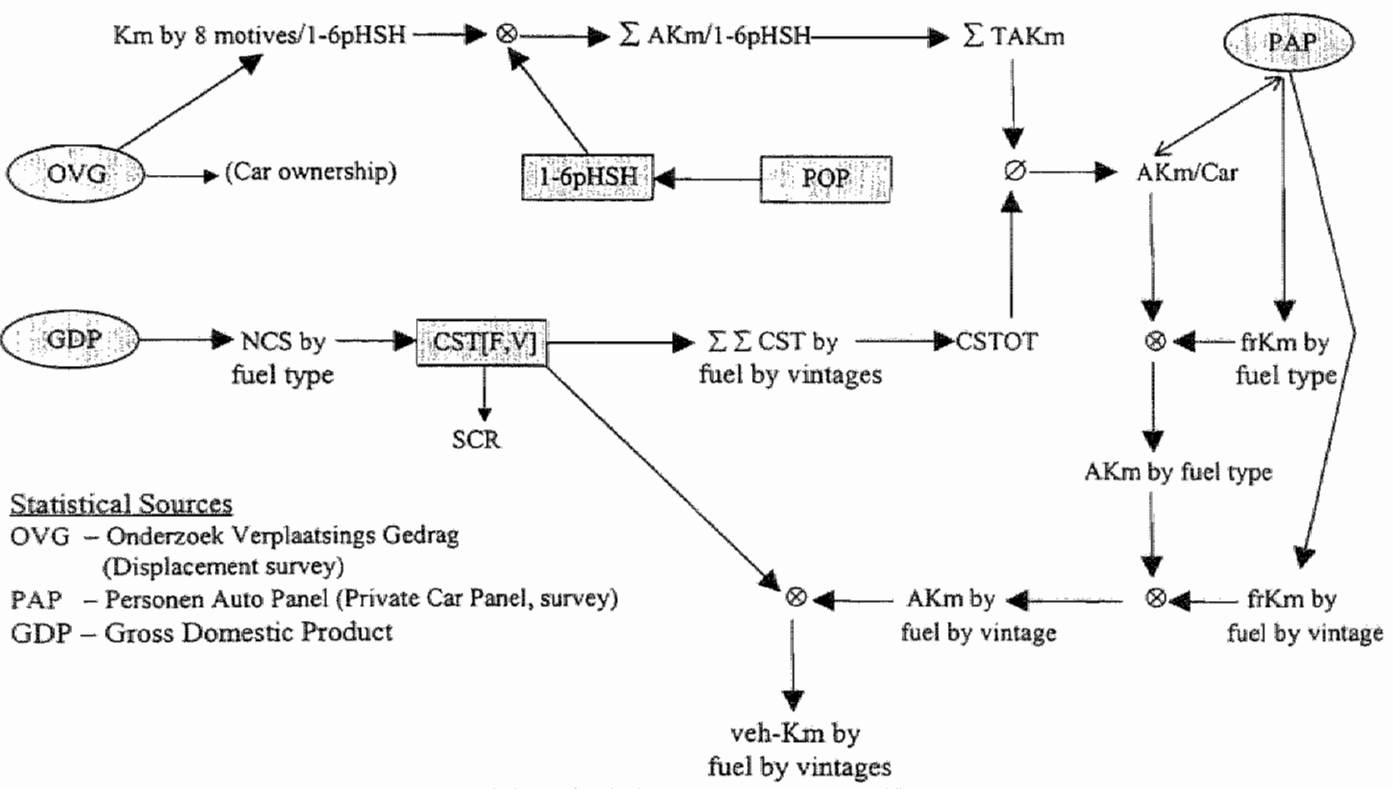

Figure 6.42 The computing sequence of the vehicle killometrage by two different models

6." The information contained in fr by fuel by wintage comes from the vintage cai stock models, as developed in chapter 5. 
stock determine the new car sales (NCS by fuel type) which again determine the composition of the car stock. By summation over vintages and fuel types the total car stock will be derived in order to continue the path to compute the vehicle kilometrage.

Note Figure 6.15 shows the total car stocks of the two different approaches and describes its differences. Based on both car stock models the total veh-km will be shown in Figure 6.43. Note the series CHAPT6C is derived from the household - car ownership model, developed in this chapter and CHAPT6E is based upon the vintage car stock model (SIGMOID), developed in chapter 5.

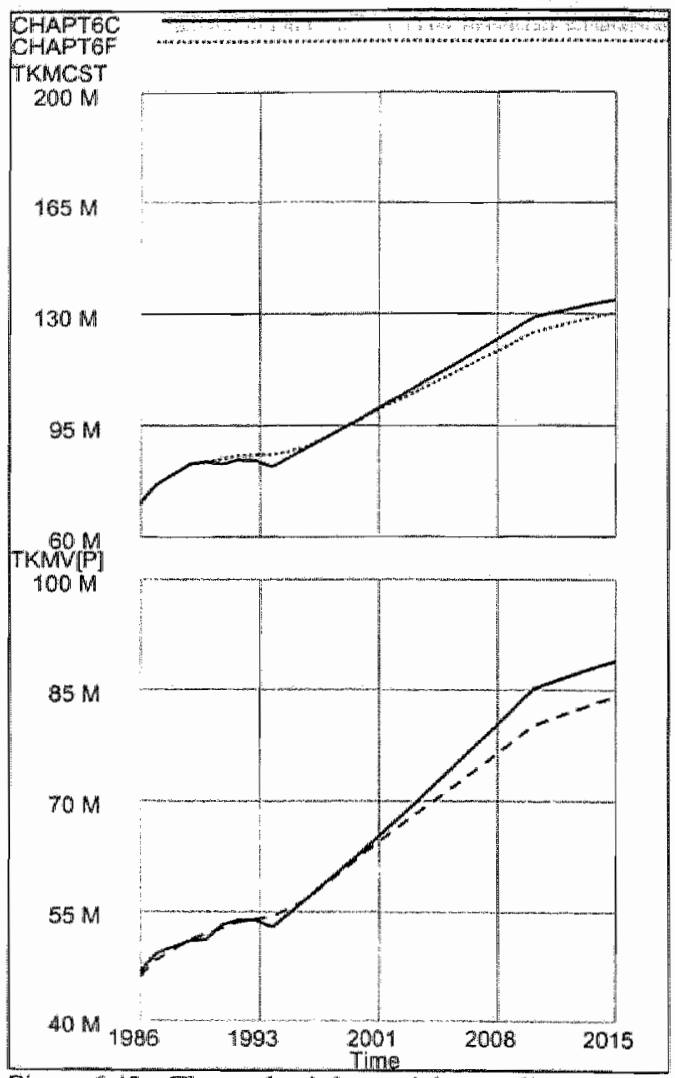

Figure 6.43 a The total velt-Him and the gasoline veh-im $(x 1000)$

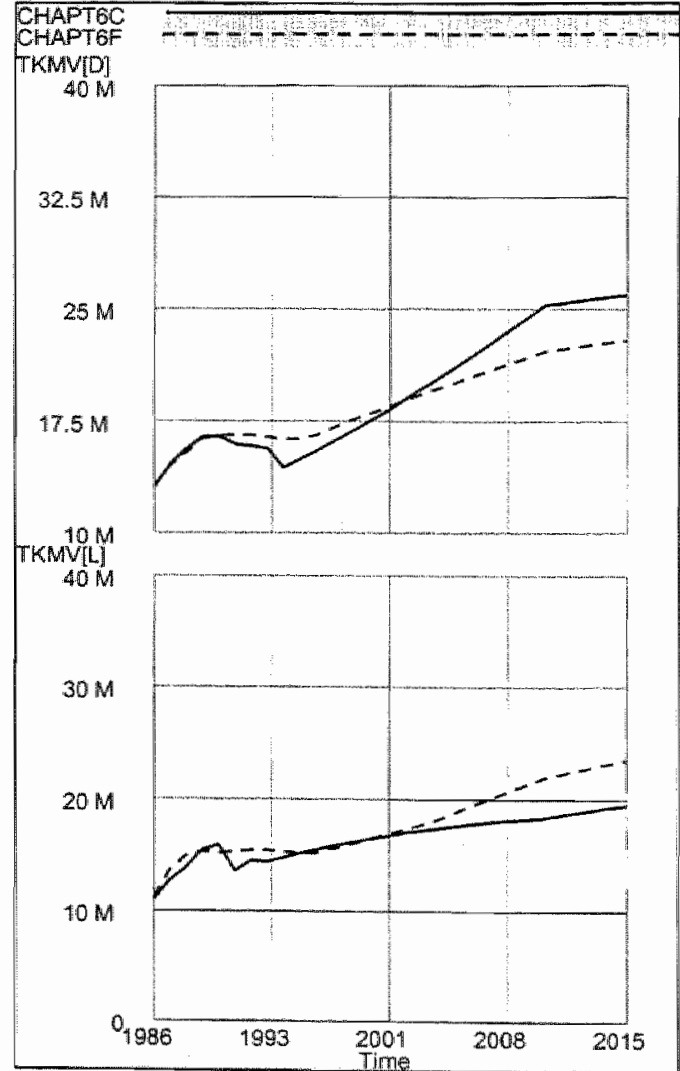

Figure 6.43 b The diesel - and LPG veh-km $(\mathrm{x} 1000)$

The total veh- $\mathrm{km}$ in 2015 counts to 133 billion, respectively 130 billion veh-km, the difference has its cause in the difference of the car stock as depicted in Figure 6.15. However seen the uncertainty it is quite close. The total veh-km (TKMCST, upper graph of Figure 6,43a) is the result of the summation of the kilometrage of the vintages respectively, the total veh-km gasoline (TKMV[P]), diesel (TKMV[D]), LPG (TKMV[L]). The final multiplication to arrive at the veh-km by fuel by vintage (Figure 6.46) equals the product of kilometrage by fuel by vintage (Figure 6.44) and the car stock by fuel by vintage (Figure 6.45). Note that the youngest vintages are the most advanced in input/output technology and take the highest killometrage on their account.

Table 6.12 shows an example of the calculation scheme of the total veh-km of the year 1990, which is the input to the emission model to be dealt with in the next chapter. For each vintage by fuel type (Vintage) the average kilometrage per wintage ( $Y \mathrm{~km} / \mathrm{vint}$ ) is multiplied by the number of cars of that vintage (vint-cars) to arrive at the total vintage hilometrage (vint-km). After summation of the 10 vintages plus the rest component the total yearly kilometrage is known. By summing the yearly vintage kilometrage by fuel type one anives at the total yearly vebicle kilometres. 


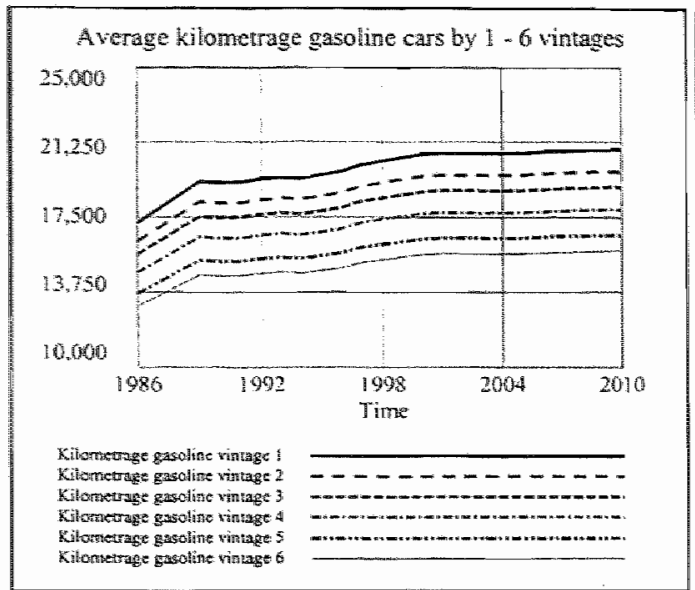

Figure 6.44 Kilometrage gasoline cars (x1000)

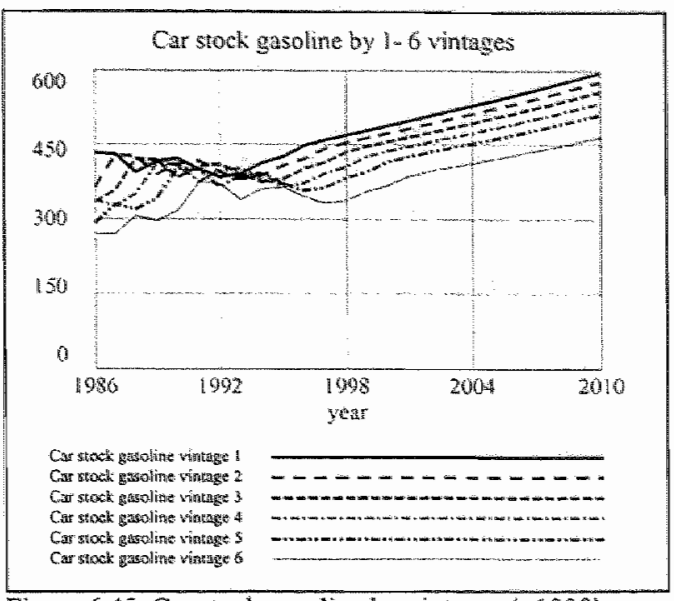

Figure 6.45 Car stock gasoline by vintages $(\mathrm{x} 1000)$

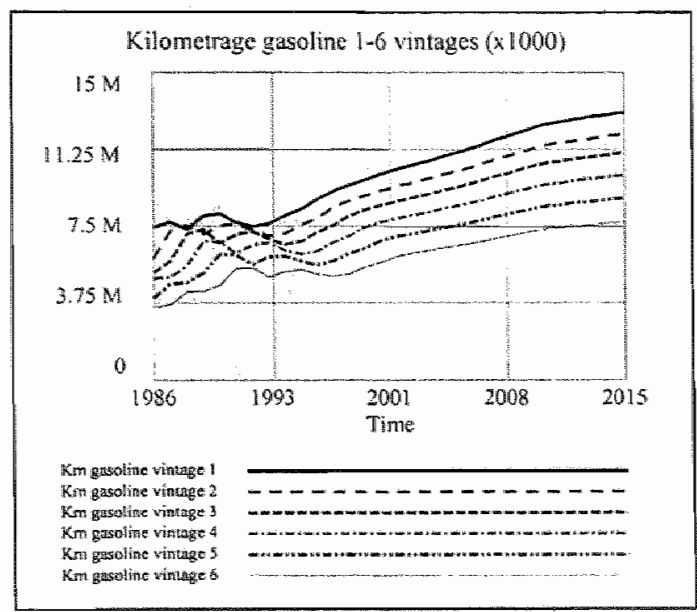

Figure 6.46 Veh- $\mathrm{Km}$ gasoline wintage car stock (x.1000)

\begin{tabular}{|c|c|c|c|c|c|c|c|c|c|c|c|c|}
\hline \multicolumn{3}{|c|}{ CASOLINE TSPO } & \multicolumn{3}{|c|}{ THIESEL IGY } & \multicolumn{4}{|c|}{ 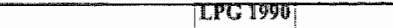 } & \multirow[b]{2}{*}{ vinterars } & \multirow[b]{2}{*}{ Fintokm } & \multirow{2}{*}{ Total } \\
\hline Protage & TKEn vint & wint-ears & Wint-Ktiti & Whatage & YkmWwint & Wintears & vhent-kimi & Vintang & Yhimint & & & \\
\hline 1990 & 181.30 & 329 & 5892250 & 1950 & 32600 & 39 & 1271400 & 1680 & 36336 & 38 & 1) 180540 & $(x] 000)$ \\
\hline 7989 & 15830 & 353 & 55790 & 1.989 & 36610 & 65 & 2379650 & T58 & 35790 & 39 & 2075940 & \\
\hline 198: & 15440 & 343 & 520520 & T988 & 39050 & 64 & 2499200 & 1985 & 31960 & 5.2 & 1861920 & \\
\hline T198? & 14030 & 398 & 5583940 & 1997 & 26800 & 69 & 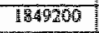 & 1978 & 36900 & 56 & 1506400 & \\
\hline 1986 & 13160 & 400 & 5264000 & 1986 & 26560 & 71 & 188576 & 7986 & 25470 & 37 & 1451780 & \\
\hline 9985 & 13120 & 343 & 4500160 & $19: 35$ & 256607 & 67 & 119220 & 1685 & 26550 & 53 & 1407150 & \\
\hline 1984 & 12280 & $\sqrt{126}$ & 39298060 & 1984 & 27260 & 55 & 1499.300 & 1984 & 22180 & 49 & 1086820 & \\
\hline 1983 & 12150 & 327 & 3973050 & 1983 & 23170 & 39 & 903630 & 1983 & 23380 & 32 & 1215760 & \\
\hline 1982 & 10920 & 274 & 2902080 & 1982 & 20976 & 31 & 650070 & 1982 & 19156 & 48 & 919200 & \\
\hline 1998 & 12150 & 226 & 2745000 & 1981 & 17580 & 25 & 439500 & 196 & 19490 & 30 & 760110 & \\
\hline$\overline{R E S T}$ & 9650 & 771 & 7.9401510 & REST & 18960 & 33 & 1004880 & KEST & 20770 & 87 & 1806990 & \\
\hline & & 4020 & 53205040 & & & 578 & 16101810 & & & 389 & $152 \pi 1920$ & $845787 \%$ \\
\hline
\end{tabular}

Table 6.12 An example of the computation of the total weh- $\mathrm{km}$ of 1990 


\author{
Chapter 7 \\ The emission model \\ from basic emission and fuel use factors \\ to \\ vintage emission and fuel use factors
}

W Objective

\# Methods

\# Data sources

Hesults

Conclusions
The development of an emission model which computes (i) the basic emission factors of $C O, V O C$, and $N O_{x}$ and (ii) the basic fuel factors of gasoline, dieseloil, and $L P G$, in order to compute (iii) the basic emission factors of $\mathrm{CO}_{2}$ and $\mathrm{SO}_{2}$. The basic emission factors are derived from a set of equations relating resistance, engine power, masses, speed and fuel efficiency. The basic emission factors (i), expressed in gram emission per vehicle kilometre, are applied to calculate the burning emissions of $C O, V O C, N O$ and $A e r$ for 3 road types (as a proxy for driving behaviour). The basic emission factors (iii), expressed in gram emission per litre used fuel, are applied to compute the burning emissions of $\mathrm{CO}_{2}$ and $\mathrm{SO}_{2}$.

A dynamic emission simulation model has been developed according to the methodology of the Instituut voor Wegtransportmiddelen TNO in order to compute the basic emission factors, which, given the expected (simulated) car stock, car use and kilometrage (called traffic performance per vintage) during the period 1990-2015, results in the Dutch car park emission factors.

Emission data, observed and estimated, for the period 1980-1994 are from CBS and RIVM.

The time-dependent basic emission and fuell-use factors of the Dutch car stock to be inputted in the car park emission model of chapter 8

The time dependent technological progress, for example, the introduction of the 3-way catallytic converter and the continuing fueluse efficiency, and penetration rate in the Dutch car stock influences the basic emission factors $\left(E F_{\dot{b}}\right)$. For example, it is to be expected that the technically based emission factors of $C O$ of gasoline cars for inner city traffic will decrease with 30\% during the period 1990-2015, $60 \%$ for rural traffic, and $80 \%$ for high=way traffic. In case of $N O_{x}$ for diesel cars the decreases are for inner city traffic $28 \%$, for rural traffic $28 \%$, and for high-way traffic $50 \%$. 


\subsection{Scope and Methodology}

\subsubsection{Introduction}

Road traffic is an emission source of high importance. Other important sources are the industry, electrical power stations, agriculture and households. Far most the largest part of the road traffic causing exhaust particles comes from the combustion of gasoline, diesel fuel and LPG.

- The exhaust of carbon oxide (CO) and hydrocarbons (VOC) arise from incomplete combustion. For diesel engines these emission are low, because they are working in an affluent oxide environment by which the combustion is practically complete. $C O$ is a toxic gas : it takes oxygen from the blood by the breathing process. VOC is a set of volatile organic compounds containing particles with car cinogenous properties and are a precursor to forming ozone (smog)

- The exhaust of nitrogen oxide $N O_{x}$ is caused by the combustion of nitrogen, for the most part coming from the air and partly from the fuel. $N O_{: I}$ consist of nitrogen monoxide (NO) and nitrogen dioxide $\left(\mathrm{NO}_{2}\right)$. The formation of $\mathrm{NO}_{x}$ increases when combustion temperatures are increasing.

- Particulates are fixed and/or fluent particles which be suspended (or float) in the air and consist for the greater part of soot. To the soot carcinogenic particles can be affixed. Diesel engines produce rellatively a lot of particulates.

- $\mathrm{SO}_{2}$ arises by the combustion of the sulphur contained in the fuel. Only diesel fuel has a sulphur content of importance.

- The exhaust of lead compounds comes from the lead compounds added to the gasoline in order to get a better engine performance. During the last decade the lead content of gasoline has been decreased among other to introduce catalyst converter.

- $\mathrm{CO}_{z}$ and vapour, arise by complete combustion of the fuel. They are not considered as pollutants, but have greenhouse properties which can have among others climatic consequences.

- The $Y O C$ emissions by road traffic are not only arising from combustion activities but also partly ( $25 \%$ ) by evaporation of the gasoline from the vehicles. By the intake of fuel and losses from the fuel control system during and after driving. The evaporation losses of diesel fuel and LPG are neglectable. For an integral effect of the emissions the activities of the manufacturing, repair, maintenance and demolition of vehicles and the emission of refinery and distribution of fuels has to be counted for.

\subsubsection{Emissions: a production function approach}

Empirical work has recently be issued by $\mathbb{K a h n}(1996)$ and focuses on a simple vehicle pollution production function, which reads as:

$$
E_{i}=\sum \gamma_{j} D_{j}+B_{1} C_{i}+U_{i}
$$

where

$$
\begin{aligned}
& E_{i}=\text { log emission of the } i^{\text {th }} \text { vehicle } \\
& C_{i}=\text { characteristics of the } i^{\text {th }} \text { wehicle, } \\
& D_{j}=\text { model year } j \text { 's dummy. }
\end{aligned}
$$

Equation 7.1. provides information on how vehicle emissions vary across model years (equivalent to or a proxy to year of comstruction or vintage). Kahn estimates equation 7.1. using cross-sectional Chicago and Califormia data on individual vehicles. Vehicle emissions testing creates a virtual census of a county's vehicle stock. Starting in 1992, Illinois and California have kept computer records on all wehicles that have been emissions tested. For each vehicle, year of construction, mileage, and two readings for hydrocarbon ( $V O C$ ) and carbon monoxide ( $C O$ ) emissions are available. Such estimates for the existing vehicle stock are relevant for forecasting the benefits of previous regulation and estimating the benefits of offering incentives to accelerate the scrap of older vehicles. The estimates also aid to predict how aggregate emissions will evolve if no further new car regulation is enacted. Model year estimates from single cross section represent a combination of vintage and age effects. Moreover, emission control may depreciate over time. Thus, older cars might pollute more, regardless of initial technology. In the regression Kahn attempts to control for vehicle ageing by including mileage. As Kahn used two different subsets (with different regulations). As California has had more 
severe new car emission regulation than the rest of the U.S. an estimation of the production function 7.1 for Californit and Chicago offers a test of the benefits of such stringency. The dependent variable is the log of WOC emissions. The independent variables include mileage and model year dummies for 1975-1989. The results shows that in 1975 and 1980 federal regulation required steep reductions in VOC (for example $45 \%$ in Chicago and $68 \%$ in California). However, the period between 1975 and 1980 shows different reaction of the two subsets, Chicago shows an increase of WOC for the model years 1976-1979 and then decline sharply in the 1980 model year. Emissions were roughly constant for makes built between 1980 and 1984. Emissions have steadily decreased for wehicles built after 1983. For the Chicago sampie, a 1986 model year car creates $89 \%$ less $V 0 C$ then does a 1974 model year car. Note that mileage has a small impact on vehicle emissions increases. A 10000 mile increase in driving increases emissions by $2 \%$. has a small impact on wehicle emission increases. The key years for California $V O C$ reduction were 1975 and 1977 . The emissions are $68 \%$ lower for 1975 model year cars relative to cars built in 1974. Unlike the Chicago sample, Kahn finds no evidence that emissions rise after 1975. Emissions for vehicles bult between model years 1975 and 1983 are roughly constant. Surprisingly, Kalm finds no evidence that emissions fell in 1977 when the Californa VOC standard fell. Again as was the case for Chicago the emission of cars built after 1983 declines rapidly. However vehicle emissions have not fallen monotonic with vehicle model year, Kahn found evidence that emissions fall when new car emission regulation becomes more stringent. The method described above is relevant for tracking the quality of the composition of the car stock, it is not suited (and actually not developed) for computing the yearly emissions by road traffic directly. The proposed emission production functions, to be described in the next sections, are in fact physicalengineering production functions, based on physical-chemical relationships between energy use, masses, (roll - and air) resistance, fuel type, combustion efficiencies, and speed or acceleration. The model specifications have been tested in laboratories under ideal circumstance in case of a "warmengine' at a temperature of $20^{\circ} \mathrm{C}$, in case of 'cold-engine and warming-up phase' at a temperature of $9^{\circ}$. The reality deviates of coarse from these ideal circumstances.

\subsubsection{Methodology}

Starting from available test data a computational methodology has been chosen by which the emissions are being computed by multiplying the extent of the pollutant activities with the emission factors (emission per unit activity). The available test data coming from different sources as: CBS, RAI, IW-TNO and TUV.

In case of road traffic the extent of the activity is being expressed or measured:

1. in traffic performance (kilometres per year or per drive),

2. fuel use, and

3. the number of cars in use (active cars stock).

The emission factors used by the computation of the combustion emissions depend among others of the vehicle category or car type and the type of fuel use (gasoline, diesel oil, LPG).

The combustion emissions are further influenced by the drive behaviour and speed, these facts provides, in principle, an infinitely number of drives with each different emission factors. Therefore, to become manageable, three drive types/road classes have been separated:

1. imner city traffic or urban traffic $\left(R T_{1}\right)$,

2. outer city traffic or rural traffic $\left(R T_{2}\right)$,

3. high way traffic $\left(R T_{3}\right)$.

The emission factors for $C O, V O C_{t} N O_{x}$ and particulates are derived from the results of measurements of vehicles, by which, by means of drive (test) cycle, the different drive types are simulated. These measurements are being performed by the Instituut voor Wegtransportmiddelen TNO (TW-TNO) in Delft, Holland and Technische Uberwachung Verein (TUV) Rheinland, Germany. The emission factors for $\mathrm{SO}_{2}$, and $\mathrm{CO}_{2}$ from respectively the sulphur, and carbon contents of the fuels. The uncertainty margins for the emission factors $\mathrm{SO}_{2}$ and $\mathrm{CO}_{2}$ are small, because the sulphur and carbon contents are known. Also the data about the lead content are highly reliable and exact. 
For the evaporation emissions relatively few research results are available. Especially about the evaporation losses during a drive little research results are available. The emission factors used in our calculations are based on research results of the EC-CORINAIR project (Eggleston et al, 1989).

Evaporation emissions are being assumed to be caused by gasoline use, $90 \%$ being released by inner city traffic. The methodology has been developed by IW-INO (CBS 1993 C).

In order to scan the future it is proposed to base the calculations on five main types of input parameters, to be inputted exogeneously or determined in adjoin modules.

i basic emission factors (this chapter),

ii vehicle stock and new car sales (from chapter 5),

iii driving conditions (this chapter),

iv total fuel consumption (this chapter):

\% other parameters (this chapter).

For these main types of input parameters, additional information (e.g. on technological improvements and innovation, vintage (year of construction) profiles of the car stock is needed in order to evaluate the technological effects on input-output, and combustion technologies. The introduction of technology will be locked to the year of construction (vintage), the penetration will therefore be dependent on the turnover of the car stock, that is, the ratio new car sales and scrap. Figure 7.10 shows the applied computation scheme.

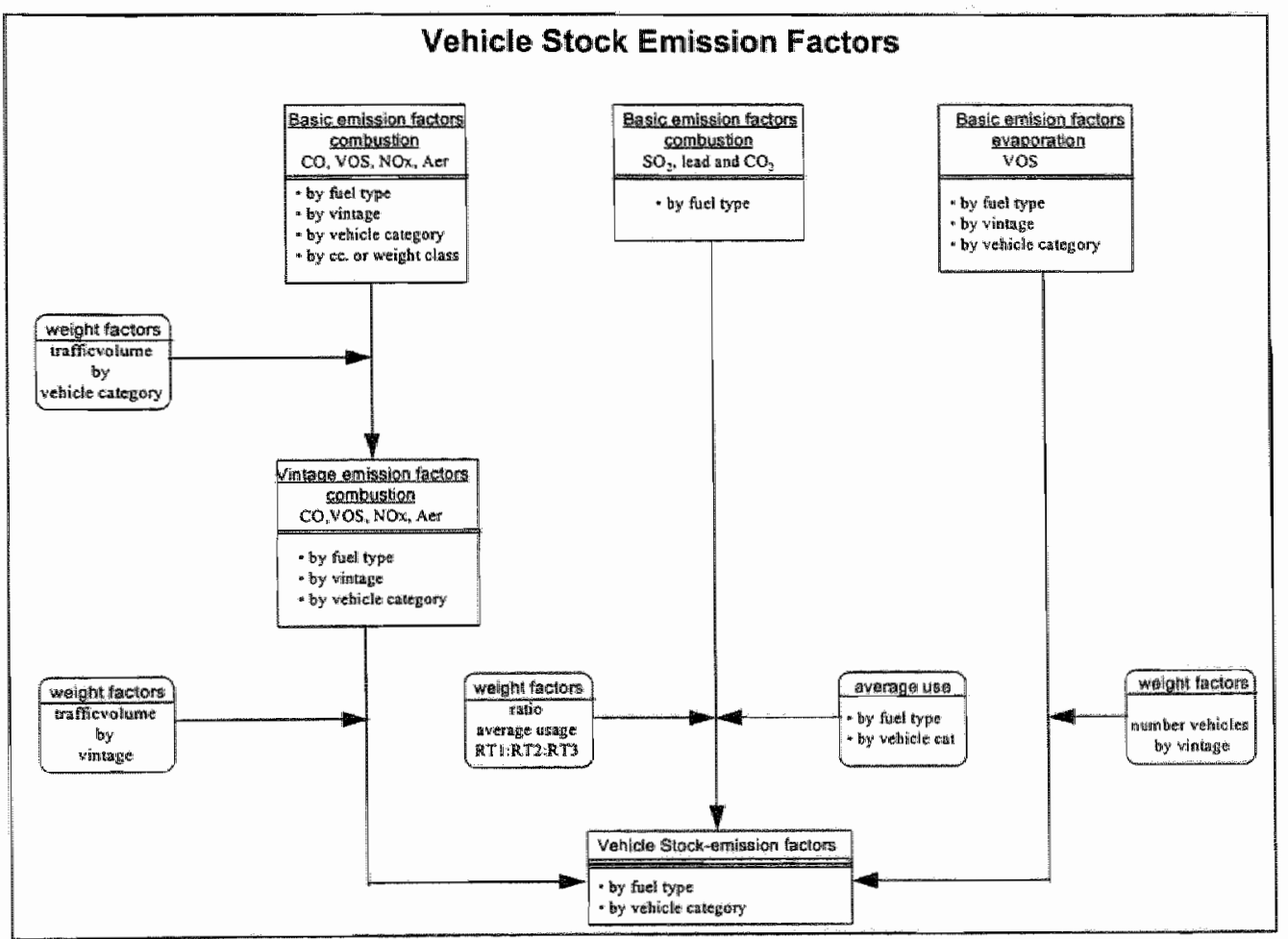

Figure 7.1 The basic computation sequence

Figure 7.1 shows the applied calculation scheme. In order to meet the EC requirements, in particular the one that data should be suitable for advanced long-range dispersion models, this infomation should be available for the smallest territorial unit (NUTS III). However, this is not the case in most countries, so that it seems to be more appropriate for these countries to start at NUTS level 0 (national level) and to allocate emissions to other NUTS levels with the aid of the available surrogate data. (For more detailed information, see EC-CORINAIR project). 


\subsection{Basic emission factors $\left(E F_{b}\right)$}

These emissions depend on a variety of factors including the distance that each vehicle drives, its speed (road type as a proxy), its age (vintage) and engine size (cc as a proxy). There are a number of other factors that may influence vehicle emissions, for example, driving behaviour, state of maintenance, climate or altitude. Howewer, for the time being, there is little information about the influence of these parameters on the vehicles so that their influence cannot yet be taken into account. Scenario analysis has to be applied. The basic formula for estimating hot (warm) emissions per year using experimentally obtained emission factors is:

Emission $[\mathrm{g} / \mathrm{y}]=$ emission factor $[\mathrm{g} / \mathrm{km}] \cdot$ vehicle kilometres per year $[\mathrm{km} / \mathrm{y}]$

where the dimension refers to:

$$
\begin{aligned}
& \text { g -- gram, } \\
& \text { y - year, } \\
& \mathrm{km} \text { - kilometres. }
\end{aligned}
$$

The emission factors and wehicle kilometres are in most cases divided into certain classes of road type $\left(R T_{k}\right)$ and vehicle categories $\left(C_{j}\right)$.

However, for many countries the only data known with any certainty is the total fuel consumption of gasoline, diesel and LPG, not vehicles kilometres. In the Dutch case, where the vehicle-km data are known, fuel consumption data are used to check vehicle kilometrage and to make a final balance.

Since emission factors can be converted from $[\mathrm{g} / \mathrm{km}]$ into $[\mathrm{g} / \mathrm{kg}$-fuel], using consumption data for all vehicles classes and road types, the calculation can be carried out either on one or the other emission factor. Note the model has been estimated for 1986 vehicle category.

If vehicle kilometres are to be used, we have:

$$
E F_{w_{i} i, j, k}=v m_{j, k} * E F_{w_{n}: 1986 ; j, j, k}
$$

If fuel consumption is to be used, we have :

where

$$
E F_{w ; i, j, k}=g_{j, k, l} * b_{j, l} * E F_{w, 1986 ; i, j, k}^{\#}
$$

$$
\begin{aligned}
& E F_{w, 1986 ;, j, k}: \text { average } 1986 \text { stock representative basic emission factor.1 in }[\mathrm{g} / \text { vehicle-km] for } \\
& E F_{w, 1986 ;, j, k}^{*} \text { : average } 1986 \text { stock representative basic emission factor in [g/kg-fuel] for the } \\
& \text { pollutant } i \text {, relevant for the wehicle category } j \text {, operated on roads of type } k \text { with } \\
& \text { hot engines. } \\
& w m_{j, k} \quad \text { : average } 1986 \text { wehicle kilometrage by vehicles of category } j \text {, for road type }(R T) k \text {. } \\
& g_{j, k}, \quad: \text { share of annual fuel consumption of type } l \text { used by vehicles of category } j \text {, driven } \\
& \text { on road type } k \text {. } \\
& b_{j, l} \quad \text { : total annual consumption of fuel type } l \text { in }[\mathrm{kg}] \text { by wehicles of category } j \text { operated } \\
& \text { in } 1986
\end{aligned}
$$

and :
$i$ (pollutants)
: 1-3 for the pollutants covered,
$j$ (vehicle category) : automobile in our case,
$k$ (road classes) : 1-3 for "urban", "rural", and "highway" driving,
I (fuel type)
1-3 for gasoline, diesel, LPG.

The application of equations (7.2.1) and (7.2.2) requires statistical data which are not available in many EC countries. Therefore, some data have to be estimated. It will be proposed to apply as a principle for these estimations the rule that those parameters which are (partly) unknown should be treated as measurement error. In practice, this means to attribute uncertainties to parameters which are

\footnotetext{
7. These factors hawe been derived from emission factors of individual cars which were grouped together according to the Dutch car stoek
} 
actually uncertain and to avoid modifications of parameters with less measurement errors. In what follows the computational sequence will be explained.

The factors $b_{j, l}$ and $g_{j, k, l}$ used in equation (7.2.2) cannot be directly introduced into the computations from statistical data but have to be estimated with the help of other parameters. As stated above, in most EC countries the total fuel consumption is only known for different fuels (e.g. gasoline, diesel, LPG) but not, as required, related to vehicle category ${ }^{7.2}$, such a case one has to distribute the total fuel figures to the vehicle categories in an iterating process, making assumptions concerning the average annual kilometrage driven per vehicle of a defined category and the distribution of the total amnual kilometrage to different road types. The data on total fuel consumption of the different fuels, the number of vehicles in each category and the average fuel consumption for each vehicle category on the different road types remain the fixed points in this process. Now start with:

I.

where

$$
m m_{j}=h_{j} * v_{j}
$$

$m_{j}$ : total annual kilometrage of vehicle category $j$

$h_{j}$ : number of vehicles of category $j$

$v_{j}:$ average annual kilometrage driven by each vehicle of category $j$

While $h_{j}$ is considered as a well-known statistical figure, $v_{j}$, is not available as independent statistical data in many countries and has to be estimated.

II. In the next step, $m_{j}$ is introduced into the formula :

where

$$
m_{j, k}=m_{j} * d_{j, k}
$$

$m_{j, k}:$ total anmual kilometrage in $[\mathrm{km}]$ of vehicle category $j$ on road class $k$

$d_{j, k}$ : share of annual killometrage driven on road class $k$ by vehicle category $j$

The parameter $d_{j, k}$ is rarely available as independent statistical data in any EC country and therefore has to be estimated. The parameter $m_{j, k}$ should then be introduced into the formula:

$$
b_{j, l}=\sum_{k=1}^{3} m_{j, k} * c_{j, k}
$$

where

$b_{j, 1}:$ totall annual consumption of fuel of type $l$ in $[\mathrm{kg}]$ by vehicles of category $j$ operated in the base year.

$c_{j, k}$ : average fuel consumption in $[\mathrm{g} / \mathrm{km}]$ of vehicle category $j$ on road class $k$

The figure $c_{j_{k}}$ is a measured value so that the computation can be carried out.

The total fuel consumption of fuel type $l$ per year is then :

$$
O_{l}=\sum_{j \in l} b_{j l}
$$

where

$$
\begin{aligned}
& O_{l}: \text { total annual consumption of fuel type } l \\
& J=\{P, D, L\} \\
& P: \text { gasoline } \\
& D: \text { diesel } \\
& L: \text { liquefied petrol gas (LPG) }
\end{aligned}
$$

As a rule, the calculated $O$, should be equal to the consumption statistic. However, it should be noted that in some countries there might be a difference between the fuel sold and the fuel consumed in that country due to fuel in transit. The official statistics always correspond to the fuel sold in a country and

73 Vehicle categories are, among ather, automobiles (cars), vans, lorries, tractors, busses. 
therefore have to be corrected if there are clear indications for a substantial export of fuel. If such an export is identified the consumption has to be attributed to another country.

If now the calculated $O_{i}$ does not match the true value, the most uncertain input parameters should be modified, possibly by optimal control techniques. Especially this will be the case for the parameters $d_{j, k}$ and/or $v_{i}$

The factor $g_{j, k}$ can be calculated as follows:

$$
\begin{aligned}
& g_{j, R T_{1}}=\frac{c_{j, R T_{1}}}{\sum_{k=1}^{3} c_{j, k} * m t_{j, k}} \\
& g_{j, R T_{2}}=\frac{c_{j, R T_{2}}^{3}}{\sum_{k=1}^{3} c_{j, k} m_{j, k}} \\
& g_{j, R T_{3}}=\frac{c_{j, R T_{3}}^{3}}{\sum_{k=1}^{3} c_{j, k} * m_{j, k}}
\end{aligned}
$$

where:

$$
\begin{aligned}
& R T_{k}: \text { road type } k \\
& \begin{aligned}
k=1 & : \text { urban road type } \\
= & : \text { rural road type } \\
= & 3: \text { highway road type }
\end{aligned} \\
& c_{j, k}: \text { : average fuel consumption in }[\mathrm{g} / \mathrm{km}] \text { of vehicle category } j \text { on road class } k \\
& m_{j, k}: \text { : total annual kilometrage in }[\mathrm{km}] \text { of vehicle category } j \text { on road class } k
\end{aligned}
$$

All elements of these equations are known, so that the calculation can be carried out directly. The emission factor $E F_{b, 1986 ; i j, k}$, expressed in $[\mathrm{g} / \mathrm{km}]$, will be computed by our computer program (section 7.4) and should be converted, wherever necessary, into [g/kg-fuel] as follows:

where

$$
E F_{w, 1986 ; i, j, k}^{\text {菏 }}=\frac{E F_{w, 1986 ;, j, j, k}}{c_{j, k}}
$$

$$
\begin{aligned}
& E F_{w, 1986, j, k} \text { : average } 1986 \text { stock representative basic emission factor in }[\mathrm{g} / \mathrm{km}] \text { for } \\
& \text { the pollutant } / \text { for the vehicle categrory } j \text {, operated on toads of type } k \text { with hot } \\
& \text { engines } \\
& \text { : average fuel consumption in }[\mathrm{kg}-\mathrm{fuel} / \mathrm{km}] \text { of vehicle category } j \text { on road } \\
& \text { type } k
\end{aligned}
$$

\subsubsection{Cold start emissions}

Cold starts, compared with the "hot emissions", results in additional emissions. They take place under" all three driving conditions, however, they seem to be most likely for urban driving $\left(R T_{1}\right)$. In principle they occur for all wehicle categories. However, emission factors are only available or can be reasonable estimated for gasoline, diesel and $\mathbb{L P G}$ passenger cars and assuming that these vehicles behave like passenger cars -light duty vehicles (vans), so that just these categories are covered by the methodology. Moreover, they are considered not to be a function of vehicle age (vintage). 


\subsection{Emission model}

7.3.1. $\mathrm{CO}, \mathbb{V O C}$ and $N O$ by passenger cars

The basic emission factors for gasoline cars of type "conventional" $\left(N+B_{*} N B\right.$ array or vector in the emission model) are derived from $\mathrm{EC}$ directives for maximum exhaust emissions. The emission factiors for the other types (e.g. improved conventional ( $\mathrm{S}, I N B$ array or vector), open loop catalytic (K6-O and $\mathbb{K} 9, O L$ array or vector) and closed loop (3 way) catalytic (K6-G and U9, $C L$ array or vector) are derived from formulas based on the results of the test cycles measurements by IW-TNO and TUV [Rijkeboer et al, 1990; TUV, 1991]. The text tables $7.2-7.6$ contain the technical engineering formulas and parameters.

The computed emission factors - by car type and cc - applies to driving with a hot engine under laboratory conditions $\left(20^{\circ} \mathrm{C}\right)$. In reality the mean outdoor temperature is lower than $20^{\circ} \mathrm{C}$ and a great part of the traffic performance will be carried out by means of cold or notwarmed-up engine (text table 7.2). Cars with a closed loop catalytic converter show the greatest impact of a cold engine, especially for the emissions of $C O$ and $V O C$. Therefore correction factors has been estimated for the warming-up phase. The warming-up phase lasts $4 \mathrm{~km}$ after a cold start by a average temperature of $9^{\circ} \mathrm{C}$ (text table 7.3 ).

The computation of the basic emission factors, $E F_{b ; i}, i \in I, I=\{C O, V O C, N O$, takes two steps:

1 computation of the emission factors for warm or hot engine, $E F_{w ; i}$

2 correction for "warming-up" driving.

The basic emission factors for cars, $E F_{b ; i}$, by car type, fuel and road type, will de determined by:

$$
E F_{b ; i, l_{i}, \cdots, c, R T_{k}}=\left(\left(1-A_{c ; R T_{k}}\right)+A_{c ; R T_{k}} \cdot C_{c ; R T_{k}}\right) E F_{w i_{i} i_{b}, j, c c, R T_{k}}
$$

where

$$
\begin{aligned}
& E F_{b, i, l, j, c c, R T_{k}}: \begin{array}{l}
\text { basic emission factor } i \text { by fuel type } l_{\imath} \text { by car type } j, \text { by cylinder } \\
\text { content } c c \text { and road type } R T_{k}
\end{array} \\
& i \in I, I=\left\{C O, V O C, N O_{x}\right\}
\end{aligned}
$$

where

$C O$ : carbon monoxide

VOC : volatile organic compounds.

$N O_{x}$ : nitrogen oxides

$$
j \in J, J=\left\{N B, I N B, O l_{s} C L\right\}
$$

withere

$$
\begin{array}{ll}
N B & \text { : conventional car } \\
I N B & \text { : improved conventional car } \\
O L & \text { : open loop catalytic } \\
C L & \text { : closed loop catalytic }
\end{array}
$$

$$
l \in L, L=\{P, D, L P G\}
$$

where

$$
\begin{array}{cl}
P & : \text { gasoline } \\
D & : \text { diesel } \\
L P G & : \text { liquefied petrol gas } \\
C C & \in C C, C C=\{S, M, L\}
\end{array}
$$

where:

$S \quad:$ small size engine, $>1,4$ litre

$M$ : medium size engine, $1.4-2.0$ litre

$L \quad$ : large size engine, $<2.0$ litre 


$$
R T_{K}, K \in R, K=\{1,2,3\}
$$

where

$$
1 \text { : urban traffic }
$$$$
2 \text { : nural traffic }
$$

3 : highway traffic

$A_{w}$ : fraction of driving with warm engine in the traffic performance $\left(1-A_{c}\right)$

$A_{c}=$ fraction "warming-up" driving in the traffic performance

$C_{c}=$ correction factor for "warming-lip" driving

\begin{tabular}{|c|c|c|c|c|c|c|}
\hline Fuel-type & CO & & VOC & & $\mathrm{NO}_{x}$ & \\
\hline Carmclass & urban & non-urban & utban & non-urban & urban & non-urban \\
\hline Cylinder content & $\mathrm{RT} 1$ & $\mathrm{RT2,RT3}$ & $\mathrm{RTI}$ & RT2,RT3 & $\operatorname{RTI}$ & RT2,RT3 \\
\hline \multicolumn{7}{|l|}{ Gasoline } \\
\hline conventional & 2.5 & 2.5 & 2.25 & 2.25 & 1.25 & 1.25 \\
\hline $\begin{array}{l}\text { improved convential } \\
\text { open loop catalytic }\end{array}$ & 2.25 & 2.25 & 2.1 & 2.1 & 1.1 & 1.1 \\
\hline$<1.4$ litine & 3.25 & 2 & 2.75 & 1.9 & 1.55 & 1.55 \\
\hline$\geq 1.4$ litre & 6.5 & 3 & 5.5 & 2.6 & 1.5 & 1.5 \\
\hline closed loop catalytic & 13 & 4 & 11 & 4.8 & 3.2 & 3.2 \\
\hline Diesel & 1.3 & 1.3 & 1.3 & 1.3 & 1.3 & 1.3 \\
\hline \multicolumn{7}{|l|}{ LPG } \\
\hline (improved) convential & 11.3 & 1.3 & 1.3 & 1.3 & 1.3 & 1.3 \\
\hline open loop catalytic & 3 & 1.3 & 3 & 1.3 & 1.5 & 1.3 \\
\hline cllosed loop catalytic & 3 & 1.3 & 3 & 1.3 & 3.5 & 1.3 \\
\hline
\end{tabular}

Table 7.1 Correction factors "warming-up" driving of passenger cars $\left(C_{c}\right)$

\begin{tabular}{|lccc|}
\hline Fraction "warming-up" & driving in the traffic performance of passenger cars \\
& Urban & Rural & Highway \\
Fraction & 0.51 & 0.08 & 0.05 \\
\hline
\end{tabular}

Table 7.2 Fraction "warming-up" driving in the traffic performance of passenger $\operatorname{cars}\left(A_{C}\right)$ 


\subsubsection{Computation of the emission factors warm engine ( $\left.E F_{w}\right)$}

The emission factor functions for warm engine cars are described in text table 7.3 as $E F_{C O}$. EF VOC and $\mathbb{E}_{C} H_{\alpha}$. They are related to the different variable as are : energy use, fuel use, efficiency, roll resistance, air resistance, mass, stroke volume and speed, as shown in text table 7.4. The technical formulas are derived and estimated by IW-TNO and TUV

\begin{tabular}{|c|c|}
\hline Text table 7.3 Description & Formula \\
\hline Emission factor $C O(\mathrm{~g} / \mathrm{km})$ & $E F_{C O}=C_{C O} * E^{P * b}$ \\
\hline Emission factor $\mathscr{V O C}(\mathrm{g} / \mathrm{km})$ & $E F_{V O C}=C_{V O C} * E^{\mathbb{*} * b}$ \\
\hline Emission factor $N O_{x}(\mathrm{~g} / \mathrm{km})$ & $E F_{N O_{x}}=\frac{1}{v} *\left(C_{M 1} * E+C_{N 2} * E^{2}\right)$ \\
\hline \multicolumn{2}{|l|}{ ENERGY USE E (g/hour) } \\
\hline at varying speed & $E_{v}=\left(f_{R}+2.9\right) * M * v_{v}+0.32 * C_{x} * 10^{6} * v_{v}$ \\
\hline at constant speed. & $E_{c}=f_{R} * M * v_{c}+98 * C_{x} * v_{c}^{3}$ \\
\hline FUEL USE ( $/ \mathrm{kmn})$ & \\
\hline idem (g/hour) & $B=\frac{1}{\eta} * E+b_{0}$ \\
\hline gasoline, class $\mathbb{I N B}$ & $b_{01}=190+350 * V_{s}+t^{*} 6 * V_{s}$ \\
\hline gasoline, class OL, CL & $b_{02}=35+400 * V_{s}+t^{*} 6 * V_{s}$ \\
\hline diesel, IND & $b_{03}=100+210 * V_{s}$ \\
\hline diesel, DI & $b_{04}=75+160 * V_{s}$ \\
\hline LPG & $b_{05}=175+325 * V_{s}+t * 6 * V_{s}$ \\
\hline EFFICIENCY & $\eta=\eta_{90}-(t * 0.002)$ \\
\hline efficiency vintage 1990 & see Table 7.5 \\
\hline $\begin{array}{l}\text { ROLL RESISTANCE } \\
\quad \text { roll resistance vintage } 1990 \\
\text { AIR RESISTANCE }\end{array}$ & $\begin{array}{l}f_{R}^{*}=f_{\mathrm{RgO}}+(t * 0.05) \\
\text { see Table } 7.5\end{array}$ \\
\hline gasoline & $C_{x p}=(1+(t * 0.02)) *\left(7.1+\left(1.65 * M_{0}\right)\right)^{*} 10^{-6}$ \\
\hline diesel & $C_{x d^{f}}=(1+(t * 0.02)) *\left(7.1+\left(1.65 * \frac{M_{0}}{1.075}\right)\right) * 10^{-6}$ \\
\hline LPG & $C_{x L P G}=(1+(t * 0.02)) *\left(7.1+\left(1.65 * \frac{M_{0}}{1.05}\right)\right) * 10^{-6}$ \\
\hline \multicolumn{2}{|l|}{$M A S S$ (ton) } \\
\hline gasoline, class S & $M_{01}=\frac{V_{s}}{2.2}+0.245$ \\
\hline gasoline, class OL, CL & $M_{\mathrm{OD}}=\frac{W_{s}}{2.33}+0.245$ \\
\hline diesel & $M_{\mathrm{Od}}=\frac{V_{s}}{1.95}+0.09$ \\
\hline LPG & $M_{O L P G}=1.05 *\left(\frac{V_{s}}{22}+0.245\right)$ \\
\hline masses on the road & $\begin{array}{l}M_{0 R}=M_{0}+0 \\
\text { see Table } 7.6\end{array}$ \\
\hline \multicolumn{2}{|l|}{$S P E E D(\mathrm{~km} / \mathrm{hour})$} \\
\hline at varying speed & $v_{n}$ see Trable 7.6 \\
\hline at constant speed & $\nu_{c}$ see Table 7.6 \\
\hline Technical progress factor & $t=\mathrm{T}_{0}-\mathrm{T} \quad\left(\mathrm{T}_{0}=1990\right)$ \\
\hline
\end{tabular}




\begin{tabular}{|c|c|c|c|c|c|c|c|c|c|c|}
\hline & $\begin{array}{c}\text { Gasoline } \\
\text { WNE }\end{array}$ & $\begin{array}{r}O L \\
<1.4 L \\
\end{array}$ & $\begin{array}{r}O L \\
\geq 1 . L \\
\end{array}$ & $C L$ & $\begin{array}{r}\text { Diesel } \\
\text { IND }\end{array}$ & $D I$ & $\begin{array}{c}\mathrm{LPG} \\
I N B\end{array}$ & $\begin{array}{r}O L \\
<141 \\
\end{array}$ & $\begin{array}{c}O L \\
\geq 1.4 \mathrm{~L} \\
\end{array}$ & $C L$ \\
\hline$f_{R} v_{n}$ & 3.5 & 3.5 & 3.5 & 3.5 & 3.5 & 3.5 & 3.5 & 3.5 & 3.5 & 3.5 \\
\hline Thigo & 0.32 & 0.31 & 0.31 & 0.31 & 0.32 & 0.425 & 0.36 & 0.36 & 0.36 & 0.36 \\
\hline$c o$ & 0.2 & 0.023 & 0.09 & 0.23 & 0.235 & 0.235 & 0.9 & 0.3 & 0.3 & 0.23 \\
\hline$p$ & .0 .1 & 0.25 & -0.15 & -0.45 & -0.5 & -0.5 & -0.5 & -0.45 & -0.045 & -0.45 \\
\hline croc & 0.075 & 0.064 & 0.0515 & 0.0091 & 0.02 & 0.02 & 0.011 & 0.017 & 0.017 & 0.0091 \\
\hline 9 & -0.2 & $-0,25$ & -0.45 & 0.25 & -0.3 & -0.3 & 0.13 & -0.25 & -0.25 & -0.25 \\
\hline $\mathrm{CN}_{1}$ & 0.11 & 0.048 & 0.04 & 0.014 & 0.05 & 0.11 & 0.1 & 0.05 & 0.05 & 0.025 \\
\hline $\mathrm{CN}_{2}$ & 0.0001 & 0.00015 & 0.00013 & $1.4 \mathrm{E}-05$ & $5 E-06$ & 0.00001 & 3.3E-05 & $2.5 \mathrm{E}-05$ & 2.5E-05 & $2.5 \mathrm{E}-0.5$ \\
\hline
\end{tabular}

Table 7.4 Variables in formulas for determining the emission factors $C O, V O C$ and $N O x$ for passenger cars by type or class

\begin{tabular}{|ccccc|}
\hline & Unit & Gasoline & Diesel & LPG \\
\hline Mean stroke volume $(V S)$ & & & & \\
$<1.4$ & liter & 1.18 & 1.08 & 1.18 \\
$1.4-3.0$ & $" \prime$ & 1.67 & 1.74 & 1.67 \\
$>2.0$ & & 2.46 & 2.40 & 2.46 \\
Mean speed $(V)$ & & & & \\
Road type 1 $(R T I)$ & km/hour & 22 & 22 & 22 \\
Road type 2(RT2) & $"$ & 51 & 51 & 51 \\
Road type 3 $(R T 3)$ & $"$ & 110 & 110 & 110 \\
\hline
\end{tabular}

Table 7.5 Remaining variables in formulas for determining emission factors for passenger cars

\subsubsection{Embodied technical progress, fuel use and emissions.}

Apart from the input-output and fuel-air mixture technologies (as there wrill be direct fuel injection, the closed loop catalytic converter, etc.), the other vintage-embodied and time-dependent technical improvements has been introduced exogeneously by way of improved (diminished) air resistance $(2 \% /$ year), diminished roll resistance ( $5 \% /$ year), improved combustion efficiency $(0.2 \% /$ year), ending all up in diminished fuel use. In the base run the resultant recuction fuel use amounts to $\pm 40 \%$ for the period 1986-2015. Figure 7.2 shows the structure in detail and where the technical improvements. enters the computations.

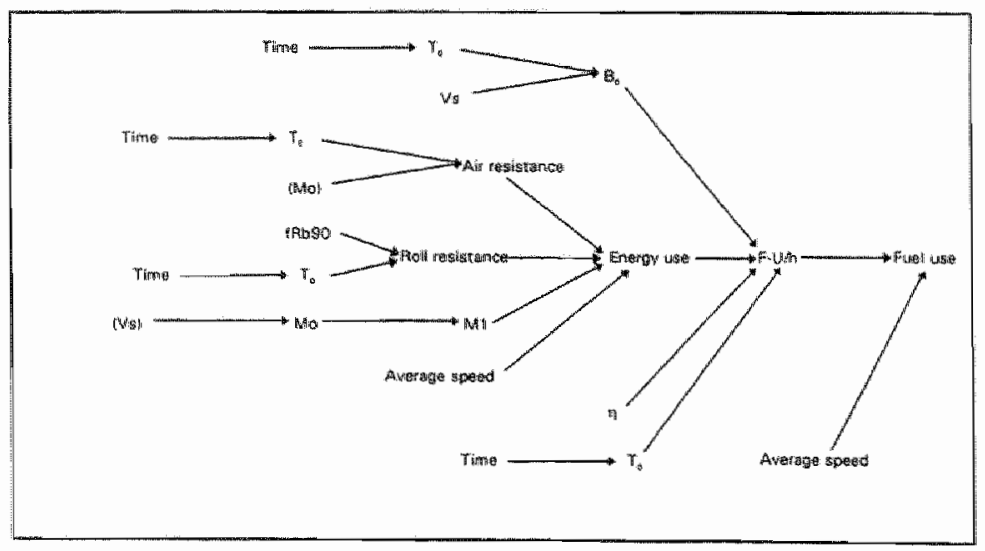

Figure 7.2 The flow chart of the fuel use $\mathrm{km}$ computation as formalised in text table 7.3 
Moreower, there is a direct link between, for example, the emission of $C O$ and the energy use $(E)$ and fuel use (b), according to the functional relationships explained in text table 7.3. On the other hand a direct link exists between fuel-use/km, the energy use per hour and the average speed ( $\mathrm{km} / \mathrm{hour}$ ). Figure 7.2 shows the direct and indirect linkages of physical phenomena (like resistance, masses), the assumed time dependent improvements and the fuel use per $\mathrm{km}$. Figure 7.3 shows the final results of all these linkages with an emission level of $\pm 9.5(\mathrm{~g} / \mathrm{km})$ in 1986 decreasing to $\pm 6.8(\mathrm{~g} / \mathrm{km})$ in 2015 , a reduction of $\pm 30 \%$, due to the above mentioned continuous technical improvements. By way of demonstration it will be shown how these technical improvements influence the basic emission factors $\left(E F_{b}[\cdot]\right)$, acciording to equation 7.3 .1 , and how the emission model computes these basic emission factors, we take as an example the case of $C O$, emitted by a gasoline car $(P)$, with closed loop catalytic converter (CL), medium (M) weight class (1.4-2.0L) driving in the city region (urban road, $R T l$ ) with variable speed, or as model variable $E F_{\text {a }}[C O, P, C L, M, R T I]$.

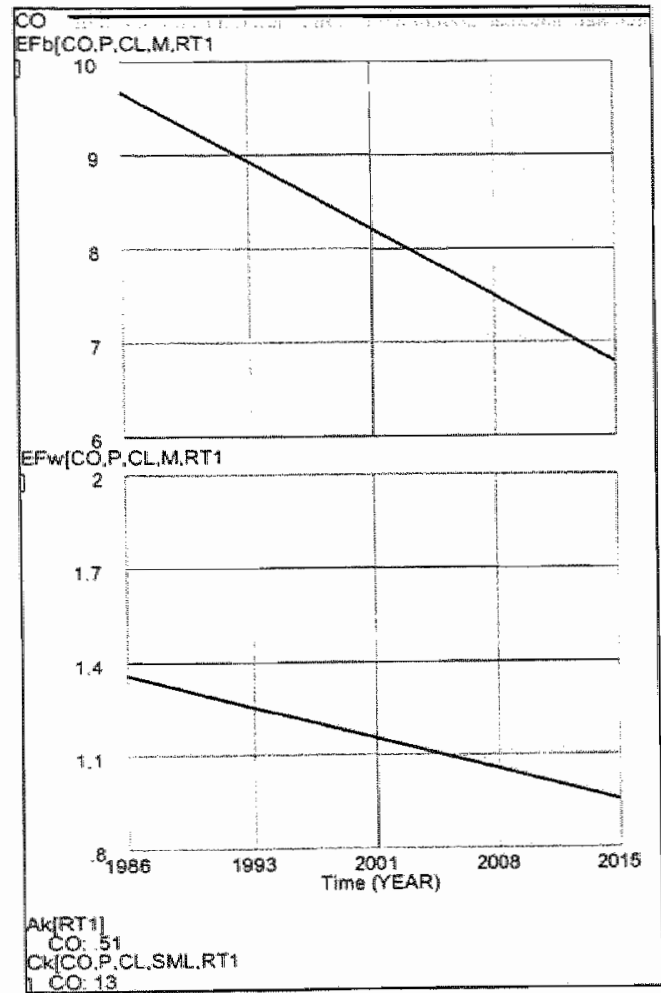

Figure 7.3 The basic emission factor $E_{0} F_{b}[$. ]

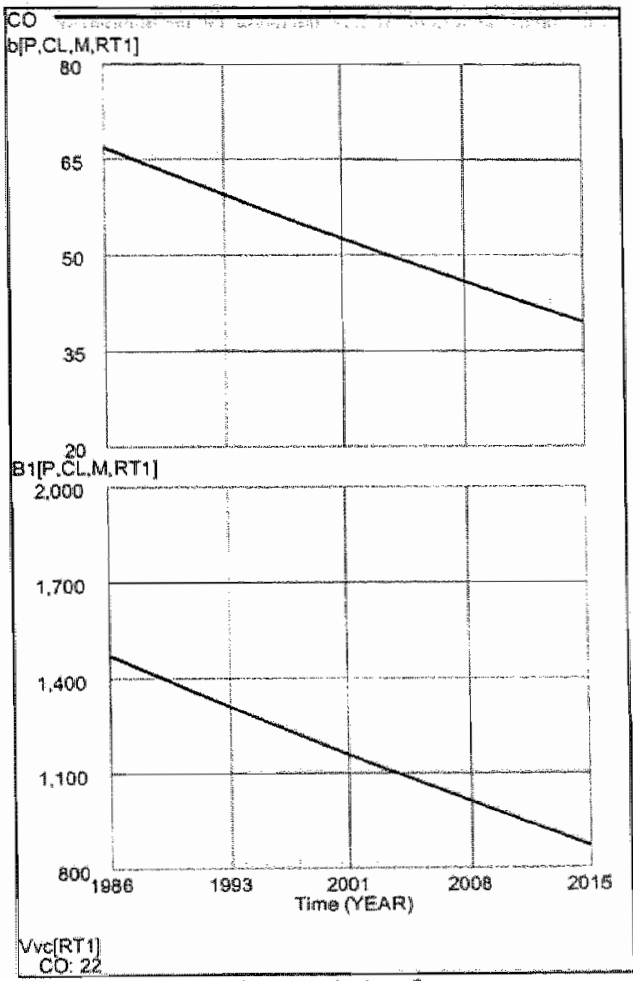

Figure 7.4 The fulel use emission factors

Following the structure of Figure 7.2 the linkages between the physical properties (resistance, masses, etc.) and the chemical (fuel) economy results in decrease of fuel use $(b[\cdot]$ in Figure 7.4 ) of $40.8 \%$ (from $66.9 \mathrm{~g} / \mathrm{km}$ in 1986 to $39.6 \mathrm{~g} / \mathrm{km}$ in 2015 ). Moreover there exists a big difference between the intermediate $\left.E F_{w L} \cdot\right]$ and the resultant $E F_{b}[\cdot]$ (equation 7.4.1).

The difference in fuel use between cold start and the warm (hot) gasoline engine is impressive. A cold start and the warming-up phase require a richer fuel-air mixture, due to physical properties of the materials involved (cylinder wall, valwes, etc.) and low temperature conditions, that means that fuel crops precipitates on the cylinder wall, valves and do not take part of fuel gas processes and combustion. On average the first kilometre the fuel use is $50 \%$ higher, the second kilometre $30 \%$, after 4-5 kilometre the engine is warmed-up to normal fuel use conditions (Figure 7.14) 


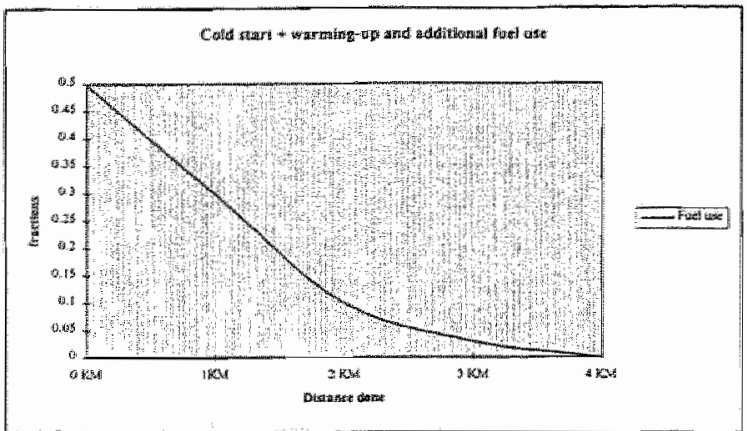

Figure 7.5 The cold start + warming-up phase
Note that

1. in a cold winter situation the figures are even worse and wice versa during a warm summer;

2. the same situation exists for direct and indirect fuel injection:

3. the cold start conditions do not apply to the diesel engine, that means the normal fuel-air mixture is immediately present.

As already noted above, Figure 7.3 show the time trajectory of the basic emission factor of $C O$ of a 1.4-2.0L gasoline car

equipped with a closed catalytic converter driving in the urban area with variable speed $\left(E F_{s}[C O, P, M, R T I]\right)$ as the sum of the cold part and its warm counterpart $\left(E F_{w}[C O, P, C L, M, R T I]\right)$, equation 7.4.1, and its parameter values indicate that 51\% (Table 7.2) of the urban traffic belongs to the category cold starts + warming-up phase $(0-4 \mathrm{KM})$. This means that in our example of an urban drive $93 \%$ of the $C O$ emission originates from this phase.

\subsection{The Emission Computer Model}

The developed computer model computes the 3 basic emission functions of 'Text table 7.4. For example, the yearly basic emission factors $C O, V O C$ and $N O$ for passenger cars:

In general : where

$$
E F_{b}[E F, F, T, c c, R T]=\left(\left(1-A_{c}[R T]\right)+A_{c}[R T]^{*} C_{c}\left[E F_{,} F_{n} T, c c, R T\right]\right)^{*} E F_{w}\left[E F, F, T, c c_{n} R T\right]
$$

$E F_{b}[\bullet]$ : basic emission factor

$E F_{w}[\cdot]$ : emission factor warm engine

$A_{c}[-] \quad$ : fraction warming-up driving in the traffic performance by $R T$

$C_{c}[-] \quad$ : correction factors for cold starts or warming-up phase

The dimensions, arrays or vectors are elements of the following sets and subsets: where

$$
E F \in\left\{C O, N O C, N O_{x}\right\}
$$

$$
\begin{array}{cl}
C O & : \text { carbon monoxide } \\
V O C & : \text { volatile organic compounds } \\
N O x \quad & \text { : nitrogen oxides } \\
F \in\{P, D, L P G\}
\end{array}
$$

where

$$
\begin{array}{cl}
P & : \text { gasoline } \\
D & : \text { diesel oil } \\
L P G & : \text { liquefied petrol gas } \\
T \in\{(P, L P G): N B, I N B, O L, C L ;(D): I N D, D N\}
\end{array}
$$

where

$$
\begin{array}{ll}
N B & \text { : conventional (gasoline, LPG) } \\
\text { INB } & \text { : improwed conventional (gasoline, LPG) } \\
O L & \text { : open loop catalytic (gasoline, LPG) } \\
C L & \text { : closed loop catalytic (gasoline, LPGx) } \\
\text { IND } & \text { : indirect injection (diesel) } \\
D I & \text { : direct injection (diesel) }
\end{array}
$$




$$
\begin{aligned}
& \text { where } \begin{array}{l}
c \in \in S, M, L\} \\
S \quad: \quad>1.4 \text { litre } \\
M \quad: \quad 1.4 \mathrm{~L}<2.0 \mathrm{~L} \\
L \quad:>2.0 \text { litre } \\
R T \in\{R T I, R T 2, R T 3\}
\end{array}
\end{aligned}
$$

where

RTI : urban roads

$R T 2 \quad:$ rural roads

RT3 : highway

$$
E F_{w}[E F, V, F, T, c c, R T]=\operatorname{Cco}\left[F, T_{n} c c\right]^{*} b[F, T, c c, R T]^{*} E\left[F_{u} T, c c_{2} R T\right]^{[F, T, c]}
$$

where

$E F_{w}[-]$ : emission factor warm or hot engine

$C$ co $[\cdot]$ : emperical technical parameter in Text table 7.5

$E[\cdot]$ : energy use (g/hour)

$p[\cdot] \quad$ : emperical technical parameter in Text table 7.5

$b[\cdot] \quad$ : fuel use $(\mathrm{g} / \mathrm{km})$

In sum, $270 E F_{b}$ combinations have to be computed for each time unit (year), totalling to 8100 for: each run of the period 1986-2015. 


\subsection{From basic emission factors to vintage emission factors}

As explained above, the basic emission factors are completely detemined by technical and average driving conditions, and are the starting points to arrive at the yearly Dutch auto park emission. The auto park emisision depends on the traffic performance of each vintage in the car stock and the technological composition of the car stock or vintage structure of the car stock, as shown in Figure 7.1. The vintage emission and fuel use factors will be treated hereafter, the park emissions will be dealt with in the next chapter.

The vintage emission factor, $E F_{y,}$ (a scalar) equals the inner product of the row vector $\left[W^{\prime} F\right]^{*}$ (weight factors in vintage) and the vector $\left[E F_{b}\right]$ (basic emission factors), or

$$
\left[V F_{w}\right]^{\prime} \cdot\left[E F_{b}\right]=E F_{u}
$$

The dimension of the vintage emission factors are gram/weh- $\mathrm{km}(\mathrm{g} / \mathrm{km})$.

Figure 7.6 The $C O, N O x, V O C$ vintage emission factors for gasoline cars for 3 different road types
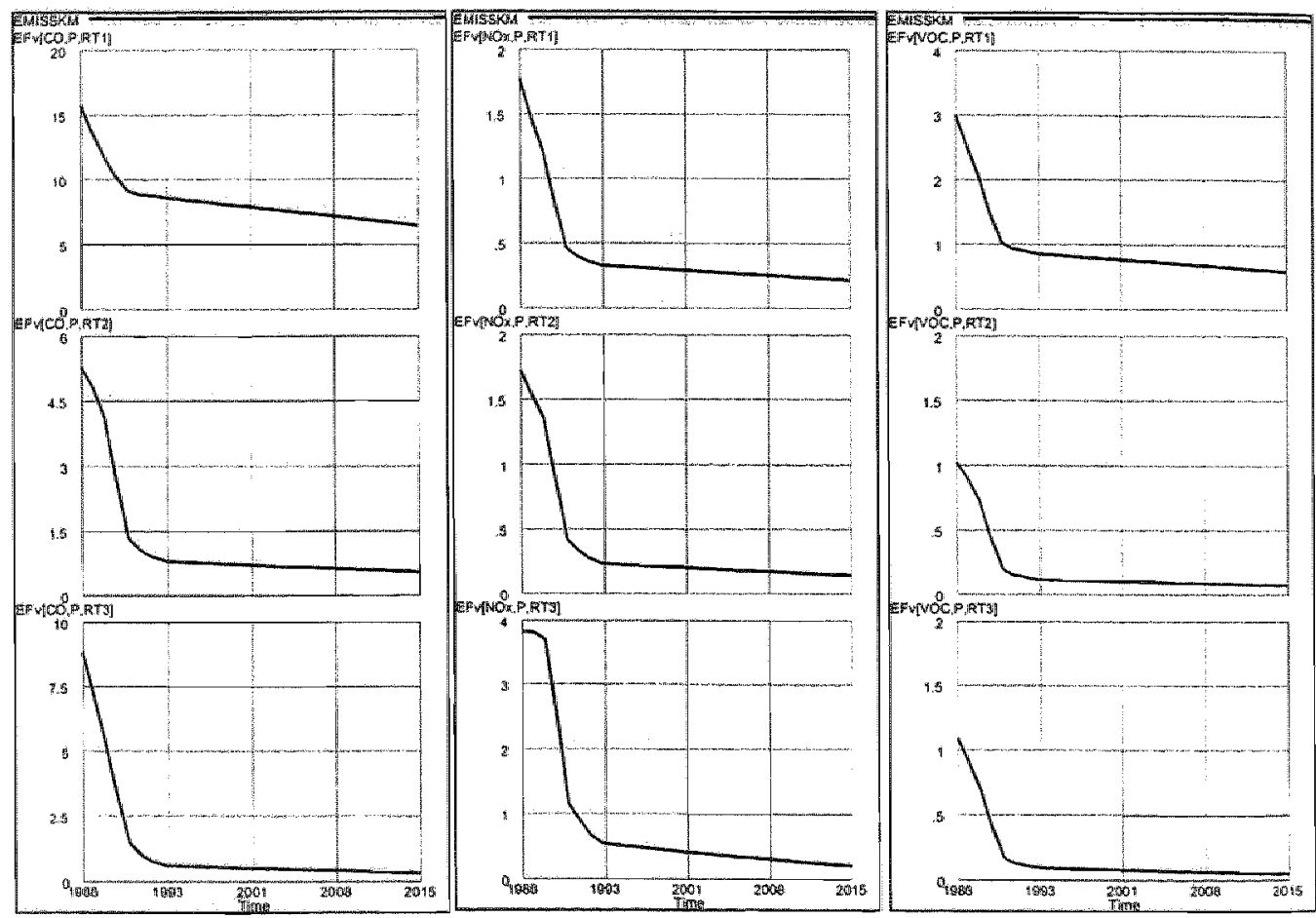

The vintage ernission factors for gasoline (figure 7.6) and LPG (Figure 7.8) engines show impressive decreases for the period 1986-1992 due to:

- the introduction of the open loop and closed loop catalytic converter (output technology), and

- high penetration rate (high turnover or new car sales) of the new output technology

From 1993 on no new technological engine and/or design innovation has been assumed, only the continual technological improvement remains active. These technological improvements are described in section 7.3.2. The technological innovation in case of input and combustion processes will be described and simulated in the next chapter. Note as explained in section 7.1 the diesel engine follows a different combustion process and was from the beginning on a relative low emission process, reinforced by the introduction of the direct injection technique and catalytic converter (Figure 7.7). 

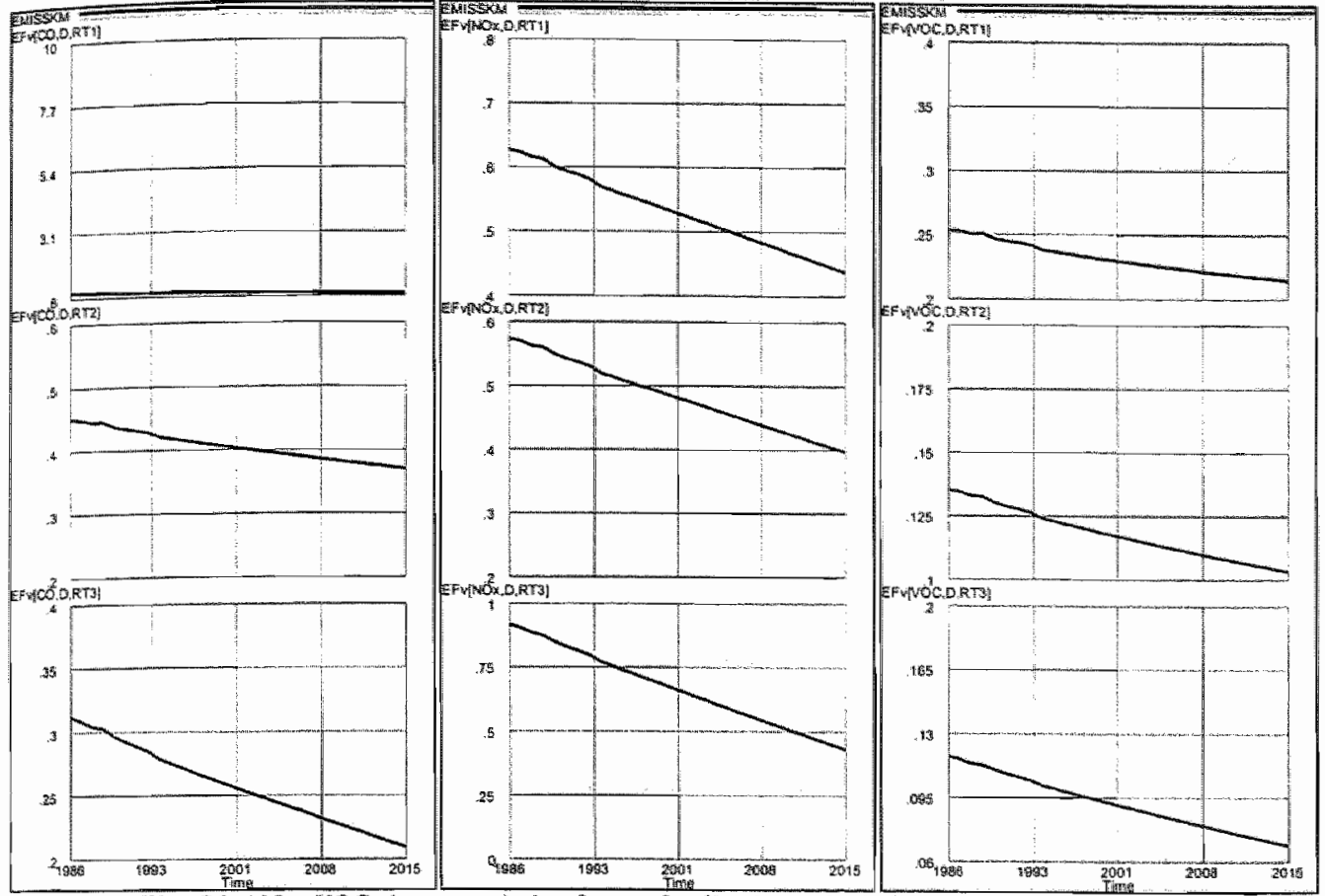

Figure 7.7 The $C O$, NOx, $V O C$ vintage emission factors for diesel cars for 3 different road types
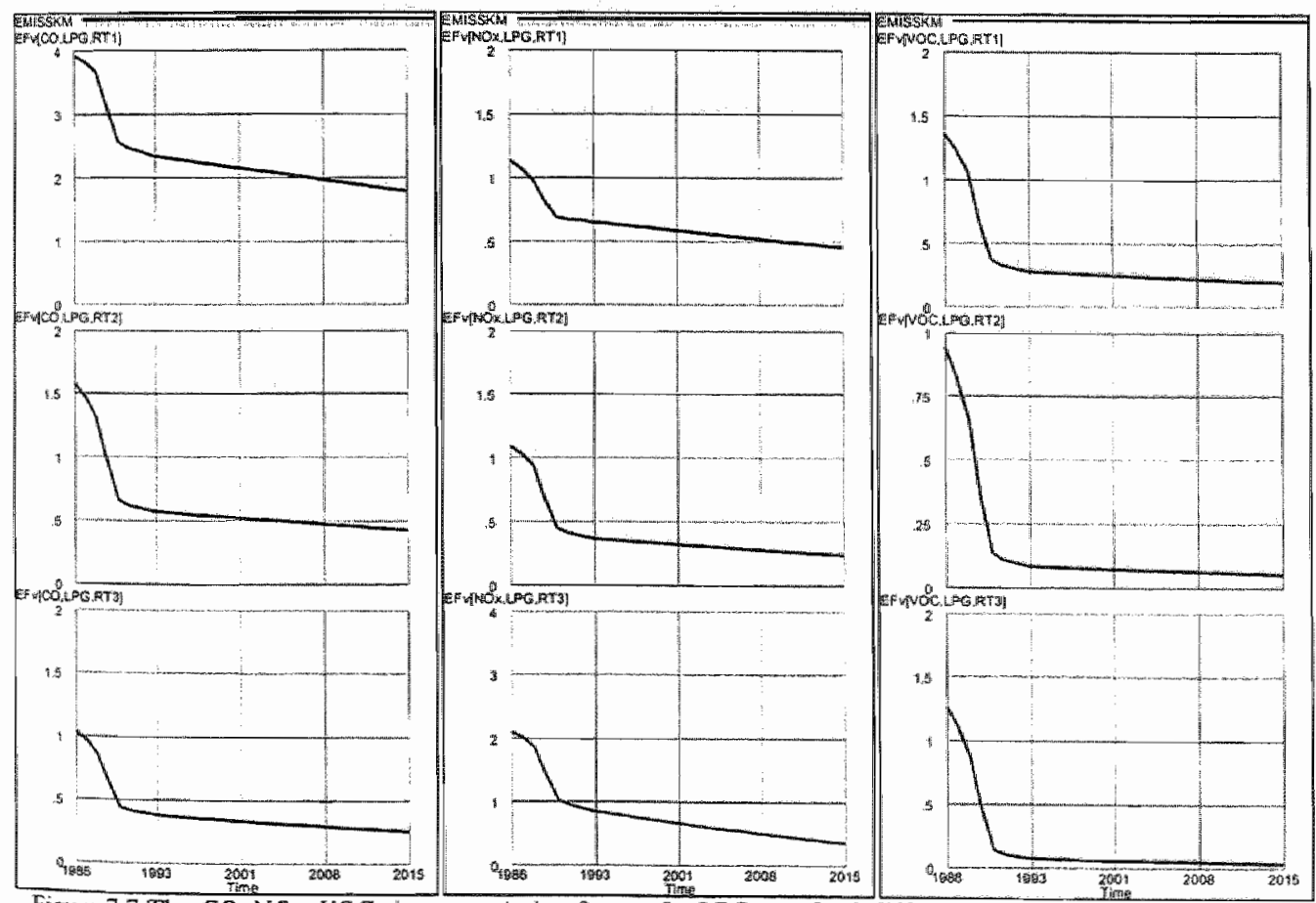

Figure 7.7 The $C O, N O x$, VOC vintage emission factors for $L P G$ cars for 3 different road types 


\subsubsection{The $\mathrm{CO}$-mission in 1990 , a computational exercise and validation}

As referenced above the vintage-emission factors for $C O . V O C$, and $N O_{x}$ will be deduced from the basic-emission factors by applying weight factors. These weight factors represents the share of the several vehicle classes $(T)$ which participates in the traffic performance per vintage (year of construction) by the same velucle categories. These shares are based upon the new car sales of each vehicles per class $T$ of Table 5.2. For the year 1990 Table 7.6 gives an example how to arrive to the vintage-emission factors for tuel type gasoline and urban road type RTI.

\begin{tabular}{|c|c|c|c|c|}
\hline \multicolumn{3}{|c|}{ Wintage-Emission foctors TODO } & \multirow[b]{2}{*}{ Easic } & \multirow[b]{2}{*}{ Vintage :" } \\
\hline WTI & & Wreigh & & \\
\hline & & Factor & Emission & Ermission: \\
\hline Gasoline & & Wintage & Factors & Factors \\
\hline \multirow[t]{4}{*}{ Q W 4 inter } & Conwentional & 0.02 & 15.40 & 0.31 \\
\hline & Improved conv. & 0.02 & 16.30 & 0.21 \\
\hline & Open loop Cat. & 0.07 & 890 & 0.62 \\
\hline & Closed loop Cat. & 0.31 & 7.80 & 239 \\
\hline \multirow[t]{4}{*}{ T. 4 - 2.0 liter } & Conventuonal & 0.01 & 18.00 & 0.18 \\
\hline & Improved conv. & 0.01 & 1250 & 0.13 \\
\hline & Open loop Cat & 0.10 & 960 & 0.96 \\
\hline & Closed loop Cat. & 0.42 & 920 & 3.86 \\
\hline \multirow[t]{4}{*}{ s $2.07 i t e r$} & Conventional & 0.00 & 2100 & 0.00 \\
\hline & Improved conv. & 0.00 & 0.00 & 0.00 \\
\hline & Open loop Cat. & 0.00 & 0.00 & 0.00 \\
\hline & Clased loop Cat & 004 & 71.20 & 0.45 \\
\hline Total & & 1.00 & & 9.10 \\
\hline
\end{tabular}

Table 7.6 The Wintage-emission factor $C O$ for RT1 1990
The weight factors are from Table 5.2 and represent the share of the new car sales in 1990 of the possible classes $T$. By multiplying the weight factors (column 3) with the related basic-emission factors, computed by the emission model one arrives at the vintageemission factor, which has to be summed. The value $9.10 \mathrm{~g} / \mathrm{km}$ returns in Table 7.7 first entry column 5 .

Note $9.1 \mathrm{~g} / \mathrm{km}$ will be labelled to the "vintage 1990 ", for CO emission road type RTl, during the whole lifetime till the moment "wintage $1990^{\prime \prime}$ has been scrapped from the Dutch car stock.

The analogue procedures takes place for the $R T 2$ and $R T 3$ road types. The same

procedures holds for the diesel and LPG cars. It is in this way how the vintage-emission factors are computed and applied in order to compute the total $C O$ emission.

In order to get more insight in the computational procedures the total $C O$-emission will be presented for the year 1990 , the figures will be checked against the official CBS (computed) emission data. As noted above from the basic-emission factors we have to go to the vintage-emission factors (this is the weighted (by technology by cc) emission factor per vintage) for three road types (as a proxy for drive behaviour). These vintage-emission factors should be multiplied by the traffic performance per vintage (kilometrage per vintage by fuel class). Table 7.7 shows the results of the computational procedures. The yearly kilometres per vintage (column 2) comes from the veh-km model developed in chapter 6, the car-vintage (column 3) are from the car models developed in chapter 5, and multiplying column 2 by 3 one arrives at the kilometres of each vintage. The vintage-emission factors (column 5,6 , and 7 ) are computed by the emission model developed in this chapter. The road type distribution (column 8,9 , and 10 ) is from the CBS and remains constant. To compute the overall emission on has to compute first the $\mathrm{RT} 1, \mathbb{R} T 2$, and the $\mathrm{RT}$ 3 wintage-park-emission (column 12, 13 , and 14). This is performed by multiplying column 4 , column 5 , and column 8 to get the result of column 12 . After summation over all vintage and over the three road types one arrive at the total $C O$ emission for the several fuel types. 


\begin{tabular}{|c|c|c|c|c|c|c|c|c|c|c|c|c|c|}
\hline$I$ & 3 & 3 & $\frac{4}{12 \pi}$ & 5 & $\frac{6}{6}$ & 9 & s. & 3 & उत & 11 & II & is. & 24 \\
\hline & & & \multicolumn{4}{|c|}{ 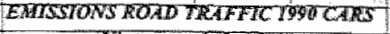 } & & & & RT & RTI & RT: & $\mathrm{RT}$ \\
\hline \multicolumn{2}{|c|}{ TOASOLNE $15 \%$} & & & \multicolumn{3}{|c|}{ 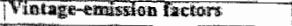 } & Rond Dpe & 4 of & & \multicolumn{3}{|c|}{ 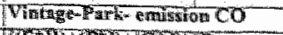 } & \\
\hline Wh thatse & Whaving & vinit-edrs & 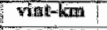 & RTi & ET & Ris & RTI & RT & $\mathrm{RY}$ & \multicolumn{3}{|c|}{ 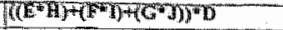 } & \\
\hline I994 & 18310 & 325 & 51892290 & 9. & 9.40 & 7.58 & $0.21 \%$ & 4,3 & 0.38 & 39.36 & 12.89 & 3.13 & $3 \cdot 3 \pi$ \\
\hline Fis & 3.5830 & 353 & 2567990 & 10.00 & 2.90 & 3.46 & 0.24 & ब. & 0.35 & 26.73 & T3. 42 & 6.10 & 7. 12 \\
\hline 7938 & 9540 & $34 \sqrt{3}$ & E295920 & 12.60 & 4.00 & 5.20 & $0.2+2$ & (19.8 & 0.31 & 33.72 & 15.25 & 8. & 27.46 \\
\hline 258 & 24030 & 398 & 558394 & 84.60 & 4. 6 & 7.10 & 0.24 & 30 & (5. . 3 & 44.61 & 18.76 & 36.14 & 25.67 \\
\hline 7986 & 53160 & 400 & $\$ 260004$ & 28.1010 & $5.3 \overline{0}$ & 8.90 & 0.24 & 8.38 & 1. 39 & 48.62 & 20.23 & 70.60 & 94.80 \\
\hline 393 & 13720 & 3,43 & 4500960 & 19.001 & 6.00 & 11.60 & 5.24 & 5.58 & 0.38 & 49.59 & 20,52 & 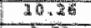 & D. Th \\
\hline 584 & 22280 & 3210 & $392960 \%$ & 20.00 & 6.50 & 12.60 & 8.24 & 10.38 & 6.38 & $45-19$ & 3.66 & 4.7 & पूर 92 \\
\hline 3583 & 22150 & 327 & 39730680 & $2 \overline{2}+00$ & 7.20 & 43.06 & 2.24 & 0.38 & 0.38 & 54.32 & 20.98 & 20.72 & 18.63 \\
\hline 1.562 & I0929 & 278 & 2952620 & 22.90 & 7.11 & 53.28 & 0.21 & 4.35 & 0.38 & 38.55 & 15.60 & 9.6 & 4.48. \\
\hline 1501 & 2ALS & 226 & 2745900 & 22.00 & 7.26 & $E 3$. & 0.34 & 0.36 & 0.55 & 39.47 & 34.50 & 5,42 & 1. $\$ 5$ \\
\hline \multirow[t]{3}{*}{ W } & 9650 & $77 \mathrm{~g}$ & y. & 40.00 & 5. 0109 & 13.80 & 0.24 & 9.35 & 0.38 & 130.80 & 71.43 & 22.62 & उद. \\
\hline & & 4080 & 53,205040 & & \multicolumn{5}{|c|}{ 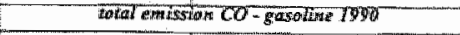 } & 3342 & 212,39 & 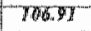 & 773.79 \\
\hline & & & & & & & \multirow{2}{*}{\multicolumn{3}{|c|}{ I Ro id type distribution }} & & & & \\
\hline \multicolumn{2}{|c|}{ DIESEL 1900 } & & \multicolumn{4}{|c|}{ 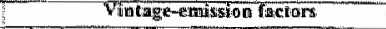 } & & & & \multicolumn{3}{|c|}{ Whitge-park-erassion $\mathrm{CO}$} & \\
\hline Wintase & Thomint & Fint-cary & Wint-Gont & Ril & $\mathrm{TR}$ & $\mathrm{Rm}$ & $\mathrm{ATT}$ & $\min$ & ming & $(W \mathrm{E} T)+(\mathrm{F}$ & 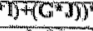 & & \\
\hline is & 32500 & उध & 1272.60 & 0.54 & 0.42 & a. 30 & 0.21 & 0.38 & 0.38 & 6.63 & Q. & 0.25 & 0.2 .4 \\
\hline 4918 & $366 i 10$ & 85 & 2379650 & 0.94 & 9.42 & 0.30 & 0.24 & 6.38 & 0.32 & $2 .+9$ & 6.94 & 6.35 & 0,3 \\
\hline Mige git & 39050 & 54 & 2449200 & 0.95 & 6.42 & 0.30 & 0.24 & 3.38 & 0.38 & 9.25 & $0.5 \%$ & 0.40 & 0.28 \\
\hline 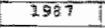 & 25000 & 59 & 2845200 & 0.95 & 0.42 & 0.30 & 0.24 & D. 38 & $0: 38$ & 10.93 & $0 .-12$ & 0,30 & 0.21 \\
\hline 49 & 26550 & 71 & 28.85760 & 0.34 & 0.42 & 0.30 & 0.24 & 0.38 & 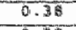 & 0.94 & 0.83 & 0.30 & 0.21 \\
\hline 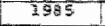 & 25660 & 57 & $77922 \%$ & 1. .20 & 0.50 & 0.510 & 0.24 & 5.38 & 6.36 & 1.15 & 0.50 & 6. 33 & 6. 13 \\
\hline 259 & 27260 & 55 & 1499300 & 1.50 & 0.60 & 0,0 & 0.24 & 5.30 & 0.3 & $=34$ & 0.54 & $6 \cdot 314$ & 0.45 \\
\hline 1983 & 23150 & 3 & 903630 & 1.60 & 6.70 & 1.00 & $0 \ldots 24$ & 0.38 & 0.38 & 0.9 & g. 39 & 6.24 & 0.34 \\
\hline 192 & 20970 & 31 & 650076 & 2.10 & 10.60 & 3.30 & 0.24 & $0.3 \mathrm{a}$ & 0.38 & 0.85 & 0.39 & 6.30 & 0.33 \\
\hline 3901 & 3758 & 25 & 4395000 & 2.40 & 0.90 & 1.5. & 0.28 & $0.3 \mathrm{E}$ & 0.38 & 0.65 & 0.25 & 0.13 & $0.2 \pi$ \\
\hline \multirow[t]{3}{*}{ RS } & 78900 & 53 & 300480 & 3.50 & 3.20 & 2.百和 & 0.23 & (1.38 & 6.36 & 2.07 & 0.6 & ㅂ. & 0.76 \\
\hline & & 578 & 15101820 & & & \multicolumn{3}{|c|}{ total emingion $\mathrm{CO}$ - dies } & & 5.97 & 309 & 3.25 & $35 \%$ \\
\hline & & & & & & & & & & & & & \\
\hline $1 \mathrm{PCO} 1900$ & & & & \multicolumn{3}{|c|}{ 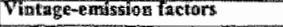 } & \multicolumn{3}{|c|}{ Theall type distribution } & \multicolumn{3}{|c|}{ Pintege-Parta-emisston CO } & \\
\hline Vintoge & YKAn wint & wint-cars & Wht-kwn & FTil & $\mathrm{RT} 2$ & RTs & RTI & RT2 & RTM & 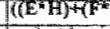 & $(\mathrm{d}+(\mathrm{C}-\mathrm{Jj})$ & & \\
\hline 195 & 36330 & 38 & 1320510 & 2.60 & 0.70 & 9.46 & $0 . \overline{2} d$ & 5.98 & $0.3 \%$ & i. $4 \mathrm{~g}$ & 6.06 & 0.37 & 0.25 \\
\hline isting & 35780 & 58 & 2075280 & 3.20 & 1.00 & 0.68 & $\hat{4}, 2$. & 0.36 & 0.35 & 2.96 & 1.59 & 0.79 & 0.52 \\
\hline 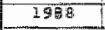 & 31960 & 52 & 16151920 & 3.60 & 3.30 & 0.83 & 0.34 & 0.38 & 0.30 & 2.78 & 1.4 & 0.02 & 0.52 \\
\hline 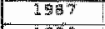 & 26900 & 56 & 1506400 & 3.60 & 1.50 & 0.98 & 0.20 & 0.316 & 0.3 & 2.77 & 1.34 & 0.8 .6 & 0.54 \\
\hline 158 & 25470 & 57 & 1451790 & 4.00 & 1.70 & 1.10 & 0.24 & 0.391 & 0.38 & 2.94 & 1.35 & 0.94 & 0.65 \\
\hline 255 & 26550 & 53 & 1407150 & 4.20 & 1.70 & 1.10 & 0.34 & औ. 39 & 0.318 & 2.92 & 1.12 & d. 91. & 0.59 \\
\hline 1904 & 22280 & 49 & 2086620 & 4.20 & 2.70 & 1.19 & 0.34 & 0.3 & 0.3 .3 & 2.25 & 1.10 & 0.70 & 0.45 \\
\hline 1983 & 23380 & 52 & 1215760 & 4.26 & 1. 70 & 1.10 & 0.24 & $0.3 \%$ & 0.38 & 2,52 & 2.23 & 6.79 & 0.51 \\
\hline 1942 & 19150 & 48 & 9592018 & 4.20 & 1.70 & 2.10 & 0.24 & $0.3 \pm$ & 0.3 .8 & 1.98 & 0.93 & 0.59 & 0,31 \\
\hline 29: 1 & 19490 & 39 & 770110 & 4.20 & 1.70 & 1.10 & 0.36 & $8.3 \overline{11}$ & 0.38 & $1.5 \%$ & 0.77 & 0.49 & 0.32 \\
\hline REST & $20 \div 70$ & 87 & 1906990 & 4.20 & 1.70 & 7.20 & $0 . \overline{24}$ & 0.31 & 0.38 & 3.74 & 1.82 & 2.17 & 0.76 \\
\hline 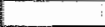 & : & 5189 & 1.5271930 & & & Totrar antiosi & $\tan C \sigma-2$ & 26590 & & $27 \%$ & $\pi 39$ & 8.42 & 3,48 \\
\hline
\end{tabular}

Table 7.7 An example of the simulated CO emission for the year 1990

\begin{tabular}{|c|c|c|}
\hline \multicolumn{3}{|c|}{ Comparison with CiBS figures } \\
\hline 1990 & $\mathrm{CBS}$ & Sirnulated \\
\hline \multicolumn{3}{|l|}{$60(\mathrm{~m} w \mathrm{~h} / \mathrm{kg}$} \\
\hline Tothl & 365 & 565 \\
\hline \multicolumn{3}{|l|}{ of nifulich } \\
\hline KTI & 279 & 262 \\
\hline $\mathrm{RT2}$ & 117 & 118 \\
\hline RTY & T68 & 183 \\
\hline \multicolumn{3}{|l|}{ of which } \\
\hline gasoline & 525 & 525 \\
\hline diesel: & 12 & 12 \\
\hline $\mathrm{LPG}$ & 28 & 28 \\
\hline
\end{tabular}

Table 7.8
The CBS computations (Table 29, page 49, (CBS, 1992)) for CO by cars for the year 1990 (Table 7.8 ) arrive at $565 \mathrm{~m} \mathrm{~kg}$, by summing column 11 we arrive at $564.6 \mathrm{~m} \mathrm{~kg}$, which is in the same order of magnitude. There are some differences in the urban road drives (RT1) and the RT3 (high way) emissions, but seen the uncertainties of the distribution of the road type the differences are neglectable. 


\subsection{From basicic fuel ase factors to vintage fuel use factors}

\subsubsection{Introduction}

The emission model computes the fuel use in $g / \mathrm{km}$ (see Text table 7.3), in order to arrive at the basic fuel use factor in litres per kilometre $(1 / \mathrm{km})$ we make use of the following conversion factors, Table $79,(\mathrm{CBS}, 1992 \mathrm{C})$ and the following defintions:

\begin{tabular}{|lcl|}
\hline Conversion factors energy carriers & \\
Futel & $\mathrm{kg} /$ titre & $\mathrm{PJ} / \mathrm{m} \mathrm{ln}$ litr \\
Gasoline & 0.748 & 0.032912 \\
Diesel & 0.84 & 0.035868 \\
LPG & 0.53 & 0.023954 \\
\hline
\end{tabular}

$$
\begin{aligned}
& \text { fuel use }(\mathrm{g} / \mathrm{km})=(\mathrm{g} / \mathrm{h}) /(\mathrm{km} / \mathrm{h}) \text {, or } \\
& \text { fuel use }(\mathrm{L} / \mathrm{km})=(\mathrm{g} / \mathrm{km}) /(\mathrm{g} / \mathrm{L}) \\
& \text { where } \\
& \qquad \begin{array}{l}
\mathrm{g}=\text { gram } \\
\mathrm{h}=\text { hour } \\
\mathrm{L}=\text { litre } \\
\mathrm{km}=\text { killometre }
\end{array}
\end{aligned}
$$

Once again, as was the case of the emission factors, a correction has to be made for cold starts and warming-up phase during the first four kilometre. In order to get a general impression of the relationship between cold star and warming-up phase $(0-4 \mathrm{~km}$, average speed $22 \mathrm{~km} / \mathrm{h})$ and the fuel use, this relation can be approximated by the empirical relationship between average vehicle speed $(\mathrm{km} / \mathrm{h})$ and litres $100 \mathrm{~km}$ (Redsell et al, 1988) depicted in figure 7.8 . Note the function relates to a gasoline engine, $1600 \mathrm{cc}_{\mathrm{s}}$ vintage 1985 .

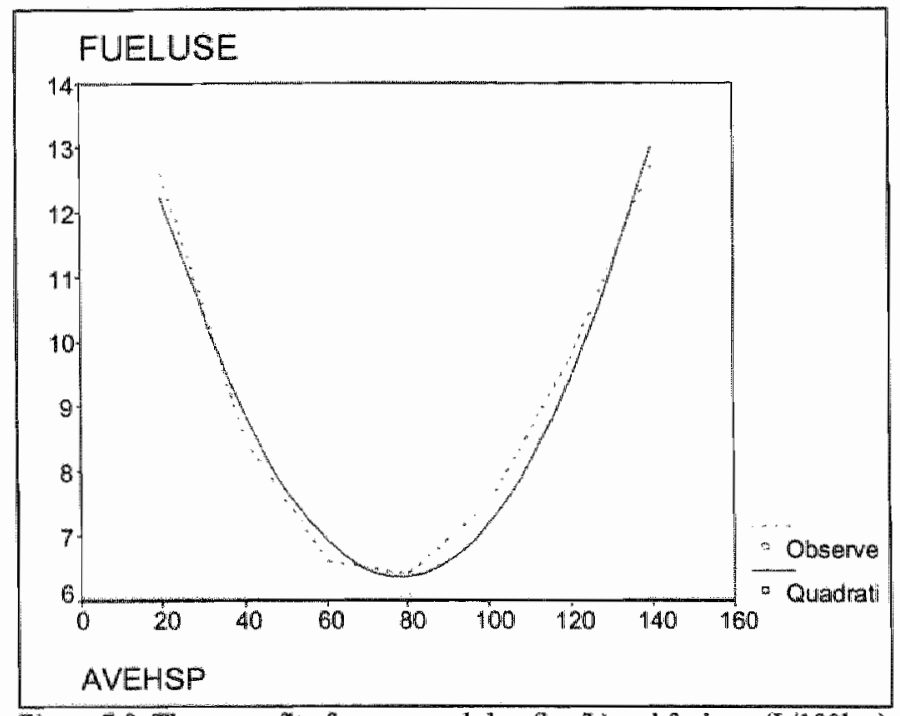

Figure 7.8 The curve fit of average veh- $\mathrm{km}(\mathrm{km} / \mathrm{h})$ and fuel use (L/100km)

The fitted parabola runs as follows:

where

$$
F_{u}=17.2-0.2726 S+0.0017 S^{2}
$$

$$
\begin{aligned}
& F u: \text { fuel use }(\mathrm{L} / 100 \mathrm{~km}) \\
& S: \text { average vehicle speed }(\mathrm{km} / \mathrm{h})
\end{aligned}
$$

The same relationship has been fitted with numerical output of the simulation model for ali type of car's of vintage 1995 , where the average speed where set at $20,35,50,80,110,120 \mathrm{~km} / \mathrm{h}$. Table 7.10 shows the results of the parabolic fit. Figure 7.9 shows the comparison between the 1985 quadratic function and the 1995 on. In comparison with equation 7.7 the ten year of fuel use economy is clear and distinct. It is the demonstration of gradual technological improvements. 


\begin{tabular}{|c|c|c|}
\hline \multicolumn{3}{|c|}{ Parabolic fit fwel wse by average vehicle speed (vintage 1995) } \\
\hline \multicolumn{2}{|c|}{ Grasolne closed catalyuc converter } & $\mathrm{R}^{2}$ \\
\hline$<1.4 L$ & $F_{L}=8.33-0.1245+0.0009 \mathrm{~s}^{2}$ & 0.991 \\
\hline $1.4 .2 .0 \mathrm{~L}$ & $F_{L}=10.4 s-0.1495 \mathrm{~S}+0.001 \mathrm{~s}^{2}$ & 0.990 \\
\hline$>2.01$ & $F_{t}=13.85-0.195+0.0012 s^{z}$ & 0.983 \\
\hline \multicolumn{3}{|c|}{ Diesel indirect } \\
\hline$<1.4 \mathrm{~L}$ & $F_{t S}=5.925-0.0894 \mathrm{~S}+0.0007 \mathrm{~S}^{2}$ & 0.985 \\
\hline $1.4-2.0 \mathrm{~L}$ & $F u=7.7-0.104 S+0.0007 S^{3}$ & 0.992 \\
\hline$>2.0 \mathrm{~L}$ & $F t=9.515-0.119 S+0.0008 S^{3}$ & 0.990 \\
\hline \multicolumn{3}{|c|}{ Diesel direct injectio } \\
\hline$<1.4 \mathrm{~L}$ & $F_{v}=4.498-0.0681 \mathrm{~S}+0.0005 \mathrm{~S}^{2}$ & 0.986 \\
\hline $1.4-2.0 \mathrm{~L}$ & $F_{u}=5.872 \cdot 0.0796 S+0.00106 S^{2}$ & 0.993 \\
\hline$>2.0 \mathrm{~L}$ & $F_{u}=7.247-0.0914 S+0.00068^{?}$ & 0.990 \\
\hline \multicolumn{3}{|c|}{ LPG closed cat converter } \\
\hline$<1.41$ & $F u=11.748-0.1739 s+0.0012 S^{2}$ & 0.988 \\
\hline $1.4-2.01$ & $F_{u}=140225-0.2011 \mathrm{~S}+0.0013 \mathrm{~S}^{2}$ & 0.988 \\
\hline$>2.0 \mathrm{~L}$ & $F_{u}=18.298-0.2477 \mathrm{~S}+0.0015 \mathrm{~S}^{*}$ & 0.980 \\
\hline
\end{tabular}

Tabile 7.10 The quadratic fitted model output

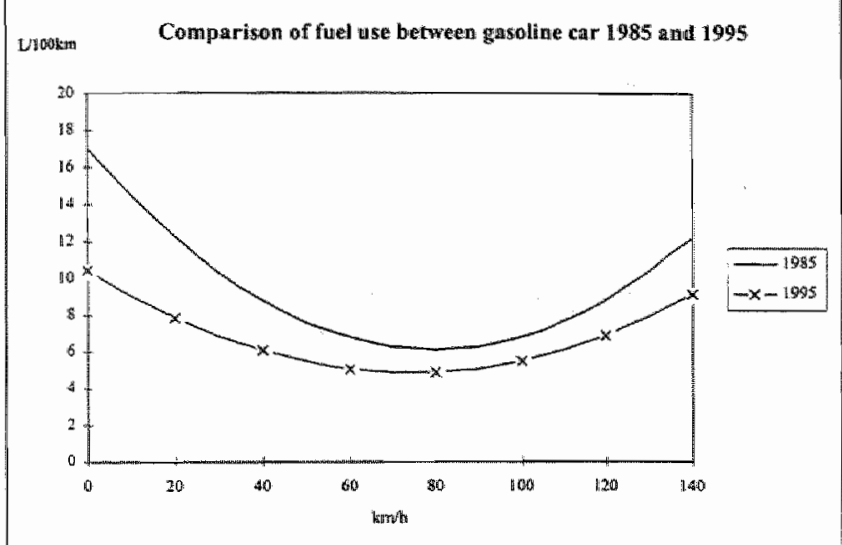

Figure 7.9 Comparison of fue use gasoline car vintage 1985 and 1995

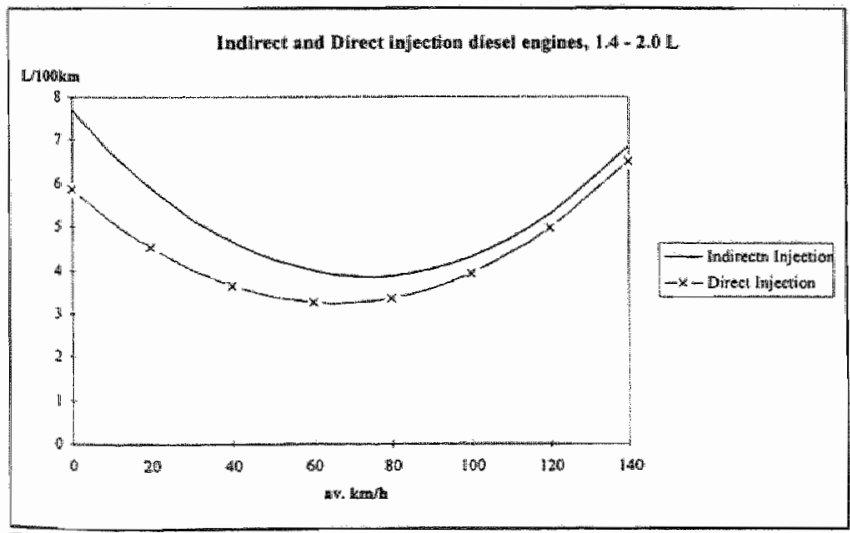

Figure 7.10 Indinect $~$ and direct injection diesel engine (1.4-2.0L)
Figure 7.9 shows the difference between the fuel use of an average gasoline car (1.4-2.0L) vintages 1985 and those of vintage 1995. The same process: of continuously technological improvements refers to the LPG cars and diesel engine cars, with the exception that in the diesell case the introduction of the direct fuel injection technique was a technological innovation in the combustion process optimising the fuel use economy as can be seen by comparing the related equations in Table 7.10 or the curves in Figure 7.10. The greatest impact of the direct injection technique occurs in the low speed trajectory where the fuel use and emissions of the direct injection technique outperforms those of the indirect injection techniques. The same picture arise in the lower and upper cc-class.

From the equation and figures shown above it will be clear how important a distinction by fuel type, by weight classes (ccclasses as proxy) and technology is in case of emission abatement or control strategies. The vintage structure of car stock. incorporates the time-related development of the qualitative aspects of the composition of the car stock. That is why the vintage fuel use factors is a consistent approach to deal with the exhaust of carbon dioxide, $\mathrm{CO}_{2}$, (a Greenhouse gas) and sulphur dioxide, $\mathrm{SO}_{2 *}$ (an Ozone gas). 


\subsubsection{Deriving the wintage fuell use factors}

In order to derive the basic fuel use factors, the weighted share of cold and warm phase by road type, according to Table 7.3, will be computed in onder to arrive at the basic fuel use factors for each year of comstruction $\left(F F_{b}\right)$. Note that the cold phase ( $A$ is used as a proxy) consists of three elementary Pacts:

1. a cold start, and

2. a warming-up trajectory from $0-4 \mathrm{~km}$

3. a constant temperature of $9^{\circ} \mathrm{C}$

The formulation reads as follows:

$$
F F_{b}[F, R T]=(1-A k[R T])^{*} F F_{*}+A k[R T]^{*} F F_{\mathrm{s}}
$$

where

$$
\begin{aligned}
F \in\{P, D, L P G\} \text { fuel type } \\
P \text { : gasoline } \\
D: \text { diesel } \\
L: L P G \\
R T \in\{R T I, R T 2, R T 3\} \text { road type } \\
R T 1: \text { urban roads } \\
R T 2 \text { : rural roads } \\
R T 3: \text { highways }
\end{aligned}
$$

$A k[$. ]: share cold start and warming-up phase in road type

$F F_{b}[\cdot]:$ basic fuel use factor

$F F_{\text {w }}[\cdot]$ : basic fuel use factor warm engine

$F F_{\alpha}[\cdot]$ : basic fuel use factor cold engine

The vintage fuel use factors, $F F_{v}$, are computed analogous with the vintage emission factors and equals the inner product of the row vector $\left[V F_{w}\right]^{\prime}$ (weight factors in vintage) and the vector $\left[F F_{b}\right]$ (basic fuel use factors), or

$$
\left[V F^{*}\right]^{\prime} \cdot\left[F F_{b}\right]=F F_{y}
$$

For each time period (in our case a year) the vintage fuel use factor has to be multiplied with the vintage kilometrage to arrive at the total vintage fuel use and summed over all vintages equals to the yearly fuel use of the car stock by fuel type. The next section gives an example of the derivation of the fuel use and the related $\mathrm{CO}_{2}$ and $\mathrm{SO}_{2}$ for the year 1990 .

\subsubsection{Fuel use, $\mathrm{CO}_{2}-$ and $\mathrm{SO}_{2}$ emission in 1990 , a computational exercise and validation}

In order to validate the proposed "vintage-fuel-use-factor" methodology the simulation results will be compared with the CBS figures for 1990 (CBS, 1996 B). Note CBS computes (not measured) the total fuel use of cars by multiplying aggregate figures, as total car stock gasoline (cars) times average total $\mathrm{km}$ per gasoline car $(\mathrm{km} / \mathrm{car})$ divided by average fuel use $(\mathrm{km} / \mathrm{Litre})$. The 'vintage-fuel-usefactor' method uses vintage figures, as the number of vintage gasoline cars times vintage average km divided by vintage fuel use $\left(F F_{v}\right)$ per road type $(R T)$ to arrive at the total vintage fuel use by road type. If summed over 11 vintages one arrives at the total fuel use for a specific year by road type,

\begin{tabular}{|l|c|c|c|}
\hline \multicolumn{4}{|c|}{ Comparison fuel use (min litres) with CBS figures } \\
\hline 1990 & CBS & CBS & Simulation \\
\hline & (original 1992) & (revised 1996) & \\
\hline gasoline & 4156 & 4330 & 4350 \\
\hline diesel & 1134 & 1190 & 1170 \\
\hline LPG & 1410 & 1430 & 1425 \\
\hline
\end{tabular}

Table 7.10 Comparison simulated and CBS results 1990 which after summing over the road types becomes the total yearly fuel use by fuel type. Table 7.11 shows the relationship or linkage between the variables described. above. The results are compared with the CBS figures for $1990 \mathrm{in}$ Table 7.10. Seen the different applied routes the closeness of the results walidates the vintage approach.

Emission of $\mathrm{CO}_{3}$ and $\mathrm{SO}_{2}$ are directly linked to the combustion of fuel, and the emission factors of $\mathrm{CO}_{2}$ and $\mathrm{SO}_{2}$ are derived from the sulphur- and carbon content of the fuels. The uncertainty margins of the emission factors of $\mathrm{CO}_{2}$ and $\mathrm{SO}_{2}$ are small, because the sulphur-and carbon contents of the 
fuels are well measured. For the determination of $\mathrm{SO}_{3}$ it is assumed that $95 \%$ of the sulphur content of the fuel will be exhausted as air polluting $\mathrm{SO}_{2}$. Seen the very low sulphur content of gasoline, and therefore very difficult to measure the fluctuations, we assume that the emission factor for $S O$, remain constant during the simulation period $1990-2015$, and will be fixed at 0.3 gram per litre. The $S O$. emissions for the combustion of LPG are neglectable. On the contrary the emission factors of the diesel oil is 10 times higher and fluctuates conform the fluctuation of the crude.

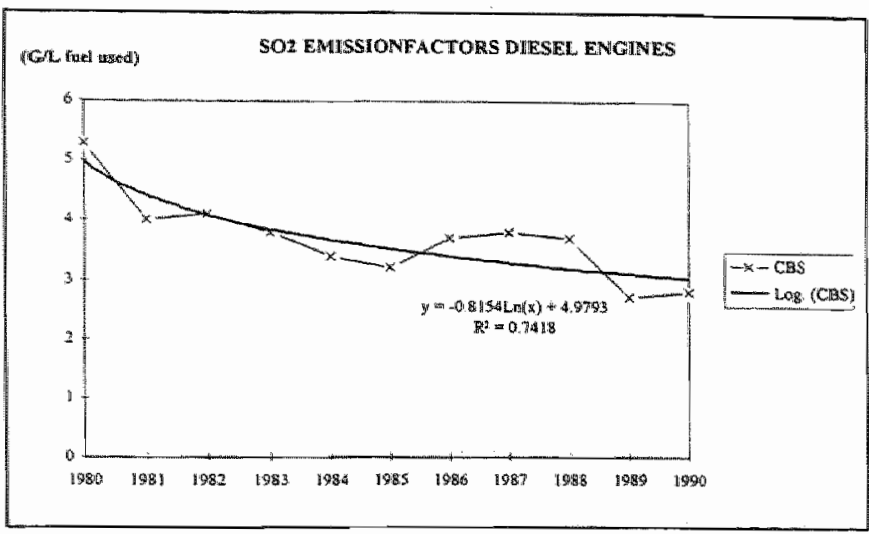

Figure 7.11 The emission factor of $\mathrm{SO}_{2}$ for the period $1980 \mathrm{~m} 1990$
The emission factors of $\mathrm{SO}_{\text {, for }}$ the period 1980-1990 are from the CBS (CSB 1993 C) and depicted in Figure 7.11. The logarithmic time trend will be applied in the simulation run which means the emission factor of $\mathrm{SO}_{3}$ will approach the value $2.0(\mathrm{~g} / \mathrm{L})$ in 2015 .

The emission factors of $\mathrm{CO}_{2}$ are based on the assumption of constancy of the carbon content of the fuel type for the simulation period 1990-2015 and the assumption that all carbon in will be converted in $\mathrm{CO}_{2}$. In fact this last assumption of complete combustion is not true, but in relation to the exhausted quantity of $\mathrm{CO}_{2}$ a correction would be neglectable.

Table 7.12 shows the emission factors applied in the simulation models.

\section{Conclusion}

The IW-TNO emission model complemented with our basic - and vintage fuel use factors is a furst attempt to describe the emissions of toxic, greenhouse and ozone particles and compounds. For the moment it is most detailed engineering model for the road traffic available and its development is an still ongoing process. The different fuel-use-reduction (FUR) technologies available have to be transformed into four indicators: 1. fuel use, 2. traction efficiency 3. roll resistance, 4. air resistance. In this way the four technology parameters describe the effects on the emissions given the kilometrage by fuel type, vintage and the weighted road drives (inner city ", urban -, and highway road types). 


\section{Chapter 8 \\ Automobility and emissions}

\# Objective

\#Methods

\# Data sources

\#Results
The linkage of the five modules, developed in chapter 2 to 7 in order to perform scenario analysis. In principle a large number of possible scenarios can be run, and the scenarios illustrated in this chapter is only a very small subset, due to lack of space. Recall that scenarios are are not at all forecasts, and the only purpose is to show how the developed model of the traffic system will behave under changing assumptions, cet. par.

Simulation methodology and scenario analysis

See chapter $2-7$

The results of the illustrated scenarios are indications for the central and local authorities to optimise a policy mix, illustrating the trade-off between the (alleged needed) volume growth of displacements and the pollution abatement. 


\subsection{The Dutch car park emission $\mathbb{1 9 9 0 - 2 0 1 5}$}

\subsubsection{Reference run}

A number of scenario's will be run and analysed with the reference run acting as a benchmark. The assumptions of the reference run have been dealt with in the preceding chapters and will be summarised hereafter.

The assumptions refer to the development of the:
I. Population
II. Households
III. Car ownership
IV. Automobility
V. Kilometrage
VI. Emission abatement technology
VII. Fuel use

Ad I. In chapter 2 the population dynamics was investigated and modelled in order to drive the household model. A parsimonious representation of the CBS population model was developed and

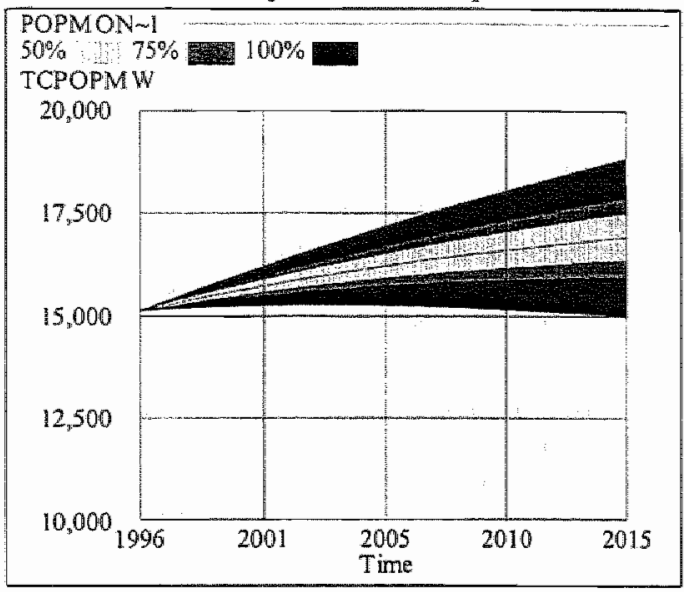
estimated with the prognoses of the CBS population model. The mid-variant prognoses act as the benchmark. Figure 8.11 shows the projected population figures.

The mean mid-variant Dutch population in 1915 is about 17.3 million persons. The expected births, originating also from $\mathrm{CBS}$, cascades through the 6-age classes, and summed each time period to the total Dutch population. The projected population figures act as an input driver of the n-person household model. The n-person household model is needed, in explaining the mobility aspects, because of the divergent development from the sixties on, as explained in chapter 1.

Figure 8.1 The Monte-Carlo simulation run

Ad II. Analogous to the population model a parsimonious representation of the household model has been developed (chapter 3) with the CBS household forecasts as benchmark for estimation purpose.

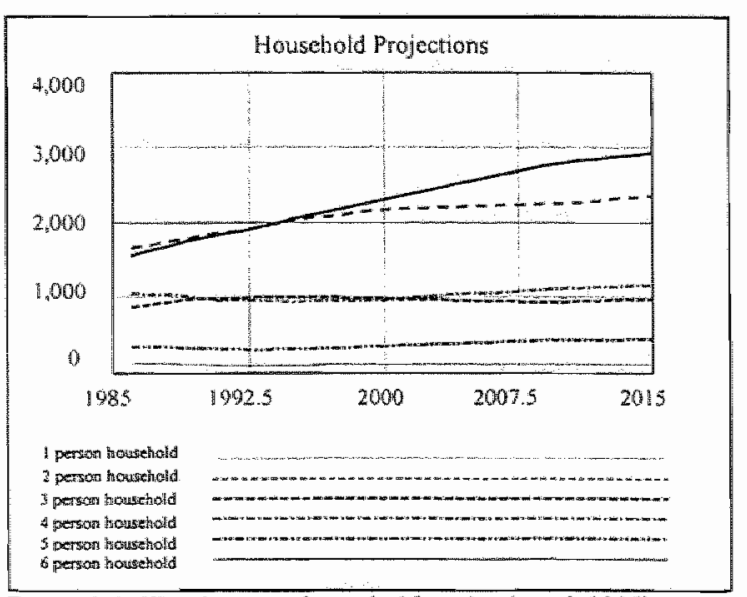

Figure 8.2 The 6-person household projections (x1000)
Figure 8.2 shows the projected 6-person household numbers. Note the strong increase of the 1 person households and the increase of the 2 person households, reflecting among others the greying of the Dutch population. This aspect has far reaching consequences on the mobility because the future elder people (the 40 . 50 s now) are more mobile and remains so than the actual elder. Because not only the increase in numbers but also the increase in mobility behaviour the future households accounts for a non-linear increase of the mobility, even for the auto kilometrage in correspondence with the non-linear increase of air mileage. 
Ad III. The expected penetration of the car-ownership over the $n$-person households will last for the 1- and 2-person households and saturates for the remainder 3- to 6-person households. The reason for the penetration rate to increase from $44.9 \%(1995)$ to $55 \%(2015)$ is the expected increasing elderly share of the 1-person households (Table 8.2).

\begin{tabular}{|c|c|c|c|c|c|c|c|}
\hline \multicolumn{8}{|c|}{ Housebolds by size and car ownership } \\
\hline 1995 & 1 car & 2 cars & $>2$ cars & $2010 / 2015$ & $1 \mathrm{car}$ & 2 cars & $>2$ cars \\
\hline $1 \mathrm{pHSH}$ & 44.9 & & & 1 PHSH & 55.0 & & \\
\hline 2pHSH & 68.3 & 14.9 & & 2 pHSH & 70.0 & 30.0 & \\
\hline $3 \mathrm{pHSH}$ & 60.5 & 27.9 & 2.2 & 3pHSH & 70.0 & 30.0 & 5,0 \\
\hline 4pHSH & 68.9 & 21.6 & 3.1 & 4pHSH & 70.0 & 30.0 & 5.0 \\
\hline 5pHSH & 67.7 & 22.9 & 3.2 & SpHSH & 70.0 & 30.0 & 5.0 \\
\hline GpHSH & 63.8 & 21.8 & 5.0 & 6pHSH & 70.0 & 30.0 & 5.0 \\
\hline
\end{tabular}

Table 8.2 The actual and expected car penetration rate $(\%)$

The increase of the perietration rate of the 1- and 2-car ownership of the 2-person households is deduced from the expected increase of the women labour participation rate which cause the 2-car ownership to increase from $15 \%$ (1995) to $30 \%$ in 2015 . Both figures are assumed trends based on logarithmic time functions, as explained in chapter 6 and applied in the reference run.

The share of the new car sales and the composition of the car stock remain constant at 1995 figures:

- $82 \%$ gasoline

- $11 \%$ diesel

- 7\% LPG cars

The forecast growth of the real disposable income for the period $1995-2015$ is $2.5 \%$ and real constant oil prices in guilders are assumed.

Ad IV. The automobility of the $n$-person households as a behavioural variable is assumed to be constant for the 3- to 6-person households at 1995 figures, but is assumed to increase for the 1 - and 2person households, especially the recreation/sport motive accounts for the increase, this means that, except for the 1- and 2-person households, the volume is only dependent of the development of the nperson households

Ad V. As explained in chapter 6 the kilometrage of the Dutch households has been attained by two independent statistical sources:

1. The OVG survey (Onderzoek verplaatsingsgedrag van de Nederlandse bevolking) period 1985 1995 furnish us with the daily average distance done by car by motives by $n$-person households ( $n$ $=6$ ) which after multiplication's and summing over $n$-person households comes up with the

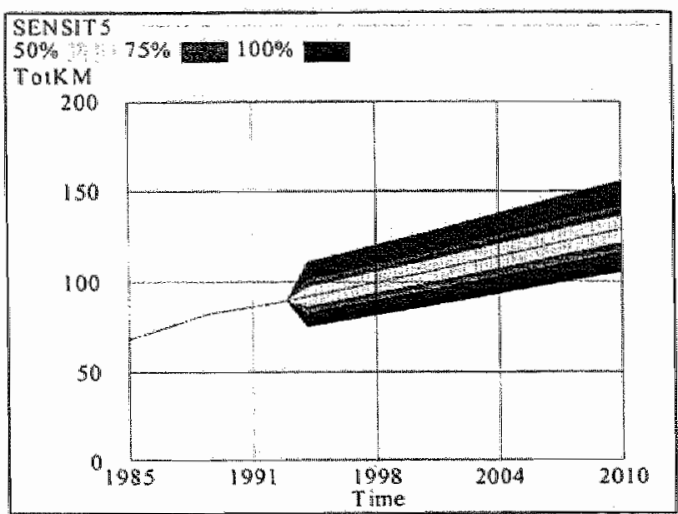

Figure 6.31 The sensitivity of total veh-km desired yearly auto-kilometrage of the Dutch households.

1. From the PAP survey (Personen auto panel) the average yearly kilometrage per fuel type per vintage are available and by the needed multiplication of these figures with the active vintage car stock by fuel type we arrive at the desired average total yearly vehicle kilometres of the Dutch car fleet.

Both approaches comes up with equal figures and the only assumption to be stated are the future development of the $n$-person households ( ad 2.) and the future expected travel behaviour. Figure 6.13 shows a Monte Carlo simulation of the projected $n$-person households and car-use by these households. The 1-to 6-or-more person 
households and the car use by motive ( 8 variables) are allowed to vary between $+10 \%$ and $-10 \%$, simultaneously and independently crawn from a uniform pseudo random generator during 1500 runs. The numbers are random drawn from an uniform distribution. The results are shown in figure 8.15 by graphical time plot with three confidence bounds included the mean value. Figure 8.15 shows the graph with the uncertainty in total vehicle kilometres, TotKM (*9), as it changes over time. Half of the simulations ( 750 ) have generated a value within the $50 \%$ region, white band, around the mean value of \pm 130 billion vehicle kilometres, with $50 \%$ upper bound of \pm 135 billion vehicle kilometres and $50 \%$ lower bound of \pm 125 billion vehicle kilometres. Three quarters of the simulations (1000) have generated a value within the $75 \%$ region, grey shaded band plus the white band and all the simulations ( 1000$)$ have generated a value within the $100 \%$ region, the black shaded bound with upper bound \pm 155 billion vehicle kilometres and lower bound \pm 115 billion vehicle kilometres.

Ad VI and VII. In 1970, an EC policy on passenger car emissions was established by the introduction of a first EC Directive. That initiative has already been amended since that time six times (EC, 1993 ). Each time, more stringent limit values were announced which were net by the car manufacturers" technical progress. The 1990 amendment, which came into force by the end of 1992, would lead to a total reduction in new car emission levels since 1970 of about:

$$
\begin{aligned}
& \text { - } 90 \% \text { for } C O \text { and } \\
& \text { - } 80 \% \text { for } H C+N O x
\end{aligned}
$$

The most recent EC Directive states that in the year 2000 the emission norms should be lower by 20 to $40 \%$ than 1996 standards. In 2010 these figure will be 50 to $70 \%$. The norms for the years 2000 and 2005 goes further than the US 1990 Clean Air Act standards and are comparable with the California norms. From 2000 on the fuels gasoline and diesel should be much cleaner, gasoline must completely unleaded and diesel oil is allowed to contain $500 \mathrm{ppm}$ sulphur in 1997, against 2500 in 1995 and even $350 \mathrm{ppm}$ by the year 2000 . The last directive concerns the introduction of an electronic controlled catalytic converter (closed loop $+\lambda$ sensor) for all (old and new) gasoline/LPG cars in the ysear 2000 and the average fuel use will be 4.5 litre per $100 \mathrm{~km}$ for gasoline cars (12 L in 1995) and 5.5 litre per $100 \mathrm{~km}$ for diesel ( $14.5 \mathrm{~L}$ in 1995) cars in 2005 . These stringent norms can only be reached by introducing the direct fuel injection technology for gasoline engines, which are, for the time being, only available for diesel engine cars.

As can be seen from this review, there has been a permanent pattern of reduction over the years, which has forced manufacturers to play a perpetual game of leapfrog with politicians and authorities. Every time a new standard has been set, the R\&D activities realised to meet it. But no sooner is it met than new, even higher ones are imposed. This trend has become virtually automatic. For example at the moment electronic engine management in combination with advanced mixture formation, advanced distributorless ignition systems and advanced combustion systems (in-cylinder geometry and in-cylinder flow) ensure improved combustion at all operating points. A closed loop (3-way catalyst) in combination with an exhaust oxygen sensor is effective to control and reduce the level of all 3 types of emission components in the exhaust. Exhaust gas re-circulation contributes to further $\mathrm{NO}_{\mathrm{x}}$-reduction. Intake preheating and, if required, air-injection into the exhaust system belps to improve emission behaviour during the warm-up phase after a cold start. A carbon canister stores the $H C$ emission, due to hot fuel vapour ventilation from the fuel tank when the engine is not ruming, and allows this fuel to be purged from the canister into the intake air during engine operation. However, it needs to be understood that further incremental technical improvements:

- will no longer result in the impressive achievements of the recent past (diminishing marginal improvements), and that

- these smaller more difficult improvements will involve disproportionately high additional cost, due to the growing sophistication of the technology required (increasing marginal cost),

- in addition, the improvements will be limited to specific aspects of overall motor vehicle performance. 
These aspects concens the incremental technical improvement whereas the expected introduction of the gasoline direct injection marks a major technical improvement with an one-time drop of fuel use of 20-30\%. At present, experts do not expect a major technological breakihrough (electric, hydrogen fuelled cars) before the year 2005 with an additional time lag of 5 and more years needed for the build-up mass production facilities. Seen our time horizon these radical breakthroughs are marginal rellevant for our study.

The latest emission abatement techriology in the reference run is the closed loop catalytic converter of which the turnover of the car stock will be completed after 2000 . It is assumed that the emission abatement technology is completed and not subject to incremental improvements as such. The observed and assumed future technical improvements refers to design and engine (combustion) aspects of the new cars. Apart of the built-in incremental technical improvernents, as explained in chapter 7 , no break-through technologicall innovation has been assumed for the time being. The assumed incremental technical improvement refers to:

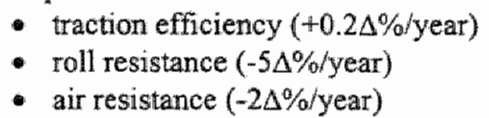

by summing over technology, co and road - and fuel type we arrive at the total basic emission factor, as derived in 7.4 :

$$
\begin{aligned}
& T E F b[t]_{P, L P G}^{C O, N O C_{N} N O x}=\sum_{R T=1}^{3} \sum_{c c=1}^{3} \sum_{T=1}^{4} E F b[t]_{P, L P G}^{C O, V O C_{N} N O x} \\
& T E F b[t]]_{D}^{C O, V O C, N O x}=\sum_{R T=1}^{3} \sum_{c c=1}^{3} \sum_{T=5}^{6} E F b[t]_{D}^{C O, N O C_{,} N O x}
\end{aligned}
$$

The dimensions, arrays or vectors are elements of the following sets and subsets:

$$
E F \in\{C O, V O C, N O x\}
$$

where

$$
\begin{aligned}
& \text { CO : carbon monoxide } \\
& \text { VOC : volatile organic compounds } \\
& \text { NO } \quad \text { : nitrogen oxides } \\
& \text { Mro } \\
& F \in\left\{P_{x} L P G_{0} D\right\}
\end{aligned}
$$

where

$$
\begin{array}{ll}
P & \text { : gasoline } \\
\angle P G & \text { : liquefied petrol gas } \\
D & \text { : diesel oil }
\end{array}
$$

$T \in\{(P, L P G): N B, I N B, O L, C L ;(D) ; I N D, D\}$ where

$$
\begin{array}{ll}
\text { NB } & \text { : conventional (gasoline, LPG) } \\
I N B & \text { : improved conventional (gasoline, LPG) } \\
O L & \text { : open loop catalytic (gasoline, LPG) } \\
C L & \text { : closed loop catalytic (gasoline, LPGX) } \\
I N D & \text { : indirect injection (diesel) } \\
D I & \text { : direct injection (diesel) }
\end{array}
$$

where

$$
c c \in\{S, M, L\}
$$

$\begin{array}{ll}S & :>1.4 \text { litre } \\ M & : 1.4 \mathbb{L}<2.0 \mathbb{L} \\ L & :>2.0 \text { litre }\end{array}$




$$
\begin{array}{cl}
R T \in\{R T 1, & R T 2, R T 3\} \\
\text { where } & \\
R T 1 & \text { : urban roads } \\
R T 2 & \text { : rural roads } \\
R T 3 & \text { : highway }
\end{array}
$$

\begin{tabular}{|c|c|c|c|c|}
\hline \multicolumn{5}{|c|}{ Gasoline + LPG (Note closed loop catalytic converter) } \\
\hline$\Delta \%$ & $<1.4 \mathrm{~L}$ & $1.4-2.0$ & $>2.0 \mathrm{~L}$ & Total \\
\hline $\mathrm{CO}$ & -30 & -30 & -40 & -31 \\
\hline VOC & -35 & .36 & -48 & -36 \\
\hline NOx & -36 & -39 & -65 & -50 \\
\hline \multicolumn{5}{|c|}{ Diesel (Note direct injection) } \\
\hline$\Delta \%$ & $<1.4 \mathrm{~L}$ & $1.4-2.0$ & $>2.0 \mathrm{~L}$ & Total \\
\hline $\mathrm{CO}$ & -10 & -18 & -33 & -16 \\
\hline VOC & -15 & -25 & .42 & -27 \\
\hline Nox & -33 & -34 & -53 & -41 \\
\hline
\end{tabular}

and results in the following decreases (Table 8.3) over the period 1990-2015.

The park emission by vintage, by road - , and fuel type equals the product of the yearly vintage emission factors, $\left[E F_{y}\right]$, developed in chapter 7.5 , and the yearly average kilometrage of each vintage, developed in chapter 6 . The vintage emission factors equals the basic emission factors multiplied by the $c c$ - and technology share of the new car sales of the year in question. The total yearly $(t)$ park emission, $T E F p[t]^{C O V O C, N O x}$, is obtained by successive summation over vintages $(\mathrm{H})$, road type $(R T)$, and fuel type $(F)$ of the product of vintage emission factors $E F_{v}[\bullet]$ and its kilometrage $k m[\bullet]$ :

$$
T E F p[t]^{C O, V O C, N O x}=\sum_{F=1}^{3} \sum_{R T=1}^{3} E F_{v}[t]_{R T_{x} F}^{C O, V O C, N O x} * K m[t]_{R T, F}^{C O, N O C, N O x}
$$

As treated in chapter 7 the emission abatement policies started in the mid 80 s with the introduction of the clean engime and open loop catalytic converter, and after 1990 with the closed loop catalytic converter for the gasoline and LPG engine cars. The diesel engine cars the introduction in 1990 of the Iurbo Direct Injection (TDI) technology leading to reduced fuel use and emission control was followed in 1995 with the introduction of the diesel catalytic converter which further controlled the emissions. The fuel efficiency policy can be described as incremental, car/engine technical improvements for the period 1985 - 1990, with

$$
\begin{array}{ll}
\text { - Traction efficiency } & +0.2 \Delta \% \text { year } \\
\text { - Roll resistance } & -5.0 \Delta \% / \text { year } \\
\text { - Air resistance } & -2.0 \Delta \% / \text { year }
\end{array}
$$

with a stabilisation after 1990 (in case of gasoline and LPG engine). The introduction of the diesel direct injection (TDI) engine cars can be described as a new combustion technology with a once and for all $20-30 \%$ reduction of fuel use.

The effects of the catalytic converter and the incremental technical improvements on the basic emission factors $[E F b]$ and basic fuel use factors $[F F b]$ are dealt with in chapter 7 and will not repeated here. The development of the auto park emissions between 1986-1995 wil] be summarised in the figures below. 
- CO-emission

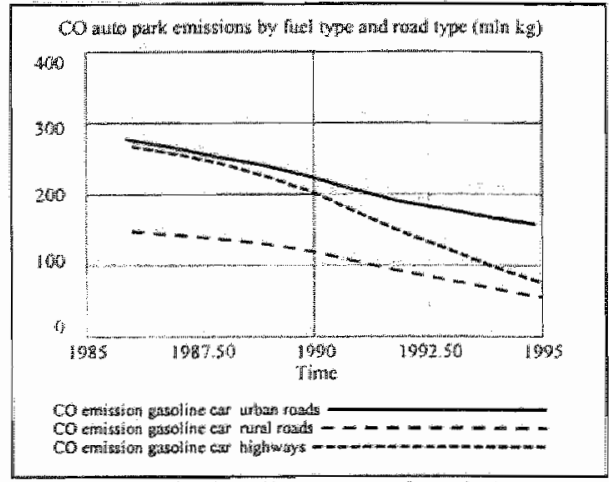

Figure 8.4 CO-Gasoline auto park emission

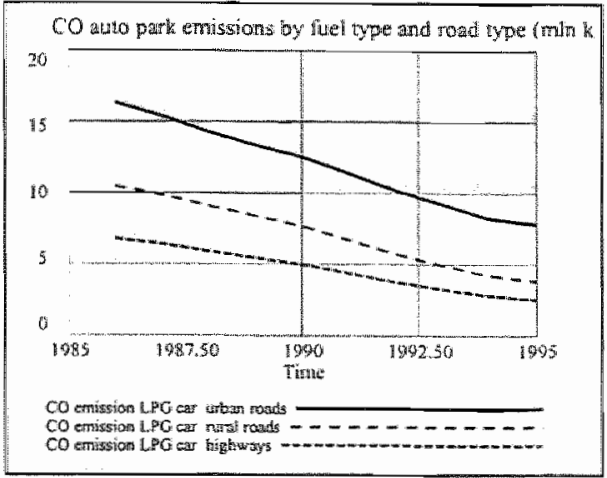

Figure 8.5 CO- LPG auto park emission

Figure 8.4 to 8.7 shows the development of the $C O$-emissions of the gasoline, LPG and diesel engine cars measured in mln $\mathrm{kg}$. The CO-park emissions are dominated by the sharp drop of the CO-exhaust of the gasoline engine cars since the introduction in 1986 of the open loop and since 1990 of the closed loop catalytic converter.

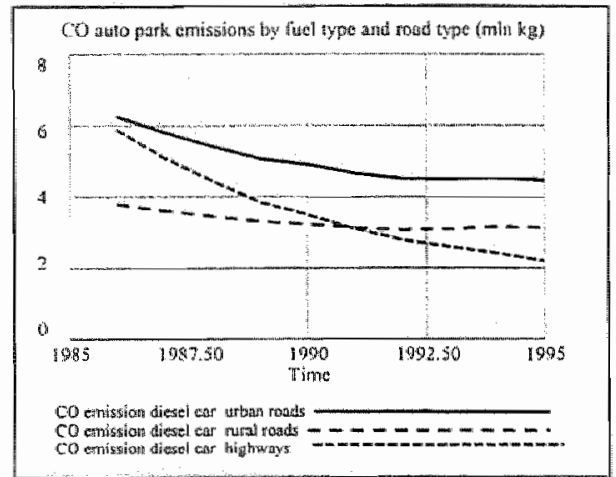

Figure 8.6 CO- Diesel auto park emission

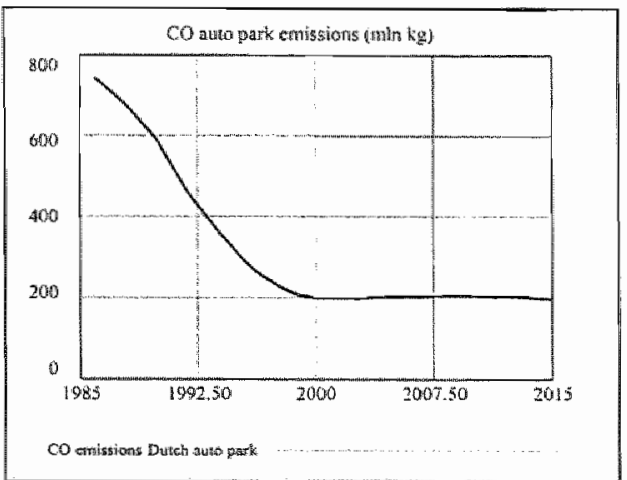

Figure $8.7 \mathrm{CO}$ - Dutch auto park emission.

\section{- VOC-emission}

The VOC-emission pattern shows a reversed pattern for the highway road type for the LPG engine (Figure 8.9) cars as the high speed exhaust of $V O C$ is higher than in case of gasoline (Figure 8.8) or diesel engine cars (Figure 8.10)

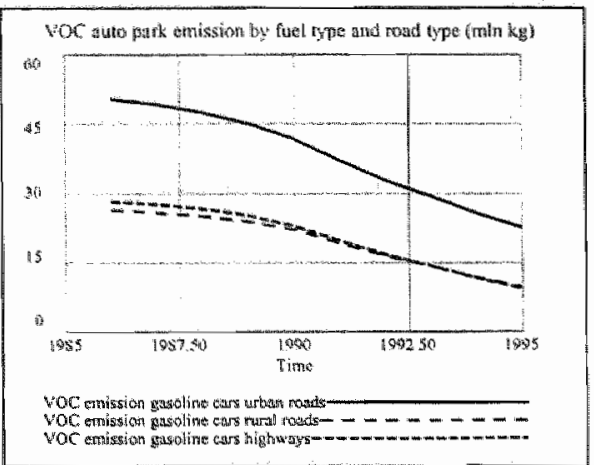

Figure 8.8 KOC-Gasoline auto park emission

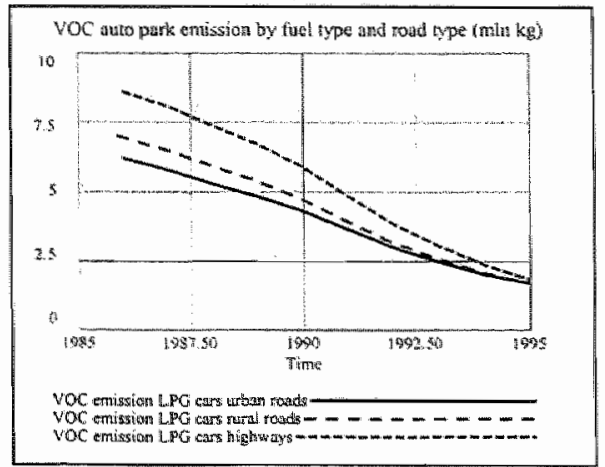

Figure 8.9 VOC-LPG auto park emission 


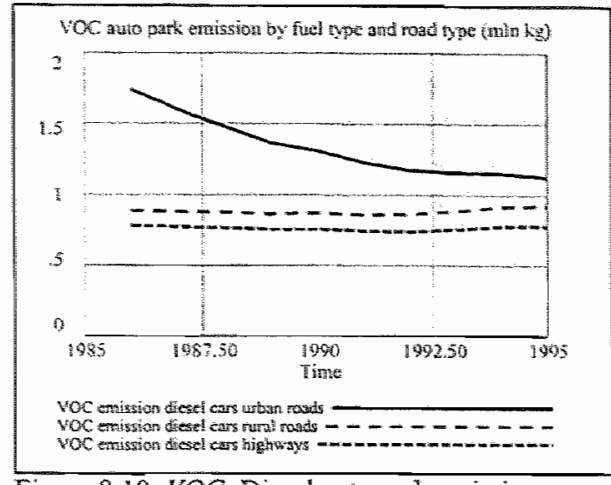

Figure 8.10 VOC. Diesel auto park emission

\section{- $N O_{x}$-emissions}

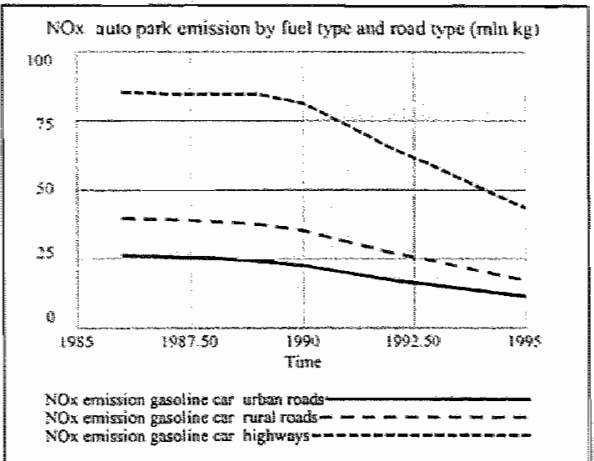

Figure 8.12 $\mathrm{NO}_{x^{-}}$-Gasoline auto park emission

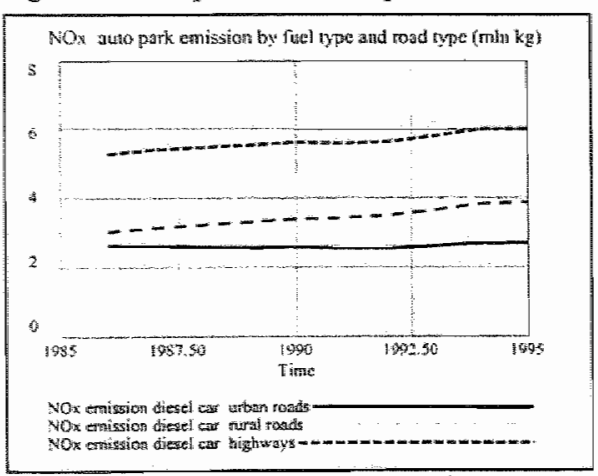

Figure $8.14 \mathrm{NO}_{x}$ - Diesel auto park emission

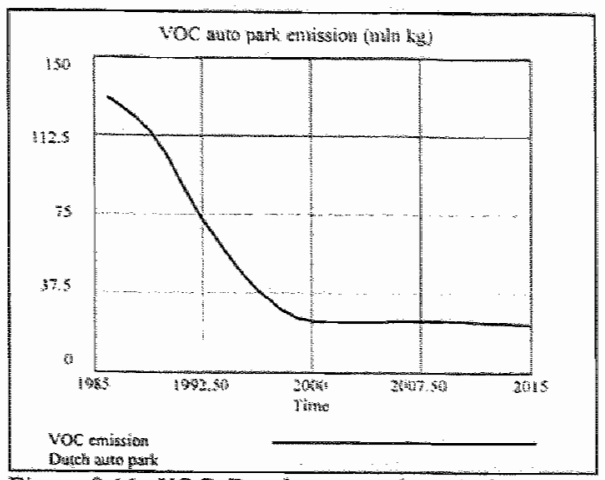

Figure 8.11 KOC-Dutch auto park emission

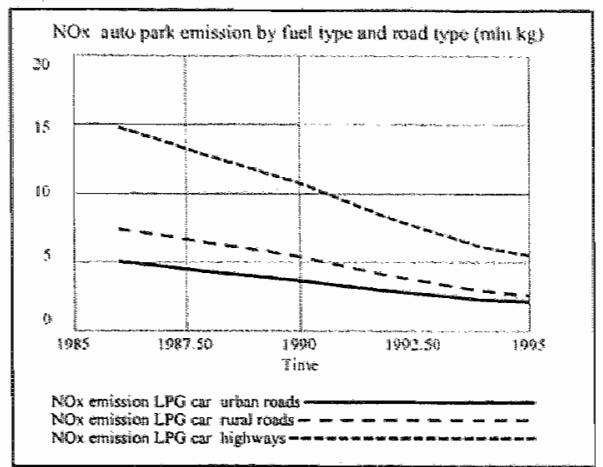

Figure 8.13 $\mathrm{NO}_{x^{-}}$LPG auto park emission

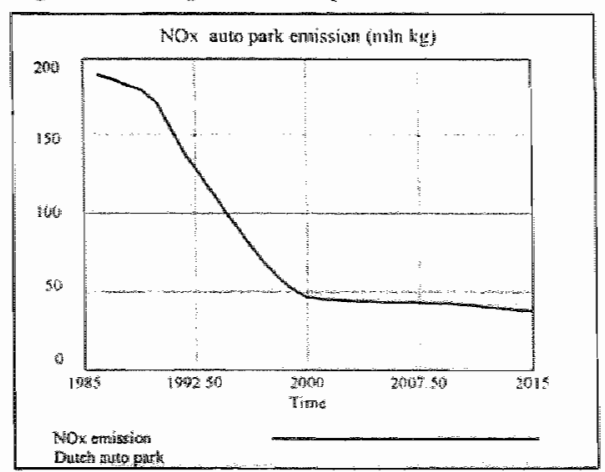

Figure 8.15 $\mathrm{NO}_{x}$ - Dutch auto park emissions

Note the relative clean emissions of the diesel engine cars, in all the 3 emission categories shown above. 


\section{Fuel use}

The fuel types used up by car driving delivers the energy for traction power. The quantity of energy delivered by a litre fuel is not equal for the different fuel types. In order to compare the fuel usage one has to convert from litres to an energy-unit (joule) or better to PJ (petajoule $=10^{25}$ joule).

From 1980 on the total Dutch energy use decreased for some years to increase again in the second half of the $80 \mathrm{~s}$. The 1990 lewel equalled the 1980 level (Table 8.4). In 1995 the total energy use was $8 \%$ higher than in 1990 . However the total energy use by the road traffic continued to grow from 1980 on and was in $199537 \%$ higher than in 1980 .

\begin{tabular}{|lccccc|}
\hline Energy use & 1980 & 1985 & 1990 & 1995 \\
National use & PJ & 2733 & 2544 & 2735 & 2960 \\
& & & & & \\
Road traffic & 276.4 & 292.1 & 338.7 & 378.2 \\
of which automobiles & 183.3 & 198.2 & 219.7 & 239.6 \\
\hline Table 8.4 & & & & Source: CBS 1996
\end{tabular}

The energy use of automobiles increased with $31 \%$ during the period 1980-1995, a yearly average growth of $1.8 \%$. The yearly kilometrage increased during the same period with $47 \%$, a yearly average of $2.6 \%$. Therefore the energy use per

kilometre decreased. The share of automobiles in the national energy consumption increased from $7 \%$ in 1980 to $8 \%$ in 1995 . In the road traffic the automobile accounts for two third $(2 / 3)$ of the energy use (Table 8.5). For gasoline and LPG this share is $\pm 95 \%$. The diesel automobiles use $\pm 1 / 4$ of the total diesel use.

\begin{tabular}{|lcccc|}
\hline $\begin{array}{c}\text { Fuel use road traffic } \\
\text { mIn litres }\end{array}$ & 1980 & 1985 & 1990 & 1995 \\
$\begin{array}{c}\text { Total road traffic } \\
\text { gasoline }\end{array}$ & 4910 & 4521 & 4608 & 5365 \\
diesel & 2579 & 3061 & 4218 & 4788 \\
LPG & 941 & 1398 & 1492 & 1250 \\
& & & & \\
Automobiles & & & & \\
gasoline & 4537 & 4207 & 4326 & 5105 \\
diesel & 356 & 772 & 1195 & 1193 \\
LPG & 896 & 1335 & 1435 & 1202 \\
\hline
\end{tabular}

The absolute use of LPG increased substantial in the $80 \mathrm{~s}$, but decreased in the 90 s. Also the popularity of the diesel automobile increased substantially in the 80 s. The usage has been risen three times. In the eariy 90 s the diesel use decreased somewhat, but from 1995 on the diesel use increased again.

Table 8.5

Source: CBS 1996

\section{Scenario analysis}

The scenarios selected apply to the following topics:

- the expected technical progress in clean engine technology and design;

- the expected influx of the baby boomers from 2005 on into the category of "young elder" with its impact on the (auto)mobility;

- the urban or short drive behaviour by other means of transport;

- reducing average speed on highways;

- the introduction of the direct injection diesel engine (TDN);

- the introduction of the direct injection gasoline engine $(G D N)$.

\section{Scenario 1: Stabilisation fuel efficiency}

During 1980 and 1985 the kilometrage increased $1 / 2$ time the energy use, indicating rising fuel efficiency. In the average the gasoline and LPG cars fuel efficiency increased with $10 \%$ and for diesel cars even $20 \%$, however the largest part of the fuel efficiency has been realised in the period 1980-1990, after 1990 the fuel efficiency stabilised, except for the diesel cars.

For the period 1980-1990 the following assumptions holds :
- Traction efficiency
$+0.2 \mathrm{~A} \%$ year
- Roll resistance
$-5.04 \% /$ year
- Air resistance
$-2.0 \Delta \% /$ year

Scenario 1 simulates these facts with the assumption of no future fuel efficiency improvements, except for the diesel engine with the introduction in the early 90 s of the direct injection (TDI) 
technology, with fuel efficiency of $\$ 30 \%$. The growth of the kilometrage (car use) and the car ownership are, for the gasolme and LPG cars, the ultimate active forces determining the future fuel use. Figure 8.16 mimics these features and shows the moderate increase of the gasoline fuel use for the period 1986-1990 and the strong increase for the period 1990-1995. For the period 1996-2015 the stabilisation of the fuel efficiency is maintained.

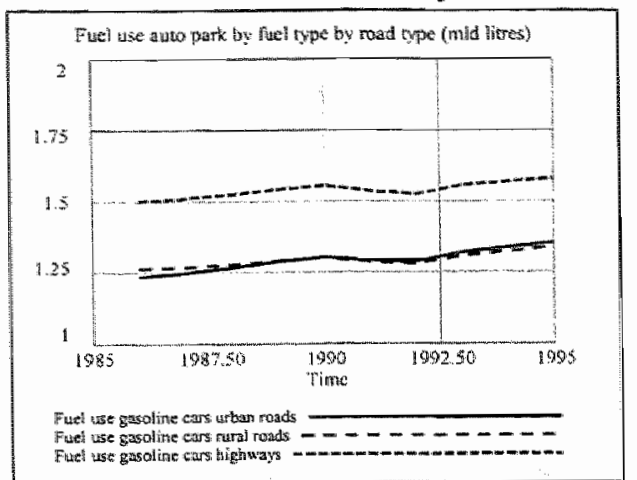

Figure 8.16

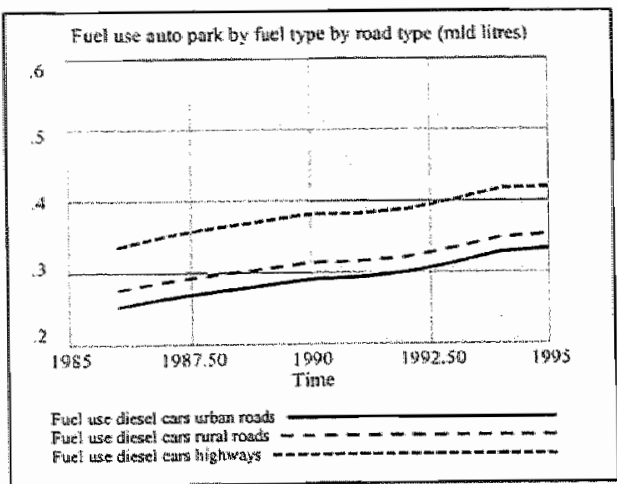

Figure 8.17

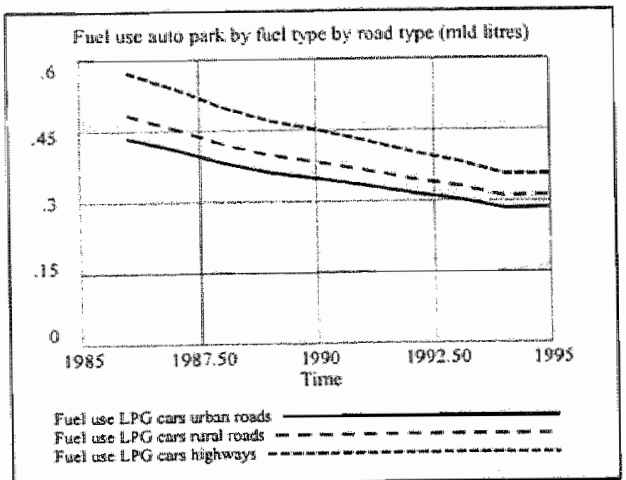

Figure 8.18
Note the stabilisation of the fuel use after 2010 is determined by the assumptions that:

- the household formation by size saturates,

- mobility behaviour remains constant, and

- therefore the kilometrage will samute after 2010 ,

however if one assumes a continuation of the 1980 90 fuel efficiency development, the picture will of coarse be totally different, as will be shown in the scenario 1.

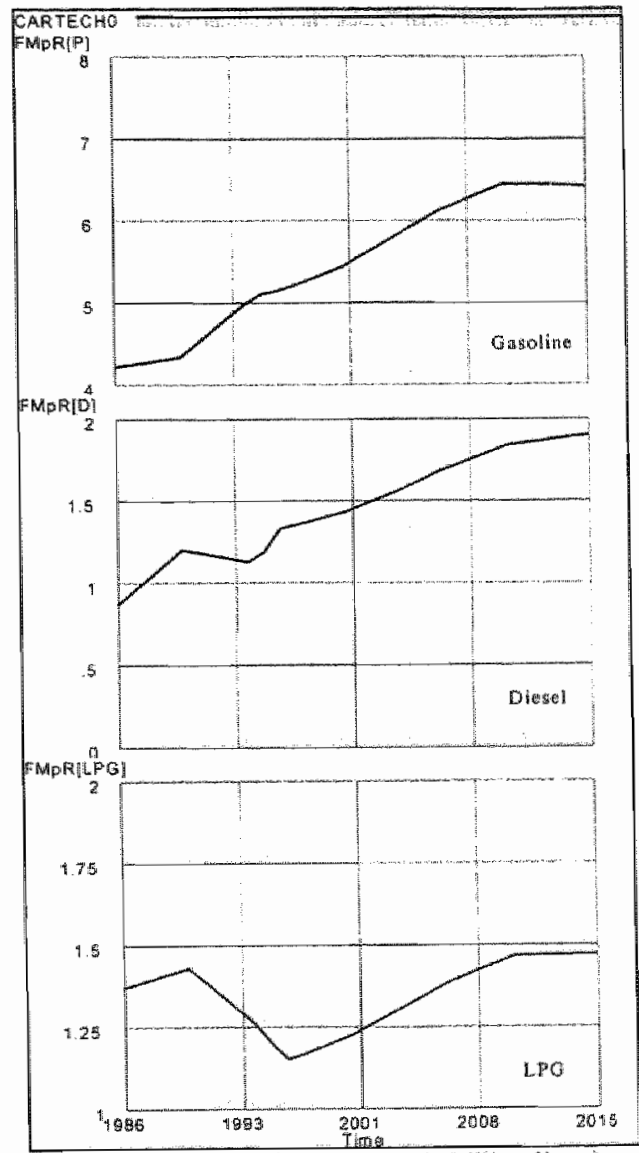

Figure 8.19 fuel use by fuel type ( $x$ billion litres) 


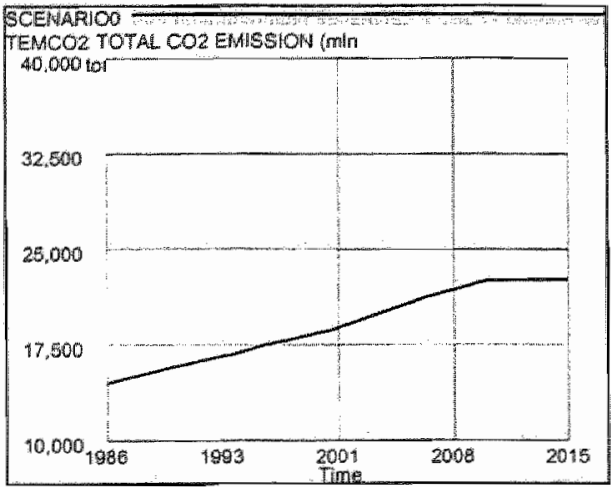

Figure $8.20 \quad \mathrm{CO}_{2}$-atuto park emission
Note the fuel use decrease of the LPG cars (Figure 8.18) is in agreement with the improved fuel efficiency till 1990, and the subsequent decrease of the LPG car stock and kilometrage since 1990. After 1994 LPG growth resumes (Figure 8.19). The diesel cars shows the stabilisation of its share in the car stock for the period 1990-1994 and regained strong since that time at the cost of the IPG cars.

Figure 8.20 shows the effects of this scenario for the $\mathrm{CO}_{2}$-emission and it is quite clear that the emission follows the growth rate of the kilometrage.

\section{Scenario 1 A (dotted line)}

As indicated before incremental technical improwements of the fuel efficiency took place during the period 1980-90 and staggered during the period 1990-95. On can image two scenario's with the fuel efficiency pattern of the 80 s restart in 1996 till 2015 or the fuel efficiency improwements are subject to diminishing marginal efficiency, therefore we assume that the incremental technical improvements are reduced by $50 \%$ for the period 1996-2015.

For the period 1980-1990 the following assumptions holds:
- Traction efficiency
$+0.2 \Delta \%$ year
- Roll resistance
$-5.0 \Delta \% /$ year
- Air resistance $-2.04 \% /$ year

for the period 1991-1995 the following assumptions holds:
- Traction efficiency
$0.0 \Delta \% /$ year
- Roll resistance
$0.0 \Delta \% /$ year
- Air resistance
$0.0 \Delta \% /$ year

and for the period 1996-2015
- Traction efficiency $+0.1 \Delta \% /$ year
- Roll resistance $\quad-2 / 2 \Delta \% /$ year
- Air resistance $\quad-1,0 \Delta \% /$ year

Scenario 1D(solid line)

For the period 1980-1990 the following assumptions holds:
- Traction efficiency
$+0.2 \Delta \% /$ year
- Roll resistance
$-5.0 \Delta \% /$ year
- Air resistance
$-2.0 \Delta \% /$ year

for the period 1991-1995 the following assumptions holds :
- Traction efficiency
$+0.0 \Delta \%$ year
- Roll resistance
$-0.0 \Delta \% /$ year
- Air resistance
$-0.04 \% /$ year

and for the period 1996-2015
- Traction efficiency
$+0.2 \Delta \% /$ year
- Roll resistance
$-5.0 \Delta \% /$ year
- Air resistance
$-2.0 \Delta \% /$ year

Note that besides the assumptions of the incremental technical improvements, the total park emissions and fuel use of the Dutch car stock are computed under assumed development of the households by

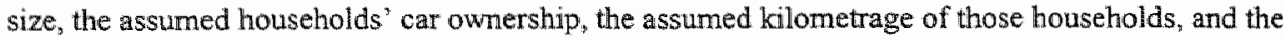
auto mobility (car use). 


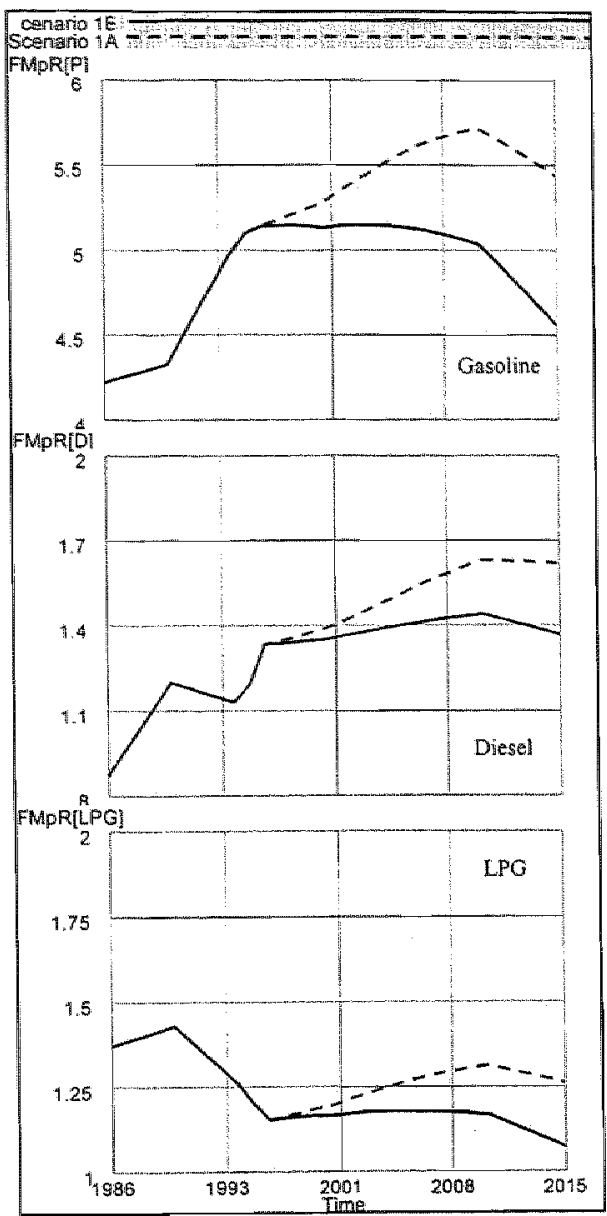

Figure 8.21 Fuel use auto park by fuel type ( $\mathrm{x} \mathrm{mln}$ litres)

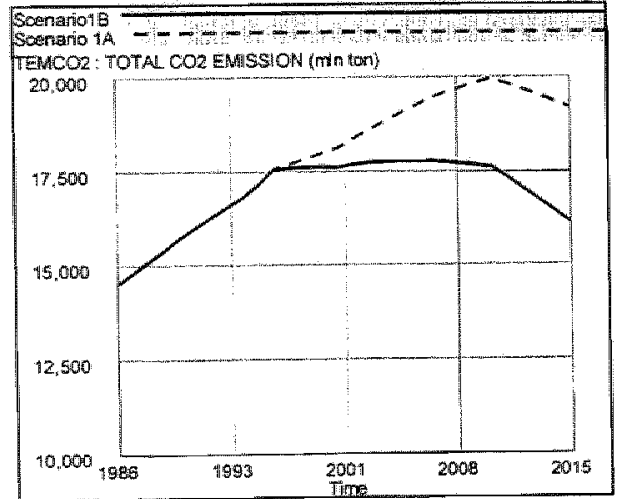

Figure 8.23 $\quad \mathrm{CO}_{2}$-auto park entission
The effects of halving the assumed incremental technical improvements on behalf of the fuel efficiency is clearly shown in Figure 8.21. The solid line represents the scenario 2 assumption, the dotted line the scenario 1 revised (halving) future technical improvements as indicated above. In the new case the fue] use remains increasing albeit at a lesser degree as in the early 90 s. The combined effect of the expected kilometrage and the techical improvement on fuel efficiency determines the development of the $\mathrm{CO}_{2}$ and $\mathrm{SO}_{2}$ emissions.

\section{$\mathrm{CO}_{2}$ and $\mathrm{SO}_{2}$ park emissions}

The fuel use determines the emission of $\mathrm{CO}_{3}$ and $\mathrm{SO}_{3}$ so the trajectories of both emissions are equivalent to those of the fuel use. Figure 8.22 shows these emission for scenario 1 (dotted line) and 2 (solid line)

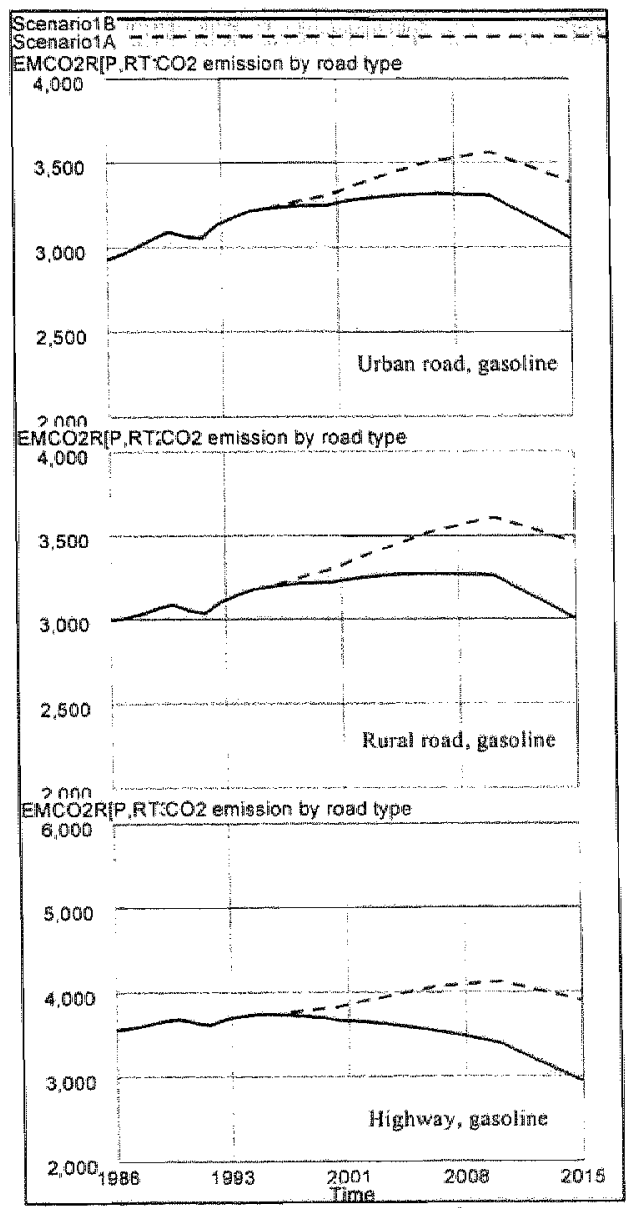

Figure $8.22 \mathrm{CO}_{2}$-emission by road type 
Note the Dutch policy objective of tetuming in 2010 to the $1990 \mathrm{CO}$, level does not materialise even with the stringent scenario $1 \mathrm{~B}$. The 1990 level will be reached in 2015 after the zero-growth in kilometrage and continued incremental fuel efficiency improvement take place during the period $2010-2015$

\section{Scenario 2 Automobility and household formation, the elderly case}

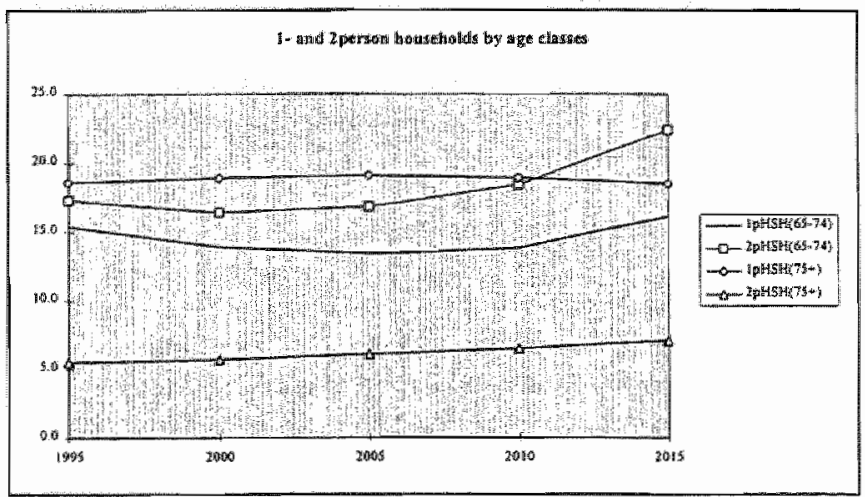

Figure 8.24

The mobility and especially the automobility of elderly is one of increasing importance in the near future. Elder mobility changes and by increasing greying more and more elderly take part in the traffic. On $1 / 11995 \pm 3.5$ million Dutch inhabitants were over 55 year old, that is $22 \%$ of the total population. Since 1986 this is an increase of nearly $12 \%$, while the total population increased with $6 \%$. In the period $2010-15$ the strongest increase will come from the 2-person households of young elderly (65-74 year), followed by the 1-person households (Figure 8.24), they represent the baby boom after World War 2. It will be plausible to assume their (auto)mobility to be greater than the contemporary elderly of the same age class.

\begin{tabular}{|cccc|}
\hline \multicolumn{5}{|c|}{ Car ow ership by sex and age } \\
Women & 1985 & 1990 & 1995 \\
$16-44$ & 25 & 30 & 36 \\
$45-54$ & 20 & 33 & 41 \\
$55-64$ & 17 & 22 & 28 \\
$65-74$ & 10 & 14 & 18 \\
$75+$ & 4 & 5 & 12 \\
Men & & & \\
$16-44$ & 65 & 61 & 56 \\
$45-54$ & 82 & 82 & 78 \\
$55-64$ & 75 & 78 & 80 \\
$65-74$ & 55 & 63 & 66 \\
$75+$ & 37 & 40 & 50 \\
\hline 70.6 & & & \\
\hline
\end{tabular}

Not only the car ownership (Table 8.6), but also the displacement behaviour and distances done (Table 8.7) will increase. The reference run treated the elderly as a homogenous group, in scenario 2 the elderly are divided in two groups, the 'young' elderly (65-74 year), and the "old' elderly $(75+)$, each with their own specific car ownership, displacement behaviour and distances done.

The kind of traffic participation within the age class $65+$ is rather diverse. In general wealth and health conditions determine car ownership and car use. However health condition and not financial wealth determines the car ownership and car use for elderly people. Though the car owmership of elderly is

\begin{tabular}{|c|c|c|c|c|}
\hline \multicolumn{5}{|c|}{ Displacements by age and means of transport, 1995} \\
\hline & $\begin{array}{l}\text { Car } \\
\text { driver }\end{array}$ & $\begin{array}{l}\text { Car } \\
\text { passengar" }\end{array}$ & $\begin{array}{l}\text { Public } \\
\text { transport }\end{array}$ & Rest \\
\hline \multicolumn{5}{|l|}{ Woment } \\
\hline $45-54$ & 32.1 & 18.2 & 3.4 & 46.3 \\
\hline $55 \times 64$ & 22.1 & 22.5 & 40 & 51.4 \\
\hline $65-74$ & 14.7 & 23.6 & 8.0 & 53.7 \\
\hline $75+$ & 10.8 & 24.5 & 12.5 & 522 \\
\hline \multicolumn{5}{|l|}{ Men } \\
\hline $45-54$ & 58.4 & 6.5 & 3.3 & 31.8 \\
\hline $55-64$ & 53.1 & 5.9 & 2.6 & 38.4 \\
\hline $65 \times 74$ & 43.1 & 6.9 & 3.5 & 46.5 \\
\hline $75+$ & 36.4 & 9.6 & 5.7 & 48.3 \\
\hline
\end{tabular}
on average less then with younger, during the period 1985 1995 it rose substantially, especially with men of age $65+$.

Remarkable is the lower car ownership of women. The car ownership of women of age 55-65 year rose most, and seen the strong increase of car ownership of women aged 4555 year, next decade more elder women will participate car driving. People aged 55-65 year used most frequently the car, this age class is characterised by intensive and active leisure behaviour, and will continue this behaviour the next decade as $65+$. However, old elderly, $75+$, have different leisure behaviour, and their share in car traffic as 
driver is lower than the share in the population. This reduced car use is compensated by using other means of transport, especially public traffic, bike and walking. Moreover elder car drivers make less kilometres, than the average of the Dutch per day per person, that is in $1995 \pm 19 \mathrm{~km}$. The same distance holds for the age class 55-64 year, however for the young elder (age-class 65-74 year), on the average, less than $9.5 \mathrm{~km}$. The old elder (age class $75+$ ) car drivers, the average distance per day is slight more than $4 \mathrm{~km}$, that means the cold start phase. However elder car drivers do no more short distance travels as youngsters do. About $60 \%$ of car using displacements are shorter than $10 \mathrm{~km}$, this about the same for elderly.

\begin{tabular}{|c|c|c|c|c|}
\hline \multicolumn{5}{|c|}{ Displacements by car of households by size, 1995} \\
\hline & \multicolumn{2}{|c|}{ One person HSH } & \multicolumn{2}{|c|}{ More person HSH } \\
\hline & Driver & Passienger & Driver & Passenger \\
\hline & \multicolumn{4}{|c|}{ Average per person per day } \\
\hline \multicolumn{5}{|l|}{ Women } \\
\hline $55-64$ & 1.02 & 0.25 & 0.54 & 0.78 \\
\hline $65-74$ & 0.47 & 0.25 & 0.24 & 0.73 \\
\hline $75+$ & 0.20 & 0.29 & 0.13 & 0.55 \\
\hline \multicolumn{5}{|l|}{ Men } \\
\hline $55-64$ & 1.54 & 0.13 & 1.77 & 0.20 \\
\hline $65-74$ & 11.15 & 0.16 & 1.21 & 0.20 \\
\hline $75+$ & 0.70 & 0.20 & 0.76 & 0.19 \\
\hline
\end{tabular}

One can wonder how this picture will look like in $2010 / 15$. Will the number of car using displacements change and in what direction? The same story holds for the average distances done per elder person. Car using displacements by motives in 1995 shows increasing percentages with older age classes $(55-64,65-74,75+)$, so for visits $(18.5 \%, 22 \%, 23.5 \%)$, for shopping $(25 \%, 29 \%, 32.5 \%)$, for recreation/sports $(12 \%, 14 \%, 10.5 \%)$, the commuting motive will of course show strong decreases, and the remainder is about $30 \%$ for the three age classes in question. Again one can wonder how these figures will move with the cohorts through time, for example the recreation/sports motive in 1995 is lower for the $75+$ than for the otlyer age classes in question, but seen the expected increasing life expectancies along with an expected improvement of the physical condition the 1995 situation can reverse. In the scenario 3 we assume:

- the displacements for three motives only (shopping, visits, and recreation/sports) will increase by $1 \%$ per year for the young elder and $1 / 2 \%$ per year for the old elder from 1995 on. The average: distance done per person remains constant.

\section{Results}

The total vehicle kilometrage will increase from \pm 125 to \pm 137 billion $\mathrm{km}$, particular caused by an active leisure behaviour. As scenario 1 conditions remains active, the fuel use and the $\mathrm{CO}_{2}$, and $\mathrm{SO}_{3}$. emissions increase proportionally more than the vehicle kilometres increase, counteracted by the fact that elderly's car stock is of gasoline fuel type and on the average older, and therefore more polluting, than the rest of the car owners. Moreover urban and rural road type drives are in the majority.

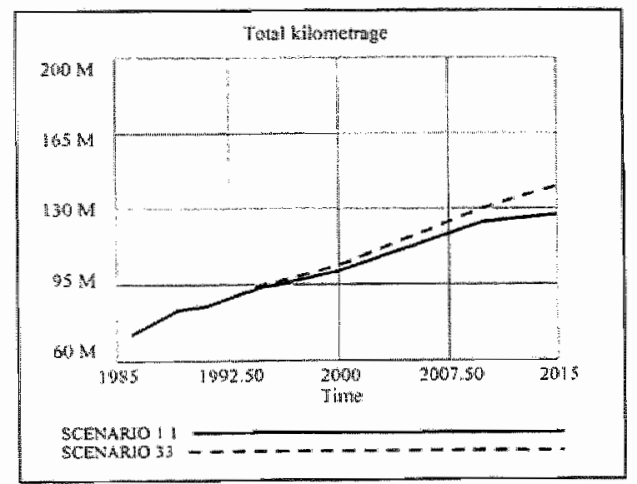

Figure 8.25 Total kilometrage $(x 1000)$

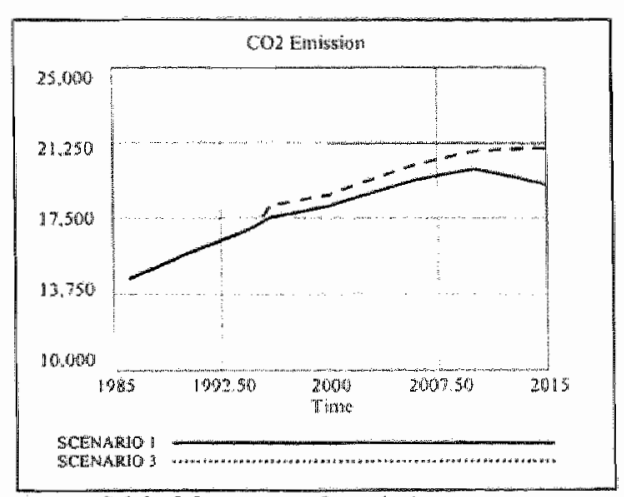

Figure $8.26 \mathrm{CO}_{\mathrm{z}}$-auto park enission 


\section{Scemario 3 Eliminating car use for the short distance traffic $(<7.5 \mathrm{~km})$}

As explained in chapter 3 men on average drive more kilometres than women. This is valid for the short $(<7.5 \mathrm{~km}$ ) as for long distances. However women take more short distances for their account, two third (2/3) of their car displacements are short distance travels. Two third (2/3) of housekeepers' car use (as part of the home production) are for short distance travel. Daily activities like shopping, fetching and delivering of children, visiting friends, sport activities, cause short distance travels, and as the task combinations of the partners increases with increasing woman (often part-time) labour participation, these activities are taking place under increasing time pressure. Time-management of the housekeeping tasks + net leisure time (= non-labour time) are the driving forces of the car use for the increasing short distance travels. As explained in chapter 7 short distance travels by car (urban road type) are not only congesting, but extremely polluting and fuel using (cold starts, warming-up

\begin{tabular}{|c|c|c|c|c|c|c|}
\hline \multicolumn{7}{|c|}{ Short distance traffec 1995} \\
\hline & $\begin{array}{l}\text { Gasoline } \\
\text { distance }\end{array}$ & usage & $\begin{array}{l}\text { Diestel } \\
\text { distance }\end{array}$ & usiage & $\begin{array}{l}\text { LPG } \\
\text { distance }\end{array}$ & usage \\
\hline \multicolumn{7}{|c|}{80} \\
\hline Short distance traffic & 13.8 & 1922 & 7.6 & 10.0 & 6.8 & 9.4 \\
\hline$<2.5 \mathrm{~km}$ & 2.4 & 3.7 & 1.2 & 1.7 & 1.1 & 1.7 \\
\hline $25-5 \mathrm{~km}$ & 4.5 & 6.3 & 2.4 & 3.2 & 2.2 & 3.1 \\
\hline $5-7.5 \mathrm{kmm}$ & 7.0 & 9.2 & 3.9 & 5.0 & 3.5 & 4.6 \\
\hline Long distance uraffe & 86.2 & 80.8 & 92.4 & 900 & 93.2 & 90.6 \\
\hline
\end{tabular}

Table 8.9 Short distance traffic distribution Sounce: CBS 1996 phase, stop-go runs), especially for gasoline engine cars, therefore the government policy should aim at restricting the car use in order to "save the enwiromment" and to abate the silting up of the road infrastructure. The silting up of roads reinforce the pollution process by stop-go runs and low average speed. Short distance traffic policy is a potential source of reducing emissions and fuel use by substituting car use by other means of transport, like electric cars, or busses, biking.. In 1995 short distance traffic accounts for 10.3 billion kilometres (93 billion $\mathrm{km}$ in total), however $1 / 9$ of the total kilometrage accounts for $4 / 9$ of the total $C O$ and $\mathrm{VOC}$ emission as do show Figure 8.27 and 8.28.

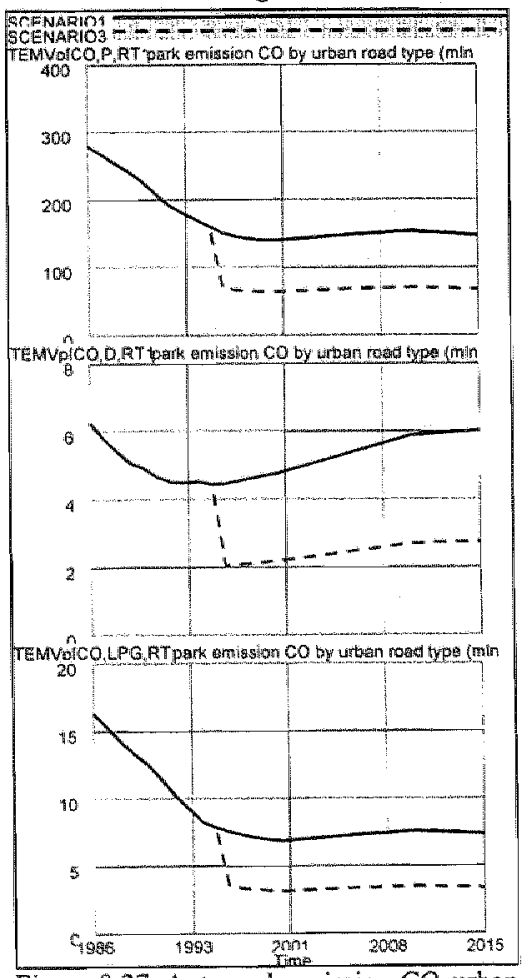

Figure 8.27 Auto park emission $C O$ urban road (RT1) by fuel type.

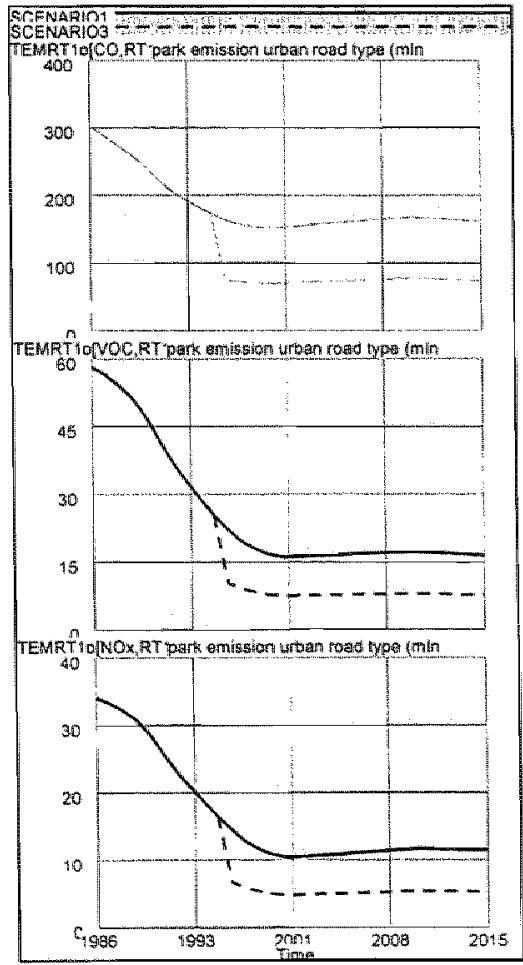

Figure 8.28 Auto park emission $C O$. $1 O C_{n}$ and $N O_{x}$ by urban road ( $\left.R T 1\right)$ 


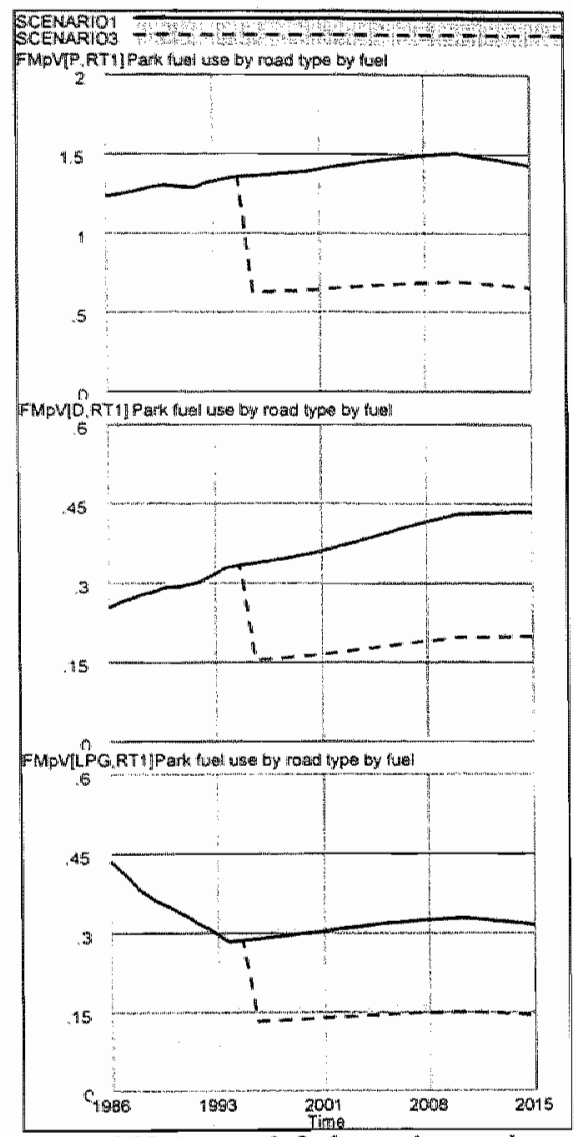

Figure 8.29 Auto park fuel use urban road (RT1)

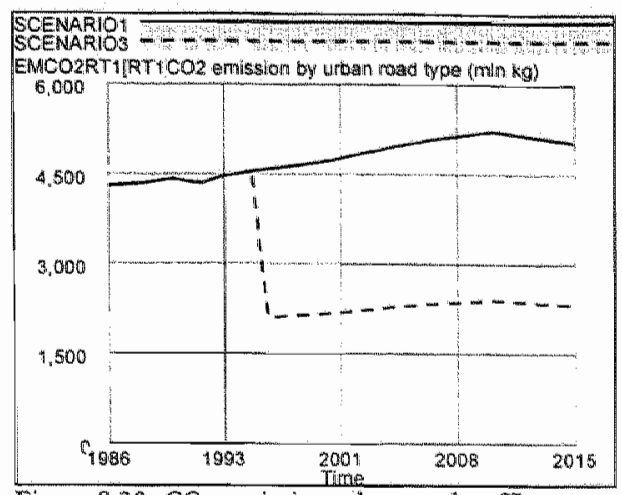

Figure $8.30 \mathrm{CO}_{2}$-emission urban road traffic

Note that the car use of elder people $(65+)$ can more or less be characterised by short distance drives. The simulation run of scenario 3 shows a substantial and impressive reduction in either $\mathrm{CO}, \mathbb{P O C} \mathrm{NO}_{\mathrm{x}}$ emissions as well as in fuel use and therefore $\mathrm{CO}_{2}$ and $\mathrm{SO}_{2}$. From the figures shown the conclusion can be inferred that imer city-and suburban public traffic policies are one of the most productive investment in anti-pollution and congestion policies. Note that the elimination of the short distance drives ( $<7.5 \mathrm{~km}) 10.3$ billion $\mathrm{km}$ out of 22 billion $\mathrm{km}$ of the urban drives from 1996 on take place under the fuel efficiency assumptions of scenario 1. 
Scenario 4 Redacing average speed on highways.

In chapter 7 the relationship between average speed and fuel use was examined and estimated. The

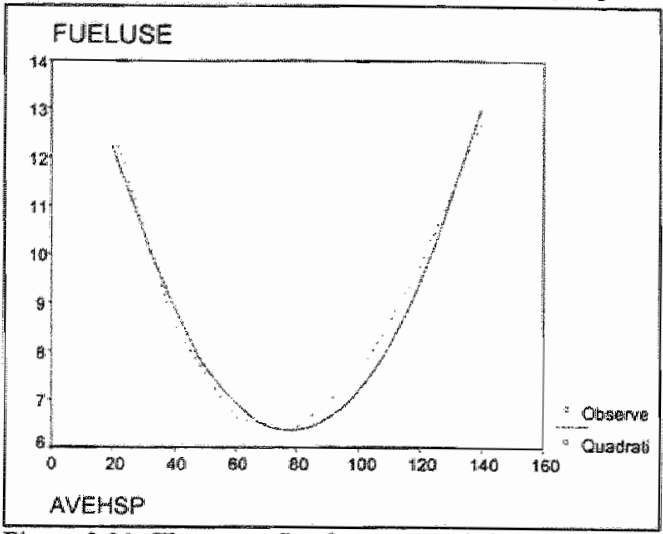

Figure 8.31 The curve fit of average veh- $\mathrm{km}(\mathrm{km} / \mathrm{h})$ and fuel use (L/100km)

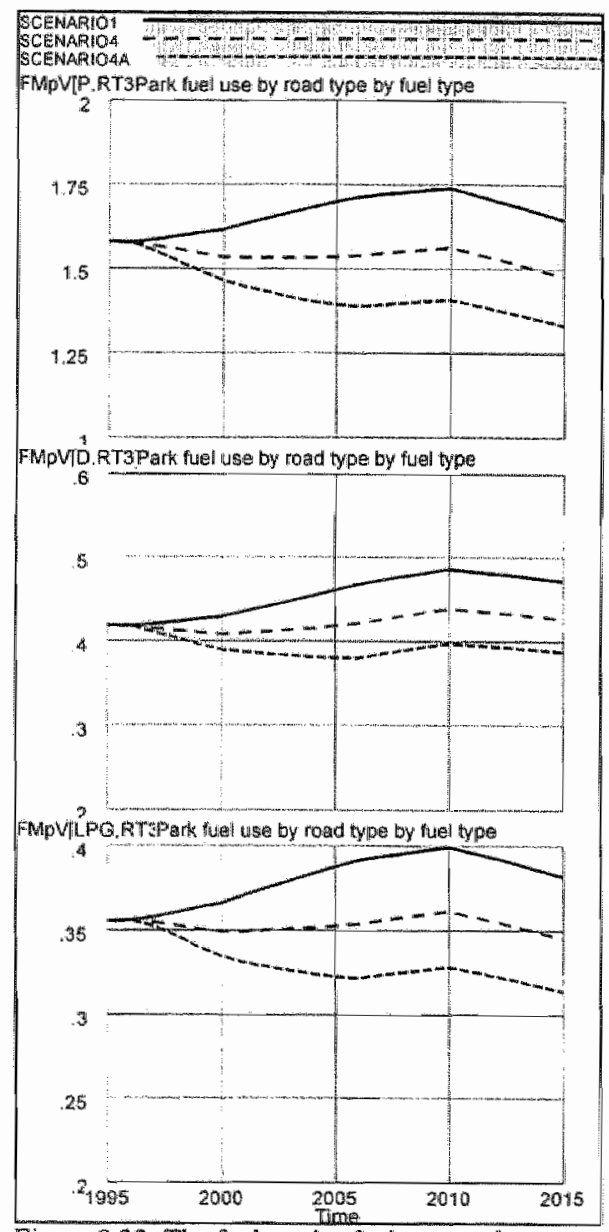

Figure 8.32. The finel use by fuel type and bighway drive (RT3) fitted parabola of Figure 8.31 (from the original Figure 7.8), indicates that the minimum fuel use will be reached at $\pm 80 \mathrm{~km} / \mathrm{h}$. After that point the fuel use rise substantially with increased average speed. The scenario 4 will consist of 4 runs with varying average speeds from 110 - to $80 \mathrm{~km} / \mathrm{h}$ and the resulting effects on emissions and $\mathrm{CO}$, and $\mathrm{SO}_{3}$

Figure 8.32 shows the impact of reducing awerage speed from 110- (SCENARIO1), 100 (SCENARIO4) and $90 \mathrm{~km} / \mathrm{h}$ (SCENARIO4A). The greatest impact is on the gasoline and $L P G$ cars, as the diesel engine is already fuel efficient, especially the TDI-diesel engine, therefore the reduction in $\mathrm{CO}_{3}$ and $\mathrm{SO}_{3}$ is substantial. The 1995 level of $C O$, will be catch again in 2015 at an average speed of $80 \mathrm{~km} / \mathrm{h}$ (Figure 8.33). The $\mathrm{SO}$, figures are even more fawourable (Figure 8.34).

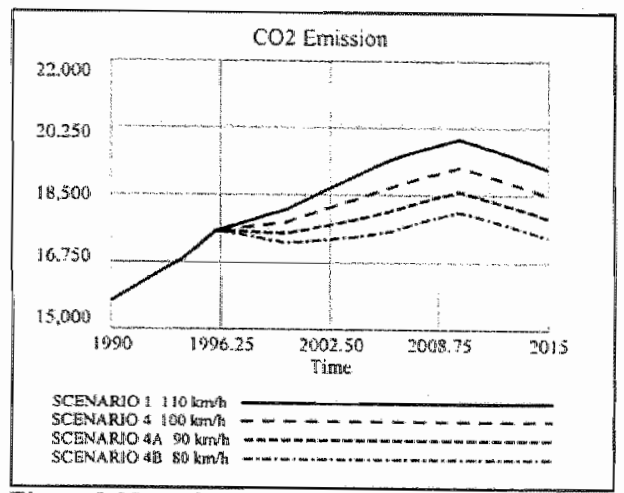

Figure $8.33 \quad \mathrm{CO}_{2}$-Auto park emission ( $\mathrm{x} / \mathrm{mln} \mathrm{kg}$ )

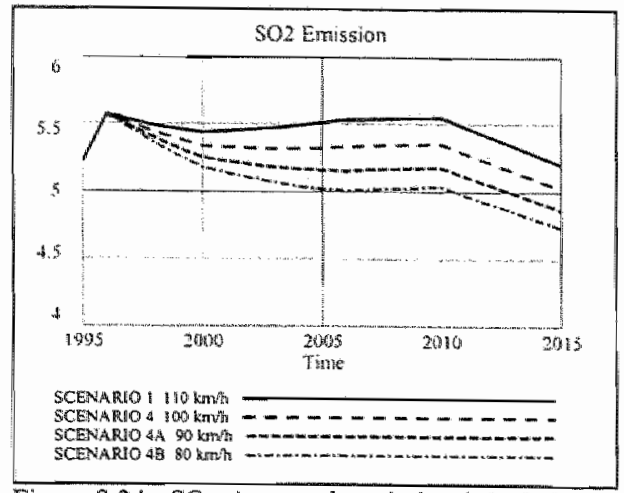

Figure $8.345 O_{y}-$ Auto park emission $(x \operatorname{lmln~} \mathrm{kg})$ 


\section{Scenario 5 Indirect and direct injection diesel motor (TDD)}

In 1989 the direct injection (turbo direct injection or TDD) for the diesel engine was introduced which improved the fuel efficiency about $=30 \%$. The emission model assumes the following quadratic equations:

$$
\begin{aligned}
& F U_{I J}=0.0787-0.01 S+7.2 \mathrm{E}-6 S^{5} \\
& \text { where } \quad \\
& F U_{T D I}=0.0597-0.0008 S+5.5 \mathrm{E}-6 S^{2} \\
& F U_{u}: \text { fuel use indirect injection }(\mathrm{L} / \mathrm{km}) \\
& F U_{r D H}: \text { fuel use direct injection }(\mathrm{L} / \mathrm{km}) \\
& S: \text { average speed }(\mathrm{km} / \mathrm{h})
\end{aligned}
$$

\section{$S$ : average speed $(\mathrm{km} / \mathrm{h})$}

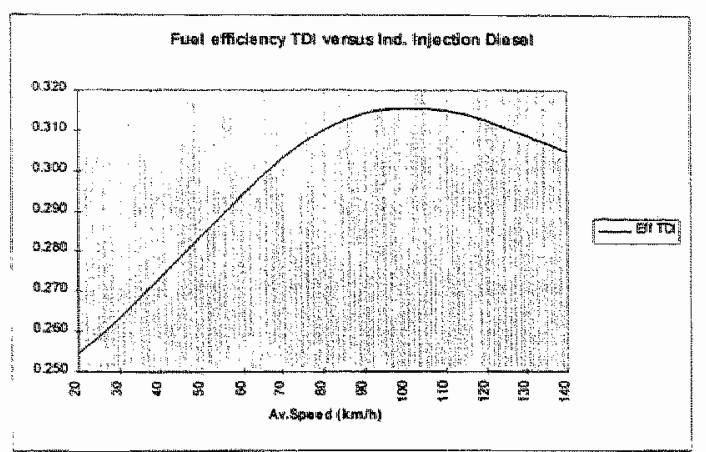

Figure 8.35

pressure. In a combustion engine the air/fuel ratio is $(\mathrm{kg}) 14.7: 1$ or $\lambda=1$. The diesel engine produces, despite affluent air $(\lambda=1.15)$ particulates, because the initernal mixing does not guarantee an optimal mixture of fuel and air. In a low load situation the diesel engine has an affluent air environment $(\lambda>7)$. With high load the process of particulate formation occurs at critical $\lambda=1.15$ levels referenced above. By way of the turbo compressor (direct injection or TDD the diesel engine with catalytic converter are loaded up with 0.6 bar, so that in the critical ranges an air surplus of $\lambda=$ 1.5 will be reached. With these technical measures, loading-up of the engine without a higher fuel/air ratio, a reduction of $50 \%$ of the particulate emission is possible, plus the traction power increases somewhat.

In the exhaust gasses of diesel engines there are beside the well known gasoline engine toxic carbon monoxide $(C O)$, hydrocarbons $(H C)$ and nitrogen oxide $\left(N O_{x}\right.$ ), the particulate emission (fixed particles or soot). In comparison with the exhaust gas composition of a gasoline engine with the conventional diesel engine, than the diesel engine without an after-treatment of the exhaust gasses lower $\mathrm{CO}$ and $H C$-values. Concening the nitrogen oxides the concentrations are more or less equal, however the particulate emission is a disadvantage of the diesel engine with regard to the gasoline or LPG engine. In the particulate emission the nucleus of the fixed particles exists of pure carbon, however around this nucleus several hydrocarbon compounds (like methane, ethane, ethylene, etc.), metal oxides and sulphur will attach. The formation of sulphur ( $5 O$.) depends of the exhaust temperature. With urban traffic (RTI) the direct injection (TDI) is sulphur free because of the lower exhaust temperatures, however with higher speed (TR2, RT3) and higher exhaust temperatures even for the TDI engine sulphur formation takes places, albeit at a much lower level.

\section{Diesel exhaust gas clean-up}

\section{Hydrocarbon and carbon monoxide}

The hydrocarbon compounds $(H C s)$ not yet attached to the carbon nucleus and the carbon monoxide (CO) can be chemically converted in an oxidation catalytic into water wapour $\left(\mathrm{H}_{3} \mathrm{O}\right)$ and carbon dioxide $\left(\mathrm{CO}_{2}\right)$. This oxidation will be favoured in the oxidation catalytic converter by way of the high(er) oxide share in the exhausi gasses of diesel (TDI) engine. 


\section{Particulate emission}

Because the combustion occurs in an air affuent environment, especially in the critical region (referenced abowe) the production of fixed particles will be reduced with $\pm 50 \%$ in case of the TDI diesel engine. However further reduction will be performed by way of particle filters after which they have to be burned. The design and implementation of this process is still subject to research.

\section{Nitrogen oxides}

In contrast to hydrocarbon and carbon monoxide (oxidation), oxide has to be withdraw from nitrogen oxide (reduction) in order to clean it. The reduction of mitrogen oxide in a closed loop catalytic converter, like in case of gasoline/LPG engine, is not possible owing to the high oxide content in the exhaust gasses of the diesel engines. Therefore in order to reduce the release of nitrogen oxides on has to search after:

- optimising the combustion chamber and the injection system, and

- a new $\mathrm{O}_{x}$ catalytic converter.

\section{Emission comparison of diesel indirect injection and direct injection (TDI)}

In order to compare the emission performance of the injection systems we run two additional scenario"s:

1. In 1996 the diesel car stock is completely converted overnight from indirect into direct injection (scenario 5), and

2. the diesel new car sales are, from the year 2000 onwards, equipped with the direct injection (TDI) system (scenario $5 \mathrm{a}$ ).

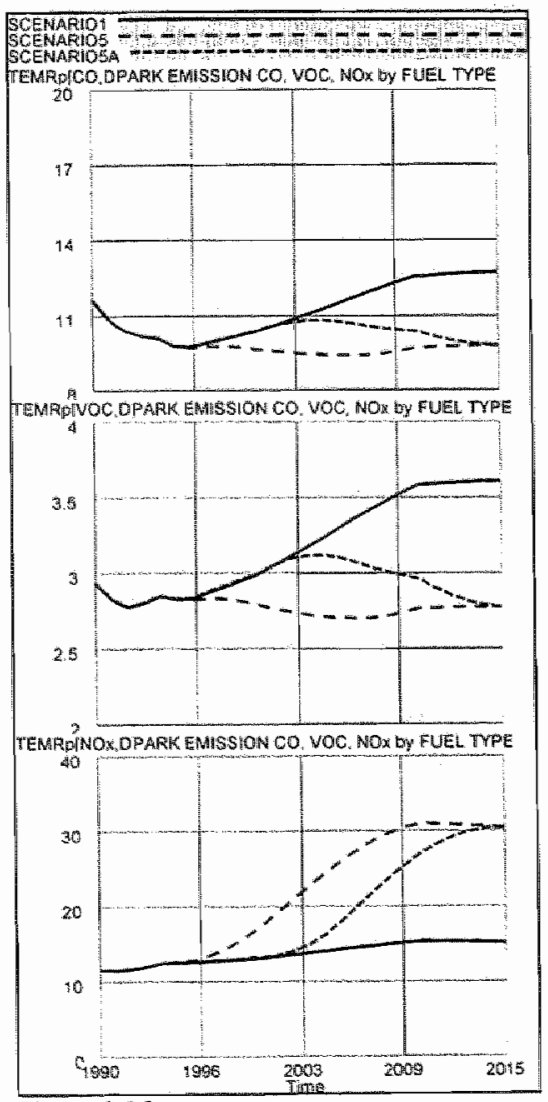

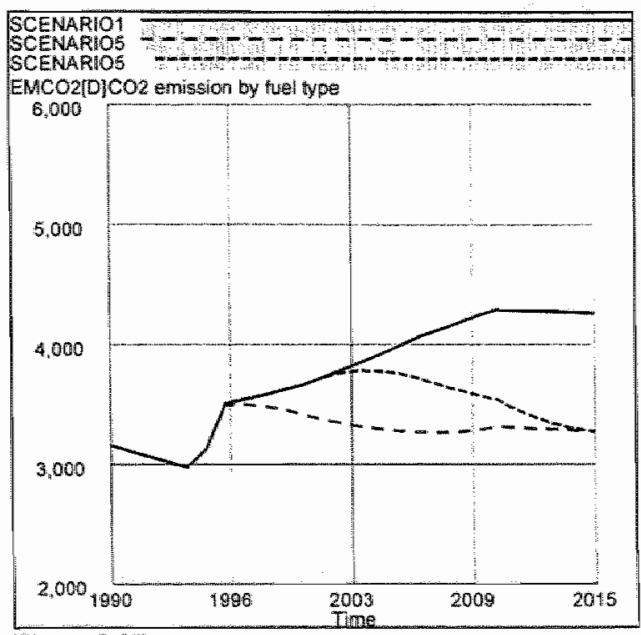

Figure 8.37

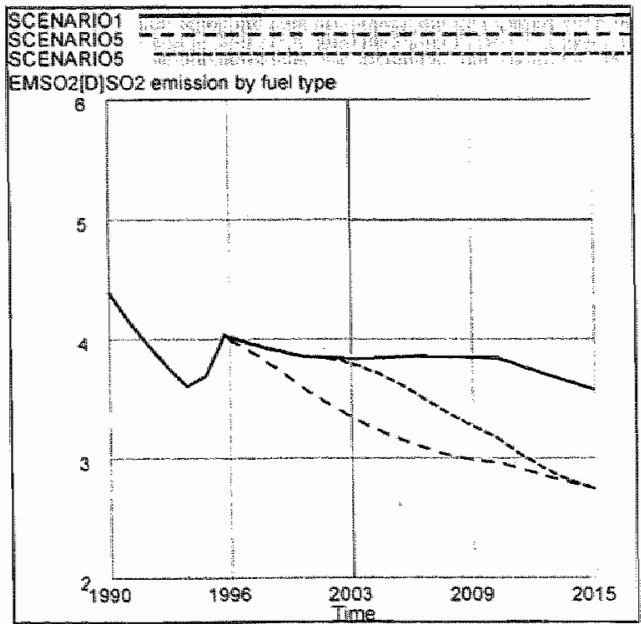

Figure 8.38 
The effects are quite substantial especially for the $S O_{i}$ (Figure 8.38 ). The unrealistic integral conversion of the indirect injection into the direct injection in 1996 shows the opportunity losses of not using the alternative cleaner technology and can be computed as the integral (of the surface between the both curves) of the difference of the fuel use between both technologies and is more or less an indication of the quality of the new (TDD) technology. The introduction of the TDI-technology by way of the new car sales from the year 2000 on shows that the diesel car stock will be completely turned over after 2010. The figures for the $\mathrm{CO}$ and $7 O C$ emissions shows a reduction of $\pm 30 \%$ after 2010 , however at the cost of a substantial increase of the $N \mathrm{~N}_{x}$ which should be abated among others by the new $N \mathrm{~N}_{x}$-catalytic converter. (see also scenario 6 ). 


\section{Scenarion 6 Introduction basic technological innovation : Gasoline Direct Injection (GDI)}

The GDI engine is the first conscript of a new generation of gasoline engine which are more efficient and cleaner than the indirect injection or conventional gasoline engine. The GDI concept was developed 25 years ago after the first oil crises in order to search after more efficient combustion technology whereas the development phase started after 1985. GDI technology is really an analogy of the diesel direct injection (TDD), successfully introduced in 1989. In contrast to the conventional gasoline engine the GDI engine both air and fuel are injected into the cylinders where by way of intensive mixing an explosive mixture is formed. A direct injection into the cylinders has major pollution effects. Because the minuscule fuel drops (with a diameter $<20$ micrometer) are intensively and homogeneously mixed with affluent combustion air, the ignition temperature will be lower and in this situation the combustion process can not be integral combusted, and a phased process with oxygen near the walls and surface of the cylinders and an appropriate air/fuel mix around the ignition mechanism (spark plug) can be designed. The cylinder wall will therefore become less warm than in the conventional engine, with less heat losses: more available energy content in the fuel will be applied for the ultimate target, the up- and down movement of the piston. Theoretically $20-40 \%$ fuel efficiency will become possible depending from the load conditions. In a situation of low load (RT) and RT2 type road) a very poor air/fuel ratio of say $>40: 1$ is technically possible to reach, whereas in the conventional indirect injection engines the desired air/fuel ration will be $14.7: 1$, the so called $\lambda=1$, because the closed catalytic converter can then abate the emission in an optimal way. As the catalytic optimal air/fuel ratio of $14.7: 1$ can only be reached in high load condition (RT3 road type), new design strategies have to be developed in order to cope with the degenerated catalytic conversion process. Feedback control electronics is the new direction in optimising the air/fuel ratio. In the GDI engine the gasoline will be burned in a air affluent environment, by which a poorer mixture is created resulting in an efficient combustion process. The combination of the effects described above results

\begin{tabular}{|lcc|}
\hline CC norms Nitrogen Oxides (NOX) \\
& 2000 & 2005 \\
Otto engine & 0.15 & 0.08 \\
Diesel engine & 0.50 & 0.25 \\
\hline
\end{tabular}

Table 8.10 also in an increase of $\pm 10 \%$ of the traction power. Because of the lower combustion temperature less $\mathrm{CO}$ will be produced and less unburned halogen (hydrocarbons) are exhausted. Moreover because of the lower combustion temperature less acid compounds or bonds are created in comparison with the conventional engine. However the exhaust of nitrogen oxides $\left(\mathrm{NO}_{x}\right)$ remains a problem for the time being. In principle the

${ }_{N O} \mathrm{~N}_{\mathrm{r}}$ can be cauglnt with the closed loop catalytic converter, however the poorer the air/fuel ratio (less fuel vis a vis the air) with relative affluent air in the exhaust worsened the catalytic conversion of nitrogen oxides into harmless nitrogen - and oxygen gas. Therefore a new class of catalytic converters has to be developed the thext decade, seen the future EC emission norms (Table 8.10).

With the recirculation possibilities of $40 \%$ into the cylinders, a reduction of $\pm 80 \%$ (to $0.6 \mathrm{~g} / \mathrm{km}$ ) are possible, and together (in combination) with a suitable catalytic converter system the $N O_{i}$ can be cleaned-up to $97 \%$.

\section{Results}

In order to analyse the effects of an introduction of a new injection technology one has to made assumption about the diffusion speed and the fraction of new cars equipped with the new technology entering the car stock. The diffusion speed depends on the turnover of the car stock and can be policy relevant, for example, to speed up the scrap rate. However in our case the turnover dependis on the mean scrap rate measured in the past and on the new car sales, depending of the discrepancy between desired car ownership and the actual car ownership of the households by size. 


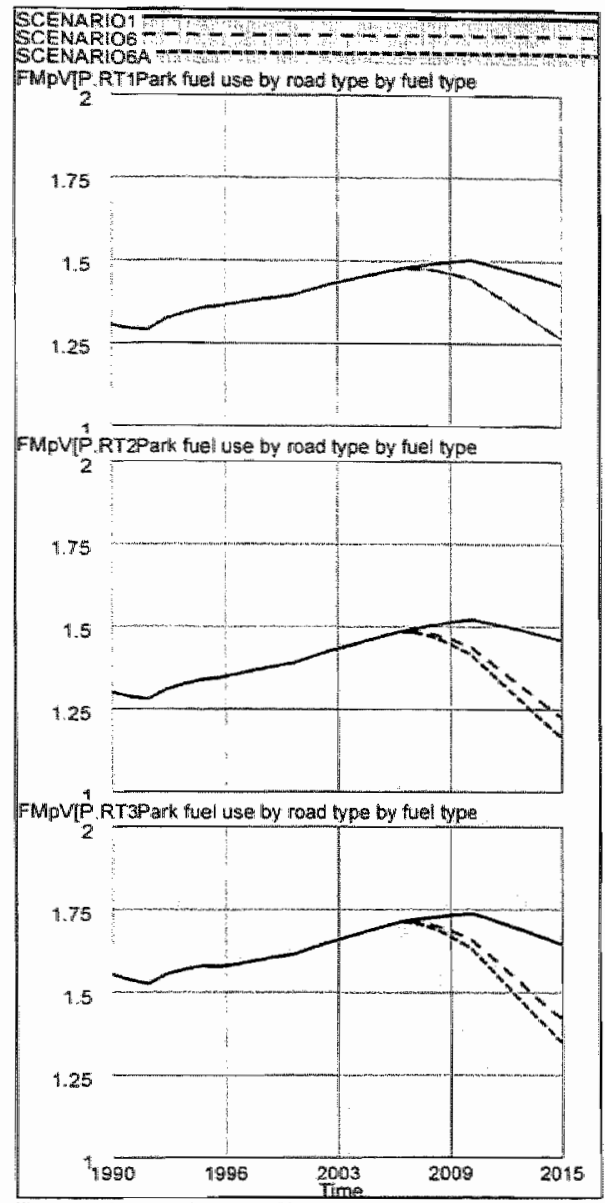

Figure 8.39 The gasoline auto park fuel use by road type
Scenario 6 (Figure 8.39) runs under the assumption that from year 2005 on all gasoline and LPG new cars sales of all cc-categories are equipped with direct injection technology as described above. As there exist for the time being no empirical measured (test cycle) results we have to assume the fuel efficiency for the three drive styles or road types. The following assumptions about the fuel efficiency are: urban traffic $\quad$ RTI $=20 \%$ (medium load) rural traffic $\quad \mathrm{RT} 2=30 \%$ (low load) highway traffic $\mathrm{RT} 3=35 \%$ (high load) However, Scenario $7 \mathrm{~A}$ assumes the following assumptions with $100 \%$ of the new cars equipped with direct injection):

urban trafific $\mathrm{RT} 1=20 \%$ (medium load)

rural traffic $\quad \mathrm{RT} 2=35 \%$ (low load)

highway traffic RT3 = $30 \%$ (high load)

These changes have hardly any effect on the volume $\mathrm{CO}_{2}$ and $\mathrm{SO}_{2}$ emissions.

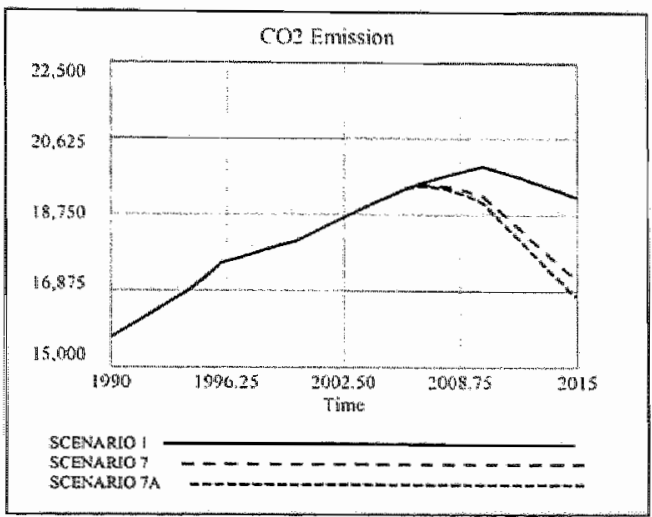

Figure 8.40 $C O_{3}$-Auto park emission 


\section{Closing remarks}

Individual mobility, that is travelling spatial distances as an explicit goal, is not a new phenomenon in history, nor was it a privilege reserved to the elite groups in the society. During centuries people were on the run and have travelled long distances, in time as well as spatial dimensions. However, what really increased dramatically was the distance travelled per person per unit of time by using the new transport systems. At the same time the cost of transport per kilometre travelled decreased with the same ratio. These new transport systems were the carriers of the industrial revolution and at the same time a prodwet of the industrial innovation. Technology introduces faster and faster means of transport, which also are more time-intensive in terms of time of use. These new technologies are introduced roughly every 60 year in tune with the Kondratiev cycle. Their complete adoption or diffusion takes about 100 years. In the beginning of each new transport system the usage was reserved to the political - and high-income elite, but as the cost decreases the diffusion of the new transport system advanced. Thanks to the advanced technical means of transport, implying travelling distances at high speed in a 'sitting' mode, mobility now demands only small physical efforts. What strikes most is the observation that the increase of the distance travelled per unit of time has not decreased the total travel time, while increasing the net leisure time, but on the contrary has increased the totall number of killometres travelled. So one can conclude: not the travel tme is minimised, but the number of kilometres travelled is maximised. This relative constant travel time behaves like an anthropologic invariant. Some scholars pretend that transportation and not communication is the unifying principle of the world. The revolution in communication during the last 20 years did not dent transportation expansion (no substitution); on the other hand, they tend to move together, a co-movement. Therefore the often heard assertion that the communication revolution will reduce the transportation need and therefore the congestion is at stake. Home- or tele-work as the solver for the congestion is questionable and looks like wishful thinking in the political arena.

Moreover, there is another fundamental observation made by Zahavi (1981) that links behaviour and money. Because of its generality it could be dubbed as a money instinct. People spend about $13 \%$ of their disposable income on travelling. The percentage is the same, for example, in Germany and Canada, today or in 1930. Within this budget, time and money are allocated between the various modes of transport available to the travellers in such a way as to maximise mean speed. For example, car owners use it for about one hour a day and travel about $50 \mathrm{~km} /$ day. Therefore it is to be expected that the increase in (auto)mobility comes from the increase of the number of households.

Based on the results of this research we can state the following conclusions:

- Demograplic developments, like changes of the number and the age structure of the population, the number of households and the composition of the households influence strongly the development of the mobility. Forecasting the mobility, the uncertainties of the demographic developments has to be taken into account.

- The car ownership and car use will increase in the near future influenced by three developments:

i. the expected increase in the number of households [Chapter 3];

ii. the expected economic growth ( $2 \% /$ year), and

iii. the relative price decrease of car ownership and/or car use, due to technical improvements in material quality and fuel economy.

- Dutch car ownership is expected to increase steadily, from a total of 4.7 million in 1990 to $7.5-8$ million in 201.0/15 [Chapter 6]. Nearly all of this $\pm 65 \%$ increase is due to the $\pm 27 \%$ growth of the number of households, especially the one-and two person households, backed by a sustained growth of $2 \%$ of yearly income. However, there is a partial off-set between the rise in income and the stable or small decrease of the more-than-three person household. This also shows the increase of the more-than-one car ownership per household figure. The car ownership per household is to be expected to rise from 0.8 in 1990 to 1.0 car/household in 2015 .

- Of interest is the role of the second car in a household. In $198611 \%$ of the households owned a second car, in 1994 this was $16 \%$ and it is expected to increase further in the near future. In the rural areas $22 \%$ of the houselnolds owns a second car, against $8 \%$ in the cities. The second car changed from a luxury good into a (near) necessity good, (in principle the income elasticity will decline and become less than one). Especially the number of women with a car of their own increased with $40 \%$ during the period 1990-1994. Women use the car for, among other, shopping 
(30\% of the trips) and commuting (20\%). The notion 'shopping-car" is a wrong term for the significance of the second car. It's the emancipatory development of increasing woman's independence.

- The car driver is in $60 \%$ of the car trips the only person in the car or in $58 \%$ of the distance travelled. The 1 -person and 2-person households score less than the average occupation rate of 1.6 person per car. The more cars a household owns the lower the occupation rate per car. The occupation rate depends on the motives of displacements. The advance of the second car overshadows an environmental friendly trend as car-pooling. Commuting accounts for 2.3 million. car uses daily (OWG, 1995), of which 320.000 as car-pooling. The occupation rate in case of commuting is quite stable, sinc1985 1.2 persons travel together on average.

- Vehicle kilometres travelled by the Dutch households is expected to rise from 85 billion in 1990 to \pm 125 billion in 2015, an increase of $\pm 40 \%$. Again this growth is mainly due to increased number of households and the resultant increase of car ownership and car use.

- Despite the $40 \%$ expected increase of the vehicle kilometres travelled, fuel consumption and $\mathrm{CO}_{2}$ emissions are projected to return to the 1995 level by 2015 , given the assumption that all new cars from 2005 on are of the latest direct fuel injection type (TDI and GDI), as explained in Chapter 8 , scenario 6 , since on-road fuel efficiency rises by $\pm 30 \%$ depending on the different road-type drives.

- Since increased fuel efficiency means lower operating cost cet. par. vehicles kilometres travelled will tend to increase. This increased fuel efficiency provides extra consumer surplus, but translate into less fuel savings than would otherwise be obtained if the fuel efficiency improvement were not accompanied by more driving, called the "take-back' effect. US research suggests about $25 \%$ of the potential savings are lost. However, Green (1.991) reviews and critiques these previous studies and argues that the take-back effect is actually lower, in the range of $10-15 \%$ or less.

- An ecotax on motor fuel will become less and less effective due to:

1. the open economy of the Netherlands,

2. the ongoing improvement of the fuel efficiency of direct injection systems,

3. the variable net leisure time put under pressure (page 107).

Another related problem, besides the congestion, is that of the harmful exhaust gasses. The ECmembers and the EC-Parliament have accorded, to state it in non-technical words, that from 2005 on the new cars have to emit $70 \%$ less harmful exhaust gasses than the vintage $1998^{\prime}$ and simultaneously an increase of the fuel quality has to be achieved.

The reference run of chapter 8 , assuming, among others, incremental technical improvement of combustion technology, roll - and air resistance, does not succeed in obtaining the $70 \%$ targets. The direct fuel injection technique (TDI and GDI) should be introduced at a higher speed and preferably also the diffusion or tumover of the car stock. The EC directive does adopt the rebate-fee policy to induce a) the households to buy the most fuel efficient cars, and b) the manufacturers to introduce fuel efficient engine cars, besides that the EC also applies legislation and time schedules. Therefore to obtain the targets and to stick to the scenarios 4,5 and 6 the following instruments could be applied:

A. Introducing maximum speed on highways of $80.90 \mathrm{~km} /$ hour (chapter 7 and chapter 8 , scenario 4)

B. Rebates on new vehicles with higher-than-average fuel efficiency, emissions rates, or other attributes and levy fees on vehicles with less efficiency, called "feebate". A fee can be added to the sales price of vehicles with, for example, low fuel efficiency, and a rebate is subtracted from the sales price of vehicles with high fuel efficiency. The rebates and fees may be applied to new vehicles at the time of purchase, and the rates are set such that the total outlay for rebates equal the revenues from fees. The choice of the 'zero-point' of the feebate schedule is of all importance, because it represents the point where fee and rebate are zero at a chosen level of fuel efficiency. A number of feebate scenarios have to be developed on basis of cost-benefit analysis, in order to

\footnotetext{
1 Note how important the reference year is. For example, the CO emission: for the period 1986-2015 a decrease is expected of $\pm 75 \%$, for the period $1990-2015 \pm 45 \%$ (reference run)
} 
approximate the optimal path towards the desired future fuel efficiency. Especially car manufactory's response in design and size on feebate schedules is decisive.

Because the car lifetime has increased during the last decade, due among others to improved material quality, the overall fuel efficiency of the car stock is lagging behind.

In order to speed up the renewal of the car stock, that is to increase the turnover of the vintages, several policies are possible:

C. the same option as B: rebating the small cars ( $<1.2$ Litre cc) and levying the heavy cars (> 2 Litre co):

D. afford a premium to 10 years old cars when buying a new car; these traded-in old cars should, of course, be offered as scrap and wrecked.

E. levy a proportional increase of the road-tax from say 5 years old cars.

The simultaneous introduction of instruments $A, \ldots, E$ offers the second-best solution to the emission problem, as the auto mobility is an autonomous invariant process.

\section{Future research agenda}

Experience of California's 'feebates'(fee plus rebate scheme) shows that the effect on the demand response only is very small in raising the overall fuel efficiency (Train et al. 1997), the effect on manufacturers" design decision (supply side), however, is substantial.

A. Supply

So modelling the supply side on basis of the subclasses described in chapter 5 and 6 , based on fuel type, input-output characteristics and $\mathrm{cc}_{\text {, }}$ is important to forecast the atiributes of vehicle offerings. However, besides the traditional private car the vans and pickups (standard, mini - and compact) have to be added owing to their growing share in the future car fleet. On the technology side the number of emergence technologies have to be described in detail with their contribution to the four efficiency criteria described in chapter 7 , fuel use, traction efficiency, roll resistance and air resistance and the cost involved. The supply model should determine the extent to which each technology is adopted by comparing the cost and benefits of the technology in question. The benefits should be calculated as the net present value of the fuel savings that result from the applied technology in question, summed over $n$-year period discounted at $x \%$ annually, plus an additional variable to count for the fact that the adoption of some technologies increases also the performance (horsepower). Two examples illustrate this proposal:

a. adoption of the technology 'Multi-point Injection' will lead to a change in fuel economy of $3.5 \%$ and a $10 \%$ change in horspower at the additional cost of $f 1150$.

b. adoption of a turbo-charger results in a change in fuel economy of $5 \%$ and change in horsepower of $45 \%$ at the cost of 111100 .

The costeffectiveness of the technology in question can be calculated. The proportion of vehicles in question for which technology $j$ is adopted can be modelled as a logistic function where the maximum represents a production constraint that rises over time. The price of the vehicle in question has to be raised to cover the cost of the technology in the share of vehicles in which the technology is adopted. After that the cost benefit analysis can start to investigate the feebate schedules.

\section{B. Dernand}

In choosing the most suitable demand model to represent consumers' choice among the vehicles that manufacturers offer, a portfolio model of vehicle holdings is an alternative description to the applied one in this research. However the portfolio model has to be based on a survey or preferably on yearly surveys to acquire panel data, but is, in the Netherlands, at the moment non-existent. The portfolio model has to be a customer-level discrete/continuous model of the household's choice of how many vehicle to own, which subclasses and vintages (new, one year old, etc.) of vehicles to own, and how much to drive each vehicle annually. McFadden (1978) has developed a portfolio madel for the choice of residential location which has for our purpose all the desired properties. Let $i$ denote a particular portfolio of vehicle holdings, where a portfolio represents a number of vehicle, zero included, the subclass of each vehicle, and the vintage of each vehicle. Let $I(n)$ denote the set of all portfolios with $n$ vehicles. $Y(0)$ contains only one portfolio (denote $i=0$ for no vehicle holdings), $l(1)$ contains each possible subclass/vintage, and $I(2)$ contains each possible pair of subclass/vintage combination. The urility that household $h$ obtains from portfolio $i$ is denoted $U_{h \text {, }}$, consisting of a portion $V$ that depends 
on observed characteristics of the portfolio and the household, and a portion that is unobserved: $U_{h i}=$ $V_{h i}+\varepsilon_{h i}$ Assuming that $\varepsilon_{h i}$ for all $i$ is distributed Generalised Extrene Value with correlation over $i$ within each set $I(n)$ but not across these sets, then the probability $P_{h:}$ that the household $p$ owns portfolio $i$ is nested logit (McFadden, 1978):

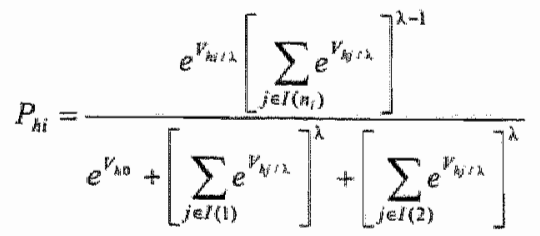

where $n_{i}$ is the number of vehicles in portfolio $i$. The parameter $(1-\lambda)$ is a measure of the correlation of households car ownership, hi, within each nest. $V_{h i}$ is linear in parameters with explanatory variables that include: the sales price, fuel cost, that is the price of fuel divided by $\mathrm{Km} / \mathrm{L}$, weight or horsepower (cc) as proxy of each vehicle in the portfolio, as well as number of household members, household income, number of workers.

C. Kilometrage

Conditional on its portfolio, the number of households' car trips is given by a (non)linear system of equations with a number of explanatory variables as the operating cost (actual and expected), the number of household members, the motive of travelling, number of workers, and a dummy indicating whether the vehicle is the newer one in two-or-more vehicle portfolio. After summations over the portfolio of the probabilities and weighted by the drive-type (chapter 7), the total derived kilometrage by vehicle type are the required inputs for the emission model, as explained in chapter 7. 


\section{Appendix A}

Mathematical definitions

A.1 State Space model and linearisation

State Equation:

$$
x(n)=f[x(n-1), y(n), w(n), n]
$$

Measurement Equations:

$$
x(n)=h[x(n), v(n), n]
$$

Index of Data Samples :

$$
n=1, \ldots, N
$$

Initial Conditions :

$$
\mathbf{x}(0)=N\left[\mathbf{x}_{0}, \psi\right] \#
$$

Equations Error (Driving Noise):

$$
w(n)=N[0, Q(n)]]
$$

Measurements ErTors:

$$
\mathbf{v}(n)=N[0, \mathbf{R}(n)]
$$

\# $N[\mathbf{m}, \Gamma]$ denotes a normal, white process with mean $\mathbf{m}$ and covariance matrix $\Gamma$.

Linearisation about estimated state :

$$
\begin{array}{ll}
\widetilde{\mathbf{F}}(n)=\left.\frac{\partial \mathbf{r}}{\partial \mathbf{x}}\right|_{\hat{\mathbf{x}}(n-1 \mid n-1)} & \widetilde{\mathbf{H}}(n)=\left.\frac{\partial \mathbf{h}}{\partial \mathbf{x}}\right|_{\hat{\mathbf{x}}(n \mid n-1)} \\
\widetilde{\mathbf{Q}}(n)=\left.\left(\frac{\partial \mathrm{f}}{\partial \mathbf{w}}\right) \mathbf{Q}(n)\left(\frac{\partial \mathrm{r}}{\partial \mathbf{w}}\right)^{\prime}\right|_{\mathbf{w}=0} & \widetilde{\mathbf{R}}(n)=\left.\left(\frac{\partial \mathbf{h}}{\partial \mathbf{v}}\right) \mathbf{R}(n)\left(\frac{\partial \mathbf{h}}{\partial \mathbf{v}}\right)\right|_{\mathbf{v}=0}
\end{array}
$$




\section{Appendix B}

\section{A.2 Filter Equations}

Predicted state:

$$
\hat{\mathbf{x}}(m \mid n-1)=\mathbf{f}[\hat{\mathbf{x}}(n-1 \mid n-1), \mathbf{u}(n)]
$$

Predicted measurement : $\quad \hat{\mathbf{z}}(n \mid n-1)=\mathbf{h}[\hat{\mathbf{x}}(n \mid n-1)]$

Residuals :

$$
\delta_{z}(n \mid n-1)=z(n)-\hat{z}(n \mid n-1)
$$

Predicted state

$$
\text { covariance : } \quad \sum_{\mathrm{x}}(n \mid n-1)=\widetilde{\mathbf{F}}(n) \sum_{\mathrm{X}}(n-1 \mid n-1) \widetilde{\mathbf{F}}^{\prime}(n)+\widetilde{\mathbf{Q}}(n)
$$

Predicted measurement

$$
\text { covariance: } \quad \sum_{z}(n \mid n-1)=\widetilde{\mathbf{H}}(n) \sum_{x}(n \mid n-1) \tilde{\mathbf{H}}^{\prime}(n)+\widetilde{\mathbf{R}}(n)
$$

Normilised predicted

$$
\text { measurement residuals: } \quad \widetilde{\delta}_{z}(n \mid n-1)=\sqrt{\sum_{z}(n \mid n-1)^{-1}} \delta_{x}(n \mid n-1)
$$

Updated state

$$
\text { covariance : } \quad \sum_{x}(n \mid n)=\left[\sum_{x}^{-1}(n \mid n-1)+\widetilde{\mathbf{H}}^{\prime}(n) \widetilde{\mathbf{R}}^{-1}(n) \tilde{\mathbf{H}}(n)\right]^{-1}
$$

Filter gain : $\quad \mathbf{K}(n)=\sum_{\mathrm{x}}(n \mid n-1) \widetilde{\mathrm{H}}^{\prime}(n) \sum_{\mathrm{x}}^{-1}(n \mid n-1)$ 


\section{Appendix C}

Trace results of the Verbulst-Pearl function gasoline cars, base period 1980-1994

In this section and the next three section a sensitivity analysis of the search parameters will be performed, due to lack of space a subset of the search parameters (gasoline only) will be shown in table box 5.16

\begin{tabular}{|l} 
Box 516 Log likelihood $95 \%$ Confidence intervals \\
$-1.89964 \leq q[\mathrm{P}]=-1.8867 \leq-1.87442$ \\
$1.38576 \leq \mathrm{B}[\mathrm{P}]=1.39 \leq 1.39378$ \\
$10.023 \leq \varphi[\mathrm{P}]=10.124 \leq 10.192$ \\
The base payoff is -57.419
\end{tabular}

The trace-procedure shows the parameter values and payoffs at different iterations. The time axis is simply an index that increases by one on each simulation. Figures 5.52 to 5.55 shows smooth search trajectories of the search parameter values and idem dito for the payoff values. As the other modell estimations shows similar characteristic search trajectories their trace plots are not shown here.

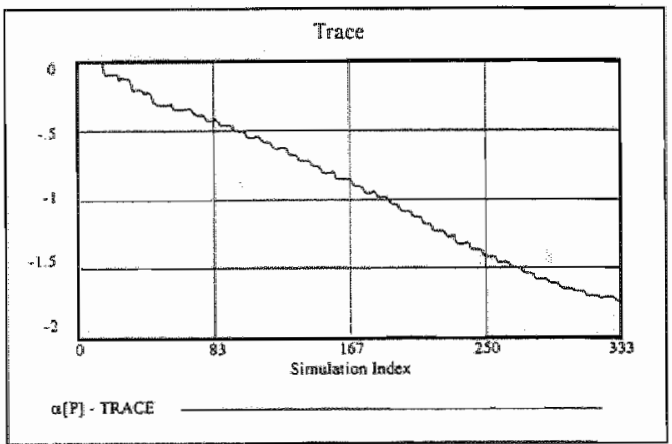

Figure 5.52 The trace of the $\alpha$-parameter

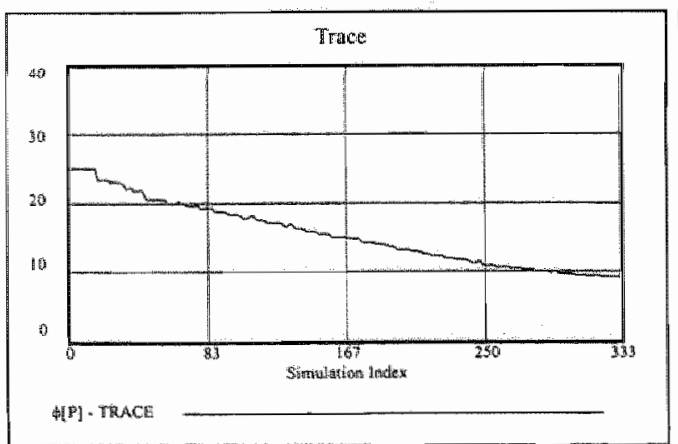

Figure 5.54 The trace of the $\phi$-parameter

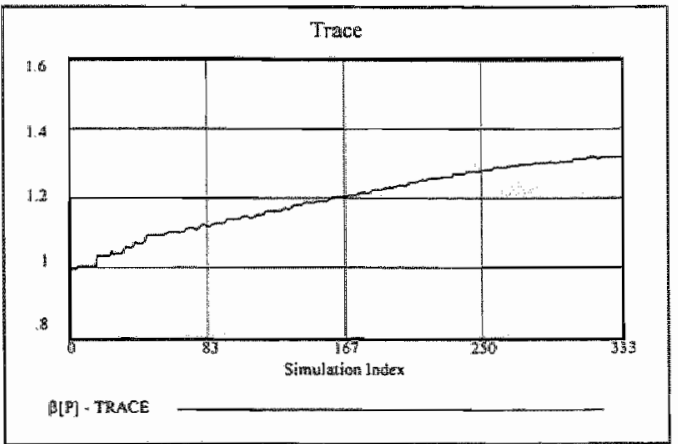

Figure 5.53 The trace of the $\beta$-parameter

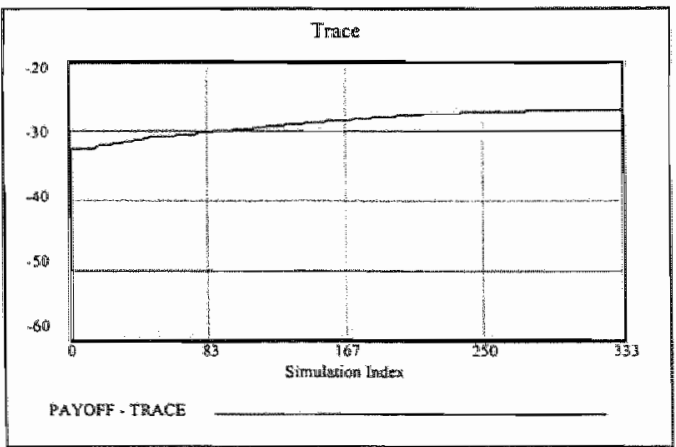

Figure 5.55 The trace of the payoff 


\section{Vector search with no optimisation (Verhulst-Pearl logistic function, gasoline)}

The procedure vecior search without optimisation shows the payoff as a function of the search parameters value and is very suited for examining the global stability of the likelihood surface. The starting points are computed over uniformly partitioned values of each search parameter. The first parameter will be searhed from its minimum to maximum values, then the second, and so on. The partition is the maximum - minimum value over the setting of the vector points, here 25 . As can be shown in the Figures below no separate cuts has been shown up.

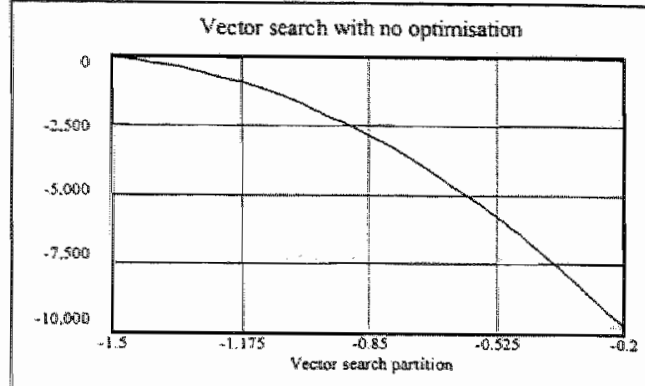

X[P] - VECTOR

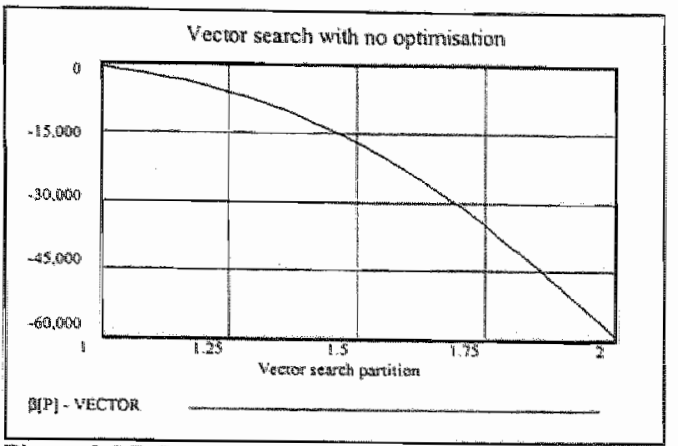

Figure 5.5.7 The vector search of the $\beta$-parameter

Figure 5.5.6 The vector search of the $\alpha$-parameter

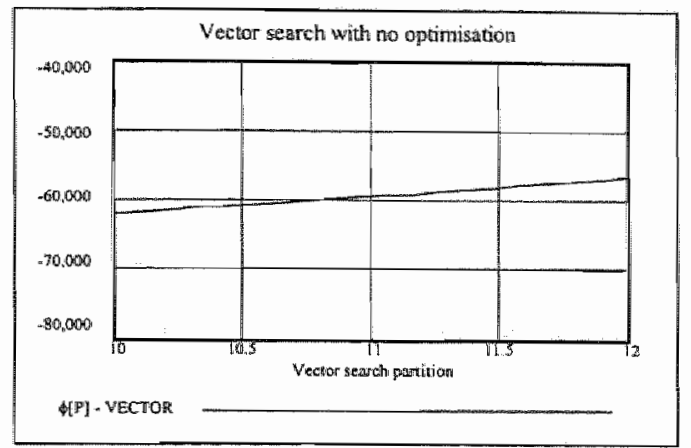

Figure 5.5.8 The vector search of the $\phi-p a r a m e t e r$

The procedure wector search with optimisation (Figure box 5.5.9) furnishes information about the sequential change of each separate search parameter, the starting points are computed over uniformly partitioned values of each search parameter (in our example 25). The endpoints (Figure E, $\ldots,{ }_{1} \mathrm{H}$ ) are the final values after optimisation has been reached (in totall 75 optima). Unlike the grid search, vector search changes only one parameter at a time according to the following schema.

\begin{tabular}{|c|c|c|c|c|}
\hline Domain & $0<1 \leq 25$ & $25<I I \leq 50$ & $50<\mathrm{III} \leq 75$ & \\
\hline Range & & & & \\
\hline$\alpha$ & $-2 \rightarrow-1$ & -1 & .1 & figure A \\
\hline$\beta$ & 1 & $1 \rightarrow 2$ & 1 & f" igure $\mathbb{B}$ \\
\hline$\phi$ & 10 & 10 & $10 \rightarrow 12$ & Figure C \\
\hline
\end{tabular}

The $\beta$ - and $\phi$-parameter and the payoff reach already their near-optimum values when the $\alpha$ parameters reaches its optimum value. Figures $5.5 .9 \mathrm{~F}, \mathrm{G}$ and $\mathrm{H}$ shows this effect quit clearly. Changing the values of the $\beta$ - and $\phi$-parameters has hardly any effect on the optimum $\alpha$-value. As explained in chapter 3 and 4, the period 1980-1994 was hit by two severe recessions with strong direct responses of the new gasoline car sales and indirect of the gasoline car stock, the maximum share of gasoline type cars of the total car stock and the replacement did hardly infuence the effect of the income component of the new car sales function (CS[P]). 


\section{Vector search with optimisation}

Figure box 5.5 .9
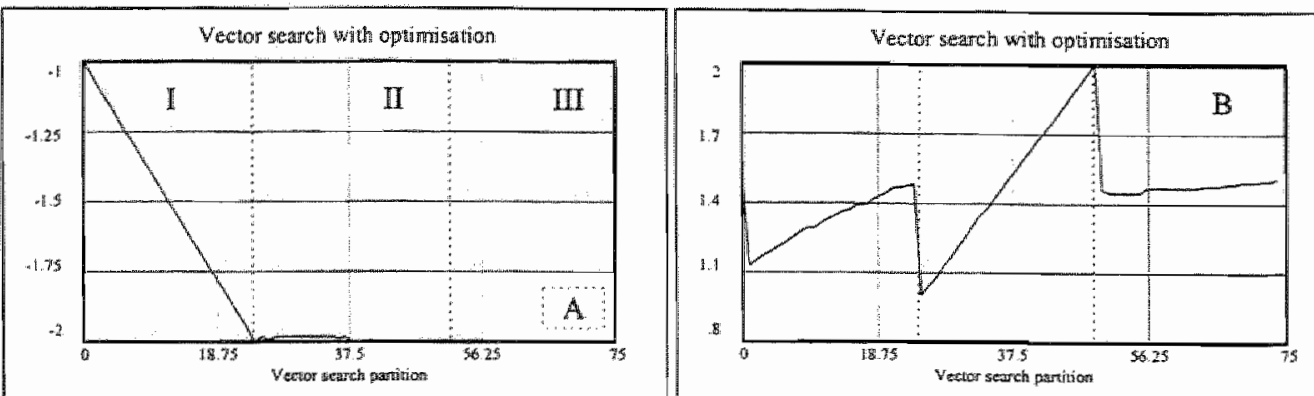

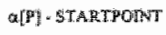

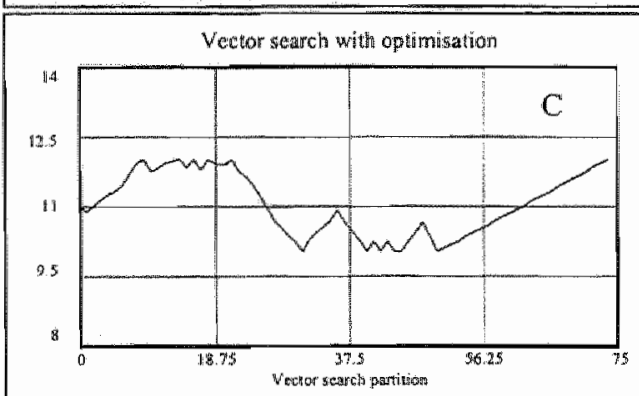

M.F] - STARTPONT

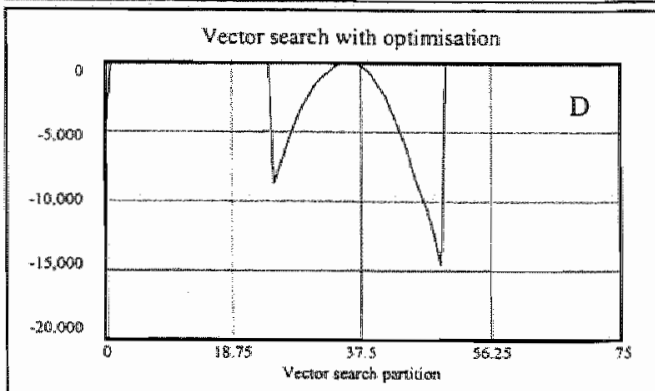

APJ - STARTPGOMTI

PAYOIFF - STARTPONNT

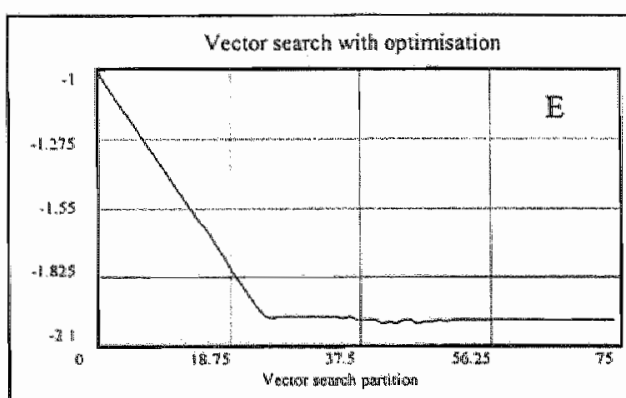

aIP - HADOANT

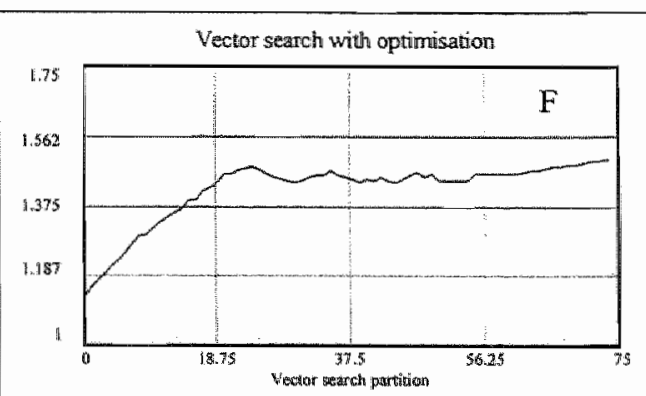

M[PI - ENDPCONTI
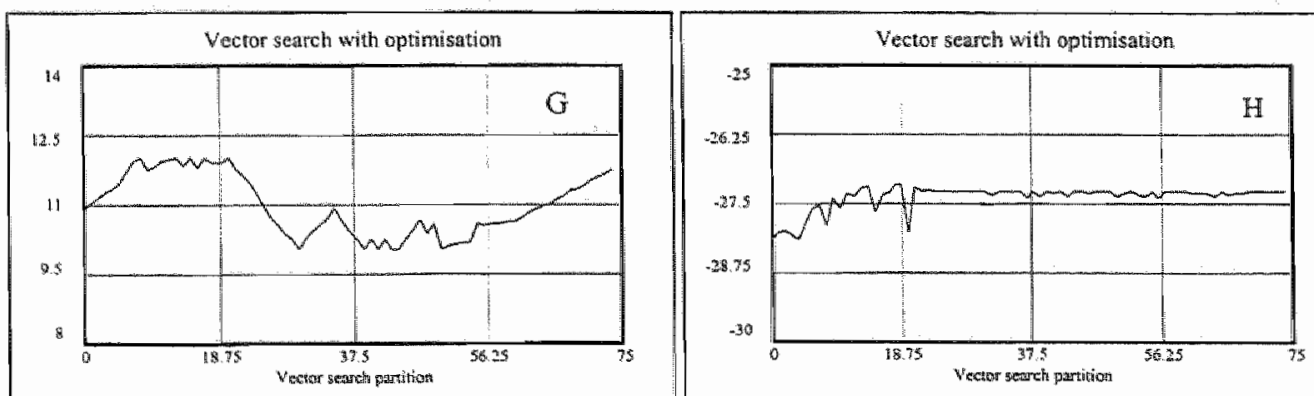

此? - ENDRORT

PAYOFE * ENDPOINT 


\section{Grid search with optimisation}

Figure box 5.5.10
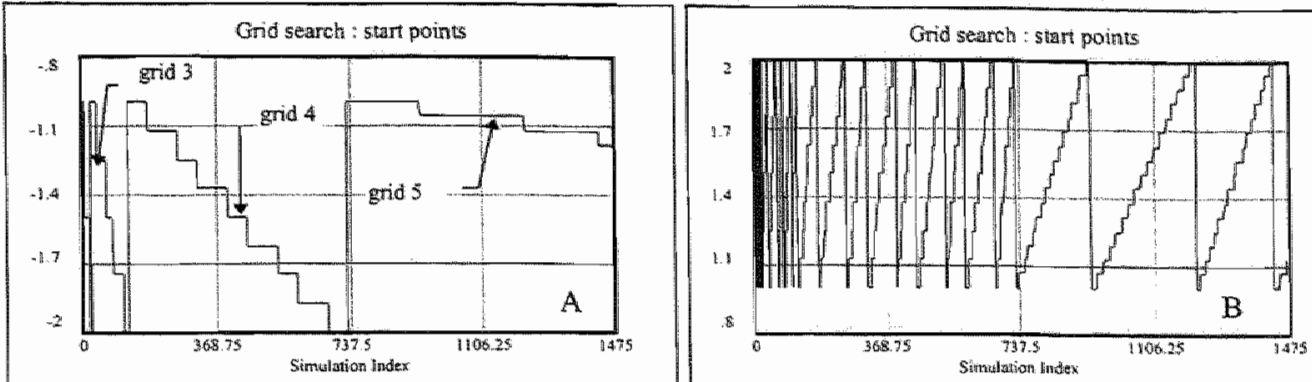

a:PI STARTPORT

ART - STARTPOINT
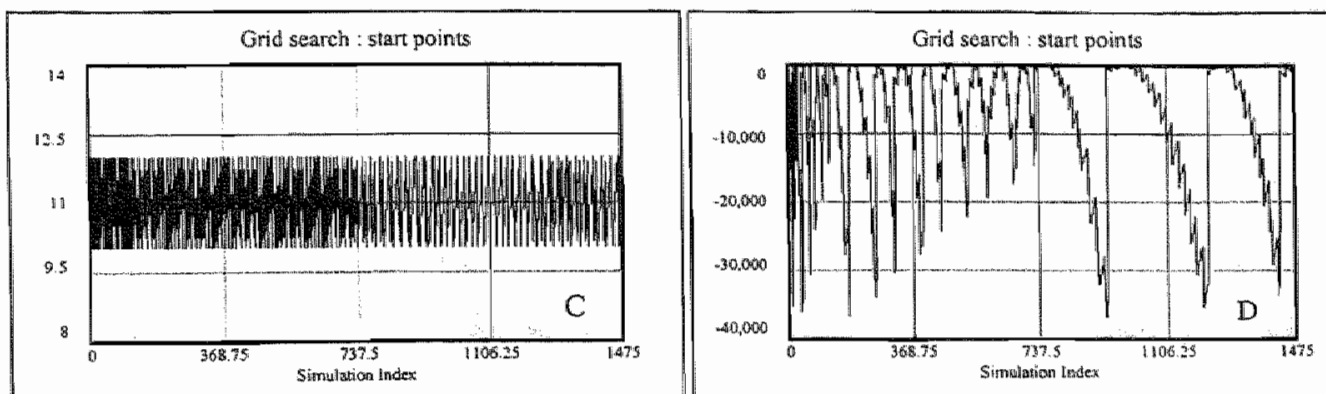

EP] - STARTPONT

PAYOFF - STARTPOINT
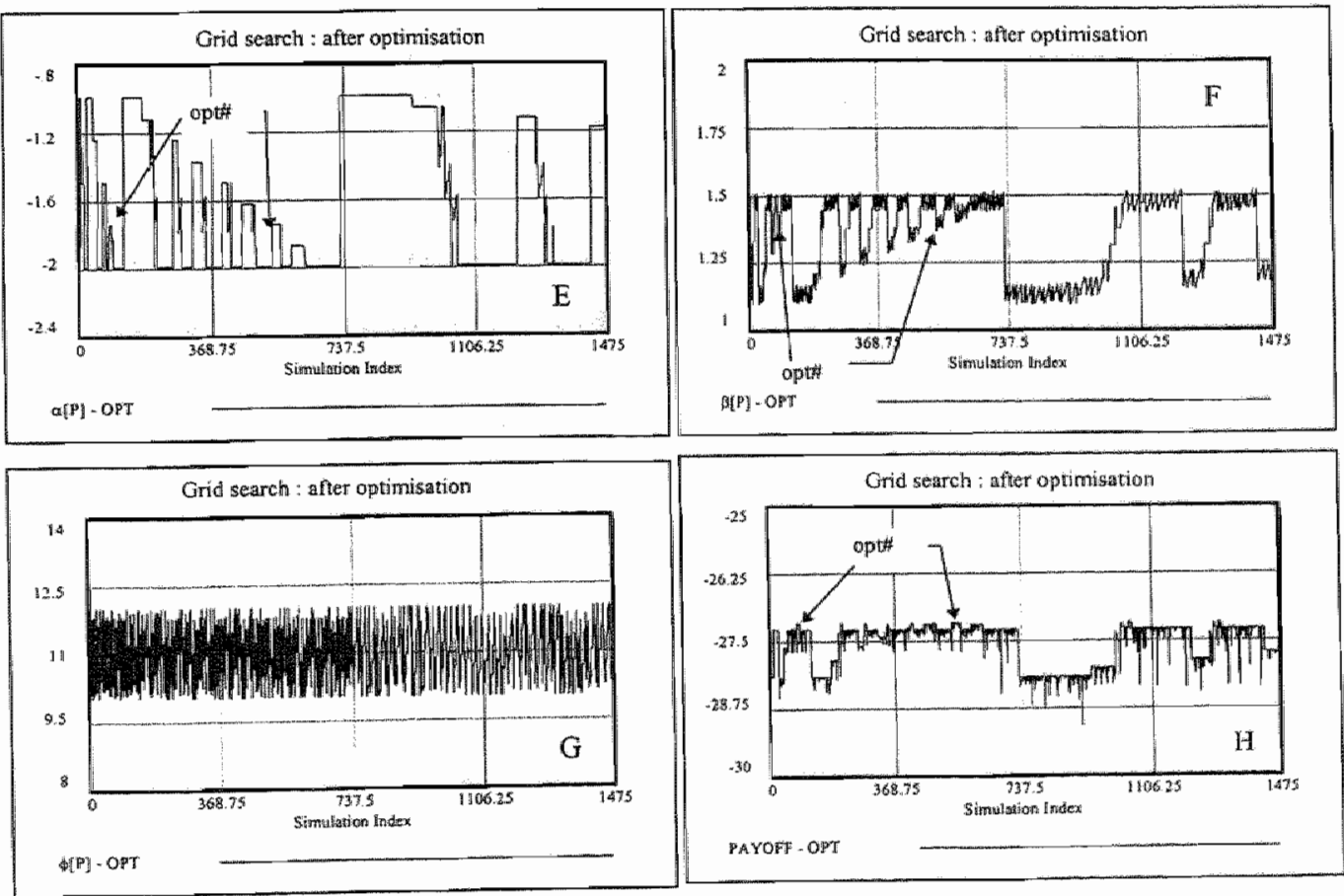

PAYOFE - OPT 
The grid search procedure computes the starting points over successively finer grids over the range of each search parameter. The first grid computes the endpoints of the ranges, the next grid computes also the midpoints, and each successive grid divides the previous grid by 2 . The number of points equals $2^{m-1}+1$, where $n$ is the number of grids $(n \geq 1)$. In case of more than one search parameter the sequence is as follows: for grid 4 start with $\alpha=-2$ and $\beta=1,1,125, \ldots, 1.875,2$ (9 numbers equally spaced from 1 to 2 inclusive), then for $\alpha=-1.875$ and $\beta=1,1.125, \ldots, 1.875,2$, and so on. An equivallent nested sequence applies for 3 and more search parameters. This sequence is clearly visible in plot $A$ and $B$ in. Figure box 5.5.10. This continues for up to 1024 divisions, which could take an unreasonable long time, unless it is interrupted. The potential number of simulations is 1024 to the power of the total number of search parameter. Note The ranges for parameters are specified as constraints on the parameters being optimised.

For example, take the $\alpha$-search parameter with endpoints -2 and -1

\begin{tabular}{|c|c|c|c|c|c|c|c|c|c|}
\hline Grid & staripe & & & & & & & & startpoint \\
\hline 1 & -2 & & & & & & & & -1 \\
\hline 2 & -2 & & & & -1.5 & & & & -1 \\
\hline 3 & -2 & & -1.75 & & -1.5 & & -1.25 & & -1 \\
\hline 4 & -2 & -1.875 & -1.75 & -1.675 & -1.5 & -1.375 & -1.25 & -1.125 & -1 \\
\hline
\end{tabular}

These points can be checked in the left part of plot A of Figure box 5.5.10.

At each computed grid, an optimisation will be performed for each stantpoint of the search parameters simultaneously (shown in plot $A, B, C$, and D), in our case for the $\alpha_{-}, \beta$, and $\phi$ search parameter, the 'opt'-points refers to the local optima, given the startpoints (shown in plot E, F, G, and $\mathrm{H}$ ).

From the grid search the same conclusion can be drawn as from the vector search, in that the $\alpha$ parameter globally dominates the optimisation process, however the grid search shows us that the optimum $\alpha$-parameter by going through the alternate decreasing $\leftrightarrow$ constant startpoint (see grid 4 as an example in plot $A$ and $E$ ) forces the $\beta$-parameter to move upwards within the range $\sim 1.2 \ldots \sim 1.5$, as plot $F$ shows, because startpoint values of $\beta>\sim 1.5$ result in a dramatic drop of the payoff as can be seen in plot $\mathrm{D}$ of Figure box 5.5.9., and plot $\mathrm{D}$ in Figure box 5.5.10.

But local information is also available from the grid search, for example, if $\alpha<-1$ and $\pm 1.2<\beta<$ 2 then a switch in optimal a acours, (see plot $A, B$, and $E$ ), at $2 \leq \beta<\sim 1.2$ a reswitch takes place, till the next cycle in the $\beta$-range, etc. The local- and global optimum meets each other in the point $o p t^{*}(\alpha, \beta, \phi)=(-1.88,1,39,10,1)$ as indicated in Box 5.16 and in plot $E$, $F$, and $H$ for grid 3 and 4 , the deeper one digs into the grids the more elaborate the surface around opt" can be analysed and the more reliable statements can be presented.s 


\section{Literature}

Bajic, V., 1993, Automobile and implicit markets, Applied Economics, 25, 541-51.

Becker, G., 1965, A Theory of the Allocation of Time, Economic Joumal, 75, 1965.

Blockmans, W. (red), 1993, De mens in beweging, HD Uitgeverij, Hilversum, Nederland.

Blomqvist, A. and Haessel, W., 1978, Small cars, large cars and the price of gasoline Canadian Joumal of Economics, 11, 470-89.

CBS, 1986, Afvalstoffen Voertuigwrakken (Solid Waste Wrecks) 1983.

CBS, 1991, Het bezit en de aanschafplannen van auto"s in particuliere huishoudens 1972-1990

Car ownership and buying plans in households 1972-1990, Suppl soc-econ mudstat $91 / 4$.

CBS, 1992, Nationale Huishoudensprognose 1992, Mndstat bewolk 92/7.

CBS, 1992 A, Het PRIMOS-huishoudmodel, 1992, Mndstat bevolk 92/11.

CBS 1992 B Luchtverontreiniging, emissies door wegverkeer, 1980-1990, Den Haag, SDU.

CBS 1992 C De Nederlandse Energiehnishouding 1991, Den Haag 1992.

CBS, 1993 A, Voomaamste uitkomsten van de jaarlijkse huishoudensstatistiek 1988-1992, Suppl soc-econ mndstat $93 / 6$.

CBS, 1993 B, Households explosion in the Netherlands? 1993, Mndstat bewolk 93/4.

CBS, 1993 C, Luchtverontreiniging, emissies door wegverkeer, methodiek vaststelling emissiefactoren, M45 Statistische Onderzoekingen, Den Haag, SDU.

CBS, 1993 C, Luchtwerontreining, Enissies door wegverkeer, methodiek vaststelling

emissiefactoren. Statisticshe Onderzoekingen M45.

CBS, 1994 A, Uitkomsten Bevolkings-en Huishoudensprognose 1993, Mndstat bevolk 94/1.

CBS, 1994 B, Jaarlijkse Huishoudensstatistiek, 1988-1993, Mndstat bevolk 94/12.

CBS, 1994 C, Statistiek van de Motorvoertuigen $\mathbb{1}$ augustus 1994.

CBS, 1995, Uitkomsten Bevolkings-en Huishoudensprognose 1994, Mralstat bevolk 95/1.

CBS, 1996, Vitkomsten Bevolkings-en Huishoudensprognose 1995. Mndstat bevolk 9611.

CBS, 1996 A, Toekomstige huishoudensontwikkeling: demografie of gedrag? 1996, Mndstat bevolking $96 / 4$.

CBS, 1996 B, Energieverbruik in het wegverkeer.Mndstat verkeer $96 / 9$.

Cigno, A., 1991, Economics of the Family, Clarendon Press, Oxford, UK.

Chow, G. C., 1957, The Demand for Automobiles in the United States, Amsterdam, North Holland Publishing Co, NL.

Cowling, K. and Cubbin, J., 1971, Price, quality and adwertizing competition: an econometric investigation of the U.K. car market, Economica, 38, 378-94.

EC, 1993, Auto Emissions 2000, Commission of the European Communities, European Symposium.

Eggleston, H.S., Gorissen, H.S., Joumard, R., Rijkeboer, R.C., Zamaras, Z., Zierock, K..H., 1989, 
Summary Report of the CORNNAIR Working Group on Emission Factors for calculating 1985 Emissions from Road Traffic. Berlin, EnviCon.

Enders, W., 1995, Applied Econometric Time Series, Wiley \& Sons, New York, US.

Farrel, M. J., 1954, The Demand for Motor Cars in the United States, Journal A of the Royal Sitatistical Society,

Griliches, Z, 1963, Capital Stock in Investment Function, in Measurement in Economics, Christ and others, (eds) Standford University Press, Standford, US.

Griliches, Z, 1971, Hedonic price indexes for automobiles; an econometric analysis of quality change, in Price Indexes and Quality Change. Griliches, Z (ed.) Harvard University Press, Cambridge, US.

Harberger, A. C., 1960, The Demand for Durable Goods, University of Chicago Press, Chicago, US. deJong, F. J., 1967, Dimensional Analysis for Economists, Amsterdam, NL.

Jgrgenson, D. and Siebert, C., 1968, A comparison of alternative theories of corporate investment behaviour, The American Economic Review, 58, 681-712.

Jørgensen, F., and Wentzel-Larsen, T., 1990, Forecasting Car Holding, Scrappage and New Car Purchase in Norway, Joumal of Transport Economics and Policy, 24, 139-156.

Kahn, M. E., 1996, New evidence on trends in vehicle emissions, Rand Joumal of Economics, 27, No.1, Spring, pp. 183-196.

Klaassen, L, H., 1972, Regional Economie, Wolters-Noordhoff, Gromingen, NL.

Lancaster, K., 1966, A new approach to consumer theory, Joumal of Political Economy, 74, 132-157. Lutz, W. (ed), 1994, The Future Population of the World, IIASA Earthscan, London, UK.

McFadden, D., 1978, Modeling the choice of residential location, In Spatial Interaction Theory and Planning Models, eds A. Karquist et al. North Holland, Amsterdam.

Muth, F, 1966, Household Production and Consumer Demand Function, Econometrica, 34, Oort. C., 1969, Evaluation of Travelling Time Journal of Transpor Economics and Policy, september $1969, \mathrm{pp} 279.286$.

RAI, 1995. Segmentenoverzicht, Personenwagens op registratiedatum 1990-1995, RAI Vereniging, Ansterdam, NL

Rijkeboer, R.C., Sloten, P. van, Haagen, M.F. van der, 1990, Steekproefcontroleprogramma, Publikatie Reeks Lucht nr. 89., Staatsuitgeverij/DOP, Den Haag, NL.

Rijkeboer, R.C., Haagen, M.F. van der, 1992. Koude start en conditioneringstemperatuur bij U9auto's. Rapportnr.733139000/1, in opdracht wan VROM, IW-TNO, Delft, NL.

Rippe, R. and Feldmnan, R., 1976, The impact of residential construction on the demand for automobiles: an omitted variable, The Joumal of Business, 10, 389-401.

Romanowicz, T.M., and Owinski, J.W., 1988, On Dynamic Modeling of Car Populations. Part I, 
Technological Forecasting and Social Change 34, 81-94.

Roos, C., F., and V. von Szeliski, 1939, Factors Governing Changes in Domestic Automobile Demand, The Dynamics of Automobile Demand, GMC, US.

Rosen, $S_{*}, 1974$, Hedonic prices and implicit markets: product differentiation in pure competition, Journal of Political Economy, 72, 34-55.

Schultz, T. Paul., 1994, Human Capital, Family Planning, and Their Effects on Population Growth, 1994, AEA Papers and Proceedings May, US.

SCP, 1993, Sociall-culturele beweegredenen, Rijswijk, NL.

SCP, 1994, Sociaal Cultureel Rapport 1994, Rijswijk, NL.

SCP, 1995, Tijdopnamen (Time Budget Survey), Sociaal en Culturele Studies 22, Rijswijk, NL.

Suits, D., 1958, The Demand for New Automobiles in the United States1929-1956, The Review of Econowics and Statistics, 40.

Train, Kenneth E, Davis W. B. and M. D. Levine, 1997, Fees and Rebates on new vehicles: Impacts on fuel efficiency, carbon dioxide emissions, and consumer surplus, Transprtt Res. $E$ (Logistics and Transpri Rev), 33, No. 1, pp. 1-13.

UBA/TUV-Rheinland, 1987, Das Abgas-emissionsverhalten von Personenkrfwagen in der Budesrepublik Deutschland im Bezugsjahr 1985. Berichte 7/87., Erich Schmidt Verlag, Berlin, Dtsi.

Wykoff, F., 1973, A user cost approach to new automobile purchases, Review of Economic Studies, $40,377-90$.

Zachariadis, Th., Samaras, Z. and K-H. Zierock, 1995, Dynamic Modeling of Vehicle Populations: An Engineering Approach for Emission Calculations, Technical Forecasting and Social Change, 50, 135-149. 


\section{Samenvatting}

Onderhavige studie legt een relatie tussen de Nederlandse huishoudenssamenstelling, automobiliteit en de hieruit resulterende emissies. Voor het bestuderen van de kwantitatieve ontwikkelingsprocessen van bovengenoemde relaties geldt de periode 1980-1995 op basis waarvan de naasite toekomst wordt verkend. Teneinde de emissies (hoofdstuk 7) te berekenen dient enerzijds het Nederlandse autopark zowel kwantitatief als kwalitatief (hoofdstuk 4 en 5) ên de verkeersprestaties of automobiliteit van de. Nederlandse huishoudens naar grootte (hoofdstuk 6) gemodelleerd te worden.

Hoofdstuk 1 geeft een uitwoerig samenvatting van deze studie.

In hoofdstuk 2 wordt het bevolkingsmodel naar zes leeftijdsklassen ontwikkeld welke als input dient woor het te ontwikkelen huishoudensmodel naar grootte (éen - tot zes persoonshuishoudens). Als gegevensbronnen dienen de bevolkingsmatrices van $1980-1990$ welke beschikbaar werden gesteld door het CBS. Op basis van deze gegevens wordt het bevolkingsmodel geschat. Enkele scenario"s (zoals hoge/lage geboortecijfers, hoge/lage migratiecijfers) worden doorgerekend teneinde de toekomst te werkennen. Dit geschiedt door midde] van een Monte-Carlo simulatie.

In hoofidstuk 3 wordt het huishoudensmodel ontwikkeld welke de ontwikkeling van de eén - tot zes persoonshuishoudens beschrijft en tracht te voorspellen op basis van het in hoofdstuk 1 ontwikkelde bevolkingsmodel. Als referentieperiode geldt de periode 1960-1995. Het meest in het oogspringende feit is de turbolente ontwikkeling van de huishoudens ten opzichte van de bevolkingsontwikeling, in het bijzonder die van de één - en twee persoonshuishoudens. Deze ontwikkeling zal in het eerste decennium van de volgende eeuw nog voortgang vinden. Dit heeft uiteraard gevolgen woor de automobiliteit, zoals in het tweede deel van dit hoofdstuk wordt geanalyseerd aan de hand van de begrippen 'bruto' en 'netto" vrije-tijd, de maatschappelijke ontwikkeling van met name de één - en twee persoonshuishoudenis, de tijdsdruk op de netto vrije-tijd en de hieruit resulterende toenemende kapitaalintensiteit van de buisproductie inclusief de automobiliteit. Het huishoudensmodel dient enerzijds voor het bepalen van het autobezit (hoofdstuk 4) en het autopark (hoofdstuk 5) en anderzijds voor het bepallen van de automobiliteit of verkeersprestatie uitgedrukt in kilometrage per huishouden naar grootte naar motief (hoofdstuk 6).

Hoofdstuk 4 wordt de evolutie van liet autobezit nader geanalyseerd en blijkt het mogelijk te zijn een aantal logistisclne functies te schatten welke de autoverkopen naar brandstof type, benzine, diesel en LPG, bepaald. De gegevens van de autoverkopen gedurende de periode 1980 -1994 zijn afkomstig van de motorvoertuigen statistiek en van de RAI. Op deze manier wordt een eerste stap gezet naar een kwalitatieve beschrijving of samenstelling van het Nederlandse autopark.

In hoofdstuk 5 wordt het autopark naar brandstof type "ontwikkeld in hoofdstuk 4 , verder ontleed in termen van input/output technologie (in- of directe inspuiting, katalysatoren) en bouwjaren, in economisch jargon 'jaargangen' genaamd. Op een dergelijke wijze is een kwalitatieve samenstelling of opbouw van her Nederlandse autopark mogelijk. Daartoe is naast de autoverkopen ook een bschrijwing en schatting van het afstootproces noodzakelijk op basis van de statistiek van de voertuigwrakken.

Hoofdstuk 6 analyseert de automobiliteit of verkeersprestaties van de Nederlandse huishoudens naar grootte op basis van een tweetal onaflnankelijke CBS statistieken, nl. Onderzoek VerplaatsingsGedrag (OVG) en PersonenAuto Panel (PAP), getracht wordt de onderliggende dynamiek modelmatig te beschrijven teneinde op deze wijze het recente verleden en de toekomstige verwachtingen te berekenen. Eén van de conclusies luidt dat de toekomstige mobiliteit bepaald wordt door de 
ontwikkeling van het aantal huishoudens en de ontwikkeling eq. toename van de tweede of derde auto per huishouden.

Hoofdstuk 7 beschrijft het emissiemodel, ontwikkeld door het Instituut voor wegtransport van het TNO, op basis waarvan de emissies per voertuigkilometer wordt berekend rekening houdend met een drietal technologische ontwikkelingen. De brandstof basisfactoren en brandstof bouwjaarfactoren zijn door de auteur afgeleid $\mathrm{cq}$. ontwikkeld en als module toegevoegd. Op deze wijze wordt een consistente beschrijving van het verloop van o.a. broeikasgassen verkregen. Verondersteld wordt dat ieder bouwjaar naar brandstoftype een eigen emissiekarakteristiek of emissieprofiel heef welke pas door afstoot of verwrakking uit het autopark verdwijnt. Op een dergelijke wijze kan de invloed van technologische verbeteringen in ontwerp en motorperstaties op de emissies gevolgd worden.

In hoofdstuk 8 worden de twee modules, te weten de kwantitatieve en kwalitatieve samenstelling van het Nederlandse autopark én de verkeersprestaties van de Nederlandse huishoudens naar grootte gekoppeld en gesimuleerd. Een groot aantal scenario's zijn door de auteur gesimuleerd, waarvan slechts een kleine deelverzameling hier gepubliceerd wordt.

De studie eindigt met een aantal slotopmerkingen welke een werkennend karakter hebben. 



\section{Curriculum Vitae}

Eugène Antoine Marie Schenk werd geboren op 17 januari 1946 te Maastricht. Voltooide zijn middelbare opleiding in 1965 en het doktoraal examen in de Algemene Economie aan de Katholieke Universiteit Brabant in 1971. Van 1972 tot 1974 ontving hij een beurs van de Belgische Staat ter vervolmaking van zijn studie in de logica aan het Hoger Instituut van Wijsbegeerte van de Katholieke Universiteit Leuwen. Van 1973 tot 1978 werd hij aangesteld als wetenschappelijk medewerker verbonden aan het Centrum wan Economische Studiën van de KUL aldaar. Gedurende de periode 1978-1980 trad hij als docent in dienst bij het Jeanne d'Arc College te Maastricht. Van 1980 tot 1984 was hij als wetenschappelijk medewerker verbonden aan de Erasmus Universiteit Rotterdam, in 1985 trad hij in dienst bij de Faculteit der Economische Wetenschappen van de Universiteit Maastricht. 